\title{
Bioinspired Activation of Oxygen with Pyrazole-Supported Dinuclear Copper Complexes
}

\author{
Dissertation \\ zur Erlangung des mathematisch-naturwissenschaftlichen Doktorgrades \\ "Doctor rerum naturalium" \\ der Georg-August-Universität Göttingen
}

im Promotionsprogramm Biometals

der Georg-August University School of Science (GAUSS)

\author{
vorgelegt von \\ Kristian Erwin Dalle \\ aus Brisbane
}

Göttingen, 2014 


\section{Betreuungsausschuss}

Prof. Dr. F. Meyer, Institut für Anorganische Chemie, Georg-August-Universität Göttingen

Prof. Dr. U. Diederichsen, Institut für Organische und Biomolekulare Chemie, Georg-AugustUniversität Göttingen

\section{Mitglieder der Prüfungskommission}

Referent:

Prof. Dr. F. Meyer, Institut für Anorganische Chemie, Georg-August-Universität Göttingen

Korreferent:

Prof. Dr. U. Diederichsen, Institut für Organische und Biomolekulare Chemie, Georg-AugustUniversität Göttingen

Weitere Mitglieder der Prüfungskommission:

Prof. Dr. G. Clever, Institut für Anorganische Chemie, Georg-August-Universität Göttingen

Prof. Dr. K. Tittmann, Albrecht-von-Haller-Institut, Georg-August-Universität Göttingen

Jun.-Prof. Dr. R. Mata, Institut für Physikalische Chemie, Georg-August-Universität Göttingen

Dr. I. Sievert, Institut für Anorganische Chemie, Georg-August-Universität Göttingen

Tag der mündlichen Prüfung: 22.10.2014 


\section{Table of Contents}

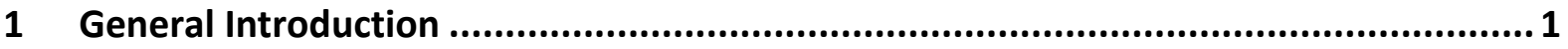

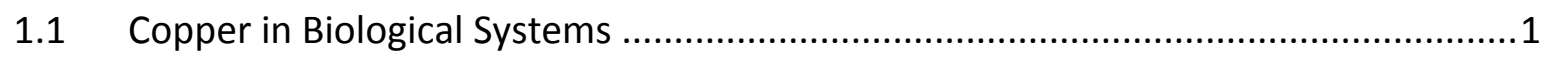

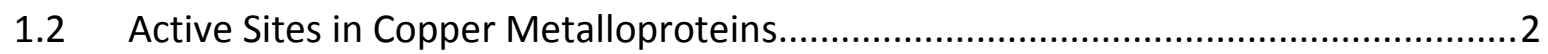

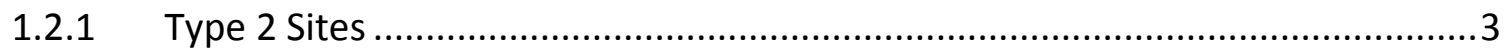

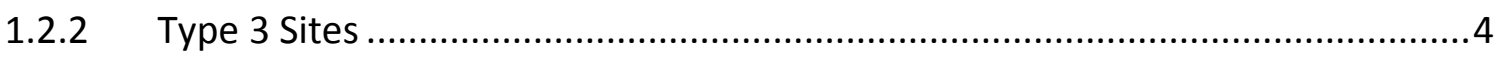

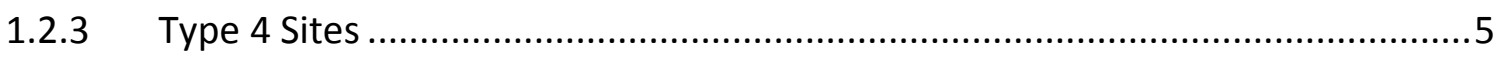

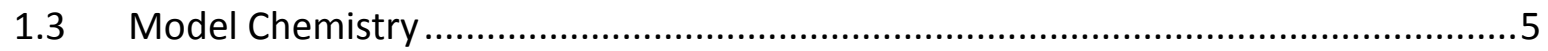

1.3.1 Synthetic Copper-Dioxygen Adducts Supported by N-donor Ligands ................ 7

1.3.2 An Inorganic Model for pMMO.................................................................. 10

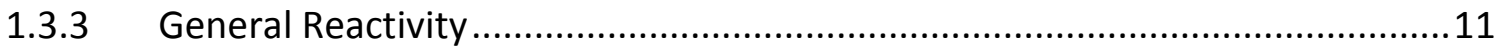

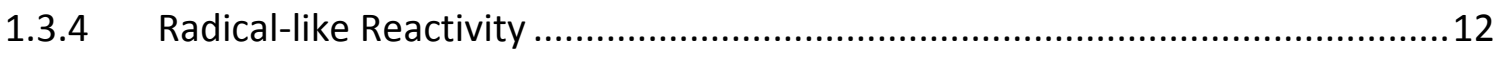

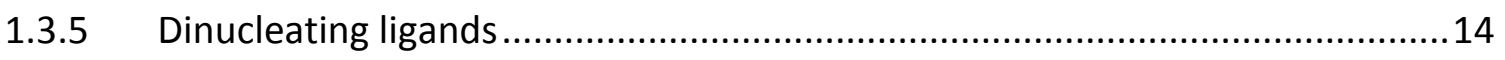

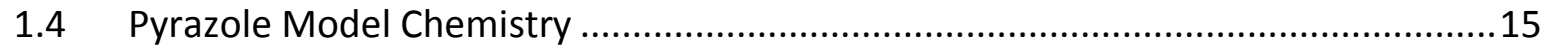

1.4.1 Copper Chemistry Supported by 3,5-Disubstitued Pyrazole Ligands ................16

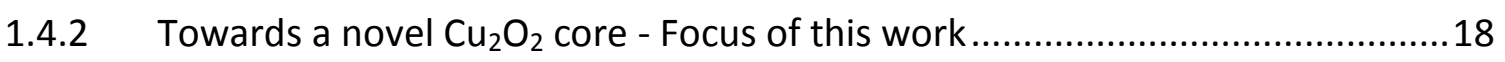

2 Dinucleating Pyrazole Ligands for Copper-mediated Dioxygen Activation ................. 20

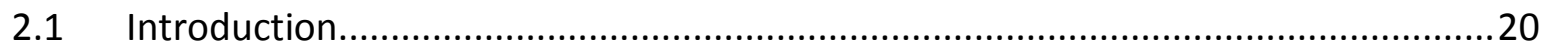

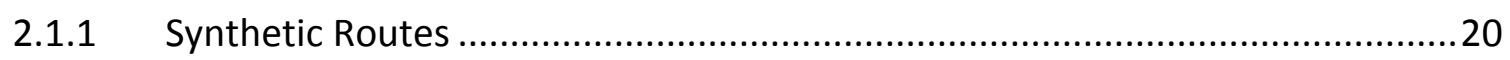

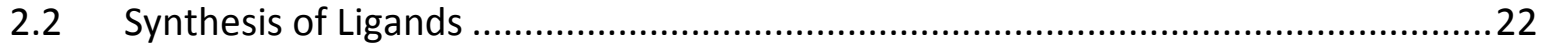

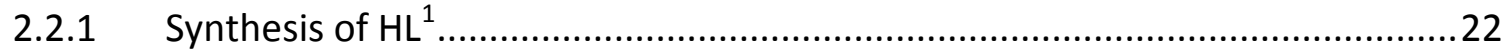

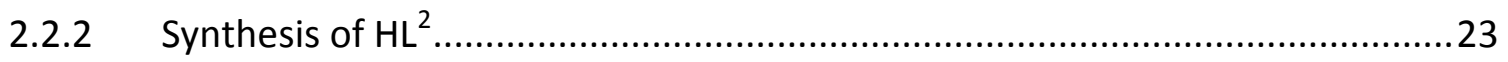

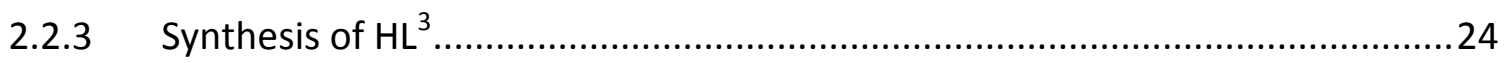

2.3 Characterisation of Ligands and Ligand Precursors ...........................................25

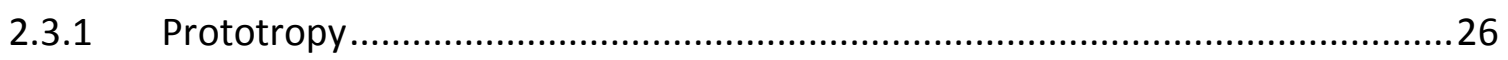

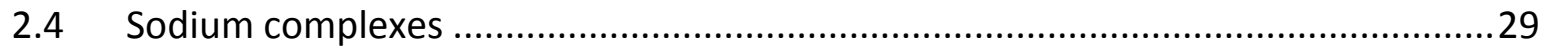

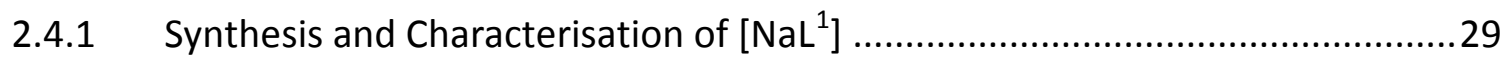

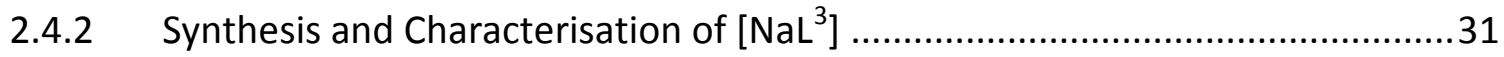

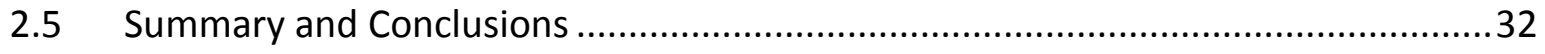




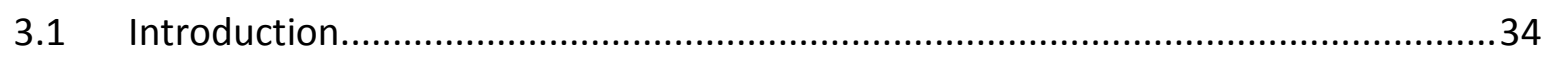

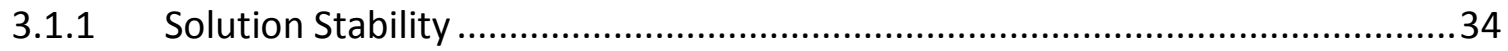

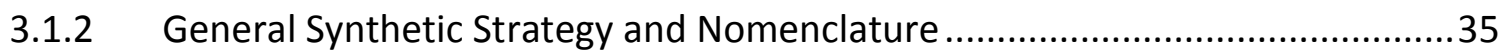

3.1.3 Speciation and Dynamic Processes of Relevance to Characterisation ...............37

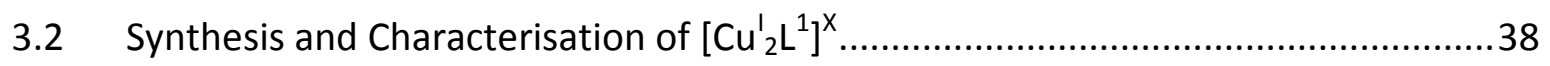

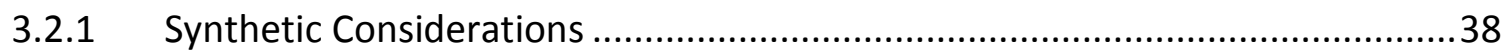

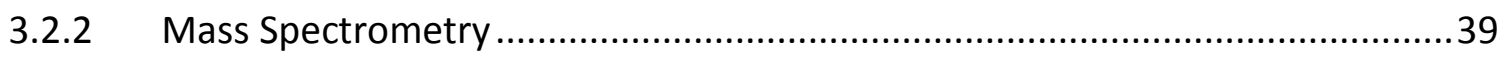

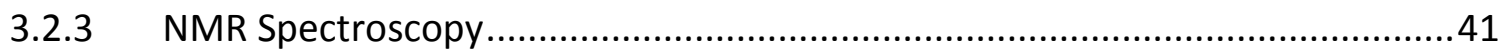

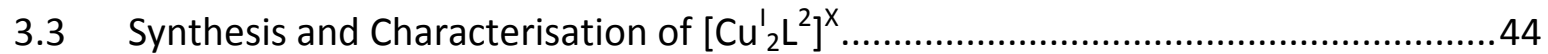

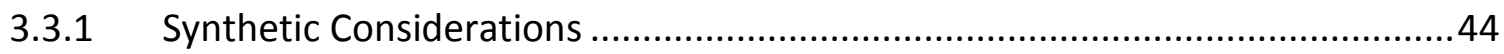

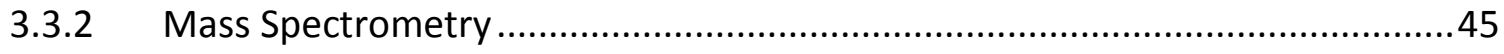

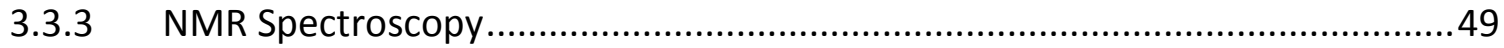

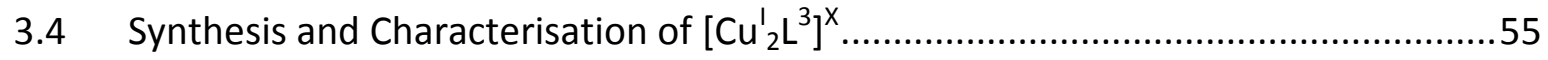

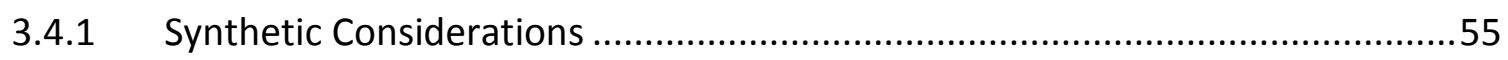

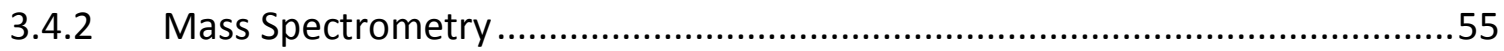

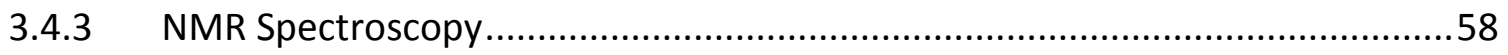

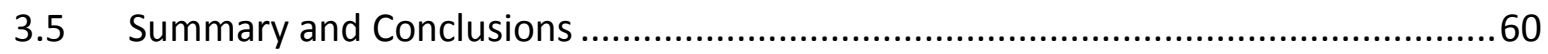

4 Dioxygen Activation Chemistry - Novel Copper-Peroxo Adducts ............................62 62

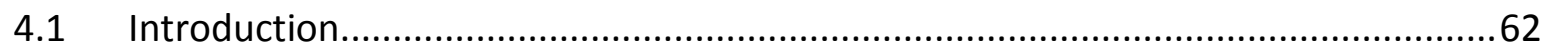

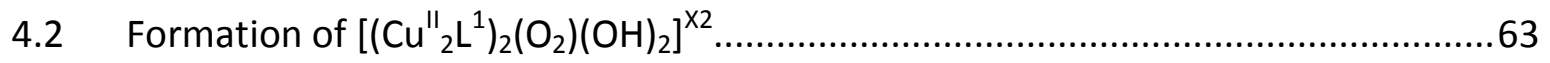

4.2.1 Prior Work and Present Motivation ...............................................................63

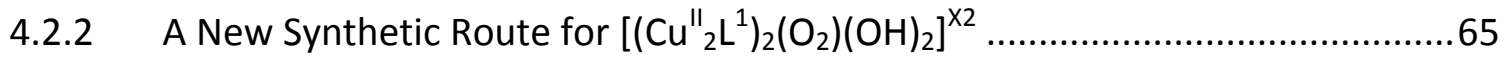

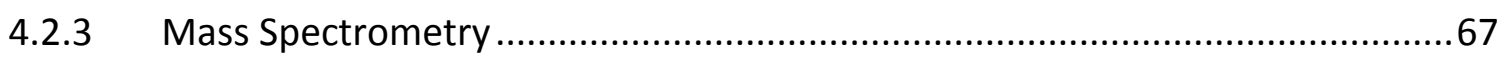

4.2.4 The Role of Water in $\left[\left(\mathrm{Cu}_{2}{ }^{\prime \prime}{ }^{1}\right)_{2}\left(\mathrm{O}_{2}\right)(\mathrm{OH})_{2}\right]^{\mathrm{X} 2}$ Formation .................................68

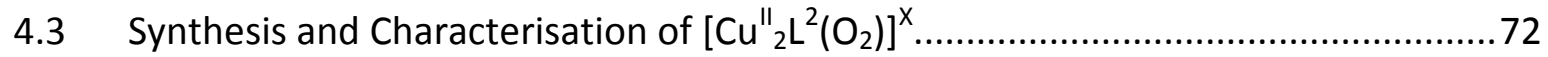

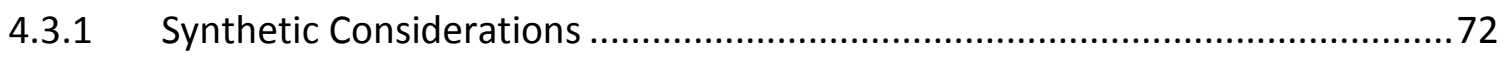

4.3.2 Spectroscopic Characterisation and $\mathrm{O}_{2}$ uptake ….......................................73

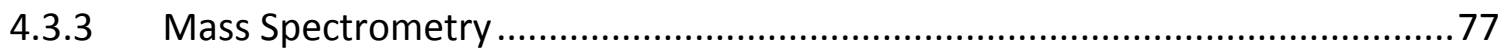

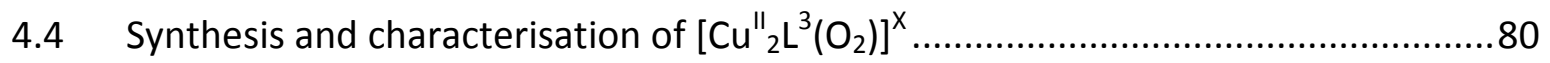

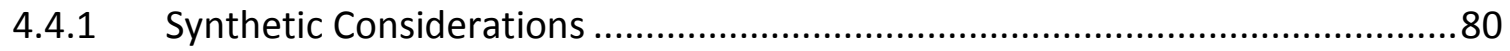

4.4.2 Spectroscopic Characterisation and $\mathrm{O}_{2}$ uptake ........................................... 81 


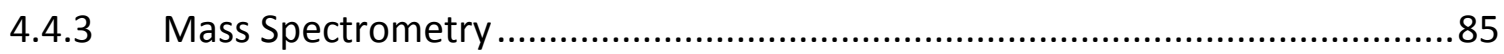

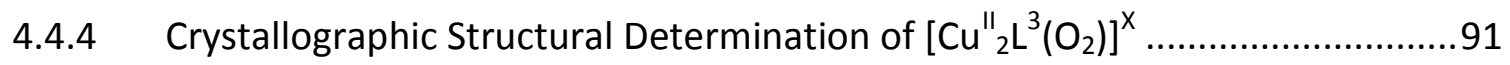

4.4.5 Comparison of the $\left[\mathrm{Cu}_{2}{ }_{2} \mathrm{~L}^{2}\left(\mathrm{O}_{2}\right)\right]^{\mathrm{X}}$ and $\left[\mathrm{Cu}^{11}{ }_{2} \mathrm{~L}^{3}\left(\mathrm{O}_{2}\right)\right]^{\mathrm{X}}$ adducts ............................9.

4.4.6 Varying Counterions - Further Solid State Structures of $\left[\mathrm{Cu}^{\prime \prime}{ }_{2}{ }^{3}\left(\mathrm{O}_{2}\right)\right]^{\mathrm{X}} \ldots \ldots \ldots \ldots . . . . .95$

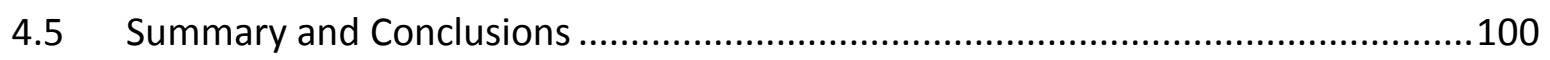

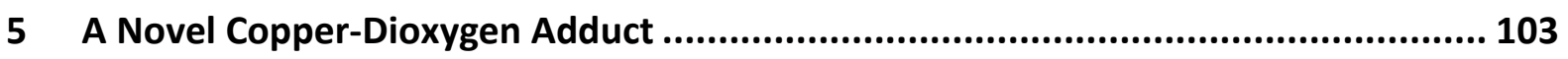

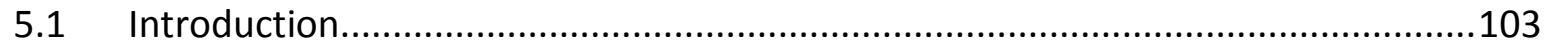

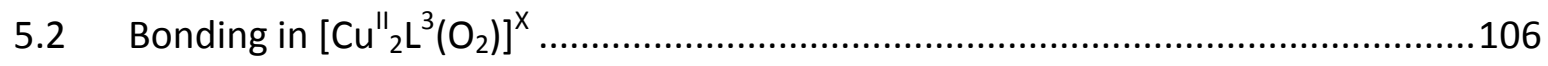

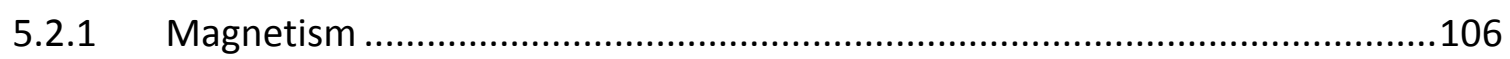

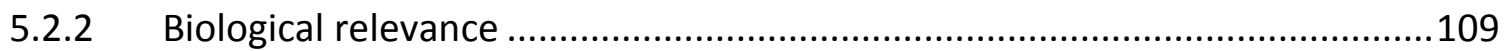

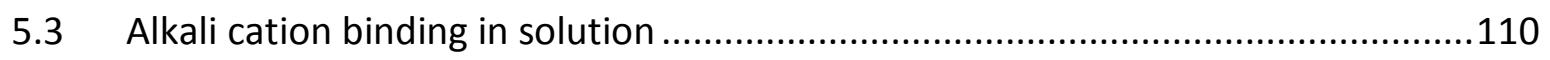

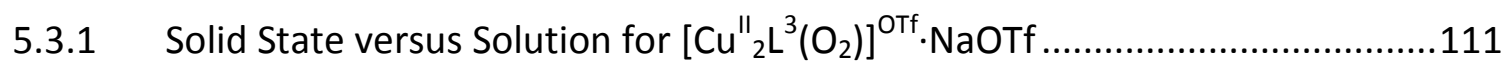

5.3.2 Solution State Resonance Raman Spectroscopy ........................................112

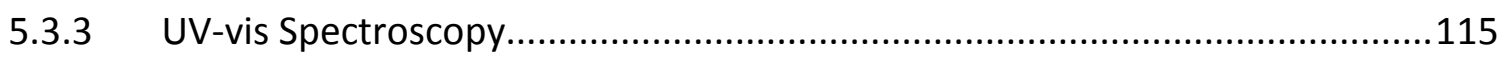

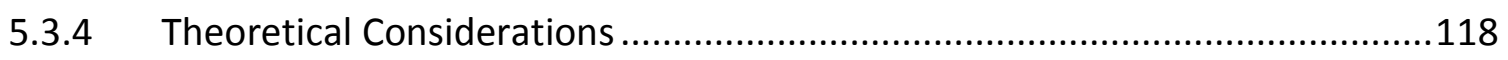

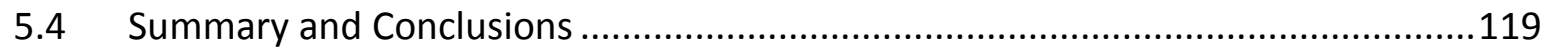

6 Reactivity of Copper-Dioxygen Adducts............................................................ 122

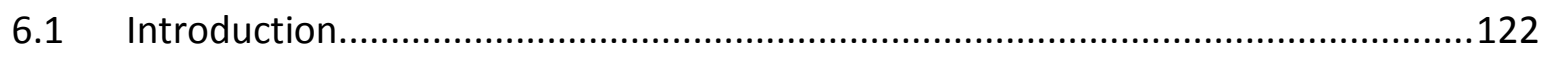

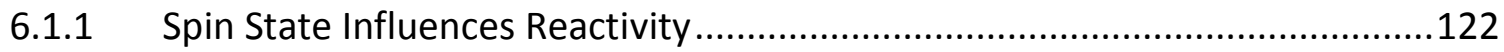

6.1.2 Hydrogen Abstraction and Intra-molecular Decomposition ...........................123

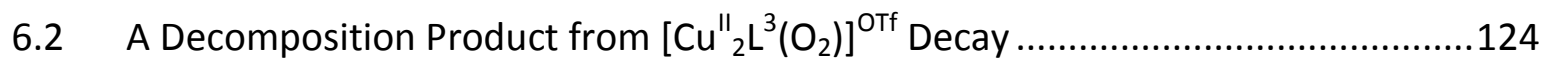

6.2.1 Isolation and Crystallographic Structural Determination ..............................124

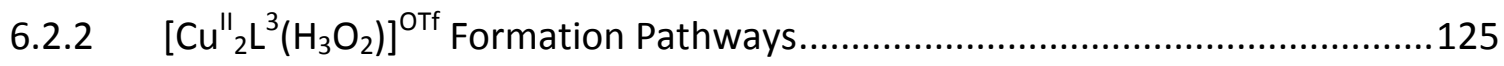

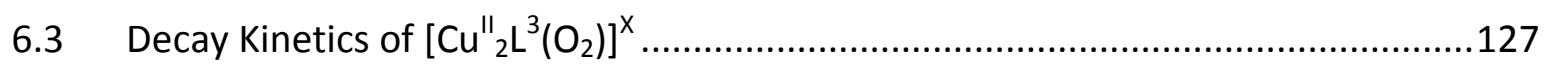

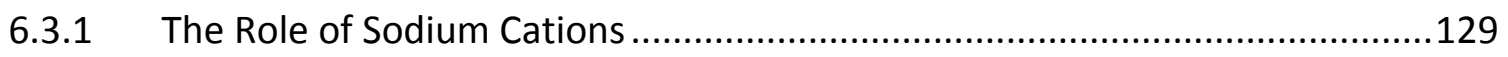

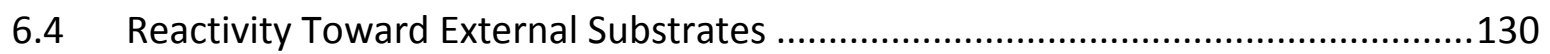

6.4.1 The Active Oxygenating Species in Tyrosinase ............................................. 130

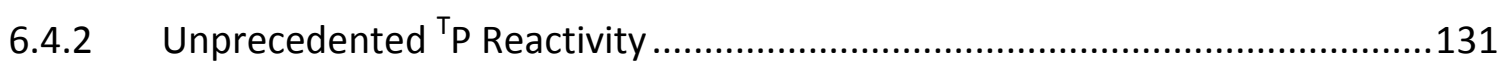

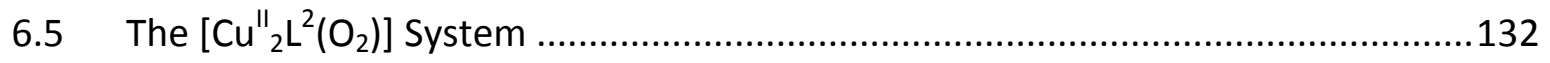

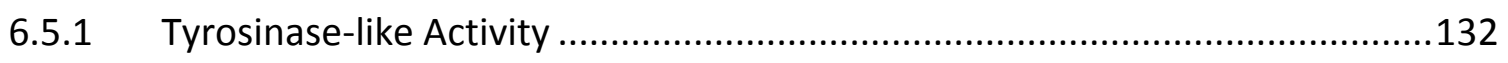

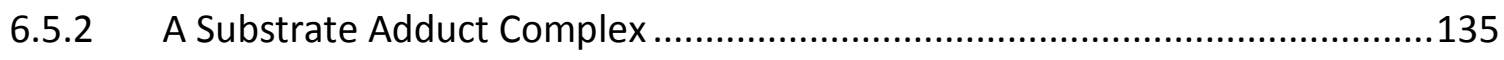

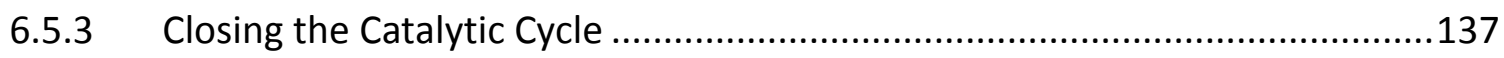




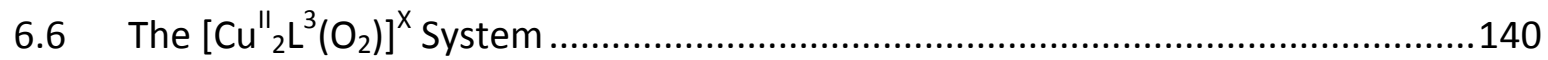

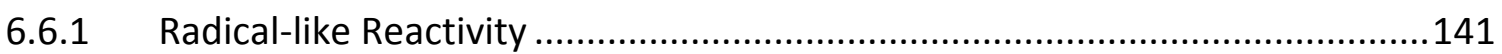

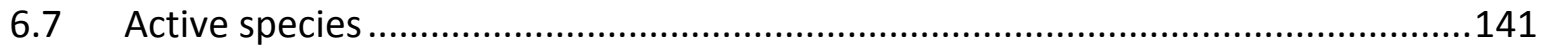

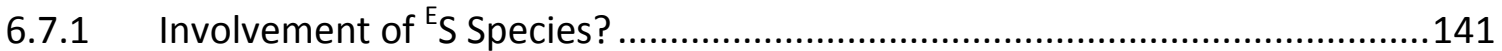

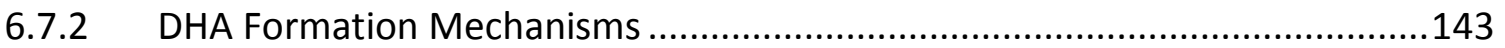

6.7.3 $\left[\mathrm{Cu}_{2}{ }_{2} \mathrm{~L}^{2}\left(\mathrm{O}_{2}\right)\right]^{\mathrm{X}}$ versus $\left[\mathrm{Cu}_{2} \mathrm{~L} \mathrm{~L}^{3}\left(\mathrm{O}_{2}\right)\right]^{\mathrm{X}}$ - Comparing Reactivity ............................... 144

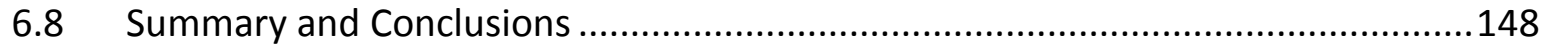

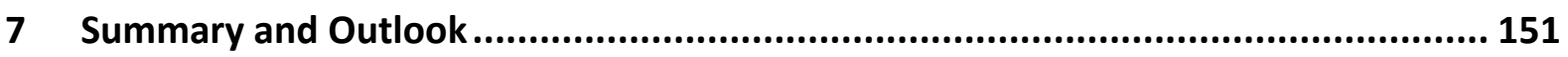

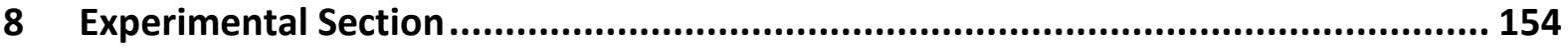

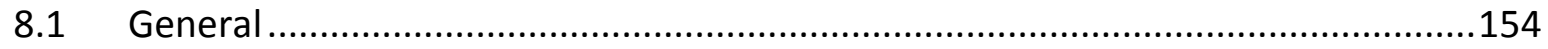

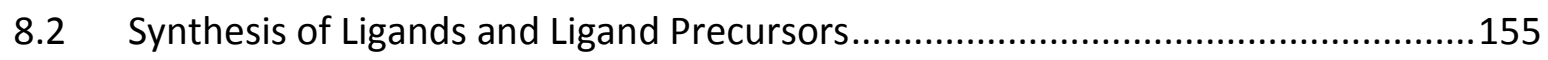

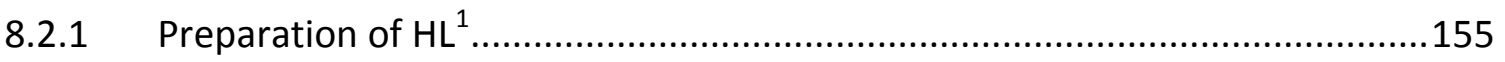

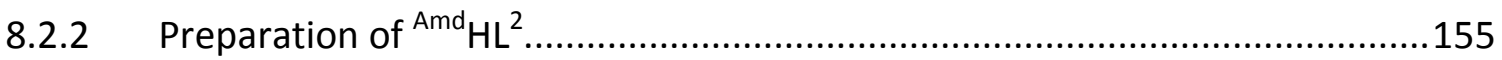

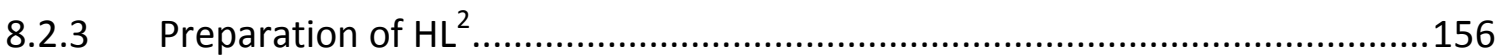

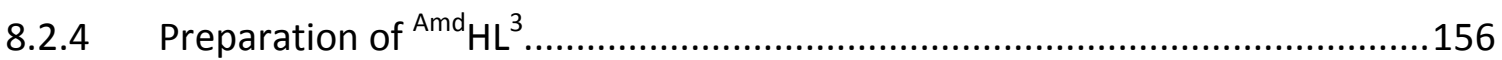

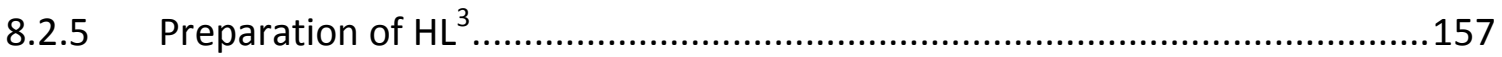

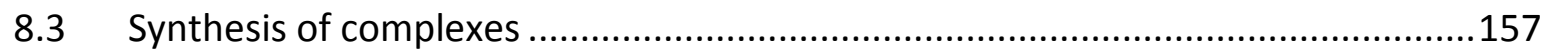

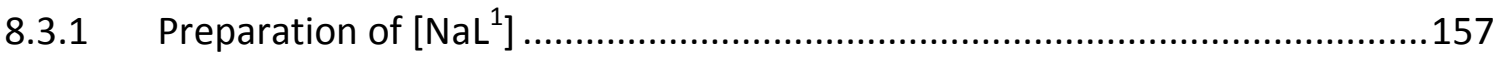

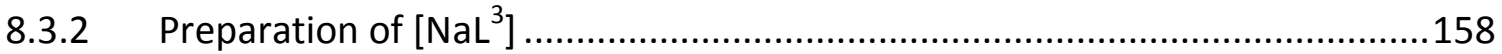

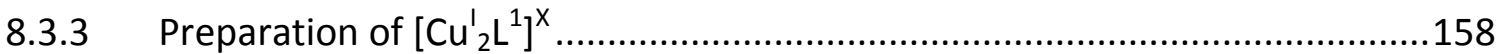

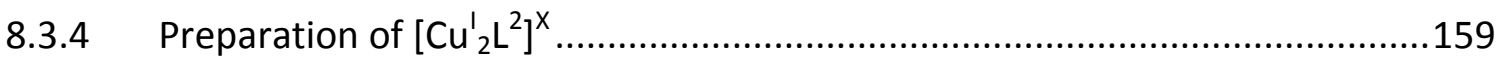

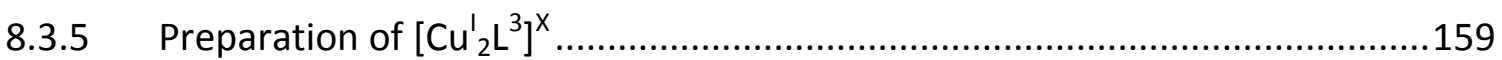

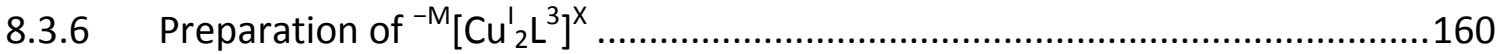

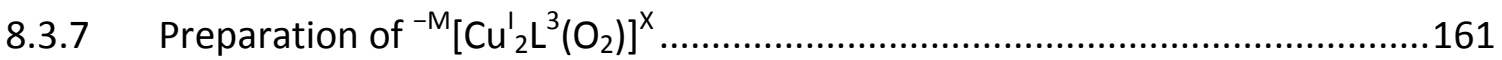

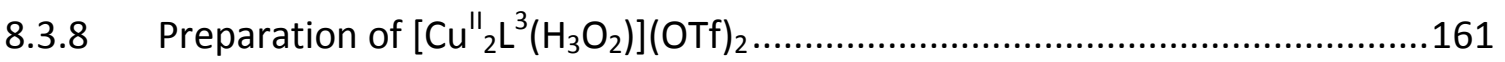

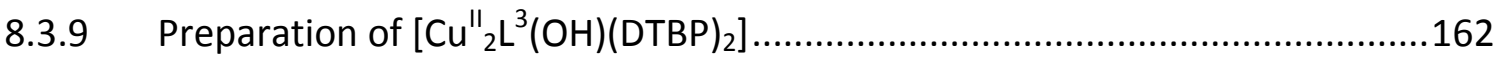

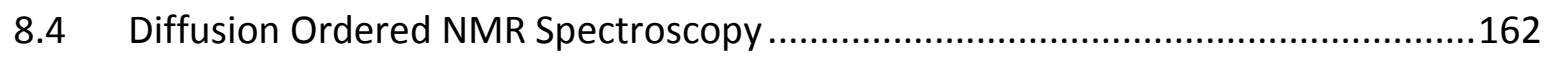

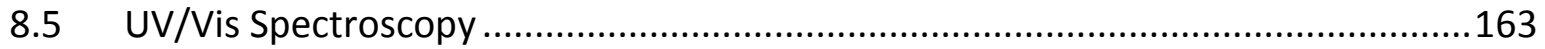

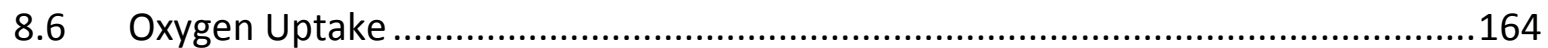

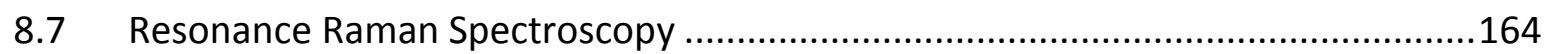

8.8 Magnetic Susceptibility Measurements......................................................... 165

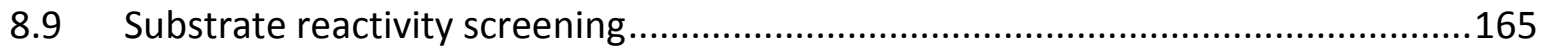


8.10 Crystallographic Details 166

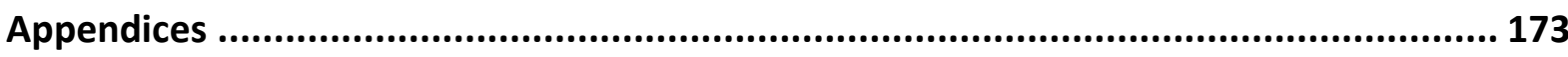

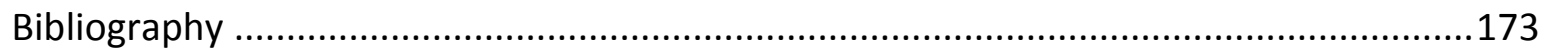

Structures of Ligands, Ligand Precursors, and Sodium Complexes ...............................188

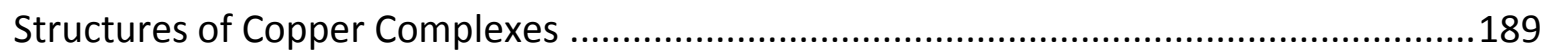

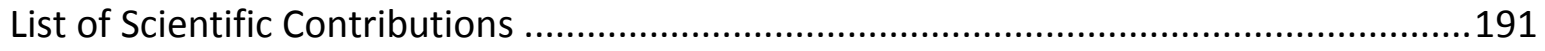

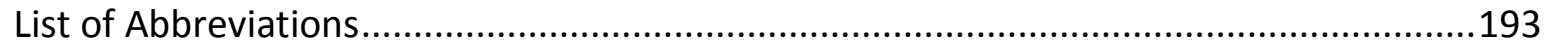

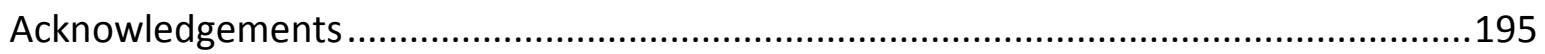





\section{General Introduction}

\subsection{Copper in Biological Systems}

Copper is an extremely widespread trace element in biological systems, being surpassed in abundance in the human body by only iron and zinc. This prevalence in nature primarily results from the vast array of biochemical activity mediated by copper containing metalloproteins. ${ }^{1}$ In addition to dealing with copper acquisition these proteins participate in electron transfer reactions, functionality which enables them to achieve extremely impressive chemistry such as the selective oxidation of methane to methanol, or the reduction of nitrous oxide to dinitrogen (Scheme 1.1). ${ }^{2,3}$ This remarkable reactivity serves as inspiration for coordination chemists. Studies of these systems aim to gain an appreciation of how such functionality might be reproduced in the laboratory, but also find intrinsic value in furthering our fundamental understanding of the unusual mechanistic aspects and interplay of cooperative effects nature uses. ${ }^{4}$

$$
\begin{array}{clc}
\mathrm{CH}_{4}+\mathrm{O}_{2}+2 \mathrm{H}^{+}+2 \mathrm{e}^{-} & \stackrel{\text { Dinuclear Copper }}{\text { Metalloprotein }} & \mathrm{CH}_{3} \mathrm{OH}+\mathrm{H}_{2} \mathrm{O} \\
\mathrm{N}_{2} \mathrm{O}+2 \mathrm{H}^{+}+2 \mathrm{e}^{-} & \stackrel{\text { Tetranuclear Copper }}{\text { Metalloprotein }} & \mathrm{N}_{2}+\mathrm{H}_{2} \mathrm{O}
\end{array}
$$

Scheme 1.1: Impressive chemical transformations mediated by copper-containing metalloproteins.

Aside from the exceptional examples in Scheme 1.1, copper metalloproteins are involved in diverse physiological roles. These include dioxygen transport, ${ }^{5}$ neurotransmitter production, cell differentiation and growth, ${ }^{6,7}$ and innate immunity, ${ }^{5,7}$ and provide additional motivation for investigation of these systems from the perspective of health and disease. The functionality described here once again stems from the redox capability imparted by copper, which allows these biomolecules to utilise molecular oxygen as an electron acceptor, granting them the ability to catalytically and specifically transform a variety of organic substrates. ${ }^{1,8}$ The oxidase and oxygenase enzymes which respectively perform these oxidation and oxygen transfer reactions thus additionally act as archetypes for the design of 'green' catalysts, potentially able to operate under mild aerobic conditions while generating only environmentally benign by-products. ${ }^{4}$

Ranging from the pharmaceutical to the polymer chemical industries, such catalysts would be extremely valuable in selective functionalisation of intermediates, and conversion of raw materials into useful chemical building blocks. ${ }^{9,10}$ Recent experimental evidence has emerged that indicates both natural and artificial dinuclear copper sites can achieve direct 
oxidation of methane to methanol. This highlights that, with the right catalyst, economically viable utilisation of natural gas resources as industrially relevant feedstock might indeed be possible. ${ }^{3,11}$ An intimate understanding of how copper centres facilitate the activation of dioxygen is thus highly desirable, and relevant in fields from biology and medicine to chemical engineering.

\subsection{Active Sites in Copper Metalloproteins}

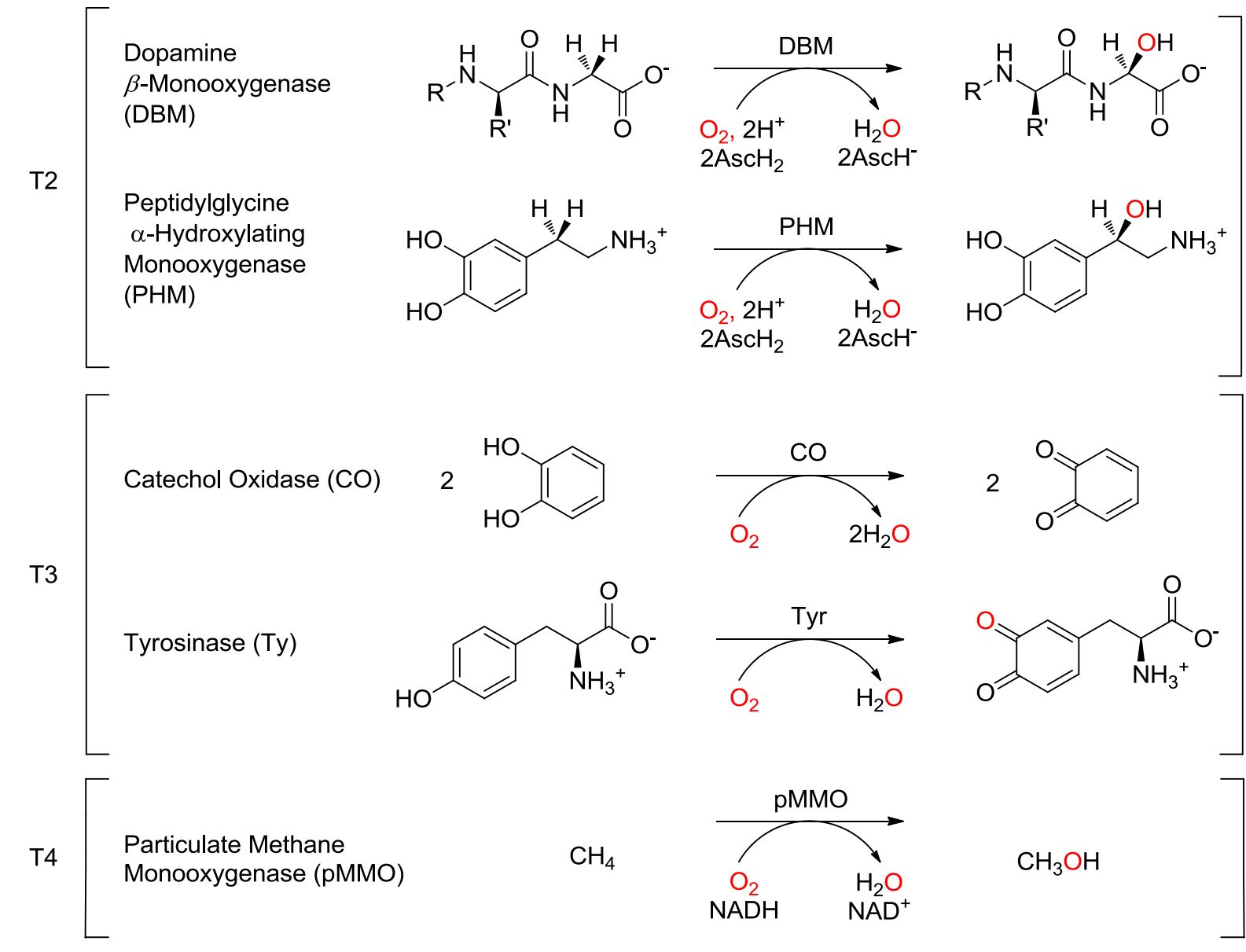

Scheme 1.2: Representative examples of oxygenation of organic substrates catalysed by dioxygen-activating copper metalloproteins, categorised by copper centre type.

Copper containing proteins can be classified into seven different types based on the spectroscopic properties of their active sites. ${ }^{1,8}$ Those which use dioxygen as an electron acceptor and are primarily involved in oxidation and oxygenation of organic substrates are types 2, 3 and 4 (T2, T3 and T4, respectively, Scheme 1.2). All utilise the copper(I)/copper(II) redox pair, whereby the copper(I) state facilitates initial dioxygen binding by electron transfer. Owing to its $\mathrm{d}^{10}$ configuration copper(I) is relatively silent spectroscopically, and so the type classification described above is based on the spectroscopic features of the oxidised $\mathrm{d}^{9}$ copper(II) states. ${ }^{1,12}$ Copper(III) has traditionally not been considered of biological relevance because of its redox inaccessibility when ligated solely by amino acid side chains. ${ }^{13,14}$ However, several mechanistic scenarios have more recently emerged which 
propose involvement of copper(III)-oxygen species as reactive intermediates. ${ }^{15,16}$ The three types of copper centres mentioned above possess a histidine rich coordination environment, containing at least two of these aromatic nitrogen donors per copper ion in all but a single case (Section 1.2.3). ${ }^{1,17,18}$ The number and arrangement of copper ions in each type of centre differs, as does the oxygen binding mode, both of which are discussed in more detail below.

\subsubsection{Type 2 Sites}

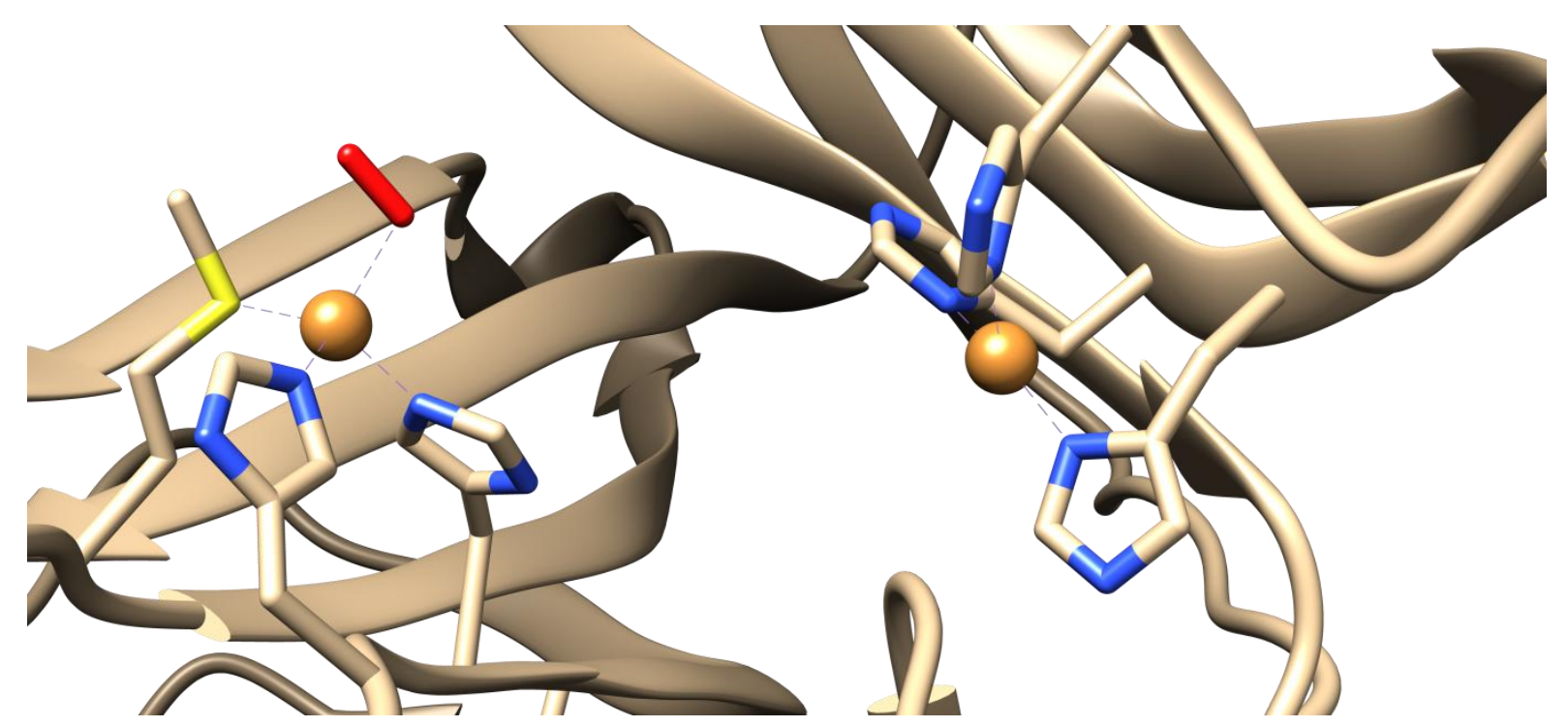

Figure 1.1: Active site of PHM showing the end-on binding mode of dioxygen (left), and the second distal T2 copper centre (right, PDB Code: 1 SDW). ${ }^{19}$

Type 2 centres are also referred to as 'normal' as a result of their distinguishing electron paramagnetic resonance (EPR) spectroscopic signals, which are similar to those of 'normal' tetragonal copper(II) complexes. ${ }^{1,12,17}$ Representative metalloenzymes possessing T2 centres include galactose oxidase, ${ }^{1,8}$ amine oxidase, ${ }^{6,12}$ dopamine $\beta$-monooxygenase (DBM) $)^{1,8,17}$ and peptidylglycine $\alpha$-hydroxylating monooxygenase (PHM) ${ }^{12,17}$ The oxidase enzymes are truly mononuclear, requiring an additional redox-active organic cofactor to shuttle the extra electron needed for oxidation of their respective substrates and reduction of dioxygen to peroxide. ${ }^{17,20}$ On the other hand DBM and PHM, which both catalyse aliphatic hydroxylation reactions, ${ }^{21}$ contain two T2 centres separated by at least $7 \AA^{20}{ }^{20}$ This separation is evidenced by their lack of magnetic interaction, and they are thus also known as non-coupled dinuclear centres. ${ }^{17,20}$ One of these copper ions is coordinated by three histidine side chains, whereas the second is ligated by two histidine donors in combination with a methionine residue (Figure 1.1). While both copper ions are involved in storage and transfer of the electrons required to achieve reactivity, dioxygen binding and substrate transformation occurs exclusively at the $\mathbf{T} 2$ site ligated by methionine. ${ }^{21}$ Dioxygen initially undergoes single electron reduction upon binding to the copper(I) ion at this site to give an end-on copper(II)superoxo $\left(\mathrm{Cu}^{\mathrm{II}}-\mathrm{O}_{2}{ }^{\cdot},{ }^{\mathrm{E}} \mathrm{S}\right.$, Scheme 1.4$)$ adduct which is thought to then react directly with the substrate. ${ }^{16,18,19}$ 


\subsubsection{Type 3 Sites}

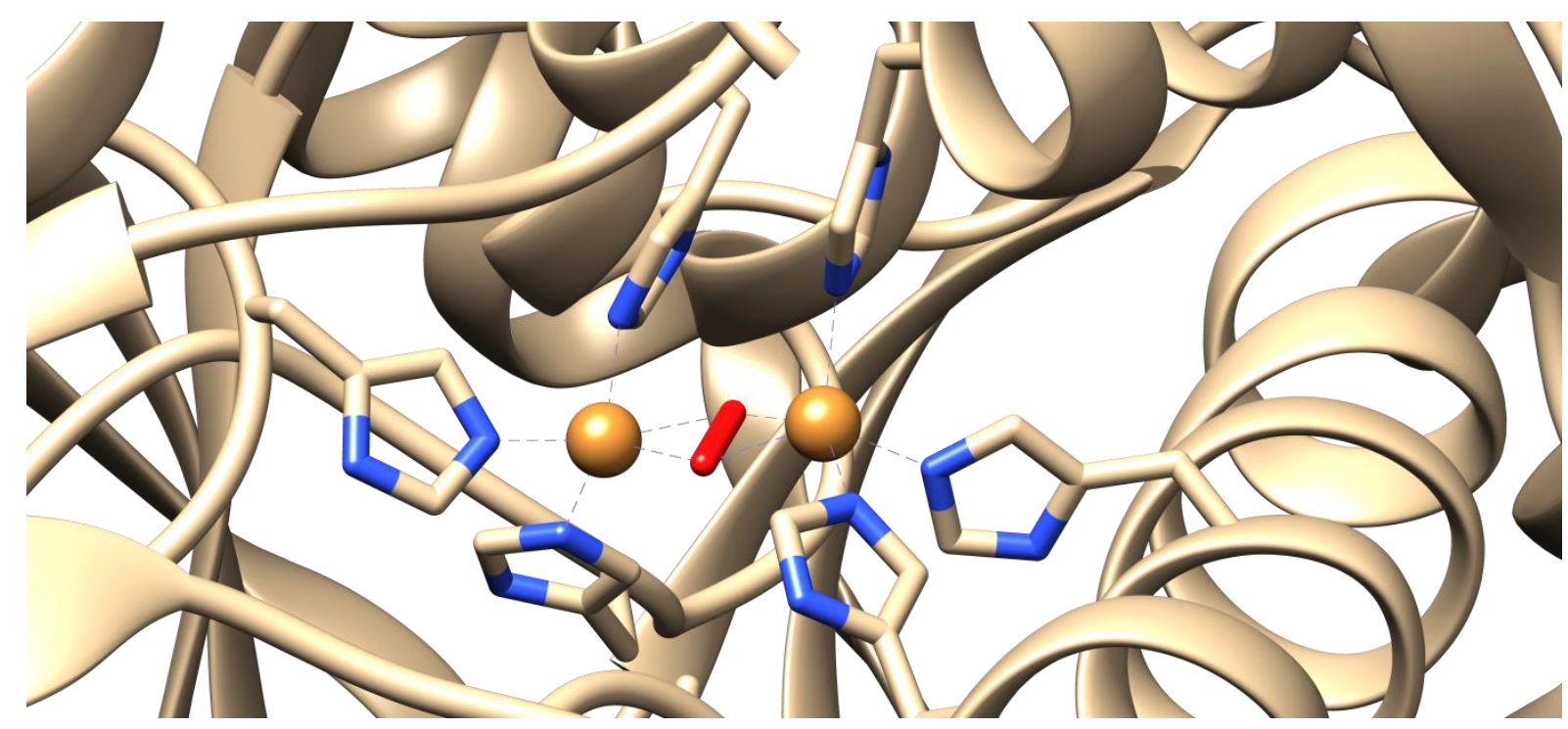

Figure 1.2: Active site of Hc showing the side-on binding mode of dioxygen (PDB Code: 1 JS8). ${ }^{22}$

Type 3 centres contain two closely spaced copper ions which show strong antiferromagnetic coupling in the copper(II) state. This interaction leads to EPR silent behaviour, ${ }^{12,16}$ and hence these sites are also known as coupled binuclear centres. The three members of this class, hemocyanin $(\mathbf{H c})$, tyrosinase (Tyr) and catechol oxidase (CO), all bind dioxygen between their two copper ions reversibly, with the same bridging mode. ${ }^{23}$ This results from their almost identical active site structures, with both copper ions ligated by three histidine residues each (Figure 1.2). Dioxygen binding causes a significant contraction of the $\mathrm{Cu} \cdots \mathrm{Cu}$ distance (from ca. $4.5 \AA$ to $3.3 \AA)^{1,14,17}$ and establishes the strong superexchange pathway that couples the two copper(II) ions. ${ }^{16,18,24}$ Although Hc acts only as an oxygen carrier, both CO and Tyr can oxidise catechols to o-quinones, and Tyr additionally hydroxylates monophenols. ${ }^{1,25}$ These differences in function are in part thought to arise from restricted substrate access to the active site, imposed by flanking amino acid residues in $\mathbf{H c}$ and co. ${ }^{17,18,23}$ Dioxygen receives one electron from each of the two copper $(I)$ ions in the active site upon binding, resulting in a side-on di-copper(II)-peroxo $\left(\mu-\eta^{2}: \eta^{2}-\mathrm{O}_{2},{ }^{5} \mathbf{P}\right.$, figure Scheme 1.4) adduct. However, the actual species responsible for oxygen transfer in Tyr is still under debate (see Section 1.3.3 for more detail). 


\subsubsection{Type 4 Sites}

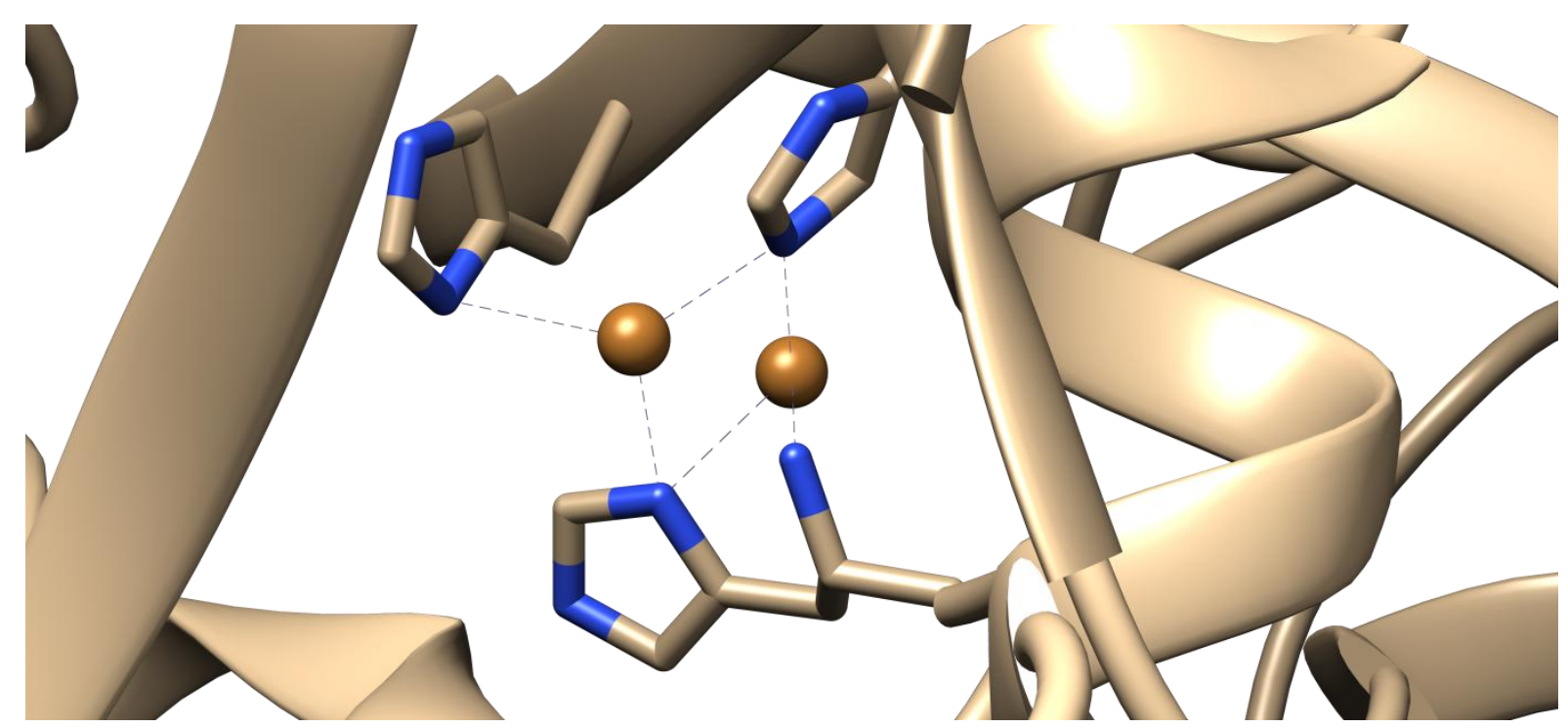

Figure 1.3: Active site of $\mathrm{pMMO}$ showing the unusual $\mathrm{N}$-terminal donor (PDB Code: $3 R G B){ }^{26}$

Type 4 copper centres consist of a mononuclear $\mathbf{T} 2$ site and a coupled binuclear T3 site. ${ }^{1,8}$ These are clustered together in a triangular arrangement, at which the four-electron reduction of dioxygen occurs to give two molecules of water. ${ }^{18}$ Representative examples of proteins containing T4 sites include ascorbate oxidase and the large and diverse family of laccase metalloenzymes. ${ }^{1,8,17,18}$ The T4 site itself is not of exceptional relevance to the current work, however, a related configuration of copper ions has been identified in particulate methane monooxygenase (pMMO). ${ }^{27}$ This metalloenzyme possesses a T2-like mononuclear site, and an unusual dinuclear copper centre more than $20 \AA$ away. The dinuclear centre has a short $\mathrm{Cu} \cdots \mathrm{Cu}$ distance of $2.6 \AA$, with one copper ion coordinated by two histidine side chains. The second active site copper ion is chelated by a single histidine residue, which coordinates through the side chain and additionally exhibits unusual $\mathrm{N}$ terminal ligation (Figure 1.3). ${ }^{27}$ It has recently been shown that oxidation of methane occurs at this dinuclear copper centre, ${ }^{3}$ yet the mode of dioxygen binding and resulting active oxygenating species are still unknown (Section 1.3.2). That the remarkable reactivity of pMMO stems from an atypical dinuclear copper site helps to emphasise the importance of copper-mediated dioxygen activation, and has provided fresh motivation for bioinorganic research efforts, including in the field of model chemistry. ${ }^{11,15}$

\subsection{Model Chemistry}

Synthetic analogues have successfully been used to gain insights into the structure and function of copper metalloproteins. ${ }^{4,16,18}$ A prominent example of such success is the determination of the ${ }^{\mathbf{S}} \mathbf{P}$ dioxygen binding mode in $\mathbf{H c}$ before it was observed in the metalloprotein crystal structure. ${ }^{28}$ As illustrated above, the natural systems very often contain two copper ions which work together in order to enable reactivity. Dinuclear $\mathrm{Cu}_{2} \mathrm{O}_{2}$ model systems are thus amongst the most intensely studied, and their structural and 
spectroscoptic features have provided a benchmark for oxygen intermediates in other copper enzymes. ${ }^{20}$ In addition, these investigations allow for structure-reactivity correlations, which can offer further insights into the natural systems. ${ }^{15,29}$ For example, such correlations form the basis of the ongoing debate over the oxygenation mechanism in Tyr. $^{16,18,25}$ Research efforts using copper model complexes for dioxygen activation comprise an extensive field which now spans over 30 years. Consequently, a significant volume of literature now exists on the topic, and many reviews and books are available. The material in this introduction is therefore most often presented in a general sense, but is supported by a significant number of scientific studies. Nevertheless, selected examples which illustrate concepts or complications relevant to the current work are discussed in more detail here and in later chapters.

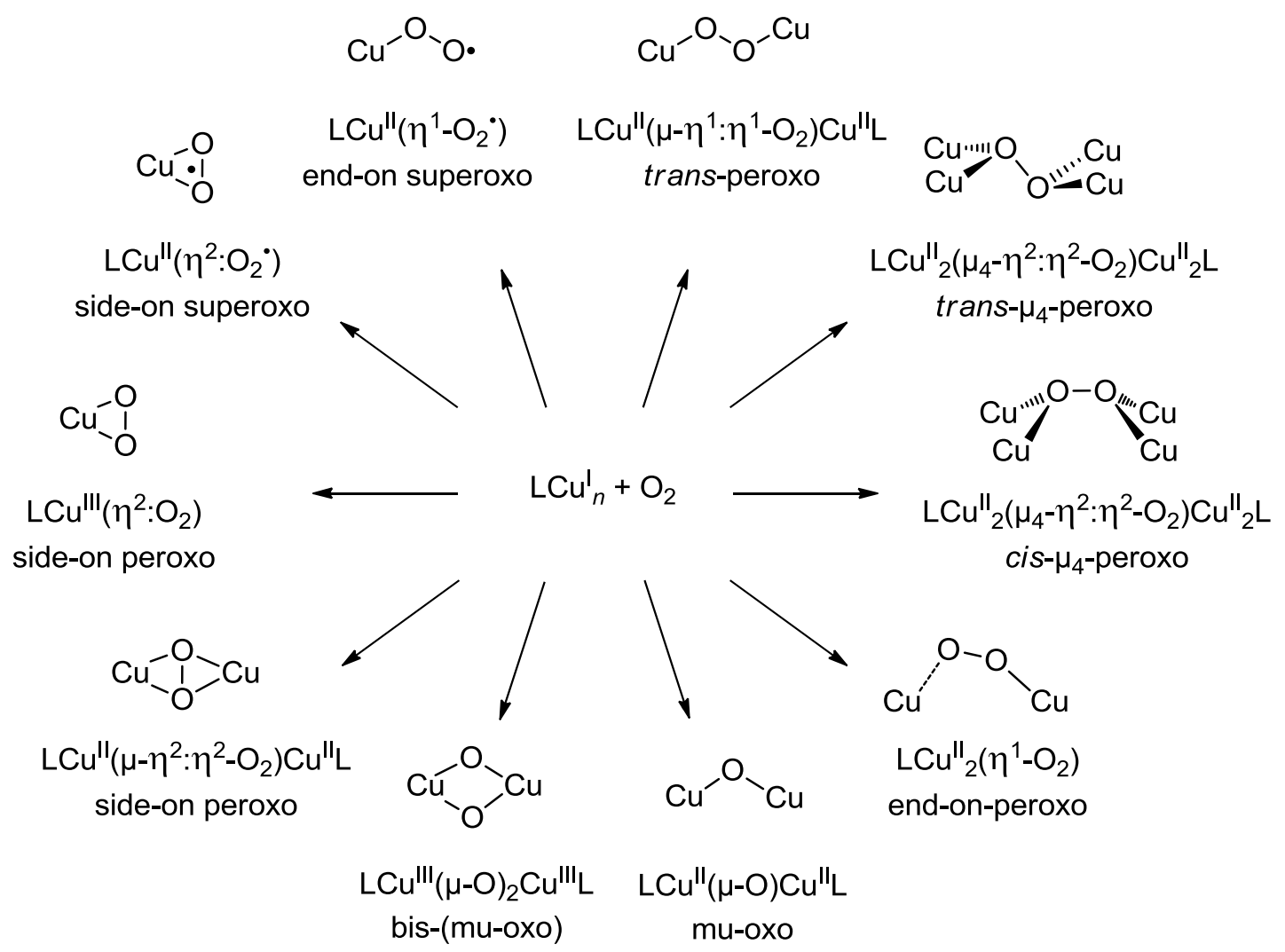

Scheme 1.3: Examples of the numerous copper-oxygen adducts which have been identified upon reaction of dioxygen with mononuclear $(n=1)$ or dinuclear $(n=2)$ copper $(I)$ model complexes.

Various copper-oxygen adducts have been characterized upon reaction of copper(I) model complexes with dioxygen (Scheme 1.3), including many not observed in the parental enzymes. ${ }^{10,14,30}$ Such diversity is promoted by the several possible formal oxidation states accessible for both the copper ions and dioxygen-derived ligands. ${ }^{14}$ As illustrated above, the natural systems most often coordinate copper through aromatic nitrogen atoms provided by histidine side chains. This has led to the extensive use $\mathrm{N}$-donor chelates in the model systems. Supporting ligands possessing entirely aromatic, entirely aliphatic, or mixed nitrogen donor sets are employed, and all have been shown to be capable of supporting a diverse range of copper-dioxygen adducts. ${ }^{10,15,30}$ Although less common, oxygen, sulfur, and 
phosphrous donors are also represented, ${ }^{14}$ though the majority of examples discussed herein are of the strictly $\mathrm{N}$-donor type, in agreement with literature precedent.

The most frequently observed copper-oxygen adducts are those with a $\mathrm{Cu}_{2} \mathrm{O}_{2}$ stoichiometry, owing in part to the more thermodynamically favourable two electron reduction of dioxygen to peroxide, rather than the one electron reduction to superoxide. ${ }^{14}$ This is reflected in the widespread use of mononuclear copper(I) complexes which undergo selfassembly upon reaction with dioxygen, giving dimeric $\mathrm{Cu}_{2} \mathrm{O}_{2}$ species. ${ }^{14,31-33}$ This general synthetic approach has furthermore led to the observation and characterisation of several isoelectronic forms of the $\mathrm{Cu}_{2} \mathrm{O}_{2}$ core. While it is now possible to differentiate between each of these species on the basis of their distinctive spectroscopic features (Section 4.1), the original assignments relied largely upon structural data obtained from single crystal X-ray diffraction studies.

\subsubsection{Synthetic Copper-Dioxygen Adducts Supported by N-donor Ligands}

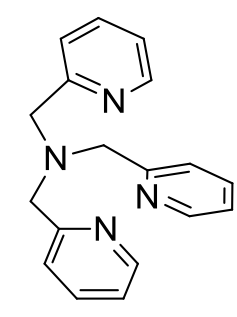

TMPA

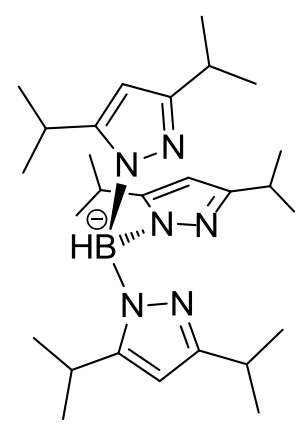

$\mathrm{HB}\left(\mathrm{Pz}^{\mathrm{i}} \mathrm{Pr}_{2}\right)_{3}$<smiles>CC(C)N1CCN(C(C)C)CCN(C(C)C)CC1</smiles>

i $\mathrm{Pr}_{3} \mathrm{TACN}$<smiles>[AlH2]OOCl</smiles><smiles></smiles><smiles>[Ge]O[Se]</smiles>

Bo<smiles>CN(C)CCN(CCN=C(N(C)C)N(C)C)CCN=C(N(C)C)N(C)C</smiles><smiles>[O]O[AlH2]</smiles>

Es

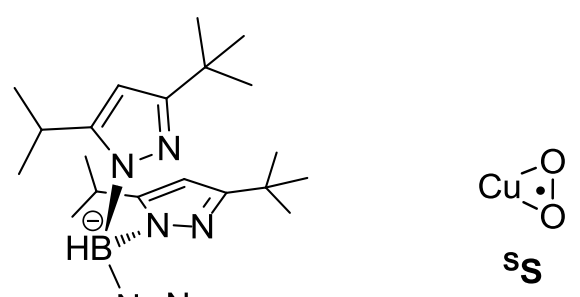

$\mathrm{HB}\left(\mathrm{Pz}^{i} \mathrm{Pr}^{\mathrm{t} B u}\right)_{3}$

Scheme 1.4: The first structurally characterised copper-dioxygen species and their corresponding ligands. Oxidation state and stoichiometry are omitted. 
The first discrete $\mathrm{Cu}_{2} \mathrm{O}_{2}$ configuration to be unambiguously identified by crystallographic characterisation in 1988 was the trans-peroxo adduct $\left({ }^{\top} \mathbf{P}\right)$, which features the peroxide dianion bridging two mononuclear copper(II) units in an end-on $\left(\mu-\eta^{1}: \eta^{1}-\mathrm{O}_{2}\right)$ transarrangement (Scheme 1.4). ${ }^{34}$ This was followed shortly thereafter in 1989 by the ${ }^{\mathrm{S}} \mathbf{P}$ species, which also possesses two mononuclear copper(II) fragments bridged by an $\mathrm{O}_{2}{ }^{2-}$ moiety but in this case with a side-on $\left(\mu-\eta^{2}: \eta^{2}-\mathrm{O}_{2}\right)$ planar coordination mode. ${ }^{28}$ Notably, spectroscopic comparison between these two species and oxygenated Hc then allowed for assignment of the dioxygen binding mode in the metalloprotein (Figure 1.2). ${ }^{35}$ Quite some time later in 1996 structural determination of the bis-mu-oxo isomer $\left({ }^{\mathbf{B}} \mathbf{O}\right)$ revealed an arrangement in which each copper centre had donated an additional electron relative to the ${ }^{\mathbf{T}} \mathbf{P}$ and ${ }^{\mathbf{S}} \mathbf{P}$ configurations, thereby facilitating full reduction of the bridging moiety to give a $\mathrm{Cu}_{2}{ }_{2}(\mu-\mathrm{O})_{2}$ core. $^{36}$

A substantial amount of literature now exists which indicates that the formation of $\mathrm{Cu}_{2} \mathrm{O}_{2}$ adducts from mononuclear copper(I) complexes proceeds through copper(II)-superoxide intermediates. ${ }^{14,30,32}$ Initial observations implicating transient $\mathrm{Cu}^{11}-\mathrm{O}_{2}{ }^{\bullet}$ species came from low temperature stopped-flow UV-vis spectroscopic studies of ${ }^{\top} \mathbf{P}$ systems in the early

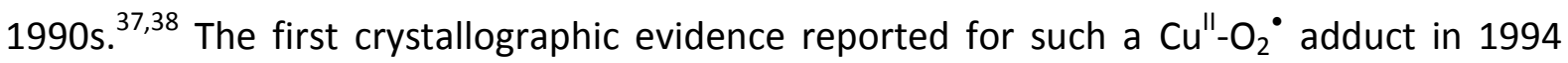
revealed a side-on binding mode $\left({ }^{5} \mathbf{S}\right)$ of the dioxygen-derived superoxide ligand (Scheme 1.4). ${ }^{39}$ Detailed spectroscopic studies showed that the latter species was different to that observed by stop-flow techniques, ${ }^{40}$ and finally in 2006 the related end-on superoxo adduct ( $\left.{ }^{\mathrm{E}} \mathrm{S}\right)$ could be structurally characterised. ${ }^{41}$ Significantly, the same ${ }^{\mathrm{E}} \mathbf{S}$ binding mode has been crystallographically observed for the PHM catalytic site. ${ }^{19}$ This observation highlights that these $\mathrm{Cu}^{\prime \prime}-\mathrm{O}_{2}{ }^{\bullet}$ adducts represent more than just intermediates in the self-assembly of $\mathrm{Cu}_{2} \mathrm{O}_{2}$ systems, but are important potentially reactive copper-oxygen species in their own right.

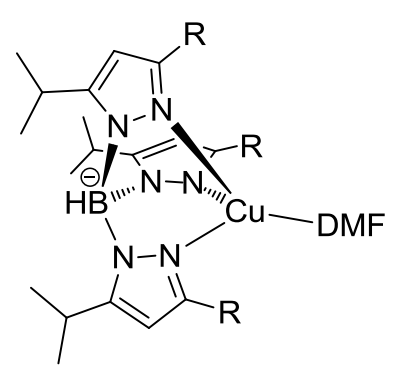

when $\mathrm{R}=$ iso-propyl<smiles>[AlH2]O[GeH3]</smiles>

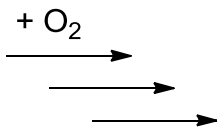

when $\mathrm{R}=$ tert-butyl

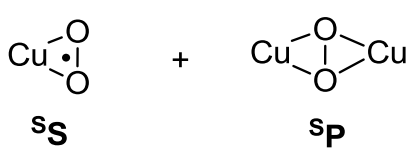

when $\mathrm{R}$ = adamantyl<smiles>O1O[Al]1</smiles>

$\mathbf{s}_{\mathbf{S}}$

Scheme 1.5: Reaction of $\mathrm{HB}\left(\mathrm{Pz}^{i} \mathrm{PrR}\right)_{3}$ supported copper(I) complexes with $\mathrm{O}_{2}$ leads to different copperdioxygen adducts, depending on the steric demands of the ligand employed. Oxidation state and stoichiometry are omitted.

Many further examples of model systems which form these copper-oxygen adducts have since been reported. ${ }^{14,15,30,42-44}$ These investigations have revealed that ligand attributes such as denticity, charge, chelate ring size, steric demand, and donor atom type can to a 
large extent be used to bias which of these type of structures forms. ${ }^{14} \mathrm{The} \mathbf{H B}\left(\mathbf{P z}^{i} \mathbf{P r}_{2}\right)_{3}$ and $\mathbf{H B}\left(\mathbf{P z}^{i} \mathbf{P r}^{t} \mathbf{B u}\right)_{3}$ ligands which respectively led to isolation of the first ${ }^{\mathbf{S}} \mathbf{P}$ and ${ }^{\mathbf{S}} \mathbf{S}$ species provide a good example of the role of steric effects. The initial dioxygen adduct in both systems is most likely a ${ }^{S} \mathbf{S}$ species. In the case of the $\mathbf{H B}\left(\mathbf{P z}^{i} \mathbf{P r}_{2}\right)_{3}$ system, this species can then subsequently react with a second copper(I) complex to give the ${ }^{S} \mathbf{P}$ product (Scheme 1.5). ${ }^{28}$ In contrast, the steric bulk of the $\mathbf{H B}\left(\mathbf{P z}^{i} \mathbf{P r}^{t} \mathbf{B u}\right)_{3}$ system prevents this dimerisation, allowing for isolation of the ${ }^{\mathrm{S}} \mathbf{S}$ intermediate. ${ }^{39}$ It is worth noting that further solution studies of the $\mathbf{H B}\left(\mathbf{P z}^{i} \mathbf{P r}^{t} \mathbf{B u}\right)_{3}$ system revealed the presence of a ${ }^{\mathbf{S}} \mathbf{P}$ species in addition to the isolated ${ }^{\mathbf{S}} \mathbf{S}$ intermediate, indicating that the tert-butyl groups were not sufficient to completely inhibit dimerisation. ${ }^{40}$ In the same investigation the analogous adamantyl-substitued ligand, $\mathbf{H B}\left(\operatorname{Pz}^{i} \operatorname{Pr} \mathbf{A d}\right)_{3}$, was then employed instead, leading to pure solutions of the corresponding ${ }^{\mathbf{S}} \mathbf{S}$ adduct. This serves to illustrate how rational ligand design can be used to favour the formation of specific copper-dioxygen species. However, in some cases different $\mathrm{Cu}_{2} \mathrm{O}_{2}$ adducts can result, even from the same supporting ligand scaffold. These species can furthermore interconvert depending on the experimental conditions, as described below.

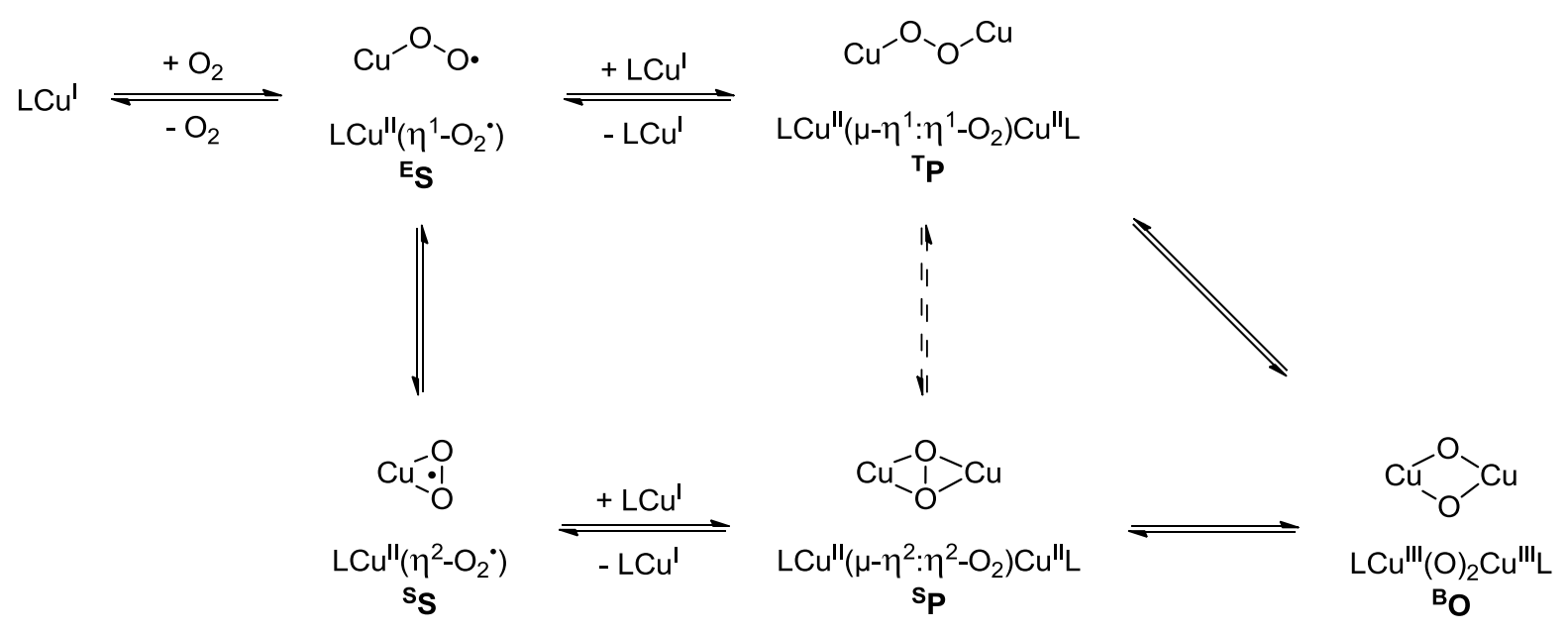

Scheme 1.6: Interconversion pathways between copper-oxygen adducts formed from mononuclear copper(I) complexes.

Original determination of the ${ }^{\mathrm{B}} \mathrm{O}$ structure by X-ray diffraction was further accompanied by the revelation that this type of adduct can exist in equilibrium with the ${ }^{\mathbf{S}} \mathbf{P}$ configuration. Interconversion could be achieved by simply diluting solutions with a different solvent. ${ }^{36}$ Further work has since emerged which is indicative of an equilibrium between the ${ }^{\top} \mathbf{P}$ and ${ }^{\mathbf{B}} \mathbf{O}$ adducts. ${ }^{45-49}$ Curiously, interconversion between the ${ }^{\top} \mathbf{P}$ and ${ }^{S} \mathbf{P}$ species is relatively unknown, although it has been proposed on the basis of unusual reactivity exhibited by a ${ }^{\mathbf{T}} \mathbf{P}$ species. ${ }^{50}$ Nevertheless, the three isoelectronic species can be thought of as a series leading toward scission of the dioxygen-derived bridging ligand (Scheme 1.6). The ${ }^{\mathrm{E}} \mathbf{S}$ and ${ }^{\mathrm{S}} \mathbf{S}$ adducts discussed earlier also clearly contribute to this overall mechanistic picture of dioxygen activation. ${ }^{47}$ Indeed, the $\mathrm{Cu}^{\prime \prime}-\mathrm{O}_{2}{ }^{\bullet}$ structures exhibit shorter $\mathrm{O}-\mathrm{O}$ bond lengths $(\approx 1.2-1.3 \AA)$ than the $\mathrm{Cu}_{2} \mathrm{O}_{2}$ peroxo-adducts $(\approx 1.4-1.5 \AA)$, in agreement with the intermediate role of the former mononuclear species. ${ }^{14}$ Of the dinuclear species, the ${ }^{\top} \mathbf{P}$ adduct possesses the least 
activated $\mathrm{O}-\mathrm{O}$ bond (evident from spectroscopy, see Section 4.1). Progression to the ${ }^{\mathrm{S}} \mathbf{P}$ core leads to further weakening until cleavage finally occurs in the ${ }^{B} O$ species. This is accompanied by contraction of the $\mathrm{Cu} \cdots \mathrm{Cu}$ distance from approximately $4.4 \AA^{\circ}\left({ }^{\top} \mathbf{P}\right)$, through $3.5 \AA\left({ }^{\mathrm{S}} \mathrm{P}\right)$, to $2.8 \AA\left({ }^{\mathrm{B}} \mathrm{O}\right) .{ }^{14}$ The binding mode, electronic structure, and degree of dioxygen activation in these cores are intimately related, and largely contribute to determining their resulting reactivity patterns.

\subsubsection{An Inorganic Model for pMMO}

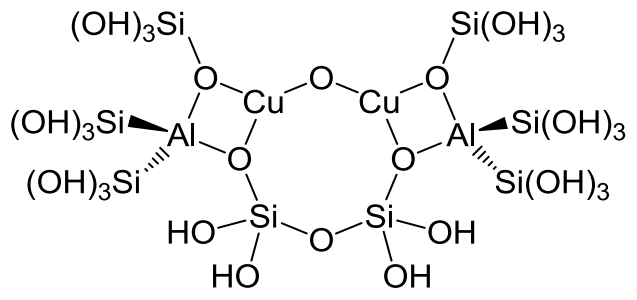<smiles></smiles>

Scheme 1.7: The Cu-ZSM-5 zeolite (left) and pMMO (right) active site models containing the ${ }^{\mathrm{M}} \mathrm{O}$ species used for DFT studies. Charges are omitted.

Two closely spaced $(2.6 \AA)$ copper ions are present in the catalytic site of pMMO, but despite this the reactive species is thought to differ from all of those described above. This largely results from investigations of a copper-loaded aluminosilicate zeolite (Cu-ZSM-5), ${ }^{51-}$ ${ }^{53}$ which is the only well-defined functional dinuclear model system of pMMO at this time. ${ }^{18}$ Reaction of the reduced copper(I) form of Cu-ZSM-5 with dioxygen gas at elevated temperatures $\left(\geq 175^{\circ} \mathrm{C}\right)^{51-53}$ gives rise to a species which was originally identified as a ${ }^{\mathrm{B}} \mathbf{O}$ type adduct. ${ }^{52,53}$ Subsequent resonance Raman (rR) spectroscopic analysis, aided by the significant amount of data available for other copper-dioxygen species, led to reassignment of this CU-ZSM-5 dioxygen-adduct as a dinuclear copper(II) mu-oxo structure $\left(\mathrm{Cu}_{2}{ }_{2}(\mu-\mathrm{O})\right.$, $\left.{ }^{\mathrm{M}} \mathbf{O}\right) .{ }^{51}$ DFT studies carried out on the ${ }^{\mathrm{M}} \mathbf{O}$ motif were then shown to accurately reproduce the spectroscopic features of the dioxygen-activated Cu-ZSM-5. ${ }^{51}$ Furthermore, this ${ }^{\mathrm{M}} \mathbf{O}$ species was shown to be competent for hydrogen-atom abstraction from methane when computationally modelled into both the Cu-ZSM-5 ${ }^{51}$ and the active site of pMMO (Scheme 1.7). ${ }^{16}$ It has since been found that dioxygen initially binds to the zeolite as a ${ }^{5} \mathbf{P}$ adduct at $\mathrm{RT}$, and the reactive ${ }^{\mathrm{M}} \mathrm{O}$ species is formed at higher temperatures from this $\mathrm{Cu}_{2} \mathrm{O}_{2}$ precursor. ${ }^{54}$ 


\subsubsection{General Reactivity}

The reactivity characteristics of the above described dioxygen-adducts have, in the majority of cases, been extensively investigated. The possibility of interconversion between species can clearly complicate such studies, and this aspect must be taken into account when interpreting cases involving unprecedented reactivity. Nonetheless, good correlation between the type of copper-dioxygen adduct formed and the resulting reactivity have been observed for many systems, allowing for generalised structure-reactivity relationships to be proposed. Of the $\mathrm{Cu}_{2} \mathrm{O}_{2}$ species the least activated ' $\mathbf{P}$ type tends to exhibit basic or nucleophilic reactivity, readily becoming protonated and lacking the ability to transfer oxygen atoms to organic substrates. ${ }^{15,29}$ This is in stark contrast with the electrophilic behaviour displayed by the ${ }^{\mathbf{S}} \mathbf{P}$ and ${ }^{\mathrm{B}} \mathbf{O}$ cores, which often undergo decomposition through pathways which involve oxidative attack upon their supporting ligand scaffolds. ${ }^{15,25,29,30}$ The ${ }^{\mathbf{S}} \mathbf{P}$ type is considered to be particularly biologically relevant, as this state has been crystallographically observed in the parent T3 enzymes, including Tyr. ${ }^{18}$ The corresponding model systems which form this ${ }^{S} \mathbf{P}$ moiety can furthermore carry out aromatic hydroxylation. ${ }^{25,29,33,55}$ However, observation of the equilibrium between this and the ${ }^{\mathrm{B} O}$ adduct implicates the latter as an alternative candidate for the biologically relevant hydroxylating species in Tyr. ${ }^{16,18,25}$

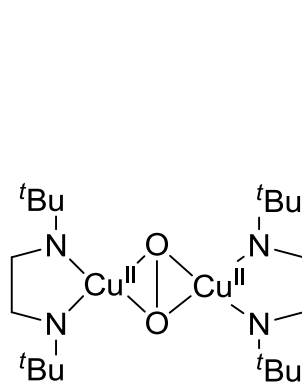<smiles>CC(C)(C)c1ccc(O[N+](=O)[O-])c(Br)c1</smiles>

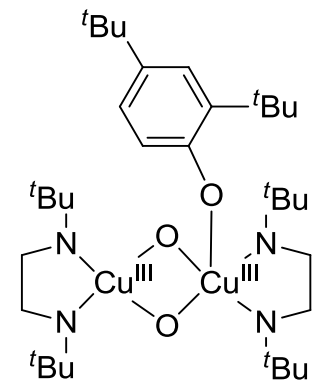

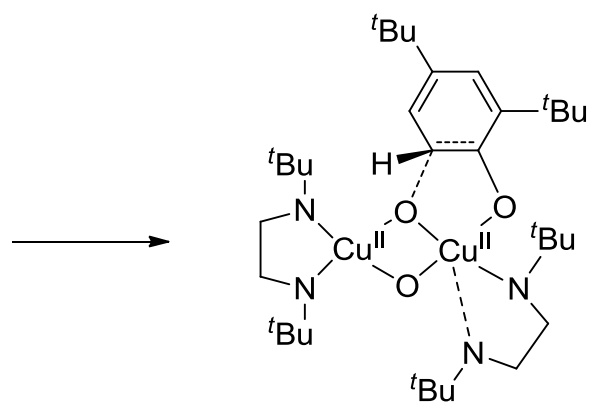<smiles>[13CH3]N1CCN([13CH3])C1O</smiles><smiles>CC(C)(C)CN1CCN(CC(C)(C)C)C12Oc1cc(C(C)(C)C)cc(C(C)(C)C)c1O2</smiles>

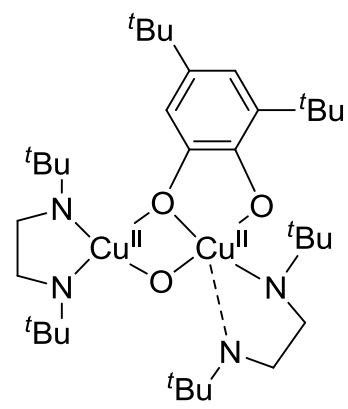

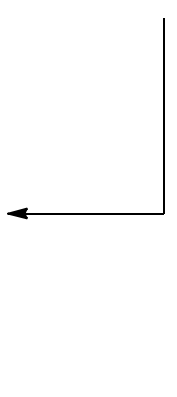

Scheme 1.8: Mechanism of phenolate hydroxylation mediated by a ${ }^{\mathrm{B} O}$ species by the neutral diamine DBED ligand. Counterions are omitted.

Indeed, ${ }^{B} \mathbf{O}$ type cores are also capable of hydroxylating aromatic substrates. ${ }^{25}$ Regardless of whether mediated by the ${ }^{\mathrm{S}} \mathbf{P}$ or ${ }^{\mathrm{B}} \mathrm{O}$ species, it is evident from the negative slope of the 
corresponding Hammett parameters that these aromatic hydroxylation reactions occur by an electrophilic aromatic substitution mechanism, in agreement with the native Tyr system. ${ }^{18}$ Although the ${ }^{\mathrm{B}} \mathrm{O}$ adduct has never been directly observed in enzymatic systems, ${ }^{15}$ it has been shown to be a viable mechanistic intermediate through investigation of a model system which employs the $N, N^{\prime}$-di-tert-butyl-ethylenediamine, DBED, ligand system (Scheme 1.8). ${ }^{56}$ The corresponding copper(I) complex supported by this ligand initially gives an ${ }^{\mathbf{S}} \mathbf{P}$ species upon reaction with dioxygen. However, binding of external phenolate to one of the copper centres in the ${ }^{\mathbf{S}} \mathbf{P}$ adduct has been shown to induce conversion into an ${ }^{\mathbf{B}} \mathbf{O}$ core, which subsequently hydroxylates the coordinated phenolate substrate. This provides experimental precedent for an analogous mechanism in Tyr, and has significantly contributed to the debate over whether the natural system uses a ${ }^{5} \mathbf{P}$ or ${ }^{B} \mathbf{O}$ species to achieve aromatic substrate hydroxylation (see Section 6.4.1 for further detail).

\subsubsection{Radical-like Reactivity}

$$
\begin{aligned}
& \mathrm{Cu}^{\prime}{ }^{-} \mathrm{Cu} \underset{\text { polarisation }}{\stackrel{\mathrm{TS}}{\longrightarrow}} \mathrm{Cu} \stackrel{\mathrm{O}:}{\mathrm{C}} \mathrm{Cu} \\
& \begin{array}{c}
\mathrm{Cu}^{\prime \prime}(\mu-\mathrm{O}) \mathrm{Cu}^{\prime \prime} \\
\text { mu-oxo } \\
\mathrm{Cu}^{\prime \prime}\left(\mathrm{O} \cdot \cdots \mathrm{Cu}^{\prime}\right. \\
\text { cupric-oxyl }
\end{array} \\
& \mathrm{Cu}_{-\mathrm{O}^{\prime}}^{-\mathrm{O}} \mathrm{Cu} \underset{\text { cleavage }}{\stackrel{\mathrm{Cu}-\mathrm{O} \text { bond }}{\rightleftarrows}} \mathrm{Cu}_{\mathrm{O}^{\prime}}^{/ /} \mathrm{Cu} \rightleftarrows \mathrm{Cu}_{\mathrm{O}^{\prime}}^{\mathrm{O}} \mathrm{Cu} \\
& \begin{array}{ccc}
\mathrm{Cu}^{\prime \prime \prime}(\mu-\mathrm{O})_{2} \mathrm{Cu}^{\prime \prime \prime} & \mathrm{Cu}^{\prime \prime \prime}(\mathrm{O})(\mu-\mathrm{O}) \mathrm{Cu}^{\prime \prime \prime} & \mathrm{Cu}^{\prime \prime}(\mathrm{O} \cdot)(\mu-\mathrm{O}) \mathrm{Cu}^{\prime \prime \prime} \\
\text { bis-(mu-oxo } & \text { cupryl-oxo } & \text { cupric-oxyl }
\end{array}
\end{aligned}
$$

Scheme 1.9: Terminal (pseudo-)mononuclear copper-oxygen reactive species capable of oxygenating methane on the basis of computational studies.

Aside from aromatic hydroxylation, ${ }^{\mathrm{B}} \mathrm{O}$ species have been shown to promote oxidative $\mathrm{N}$ dealkylation, phenol coupling, and aliphatic hydroxylation reactions. ${ }^{11,46,47}$ These are most often found to be initiated by hydrogen-atom abstraction. ${ }^{15,25,30}$ Although this radical-type reactivity is not strictly applicable to T3 copper centres with respect to their biological phenolic substrates, it is thought to play a role in the hydroxylation of methane by pMMO. ${ }^{16,18}$ The active intermediate proposed in the case of pMMO is an ${ }^{\mathrm{M}} \mathbf{O}$ species, a conclusion based on the identification of an equivalent active species in the Cu-ZSM-5 zeolite, which also possesses the ability to hydroxylate methane (Section 1.3.2). A key concept involved in achieving this reactivity in both the pMMO and Cu-ZSM-5 systems is asymmetric polarisation of the $\mathrm{Cu}_{2}{ }_{2}(\mu-0)$ species in the transition state, which gives it cupric-oxyl ( $\left.\mathrm{Cu}^{\prime \prime}-\mathrm{O}^{\circ} \cdot \mathrm{Cu}^{\prime}\right)$ radical character (Scheme 1.9). ${ }^{16,18,51}$ Although computationally disfavoured on energetic grounds, ${ }^{57}$ an alternative proposal for the enzyme involves cleavage of an initial ${ }^{\mathrm{B}} \mathrm{O}$ adduct to expose an analogous terminal cupryl-oxo/cupric-oxyl $\left(\mathrm{Cu} \mathrm{III}^{\mathrm{II}}=\mathrm{O} \leftrightarrow \mathrm{Cu}^{\prime \prime}-\mathrm{O}^{\circ}\right)$ species (Scheme 1.9). ${ }^{11,15}$ The tendency for these terminal (pseudo- 
Imononuclear species to participate in radical-type chemistry is also relevant to the aforementioned copper(II)-superoxide species.

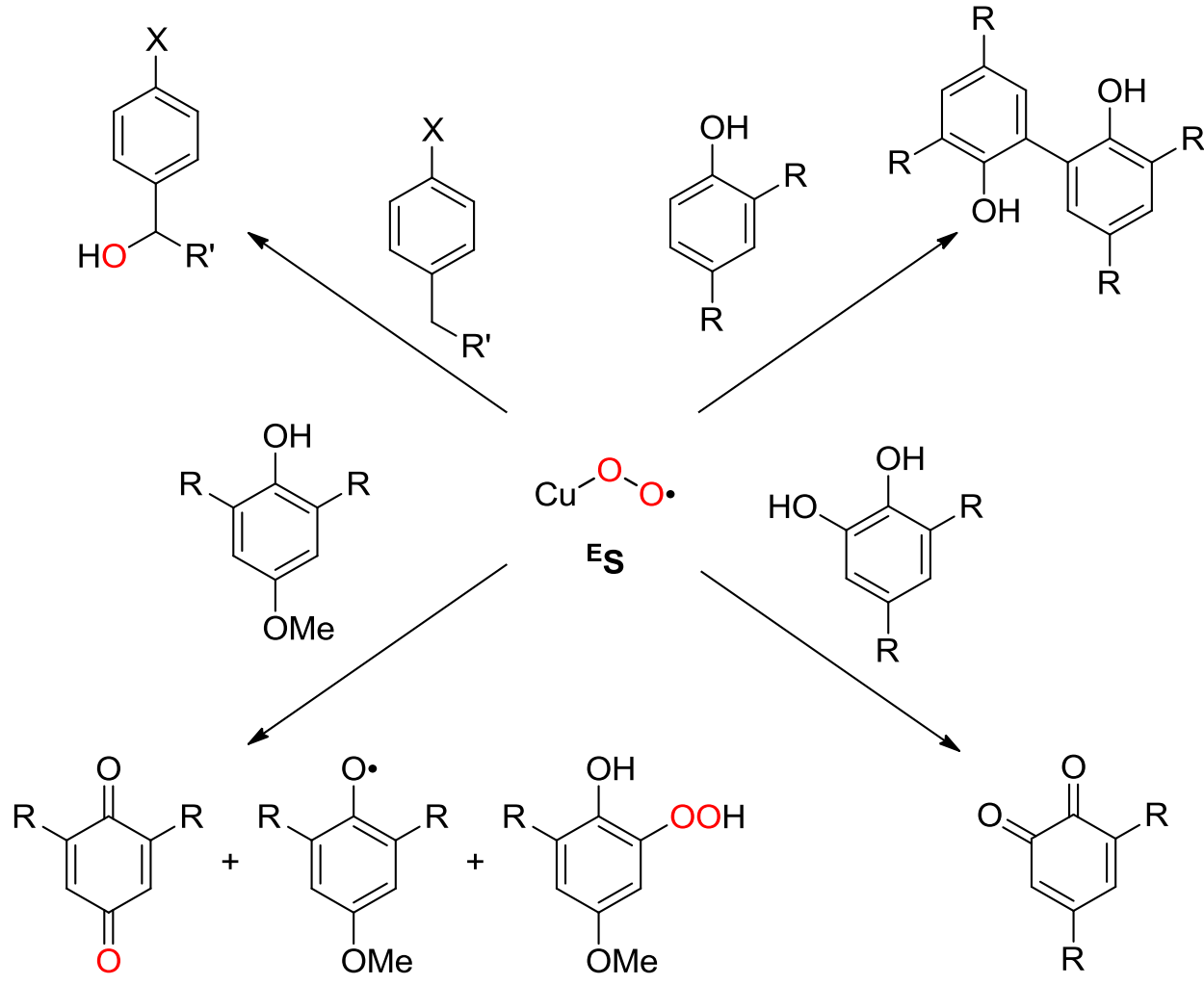

Scheme 1.10: Reactivity displayed by ${ }^{\mathrm{E}} \mathrm{S}$ species. $\mathrm{R}=$ tert-butyl, $\mathrm{R}^{\prime}=N$-methanediyl- $N^{\prime}-(2$-pyridylethyl)-1,5diazacyclooctane (see Scheme 6.1 for full ligand structure and more reaction detail), $\mathrm{X}=\mathrm{OMe}, \mathrm{Me}, \mathrm{H}, \mathrm{Cl}, \mathrm{NO}$.

A mononuclear copper-dioxygen adduct is thought to perform the $\mathrm{C}-\mathrm{H}$ abstraction which facilitates substrate hydroxylation in both the DBM and PHM enzymes. ${ }^{16,18,21}$ This has inspired investigation of these species as more than just intermediates in the self-assembly of $\mathrm{Cu}_{2} \mathrm{O}_{2}$ systems, but as catalytic sites in their own right. While it has been computationally predicted that the ${ }^{\mathrm{S}} \mathrm{S}$ type adduct is activated for homolytic $\mathrm{C}-\mathrm{H}$ bond scission, ${ }^{13,16}$ no experimental evidence supporting this finding has yet been reported. ${ }^{58}$ Conversely, a growing amount of literature has recently become available which indicates that ${ }^{\mathrm{E}} \mathbf{S}$ species are capable of mediating phenol coupling reactions, oxidation of activated organic molecules, ${ }^{59,60}$ and oxygen transfer to aliphatic ${ }^{43,44,60}$ and aromatic ${ }^{60,61}$ substrate positions, all of which are thought to be initiated by $\mathrm{H}$-atom abstraction (Scheme 1.10). Although this reactivity is in agreement with calculations indicating the ${ }^{\mathrm{E}} \mathrm{S}$ species is even further activated for $\mathrm{C}-\mathrm{H}$ abstraction, ${ }^{16,18}$ an example in which such an adduct exhibits basic character has also been reported. ${ }^{62}$ Furthermore, the reactivity profile for said system was very recently expanded upon to include nucleophilic behaviour toward organic carbonyl-containing substrates. ${ }^{63}$ The distinctive reactivity characteristics of this system have in both cases been attributed to the di-anionic nature of the supporting ligand. ${ }^{62,63}$ It is worth noting that the two systems so far capable of affecting aliphatic substrate hydroxylation are thought to follow divergent mechanisms which employ contrasting active species, as a result of 
differences in the number and electronic nature of the donor atoms provided by their chelating scaffolds. ${ }^{42,43,60}$ Thus, despite the fact that the above described systems all share the same ${ }^{\mathrm{E}} \mathbf{S}$ configuation, it is apparent that the characteristics of the copper-dioxygen adduct can be significantly influenced by supporting ligand scaffold.

\subsubsection{Dinucleating ligands}
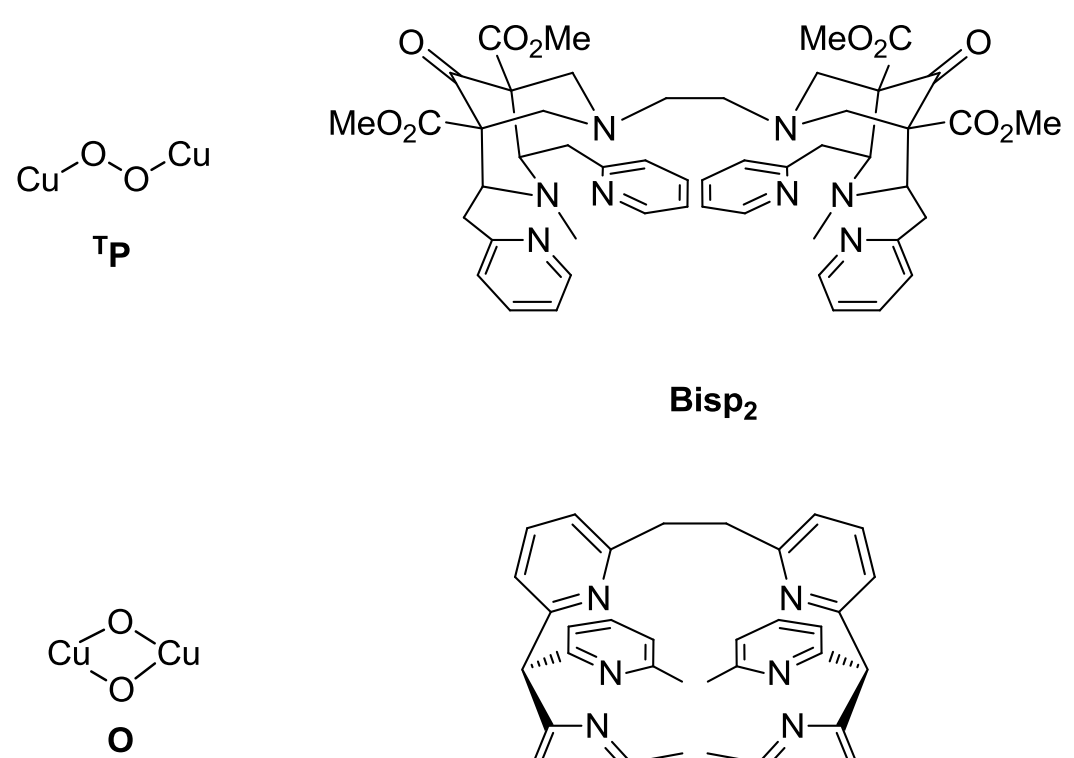

$\mathrm{Bisp}_{2}$

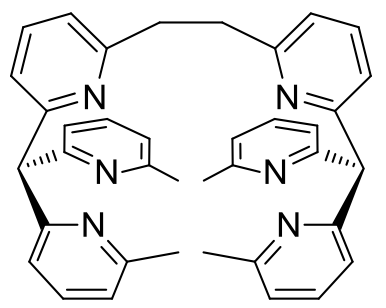

Tripy $_{2}$

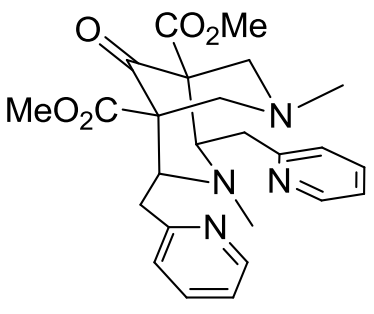

Bisp

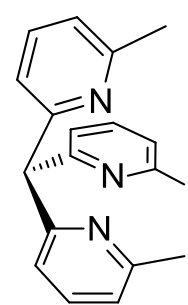

Tripy

Scheme 1.11: Two illustrative examples highlighting the potential of dincleating organic scaffolds for stabilising $\mathrm{Cu}_{2} \mathrm{O}_{2}$ species. Half-lives of the adducts formed with the mononucleating ligands were in both cases orders of magnitude shorter than their corresponding dinucleating analogues (see text for details).

Reactions aimed at isolating dioxygen adducts from mononuclear copper complexes are generally performed at low temperatures in order to suppress decomposition pathways of the often highly reactive species, and to offset the entropic costs of self-assembly. ${ }^{10,14,30,33,64}$ The structurally characterised species discussed above (Scheme 1.4) serve as examples, and were all synthesised at or below $-20^{\circ} \mathrm{C}$, with temperatures down to $-78^{\circ} \mathrm{C}$ being commonly employed. ${ }^{28,34,36,39,41}$ An alternative strategy which can enable the generation of $\mathrm{Cu}_{2} \mathrm{O}_{2}$ species under ambient conditions is to use a pre-organised dinucleating ligand. Although this approach can lead to complications involving competition between pathways which result in intra- and inter-molecular adducts (Section 4.4.5), ${ }^{65,66}$ significant enhancements in stability relative to the analogous mononucleating ligands have been observed in some cases (Scheme 1.11). For example, the ${ }^{\top} \mathbf{P}$ species supported by the dinucleating Bisp $\mathbf{B}_{\mathbf{2}}$ ligand is considerably longer lived $\left(\mathrm{t}_{1 / 2} \approx 50 \mathrm{~min}\right.$ at $25^{\circ} \mathrm{C}$ ) than that formed with the corresponding mononucleating ligand, Bisp $\left(\mathrm{t}_{1 / 2} \approx 15 \mathrm{sec}\right.$ at $\left.-23^{\circ} \mathrm{C}\right) .{ }^{67}$ Similarly, the ${ }^{\mathrm{B}} \mathrm{O}$ adduct supported by Tripy $_{2}\left(\mathrm{t}_{1 / 2} \approx 25.5 \mathrm{~h}\right.$ at $25{ }^{\circ} \mathrm{C}$ ) is remarkably robust in comparison with its counterpart, generated with Tripy, which is only observed at low temperature. ${ }^{68}$ In both cases these 
improvements have been attributed to entropic stabilisation owing to the dinucleating nature of the supporting organic scaffolds.

\subsection{Pyrazole Model Chemistry}

One strategy for synthesising dinuclear biomimetic model complexes is to employ an organic scaffold which possesses both a bridging unit and covalently linked side arms, thus creating compartmental multidentate binding pockets. The resulting preorganised chelating ligand then favours the arrangement of two or more metal ions in close proximity, with metal separations largely depending on the bridging unit. ${ }^{69}$ The pyrazole heterocycle fulfils such a role upon deprotonation. It can then act as an anionic bridge reminiscent of a carboxylate group ${ }^{70,71}$ but with suitable sites at the 3 - and 5- positions for further functionalisation (Scheme 1.12), allowing for formation of stable five- and/or six-membered chelate rings upon complexation. ${ }^{69}$
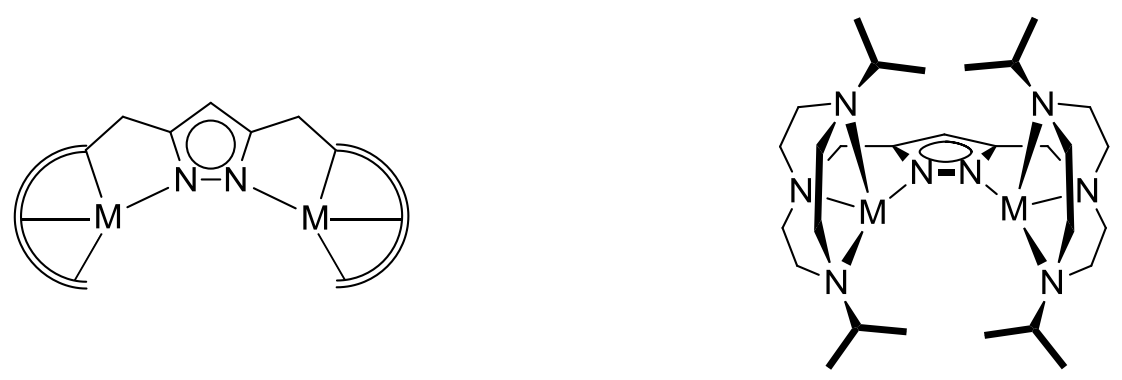

Scheme 1.12: Schematic representation of a dinuclear metal complex supported by a 3,5-substituted pyrazolebridging ligand. Complexes with nickel(II), copper(II) and zinc(II) are known for the selected ligand depicted.

The pyrazole building block thus provides synthetic flexibility, and has been proven to preorganise two metal centres in a fashion which allows cooperativity. ${ }^{72}$ Variation of the chelating side arms allows the geometric and electronic properties to be manipulated, such as denticity, identity of donor atoms, and metal separation. The latter of these can be controlled by varying the length of the chelating side arms, short lengths favouring large intermetallic distances and vice versa, with typical metal separations of $3.5-4.5 \AA{ }^{72}$ This versatility has allowed these ligand systems to be successfully applied in emulating dinuclear iron, ${ }^{73,74}$ nickel, $^{75-77}$ copper $^{78,79}$ and zinc $^{80-82}$ metallobiosites. 


\subsubsection{Copper Chemistry Supported by 3,5-Disubstitued Pyrazole Ligands}

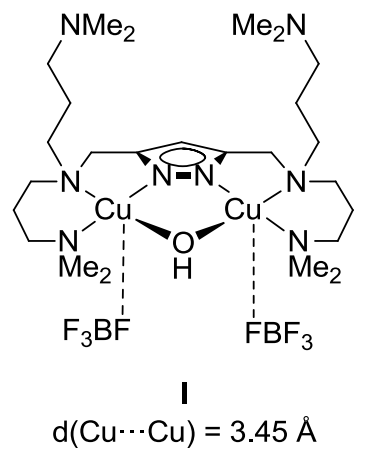

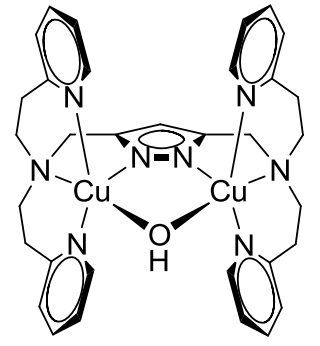

II

$\mathrm{d}(\mathrm{Cu} \cdots \mathrm{Cu})=3.52 \AA$

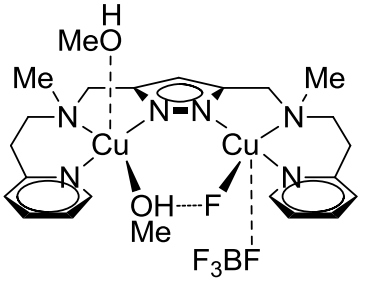

V

$\mathrm{d}(\mathrm{Cu} \cdots \mathrm{Cu})=4.29 \AA$

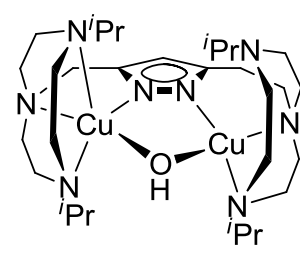

III

$\mathrm{d}(\mathrm{Cu} \cdots \mathrm{Cu})=\sim 3.5 \AA^{*}$

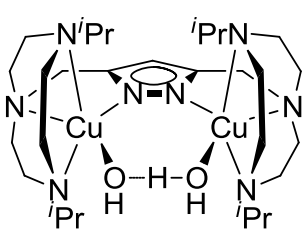

VII

$\mathrm{d}(\mathrm{Cu} \cdots \mathrm{Cu})=4.41 \AA$

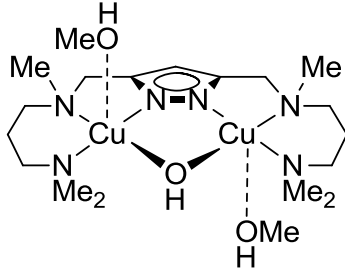

IV

$\mathrm{d}(\mathrm{Cu} \cdots \mathrm{Cu})=3.54 \AA$

Scheme 1.13: A series of related dinuclear copper(II) complexes with differing metal separations, used as functional models for the dinuclear copper(II) metalloenzyme, catechol oxidase (CO). Charges and counterions are omitted. * Distance estimated from analogous nickel(II) complex.

The use of 3,5-disubstituted pyrazole scaffolds for biomimetic applications is well illustrated by their use as functional models of the T3-site in CO enzymes. These metallobiomolecules catalyse the copper-mediated oxidation of catechols to the corresponding quinones, referred to as catecholase activity. In this exemplary model study, a diverse set of pyrazolebased supporting scaffolds with differing nitrogen-donor atom types, numbers, and side arm lengths was prepared. These ligands were employed to engineer a series of related dinuclear copper(II) complexes with a range of redox potentials and metal separations (I-VIII, Scheme 1.13). ${ }^{78,79}$ The catecholase functionality of the resulting complexes was then investigated using the activated substrate 3,5-di-tert-butylcatechol. While both redox potential and $\mathrm{Cu}$... Cu separation were found to influence activity, a general trend indicating that shorter metal-metal distances are favourable for catalytic ability could be established. This example demonstrates the potential of pyrazole-based ligand scaffolds for systematic modulation of the properties of corresponding model complexes.

A significant part of the motivation for studying biological systems stems from the desire to utilise the knowledge gained to not only reproduce but also expand upon the chemistry observed in nature, allowing for novel molecules with valuable functionality to be produced. The pyrazole unit has proven synthetically useful in this regard, for example, by condensing the features of two mononuclear metalloprotein active sites into a discrete ligand. ${ }^{83,84}$ For example, an expanded porphyrin scaffold made up of an organic framework with two adjacent metal binding pockets has recently been reported. This so-called siamese twin 
porphyrin scaffold was then used to incorporate two adjacent copper(II) ions into a bioinspired hybrid complex (IX, Scheme 1.14) with unique physicochemical properties. ${ }^{85,86}$ In a related approach, the bridging capacity of pyrazole was exploited to merge two tetradentate tripodal metal-binding compartments. The corresponding dinuclear copper(II) complexes ( $\mathbf{X}, \mathbf{X I}$, Scheme 1.14) supported by this ligand system were then shown to be capable of mediating both benzylic $(\mathbf{X})^{87}$ and phenylic $(\mathbf{X I})^{88} \mathrm{C}-\mathrm{C}$ coupling reactions. As $\mathbf{X}$ and $\mathbf{X I}$ demonstrate, the scaffolds employed combine two tris(aminoalkyl)amine binding pockets to bring two copper(II) ions into close proximity, with one binding site on each metal centre available for additional external co-ligands. This system can thus be thought of as a preorganised dinucleating analogue of the prominent TMPA and tren systems extensively utilised in studies of copper-mediated dioxygen activation (Section 1.3.1).

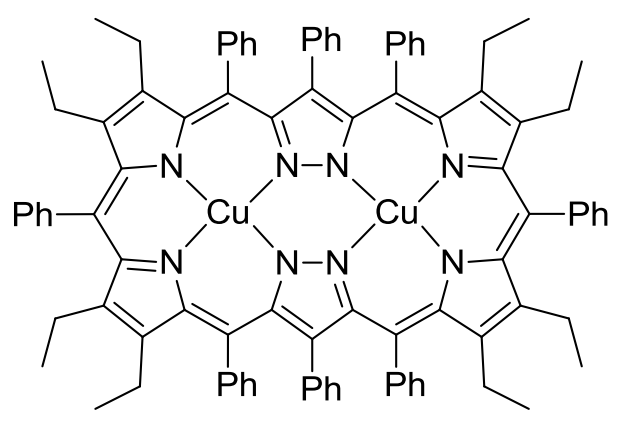

Siamese twin porphyrin

IX

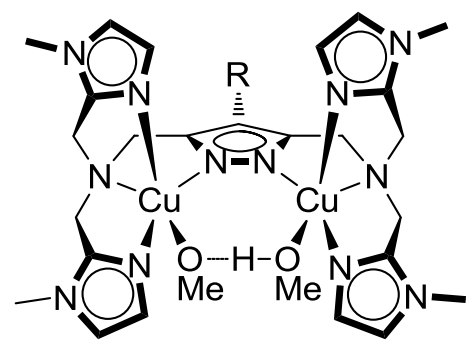

Hybrid bis-tripodal system $\mathrm{R}=\mathrm{H}=\mathbf{X}, \mathrm{R}=\mathrm{Ph}=\mathbf{X} \mathbf{I}$

Scheme 1.14: Complexes illustrating the use of pyrazole to construct dinucleating analogues of prominent mononuclear metal binding sites.

As highlighted above, pyrazole-bridging ligands of the general type shown in Scheme 1.12 are particularly versatile, showing the potential to fuse discrete metal ion binding sites into binucleating compartmental scaffolds, and further enabling modulation of metal separations in the corresponding complexes. Despite finding considerable application in the field of bioinspired copper chemistry, the use of these systems to directly investigate copper-mediated dioxygen activation is extremely limited, with only a single example in the literature. In this example, a copper(I) complex was generated in situ from the bis-tridentate pyrazole ligand $\left(\mathbf{H L}^{1}\right)$ depicted in Scheme 1.15. After ether layering and exposure to air at low temperature, a copper(II)-peroxo adduct could be isolated and crystallographically characterised. ${ }^{89}$ Although not strictly biologically relevant owing to its tetranuclear nature, this complex illustrates that pyrazole-based ligand systems are indeed suitably robust for investigations of this type of chemistry, and may even provide synthetic routes to novel copper-oxygen adducts. 
2

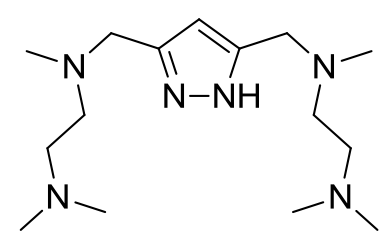

$\mathrm{HL}^{1}$

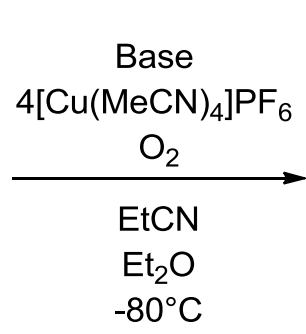

$-80^{\circ} \mathrm{C}$

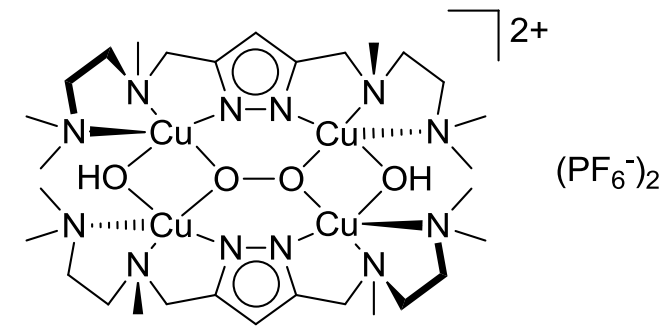

$$
\left[\left(\mathrm{Cu}_{2}{ }_{2} \mathrm{~L}_{2}\right)_{2}\left(\mathrm{O}_{2}\right)(\mathrm{OH})_{2}\right]^{(\mathrm{PF} 6) 2}
$$

Scheme 1.15: Isolation of a novel tetranuclear copper(II)-peroxo adduct, $\left[\left(\mathrm{Cu}_{2}{ }_{2} \mathrm{~L}^{1}\right)_{2}\left(\mathrm{O}_{2}\right)(\mathrm{OH})_{2}\right]$, supported by a binucleating pyrazole-based ligand scaffold. Electron and mass balance are not properly accounted for here (discussed in detail in Section 4.2).

The complex cation depicted in Scheme 1.15, $\left[\left(\mathrm{Cu}^{\prime \prime}{ }_{2} \mathrm{~L}^{1}\right)_{\mathbf{2}}\left(\mathrm{O}_{2}\right)(\mathrm{OH})_{2}\right]$, consists of two pyrazolate-bridged dinuclear copper(II) fragments linked by two flanking hydroxide units and a central $\mu_{4}$-peroxide core, a rare motif in copper-oxygen chemistry. Although there is uncertainty about the mechanistic details of formation (Section 4.2), it is evident from geometric considerations that this type of ligand can support complexes bridged simultaneously by both a pyrazolate and $\mu-1,2$-peroxide moiety. Assuming the copper $(1)$ precursor complex is indeed dinuclear, the predicted metal separation would make a reaction pathway which proceeds through a cis- $\mu-1,2$-peroxide intermediate plausible (Scheme 1.16). Furthermore, it is likely that the high flexibility and low steric demand of $\mathbf{H L}^{\mathbf{}}$, together with the free binding sites on each of the two resulting copper(II) atoms, make this system susceptible to dimerisation. Selection of an appropriately 3,5-disubstituted pyrazole scaffold which takes all of these factors into account may thus provide a strategy for hindering the dimerisation process, and isolating a novel dicopper(II)-cis- $\mu$-1,2-peroxide ( $\left.{ }^{\mathbf{P}} \mathbf{P}\right)$ motif.

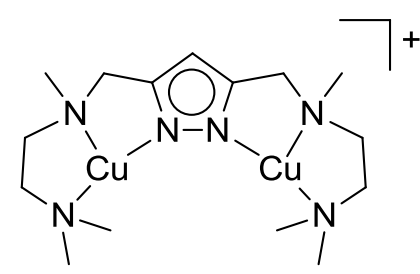

$\left[\mathrm{Cu}_{2}^{\prime} \mathrm{L}^{1}\right]$

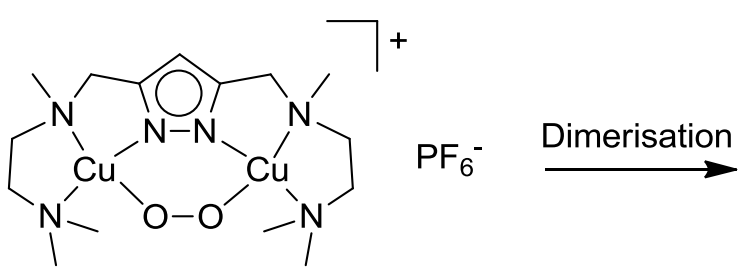

$\left[\mathrm{Cu}_{2}{ }_{2} \mathrm{~L}^{1}\left(\mathrm{O}_{2}\right)\right]$

Scheme 1.16: A plausible reaction pathway for formation of $\left[\left(\mathrm{Cu}_{2}{ }_{2} \mathrm{~L}^{1}\right)_{2}\left(\mathrm{O}_{2}\right)(\mathrm{OH})_{2}\right]$. The proposed intermediate, $\left[\mathrm{Cu}_{2} \mathrm{~L}^{1}\left(\mathrm{O}_{2}\right)\right]$, is potentially a novel type of $\mathrm{Cu}_{2} \mathrm{O}_{2}$ adduct.

\subsubsection{Towards a novel $\mathrm{Cu}_{2} \mathrm{O}_{2}$ core - Focus of this work}

A considerable number of multidentate pyrazole-bridging ligand systems capable of supporting copper-mediated reactivity have been developed, as mentioned above (Section 1.4.1). By drawing on this established knowledge it is evident that several of the organic scaffolds which chelate the complexes depicted in Scheme 1.13 hold potential as suitable candidates for isolating the elusive dicopper(II)-cis- $\mu-1,2$-peroxide species. In order to retain 
a metal-metal separation similar to that promoted by $\mathbf{H L}^{1}$, only scaffolds with shorter side arms capable of forming five-membered rings were considered. To hinder association of external co-ligands other than dioxygen, additional donor atoms are also required. The most appropriate ligands were thus deemed to be those serving as chelates in the complexes VII and VIII, $\mathbf{H L}^{2}$ and $\mathbf{H L}^{3}$, respectively. In fact, preliminary studies of the dioxygen reactivity of copper(I) complexes formed with these two sterically bulky, bis-tetradentate scaffolds have previously shown considerable promise. ${ }^{90,91}$ These prior contributions provide a starting point for the in-depth investigations detailed in the current work, and are briefly described in each of the relevant sections. In addition, many open questions remain with respect to the formation and properties of the tetranuclear $\left[\left(\mathrm{Cu}_{2}{ }_{2} \mathrm{~L}^{1}\right)_{2}\left(\mathrm{O}_{2}\right)(\mathrm{OH})_{2}\right]$ species supported by $\mathbf{H L}^{1}$, and thus this system was also further investigated herein.

In the majority of previous cases established procedures for pyrazole-bridging ligand synthesis provided material of sufficient purity to isolate the corresponding metal complexes directly. These synthetic strategies were therefore initially adopted herein. However, over the course of the current work it became evident that even though these existing routes gave the desired chelating ligand scaffolds in good yields, the presence of trace organic impurities had an especially significant negative influence on the stability of the resulting copper(I) complexes and their corresponding copper(II)-dioxygen adducts. Due to these complications, the established procedures for ligand synthesis were then reinvestigated. Strategies could thereby be developed for obtaining precursor materials which allowed for substantial enhancements in the stability of the resulting copper(I) and copper(II)-dioxygen species, which in turn greatly aided in facilitating characterisation of these complexes.

The above described re-investigation of ligand synthetic procedures proved to have a significant effect on the outcome of further experiments involving the corresponding copper complexes. Therefore, although not the principal focus of the current work, findings with respect to the isolation and characterisation of precursor materials which form the foundation of this investigation are discussed in the subsequent sections, comprising Chapter 2. Particulars regarding the synthesis and characterisation of the corresponding copper(I) complexes and their associated copper(II)-dioxygen adducts are considered in Chapters 3 and 4 , respectively. As isolation of a dinuclear monomeric ${ }^{C} \mathbf{P}$ adduct is the primary goal of the current work, these chapters have specific emphasis placed on assessing the nuclearity and association states of the copper(I) and copper(II)-dioxygen species in solution. Chapter 5 contains further detailed studies pertaining to the dioxygen-adduct supported by $\mathbf{H L}^{3}$. In Chapter 6 the decomposition pathway of said species is investigated, and the reactivity of the copper(II)-dioxygen adducts supported by both $\mathbf{H L}^{2}$ and $\mathbf{H L}^{3}$ toward a selection of external substrates is examined. Chapter 7 contains a summary of all findings. 


\section{Dinucleating Pyrazole Ligands for Copper-mediated Dioxygen Activation}

\subsection{Introduction}

\subsubsection{Synthetic Routes}

Several strategies exist in the literature for the preparation of 3,5-disubstituted pyrazoles. The most common method is reaction of hydrazine with assorted 1,3-diketones, one of the simplest examples being with acetylacetone to yield 3,5-bis(methyl)- $1 \mathrm{H}$-pyrazole $\left(\mathbf{P z}^{\mathbf{l}}\right){ }^{69,92}$ The activated benzylic carbon atoms of $\mathbf{P z}^{\prime}$ can serve as reactivity handles for further elaboration into multidentate chelates. ${ }^{69,93}$ This molecule was therefore employed as the starting point in this work, through the use of two general synthetic approaches. Both approaches have previously proven widely applicable for producing series of related ligands, and involve reaction of a diverse range of secondary amines with one of two chlorinated derivatives of $\mathbf{P z}^{\prime}$ (Scheme 2.1).

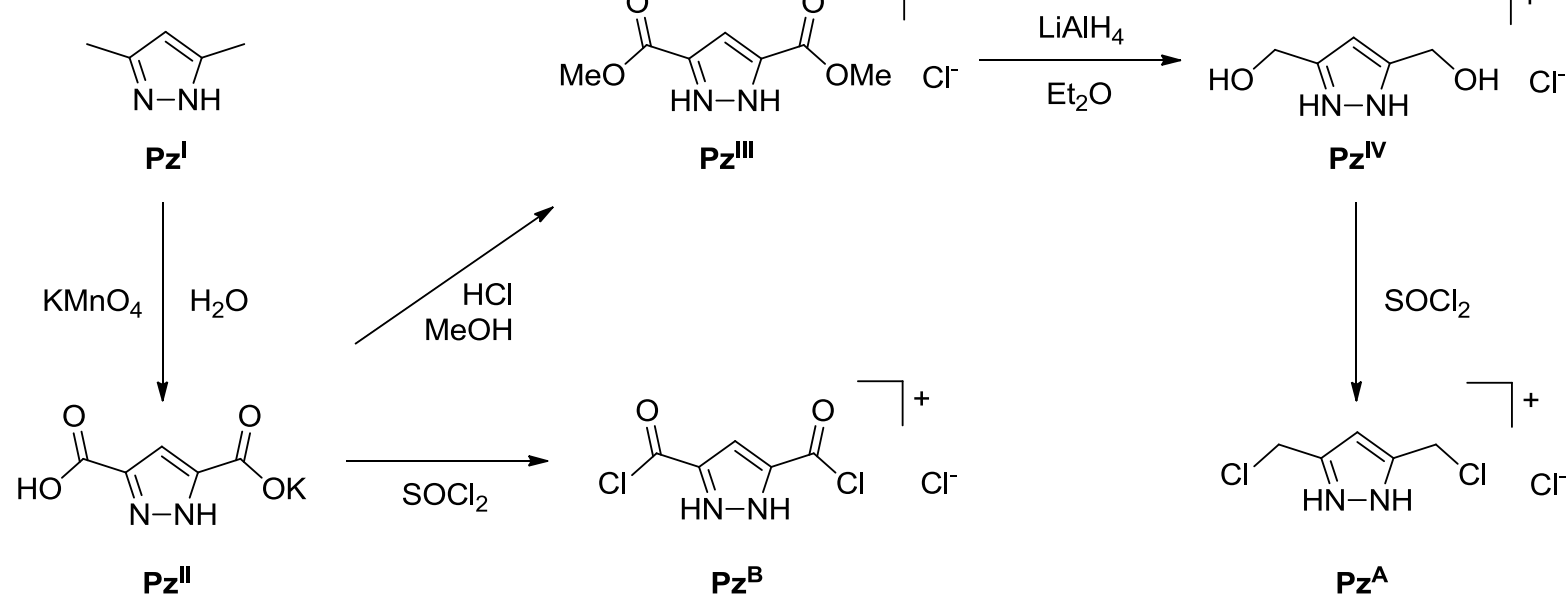

Scheme 2.1: Synthesis of pyrazole building blocks.

Oxidation of the methyl groups in $\mathbf{P z}^{\prime}$ with $\mathrm{KMnO}_{4}$ gives monopotassium 3,5-bis(carboxy)$1 \mathrm{H}$-pyrazole $\left(\mathbf{P z}^{\mathrm{II}}\right) .^{92}$ This compound is the branching point for generating the more reactive chlorinated pyrazole synthons, 3,5-bis(chloromethyl)- $1 \mathrm{H}$-pyrazole hydrochloride $\left(\mathbf{P z}^{\mathbf{A}}\right)^{92}$ and 3,5-bis(chlorocarbonyl)- $1 \mathrm{H}$-pyrazole hydrochloride $\left(\mathrm{Pz}^{\mathrm{B}}\right) \cdot{ }^{94}$ Chlorination is achieved in both cases with $\mathrm{SOCl}_{2}$. In the case of $\mathbf{P z}^{\mathbf{B}}$ direct reaction of $\mathrm{SOCl}_{2}$ with $\mathbf{P z}^{11}$ is possible. ${ }^{94}$ To obtain $\mathbf{P z}^{\mathbf{A}}$ the carboxylic acid moieties are first protected by methyl esterification of $\mathbf{P z} \mathbf{z}^{\prime \prime}$ to give 3,5-bis(methylcarboxy)-1H-pyrazole hydrochloride $\left(\mathbf{P z}{ }^{\text {III }}\right) .^{92}$ Reduction with $\mathrm{LiAlH}_{4}$ then affords 3,5-bis(hydroxymethyl)-1H-pyrazole hydrochloride $\left(\mathbf{P z}^{\mathrm{IV}}\right)$, which is subsequently chlorinated to give $\mathbf{P} \mathbf{z}^{\mathbf{A}}$. ${ }^{92}$ These chlorinated building blocks can then be reacted with two equivalents of a functionalised secondary amine side arm to give multidentate ligands. ${ }^{95}$ This can be achieved in a single step in the case of $\mathbf{P z}^{\mathbf{A}}$ (method $\mathbf{A}$ ), whereas the amides 
derived from reaction with $\mathbf{P z}^{\mathbf{B}}$ must first be reduced with $\mathrm{LiAlH}_{4}$ (Method $\mathrm{B}$ ) to give the final symmetric 3,5-bis(aminomethyl)-substituted pyrazole scaffolds (Scheme 2.2).

The numerous donor atoms in these multidentate ligands often made purification by standard column chromatography impractical. Poor separations often resulted, and extremely polar eluent mixtures were required. In some cases no suitable solvent system could be found to induce mobility of the analyte with respect to the stationary phase. The use of lipophilic Sephadex ${ }^{\circledast}$ (LH-20) showed some improvement but preparative scale retention times were in excess of $24 \mathrm{~h}$, and still gave relatively poor separations. A significant amount of effort was therefore invested in obtaining analytically pure ligands directly from the final reactions with relatively simple work-up procedures. Thus, the two general methods discussed above were both applied in the current work.

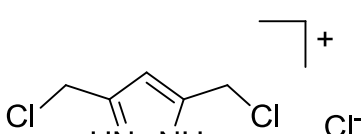

$\mathrm{HN}-\mathrm{NH}$

$\mathbf{P z}$

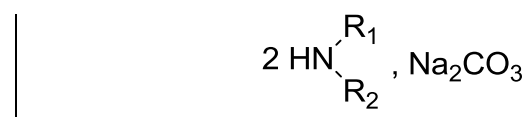

$\mathrm{MeCN}$<smiles>ClCc1cc(CCl)n(C2CCCCO2)n1</smiles>

${ }^{T H P} \mathbf{P z}^{\mathbf{A}}$
1) $2 \mathrm{HN}^{\mathrm{R}} \mathrm{R}_{2}, \mathrm{Na}_{2} \mathrm{CO}_{3}$

2) $\mathrm{HCl} / \mathrm{EtOH}$<smiles>[R]N([R])Cc1cc(CN([R])[R])[nH]n1</smiles>

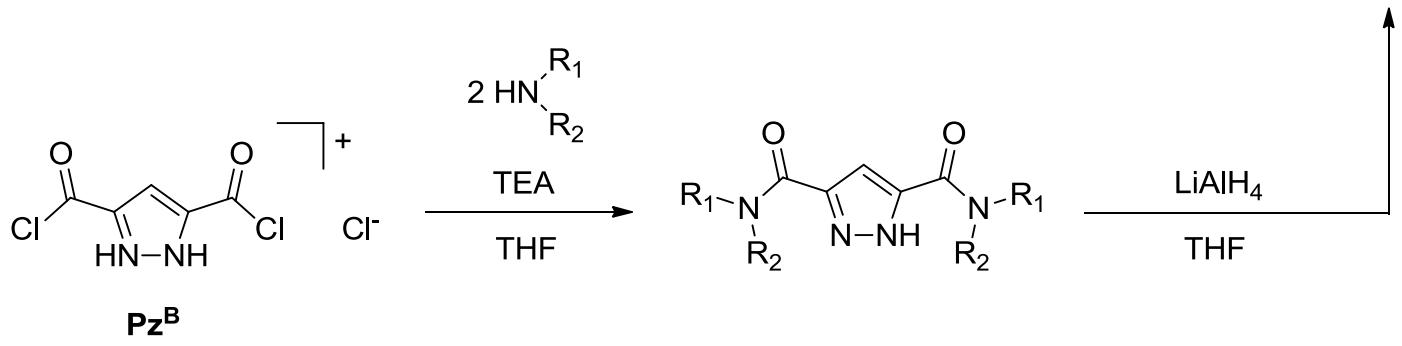

Scheme 2.2: The two synthetic routes to binucleating multidentate pyrazole-bridging ligands employed in this work. Method A (above and middle; with and without THP protection, respectively) and B (below).

$\mathbf{P z}^{\mathbf{A}}$ is the less reactive of the two pyrazole building blocks, reflected by the general use of reflux conditions when neutral amines are employed. ${ }^{84,95}$ This also makes method $A$ synthetically simpler, and thus this route was generally employed in preliminary reactions. Method $\mathrm{A}$ proceeds by attack of a primary or secondary amine nucleophile on $\mathbf{P z} \mathbf{A}^{\mathbf{A}}$, substituting the chloride atoms. The pyrazole nitrogen in $\mathbf{P z}^{\mathbf{A}}$ also possesses nucleophilic character, and so can participate in competing side reactions. The use of this method is therefore sometimes hindered by the formation of oligomeric impurities. ${ }^{95}$ Suppression of these competing pathways can be achieved by protection of the pyrazole nitrogen in $\mathbf{P} \mathbf{z}^{\mathbf{A}}$ through reaction with 3,4-dihydro-2H-pyran (DHP) to give the tetrahydropyranyl (THP) derivative $\quad 3,5$-bis(chloromethyl)-1-(tetrahydro-2 $\mathrm{H}$-pyran-2-yl)-1H-pyrazole $\quad\left({ }^{\mathrm{THP}} \mathbf{P z}^{\mathrm{A}}\right){ }^{96}$ Deprotection of the final ligand is then achieved under acidic conditions. 
Method $B$ can be described in the same general fashion as method A, whereby substitution of the chloride atoms of $\mathbf{P} \mathbf{z}^{\mathbf{B}}$ occurs by attack of a primary or secondary amine nucleophile. In this case, however, the acyl chloride $\mathbf{P} \mathbf{z}^{\mathbf{B}}$ is much more reactive than the alkyl chloride $\mathbf{P} \mathbf{z}^{\mathbf{A}}$. This allows reaction with neutral amines to occur even at room temperature (RT). This higher reactivity also makes $\mathbf{P z}^{\mathbf{B}}$ susceptible to hydrolysis, meaning that anhydrous conditions must be employed or the overall final yield of ligand is diminished. In addition, subsequent $\mathrm{LiAlH}_{4}$ reduction of the amide intermediates has often been observed to lead to side arm cleavage, ${ }^{95}$ which can also reduce the yield. Initial attempts were therefore undertaken with method $A$, however, several factors have contributed in the case of each individual ligand system.

\subsection{Synthesis of Ligands}

\subsubsection{Synthesis of $\mathrm{HL}^{1}$}<smiles>ClCc1cc(CCl)[nH]n1</smiles>

$\mathbf{P z}$<smiles>[124IH]</smiles><smiles>CNCCN(C)C</smiles>

$\mathrm{sa}^{1}$

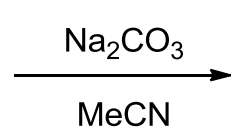
(1)

(1)

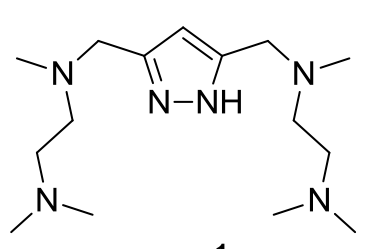

$\mathrm{HL}^{1}$

Scheme 2.3: Synthesis of $\mathrm{HL}^{1}$ using method A.

The ligand $\mathbf{H L}^{1}$ was used in the current work in order to investigate some of the unresolved questions with respect to the $\left[\left(\mathrm{Cu}_{2}{ }_{2} \mathrm{~L}^{1}\right)_{2}\left(\mathrm{O}_{2}\right)(\mathrm{OH})_{2}\right]$ complex (Sections 1.4 .1 and 4.2.1). The functionalised amine side-arm, $N, N, N^{\prime}$-trimethylethylenediamine $\left(\mathbf{s a}^{1}\right)$, is commercially available. Although synthesis of $\mathbf{H L}^{1}$ was previously reported by using method $\mathrm{B},{ }^{97}$ method $\mathrm{A}$ (without THP protection, Scheme 2.3) showed an improvement in yield of approximately $15 \%$. While column chromatography with an ethyl acetate/methanol (EtOAc/MeOH) gradient eluent system afforded a colourless oil, a second minor pyrazole species could not be separated. Trial complexation reactions with crude $\mathbf{H L}^{1}$ provided an alternative purification method, whereby crystalline material of the corresponding sodium salt ([NaL $\left.\left.{ }^{1}\right]\right)$, suitable for X-ray diffraction, could be isolated (Section 2.4). 


\subsubsection{Synthesis of $\mathrm{HL}^{2}$}<smiles>O=C(Cl)c1cc(C(=O)Cl)[nH]n1</smiles>

$\mathbf{P z}^{\mathrm{B}}$<smiles>CCN(CC)CCNCCN(CC)CC</smiles><smiles>[InH2]</smiles>

${ }^{A m d} \mathrm{HL}^{2}$<smiles>CCN(CC)CCN(CCN(CC)CC)C(=O)c1cc(C(=O)N(CCN(CC)CC)CCN(CC)CC)[nH]n1</smiles><smiles>CCN(CC)CCN(CC)CCN(CC)CCN(CC)CCN(CC)CC</smiles>

${ }^{A m d} \mathbf{H L}^{2}$<smiles>CCN(CC)CCN(CC)CCN(CC)CCN(CC)CCN(CC)CC</smiles>

Scheme 2.4: Synthesis of $\mathrm{HL}^{2}$ using method $\mathrm{B}$.

The functionalised amine side-arm, $N, N, N^{\prime}, N^{\prime}$-tetraethyldiethylenetriamine $\left(\mathbf{s a}^{2}\right)$, used to synthesise $\mathbf{H L}^{2}$ is commercially available. While method $A$ succeeded under reflux conditions with high yield, a trace impurity $(\leq 3.5 \%)$ was observed by ${ }^{1} \mathrm{H}$ NMR spectroscopy, and the product could only be obtained as a dark orange oil. THP protection appeared to substantially hinder the reaction, with product formation incomplete even after 15 days. The target product could not be acceptably purified by standard silica gel, aluminium oxide, or Sephadex column chromatography, and despite numerous attempts to isolate the corresponding lithium, sodium or potassium alkali salts no crystalline material was obtained.

Method B (Scheme 2.4) was previously applied in the literature, using only filtration as the workup procedure. ${ }^{98}$ In the present case, minor additional pyrazole species were observed after coupling to give the amide $\left({ }^{\mathrm{Amd}} \mathrm{HL}^{2}\right)$, and so an alkaline extraction workup procedure was developed to remove these (see experimental Section 8.2.2). Provided this intermediate was of high purity, $\mathrm{LiAlH}_{4}$ reduction proceeded with high yield and produced clean product, requiring only aqueous quenching and filtration for isolation. 


\subsubsection{Synthesis of $\mathrm{HL}^{3}$}

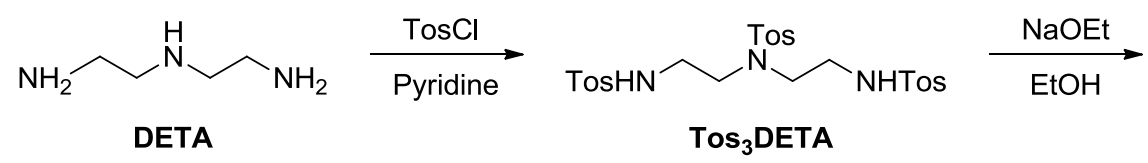

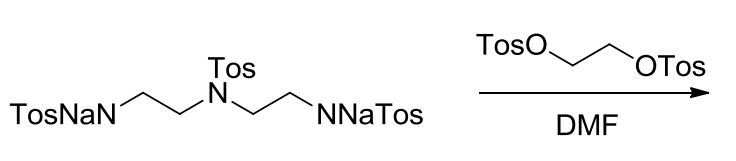

$\mathrm{Na}_{2} \mathrm{Tos}_{3} \mathrm{DETA}$<smiles>CNCCNCCS(=O)(=O)O</smiles>

TosTACN

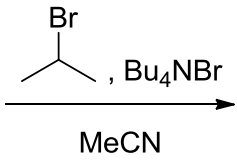

MeCN

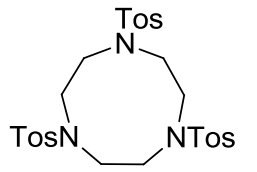

$\mathrm{Tos}_{3} \mathrm{TACN}$
$\underset{\mathrm{HBr} / \mathrm{AcOH}}{\stackrel{\text { Phenol }}{\longrightarrow}}$

Scheme 2.5: Synthesis of $\mathbf{s a}^{3}$ according to a combination of literature known procedures.

The macrocyclic amine side-arm, $N, N^{\prime}$-diisopropyl-1,4,7-triazacyclononane $\left(\mathbf{s a}^{3}\right)$, employed to prepare $\mathrm{HL}^{3}$ was synthesised using a combination of literature known procedures (Scheme 2.5). ${ }^{9,100}$ Starting from commercially available diethylenetriamine (DETA) each of the three amine functional groups are protected through reaction with $p$-toluolsulfonyl chloride (TosCl) to give $N, N^{\prime}, N^{\prime \prime}$-tris(tosyl)diethylenetriamine ( $\operatorname{Tos}_{3} \mathrm{DETA}$ ). Deprotonation of the terminal nitrogen atoms to give the corresponding disodium salt ( $\left.\mathrm{Na}_{2} \mathrm{Tos}_{3} \mathrm{DETA}\right)$ followed by reaction with tosylated ethylene glycol completes formation of the triazocyclononane ring, affording $N, N^{\prime}, N^{\prime \prime}$-tris(tosyl)-1,4,7-triazacyclononane (Tos 3 TACN). Subsequent deprotection at two of the three amide groups to give $N$-tosyl-1,4,7triazacyclononane (TosTACN) then allows for selective alkylation of these nitrogen atoms with 2-bromopropane, resulting in $N$-tosyl- $N^{\prime}, N^{\prime \prime}$-diisopropyl-1,4,7-triazacyclononane (' $\mathrm{Pr}_{2}$ TosTACN). The desired side-arm can then be obtained by cleavage of the remaining tosyl functional group under acidic conditions. The colourless oil which resulted after vacuum distillation was then used directly for coupling reactions with the chlorinated pyrazole synthons, $\mathbf{P z} \mathbf{z}^{\mathbf{A}}$ and $\mathbf{P z}{ }^{\mathbf{B}}$. 


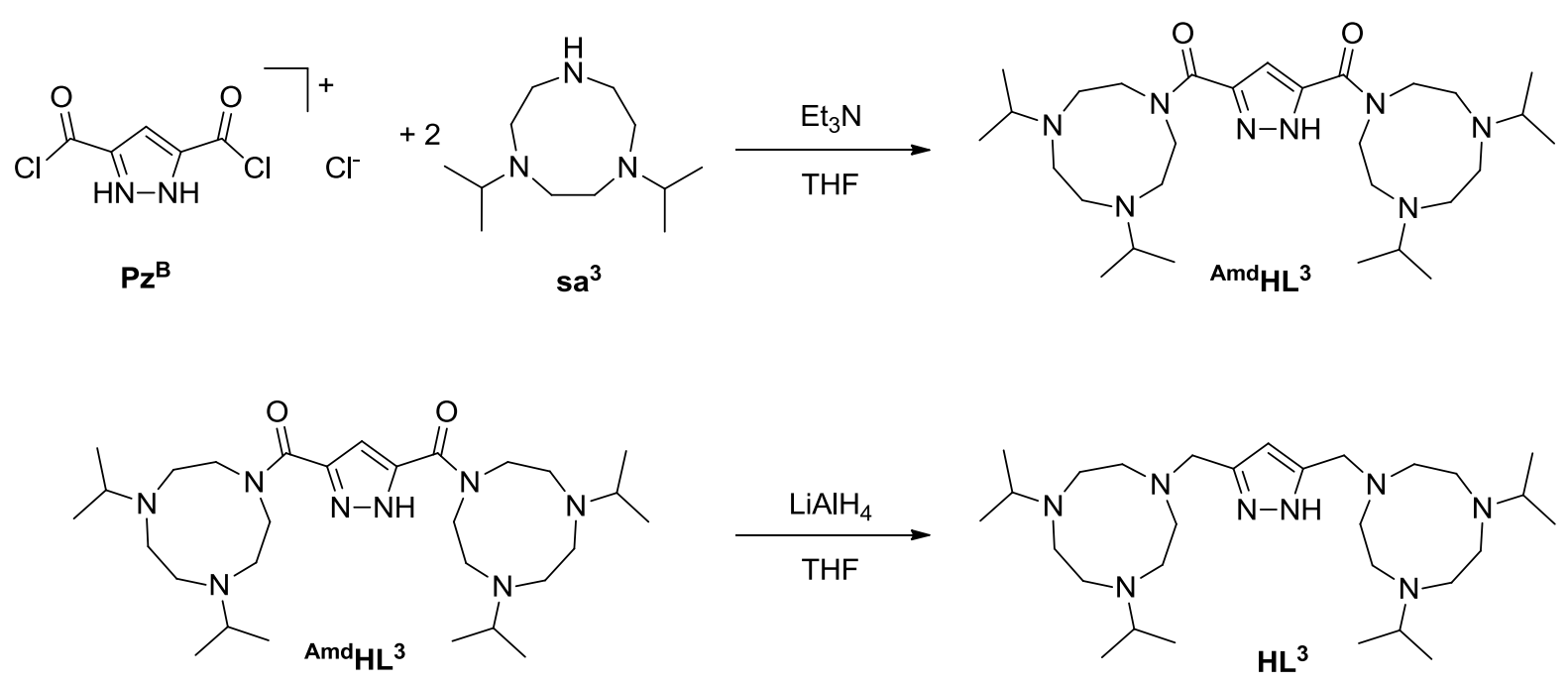

Scheme 2.6: Synthesis of $\mathrm{HL}^{3}$ using method B.

Attempts to synthesise $\mathbf{H L}^{3}$ using method A resulted in brown oily products, which could not be adequately purified. As such, the literature known method B (Scheme 2.6$)^{77}$ was utilised with one major modification to the workup, as follows. The same alkaline extraction procedure as in the case of $\mathbf{H L}^{2}$ was applied, after which the pure amide compound, ${ }^{A m d} \mathbf{H L}^{3}$, could be obtained as crystalline material suitable for $\mathrm{X}$-ray diffraction. $\mathrm{LiAlH}_{4}$ reduction of this crystalline material then gave pure $\mathbf{H L}^{3}$ as a highly viscous colourless oil. The corresponding sodium salt $\left(\left[\mathrm{NaL}^{3}\right]\right)$ could also be isolated provided the ligand was already of high purity, a requirement which limited the use of such a strategy as a purification technique in this instance.

\subsection{Characterisation of Ligands and Ligand Precursors}

Preliminary characterisation of the above products by ${ }^{1} \mathrm{H}$ and ${ }^{13} \mathrm{C}$ NMR spectroscopy was consistent with the data reported in the literature, and indicative of the expected compounds. More in-depth NMR characterisation was then carried out for all ligands, as this aided in analysing the results of further complexation reactions. For example, diffusion coefficients and nitrogen-15 chemical shifts were measured by Diffusion Ordered Spectroscopy (DOSY) and ${ }^{1} \mathrm{H}-{ }^{15} \mathrm{~N}$ NMR HMBC experiments, respectively. One consequence of this was the necessity to acquire spectra of the relevant ligands in the same solvent used for solution state characterisation of the complexes. While the NMR spectra were typically in agreement with the symmetric species reported in the literature, $\mathbf{H L}^{\mathbf{2}}$ and $\mathbf{H L}^{\mathbf{3}}$ exhibited additional signals when measured under strictly anhydrous conditions (Figure 2.1), indicating that the two halves of the molecule were no longer equivalent. 


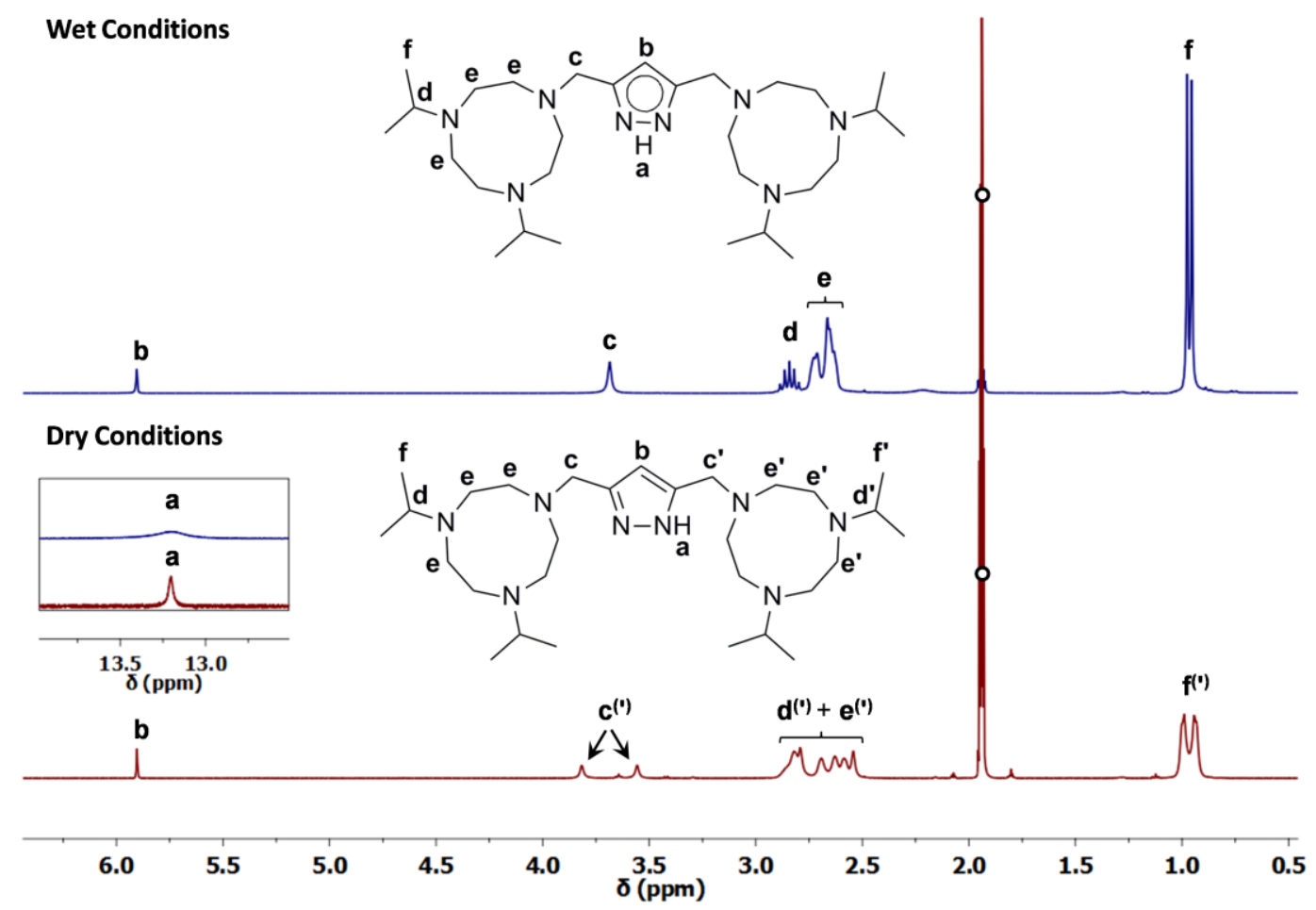

Figure 2.1: ${ }^{1} \mathrm{H}$ NMR spectra of $\mathrm{HL}^{3}$ in $\mathrm{CD}_{3} \mathrm{CN}$ when measured at $\mathrm{RT}$ under wet (undried ligand and solvent) or dry (anhydrous, sealed sample) conditions. The inset shows a comparison of the downfield region. Residual solvent signals are labelled (0).

\subsubsection{Prototropy}

Prototropy in pyrazole-NH systems has been extensively studied by NMR spectroscopy, and is one of the most thoroughly investigated examples of tautometrism. ${ }^{101}$ The activation barrier for this process is often low enough that only average ${ }^{1} \mathrm{H},{ }^{13} \mathrm{C}$ and ${ }^{15} \mathrm{~N}$ resonances are detected at RT, giving the appearance of a symmetric system. ${ }^{101}$ Ring substituents, solvent, concentration and temperature have all been found to influence the exchange rate. ${ }^{102}$ This rate can thus be slowed sufficiently under certain circumstances such that the signals from each half of the pyrazole unit are resolved on the NMR timescale. ${ }^{102}$

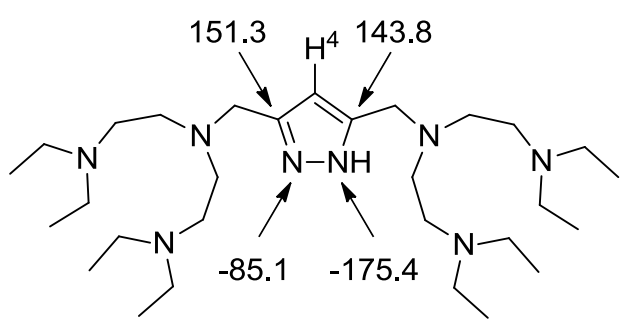

$H L^{2}$

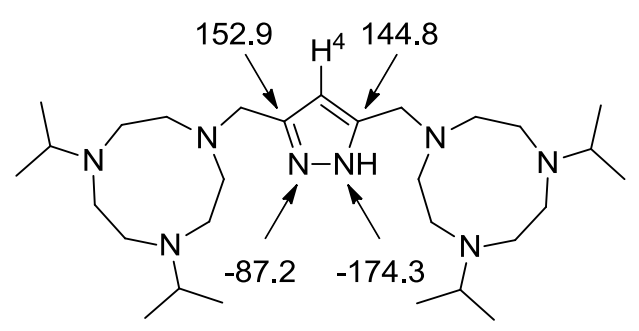

$\mathrm{HL}^{3}$

Scheme 2.7: Chemical shifts (above: ${ }^{13} \mathrm{C}$, below: ${ }^{15} \mathrm{~N}$ ) of the pyrazole ring nuclei, illustrating the asymmetry of the $\mathbf{H L}^{2}$ and $\mathbf{H L}^{3}$ ligand systems when measured under anhydrous conditions in $\mathrm{CD}_{3} \mathrm{CN}$.

The ${ }^{1} \mathrm{H}$ NMR spectra of $\mathbf{H L}^{2}$ and $\mathbf{H L}^{3}$ in dry $\mathrm{CD}_{3} \mathrm{CN}$ at $\mathrm{RT}$ both show relatively sharp resonances at approximately $\delta=13 \mathrm{ppm}$. Furthermore, in ${ }^{1} \mathrm{H}-{ }^{13} \mathrm{C}$ and ${ }^{1} \mathrm{H}-{ }^{15} \mathrm{~N} \mathrm{HMBC}$ 
experiments the pyrazole methine $\left(\mathrm{H}^{4}\right.$, Scheme 2.7$)$ proton in both systems showed correlations with two different quaternary carbon atoms, and with two nitrogen atoms, respectively. The chemical shift values of the detected nitrogen nuclei are in good agreement with literature data reported for unsubstituted pyrazole measured in $\left(\mathrm{CD}_{3}\right)_{2} \mathrm{SO}$ (-79.8 and $-173.1 \mathrm{ppm}$ for $\mathrm{N} 2$ and N1, respectively), where the pyrazole $\mathrm{NH}$ proton is localised. ${ }^{103-105}$ The chemical shifts of the quaternary carbon atoms were likewise assigned on the basis of literature comparison with unsubsituted pyrazole in $\left(\mathrm{CD}_{3}\right)_{2} \mathrm{SO}^{101}$ and 3,5bis(ethyl)- $1 \mathrm{H}$-pyrazole in the solid state, ${ }^{106}$ where the pyrazole $\mathrm{NH}$ is once again localised.

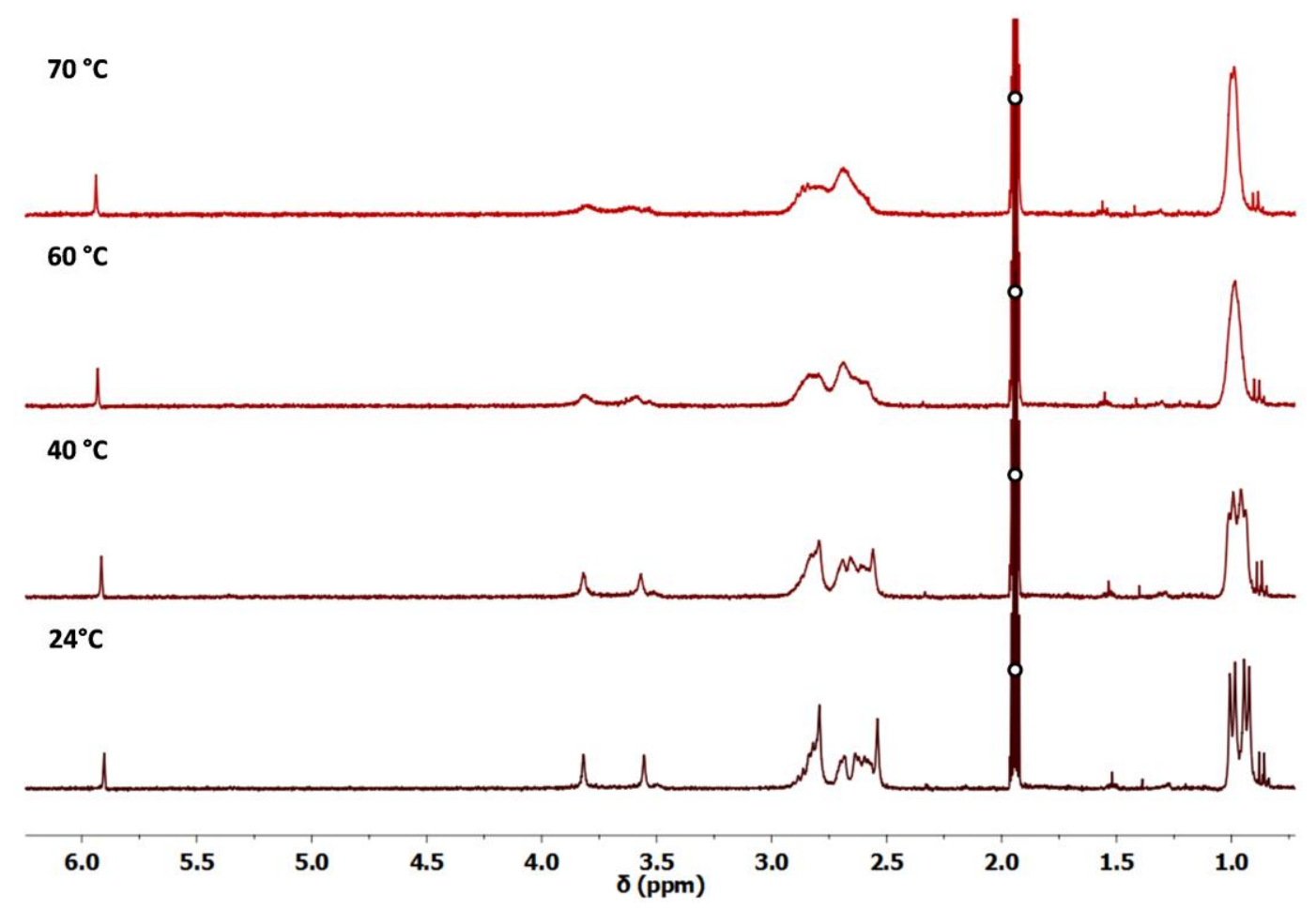

Figure 2.2: ${ }^{1} \mathrm{H}$ NMR spectra of $\mathbf{H L}^{3}$ at various temperatures under anhydrous conditions in $\mathrm{CD}_{3} \mathrm{CN}$. Partial coalescence is observed for several signals (see Figure 2.1 for assignments). Residual solvent signals are labelled (0).

Additional experiments in the cases of $\mathbf{H L}^{2}$ and $\mathbf{H L}^{3}$ showed that introduction of a proton shuttle, such as water, or heating (Figure 2.2) of the sample both induced partial coalescence of all relevant signals, thus restoring the equivalence of the two halves of the ligand being studied. The averaging of these signals is consistent with exchange of the acidic $\mathrm{NH}$ proton between the two nitrogen atoms of the pyrazole ring in each system. Taken together, the above findings unambiguously demonstrate that the $\mathrm{HL}^{2}$ and $\mathbf{H L}^{3}$ ligands are asymmetric in dry $\mathrm{CD}_{3} \mathrm{CN}$ solutions at $\mathrm{RT}$ as a result of pyrazole-NH prototropy. The slow exchange in these systems may be supported by formation of intra-molecular hydrogen bonds, such as those observed in the solid state structure of ${ }^{A m d} \mathrm{HL}^{3}$, discussed below. 


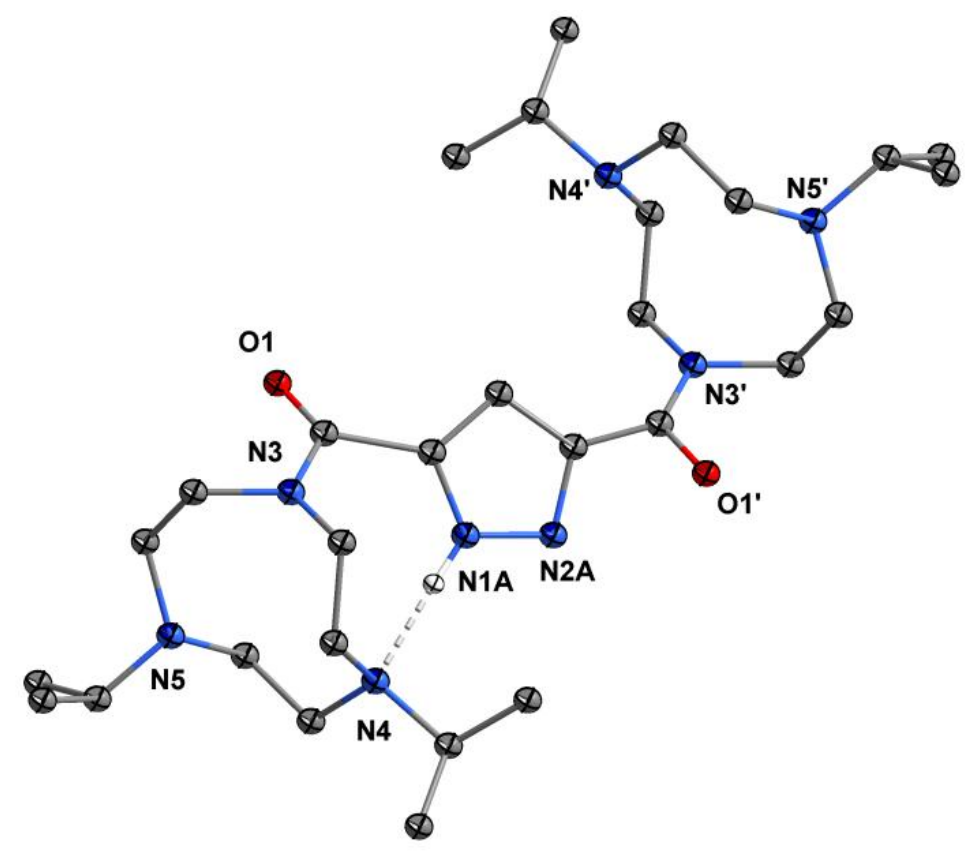

Figure 2.3: Molecular structure of ${ }^{\mathrm{Am}} \mathrm{HL}^{3}$. Atoms are represented with fixed radii. The position of the pyrazole$\mathrm{NH}$ was calculated geometrically. Symmetry operation used to generate equivalent atoms: $1 / 2-x, 1 / 2-y,-z$.

The molecular structure of ${ }^{\mathrm{Amd}} \mathrm{HL}^{3}$ is shown in Figure 2.3. This product crystallises from $\mathrm{MeCN}$ in the monoclinic $\mathrm{C2} / \mathrm{c}$ space group, with four molecules per unit cell. The pyrazole ring is disordered about four positions, two of which are associated with a crystallographically imposed inversion centre. Nevertheless, the distance and orientation between the pyrazole- and isopropyl-nitrogen atoms $(\mathrm{N} 1 \mathrm{~A} \cdots \mathrm{N} 4=2.732 \AA$ for the conformation depicted in Figure 2.3) strongly supports the presence of an intra-molecular hydrogen bond. ${ }^{107,108}$ Furthermore, NMR spectroscopy indicates that this hydrogen bond persists in solution at RT in undried non-protic solvents such as $\mathrm{CD}_{3} \mathrm{CN}$ and $\mathrm{CDCl}_{3}$. This is evident from the asymmetry of the pyrazole ring, the significant shift in resonance of one of the four isopropyl groups, and the relatively sharp pyrazole- $\mathrm{NH}$ signal. Dissolution in $\mathrm{CD}_{3} \mathrm{OD}$ once again renders the pyrazole ring symmetric by restoring the proton tautomerism, although the two halves of each macrocyclic side arm remain inequivalent due to the high rotational barrier of the amide bond. ${ }^{109,110}$ While introducing an additional degree of complexity into the NMR spectra, the lower flexibility of the amide bonds together with the intra-molecular hydrogen bond may enhance crystallisation by limiting the conformations available to the molecule in solution. Furthermore, the hydrogen bonding in ${ }^{\mathrm{Amd}} \mathrm{HL}^{3}$ may be thought of as a pronounced example of the more general case observed in $\mathbf{H L}^{2}$ and $\mathbf{H L}^{3}$. In contrast, no analogous behaviour was observed in the case of $\mathbf{H L}^{1}$. 


\subsection{Sodium complexes}

\subsubsection{Synthesis and Characterisation of $\left[\mathrm{NaL}^{1}\right]$}
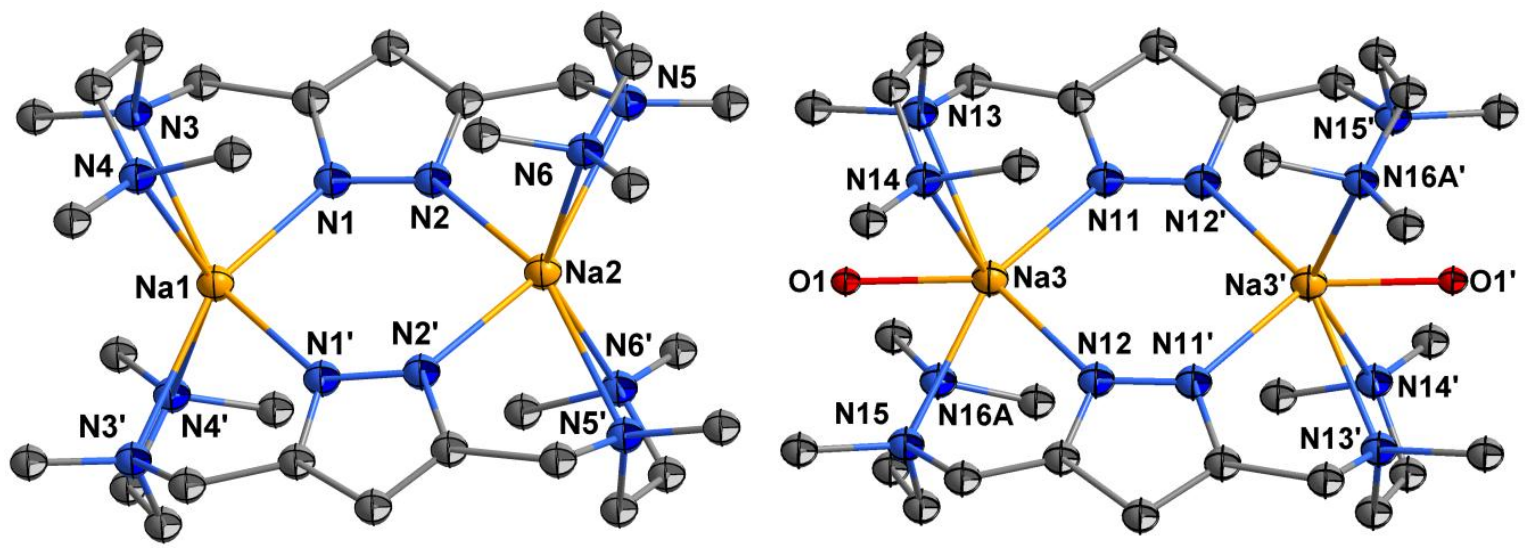

Figure 2.4: Molecular structure of dimeric $\left[\mathrm{NaL}^{1}\right]$ showing the two independent molecules found in the unit cell. For clarity their relative orientation differs from that in the solid state and hydrogen atoms are omitted.

Atoms are represented with fixed radii. Tables of bond lengths and angles can be found in experimental Section 8.10. Symmetry operation used to generate equivalent atoms: $1-x, y, 3 / 2-z$ (left); 3/2-x, 3/2-y, 1-z (right).

Solid material of $\left[\mathrm{NaL}^{1}\right]$ suitable for structural determination could be isolated through reaction of $\mathbf{H L}^{1}$ with $\mathrm{NaH}$ in THF, followed by filtration and recrystallisation from EtCN. This product crystallises in the monoclinic $C 2 / c$ space group, with eight molecules per unit cell. Although the data is not of high quality, it is clear that $\left[\mathrm{NaL}^{1}\right]$ is a symmetric dimer, $\left[\left(\mathrm{NaL}^{1}\right)_{2}\right]$ (Figure 2.4), in which both pyrazole ligands have been deprotonated and bridge two sodium cations in the typical $\mathrm{k}^{1}: \mathrm{k}^{1}$ fashion. Two independent molecules are observed in the unit cell, with one half of each molecule in the asymmetric unit. In addition to the simple dimeric adduct (Figure 2.4, left), a second dinuclear molecule is present which shows seven-fold coordination for both sodium cations, with one additional water ligand per centre lying along the sodium-sodium axis (Figure 2.4, right). These aqua ligands may originate from residual water in the solvent used for recrystallisation. Nevertheless, the presence of this coordinated water does not significantly alter the structure, and can be removed under high vacuum, evident from the elemental analysis performed under inert conditions. Unless otherwise stated, water-free material was used for all subsequent complexation experiments.

The association state of $\left[\mathrm{NaL}^{1}\right]$ in solution was investigated by Mass Spectrometry (MS) under inert conditions. In dry $\mathrm{MeCN}$ at RT essentially just two peak sets were observed corresponding to $\left[(\mathrm{Na})\left(\mathrm{L}^{1}\right)(\mathrm{H})\right]^{+}(m / z=319.0)$ and $\left[(\mathrm{Na})\left(\mathrm{L}^{1}\right)_{2}(\mathrm{H})_{2}\right]^{+}(m / z=615.5)$. However, several higher nuclearity species dominated the spectrum when the concentration was increased, including $\left[(\mathrm{Na})_{3}\left(\mathrm{~L}^{1}\right)_{2}\right]^{+}(m / z=659.5)$ and $\left[(\mathrm{Na})_{4}\left(\mathrm{~L}^{1}\right)_{3}\right]^{+}(m / z=977.8)$. While these findings appear to indicate that $\left[\mathrm{NaL}^{1}\right]$ remains associated to some extent in solution, the oligomeric species observed at higher concentrations suggest that these adducts may also 
simply be an artefact of the MS measurements. Further analysis was thus conducted by NMR spectroscopy.

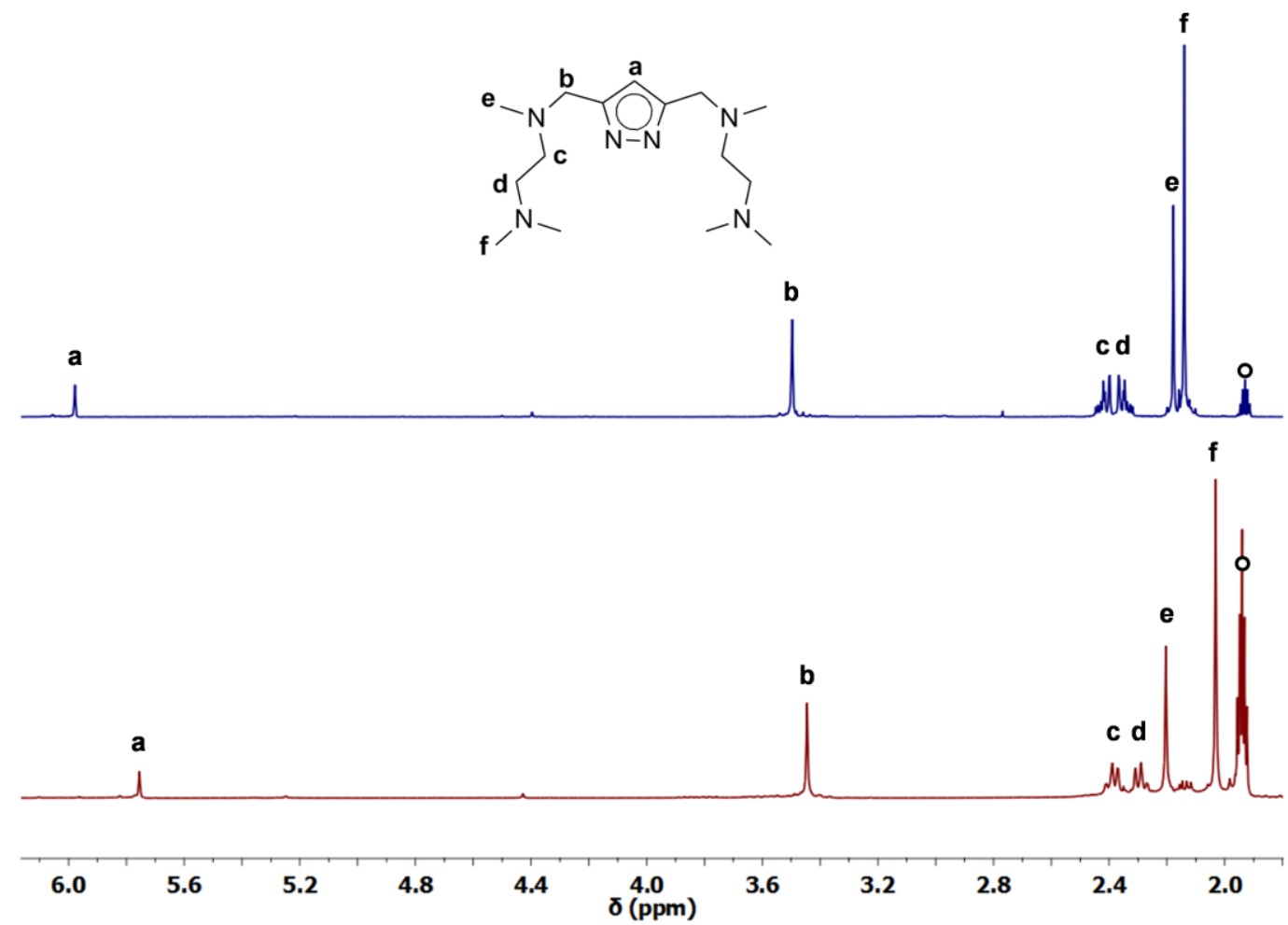

Figure 2.5: ${ }^{1} \mathrm{H}$ NMR spectra of $\mathrm{HL}^{1}$ (above) and [ $\left.\mathrm{NaL}^{1}\right]$ (below) measured under anhydrous conditions in $\mathrm{CD}_{3} \mathrm{CN}$ at RT. Both spectra are consistent with symmetric species in solution. Residual solvent signals are labelled (O).

The ${ }^{1} \mathrm{H}$ and ${ }^{13} \mathrm{C}$ NMR spectra of $\left[\mathrm{NaL}^{1}\right]$ reveal one set of sharp resonances for a saturated $\mathrm{CD}_{3} \mathrm{CN}$ solution measured under anhydrous conditions at RT. Both spectra appear similar to that of the free ligand, $\mathbf{H L}^{1}$, and are indicative of a highly symmetric species (Figure 2.5). This is not consistent with strict retention of the solid state structure in solution. Coordination to the sodium cations would prevent nitrogen inversion and hinder the free rotation of bonds. This would render the terminal methyl groups inequivalent and cause geminal coupling between the methylene protons, leading to more complicated spectra, as observed for the copper(I) complex of $\mathbf{H L}^{3}$ (Section 3.4.3). However, fast exchange processes such as dissociation and re-association of the terminal sidearm nitrogen donors could induce equivalence of the relevant groups on the NMR timescale. The results of the analytical techniques applied above are clearly ambiguous and offer little conclusive insights as to the speciation of $\left[\mathrm{NaL}^{1}\right]$ in solution. Further investigation by ${ }^{1} \mathrm{H}$ DOSY and also by variable temperature NMR experiments may provide useful information in this regard. 


\subsubsection{Synthesis and Characterisation of $\left[\mathrm{NaL}^{3}\right]$}

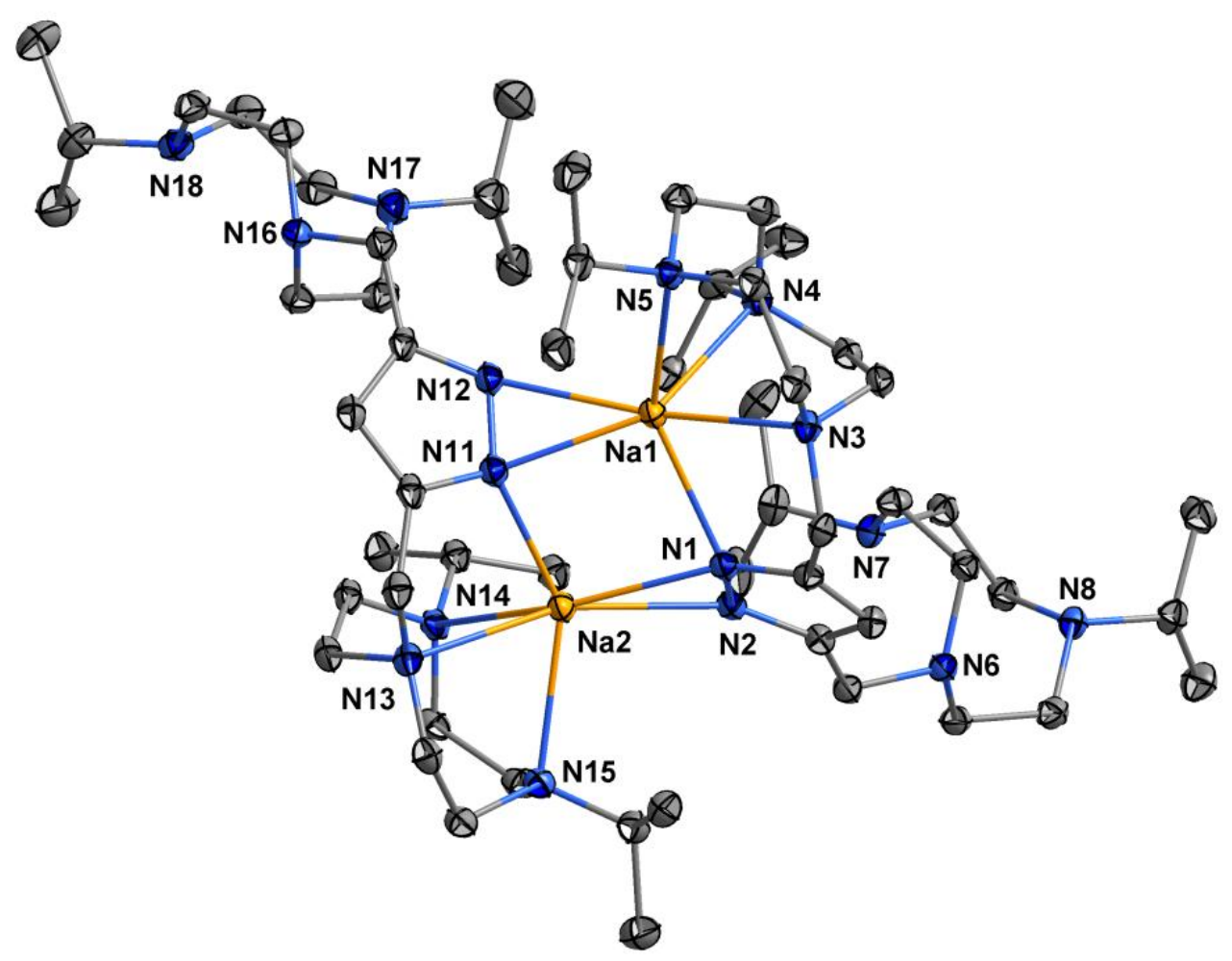

Figure 2.6: Molecular structure of [ $\left.\mathrm{NaL}^{3}\right]$. Thermal displacement ellipsoids are shown at $30 \%$ probability. Hydrogen atoms are omitted for clarity. Tables of bond lengths and angles can be found in experimental Section 8.10.

When ligand $\mathbf{H L}^{3}$ is of sufficient purity, deprotonation with $\mathrm{NaOtBu}$ in EtCN affords the corresponding sodium salt $\left[\mathrm{NaL}^{3}\right]$ after a short time at RT. The product crystallises as a dimer, $\left[\left(\mathrm{NaL}^{3}\right)_{2}\right] \cdot 0.5 \mathrm{EtCN}$ (Figure 2.6), in the monoclinic $P 2_{1} / c$ space group, with four molecules per unit cell. In the solid state $\left[\mathrm{NaL}^{3}\right]$ displays an unusual $\mathrm{K}^{2}: \mathrm{K}^{1}$ bridging motif, leaving one side arm completely uncoordinated. Due to the extremely limited solubility of $\left[\mathrm{NaL}^{3}\right.$ ] in $\mathrm{MeCN}$, analyses were initially conducted in acetone (dry $\mathrm{Me}_{2} \mathrm{CO}$ for MS, dry $\left(\mathrm{CD}_{3}\right)_{2} \mathrm{CO}$ for NMR). MS analysis under inert conditions revealed two dominant signals. These correspond to $\left[(\mathrm{Na})\left(\mathrm{L}^{3}\right)(\mathrm{H})\right]^{+}(\mathrm{m} / \mathrm{z}=541.5)$ and $\left[(\mathrm{Na})_{2}\left(\mathrm{~L}^{3}\right)\right]^{+}(\mathrm{m} / \mathrm{z}=563.5)$ and suggest that the complex is no longer dimeric in solution. ${ }^{1} \mathrm{H}$ and ${ }^{13} \mathrm{C}$ NMR spectroscopic analysis was consistent with this dissociation and showed a single set of sharp resonances, though with some broadening in the case of the macrocyclic $\mathrm{CH}_{2}$ and isopropyl $\mathrm{CH}_{3}$ carbon atom signals. When the NMR experiments were repeated in deuterated $T H F, C_{4} D_{8} O$, all signals were substantially broadened to the extent that the ${ }^{13} \mathrm{C}$ NMR spectrum is almost featureless. Repeating these measurements at $55{ }^{\circ} \mathrm{C}$ revealed significant sharpening of all signals, such that the spectra appear similar to those discussed above for $\left(\mathrm{CD}_{3}\right)_{2} \mathrm{CO}$. This is indicative of a dynamic process, which likely involves some degree of sodium cation association in solution. Low temperature NMR and ${ }^{1} \mathrm{H}$ DOSY experiments would once again aid in determining the exact nature of $\left[\mathrm{NaL}^{3}\right]$ in solution, though as evident from the above findings the speciation likely depends heavily on the properties of the solvent. A comparison between the [ $\left.\mathrm{NaL}^{1}\right]$ 
and $\left[\mathrm{NaL}^{3}\right]$ data is therefore also not plausible, as these systems were characterised in different solvents due to the limited solubility of $\left[\mathrm{NaL}^{3}\right]$ in $\mathrm{CD}_{3} \mathrm{CN}$. Of greater significance to the overall focus of this work is the further observations with respect to NMR measurements made with $\left[\mathrm{NaL}^{3}\right]$ dissolved in $\left(\mathrm{CD}_{3}\right)_{2} \mathrm{CO}$.
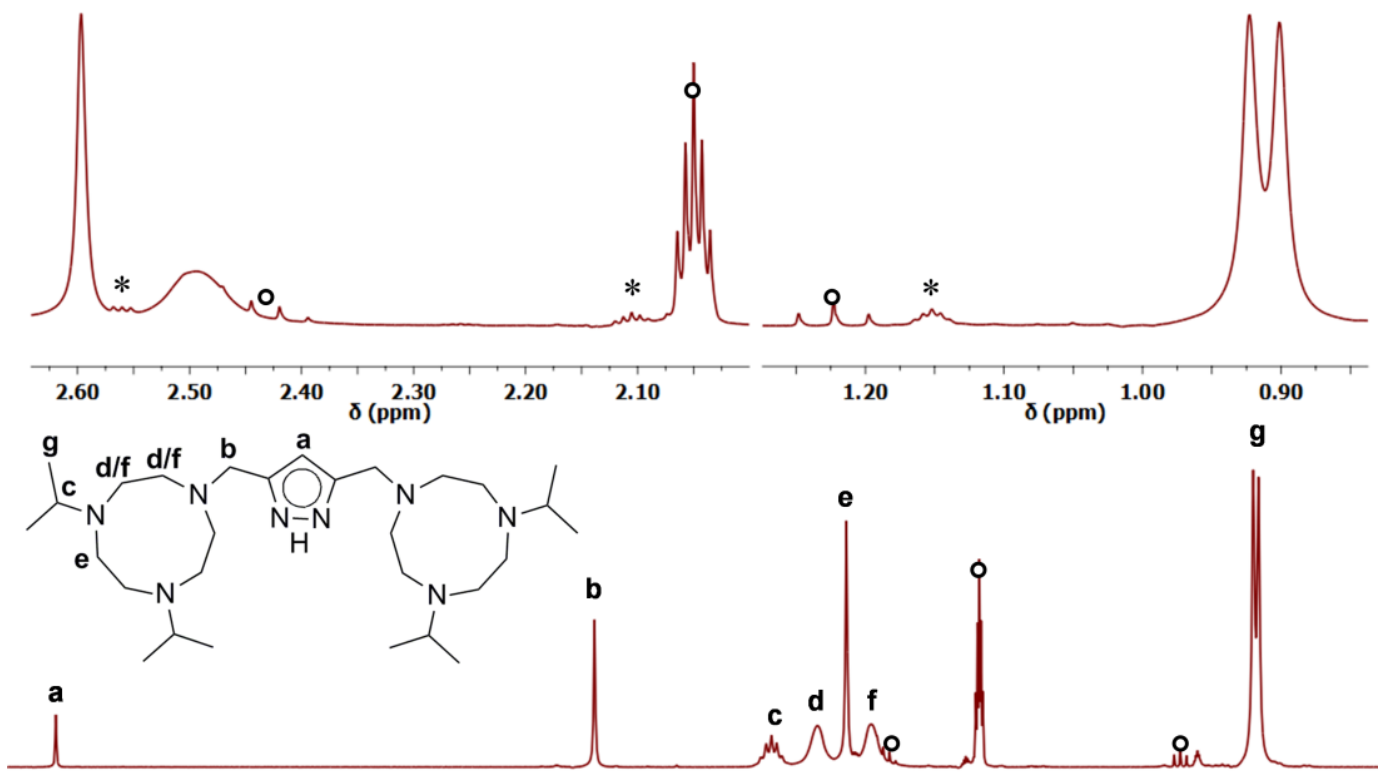

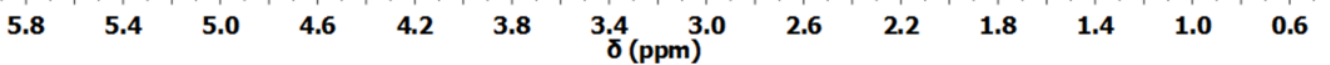

Figure 2.7: ${ }^{1} \mathrm{H}$ NMR spectrum of crystalline $\left[\mathrm{NaL}^{3}\right]$ dissolved in $\left(\mathrm{CD}_{3}\right)_{2} \mathrm{CO}$. Residual solvent signals (including $\mathrm{EtCN}$ from synthesis) are labelled (O), as are the additional deuterium containing species in the insets $\left({ }^{*}\right)$.

Although ${ }^{1} \mathrm{H}$ NMR analysis conducted in $\left(\mathrm{CD}_{3}\right)_{2} \mathrm{CO}$ was initially consistent with the presence of a single symmetric pyrazole species, additional pyrazole peaks appeared over time, and several unexpected signals displaying proton-deuterium coupling were also detected (Figure 2.7). Furthermore, extra carbonyl species which also increased in number over time were present in the ${ }^{13} \mathrm{C}$ spectrum. These observations are indicative of a reaction between [ $\mathrm{NaL}^{3}$ ] and $\left(\mathrm{CD}_{3}\right)_{2} \mathrm{CO}$, likely aldol-type condensations and/or attack of the pyrazolate- $\mathrm{N}$ upon the respective carbonyl carbon atoms. Both reactions would be enhanced under basic conditions and the latter has previously been observed in the case of unsubstituted neutral pyrazole with acetone. ${ }^{111}$ These byproducts were only minor species and therefore their formation was not further investigated. Even so, this highlights that $\mathrm{Me}_{2} \mathrm{CO}$ is not well suited for reactions in which free pyrazolate anion is present.

\subsection{Summary and Conclusions}

Starting materials of an appropriate quality provide a solid foundation for any chemical study. Although already reported in the literature, the preparative procedures used to acquire the compartmental pyrazole ligands $\mathbf{H L}^{1}, \mathbf{H L}^{2}$ and $\mathbf{H L}^{3}$ have been adapted herein to obtain precursors of suitable purity for formation of stable copper(I) complexes. In addition 
to the synthetic outcome of these modifications, several precursors could be crystallographically characterised. Structural determination of the intermediate ${ }^{A m d} \mathbf{H L}^{3}$ indirectly granted insight into the dynamic process responsible for broadening the NMR resonances of the corresponding final ligand, $\mathbf{H L}^{3}$, and this prototropy could then furthermore be demonstrated for the related ligand $\mathbf{H L}^{2}$ under anhydrous conditions. Isolation of $\left[\mathrm{NaL}^{3}\right]$ also led to a more detailed characterisation of this intermediate, revealing that $\mathrm{Me}_{2} \mathrm{CO}$ is an unsuitable solvent for the complexation strategy employed herein. In conclusion, the work described in this chapter has established a suitable basis for further investigation of bioinspired copper-mediated dioxygen activation chemistry supported by compartmental pyrazole ligand scaffolds. 


\section{Pyrazole-supported Copper(I) Complexes Speciation in Solution}

\subsection{Introduction}

\subsubsection{Solution Stability}

A general strategy for producing copper-oxygen adducts is to react cuprous complexes directly with dioxygen. A correlation exists between the structure of the copper(I) precursor and the type of adduct which results, ${ }^{14,15}$ thereby making detailed knowledge about the former invaluable. As reaction with dioxygen is typically carried out in solvent, significant efforts have been devoted herein to solution characterisation of the copper(I) complexes used in the current work. Owing to the oxygen sensitivity of these systems, all such undertakings were performed under inert conditions.

$$
2 \mathrm{Cu}^{\prime}(\mathrm{aq}) \rightleftharpoons \mathrm{Cu}^{\prime \prime}(\mathrm{aq})+\mathrm{Cu}(\mathrm{s}) \quad K=1.6 \times 10^{6}
$$

Scheme 3.1 Copper(I) disproportionation reaction. The equilibrium clearly lies far to the right at RT under aqueous conditions.

Copper(I) complexes are in some cases known to undergo spontaneous disproportionation into metallic copper and copper (II) species, a reaction which occurs readily under aqueous conditions at RT (Scheme 3.1). ${ }^{112,113}$ While the use of relatively soft aromatic nitrogen ${ }^{114}$ or nitrile $^{115}$ donors can greatly attenuate this decomposition pathway, ligands employing aliphatic nitrogen donors not suitable for stabilising copper(I) may still suffer from this drawback. Systems illustrating this behaviour which are especially relevant to dioxygen activation chemistry include the unsubstituted tren ligand and its methylated derivative, Me $_{6}$ tren, ${ }^{116}$ as well as the hexamethylcyclam, Tet $\mathbf{b}^{31}$ The corresponding copper(I) complexes of these ligands all undergo disproportionation, yet the latter two have been used to isolate and structurally characterise ${ }^{\top} \mathbf{P}$ species despite this (Scheme 3.2). ${ }^{31,32}$
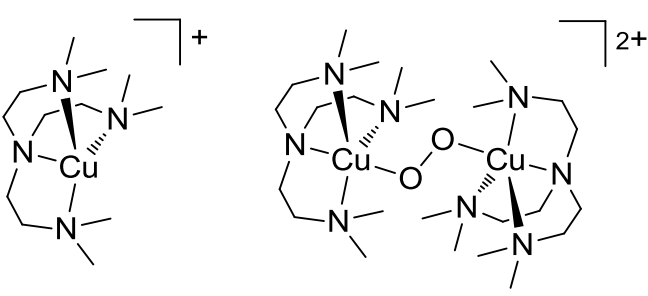

$\left[\mathrm{Cu}\left(\mathrm{Me}_{6} \text { tren }\right)\right]^{+}$

$$
{ }^{\mathrm{T}} \mathrm{P}-\left[\mathrm{Cu}_{2}\left(\mathrm{Me}_{6} \text { tren }\right)_{2} \mathrm{O}_{2}\right]^{2+}
$$

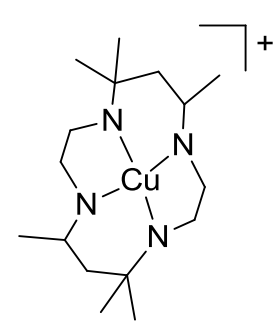

$\left[\mathrm{Cu}(\text { Tet b) }]^{+}\right.$

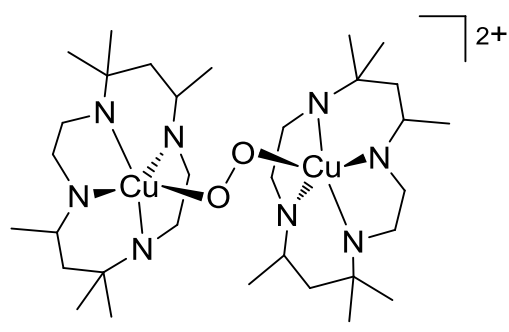

${ }^{\mathrm{T}} \mathrm{P}-\left[\mathrm{Cu}_{2}(\mathrm{Tet} \mathrm{b})_{2} \mathrm{O}_{2}\right]^{2+}$

Scheme 3.2: Tetracoordinate copper(I) complexes susceptible to disproportionation, which have been used to isolate ${ }^{\top} \mathbf{P}$ species. Metric parameters for the latter ${ }^{\top} \mathbf{P}$ species can be found in Table 5.1 .

In direct relation to the current work, it was reported in a previous investigation that the dinuclear copper(I) complex of $\mathbf{H L}^{3}$ was stable only below temperatures of $-40{ }^{\circ} \mathrm{C}$, rapidly 
decomposing to a copper(II) species above this temperature. ${ }^{91}$ It was additionally shown in a separate study that copper(I) complexes of tetramethylethylenediamine (TMED), a mononucleating analogue related to $\mathbf{H L}^{1}$, also disproportionate. ${ }^{117}$ The TMED system was furthermore found to be sensitive toward the stoichiometry employed, with slight deviations leading to unstable copper(I) complexes. ${ }^{117}$ Initial copper(I) complex crystallisation trials employing crude ligands met with no success in the present study, which was largely attributed to the above mentioned complications. This impeded the application of crystallisation as a purification procedure, and further emphasised the need for organic starting materials of high purity. While the use of sufficiently pure ligands then allowed room temperature stable copper(I) complexes to be prepared, including those of $\mathbf{H L}^{3}$, crystalline material could not be successfully obtained. Evidence for the formation of these complexes therefore relies solely on characterisation in solution by NMR and MS studies.

\subsubsection{General Synthetic Strategy and Nomenclature}
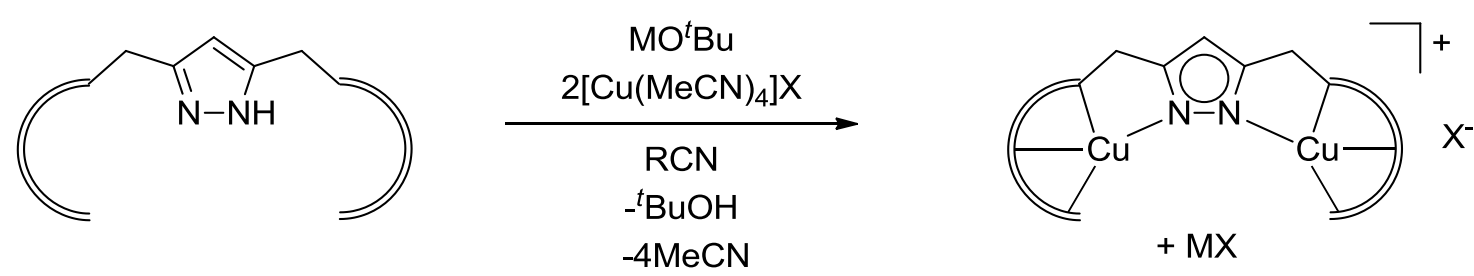

Scheme 3.3 General copper $(\mathrm{I})$ complex synthetic scheme. $\mathrm{M}=\mathrm{Na}^{+}$or $\mathrm{K}^{+}, \mathrm{X}=\mathrm{PF}_{6}^{-}, \mathrm{BF}_{4}^{-}, \mathrm{ClO}_{4}^{-}, \mathrm{OTf}^{-}$, or $\mathrm{B}\left(\mathrm{C}_{6} \mathrm{~F}_{5}\right)_{4}^{-}$, $\mathrm{R}=\mathrm{Me}$ or Et.

A general synthetic procedure was employed for producing the copper(I) complexes, $\left[\mathrm{Cu}_{2}{ }_{2} \mathbf{L}^{1}\right]^{\mathrm{X}},\left[\mathrm{Cu}_{2}{ }_{2} \mathrm{~L}^{2}\right]^{\mathrm{X}}$ and $\left[\mathrm{Cu}_{2}{ }_{2} \mathrm{~L}^{3}\right]^{\mathrm{X}}$, with some modifications for specific purposes. Ligands were deprotonated using alkali metal tert-butoxide salts $\left(\mathrm{MO}^{t} \mathrm{Bu}, \mathrm{M}=\mathrm{Na}^{+}, \mathrm{K}^{+}\right)$in $\mathrm{RCN}$ solvents $(\mathrm{R}=$ $\mathrm{Me}, \mathrm{Et})$. Tetrakis-acetonitrile salts $\left(\left[\mathrm{Cu}(\mathrm{MeCN})_{4}\right] \mathrm{X}\right)$ with various weakly coordinating counteranions (WCAs, $\mathrm{X}=\mathrm{PF}_{6}{ }^{-}, \mathrm{BF}_{4}{ }^{-}, \mathrm{ClO}_{4}{ }^{-}$, $\mathrm{OTf}^{-}$or $\mathrm{B}\left(\mathrm{C}_{6} \mathrm{~F}_{5}\right)_{4}{ }^{-}$) were employed as the copper $(\mathrm{I})$ sources (Scheme 3.3). The volatile $\mathrm{MeCN}$ and ${ }^{t} \mathrm{BuOH}$ byproducts were then removed under vacuum, and the resulting residues re-dissolved in the solvent required for subsequent study $\left(\mathrm{CD}_{3} \mathrm{CN}\right.$, EtCN, etc.). However, as the complexes were not further isolated, it should be kept in mind that one equivalent of $M X$ is generally present in the analyte solutions discussed herein. This also applies in the case of ligand $\mathbf{H L}^{1}$, where the sodium salt [ $\mathrm{NaL}^{1}$ ] was used for preparation of the corresponding copper(I) complexes, and thus one equivalent of $\mathrm{NaX}$ is present. When the presence of these additional salts in solution is significant then they are specifically highlighted. Otherwise, when referring to each system in a general sense, the ' $X$ ' superscript is used as above.

Organonitriles are often employed as solvents for these systems, as they stabilise the copper(I) state due to their strong $\sigma$-donor and $\pi$-acceptor capabilities. ${ }^{115}$ Initial synthetic attempts were thus conducted with propionitrile (EtCN) as a solvent. While significantly more toxic than MeCN, EtCN has a sufficiently lower freezing point to enable the use of 
temperatures down to and below $-80^{\circ} \mathrm{C}$. Once it was established that the copper(I) complexes were indeed stable at RT, other solvents could be trialled. Acetone was not appropriate for copper(I) complex formation reactions due to its relatively high acidity (Section 2.4). Although dichloromethane (DCM) was employed in studies of some of these complexes in a previous work, ${ }^{90}$ it can be problematic with respect to chloride abstraction reactions. ${ }^{115,118-121}$ Even in the absence of such unwanted reactivity, residual chloride can interact strongly with copper centres, blocking binding sites and attenuating subsequent reactivity toward substrates. ${ }^{122}$ In fact, literature evidence exists to suggest that chloride can competitively inhibit pyrazole-bridged dinuclear copper models of T3 active sites, ${ }^{79}$ and halide ions are furthermore known to act as inhibitors of the native Tyr itself. ${ }^{123}$ Chlorinated solvents were therefore avoided in the current work, and EtCN generally showed the best results in synthetic procedures. The main exception to this was the use of $\mathrm{MeCN}$, which was widely employed for characterisation. 


\subsubsection{Speciation and Dynamic Processes of Relevance to Characterisation}

The speciation of copper(I) complexes with tetradentate or tridentate nitrogen donor ligands in solution can be complicated. Dynamic processes such as dissociation and reassociation of nitrogen donor atoms can occur, and dimeric species are also frequently observed despite the use of mononucleating tri- or tetradentate ligands. This applies even in the cases of relatively prevalent copper(I) complexes with highly symmetric ligands like TMPA $^{115,121}$ and trispyrazolylborate $\left(\mathbf{H B}(\mathbf{P z})_{3}\right)^{124}$ and their derivatives. ${ }^{125,126}$ Binucleating organic scaffolds can lead to yet higher oligomeric structures. ${ }^{64}$ Ligands with pyrazole units capable of occupying a bridging position are especially well known for forming cyclic trimeric and tetrameric assemblies, ${ }^{127-129}$ which can furthermore exhibit fluxional behaviour in solution. ${ }^{130,131}$ With respect to bis-tridentate pyrazole-bridging chelates of the type employed in the synthesis of $\left[\mathbf{C u}_{2}{ }_{2} \mathbf{L}^{1}\right]^{\mathrm{X}}$, a binuclear copper(I) complex has been reported which shows interconversion at RT between cis- and trans- isomers (Scheme 3.4). ${ }^{132}$ The dynamic behaviour in the above described systems is generally identified by broadening of resonances in the corresponding NMR spectra. Several of the aforementioned fluxional processes are considered in interpreting the characterisation data discussed in this chapter.
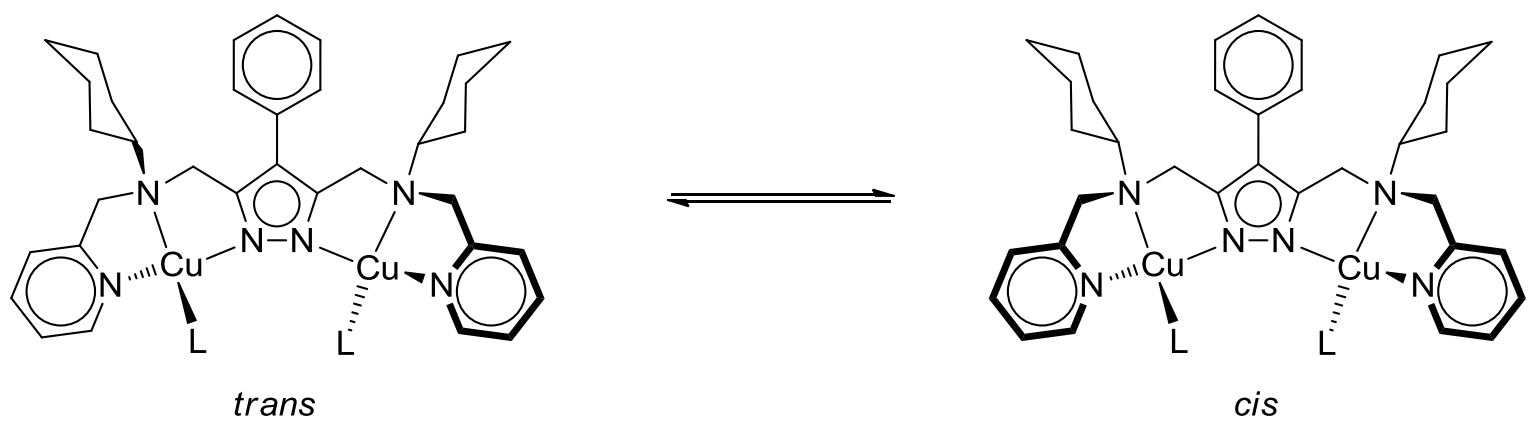

Scheme 3.4: Interconversion between cis- and trans- isomers in a pyrazole-bridged copper (I) complex. The enantiomer of the trans- isomer is not depicted above but would also be part of the equilibrium. $L=P\left(\mathrm{CH}_{3}\right)_{3}$. Charges and counterions are omittied. 


\subsection{Synthesis and Characterisation of $\left[\mathrm{Cu}_{2}^{1} \mathrm{~L}^{1}\right]^{\mathrm{X}}$}

\subsubsection{Synthetic Considerations}

$1 / 2$

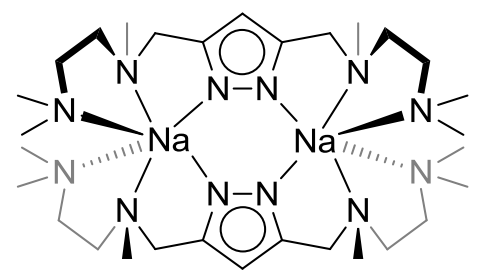

$\left[\mathrm{NaL}^{1}\right]$

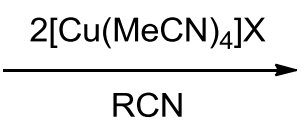

Scheme 3.5: Synthesis of $\left[\mathrm{Cu}_{2}^{1} \mathrm{~L}^{1}\right]^{\mathrm{X}} . \mathrm{X}=\mathrm{PF}_{6}{ }^{-}, \mathrm{BF}_{4}{ }^{-}, \mathrm{ClO}_{4}{ }^{-}$or $\mathrm{OTf}^{-}, \mathrm{R}=\mathrm{Me}$ or Et.

Although the synthesis of this complex was already published, $\left[\mathrm{Cu}_{2}^{1}{ }_{2} \mathbf{L}^{1}\right]^{\mathrm{X}}$ served only as an intermediate in that case and was not isolated, therefore it has not been previously characterised. ${ }^{89}$ Preliminary reactions aimed at isolating $\left[\mathrm{Cu}_{2}^{1} \mathrm{~L}^{1}\right]^{\mathrm{X}}$ in crystalline form directly from crude $\mathbf{H L}^{1}$ were conducted in the current work. The literature reported method was initially utilised, which employs tetrabutylammonium hydroxide $\left(\left[\mathrm{Bu}_{4} \mathrm{~N}\right] \mathrm{OH}\right)$ as a base. Solutions resulting from this preparative route were intense yellow in colour, and appeared to be sensitive with respect to temperature. Crystallisation attempts met with little success in the case of the $\mathrm{PF}_{6}{ }^{-}$counteranion, and while introduction of $\mathrm{B}\left(\mathrm{C}_{6} \mathrm{H}_{5}\right)_{4}{ }^{-}$led to crystalline material, structural determination revealed only $\left[\mathrm{Bu}_{4} \mathrm{~N}\right] \mathrm{B}\left(\mathrm{C}_{6} \mathrm{H}_{5}\right)_{4}$. The same by-product was also isolated when $\mathrm{Me}_{2} \mathrm{CO}$ was employed as a solvent. As a result of these findings, the use of alternative bases was investigated, leading to isolation of [ $\mathrm{NaL}^{1}$ ] (section 2.4). Unless otherwise stated, thoroughly dried $\left[\mathrm{NaL}^{1}\right]$ was then subsequently used for all complexation reactions in this work. Reaction of $\left[\mathrm{NaL}^{1}\right]$ with $\left[\mathrm{Cu}(\mathrm{MeCN})_{4}\right] \mathrm{X}\left(\mathrm{X}=\mathrm{PF}_{6}{ }^{-}, \mathrm{BF}_{4}{ }^{-}, \mathrm{ClO}_{4}{ }^{-}\right.$or $\left.\mathrm{OTf}^{-}\right)$ salts in EtCN resulted in colourless solutions which were stable for several days at RT, but often decomposed during longer time periods. While relatively few further attempts were made to obtain crystalline $\left[\mathrm{Cu}_{2}^{1} \mathrm{~L}^{1}\right]^{\mathrm{X}}$, the enhanced stability gained by this alternative synthetic strategy allowed for in situ characterisation to be conducted at RT. 


\subsubsection{Mass Spectrometry}

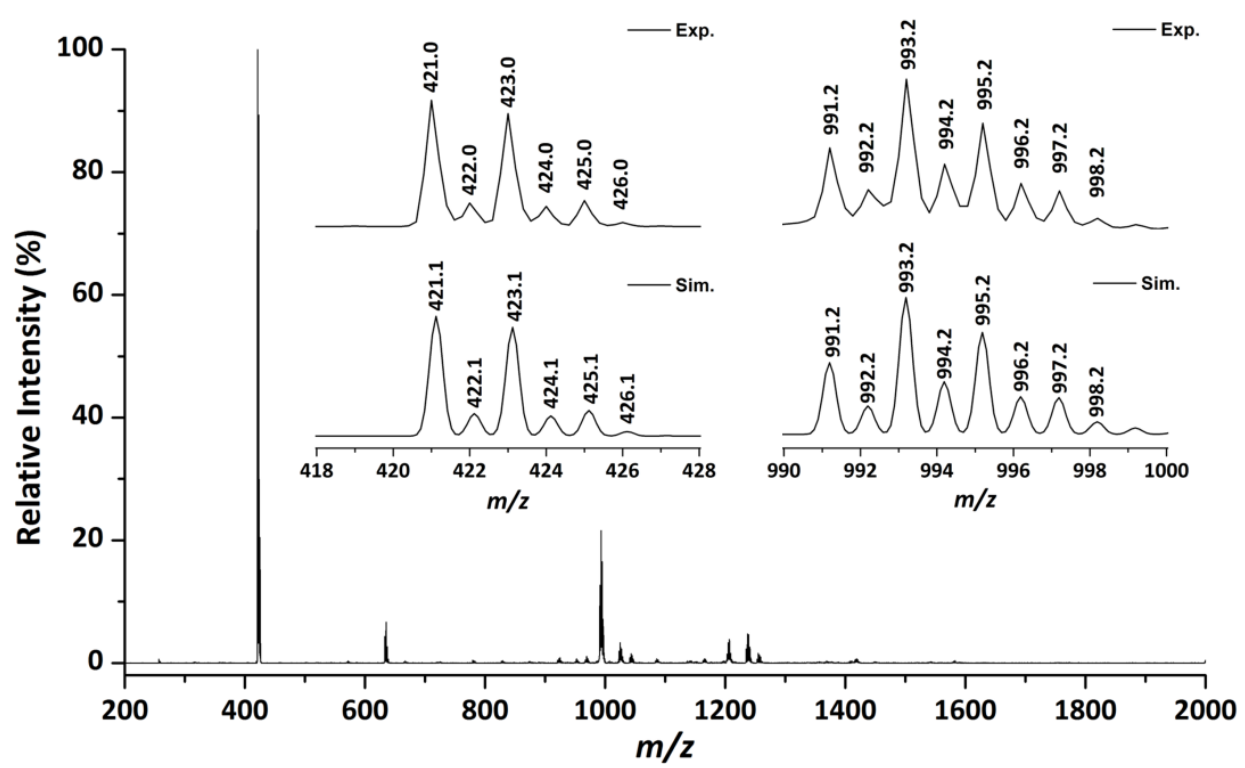

Figure 3.1: Positive mode ESI-MS spectrum of $\left[\mathrm{Cu}_{2}{ }_{2} \mathrm{~L}^{1}\right]^{\text {OTf }}$ measured in EtCN at RT. The insets show experimental and simulated isotopic distribution patterns for $\left[\mathrm{C}_{15} \mathrm{H}_{31} \mathrm{Cu}_{2} \mathrm{~N}_{6}\right]^{+}$(left) and $\left[\left(\mathrm{C}_{15} \mathrm{H}_{31} \mathrm{Cu}_{2} \mathrm{~N}_{6}\right)_{2} \mathrm{CF}_{3} \mathrm{SO}_{3}\right]^{+}$(right).

\begin{tabular}{|c|c|c|}
\hline$m / z$ & Intensity (\%) & Assignment* \\
\hline \multicolumn{3}{|c|}{ Monomeric Adducts } \\
\hline 421.0 & 100 & {$\left[\mathrm{Cu}_{2}^{\prime} \mathrm{L}^{1}\right]^{+}$} \\
\hline 635.0 & 6 & {$\left[\left(\mathrm{Cu}_{2}^{\prime} \mathrm{L}^{1}\right)(\mathrm{Cu})(\mathrm{OTf})\right]^{+}$} \\
\hline \multicolumn{3}{|c|}{ Dimeric Adducts } \\
\hline 993.2 & 24 & {$\left[\left(\mathrm{Cu}_{2}^{\prime} \mathrm{L}^{1}\right)_{2}(\mathrm{OTf})\right]^{+}$} \\
\hline 1207.1 & 3 & {$\left[\left(\mathrm{Cu}_{2}^{\prime} \mathrm{L}^{1}\right)_{2}\left(\mathrm{Cu} \mathrm{u}^{\prime}\right)(\mathrm{OTf})_{2}\right]^{+}$} \\
\hline 1239.1 & 5 & {$\left[\left(\mathrm{Cu}_{2}^{\prime} \mathrm{L}^{1}\right)_{2}\left(\mathrm{Cu}^{\prime}\right)(\mathrm{OTf})_{2}(\mathrm{MeOH})\right]^{+}$} \\
\hline \multicolumn{3}{|c|}{$\begin{array}{l}\text { * Rather than purely empirical formulas the assignments presented here are grouped in order to allow for } \\
\text { easier interpretation, although it must be highlighted that the measurements give no direct information about } \\
\text { connectivity of the elements which make up the observed ion peaks. }\end{array}$} \\
\hline
\end{tabular}

The positive mode ESI-MS spectrum of $\left[\mathrm{Cu}^{1}{ }_{2} \mathrm{~L}^{1}\right]^{\text {OTf }}$ (Figure 3.1), measured in EtCN at RT, is dominated by a peak set corresponding to $\left[\mathrm{Cu}_{2}^{\prime} \mathrm{L}^{1}\right]^{+}(\mathrm{m} / z=421.0)$ (Table 3.1). A relatively minor trinuclear adduct of this parent $[\mathrm{M}]^{+}$cation could also be identified, $\left[\left(\mathrm{Cu}_{2}{ }_{2} \mathrm{~L}^{1}\right)(\mathrm{Cu})(\mathrm{OTf})\right]^{+}(\mathrm{m} / \mathrm{z}=635.0)$. At considerably higher mass an additional signal with significant intensity is observed which displays an isotopic envelope consistent with a tetranuclear dimeric species, $\left[\left(\mathrm{Cu}_{2}{ }_{2} \mathrm{~L}^{1}\right)_{2}(\mathrm{OTf})\right]^{+}(\mathrm{m} / z=993.2)$. Trace amounts of even higher aggregates are also present, and can be assigned to $\left[\left(\mathrm{Cu}_{2}{ }_{2} \mathrm{~L}^{1}\right)_{2}\left(\mathrm{Cu}^{\prime}\right)(\mathrm{OTf})_{2}\right]^{+}(\mathrm{m} / z=1203.1)$ and to an adduct of this consistent with $\mathrm{O}_{2}$ or $\mathrm{MeOH}$ incorporation $(m / z=1239.1)$. Residual $\mathrm{MeOH}$ may be present inside the instrument, and is the more likely assignment as the 
$\left[\left(\mathrm{Cu}_{2}{ }_{2} \mathrm{~L}^{1}\right)_{2}\left(\mathrm{O}_{2}\right)(\mathrm{OH})_{2}(\mathrm{OTf})\right]^{+}$cation results upon deliberate reaction with $\mathrm{O}_{2}$ (Section 4.2.1). These findings suggest that $\left[\mathrm{Cu}_{2}{ }^{1} \mathbf{L}^{1}\right]^{\mathrm{X}}$ is largely present in solution as a dinuclear monomeric species.

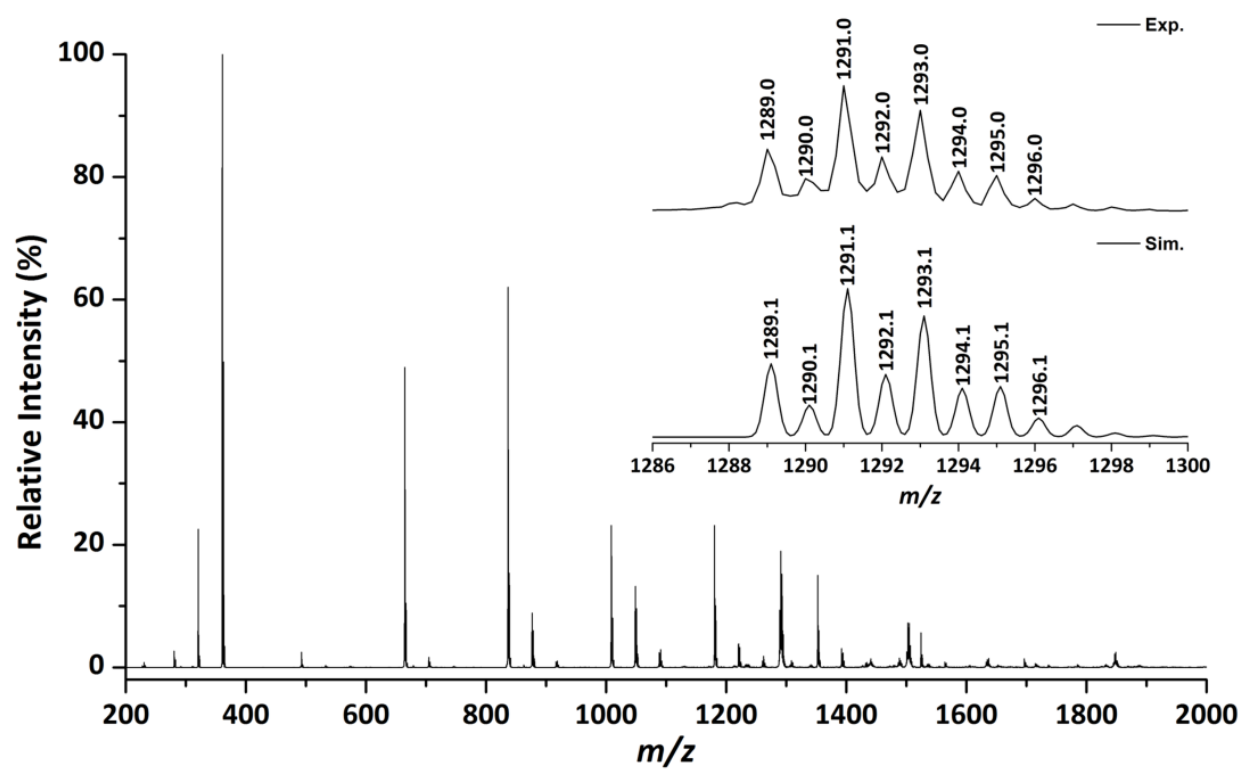

Figure 3.2: Negative mode ESI-MS spectrum of $\left[\mathrm{Cu}_{2}^{1} \mathrm{~L}^{1}\right]^{\text {OTf }}$ in EtCN. The inset shows experimental and simulated isotopic distribution patterns for $\left[\left(\mathrm{C}_{15} \mathrm{H}_{31} \mathrm{Cu}_{2} \mathrm{~N}_{6}\right)_{2}\left(\mathrm{CF}_{3} \mathrm{SO}_{3}\right)_{3}\right]^{-}$.

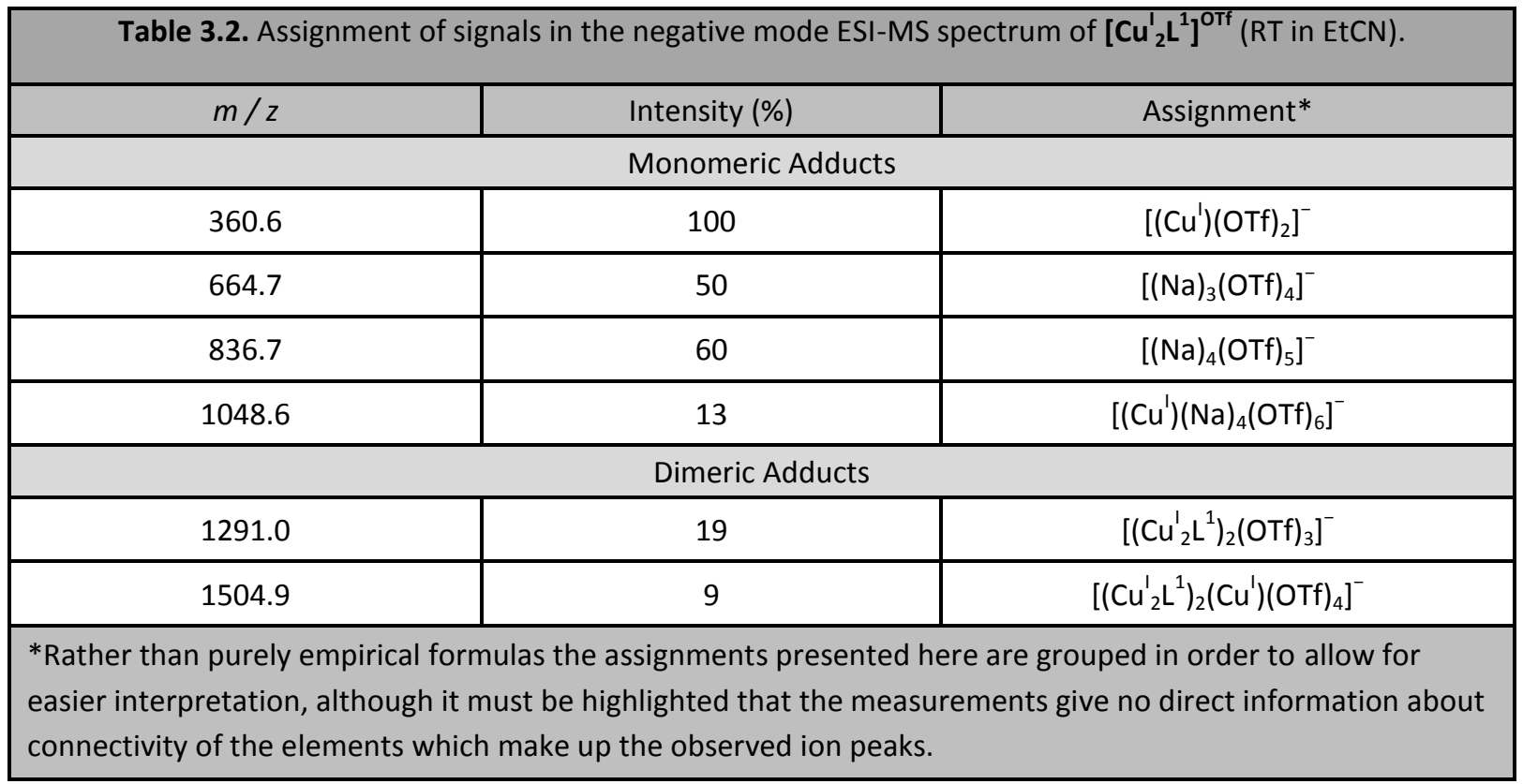

Interestingly, the simultaneously measured negative mode spectrum displays a contrasting trend (Figure 3.2). While it mainly shows inorganic adducts of the triflate anion with copper(I) and sodium ions, $\left[\left(\mathrm{Cu}^{\prime}\right)_{n}(\mathrm{Na})_{m}(\mathrm{OTf})_{n+m+1}\right]^{-}$, no monomeric adducts are detected (Table 3.2). On the other hand, peak sets consistent with analogues of the above described dimeric species are present, $\left[\left(\mathrm{Cu}_{2}{ }_{2} \mathrm{~L}^{1}\right)_{2}(\mathrm{OTf})_{3}\right]^{-}(\mathrm{m} / \mathrm{z}=1291.0)$ and $\left.\left[\left(\mathrm{Cu}_{2}{ }_{2} \mathrm{~L}^{1}\right)_{2}(\mathrm{Cu})^{\prime}\right)(\mathrm{OTf})_{4}\right]^{-}(\mathrm{m} / \mathrm{z}$ $=1504.9)$. The observation of these multinuclear clusters may indicate the presence of 
higher aggregation states in solution, thereby implying that the speciation of $\left[\mathrm{Cu}_{2}^{1} \mathbf{L}^{1}\right]^{\mathrm{X}}$ is not accurately depicted in Scheme 3.5. Indeed, the unsaturated coordination spheres of the copper(I) ions in this complex would allow for such a scenario. NMR spectroscopy was thus employed in order to ascertain whether the above findings reflect the true nature of $\left[\mathrm{Cu}_{2}^{\prime} \mathrm{L}^{1}\right]^{\mathrm{X}}$ in solution.

\subsubsection{NMR Spectroscopy}

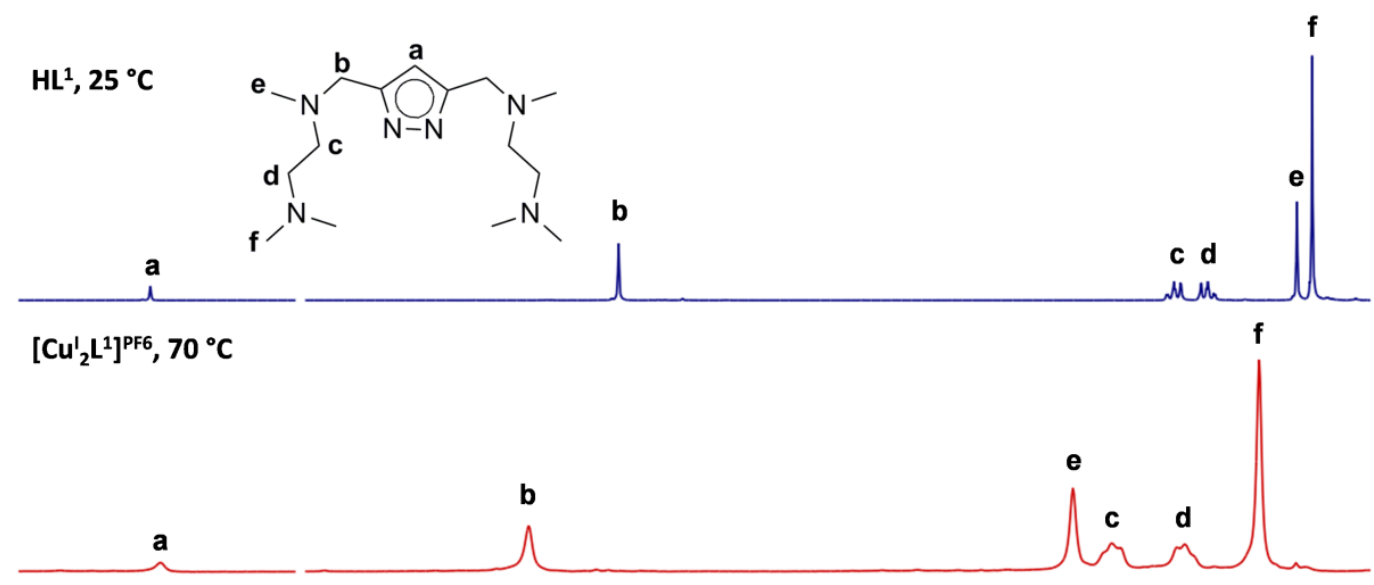

$\left[\mathrm{Cu}_{2}^{\prime}{ }^{1}\right]^{\mathrm{OTH}}, 25^{\circ} \mathrm{C}$

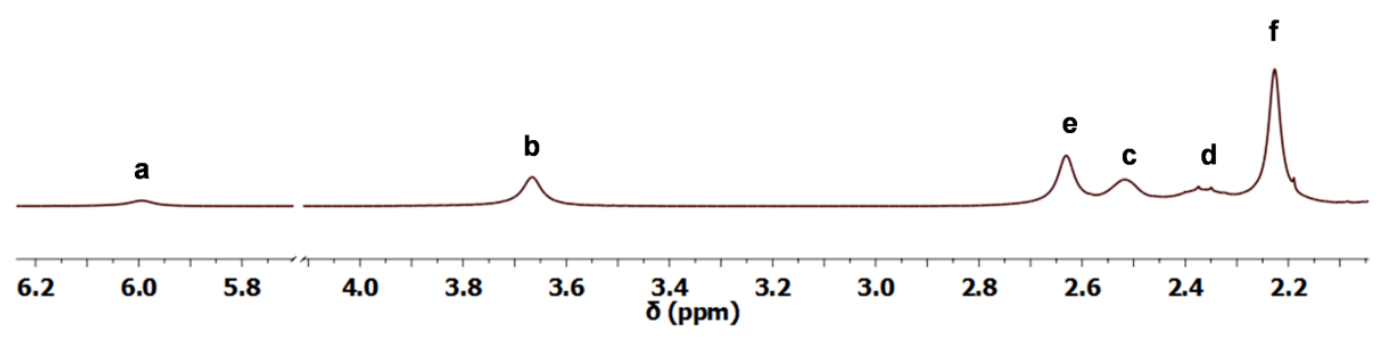

Figure 3.3: ${ }^{1} \mathrm{H} N M R$ spectra of $\mathrm{HL}^{1}\left(25^{\circ} \mathrm{C}\right)$ and $\left[\mathrm{Cu}_{2}^{1} \mathrm{~L}^{1}\right]^{\mathrm{X}}\left(\mathrm{X}=\mathrm{OTf}^{-}, \mathrm{PF}_{6}{ }^{-}\right.$for $25^{\circ} \mathrm{C}, 70^{\circ} \mathrm{C}$, respectively) measured under anhydrous conditions in $\mathrm{CD}_{3} \mathrm{CN}$. Heating the $\left[\mathrm{Cu}_{2}^{1} \mathrm{~L}^{1}\right]^{\mathrm{X}}$ sample leads to sharpening of all signals.

${ }^{1} \mathrm{H}$ and ${ }^{13} \mathrm{C}$ NMR analysis of $\left[\mathrm{Cu}_{2}^{1} \mathrm{~L}^{1}\right]^{\mathrm{X}}\left(\mathrm{X}=\mathrm{PF}_{6}{ }^{-}\right.$or $\left.\mathrm{OTf}^{-}\right)$in $\mathrm{CD}_{3} \mathrm{CN}$ at $\mathrm{RT}$ revealed one set of resonances which display altered chemical shift values to the corresponding free ligand, $\mathbf{H L}^{1}$, and sodium complex, $\left[\mathrm{NaL}^{1}\right]$. In contrast to the latter two systems, the spectra for $\left[\mathrm{Cu}_{2}{ }_{2} \mathbf{L}^{1}\right]^{\mathbf{X}}$ show significant broadening at RT for all ${ }^{1} \mathrm{H}$ resonances (Figure 3.3), and for the ${ }^{13} \mathrm{C}$ signals corresponding to the pyrazole bridging unit and the methyl groups of the shoulder tertiary nitrogen atoms. In fact, the pyrazole methine carbon atom resonance could only be detected at RT through ${ }^{1} \mathrm{H}-{ }^{13} \mathrm{C}$ HSQC experiments. Cooling the sample resulted in an increase in the line widths of all signals. Conversely, heating caused all resonances to sharpen until coupling patterns similar to those for $\mathbf{H L}^{1}$ and $\left[\mathrm{NaL}^{1}\right]$ were once again resolved. Only one set of 6 peaks corresponding to $\left[\mathrm{Cu}_{2}^{1} \mathrm{~L}^{1}\right]^{\mathrm{X}}$ is apparent at $70{ }^{\circ} \mathrm{C}$ in the ${ }^{13} \mathrm{C}$ NMR spectrum (The pyrazole methine carbon could not be observed, even with application of ${ }^{1} \mathrm{H}-{ }^{13} \mathrm{C}$ HSQC experiments), and cross-peaks corresponding to 3 nitrogen nuclei are apparent in the ${ }^{1} \mathrm{H}-{ }^{15} \mathrm{~N} \mathrm{HMBC}$ spectrum. 
These observations are consistent with the presence of a pyrazole-bridged copper(I) complex which is fluxional in solution, leading to the averaging of the chemical environments of the ligand scaffold at higher temperatures. As $\left[\mathrm{Cu}_{2}^{1} \mathrm{~L}^{1}\right]^{\mathrm{X}}$ possesses only tridentate metal-binding pockets, association of an external co-ligand is plausible. Coordination of additional donors, such as $\mathrm{CD}_{3} \mathrm{CN}$ solvent molecules, would induce asymmetry if interacting with a single copper(I) centre, or result in cis-trans isomers if associated to both copper(I) ions in $\left[\mathrm{Cu}_{2}^{\prime} \mathrm{L}^{1}\right]^{\mathrm{X}}$ (Scheme 3.6). ${ }^{132}$ Both of these processes could lead to the observed signal broadening. However, given the well-known tendency of pyrazole-bridging ligands to form trimeric and tetrameric assemblies with coinage metals, such as copper $(\mathrm{I})$, an additional molecule of complex $\left[\mathrm{Cu}_{2}{ }_{2} \mathbf{L}^{1}\right]^{\mathbf{X}}$ itself is also a viable external co-ligand. Indeed, the observation of multinuclear adducts in the MS experiments described above is consistent with the latter proposal. In order to investigate if any of the aforementioned scenarios apply to the current system, attempts were made to assess the molecular size of $\left[\mathrm{Cu}_{2}^{\prime} \mathbf{L}^{1}\right]^{\mathrm{X}}$ in solution.

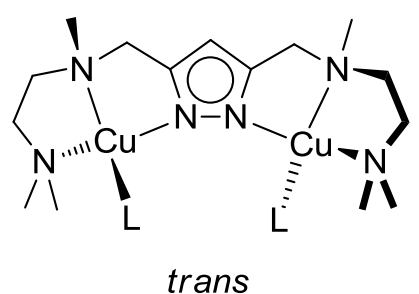

trans

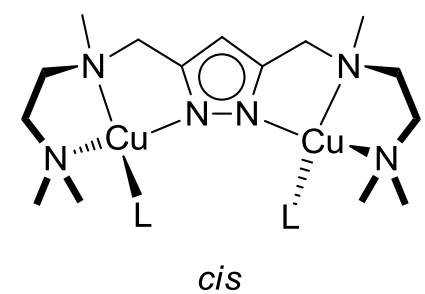

cis

Scheme 3.6 Coordination of a nitrile solvent molecule to the two copper centres in $\left[\mathrm{Cu}_{2}^{1} \mathrm{~L}^{1}\right]^{\mathrm{X}}$ could result in cisand trans-isomers, analogously to the situation depicted in Scheme 3.4. The enantiomer of the trans-isomer is not shown above but would also be part of the equilibrium. $\mathrm{L}=\mathrm{MeCN}$ or EtCN. Charges and counterions are omitted.

${ }^{1} \mathrm{H}$ NMR DOSY is a technique which is useful for gaining information about the size of a molecule in solution, as it separates signal sets by their diffusion coefficients. A large diffusion coefficient reflects a fast rate of translational motion through solution, and thus implies that the corresponding molecule is relatively small. Conversely, a small diffusion coefficient is indicative of a large molecule. Furthermore, diffusion coefficients allow for an estimate of the molecular radii and volume in solution to be derived (see Experimental Section 8.4 for details). The spectra of $\left[\mathrm{Cu}_{2}{ }_{2} \mathrm{~L}^{1}\right]^{\mathrm{OTf}}$ in $\mathrm{CD}_{3} \mathrm{CN}$ at $\mathrm{RT}$ show the presence of a single species, with a significantly smaller diffusion coefficient $\left(D=1.07 \times 10^{-9} \mathrm{~m}^{2} \mathrm{~s}^{-1}\right)$ than that found for equimolar solutions of free ligand $\mathrm{HL}^{1}\left(1.45 \times 10^{-9} \mathrm{~m}^{2} \mathrm{~s}^{-1}\right)$. The molecular radii calculated from these values reveal that $\left[\mathrm{Cu}_{2}^{1} \mathrm{~L}^{1}\right]^{\mathrm{OTf}}(r=5.5 \AA)$ occupies substantially more space in solution than the corresponding ligand $\mathbf{H L}^{1}(r=4.1 \AA) . \quad\left[\mathrm{Cu}_{2}{ }_{2} \mathbf{L}^{1}\right]^{\mathrm{OTf}}$ is thus approximately 2.5 times larger in terms of volume in solution.

It is evident from the above described data that $\left[\mathbf{C u}_{2}{ }_{2} \mathbf{L}^{1}\right]^{\mathbf{X}}$ is present in solution as a multinuclear aggregate. A tetranuclear species incorporating four copper(I) centres and two ligand molecules was observed in RT ESI-MS experiments, in both positive and negative modes. Furthermore, the difference in diffusion coefficient between $\left[\mathrm{Cu}_{2}^{1} \mathrm{~L}^{1}\right]^{\text {OTf }}$ and $\mathrm{HL}^{\mathbf{1}}$ indicate that the molecular volume approximately doubles upon complexation with 
copper(I). Although a dimeric tetranuclear species is also plausible, ${ }^{133}$ pyrazole bridging ligands are well known for forming planar trimeric assemblies with copper(I). ${ }^{127,131}$ In fact, a multinuclear aggregate containing such a cyclic triangular core was previously isolated and crystallographically characterised upon reaction of $\mathrm{CuBr}$ with a binucleating ligand closely related to $\mathbf{H L}^{1}$ (Scheme 3.7, XII). ${ }^{134}$ Furthermore, solution analysis of this species in MeCN revealed similar $\mathrm{MS}$ adducts to those observed for $\left[\mathrm{Cu}_{2}^{1} \mathrm{~L}^{1}\right]^{\mathrm{OTf}}$, and analogous broadening in the corresponding ${ }^{1} \mathrm{H}$ NMR spectrum. Taken together, the above considerations suggest that $\left[\mathrm{Cu}_{2}{ }_{2} \mathbf{L}^{1}\right]^{\mathbf{X}}$ may be present in solution as a trimeric hexanuclear species (Scheme 3.7, $\left.\left(\left[\mathrm{Cu}_{2}^{\prime} \mathrm{L}^{1}\right]^{\mathrm{X}}\right)_{3}\right)$.

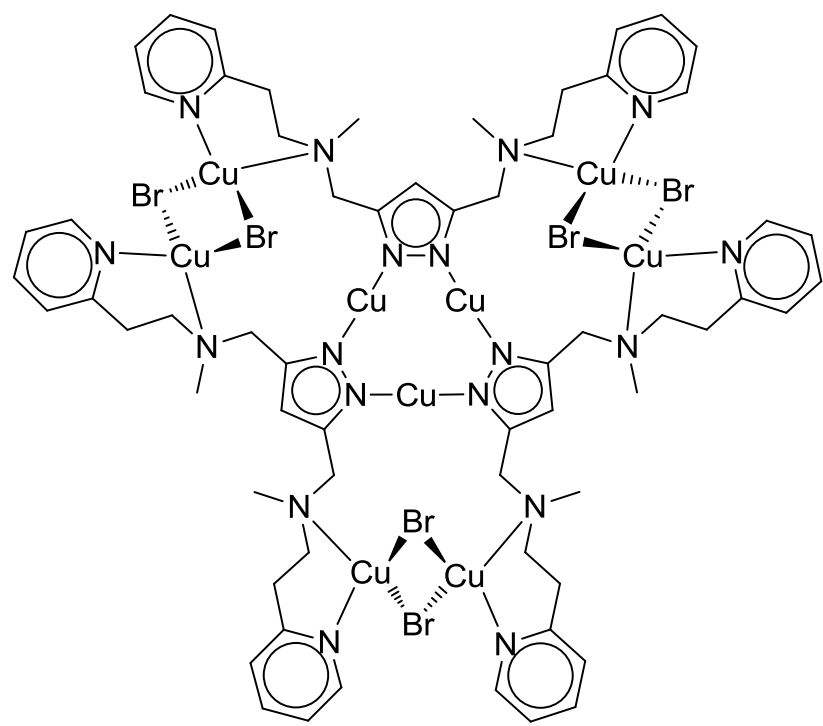

XII

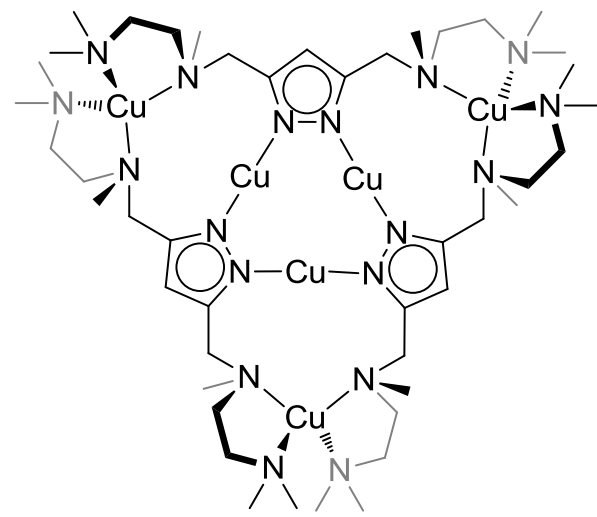

$\left(\left[\mathrm{Cu}_{2}^{\prime} \mathrm{L}^{1}\right]^{\mathrm{X}}\right)_{3}$

Scheme 3.7: Solid state structure of XII and proposed trimeric assembly of $\left[\mathrm{Cu}_{2}^{1} \mathrm{~L}^{1}\right]$ to give $\left(\left[\mathrm{Cu}_{2}^{\prime} \mathrm{L}^{1}\right]^{\mathrm{X}}\right)_{3}$ in solution. Only one of the possible relative configurations of the $\left(\left[\mathrm{Cu}_{2}{ }^{1} \mathrm{~L}^{1}\right]^{\mathrm{X}}\right)_{3}$ side-arms is depicted. Charges and counterions are omitted (XII is a neutral complex).

The exact nature of the dynamics displayed by this system are still unclear. It is worth noting that the nuclearity of pyrazole supported copper(I) metallocycles can vary depending on the experimental conditions used for synthesis. ${ }^{127}$ Furthermore, equilibrium mixtures of trimeric and tetrameric species which interconvert have been observed in solution, ${ }^{131,135}$ which could account for the observed dynamics. An additional process involving the terminal nitrogen donors might also contribute. While the cyclic pyrazole coordination motif is generally planar in these trimeric assemblies, ${ }^{127}$ the tertiary amine groups in $\left(\left[\mathrm{Cu}_{2}{ }_{2} \mathbf{L}^{1}\right]^{\mathrm{X}}\right)_{\mathbf{3}}$ likely coordinate from above or below the central plane (Scheme 3.7). Different isomers thus result depending on the relative arrangements of the three distal copper(I) centres, and interconversion between these species is conceivable. Solvent molecules could also additionally coordinate and compete with the tertiary amine donors of the ligand. Such a process is well documented in related copper(I) systems supported by multidentate nitrogen-donor ligands, and is discussed in more detail below (Section 3.3.3). Further studies are needed to fully elucidate the fluxional behaviour observed in this system, and to 
corroborate the trimeric assignment of $\left(\left[\mathrm{Cu}_{2}^{1} \mathbf{L}^{1}\right]^{\mathrm{x}}\right)_{3}$. The speciation and dynamics likely depend on both solvent and temperature. Employing a less-coordinating solvent in place of $\mathrm{MeCN}$ may thus offer insights with respect to its possible involvement. The use of alternative solvents could also allow for NMR studies to be conducted at lower temperatures, which may lead to resolution of signal sets for contributing species.

\subsection{Synthesis and Characterisation of $\left[\mathrm{Cu}_{2}{ }_{2} \mathrm{~L}^{2}\right]^{\mathrm{X}}$}

\subsubsection{Synthetic Considerations}

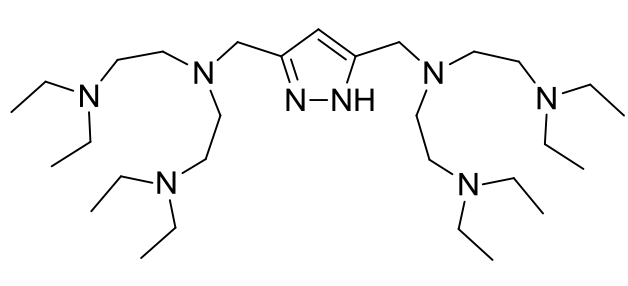

$H L^{2}$

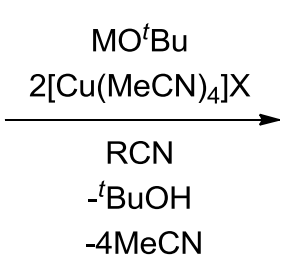

$-{ }^{t} \mathrm{BuOH}$
$-4 \mathrm{MeCN}$

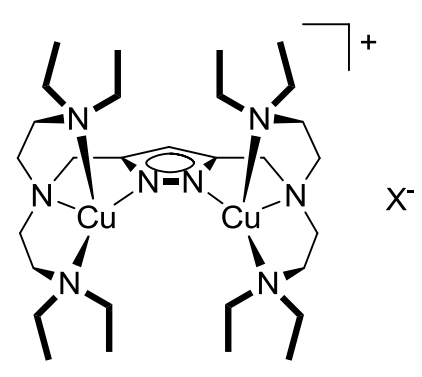

$\left[\mathrm{Cu}_{2}^{\mathrm{I}} \mathrm{L}^{2}\right]^{\mathrm{X}}+\mathrm{MX}$

Scheme 3.8: Synthesis of $\left[\mathrm{Cu}_{2}{ }_{2}{ }^{2}\right]^{\mathrm{X}}$. $\mathrm{M}=\mathrm{Na}^{+}$or $\mathrm{K}^{+}, \mathrm{R}=\mathrm{Me}$ or $\mathrm{Et}, \mathrm{X}=\mathrm{PF}_{6}{ }^{-}, \mathrm{BF}_{4}{ }^{-}, \mathrm{ClO}_{4}{ }^{-}, \mathrm{OTf}{ }^{-}$, or $\mathrm{B}\left(\mathrm{C}_{6} \mathrm{~F}_{5}\right)_{4}{ }^{-}$.

In situ formation of dinuclear complex $\left[\mathrm{Cu}_{2}^{1} \mathrm{~L}^{2}\right]^{\mathrm{PF} 6}$ upon reaction of $\left[\mathrm{Cu}(\mathrm{MeCN})_{4}\right] \mathrm{PF}_{6}$ with $\mathrm{HL}^{2}$ in EtCN (Scheme 3.8) was proposed to occur in a prior study, though no characterisation data was reported. ${ }^{90}$ Despite the use of low temperatures in the former investigation, complex $\left[\mathrm{Cu}_{2}{ }_{2} \mathbf{L}^{2}\right]^{\mathrm{X}}$ was found to be indefinitely stable at RT in the current work, giving faintly coloured yellow solutions. When compared with the other complexes investigated herein, $\left[\mathrm{Cu}_{2}{ }_{2} \mathbf{L}^{2}\right]^{\mathrm{X}}$ indeed appears to be relatively robust with respect to disproportionation. The resulting stability of $\left[\mathrm{Cu}_{2}^{1} \mathrm{~L}^{2}\right]^{\mathrm{X}}$ proved extremely useful as further work including characterisation could be conducted at RT.

The observed long term stability of $\left[\mathrm{Cu}_{2}^{1} \mathrm{~L}^{2}\right]^{\mathrm{X}}$ furthermore appeared to make it a good candidate for crystallisation attempts. Numerous attempts to produce crystalline material were performed using different counteranions and solvents, as discussed below. In addition to the commonly utilised $\mathrm{PF}_{6}{ }^{-}, \mathrm{BF}_{4}{ }^{-}, \mathrm{ClO}_{4}{ }^{-}$, OTf ${ }^{-}$and $\left.\mathrm{B}_{(} \mathrm{C}_{6} \mathrm{H}_{5}\right)_{4}{ }^{-}$, several fluorinated organic counterions such as $\mathrm{B}\left[3,5-\left(\mathrm{CF}_{3}\right)_{2} \mathrm{C}_{6} \mathrm{H}_{3}\right]_{4}{ }^{-}, \mathrm{B}\left(\mathrm{C}_{6} \mathrm{~F}_{5}\right)_{4}{ }^{-}$, and $\mathrm{Al}\left(\mathrm{OCH}\left(\mathrm{CF}_{3}\right)_{2}\right)_{4}{ }^{-}$were investigated. Although the addition of soft alkyl phosphine or isonitrile co-ligands met with success in previous instances, ${ }^{132,136}$ their strongly coordinating nature tends to result in copper(I) complexes inert to $\mathrm{O}_{2} \cdot{ }^{14}$ Therefore several more labile nitriles were trialled with a selection of counterions, including isobutyronitrile ( $\operatorname{PrCN})$, butyronitrile ( $\left.{ }^{n} \mathrm{PrCN}\right)$, valeronitrile ( $\left.{ }^{n} \mathrm{BuCN}\right)$ and pivalonitrile ( ${ }^{t} \mathrm{BuCN}$ ), with the first three employed as solvents and the latter as an additive to EtCN to allow the use of low temperatures. In an alternative approach, a new synthetic methodology was developed in order to completely exclude nitriles. This was achieved by using $\mathrm{CuO}^{t} \mathrm{Bu}$ as a copper $(\mathrm{I})$ source and adding one equivalent of $\mathrm{NH}_{4} \mathrm{X}\left(\mathrm{X}=\mathrm{PF}_{6}{ }^{-}\right.$, $\left.\mathrm{BF}_{4}{ }^{-}, \mathrm{OTf}^{-}\right)$. Employing this procedure with THF as a solvent gave oxygen sensitive yellow 
coloured solutions, but no crystalline $\left[\mathrm{Cu}_{2}{ }_{2} \mathrm{~L}^{2}\right]^{\mathrm{X}}$ could be isolated. In contrast, DCM solutions rapidly became black to dark green in colour, consistent with previously reported dehalogenation reactions observed in related TMPA analogues. ${ }^{115,118-121}$ This alternative synthetic route was not pursued further.

The use of other solvents in combination with the general synthetic strategy (Scheme 3.8) met with little success, but two combinations of reagents are worthy of further mention. When a methanolic solution of $\mathrm{NaB}\left(\mathrm{C}_{6} \mathrm{H}_{5}\right)_{4}$ was added at low temperature to $\left[\mathrm{Cu}_{2}{ }_{2} \mathbf{L}^{2}\right]^{\mathrm{PF} 6}$, preformed in $\mathrm{MeOH}$ from $\mathrm{HL}^{2}, \mathrm{NaOMe}$ and $\left[\mathrm{Cu}(\mathrm{MeCN})_{4}\right] \mathrm{PF}_{6}$, a white precipitate resulted. Unfortunately the isolated precipitate melted at RT, but techniques for cold filtration and drying may circumvent this problem and could be employed in future investigations. Similarly, addition of $\left[\mathrm{Cu}(\mathrm{MeCN})_{4}\right] \mathrm{B}\left(\mathrm{C}_{6} \mathrm{~F}_{5}\right)_{4}$ to $\mathrm{HL}^{2}$ in toluene with one equivalent of KOtBu present gave an immediate precipitate. Layering attempts were made using these reagents, whereby toluene solutions of deprotonated ligand and copper salt were allowed to mix by slow diffusion. Although these solutions remained clear for several days, an oil eventually deposited. Repeating this procedure with a range of temperatures and concentrations is thus a second promising lead for future work. Some insight into the lack of success encountered in crystallising $\left[\mathrm{Cu}_{2}{ }_{2} \mathbf{L}^{2}\right]^{\mathrm{X}}$ is provided by its in situ characterisation. The general synthetic route using nitriles (Scheme 3.8) was employed for all remaining investigations.

\subsubsection{Mass Spectrometry}

Preliminary analysis of $\left[\mathrm{Cu}^{\prime}{ }_{2} \mathrm{~L}^{2}\right]^{\mathrm{PF} 6}$ by ESI-MS at RT in MeCN showed the presence of $\left[\mathrm{Cu}_{2}{ }_{2} \mathrm{~L}^{2}\right]^{+}$ $(\mathrm{m} / \mathrm{z}=647.4)$ as the second most prominent species, with the greatest intensity peak set corresponding to the mononuclear $\left[\left(\mathrm{Cu}^{\prime} \mathrm{L}^{2}\right)(\mathrm{H})\right]^{+}(\mathrm{m} / z=585.5)$. Several additional minor species $(\approx 10 \%)$ could be identified, including $\left[\left(\mathrm{Cu}_{2}{ }_{2} \mathrm{~L}^{2}\right)(\mathrm{X})\right]^{2+}(\mathrm{m} / z=353.2$ or 360.2 where $X=$ $\mathrm{MeCO}_{2}{ }^{-}$or $\mathrm{EtCO}_{2}{ }^{-}$respectively), and $\left[\left(\mathrm{Cu}^{\prime} \mathrm{Cu}^{\prime \prime} \mathrm{L}^{2}\right)(\mathrm{Cl})\right]^{+}(\mathrm{m} / z=684.3)$. The carboxylate anion adducts originate from hydrolysis of the corresponding nitriles in the analyte solution. The source of the water required for this is likely the ubiquitous $\mathrm{H}_{2} \mathrm{O}$ present inside the spectrometer, although the relative amount of these adducts generally increased when solutions exposed to dry dioxygen were allowed to decay. Residual $\mathrm{O}_{2}$ may thus play a role, consistent with the copper(II) oxidation state of these carboxylate adducts. While it is uncertain if the chloride ions are present in the sample or inside the spectrometer, the $\left[\left(\mathrm{Cu}^{\prime} \mathrm{Cu}^{\prime \prime} \mathrm{L}^{2}\right)(\mathrm{Cl})\right]^{+}$species serves to illustrate the high affinity these complexes have toward chloride anions (Section 3.1.2). Whether the two dominant peaks are indicative of the true speciation in solution is rather unclear. Interestingly, an analogous spectrum was also observed in a related system employing a binucleating pyrazole scaffold, even though the isolated copper(I) complex had a dimeric tetranuclear structure in the solid state and crystalline material was used for the measurement. ${ }^{136}$ Some further insight in this regard was provided by Cryo-ESI-MS measurements. 


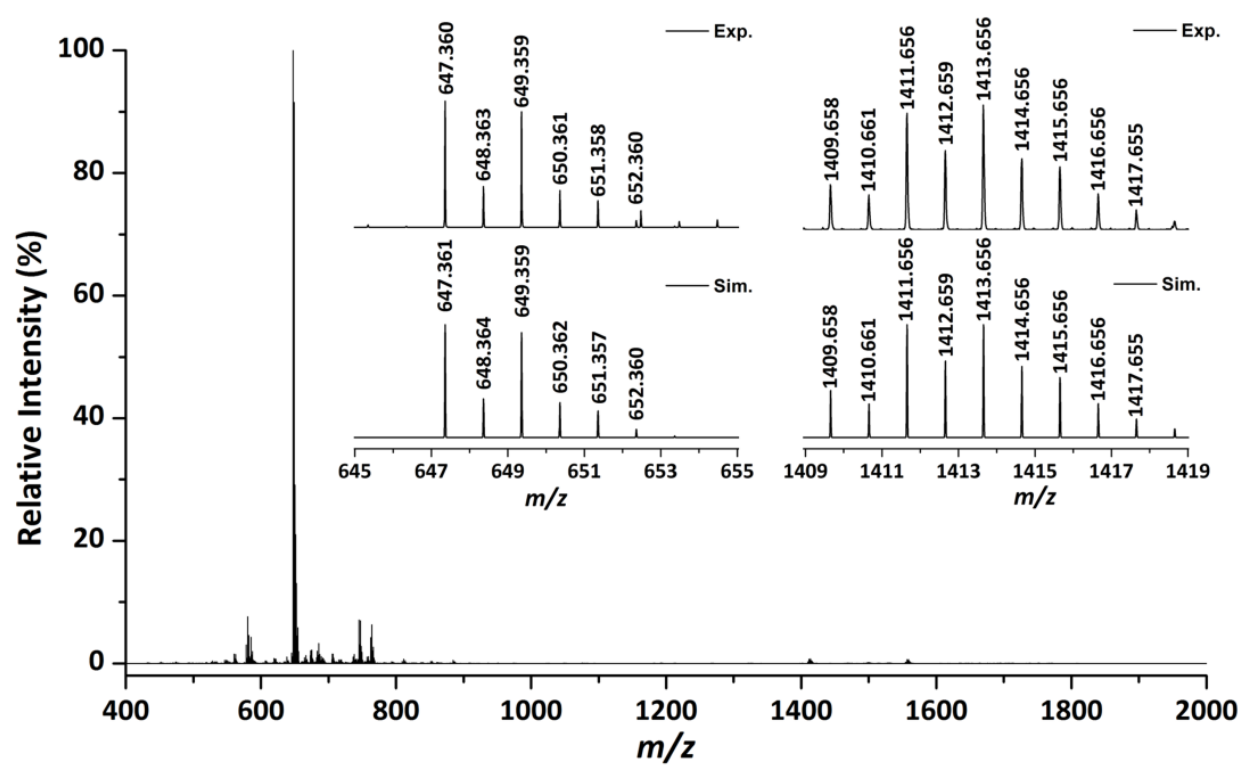

Figure 3.4: Positive mode HR-Cryo-ESI-MS spectrum of $\left[\mathrm{Cu}_{2}{ }_{2} \mathrm{~L}^{2}\right]^{\mathrm{PF} 6}$ in EtCN. The insets show experimental and simulated isotopic distribution patterns for $\left[\mathrm{C}_{29} \mathrm{H}_{61} \mathrm{Cu}_{2} \mathrm{~N}_{8}\right]^{+}$(left) and $\left[\left(\mathrm{C}_{29} \mathrm{H}_{61} \mathrm{Cu}_{2} \mathrm{~N}_{8}\right)_{2} \mathrm{Cu}(\mathrm{CN})_{2}\right]^{+}$(right).

\begin{tabular}{|c|c|c|}
\hline $\mathrm{m} / \mathrm{z}$ & Intensity (\%) & Assignment* \\
\hline \multicolumn{3}{|c|}{ Monomeric Adducts } \\
\hline 585.437 & 4 & {$\left[\left(\mathrm{Cu}^{\prime} \mathrm{L}^{2}\right)(\mathrm{H})\right]^{+}$} \\
\hline 647.360 & 100 & {$\left[\mathrm{Cu}_{2}^{1} \mathrm{~L}^{2}\right]^{+}$} \\
\hline 745.324 & 7 & {$\left[\left(\mathrm{Cu}_{2}{ }_{2} \mathrm{~L}^{2}\right)\left(\mathrm{PO}_{3} \mathrm{~F}\right)\right]^{+}$} \\
\hline 764.295 & 6 & {$\left[\left(\mathrm{Cu}_{2}^{\prime} \mathrm{L}^{2}\right)\left(\mathrm{Cu} \mathrm{u}^{\prime \prime}\right)(\mathrm{CN})_{2}\right]^{+}$} \\
\hline \multicolumn{3}{|c|}{ Dimeric Adducts } \\
\hline 1413.656 & 1 & {$\left[\left(\mathrm{Cu}_{2}^{\prime}{ }_{2}{ }^{2}\right)_{2}\left(\mathrm{Cu}^{\prime}\right)(\mathrm{CN})_{2}\right]^{+}$} \\
\hline 1558.619 & 1 & {$\left[\left(\mathrm{Cu}_{2}^{\prime}{ }_{2}{ }^{2}\right)_{2}\left(\mathrm{Cu}^{\prime \prime}\right)(\mathrm{CN})_{2}\left(\mathrm{PF}_{6}\right)\right]^{+}$} \\
\hline \multicolumn{3}{|c|}{$\begin{array}{l}\text { *Rather than purely empirical formulas the assignments presented here are grouped in order to allow for } \\
\text { easier interpretation, although it must be highlighted that the measurements give no direct information about } \\
\text { connectivity of the elements which make up the observed ion peaks. }\end{array}$} \\
\hline
\end{tabular}

The high resolution (HR) Cryo-ESI-MS spectrum of $\left[\mathrm{Cu}_{2}{ }_{2} \mathrm{~L}^{2}\right]^{\mathrm{PF} 6}$ (Figure 3.4), measured at -80 ${ }^{\circ} \mathrm{C}$ in EtCN, appears considerably different than that described above. It is dominated by just one signal, with a mass to charge ratio and isotopic distribution pattern consistent with that calculated for dinuclear $\left[\mathrm{Cu}_{2}^{\prime} \mathrm{L}^{2}\right]^{+}(\mathrm{m} / \mathrm{z}=647.360)$ (Table 3.3). Only minor amounts of additional species are observed, all with relative intensities of less than $8 \%$, including the mononuclear species $(\mathrm{m} / \mathrm{z}=585.437)$ observed above. A decomposition adduct is again present, $\left[\left(\mathrm{Cu}_{2}{ }_{2} \mathrm{~L}^{2}\right)\left(\mathrm{PO}_{3} \mathrm{~F}\right)\right]^{+}(\mathrm{m} / z=745.324)$. This species could plausibly result from decomposition of the $\mathrm{PF}_{6}{ }^{-}$counteranion, and was significantly enhanced when solutions of 
$\left[\mathrm{Cu}_{2}{ }_{2} \mathbf{L}^{2}\right]^{\mathrm{PF} 6}$ exposed to dry dioxygen were allowed to warm to RT overnight (this peak set can also be formulated as $\left[\left(\mathrm{Cu}_{2}^{\prime} \mathrm{L}^{2}\right)\left(\mathrm{Me}_{2} \mathrm{CO}_{2}\right)(\mathrm{K})\right]^{+}$, though this assignment seems less likely given the copper ion oxidation states). A species with an isotopic pattern showing inclusion of an additional copper ion is also present, $\left[\left(\mathrm{Cu}_{2}^{\prime} \mathrm{L}^{2}\right)_{2}\left(\mathrm{Cu}^{\prime \prime}\right)(\mathrm{CN})_{2}\right]^{+}(\mathrm{m} / z=764.295)$. Interestingly, at significantly higher $\mathrm{m} / \mathrm{z}$ two weak signals appear which correspond to adducts of the latter species with an additional dinuclear unit of $\left[\mathrm{Cu}_{2}^{1} \mathrm{~L}^{2}\right]^{+}$, or both $\left[\mathrm{Cu}_{2}{ }_{2} \mathrm{~L}^{2}\right]^{+}$and $\mathrm{PF}_{6}{ }^{-}(\mathrm{m} / z=$ 1413.656 and 1558.619). This suggests that dimerisation has taken place to give a multinuclear ion incorporating two ligand molecules, and may indicate that the system supported by $\mathbf{H L}^{2}$ is able to aggregate in solution.

Comparing the two measurements above suggests differences in solvent and temperature may have had a profound effect on the species present in solution. However, it is not possible to attribute the observed changes solely to the alteration in experimental conditions. The spectrometers employed were of two distinct types, an ion trap instrument was used for RT measurements, whereas a time of flight instrument was used for low temperature measurements. Furthermore, although both utilised ESI for ion generation, different ionisation processes dominate at particularly low temperatures. ${ }^{137-139}$ The variation in results between the two ESI-MS techniques employed is significantly accentuated when measurements are conducted in negative mode. This is particularly true with regard to the dimeric aggregates. While observed only in trace amounts above, their presence is especially relevant to subsequent dioxygen adduct formation (Section 4.3), and greatly enhanced when monitoring negative ions under Cryo conditions.

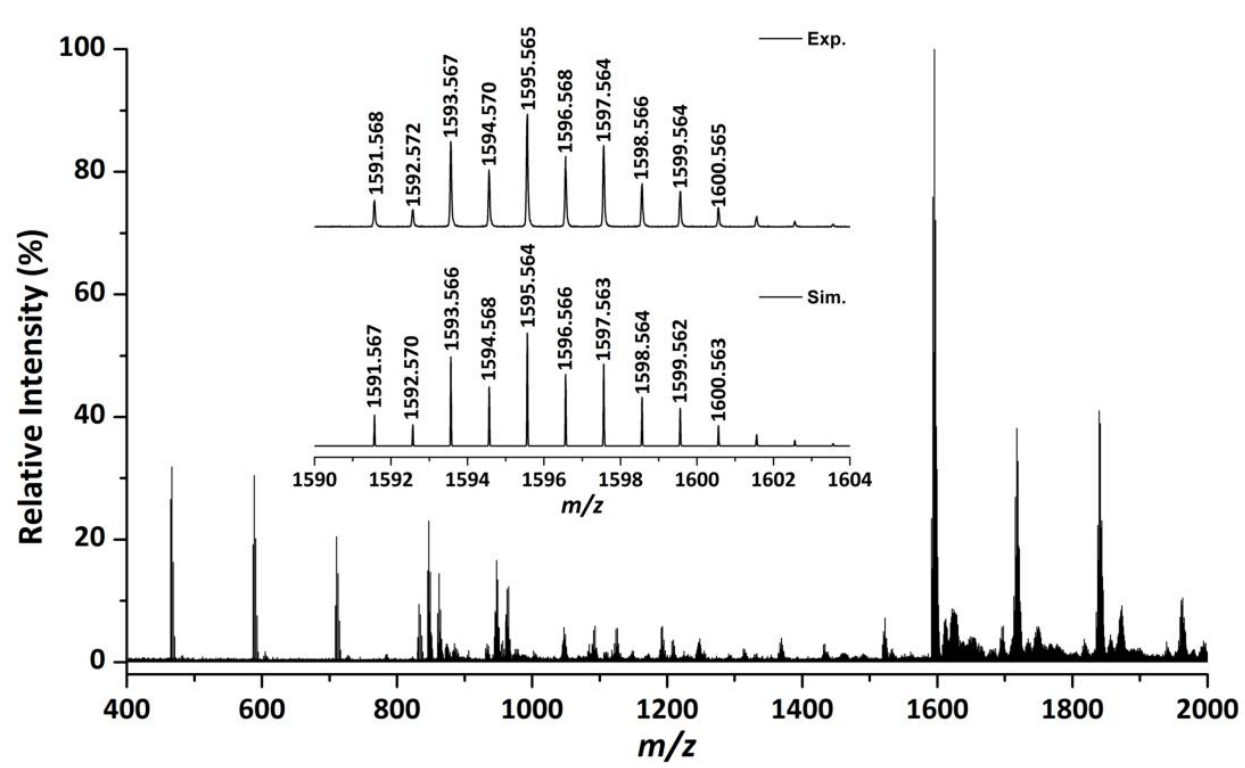

Figure 3.5: Negative mode HR-Cryo-ESI-MS spectrum of $\left[\mathrm{Cu}_{2}{ }_{2}{ }^{2}\right]^{\mathrm{clo4}}$ in EtCN. The inset shows experimental and simulated isotopic distribution patterns for $\left[\left(\mathrm{C}_{29} \mathrm{H}_{61} \mathrm{Cu}_{2} \mathrm{~N}_{8}\right)_{2}\left(\mathrm{ClO}_{4}\right)_{3}\right]^{-}$. 


\begin{tabular}{|c|c|c|}
\hline $\mathrm{m} / \mathrm{z}$ & Intensity (\%) & Assignment* \\
\hline \multicolumn{3}{|c|}{ Monomeric Adducts - $\mathrm{PF}_{6}{ }^{-}$counteranion } \\
\hline 937.294 & 58 & {$\left[\left(\mathrm{Cu}_{2}^{\prime} \mathrm{L}^{2}\right)\left(\mathrm{PF}_{6}\right)_{2}\right]^{-}$} \\
\hline 1025.306 & 100 & {$\left[\left(\mathrm{Cu}_{2}^{\prime} \mathrm{L}^{2}\right)\left(\mathrm{PF}_{6}\right)_{2}(?)\right]^{-}$} \\
\hline 1083.269 & 65 & {$\left[\left(\mathrm{Cu}_{2}^{\prime} \mathrm{L}^{2}\right)(\mathrm{H})\left(\mathrm{PF}_{6}\right)_{3}\right]^{-}$} \\
\hline \multicolumn{3}{|c|}{ Dimeric Adducts - $\mathrm{PF}_{6}{ }^{-}$counteranion } \\
\hline 1673.664 & 34 & {$\left[\left(\mathrm{Cu}_{2}^{\prime} \mathrm{L}^{2}\right)_{2}\left(\mathrm{PF}_{6}\right)_{2}(?)\right]^{-}$} \\
\hline 1731.620 & 25 & {$\left[\left(\mathrm{Cu}_{2}{ }_{2} \mathrm{~L}^{2}\right)_{2}\left(\mathrm{PF}_{6}\right)_{3}\right]^{-}$} \\
\hline \multicolumn{3}{|c|}{ Monomeric Adducts - $\mathrm{ClO}_{4}{ }^{-}$counteranion } \\
\hline 847.255 & 22 & {$\left[\left(\mathrm{Cu}_{2}^{\prime} \mathrm{L}^{2}\right)\left(\mathrm{ClO}_{4}\right)_{2}\right]^{-}$} \\
\hline 947.212 & 15 & {$\left[\left(\mathrm{Cu}^{\prime} \mathrm{Cu}^{\prime \prime} \mathrm{L}^{2}\right)\left(\mathrm{ClO}_{4}\right)_{3}\right]^{-}$} \\
\hline \multicolumn{3}{|c|}{ Dimeric Adducts - $\mathrm{ClO}_{4}^{-}$counteranion } \\
\hline 1595.565 & 100 & {$\left[\left(\mathrm{Cu}_{2}{ }_{2} \mathrm{~L}^{2}\right)_{2}\left(\mathrm{ClO}_{4}\right)_{3}\right]^{-}$} \\
\hline 1717.499 & 38 & {$\left[\left(\mathrm{Cu}_{2}^{\prime} \mathrm{L}^{2}\right)_{2}\left(\mathrm{ClO}_{4}\right)_{3}\left(\mathrm{NaClO}_{4}\right)\right]^{-}$} \\
\hline 1839.440 & 40 & {$\left[\left(\mathrm{Cu}_{2}^{\prime} \mathrm{L}^{2}\right)_{2}\left(\mathrm{ClO}_{4}\right)_{3}\left(\mathrm{NaClO}_{4}\right)_{2}\right]^{-}$} \\
\hline \multicolumn{3}{|c|}{$\begin{array}{l}\text { *Rather than purely empirical formulas the assignments presented here are grouped in order to allow for } \\
\text { easier interpretation, although it must be highlighted that the measurements give no direct information about } \\
\text { connectivity of the elements which make up the observed ion peaks. }\end{array}$} \\
\hline
\end{tabular}

The negative mode ESI-MS spectrum of $\left[\mathrm{Cu}_{2}^{1} \mathrm{~L}^{2}\right]^{\mathrm{PF} 6}$ measured at RT in MeCN shows only one weak signal with an isotopic envelope indicative of a copper containing species. This peak set has a relative intensity of just $5 \%\left(100 \%\right.$ peak $\left.=\left[\mathrm{PF}_{6}\right]^{-}\right)$and corresponds to the dinuclear species $\left[\left(\mathrm{Cu}_{2}{ }_{2} \mathrm{~L}^{2}\right)(\mathrm{H})\left(\mathrm{PF}_{6}\right)_{3}\right]^{-}(\mathrm{m} / \mathrm{z}=1083.3)$. This signal is also observed when measurements are conducted at $-80^{\circ} \mathrm{C}$ in $\mathrm{EtCN}$, though with a much greater relative intensity of $65 \%$ (Table 3.4). Almost none of the numerous additional species in the Cryo-ESI-MS spectrum could be unambiguously assigned, except for $\left[\left(\mathrm{Cu}_{2}^{\prime} \mathrm{L}^{2}\right)\left(\mathrm{PF}_{6}\right)_{2}\right]^{-}(\mathrm{m} / z=937.294)$. Despite this uncertainty, numerous peak sets displaying isotopic patterns consistent with tetranuclear copper species could be observed in the higher mass ranges. Indeed, although the most intense signal $(m / z=1025.306)$ in the spectrum could not be identified, the peak set with greatest relative intensity (34\%) above 1500 Da corresponds to an adduct of the dominant species $(\mathrm{m} / \mathrm{z}=1025.306)$ with one additional $\left[\mathrm{Cu}_{2}{ }_{2} \mathrm{~L}^{2}\right]^{+}$unit. A second tetranuclear aggregate with a considerable relative intensity of $15 \%$ could also be assigned as $\left[\left(\mathrm{Cu}_{2}^{\prime} \mathrm{L}^{2}\right)_{2}(\mathrm{H})\left(\mathrm{PF}_{6}\right)_{3}\right]^{-}$ $(\mathrm{m} / \mathrm{z}=1083$.269), which corresponds to the dimeric form of the only species observed at RT. In fact, by substituting the $\mathrm{KO}^{t} \mathrm{Bu}$ with $\mathrm{NaO}^{t} \mathrm{Bu}$ and $\mathrm{PF}_{6}{ }^{-}$counterion with $\mathrm{ClO}_{4}{ }^{-}$it was found that the major peak in the spectrum (Figure 3.5) under otherwise identical conditions becomes that of the dimeric tetranuclear species $\left[\left(\mathrm{Cu}_{2} \mathrm{~L}^{2}\right)_{2}\left(\mathrm{ClO}_{4}\right)_{3}\right]^{-}(\mathrm{m} / \mathrm{z}=1595.565$, Table 3.4). Aggregates of this adduct together with additional $\mathrm{NaClO}_{4}$ ions are also prominent, 
$\left[\left(\mathrm{Cu}_{2}^{\prime} \mathrm{L}^{2}\right)_{2}\left(\mathrm{ClO}_{4}\right)_{3}\left(\mathrm{NaClO}_{4}\right)\right]^{-}(\mathrm{m} / z=1717.499)$ and $\left[\left(\mathrm{Cu}_{2}^{\prime} \mathrm{L}^{2}\right)_{2}\left(\mathrm{ClO}_{4}\right)_{3}\left(\mathrm{NaClO}_{4}\right)_{2}\right]^{-} \quad(\mathrm{m} / z=$ 1839.440). While several monomeric dinuclear species are still present, such as $\left[\left(\mathrm{Cu}_{2}^{\prime} \mathrm{L}^{2}\right)\left(\mathrm{ClO}_{4}\right)_{2}\right]^{-}(\mathrm{m} / z=847.255)$ and $\left[\left(\mathrm{Cu}^{\prime} \mathrm{Cu}^{\prime \prime} \mathrm{L}^{2}\right)\left(\mathrm{ClO}_{4}\right)_{3}\right]^{-}(\mathrm{m} / \mathrm{z}=947.212)$, their intensities are in all cases below $30 \%$.

The above observations are somewhat ambiguous with respect to the speciation of $\left[\mathbf{C u}_{2} \mathbf{L}^{\mathbf{2}}\right]^{\mathbf{X}}$ in solution. Although the positive mode measurements conducted at low temperature indicate that $\left[\mathrm{Cu}_{2}^{1} \mathrm{~L}^{2}\right]^{\mathrm{X}}$ is a monomeric dinuclear species, the prevalence of tetranuclear clusters in the corresponding negative mode spectra suggest that this system is susceptible to dimerisation. The counteranion present $\left(\mathrm{ClO}_{4}{ }^{-}\right.$or $\left.\mathrm{PF}_{6}{ }^{-}\right)$appears to influence the ratio between the monomeric and dimeric adducts observed in negative mode, with $\mathrm{ClO}_{4}{ }^{-}$ favouring the latter, tetranuclear aggregates. This could plausibly result from the stronger coordinating ability of $\mathrm{ClO}_{4}{ }^{-}$when compared with $\mathrm{PF}_{6}{ }^{-140,141}$ However, it must be highlighted that the above measurements provide no structural information about the connectivity between the associated ions. It is also possible that the higher aggregates of $\left[\mathrm{Cu}_{2}{ }_{2} \mathbf{L}^{2}\right]^{\mathbf{X}}$ observed in the above measurements are merely artefacts of the ESI-MS measurement. To assess their relevance to the true speciation of $\left[\mathbf{C u}_{2}^{\prime} \mathbf{L}^{2}\right]^{\mathbf{X}}$ in solution, further investigation was carried out using NMR spectroscopy.

\subsubsection{NMR Spectroscopy}

The ${ }^{1} \mathrm{H}$ NMR spectrum of $\left[\mathrm{Cu}_{2}^{1} \mathrm{~L}^{2}\right]^{\mathrm{X}}\left(\mathrm{X}=\mathrm{PF}_{6}{ }^{-}\right.$or $\left.\mathrm{OTf}^{-}\right)$in $\mathrm{CD}_{3} \mathrm{CN}$ at RT shows only very broad resonances, as is the case for several of the signals in the ${ }^{13} \mathrm{C} N M R$ spectrum. However, at least two species appear to be present by examination of the pyrazole methine and shoulder $\mathrm{CH}_{2}$ group proton resonances, in an approximate ratio of 4:1 (Figure 3.6, $\mathbf{A}$ and $\mathbf{B}$ for major and minor, respectively). Increasing the temperature results in coalescence of these signals, with the shoulder groups converging already at $55^{\circ} \mathrm{C}$, but with the pyrazole $\mathrm{CH}$ resonances remaining almost indistinguishably broad even at the highest measured temperature of $70{ }^{\circ} \mathrm{C}$. At this temperature all other resonances became significantly sharper, to the extent that the coupling patterns were once again discernible. Furthermore, only one set of 6 peaks is apparent at $70^{\circ} \mathrm{C}$ in the ${ }^{13} \mathrm{C}$ NMR spectrum (The pyrazole methine carbon nucleus could not be observed), and cross-peaks corresponding to 2 nitrogen nuclei are apparent in the ${ }^{1} \mathrm{H}-{ }^{15} \mathrm{~N} \mathrm{HMBC}$ spectrum (Signals for the pyrazole nitrogen nuclei were not observed, likely owing to the extremely broad pyrazole methine hydrogen resonance ( $a$, $\delta \approx 6.2 \mathrm{ppm}$, Figure 3.6)). These results indicate that the two species become equivalent at higher temperatures as a result of fast exchange. 


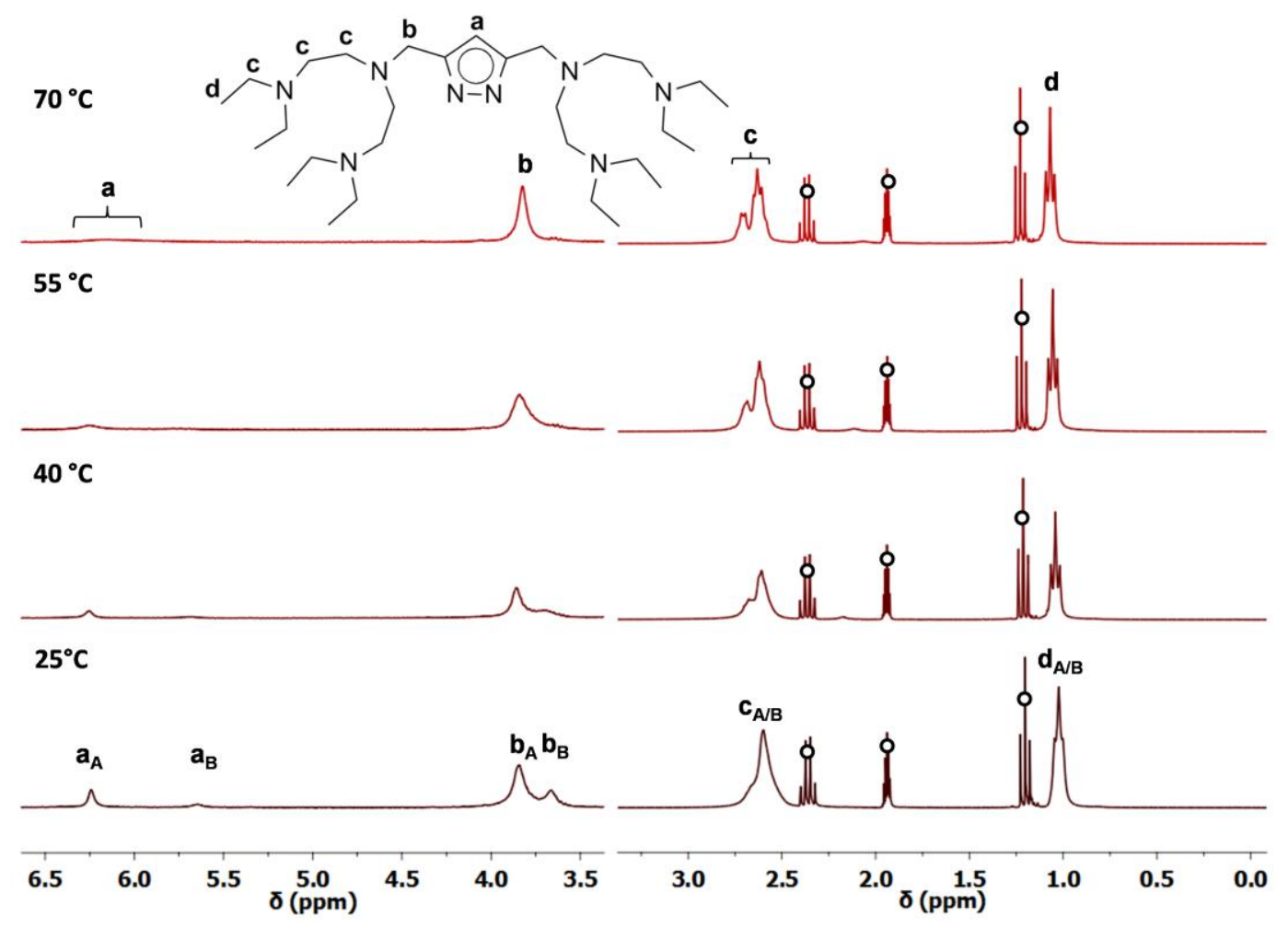

Figure 3.6: ${ }^{1} \mathrm{H}$ NMR spectra of $\left[\mathrm{Cu}_{2}{ }_{2} \mathrm{~L}^{2}\right]^{\text {OTf }}$ at various temperatures under anhydrous conditions in $\mathrm{CD}_{3} \mathrm{CN}$. Signals of the major and minor species resolved at $25^{\circ} \mathrm{C}$ are labelled (subscripts $\mathbf{A}$ and $\mathbf{B}$, respectively), but coalesce at higher temperatures. Residual solvent signals (including EtCN from synthesis) are labelled (O). The downfield region of the spectra are magnified approximately six-fold in intensity for clarity.

The ${ }^{1} \mathrm{H}$ NMR spectrum of $\left[\mathrm{Cu}_{2}^{1} \mathrm{~L}^{2}\right]^{\mathrm{X}}\left(\mathrm{X}=\mathrm{PF}_{6}{ }^{-}\right.$or $\left.\mathrm{OTf}^{-}\right)$in $\mathrm{CD}_{3} \mathrm{CN}$ at RT shows only very broad resonances, as is the case for several of the signals in the ${ }^{13} \mathrm{C} N M R$ spectrum. However, at least two species appear to be present by examination of the pyrazole methine and shoulder $\mathrm{CH}_{2}$ group proton resonances, in an approximate ratio of 4:1 (Figure 3.6, $\mathbf{A}$ and $\mathbf{B}$ for major and minor, respectively). Increasing the temperature results in coalescence of these signals, with the shoulder groups converging already at $55^{\circ} \mathrm{C}$, but with the pyrazole $\mathrm{CH}$ resonances remaining almost indistinguishably broad even at the highest measured temperature of $70{ }^{\circ} \mathrm{C}$. At this temperature all other resonances became significantly sharper, to the extent that the coupling patterns were once again discernible. Furthermore, only one set of 6 peaks is apparent at $70^{\circ} \mathrm{C}$ in the ${ }^{13} \mathrm{C}$ NMR spectrum (The pyrazole methine carbon nucleus could not be observed), and cross-peaks corresponding to 2 nitrogen nuclei are apparent in the ${ }^{1} \mathrm{H}-{ }^{15} \mathrm{~N} \mathrm{HMBC}$ spectrum (Signals for the pyrazole nitrogen nuclei were not observed, likely owing to the extremely broad pyrazole methine hydrogen resonance ( $a$, $\delta \approx 6.2 \mathrm{ppm}$, Figure 3.6)). These results indicate that the two species become equivalent at higher temperatures as a result of fast exchange.

In order to assess the molecular size in solution of the two above described species, ${ }^{1} \mathrm{H}$ NMR DOSY analysis was conducted in $\mathrm{CD}_{3} \mathrm{CN}$ at RT with $\left[\mathrm{Cu}_{2}{ }_{2} \mathbf{L}^{2}\right]^{\mathrm{PF} 6}$. The two signal sets described above show differing diffusion coefficients $\left(D=0.85 \times 10^{-9}\right.$ and $0.91 \times 10^{-9} \mathrm{~m}^{2} \mathrm{~s}^{-1}$ for $\mathbf{A}$ and $\mathbf{B}$, respectively), but both are smaller than that displayed for equimolar solutions of free ligand 
$\mathrm{HL}^{2}\left(D=0.98 \times 10^{-9} \mathrm{~m}^{2} \mathrm{~s}^{-1}\right)$. The molecular radii derived from these values indicate that both A $(r=6.9 \AA)$ and $\mathbf{B}(r=6.5 \AA)$ occupy considerably more space in solution than the corresponding ligand $\mathbf{H L}^{2}(r=6.1 \AA)$. The major species $\mathbf{A}$ is 1.5 times larger than $\mathbf{H L}^{\mathbf{2}}$ in terms of volume in solution, whereas the minor species $\mathbf{B}$ is only 1.2 times larger. These ratios are significantly smaller than that expected if either of the species $\mathbf{A}$ or $\mathbf{B}$ was a dimeric adduct in solution. Nevertheless, the above findings still strongly suggest that the speciation of $\left[\mathrm{Cu}_{2}^{1} \mathrm{~L}^{2}\right]^{\mathrm{X}}$ in solution is not that of a simple adduct between deprotonated $\mathbf{H L}^{2}$ and two copper(I) ions. Given that a mononuclear copper(I) species was also observed in the ESI-MS spectrum measured at RT, the ${ }^{1} \mathrm{H}$ NMR analysis of $\left[\mathrm{Cu}_{2}^{1} \mathrm{~L}^{2}\right]^{\text {OTf }}$ was repeated after introduction of an excess of $10 \%$ copper(I) salt (Figure 3.7). Under these conditions the second minor signal set corresponding to species B was no longer present, though it should be highlighted that all remaining signals were still quite broad.

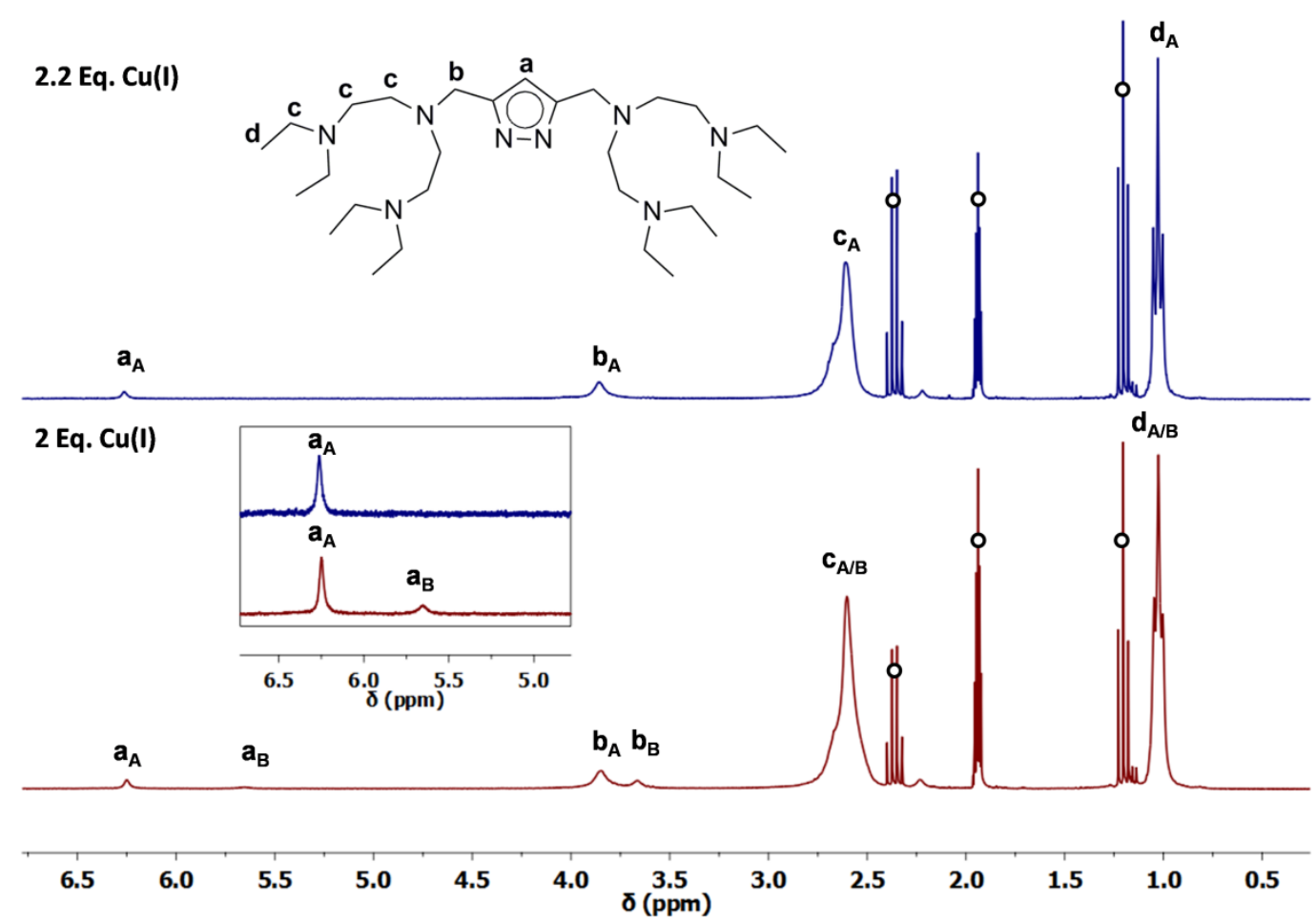

Figure 3.7: ${ }^{1} \mathrm{H}$ NMR spectra of $\left[\mathrm{Cu}_{2}^{1} \mathrm{~L}^{2}\right]^{\text {otf }}$ in $\mathrm{CD}_{3} \mathrm{CN}$ at RT when prepared with 2 or 2.2 equivalents of copper(I) salt. The inset is a magnification of the downfield region, clearly showing the presence of a second pyrazole species when only 2 equivalents are present. Resolved signals of the major and minor species are labelled (subscripts A and B, respectively). Residual solvent signals (including EtCN from synthesis) are labelled (o).

Taken together, the aforementioned findings strongly suggest that the additional minor peak set of species B observed in the above spectra can be assigned to a mononuclear copper $(I)$ adduct, $\left[\mathrm{Cu}^{\prime} \mathrm{L}^{2}\right]$, resulting from incomplete complexation. This hypothesis is further supported by the dioxygen reactivity displayed by this system (section 4.3.2), where mononuclear $\mathrm{CuO}_{2}$ adducts are observed as by-products when only two equivalents of copper(I) source are used to generate $\left[\mathrm{Cu}_{2}{ }_{2} \mathrm{~L}^{2}\right]$. This correlation thereby implies that the speciation observed in the NMR experiments at $\mathrm{RT}$ in $\mathrm{CD}_{3} \mathrm{CN}$ also applies at $-80^{\circ} \mathrm{C}$ in $\mathrm{EtCN}$, though the equilibrium position is likely shifted. Further evidence is provided by the MS 
experiments discussed above, where a mononuclear species was observed in all cases, albeit with differing relative intensities depending on the measurement conditions.

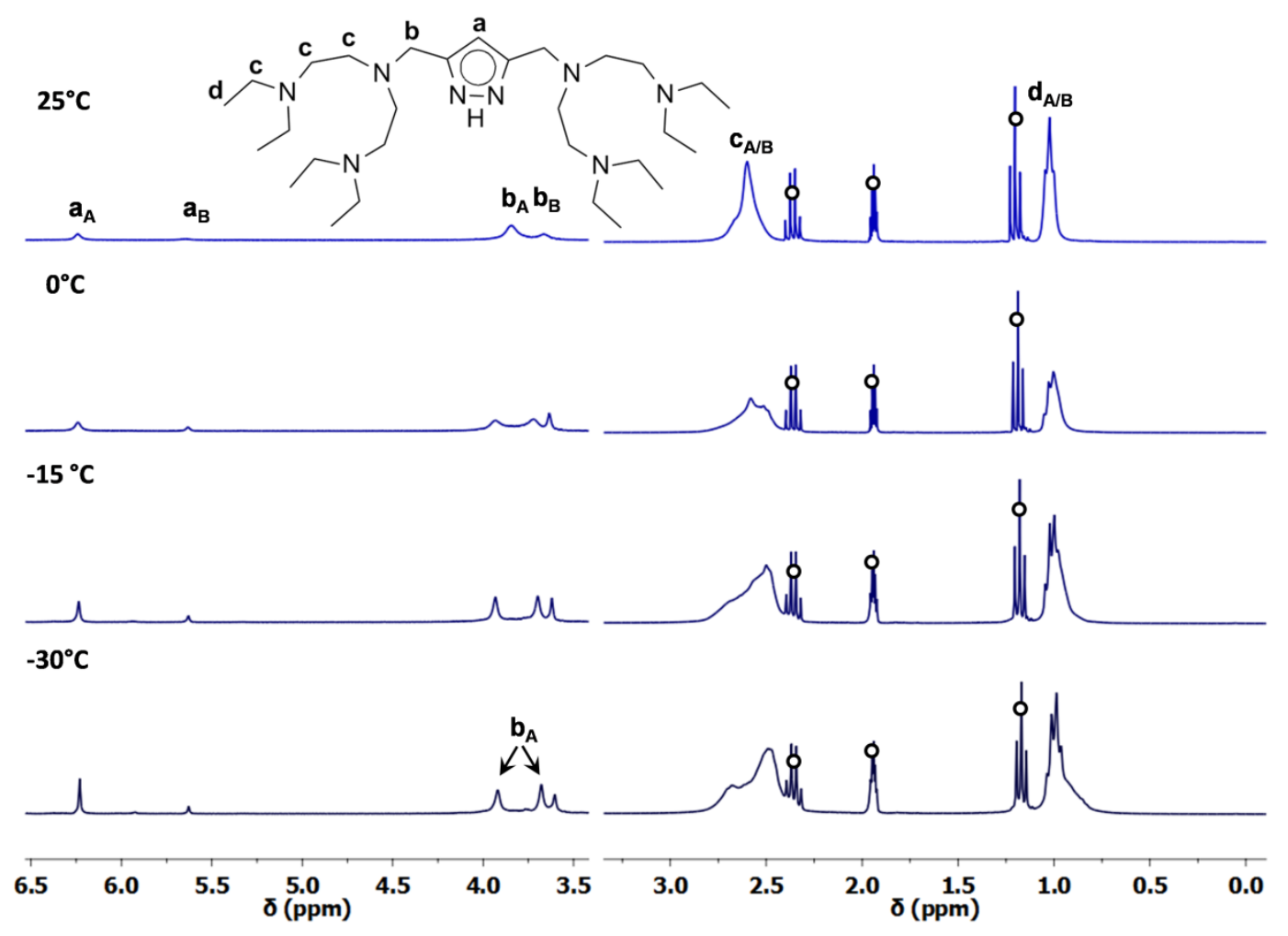

Figure 3.8: ${ }^{1} \mathrm{H} N M R$ spectra of $\left[\mathrm{Cu}_{2}^{1} \mathrm{~L}^{2}\right]^{\text {OTf }}$ at various temperatures under anhydrous conditions in $\mathrm{CD}_{3} \mathrm{CN}$. Splitting of the shoulder $\mathrm{CH}_{2}$ group is highlighted $\left(\mathbf{b}_{\mathbf{A}}\right)$. Residual solvent signals (including EtCN from synthesis) are labelled (O). The downfield region of the spectra are magnified approximately six-fold in intensity for clarity.

When samples of $\left[\mathrm{Cu}_{2}^{\prime} \mathbf{L}^{2}\right]^{\text {OTf }}$ prepared with two equivalents of copper $(\mathrm{I})$ were cooled to -30 ${ }^{\circ} \mathrm{C}$ several of the peaks sharpened significantly. The signal corresponding to the shoulder $\mathrm{CH}_{2}$ groups of the major species $\mathbf{A}$ furthermore split into two $\left(\mathbf{b}_{\mathbf{A}}, \delta \approx 3.8 \mathrm{ppm}\right.$, Figure 3.8). The large separation ( $>70 \mathrm{~Hz}$ ) between the resulting pair of peaks rules out geminal coupling, ${ }^{105}$ and implies that the two halves of the ligand in the $\mathbf{A}$ species are no longer in equivalent chemical environments. The same signal splitting as that shown above was observed for species $\mathbf{A}$ when samples were prepared with excess copper(I) source. In addition, ${ }^{13} \mathrm{C}$ and ${ }^{1} \mathrm{H}-{ }^{13} \mathrm{C}$ HSQC NMR experiments revealed two distinct resonances for the shoulder carbon atoms and for the quaternary pyrazole positions. Taken together with the results of the ${ }^{1} \mathrm{H}$ DOSY NMR experiments, the above findings suggest that the species $\mathbf{A}$ is a dinuclear copper(I) complex, $\left[\mathrm{Cu}_{2}{ }_{2} \mathrm{~L}^{2}\right]^{\mathrm{X}}$, which becomes asymmetric with respect to the two pyrazole binding pockets at lower temperatures.

The changes displayed in the NMR spectra of $\left[\mathrm{Cu}_{2}{ }_{2} \mathbf{L}^{2}\right]^{\mathrm{X}}$ when recorded at low temperatures are indicative of an additional dynamic process of relevance to the dinuclear species. It is evident from the data that $\left[\mathrm{Cu}_{2}^{1} \mathrm{~L}^{2}\right]^{\mathrm{X}}$ shows significant asymmetry about the pyrazole bridging unit at low temperatures, suggesting that the two copper(I) coordination pockets 
become inequivalent. Several of the copper(I) complexes supported by the tetradentate tripodal TMPA ligand and its derivatives are known to coordinate an additional nitrile in the solid state (Scheme 3.9), ${ }^{66,115}$ as is the copper(I) complex chelated by Bisp (see Scheme 1.11 for ligand structure). ${ }^{142}$ Furthermore, these systems are known to exhibit fluxional behaviour in solution involving substitution of one of the aromatic nitrogen donor atoms for an acetonitrile molecule. ${ }^{66,115,119,142,143}$
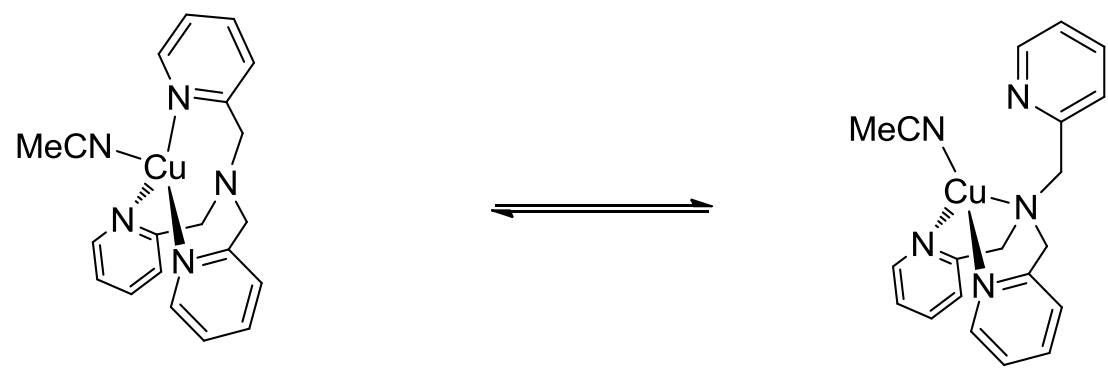

Scheme 3.9: Solution dynamics in a copper(I) TMPA complex observed by NMR spectroscopy. Charges and counterions are omitted.

An analogous scenario is a plausible explanation for the dynamics observed in the $\left[\mathrm{Cu}_{2}{ }_{2} \mathbf{L}^{2}\right]^{\mathbf{X}}$ system, whereby association of a nitrile molecule (MeCN or EtCN) with one of the two copper(I) centres would cause asymmetry with respect to the pyrazole bridge. In fact, the large differences between the chemical shifts of the corresponding ${ }^{1} \mathrm{H}$ and ${ }^{13} \mathrm{C}$ nuclei suggest that coordination of this solvent ligand may induce dissociation of the pyrazole moiety (Scheme 3.10). This proposal also accounts for the larger apparent size of $\left[\mathrm{Cu}_{2}{ }_{2} \mathbf{L}^{2}\right]^{\mathrm{X}}$ in solution when compared with $\mathbf{H L}^{2}$. It is furthermore consistent with the MS measurements, wherein the solvent-derived nitrile molecule could dissociate under the high vacuum conditions inside the instrument. One way to assess the validity of this scenario would be to repeat the NMR measurements in a less-coordinating solvent, such as deuterated THF, $\mathrm{C}_{4} \mathrm{D}_{8} \mathrm{O}$, or toluene, $\mathrm{C}_{7} \mathrm{D}_{8}$. These solvents should have much less affinity for the copper $(\mathrm{I})$ centres in $\left[\mathrm{Cu}_{2}^{\prime} \mathbf{L}^{2}\right]^{\mathrm{X}}$, and thus the dynamics observed in this system should be suppressed.
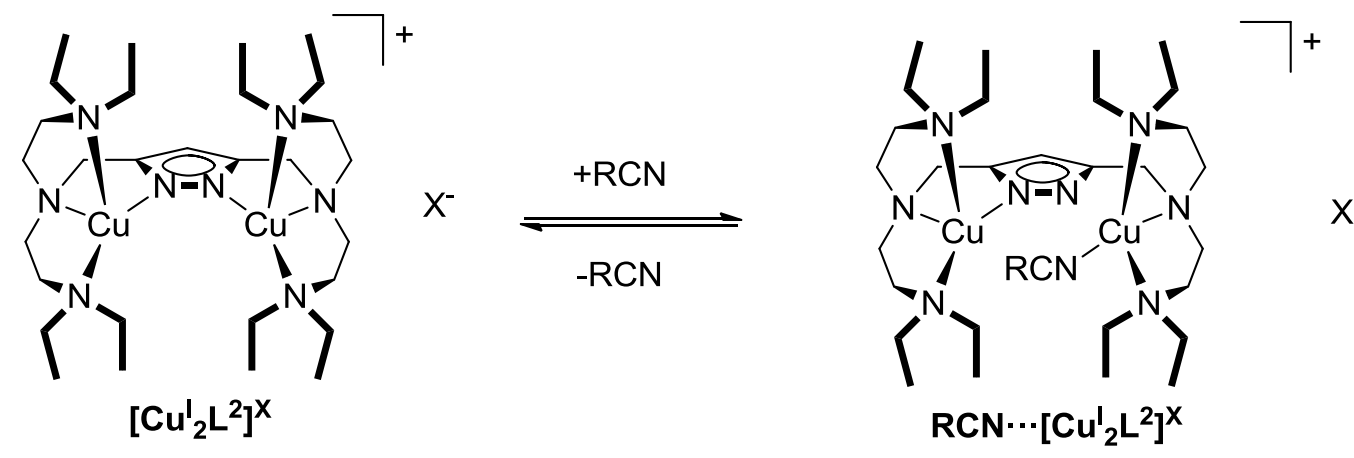

Scheme 3.10: Proposed speciation of $\left[\mathrm{Cu}_{2}{ }_{2} \mathrm{~L}^{2}\right]$ in nitrile solution. Nitrile coordination to the copper(I) centre likely induces dissociation of the pyrazole unit, analogously to the TMPA case. $\mathrm{R}=\mathrm{Me}$ or Et.

Although the dynamic processes discussed above have not been investigated quantitatively herein, they provide sufficient qualitative information to gain insights into the speciation of 
$\left[\mathrm{Cu}_{2}{ }_{2} \mathbf{L}^{2}\right]^{\mathrm{X}}$ in solution. These measurements accurately reflect the coordination state which is relevant to the subsequent investigation of dioxygen activation. This is evidenced by the above described observation of a mononuclear copper(I) species, which accounts for formation of $\mathrm{CuO}_{2}$ adducts upon reaction with dioxygen (Section 4.3.2). Furthermore, the above proposed structure for $\mathbf{R C N} \cdots\left[\mathbf{C u}_{2}{ }_{2} \mathbf{L}^{2}\right]^{\mathbf{X}}$ is also consistent with its reactivity toward dioxygen, where evidence for the formation of inter-molecular dioxygen-adducts is apparent (Section 4.4.5). An experiment which may offer additional evidence for the structure of $\mathbf{R C N} \cdots\left[\mathrm{Cu}_{2}{ }_{2} \mathrm{~L}^{2}\right]^{\mathrm{X}}$ in solution includes repeating the measurements in a different, less-coordinating solvent. Introduction of one equivalent of a more strongly coordinating donor molecule such as $\mathrm{PMe}_{3}$ or ${ }^{t} \mathrm{BuNC}$ might also offer insights. Association of these coligands to a single copper(I) centre may result in less fluxional derivatives of $\left[\cdots \cdot\left[\mathbf{C u}_{2}{ }^{\prime} \mathbf{L}^{2}\right]^{\mathbf{X}}\right.$ which show fixed speciation at RT, providing indirect support for the analogous RCN $\cdots\left[\mathrm{Cu}_{2}^{1} \mathrm{~L}^{2}\right]^{\mathrm{X}}$ structure proposed above. 


\subsection{Synthesis and Characterisation of $\left[\mathrm{Cu}_{2}^{1} \mathrm{~L}^{3}\right]^{\mathrm{X}}$}

\subsubsection{Synthetic Considerations}

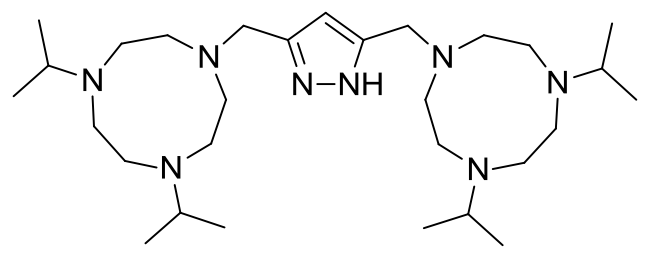

$\mathrm{HL}^{3}$

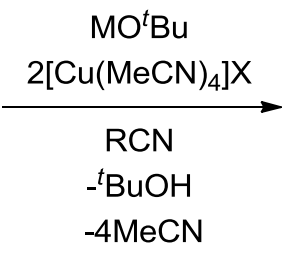

$-4 \mathrm{MeCN}$

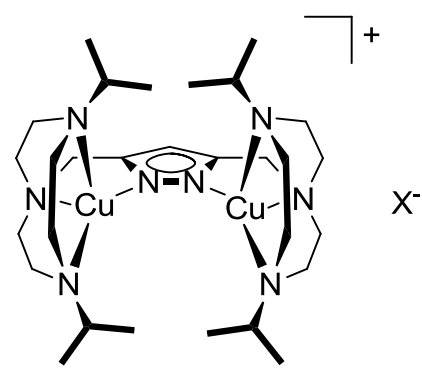

$\left[\mathrm{Cu}_{2}^{\mathrm{I}} \mathrm{L}^{3}\right]^{\mathrm{X}}+\mathrm{MX}$

Scheme 3.11: Synthesis of $\left[\mathrm{Cu}_{2}^{\prime} \mathrm{L}_{3}\right] . \mathrm{M}=\mathrm{Na}^{+}$or $\mathrm{K}^{+}, \mathrm{R}=\mathrm{Me}$ or $\mathrm{Et}, \mathrm{X}=\mathrm{PF}_{6}^{-}, \mathrm{BF}_{4}^{-}, \mathrm{ClO}_{4}^{-}$or $\mathrm{OTf}^{-}$.

Complexation of $\mathrm{HL}^{3}$ with $\left[\mathrm{Cu}(\mathrm{MeCN})_{4}\right] \mathrm{X}\left(\mathrm{X}=\mathrm{PF}_{6}{ }^{-}, \mathrm{BF}_{4}{ }^{-}, \mathrm{ClO}_{4}{ }^{-}\right.$or $\left.\mathrm{OTf}^{-}\right)$salts (Scheme 3.11) was found to be particularly dependent on the conditions employed, with initial attempts at RT giving green solutions and in some cases black colloidal precipitate, in agreement with previous studies which specified the need to use low temperatures. ${ }^{90,91}$ Even so, after extensive optimisation of the synthetic procedure it was possible to prepare RT stable solutions in EtCN which were nearly colourless, generally showing only very faint traces of pale yellow or blue-green discolouration.

To achieve this it was necessary to introduce solutions of $\left[\mathrm{Cu}(\mathrm{MeCN})_{4}\right] \mathrm{X}$ salts gradually, as direct addition of solid copper(I) sources led to solutions which showed much more intense blue-green discolouration. Precise stoichiometry appeared to have a profound effect on the outcome, providing an explanation for the observed sensitivity toward the purity of the ligand, and the way in which reagents were combined. Furthermore, once the complex was prepared the solvent could be easily exchanged without further decomposition. This allowed manipulations for further experiments to be carried out inside a glovebox at RT and generally made handling much easier during characterisation.

\subsubsection{Mass Spectrometry}

The ESI-MS spectra of $\left[\mathrm{Cu}_{2}{ }_{2} \mathrm{~L}^{3}\right]^{\mathrm{ClO}}$ at $\mathrm{RT}$ in MeCN shows only one major signal corresponding to $\left[\mathrm{Cu}_{2}{ }_{2} \mathrm{~L}^{3}\right]^{+}(\mathrm{m} / \mathrm{z}=643.4)$. Minor species with a relative intensity of around $10 \%$ could also be identified, including $\left[\left(\mathrm{Cu}^{\prime \prime}{ }_{2} \mathrm{~L}^{3}\right)(\mathrm{OH})\right]^{2+}(\mathrm{m} / z=331.1)$ and $\left[\left(\mathrm{Cu}_{2}{ }_{2} \mathrm{~L}^{3}\right)(\mathrm{OH})\left(\mathrm{ClO}_{4}\right)\right]^{+}(\mathrm{m} / \mathrm{z}=$ 761.4). Both of these cations likely result from reaction with dioxygen given their copper(II) oxidation state, although residual water cannot be ruled out as the oxygen atom source. 


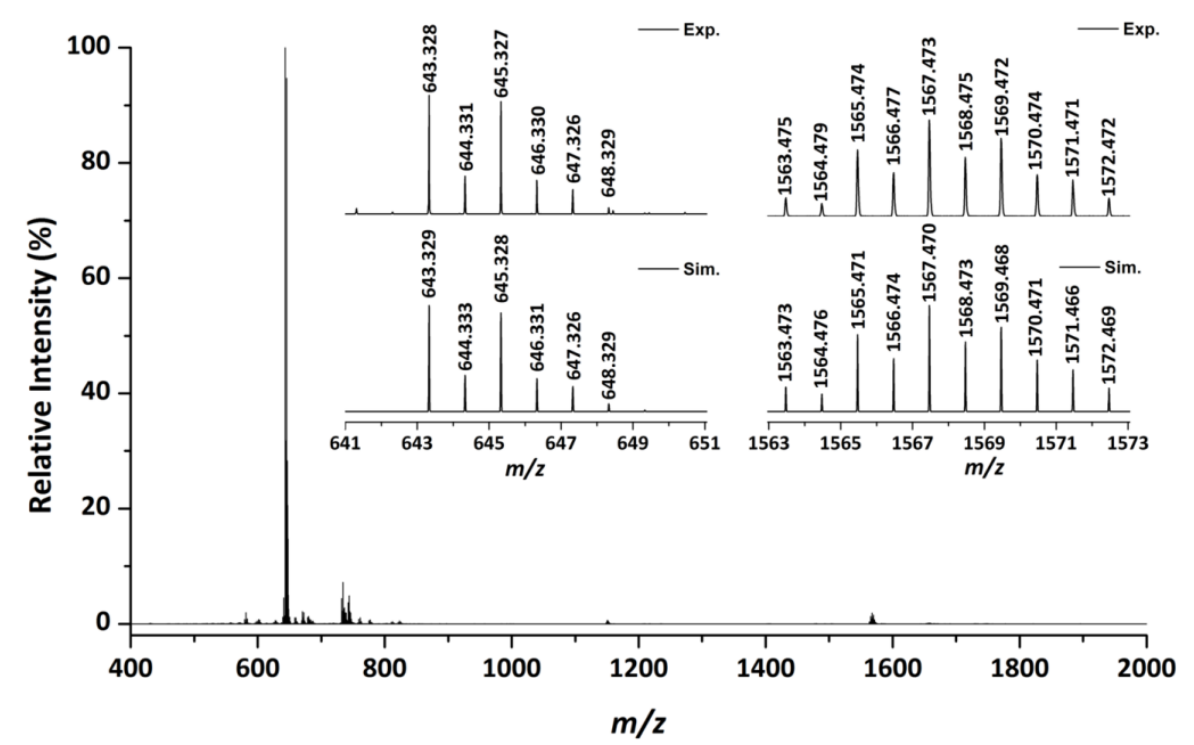

Figure 3.9: Positive mode HR-Cryo-ESI-MS spectrum of $\left[\mathrm{Cu}_{2}^{1} \mathrm{~L}^{3}\right]^{\mathrm{Cl04}}$ in EtCN. The insets show experimental and simulated isotopic distribution patterns for $\left[\mathrm{C}_{29} \mathrm{H}_{61} \mathrm{Cu}_{2} \mathrm{~N}_{8}\right]^{+}$(left) and $\left[\left(\mathrm{C}_{29} \mathrm{H}_{61} \mathrm{Cu}_{2} \mathrm{~N}_{8}\right)_{2} \mathrm{Cu}_{2}(\mathrm{CN})_{2} \mathrm{ClO}_{4}\right]^{+}$(right).

The HR Cryo-ESI-MS spectrum measured at $-80^{\circ} \mathrm{C}$ in EtCN (Figure 3.9) appears qualitatively equivalent, being dominated by the molecular ion $\left[\mathrm{Cu}_{2}{ }_{2} \mathrm{~L}^{3}\right]^{+}(\mathrm{m} / z=643.328)$, but showing only traces of $\left[\left(\mathrm{Cu}_{2}{ }_{2} \mathrm{~L}^{3}\right)(\mathrm{OH})\left(\mathrm{ClO}_{4}\right)\right]^{+}(\mathrm{m} / \mathrm{z}=761.276$, Table 3.5). While the major observable difference in the spectrum is the presence of small amounts $(<10 \%)$ of $\left[\left(\mathrm{Cu}_{2}^{\prime} \mathrm{L}^{3}\right)\left(\mathrm{Cu}^{\prime}\right)(\mathrm{CN})\right]^{+}$ $(\mathrm{m} / \mathrm{z}=734.259)$ and $\left[\left(\mathrm{Cu}^{\prime} \mathrm{Cu}^{\prime \prime} \mathrm{L}^{3}\right)\left(\mathrm{ClO}_{4}\right)\right]^{+}(\mathrm{m} / \mathrm{z}=744.275)$, at much higher $\mathrm{m} / \mathrm{z}$ a weak signal (2\%) consistent with a cation incorporating a second dinuclear unit of $\left[\mathrm{Cu}_{2}^{\prime} \mathrm{L}^{3}\right]^{+}$can be observed, $\left[\left(\mathrm{Cu}_{2}^{\prime} \mathrm{L}^{3}\right)_{2}\left(\mathrm{Cu}^{\prime}\right)_{2}(\mathrm{CN})_{2}\left(\mathrm{ClO}_{4}\right)\right]^{+}(\mathrm{m} / z=1563.476)$.

Table 3.5: Assignment of signals in the positive mode HR-Cryo-ESI-MS spectrum of $\left[\mathrm{Cu}_{2}^{1} \mathrm{~L}^{3}\right]^{\mathrm{ClO} 4}\left(-80^{\circ} \mathrm{C}\right.$ in EtCN).

\begin{tabular}{|c|c|c|}
\hline$m / z$ & Intensity (\%) & Assignment* \\
\hline \multicolumn{3}{|c|}{ Monomeric Adducts } \\
\hline 643.328 & 100 & {$\left[\mathrm{Cu}_{2}^{\prime} \mathrm{L}^{3}\right]^{+}$} \\
\hline 734.259 & 7 & {$\left[\left(\mathrm{Cu}_{2}^{\prime} \mathrm{L}^{3}\right)\left(\mathrm{Cu}^{\prime}\right)(\mathrm{CN})\right]^{+}$} \\
\hline 744.275 & 5 & {$\left[\left(\mathrm{Cu}^{\prime} \mathrm{Cu}^{\prime \prime} \mathrm{L}^{3}\right)\left(\mathrm{ClO}_{4}\right)\right]^{+}$} \\
\hline 761.276 & 2 & {$\left[\left(\mathrm{Cu}_{2}{ }_{2} \mathrm{~L}^{3}\right)(\mathrm{OH})\left(\mathrm{ClO}_{4}\right)\right]^{+}$} \\
\hline \multicolumn{3}{|c|}{ Dimeric Adducts } \\
\hline 1567.476 & 2 & {$\left[\left(\mathrm{Cu}_{2}^{\prime} \mathrm{L}^{3}\right)_{2}\left(\mathrm{Cu}^{\prime}\right)_{2}(\mathrm{CN})_{2}\left(\mathrm{ClO}_{4}\right)\right]^{+}$} \\
\hline \multicolumn{3}{|c|}{$\begin{array}{l}\text { * Rather than purely empirical formulas the assignments presented here are grouped in order to allow for } \\
\text { easier interpretation, although it must be highlighted that the measurements give no direct information about } \\
\text { connectivity of the elements which make up the observed ion peaks. }\end{array}$} \\
\hline
\end{tabular}

As in the analogous case of $\left[\mathrm{Cu}_{2}{ }_{2} \mathrm{~L}^{2}\right]^{\mathrm{X}}$ (see section 3.3.2), direct comparison between the two sets of experimental conditions (LR measured at RT and HR-Cryo) is complicated by the use of two different instruments. Although the molecular ion of $\left[\mathrm{Cu}_{2}^{1} \mathrm{~L}^{3}\right]^{\mathrm{X}}$ dominates under both conditions in the current case, it is worth noting that the dimeric species is once again only 
observed under low temperature conditions in the less polar of the two solvents. This process may be influenced by the presence of the perchlorate anion. Indeed, solution association of perchlorate anions with alkali metal cations is known to increase with reduction in the solvent dielectric constant. ${ }^{144-147}$ The difference in dielectric constant between MeCN and EtCN would thus favour ion association in the case of the less polar EtCN solvent. On the other hand, the dielectric constant of a solvent generally increases with decreasing temperature, ${ }^{148}$ which would work in opposition to the change in solvent polarity. It should also be highlighted that the electrostatic driving force which induces ion association in the case of perchlorate may be offset by the relatively lipophilic character of the $\left[\mathrm{Cu}_{2}{ }_{2} \mathbf{L}^{3}\right]^{\mathrm{X}}$ complex. The differences in the species observed between the two sets of measurement conditions are once again accentuated when monitoring the presence of anions.

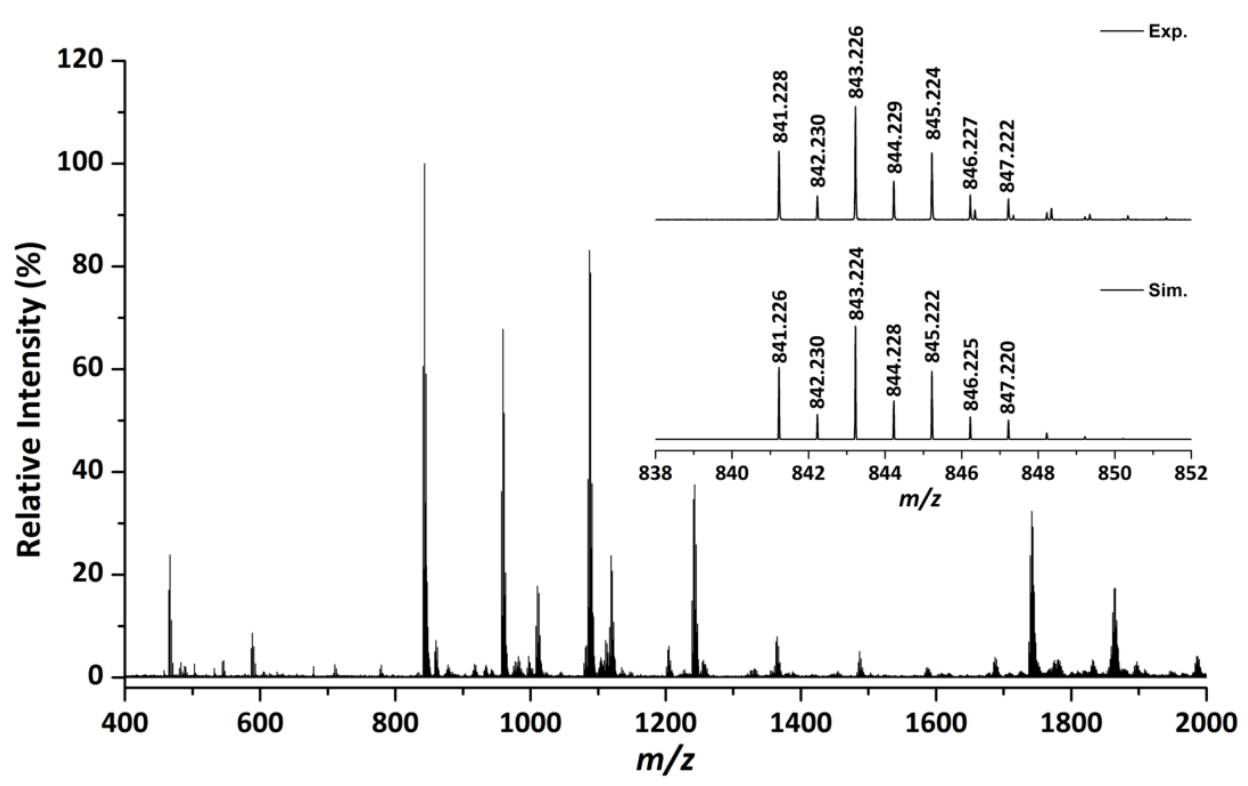

Figure 3.10: Negative mode Cryo-ESI-MS spectrum of $\left[\mathrm{Cu}_{2}^{1} \mathrm{~L}^{3}\right]^{\mathrm{cl04}}$ in EtCN. The inset shows experimental and simulated isotopic distribution patterns for $\left[\mathrm{C}_{29} \mathrm{H}_{57} \mathrm{Cu}_{2} \mathrm{~N}_{6}\left(\mathrm{ClO}_{4}\right)_{2}\right]^{-}$.

The negative mode RT ESI-MS spectrum of $\left[\mathrm{Cu}_{2}^{\prime} \mathrm{L}^{3}\right]^{\mathrm{ClO} 4}$ in MeCN shows a single signal with an isotopic envelope indicative of a dinuclear copper anion. This peak set is consistent with the species $\left[\left(\mathrm{Cu}_{2}{ }_{2} \mathrm{~L}^{3}\right)(\mathrm{OH})\left(\mathrm{ClO}_{4}\right)_{3}\right]^{-}(\mathrm{m} / \mathrm{z}=959.2)$ and has a relative intensity of approximately $10 \%\left(100 \%\right.$ peak $\left.=\left[\mathrm{Na}\left(\mathrm{ClO}_{4}\right)_{2}\right]^{-}\right)$. This signal is also observed in EtCN at $-80{ }^{\circ} \mathrm{C}$ (Figure 3.10), though with a much greater intensity of about $68 \%$ (Table 3.6). Under these cryo conditions the most prominent peak corresponds to the simple perchlorate adduct of $\left[\mathrm{Cu}_{2} \mathrm{~L}^{3}\right]^{+}$, $\left[\left(\mathrm{Cu}_{2}{ }_{2} \mathrm{~L}^{3}\right)\left(\mathrm{ClO}_{4}\right)_{2}\right]^{-} \quad(\mathrm{m} / z=843.225)$, with an additional related cluster, $\left[\left(\mathrm{Cu}_{2}{ }_{2} \mathrm{~L}^{3}\right)\left(\mathrm{ClO}_{4}\right)_{2}\left(\mathrm{NaClO}_{4}\right)_{2}\right]^{-}(\mathrm{m} / z=1087.100)$, also present in significant amounts of $83 \%$. Several other peaks sets were also observed, including some in the dimeric region, but these correspond to adducts with residual dioxygen, and are therefore discussed in the next chapter (Section 4.4.3). Other than these dioxygen adducts, all other signal sets in the dimeric region of the spectrum were observed only in trace amounts $(\leq 4 \%)$. 


\begin{tabular}{|c|c|c|}
\hline$m / z$ & Intensity (\%) & Assignment* \\
\hline \multicolumn{3}{|c|}{ Monomeric Adducts } \\
\hline 843.225 & 100 & {$\left[\left(\mathrm{Cu}_{2}^{\prime} \mathrm{L}^{3}\right)\left(\mathrm{ClO}_{4}\right)_{2}\right]^{-}$} \\
\hline 959.176 & 68 & {$\left[\left(\mathrm{Cu}_{2}{ }_{2} \mathrm{~L}^{3}\right)(\mathrm{OH})\left(\mathrm{ClO}_{4}\right)_{3}\right]^{-}$} \\
\hline 1087.100 & 83 & {$\left[\left(\mathrm{Cu}_{2}^{\prime} \mathrm{L}^{3}\right)\left(\mathrm{ClO}_{4}\right)_{2}\left(\mathrm{NaClO}_{4}\right)_{2}\right]^{-}$} \\
\hline \multicolumn{3}{|c|}{$\begin{array}{l}\text { * Rather than purely empirical formulas the assignments presented here are grouped in order to allow for } \\
\text { easier interpretation, although it must be highlighted that the measurements give no direct information about } \\
\text { connectivity of the elements which make up the observed ion peaks. }\end{array}$} \\
\hline
\end{tabular}

Despite the uncertainty about the driving force behind the observed aggregation, the above described measurements provide qualitative information about association state in solution. They are furthermore especially useful for comparing the speciation in the current case with that of the $\left[\mathrm{Cu}_{2}^{1} \mathrm{~L}^{2}\right]^{\mathrm{X}}$ complex (Section 3.3.2). In positive mode, the Cryo-ESI mass spectra of $\left[\mathrm{Cu}_{2}{ }_{2} \mathrm{~L}^{2}\right]^{\mathrm{PF} 6}$ and $\left[\mathrm{Cu}_{2}{ }_{2} \mathrm{~L}^{3}\right]^{\mathrm{ClO4}}$ are similar, and both are dominated by the respective dinuclear monomeric species. In contrast, significant differences are apparent when comparing the spectra of the two systems acquired in negative mode in the presence of $\mathrm{ClO}_{4}{ }^{-}$counterions. The majority of the signals in the spectrum of $\left[\mathrm{Cu}_{2}^{1} \mathbf{L}^{2}\right]^{\mathrm{ClO} 4}$ are identified as tetranuclear dimeric aggregates, whereas the prevailing species in the case of $\left[\mathrm{Cu}_{2}{ }_{2} \mathbf{L}^{3}\right]^{\mathrm{ClO} 4}$ are still dinuclear monomeric adducts. These findings clearly indicate that the system supported by $\mathbf{H L}^{2}$ is much more susceptible to the formation of dimeric species in solution. This conclusion is indirectly supported by the NMR spectroscopic data for $\left[\mathrm{Cu}_{2}^{\prime} \mathbf{L}^{2}\right]^{\mathrm{X}}$, which imply that the system is relatively labile. Partial ligand dissociation may faciliate the aggregation observed in the Cryo-ESI-MS experiments by allowing for free donor atoms and coordination sites to interact inter-molecularly. Such a process furthermore has significant implications for the subsequently investigated dioxygen activation chemistry.

\subsubsection{NMR Spectroscopy}

The ${ }^{1} \mathrm{H}$ and ${ }^{13} \mathrm{C}$ NMR spectra of $\left[\mathrm{Cu}_{2}{ }_{2} \mathrm{~L}^{3}\right]^{\mathrm{X}}\left(\mathrm{X}=\mathrm{ClO}_{4}{ }^{-}\right.$or OTf $\left.{ }^{-}\right)$in $\mathrm{CD}_{3} \mathrm{CN}$ or $\left(\mathrm{CD}_{3}\right)_{2} \mathrm{CO}$ show sharp resonances at RT (Figure 3.11). Changes in chemical shift values relative to the free ligand $\mathrm{HL}^{3}$ and the sodium complex $\left[\mathrm{NaL}^{3}\right]$ are apparent, suggesting that the ligand is coordinated. Interpretation on the basis of chemical shift alone is not conclusive, and is further complicated by the prototropy observed for $\mathrm{HL}^{3}$ (section 2.3.1) and uncertainty about the nature of $\left[\mathrm{NaL}^{3}\right]$ in solution (see section 2.4). The complicated splitting pattern in the aliphatic region of the ${ }^{1} \mathrm{H}$ NMR spectrum shows that each of the hydrogen atoms in the macrocyclic $\mathrm{CH}_{2}$ groups now display geminal coupling, in addition to the coupling they showed in the free ligand. Therefore, each proton in each pair is now in a unique chemical environment. This observation is consistent with prevention of nitrogen inversion imposed 
by coordination to copper(I). This is also reflected in the appearance of two distinct signals for each of the diastereotopic isopropyl-methyl groups.
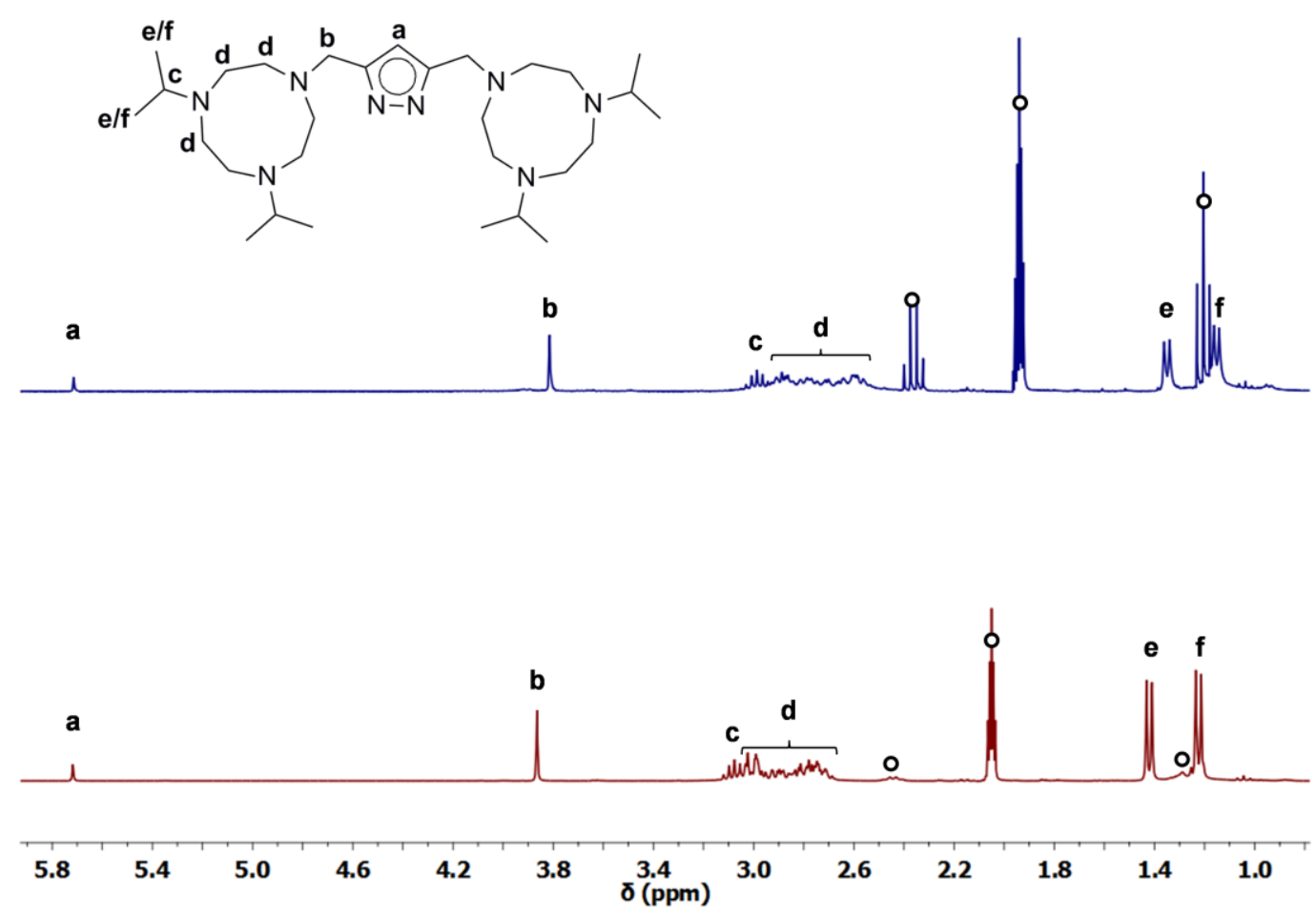

Figure 3.11: ${ }^{1} \mathrm{H}$ NMR spectra of $\left[\mathrm{Cu}_{2}^{\prime} \mathrm{L}_{3}\right]^{\text {OTf }}$ in $\mathrm{CD}_{3} \mathrm{CN}$ (above) and $\left(\mathrm{CD}_{3}\right)_{2} \mathrm{CO}$ (below) at $\mathrm{RT}$. Signals of residual solvent (including EtCN from synthesis) are labelled (o).

The appearance of the pyrazole shoulder $\mathrm{CH}_{2}$ groups as a sharp singlet, and the single $\mathrm{CH}$ isopropyl resonance in the ${ }^{1} \mathrm{H}$ spectra indicate that $\left[\mathrm{Cu}_{2}{ }_{2} \mathbf{L}^{3}\right]^{\mathrm{X}}$ is highly symmetric in solution at RT. This is further supported by the number of signals in the ${ }^{13} \mathrm{C}$ spectrum, with a single resonance for the pyrazole quaternary carbons and a total of only three for the macrocyclic $\mathrm{CH}_{2}$ groups. Furthermore, ${ }^{1} \mathrm{H}-{ }^{15} \mathrm{~N} \mathrm{HMBC}$ experiments reveal cross-peaks indicative of only 3 distinct nitrogen nuclei. Thus, the coordination environments of each of the two copper(I) metal centres are equivalent and the spectra indicate that complex $\left[\mathrm{Cu}_{2}{ }_{2} \mathbf{L}^{3}\right]^{\mathrm{X}}$ exists in solution as a $C_{2 v}$ symmetric species. The above observations demonstrate that complex $\left[\mathrm{Cu}_{2}{ }_{2} \mathbf{L}^{3}\right]^{\mathrm{X}}$ is quite rigid and well-defined in solution. ${ }^{149}$ These findings are in good agreement with the results of the MS studies, and strongly suggest that $\mathbf{H L}^{3}$ is present in solution as a monomeric dinuclear species. Further evidence for this proposal was provided by ${ }^{1} \mathrm{H} N M R$ DOSY spectroscopy.

${ }^{1} \mathrm{H}$ NMR DOSY analysis of $\left[\mathrm{Cu}_{2}{ }_{2} \mathrm{~L}^{3}\right]^{\mathrm{X}}\left(\mathrm{X}=\mathrm{ClO}_{4}{ }^{-}\right.$or $\left.\mathrm{OTf}^{-}\right)$was conducted in $\mathrm{CD}_{3} \mathrm{CN}$ at RT. The spectra reveal the presence of a single species with a diffusion coefficient $\left(D=0.96 \times 10^{-9}\right.$ $\left.\mathrm{m}^{2} \mathrm{~s}^{-1}\right)$ slightly smaller than that displayed for equimolar solutions of free ligand $\mathbf{H L}^{3}(D=$ $\left.1.02 \times 10^{-9} \mathrm{~m}^{2} \mathrm{~s}^{-1}\right)$. The molecular radii derived from these values indicate that $\left[\mathrm{Cu}_{2}{ }_{2} \mathrm{~L}^{3}\right]^{\mathrm{X}}(r=$ $5.8 \AA$ A) occupies only marginally more space in solution than the corresponding ligand $\mathbf{H L}^{3}(r$ 
$=6.2 \AA)$. In fact, $\left[\mathrm{Cu}_{2}^{1} \mathrm{~L}^{3}\right]^{\mathrm{X}}$ is only 1.2 times larger in terms of volume in solution. This ratio strongly suggests that $\left[\mathrm{Cu}_{2}^{1} \mathrm{~L}^{3}\right]^{\mathrm{X}}$ is a monomeric dinuclear species in solution. The slight increase in molecular size with respect to the free ligand $\mathbf{H L}^{3}$ may result solely from incorporation of the copper(I) ions into the binucleating organic scaffold.

\subsection{Summary and Conclusions}

Previously established synthetic methods for the preparation of the copper(I) complexes, $\left[\mathrm{Cu}_{2}{ }_{2} \mathbf{L}^{1}\right]^{\mathrm{X}},\left[\mathrm{Cu}_{2}{ }_{2} \mathbf{L}^{2}\right]^{\mathrm{X}}$ and $\left[\mathrm{Cu}_{2}{ }_{2} \mathbf{L}^{3}\right]^{\mathrm{X}}$, were re-investigated and optimised. These complexes were thereby shown to be significantly more stable at RT than previously described, ${ }^{90,91}$ which allowed for their detailed characterisation in solution.

NMR spectroscopic analysis of the $\left[\mathrm{Cu}_{2}{ }_{2} \mathrm{~L}^{1}\right]^{\mathrm{X}}$ system was conducted, and through the application of ${ }^{1} \mathrm{H}$ NMR DOSY information about the size of $\left[\mathrm{Cu}^{1}{ }_{2} \mathbf{L}^{1}\right]^{\mathrm{X}}$ in solution was obtained. In combination with ESI-MS, these measurements revealed that the structure of this complex in solution is most consistent with a multinuclear aggregate. Taking the information from these experiments together with the known tendency of similar pyrazole scaffolds to form triangular coinage metal assemblies, a cyclic hexanuclear trimeric configuration could be proposed for the complex in solution, $\left(\left[\mathrm{Cu}_{2}{ }_{2} \mathbf{L}^{1}\right]^{\mathrm{x}}\right)_{3}$. This assignment is strongly supported by comparison with a closely related system, $\mathbf{X I I}$, for which an analogous structure was previously demonstrated crystallographically. In addition, solution characterisation data for $\mathbf{X I I}$ is in good agreement with that displayed by the current system, furthermore corroborating the proposed $\left(\left[\mathrm{Cu}_{2}^{1} \mathbf{L}^{1}\right]^{\mathrm{X}}\right)_{3}$ speciation in solution.

A comparable analysis to that described above was carried out for $\left[\mathbf{C u}_{2}{ }_{2} \mathbf{L}^{2}\right]^{\mathbf{X}}$. This revealed the presence of a major and minor species in solution. The minor species could be identified as a mononuclear copper $(\mathrm{I})$ complex, $\left[\mathrm{Cu}^{\prime} \mathrm{L}^{2}\right]$, resulting from incomplete complexation. This hypothesis was strongly supported by introduction of an excess of copper(I) source, conditions under which this minor species was no longer observed. Through the use of ${ }^{1} \mathrm{H}$ NMR DOSY experiments the major species could then be identified as a dinuclear copper(I) complex. In addition, further variable-temperature NMR spectroscopic investigation of the $\left[\mathrm{Cu}_{2}{ }_{2} \mathbf{L}^{2}\right]^{\mathrm{X}}$ system showed that the complex undergoes a dynamic process in solution. Making use of the extensive literature data for related systems, a scenario to account for this fluxionality in solution could be proposed, whereby a process involving coordination of a solvent molecule to one of the two copper(I) centres in $\left[\mathrm{Cu}^{1}{ }_{2} \mathbf{L}^{2}\right]^{\mathrm{X}}$ induces asymmetry at low temperatures. This results in a $\mathbf{R C N} \cdots\left[\mathrm{Cu}_{2}{ }_{2} \mathbf{L}^{2}\right]^{\mathrm{X}}$ structure in solution which, in combination with the identification of a mononuclear $\left[\mathrm{Cu}^{\prime} \mathrm{L}^{2}\right]$ species, has important consequences for subsequent dioxygen-activation chemistry.

In contrast to the above two systems, solution characterisation data for $\left[\mathrm{Cu}_{2}^{1} \mathrm{~L}^{3}\right]^{\mathrm{X}}$ was entirely consistent with a symmetric dinuclear structure in solution. This well-defined and rigid nature allowed $\left[\mathrm{Cu}_{2}^{1} \mathbf{L}^{3}\right]^{\mathrm{X}}$ to act as a benchmark for comparison with the $\left[\mathrm{Cu}_{2}{ }_{2} \mathbf{L}^{2}\right]^{\mathbf{X}}$ system in further experiments. Thus, in addition to standard ESI-MS analysis at RT, 
measurements at cryogenic temperatures were conducted for the $\left[\mathbf{C u}_{2}{ }_{2} \mathbf{L}^{2}\right]^{\mathbf{X}}$ and $\left[\mathbf{C u}_{2}{ }_{2} \mathbf{L}^{3}\right]^{\mathbf{X}}$ systems. The data indicate that, relative to $\left[\mathbf{C u}_{2}{ }_{2} \mathbf{L}^{3}\right]^{\mathrm{X}}$, the $\left[\mathbf{C u}_{2}{ }_{2} \mathbf{L}^{2}\right]^{\mathrm{X}}$ system displays a much greater susceptibility toward aggregate formation in solution. This finding reflects the greater lability of the $\left[\mathrm{Cu}_{2}{ }_{2} \mathrm{~L}^{2}\right]^{\mathrm{X}}$ system, which can account for both this tendency for dimerisation and the fluxionality observed in the NMR spectrosopic measurements discussed above.

In conclusion, the work described in this chapter has provided significant insights into the solution speciation of the copper(I) complexes, $\left[\mathbf{C u}^{1}{ }_{2} \mathbf{L}^{1}\right]^{\mathrm{X}},\left[\mathbf{C u}^{1}{ }_{2} \mathbf{L}^{2}\right]^{\mathrm{X}}$ and $\left[\mathbf{C u}^{1} \mathbf{L}^{3}\right]^{\mathrm{X}}$. These results are especially useful for interpreting the outcome of experiments aimed at exploring the dioxygen-activating potential of these systems, which is the focus of the next chapter. 


\section{Dioxygen Activation Chemistry - Novel Copper- Peroxo Adducts}

\subsection{Introduction}

The reaction of dioxygen with copper $(\mathrm{I})$ complexes often proceeds through an inner-sphere electron transfer process involving thermally sensitive species which may go unobserved at ambient temperatures. ${ }^{14,30}$ Observation, stabilisation, and isolation of such copper-dioxygen adducts thus often requires the use of low reaction temperatures, for both entropic reasons and to enhance intermediate lifetimes (Section 1.3.5). In addition, owing to the frequently observed tendency of these species to behave as either basic or $\mathrm{H}$-atom abstracting reagents (Sections 1.3.3 and 1.3.4), aprotic solvents are generally employed. ${ }^{14}$ Halide anions are also not compatible with this chemistry (Sections 3.1.2), contributing to the widespread use of WCAs, though it should be highlighted that even these can undergo interactions with the dioxygen adducts formed. For example, the equilibrium between ${ }^{\mathrm{S}} \mathbf{P}$ and ${ }^{\mathrm{B}} \mathbf{O}$ species can be influenced by varying the basicity of the WCA present, ${ }^{150,151}$ and evidence exists to suggest that abstraction of fluoride from $\mathrm{PF}_{6}{ }^{-}$can occur. ${ }^{64,152-154}$ Each system investigated herein behaved differently, and though the above considerations cannot be applied in a general sense in the current work, almost all found relevance in at least one case.
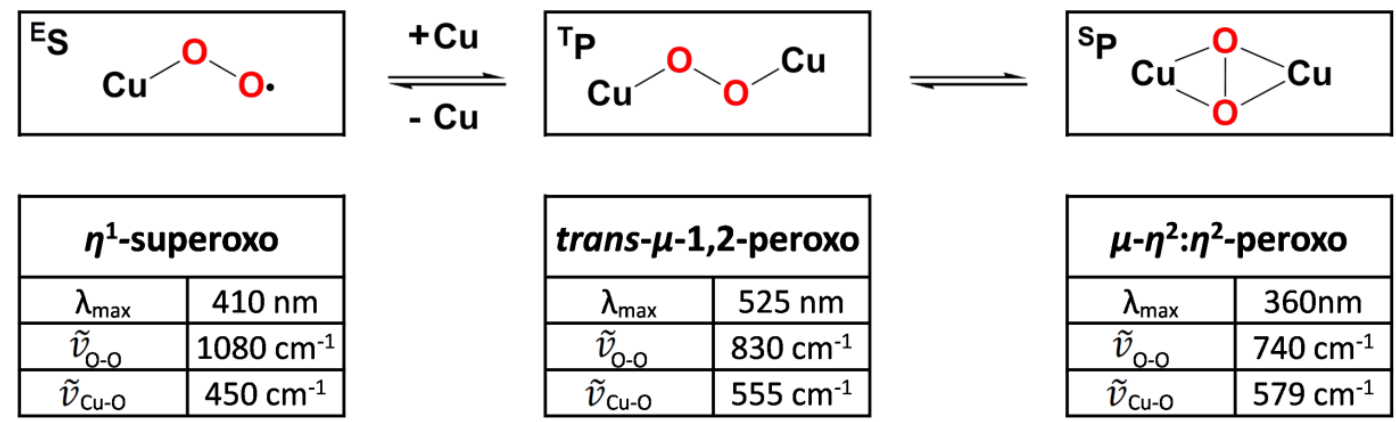

\begin{tabular}{|c|c|}
\hline \multicolumn{2}{|c|}{ trans- $\boldsymbol{\mu}$-1,2-peroxo } \\
\hline$\lambda_{\max }$ & $525 \mathrm{~nm}$ \\
\hline$\tilde{v}_{\mathrm{O}-\mathrm{O}}$ & $830 \mathrm{~cm}^{-1}$ \\
\hline$\tilde{v}_{\mathrm{Cu}-\mathrm{O}}$ & $555 \mathrm{~cm}^{-1}$ \\
\hline
\end{tabular}

\begin{tabular}{|c|c|}
\hline \multicolumn{2}{|c|}{$\boldsymbol{\mu}-\boldsymbol{\eta}^{\mathbf{2}}: \boldsymbol{\eta}^{\mathbf{2}}$-peroxo } \\
\hline$\lambda_{\max }$ & $360 \mathrm{~nm}$ \\
\hline$\tilde{v}_{\mathrm{O}-\mathrm{O}}$ & $740 \mathrm{~cm}^{-1}$ \\
\hline$\tilde{v}_{\mathrm{Cu}-\mathrm{O}}$ & $579 \mathrm{~cm}^{-1}$ \\
\hline
\end{tabular}

Figure 4.1: Typical spectroscopic features of the copper-dioxygen adducts of greatest relevance to the results discussed in this chapter. Relatively few determinations of the $\mathrm{O}-\mathrm{O}$ stretch for $\eta^{1}$-superoxo species are known,

so the value shown here is only approximate. Still, in all cases they differ significantly from $\mathrm{Cu}_{2} \mathrm{O}_{2}$ species.

Each of the known adducts which commonly form upon reaction of copper(I) complexes with dioxygen possess distinct spectroscopic features. ${ }^{14,16,18}$ Their intense colours result from oxygen to copper charge transfer (CT) transitions, which directly reflect the interactions occurring between these two ions. The corresponding UV-vis spectra are thus especially informative with regards to the copper-oxygen structural arrangement, and thereby can offer insight into the type of species formed in solution, without the need for isolation. Typical spectroscopic features of relevance to the chemistry discussed in this chapter are shown in Figure 4.1. Using the information obtained from the electronic absorption spectrum, resonance Raman $(r R)$ vibrational spectroscopy can then be applied to 
further probe the nature of bonding between copper and oxygen. This technique is especially useful as modes associated with the chromophore can be selectively enhanced. Furthermore, isotopic labelling with ${ }^{18} \mathrm{O}_{2}$ allows for definitive vibrational assignments to be made. The $\mathrm{O}-\mathrm{O}$ stretching frequency generally reflects the bond strength of the resulting dioxygen-derived ligand, and is thus diagnostic of its oxidation state. Typical O-O stretching vibrations for the corresponding adducts are shown in Figure 4.1. The origin of these physicochemical properties is briefly described in terms of the electronic structure in the introduction of the next chapter (Section 5.1).

\subsection{Formation of $\left[\left(\mathrm{Cu}_{2}{ }_{2} \mathrm{~L}^{1}\right)_{2}\left(\mathrm{O}_{2}\right)(\mathrm{OH})_{2}\right]^{\mathrm{X2}}$}

\subsubsection{Prior Work and Present Motivation}

Crystallographic structural determination of the dark green tetranuclear copper(II) peroxide adduct, $\left[\left(\mathrm{Cu}_{2}{ }_{2} \mathrm{~L}^{1}\right)_{2}\left(\mathrm{O}_{2}\right)(\mathrm{OH})_{2}\right]^{(\mathrm{PF} 6) 2}$, which results from reaction of $\left[\mathrm{Cu}_{2}^{1} \mathrm{~L}^{1}\right]^{\mathrm{PF} 6}$ formed in situ with air at $-80{ }^{\circ} \mathrm{C}$ was previously published (Scheme 4.1, where $\mathrm{X}=\mathrm{PF}_{6}{ }^{-}$). ${ }^{89}$ The unusual $\mu_{4^{-}}$ peroxide binding motif may appear to be a simple adduct on first inspection, resulting from straightforward electron transfer and dimerisation. However, several aspects with regards to formation of this complex are still unclear (Scheme 4.1). In order to generate this $\left[\left(\mathrm{Cu}_{2}{ }_{2} \mathrm{~L}^{1}\right)_{2}\left(\mathrm{O}_{2}\right)(\mathrm{OH})_{2}\right]^{\mathrm{X2}}$ framework, four copper(I) ions have lost one electron each to give four copper(II) ions in the product. This is not consistent with the six electrons necessary to produce the exogenous bridging ligands directly from dioxygen. While residual water could provide the hydroxide ions required, reduction of $\mathrm{O}_{2}$ to $\mathrm{O}_{2}{ }^{2-}$ accounts for only two of the four electrons lost by the copper atoms. Therefore neither of these scenarios adequately describes the formation of $\left[\left(\mathrm{Cu}_{2}{ }_{2} \mathrm{~L}^{1}\right)_{2}\left(\mathrm{O}_{2}\right)(\mathrm{OH})_{2}\right]^{\mathrm{X2}}$.

2

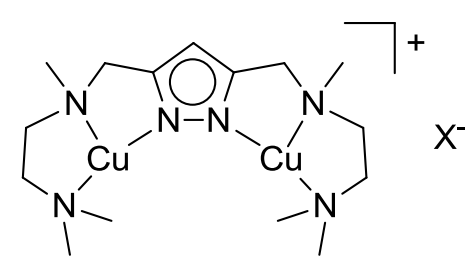

$\left[\mathrm{Cu}_{2}^{\prime} \mathrm{L}^{1}\right]^{\mathrm{X}}$

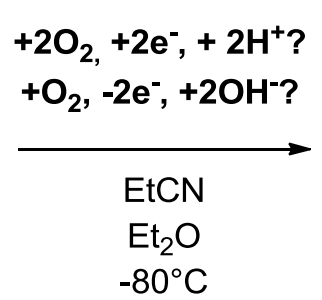

$-80^{\circ} \mathrm{C}$

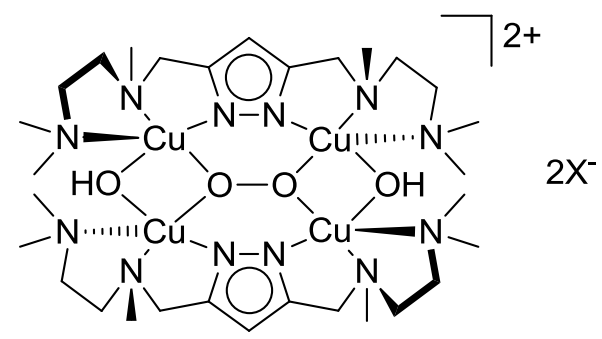

$$
\left[\left(\mathrm{Cu}_{2}{ }_{2} \mathrm{~L}^{1}\right)_{2}\left(\mathrm{O}_{2}\right)(\mathrm{OH})_{2}\right]^{\mathrm{X2}}
$$

Scheme 4.1: Formation of $\left[\left(\mathrm{Cu}_{2}^{\prime \prime} \mathrm{L}^{1}\right)_{2}\left(\mathrm{O}_{2}\right)(\mathrm{OH})_{2}\right]^{\mathrm{x} 2}$ from $\left[\mathrm{Cu}_{2}^{1} \mathrm{~L}^{1}\right]^{\mathrm{X}}$. The open questions regarding the stoichiometry are highlighted above the reaction arrow. Although $\left[\mathrm{Cu}^{1}{ }_{2} \mathbf{L}^{1}\right]^{\mathrm{X}}$ is not depicted accurately given the findings presented in the previous chapter, the same mechanistic queries apply regardless. For the known crystallographically characterised species, $\mathrm{X}=\mathrm{PF}_{6}^{-}$.

The above mentioned inconsistencies clearly indicate that a more complicated mechanism is involved in assembling $\left[\left(\mathrm{Cu}_{2}{ }_{2} \mathrm{~L}^{1}\right)_{2}\left(\mathrm{O}_{2}\right)(\mathrm{OH})_{2}\right]^{\mathrm{X2}}$, and further investigation is thus warranted. Furthermore, after several days at RT a blue coloured product, $\left[\left(\mathrm{Cu}^{1{ }_{2}} \mathrm{~L}^{1}\right)_{2}(\mathrm{OH})_{4}\right]^{(\mathrm{PF} 6) \mathbf{2}}$, could be isolated from solutions of $\left[\left(\mathrm{Cu}^{\prime \prime}{ }_{2} \mathrm{~L}^{1}\right)_{2}\left(\mathrm{O}_{2}\right)(\mathrm{OH})_{2}\right]^{(\mathrm{PF} 6) 2}$ exposed to air. Crystallographic structural determination revealed a replacement of the bridging peroxide moiety with a pair 
of hydroxide anions (Scheme 4.2, where $\mathrm{X}=\mathrm{PF}_{6}{ }^{-}$). This formally represents a two electron reductive cleavage of the peroxide bond, and yet the copper ion oxidation states remain unchanged. It is noteworthy that the bridging hydroxide groups in this product might also originate from adventitious water.

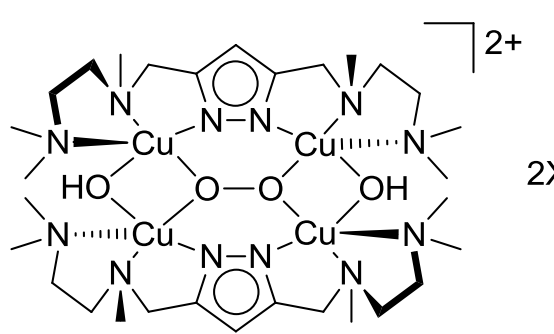

$$
\left[\left(\mathrm{Cu}_{2}{ }_{2} \mathrm{~L}^{1}\right)_{2}\left(\mathrm{O}_{2}\right)(\mathrm{OH})_{2}\right]^{\mathrm{X2}}
$$
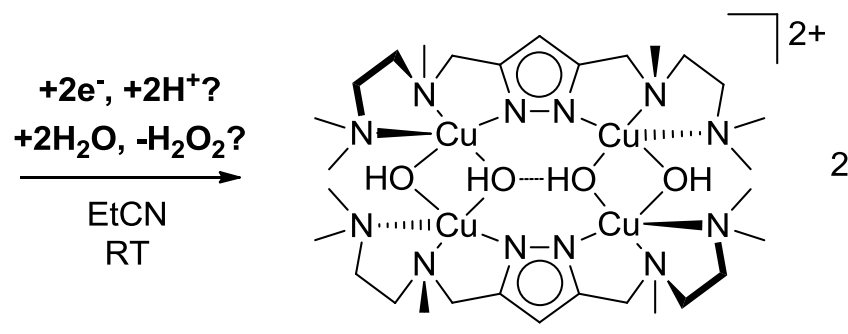

$\left[\left(\mathrm{Cu}_{2}{ }_{2} \mathrm{~L}^{1}\right)_{2}(\mathrm{OH})_{4}\right]^{\mathrm{X} 2}$

Scheme 4.2: Formation of a blue $\left[\left(\mathrm{Cu}_{2}{ }_{2} \mathrm{~L}^{1}\right)_{2}(\mathrm{OH})_{4}\right]^{\mathrm{X2}}$ species from the green tetranuclear copper-dioxygen adduct, $\left[\left(\mathrm{Cu}_{2}{ }_{2} \mathrm{~L}^{1}\right)_{2}\left(\mathrm{O}_{2}\right)(\mathrm{OH})_{2}\right]^{\mathrm{X2}}$. Whether water is involved in the reaction is unclear, as are the mechanistic details. For the known crystallographically characterised species, $\mathrm{X}=\mathrm{PF}_{6}{ }^{-}$.

The magnetic properties and reactivity of $\left[\left(\mathrm{Cu}_{2}{ }_{2} \mathrm{~L}^{1}\right)_{2}\left(\mathrm{O}_{2}\right)(\mathrm{OH})_{2}\right]^{\mathrm{X2}}$ are also of considerable interest given its unique structural arrangement. For such investigations material of a high quality is especially desirable, as trace impurities can significantly complicate the relevant analyses. A primary objective herein was thus to establish a synthetic route capable of affording crystalline $\left[\left(\mathrm{Cu}_{2}{ }_{2} \mathrm{~L}^{1}\right)_{2}\left(\mathrm{O}_{2}\right)(\mathrm{OH})_{2}\right]^{\mathrm{X2}}$. The previously reported procedure was an obvious starting point, though could not be applied successfully in the current work. One complicating aspect was the use of air in the original preparation, the water content of which is undefined. Taken together, the considerations discussed above provide motivation for understanding the factors determining formation of $\left[\left(\mathrm{Cu}_{2}{ }_{2} \mathrm{~L}^{1}\right)_{2}\left(\mathrm{O}_{2}\right)(\mathrm{OH})_{2}\right]^{\mathrm{X} \mathbf{2}}$, with a focus on the role of water in this self-assembly reaction. 


\subsubsection{A New Synthetic Route for $\left[\left(\mathrm{Cu}_{2}{ }_{2} \mathrm{~L}^{1}\right)_{2}\left(\mathrm{O}_{2}\right)(\mathrm{OH})_{2}\right]^{\mathrm{X2}}$}

Initial attempts to generate $\left[\left(\mathrm{Cu}_{2}{ }_{2} \mathrm{~L}^{1}\right)_{2}\left(\mathrm{O}_{2}\right)(\mathrm{OH})_{2}\right]^{\mathrm{X} 2}$ by using crude ligand $\mathrm{HL}^{1}$ together with dry $\mathrm{O}_{2}$ and different hydroxide free bases such as $\mathrm{NaH}, \mathrm{KN}\left(\mathrm{Si}\left(\mathrm{CH}_{3}\right)_{3}\right)_{2}$ and $\mathrm{KO}^{t} \mathrm{Bu}$ showed promising results. The system thereby behaved equally to the literature case where $\left[\mathrm{Bu}_{4} \mathrm{~N}\right] \mathrm{OH}$ was employed as the base, becoming intense green upon exposure to dioxygen at $-80{ }^{\circ} \mathrm{C}$. In situ UV-vis spectroscopic monitoring of the reaction between dry $\mathrm{O}_{2}$ and $\left[\mathrm{Cu}_{2}^{1} \mathrm{~L}^{1}\right]^{\mathrm{PF} 6}$ (generated from crude $\mathrm{HL}^{1}$ with $\mathrm{KO}^{t} \mathrm{Bu}$ and $\left[\mathrm{Cu}(\mathrm{MeCN})_{4}\right] \mathrm{PF}_{6}$ ) furthermore revealed a spectrum in agreement with those previously reported. ${ }^{89}$ Two absorption features at 360 and $631 \mathrm{~nm}\left(\varepsilon=2400,350 \mathrm{M}^{-1} \mathrm{~cm}^{-1}\right.$, respectively) thus developed directly, without accumulation of an intermediate, indicating essentially quantitative formation of $\left[\left(\mathrm{Cu}_{2}{ }_{2} \mathrm{~L}^{1}\right)_{2}\left(\mathrm{O}_{2}\right)(\mathrm{OH})_{2}\right]^{(\mathrm{PF} 6) 2}$. However, despite trialling several bases, solvents, and counteranions, and the aforementioned repetition of the procedure exactly as described in the literature, no synthetic attempts resulted in high purity crystalline material of $\left[\left(\mathrm{Cu}_{2}{ }_{2} \mathrm{~L}^{1}\right)_{2}\left(\mathrm{O}_{2}\right)(\mathrm{OH})_{2}\right]^{\mathrm{X2}}$.

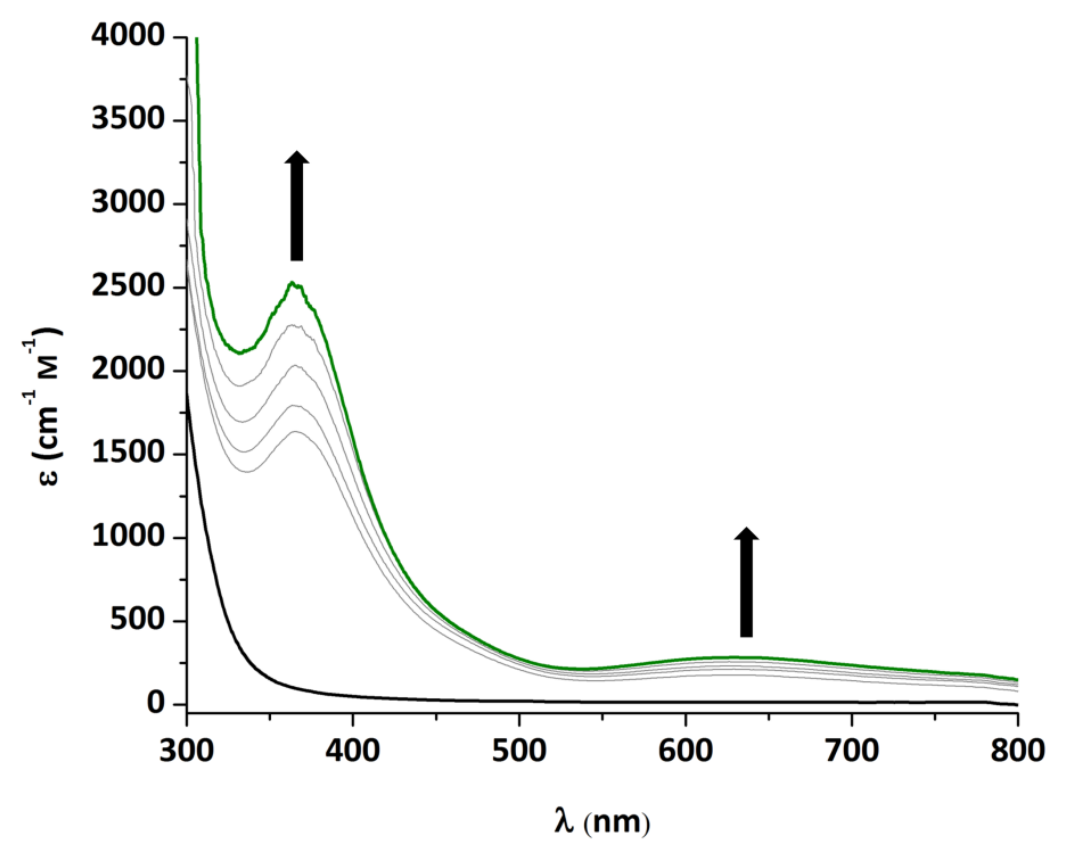

Figure 4.2: UV-vis spectroscopic monitoring of the reaction between $\left[\mathrm{Cu}_{2}^{1}{ }_{2}^{1}\right]^{\mathrm{PF} 6}$ and $\mathrm{O}_{2}$ at $-80^{\circ} \mathrm{C}$ in EtCN $(1 \times$ $\left.10^{-2} \mathrm{M}\right)$. The features are in very good agreement with those reported for $\left[\left(\mathrm{Cu}_{2}{ }_{2} \mathrm{~L}^{1}\right)_{2}\left(\mathrm{O}_{2}\right)(\mathrm{OH})_{2}\right]^{(\mathrm{PFG}) 2}$.

Owing to the lack of success described above with regards to isolating $\left[\left(\mathrm{Cu}^{\prime \prime}{ }_{2} \mathrm{~L}^{1}\right)_{\mathbf{2}}\left(\mathrm{O}_{\mathbf{2}}\right)(\mathbf{O H})_{2}\right]^{\mathrm{X} \mathbf{2}}$, an alternative synthetic strategy was developed. The converse approach of reacting a copper(II) complex directly with a peroxide source was thus utilised. During the course of the above investigation it was noted that green solutions of $\left[\left(\mathrm{Cu}_{2}{ }_{2} \mathrm{~L}^{\mathbf{1}}\right)_{\mathbf{2}}\left(\mathrm{O}_{\mathbf{2}}\right)(\mathbf{O H})_{2}\right]^{\mathrm{X2}}$ were relatively stable at $\mathrm{RT}$, and therefore trial reactions were carried out at $\mathrm{RT}$ to allow for high throughput screening. 
Reaction of sodium salt $\left[\mathrm{NaL}^{1}\right]$ with $\mathrm{Cu}(\mathrm{OTf})_{2}$ in undried $\mathrm{RCN}(\mathrm{R}=\mathrm{Me}, \mathrm{Et})$ under air resulted in blue solutions, to which were added an excess of alkali metal peroxide, $\mathrm{M}_{2} \mathrm{O}_{2}\left(\mathrm{M}=\mathrm{Li}^{+}\right.$, $\left.\mathrm{Na}^{+}\right)$. The introduction of $\mathrm{Na}_{2} \mathrm{O}_{2}$ resulted in black solutions which were not further investigated. On the other hand, while $\mathrm{MeCN}$ solutions failed to change colour upon introduction of $\mathrm{Li}_{2} \mathrm{O}_{2}, \mathrm{EtCN}$ solutions gradually turned dark green in colour. These EtCN solutions eventually became blue again upon prolonged stirring at RT under air. However, when stored in sealed vessels the green colour persisted over the course of days, or even weeks when cooled to $4{ }^{\circ} \mathrm{C}$ or below. Repeating the procedure under strictly anhydrous conditions with dry reagents ( $\left.\left[\mathrm{NaL}^{1}\right],\left[\mathrm{Cu}(\mathrm{OTf})_{2}\right], \mathrm{Li}_{2} \mathrm{O}_{2}, \mathrm{EtCN}\right)$ inside a glovebox eventually generated very faintly green coloured solutions, but only after prolonged stirring.

Taking all of the above synthetic observations into account appeared to indicate that the formation of $\left[\left(\mathrm{Cu}_{2}{ }_{2} \mathrm{~L}^{1}\right)_{2}\left(\mathrm{O}_{2}\right)(\mathrm{OH})_{2}\right]^{\mathrm{X} 2}$ is enhanced by the presence of small amounts of water. Isolation attempts were thus conducted in sealed vessels using undried $\mathrm{EtCN}$ at a range of temperatures. Layering or vapour diffusion techniques with $\mathrm{Et}_{2} \mathrm{O}$ were investigated, either after addition of $\left[\mathrm{Bu}_{4} \mathrm{~N}\right] \mathrm{PF}_{6}$ or directly with the OTf ${ }^{-}$containing solutions. What appeared to be green crystals resulted in several cases, however, closer examination revealed that the crystalline material was colourless and not sensitive to oxygen. While this product was not further characterised, it is worth noting that a related procedure led to isolatation of colourless, polymeric $\left[(\mathrm{EtCN})_{2} \mathrm{Na}\left(\mu_{3}-\mathrm{OTf}\right)\right]_{n}$. The new synthetic route detailed above thereby failed to yield pure $\left[\left(\mathrm{Cu}_{2}{ }_{2} \mathrm{~L}^{1}\right)_{2}\left(\mathrm{O}_{2}\right)(\mathrm{OH})_{2}\right]^{\mathrm{X2}}$ material. However, RT ESI-MS analysis of the green solutions resulting from this procedure provided a suitable benchmark for a more thorough investigation of the role of water in $\left[\left(\mathrm{Cu}_{2}{ }_{2} \mathrm{~L}^{1}\right)_{2}\left(\mathrm{O}_{2}\right)(\mathrm{OH})_{2}\right]^{\mathrm{X} 2}$ formation, as described below. 


\subsubsection{Mass Spectrometry}

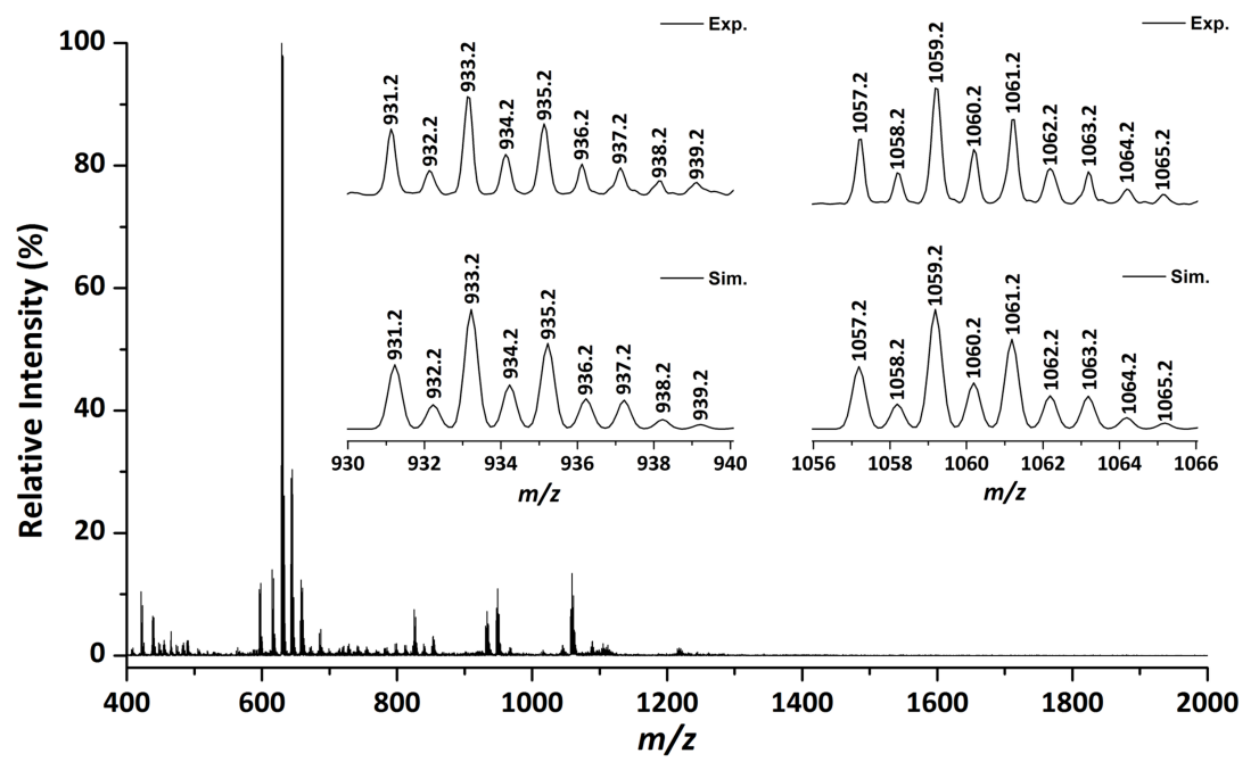

Figure 4.3: Positive mode ESI-MS spectrum of a reaction sample containing $\left[\mathrm{NaL}^{1}\right], \mathrm{CuOTf}$, and $\mathrm{Li}_{2} \mathrm{O}_{2}$ measured at $\mathrm{RT}$ in EtCN. The insets show experimental and simulated isotopic distribution patterns for

$\left[\left(\mathrm{C}_{15} \mathrm{H}_{31} \mathrm{Cu}_{2} \mathrm{~N}_{6}\right)_{2}(\mathrm{O})_{2}(\mathrm{OH})_{2}(\mathrm{Na})\right]^{+}$(left) and $\left[\left(\mathrm{C}_{15} \mathrm{H}_{31} \mathrm{Cu}_{2} \mathrm{~N}_{6}\right)_{2}\left(\mathrm{O}_{2}\right)(\mathrm{OH})_{2}\left(\mathrm{CF}_{3} \mathrm{SO}_{3}\right)\right]^{+}$(right).

Preliminary investigation of the above described intense green EtCN solutions by ESI-MS, diluted with and measured in $\mathrm{MeCN}$, showed several peak sets indicative of dinuclear copper species (Table 4.1). The two most predominant were formulated as $\left[\left(\mathrm{Cu}_{2}{ }_{2} \mathrm{~L}^{1}\right)(\mathrm{OTf})(\mathrm{X})\right]^{+}\left(\mathrm{m} / \mathrm{z}=629.1\right.$ or 643.2 where $\mathrm{X}=\mathrm{MeCO}_{2}{ }^{-}$or $\mathrm{EtCO}_{2}{ }^{-}$respectively), with the carboxylate anions most likely resulting from hydrolysis of the corresponding nitriles, MeCN and EtCN. No signals consistent with tetranuclear species were observed, however, in light of the above synthetic observations regarding MeCN, the analysis was repeated using EtCN for dilution and measurement. Under these conditions several additional signals with higher nuclearity were present. 
One of these peak sets could be assigned to the species $\left[\left(\mathrm{Cu}_{2}{ }_{2} \mathrm{~L}^{1}\right)_{2}(\mathrm{O})_{2}(\mathrm{OH})_{2}(\mathrm{Na})\right]^{+}(\mathrm{m} / z=$ 933.2), which can be thought of as a deprotonated sodium adduct of the tetra-hydroxo species described above $\left(\left[\left(\mathrm{Cu}_{2}{ }_{2}{ }^{1}\right)_{2}(\mathrm{OH})_{4}\right]^{\mathbf{X 2}}\right.$, Scheme 4.2). A related adduct was also observed but could not be unambiguously identified $(m / z=949.2$, this peak set is consistent with $\left[\left(\mathrm{Cu}_{2}{ }_{2} \mathrm{~L}^{1}\right)_{2}\left(\mathrm{O}_{2}\right)(\mathrm{OH})_{2}(\mathrm{Na})(\mathrm{O})\right]^{+}$or $\left.\left[\left(\mathrm{Cu}_{2}{ }_{2} \mathrm{~L}^{1}\right)_{2}(\mathrm{O})_{2}(\mathrm{OH})_{2}(\mathrm{~K})\right]^{+}\right)$. Most importantly, the signal with the highest intensity in this region was identified as $\left[\left(\mathrm{Cu}_{2}{ }_{2} \mathrm{~L}^{1}\right)_{2}\left(\mathrm{O}_{2}\right)(\mathrm{OH})_{2}(\mathrm{OTf})\right]^{+}(\mathrm{m} / \mathrm{z}=$ 1059.2), the mono-cationic triflate adduct of $\left[\left(\mathrm{Cu}^{\prime \prime}{ }_{2} \mathbf{L}^{1}\right)_{2}\left(\mathbf{O}_{2}\right)(\mathbf{O H})_{2}\right]^{\mathrm{X2}}$. Having established the latter signal as a possible benchmark for the formation of $\left[\left(\mathrm{Cu}_{2}{ }_{2} \mathrm{~L}^{1}\right)_{2}\left(\mathrm{O}_{2}\right)(\mathrm{OH})_{2}\right]^{\mathrm{X2}}$ in solution, the former synthetic strategy involving reaction with $\mathrm{O}_{2}$ was once again adopted in order to allow the use of isotopically labelled dioxygen-18, and further investigate the possible role of adventitious water.

\begin{tabular}{|c|c|c|}
\hline$m / z$ & Intensity (\%) & Assignment* \\
\hline \multicolumn{3}{|c|}{ Monomeric Adducts } \\
\hline 629.1 & 100 & {$\left[\left(\mathrm{Cu}_{2}{ }_{2} \mathrm{~L}^{1}\right)(\mathrm{OTf})\left(\mathrm{MeCO}_{2}\right)\right]^{+}$} \\
\hline 643.2 & 30 & {$\left[\left(\mathrm{Cu}_{2}{ }_{2} \mathrm{~L}^{1}\right)(\mathrm{OTf})\left(\mathrm{EtCO}_{2}\right)\right]^{+}$} \\
\hline \multicolumn{3}{|c|}{ Dimeric Adducts } \\
\hline 933.2 & 7 & {$\left[\left(\mathrm{Cu}_{2}^{\prime \prime} \mathrm{L}^{1}\right)_{2}(\mathrm{O})_{2}(\mathrm{OH})_{2}(\mathrm{Na})\right]^{+}$} \\
\hline 949.2 & 11 & {$\left[\left(\mathrm{Cu}_{2}{ }_{2} \mathrm{~L}^{1}\right)_{2}(\mathrm{O})_{2}(\mathrm{OH})_{2}(\mathrm{~K})\right]^{+} /\left[\left(\mathrm{Cu}_{2} \mathrm{~L}^{1}\right)_{2}\left(\mathrm{O}_{2}\right)(\mathrm{OH})_{2}(\mathrm{Na})(\mathrm{O})\right]^{+}$} \\
\hline 1059.2 & 13 & {$\left[\left(\mathrm{Cu}_{2}{ }^{\prime \prime}{ }^{1}\right)_{2}\left(\mathrm{O}_{2}\right)(\mathrm{OH})_{2}(\mathrm{OTf})\right]^{+}$} \\
\hline \multicolumn{3}{|c|}{$\begin{array}{l}\text { *Rather than purely empirical formulas the assignments presented here are grouped in order to allow for } \\
\text { easier interpretation, although it must be highlighted that the measurements give no direct information about } \\
\text { connectivity of the elements which make up the observed ion peaks. }\end{array}$} \\
\hline
\end{tabular}

\subsubsection{The Role of Water in $\left[\left(\mathrm{Cu}_{2}{ }_{2} \mathrm{~L}^{1}\right)_{2}\left(\mathrm{O}_{2}\right)(\mathrm{OH})_{2}\right]^{\mathrm{X} 2}$ Formation}

Water-free copper(I) complex $\left[\mathrm{Cu}_{2}^{\prime} \mathbf{L}^{1}\right]^{\text {OTf }}$ generated in anhydrous EtCN from thoroughly dried $\left[\mathrm{NaL}^{1}\right]$ and two equivalents of $\left[\mathrm{Cu}(\mathrm{MeCN})_{4}\right]$ OTf was used as a starting point for the following experiments. Although these solutions became green in colour when exposed to dry $\mathrm{O}_{2}$ at $-80{ }^{\circ} \mathrm{C}$, no signal for $\left[\left(\mathrm{Cu}_{2}{ }_{2} \mathrm{~L}^{1}\right)_{2}\left(\mathrm{O}_{2}\right)(\mathrm{OH})_{2}(\mathrm{OTf})\right]^{+}$was observed when ESI-MS analysis was conducted under inert conditions at RT. Deliberate introduction of water prior to $\mathrm{O}_{2}$ exposure restored the $\left[\left(\mathrm{Cu}_{2}{ }_{2}{ }^{1}\right)_{2}\left(\mathrm{O}_{2}\right)(\mathrm{OH})_{2}(\mathrm{OTf})\right]^{+}$peak set in the subsequently measured ESIMS spectrum. Approximate quantification furthermore showed five equivalents of water to be more effective than one, suggesting that the hydroxide ions in the $\left[\left(\mathrm{Cu}_{2}{ }_{2} \mathrm{~L}^{1}\right)_{2}\left(\mathrm{O}_{2}\right)(\mathrm{OH})_{2}(\mathrm{OTf})\right]^{+}$cation are water-derived under these conditions. In contrast to these findings, after one week at RT inside the glovebox both the anhydrous and watercontaining samples displayed similar spectra. The $\left[\left(\mathrm{Cu}_{2}{ }_{2} \mathrm{~L}^{1}\right)_{2}\left(\mathrm{O}_{2}\right)(\mathrm{OH})_{2}(\mathrm{OTf})\right]^{+}$signal was not observed in either case, and the corresponding region in both spectra was dominated by a 
very intense peak set $(>70 \%)$ indicative of tetranuclear $\left[\left(\mathrm{Cu}_{2}{ }_{2} \mathrm{~L}^{1}\right)_{2}(\mathrm{O})_{2}(\mathrm{OH})_{2}(\mathrm{Na})\right]^{+}(\mathrm{m} / \mathrm{z}=$ 933.1).

Direct injection of cold EtCN solutions immediately after oxygenation in the presence of one equivalent of water then proved to significantly enhance the intensity of the $\left[\left(\mathrm{Cu}_{2}{ }_{2} \mathrm{~L}^{1}\right)_{2}\left(\mathrm{O}_{2}\right)(\mathrm{OH})_{2}(\mathrm{OTf})\right]^{+}$signal. This technique was then further applied with substitution of the standard dioxygen gas for isotopically enriched ${ }^{18} \mathrm{O}_{2}$. The resulting spectrum had only one signal with significant intensity in the tetranuclear region, a new peak set consistent with $\left[\left(\mathrm{Cu}_{2}{ }_{2} \mathrm{~L}^{1}\right)_{2}\left({ }^{18} \mathrm{O}_{2}\right)(\mathrm{OH})_{2}(\mathrm{OTf})\right]^{+}(\mathrm{m} / z=1063.3)$, showing a very clear shift of 4 Da compared to the ${ }^{16} \mathrm{O}_{2}$ spectra (Figure 4.4, left). Labelling was not evident for any other signals in the spectrum but after approximately one week at RT, with the sample stored and measured under inert conditions, the $\left[\left(\mathrm{Cu}_{2}{ }_{2} \mathrm{~L}^{1}\right)_{2}(\mathrm{O})_{2}(\mathrm{OH})_{2}(\mathrm{Na})\right]^{+}$peak set $(m / z=933.2 / 935.2)$ showed a distinct though somewhat ambiguous isotopic inclusion (Figure 4.4, right).
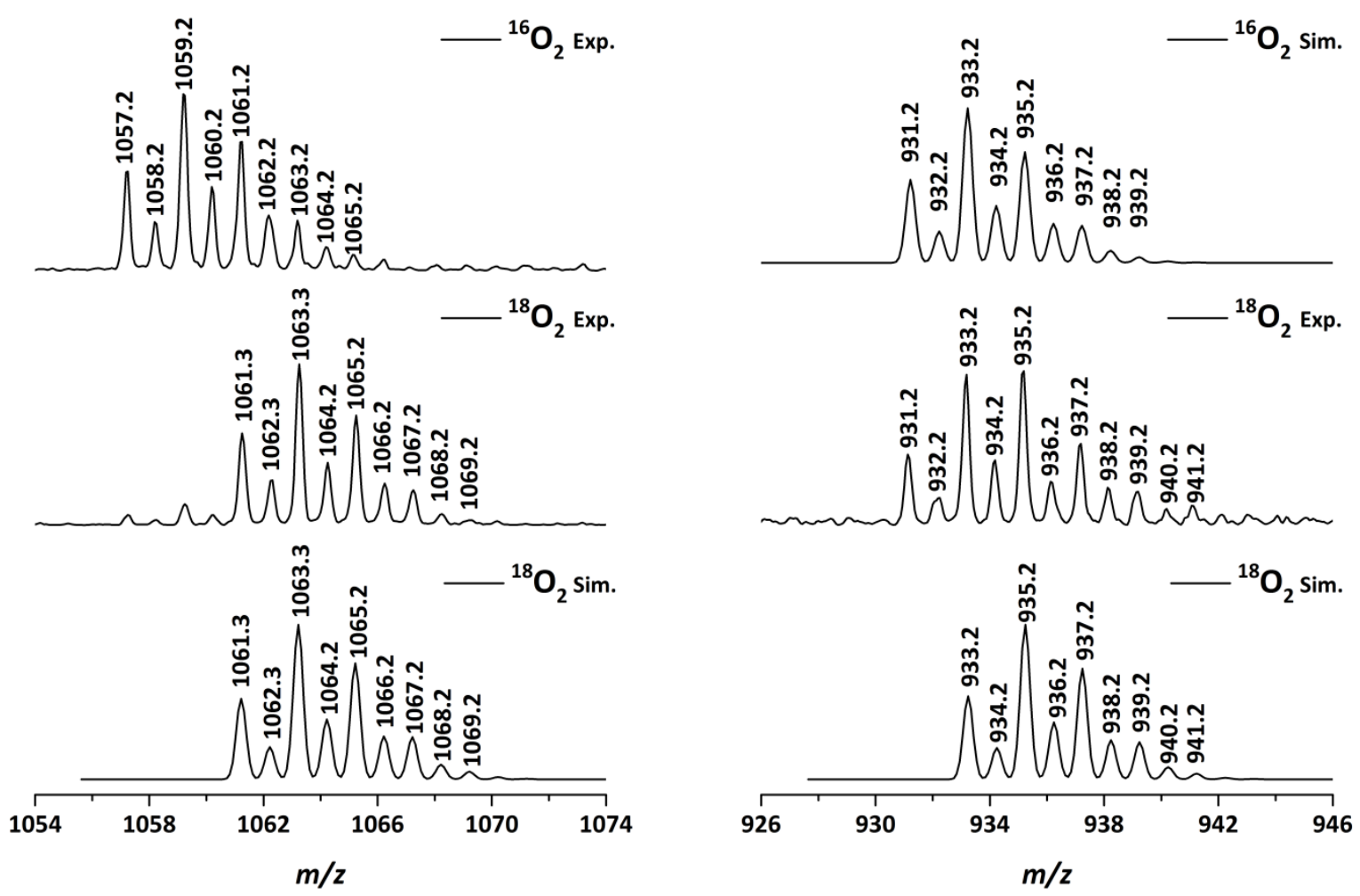

Figure 4.4: Experimental $\left({ }^{16} \mathrm{O}_{2}\right.$ and $\left.{ }^{18} \mathrm{O}_{2}\right)$ and simulated $\left({ }^{18} \mathrm{O}_{2}\right)$ isotopic distribution patterns for $\left[\left(\mathrm{C}_{15} \mathrm{H}_{31} \mathrm{Cu}_{2} \mathrm{~N}_{6}\right)_{2}\left(\mathrm{O}_{2}\right)(\mathrm{OH})_{2}\left(\mathrm{CF}_{3} \mathrm{SO}_{3}\right)\right]^{+}$(left), and experimental $\left({ }^{18} \mathrm{O}_{2}\right.$, middle) and simulated $\left({ }^{16} \mathrm{O}_{2}\right.$ and $\left.{ }^{18} \mathrm{O}_{2}\right)$ isotopic distribution patterns for $\left[\left(\mathrm{C}_{15} \mathrm{H}_{31} \mathrm{Cu}_{2} \mathrm{~N}_{6}\right)_{2}(\mathrm{O})_{2}(\mathrm{OH})_{2}(\mathrm{Na})\right]^{+}$(right).

Taken together, the above results allow some conclusions to be drawn about the formation of $\left[\left(\mathrm{Cu}_{2}{ }_{2} \mathrm{~L}^{1}\right)_{2}\left(\mathrm{O}_{2}\right)(\mathrm{OH})_{2}\right]^{\mathrm{X} 2}$ in solution. It is apparent that the presence of water has a significant influence on the reaction, with even one equivalent favouring product formation, as evidenced by ESI-MS analysis. Assignment of the $\left[\left(\mathrm{Cu}_{2}{ }_{2} \mathrm{~L}^{1}\right)_{2}\left(\mathrm{O}_{2}\right)(\mathrm{OH})_{2}(\mathrm{OTf})\right]^{+}$signal was confirmed by isotopic labelling, with the shift of only $4 \mathrm{Da}$ strongly supporting the hypothesis that the hydroxide ligands are water-derived. While fast exchange of these hydroxide bridging moieties with adventitious oxygen-16 water could potentially occur, this 
would lead to significant spreading of the peak distribution for this signal. Such a scenario involving scrambling is inconsistent with the extremely well-defined nature of the isotopically labelled $\left[\left(\mathrm{Cu}_{2}{ }_{2} \mathrm{~L}^{1}\right)_{2}\left({ }^{18} \mathrm{O}_{2}\right)(\mathrm{OH})_{2}(\mathrm{OTf})\right]^{+}$peak set.

The above findings with respect to the $\left[\left(\mathrm{Cu}_{2}{ }_{2} \mathrm{~L}^{1}\right)_{2}\left({ }^{18} \mathrm{O}_{2}\right)(\mathrm{OH})_{2}(\mathrm{OTf})\right]^{+}$peak set are in stark contrast to the signal observed after one week at RT for the tetrahydroxo product, $\left[\left(\mathrm{Cu}_{2}{ }_{2} \mathrm{~L}^{1}\right)_{2}(\mathrm{OH})_{4}\right]^{\mathrm{X2}}$. The signal corresponding to this species, $\left[\left(\mathrm{Cu}_{2}{ }_{2} \mathrm{~L}^{1}\right)_{2}(\mathrm{O})_{2}(\mathrm{OH})_{2}(\mathrm{Na})\right]^{+}$, showed fluctuating relative intensities within the isotopic envelope over the course of the measurement. This reflects variability in the isotopic enhancement, and is indicative of a scrambling process. In fact, the distribution of isotope peaks in this case is in good agreement with overlap between an entirely natural-abundance oxygen-16 species and one incorporating a single atom of oxygen-18 (Figure 4.4, right). This finding furthermore implies that the ${ }^{18} \mathrm{O}_{2}$ bond has been cleaved. Such reactivity has been previously considered in the context of this system, ${ }^{89}$ and the ability of copper complexes and their related enzymes to achieve the four electron reduction of dioxygen is well-known in the literature. ${ }^{14,16,18,122}$

It is worth noting that the peak set corresponding to $\left[\left(\mathrm{Cu}^{\prime \prime}{ }_{2} \mathrm{~L}^{1}\right)_{2}(\mathrm{OH})_{4}\right]^{\mathrm{X2}}$ was observed even when there was no indication for the formation of $\left[\left(\mathrm{Cu}_{2}{ }_{2} \mathrm{~L}^{1}\right)_{2}\left(\mathrm{O}_{2}\right)(\mathrm{OH})_{2}\right]^{\mathrm{X2}}$. This suggests that a pathway exists for dioxygen bond scission, without the involvement of $\left[\left(\mathrm{Cu}_{2}{ }_{2} \mathrm{~L}^{1}\right)_{2}\left(\mathrm{O}_{2}\right)(\mathrm{OH})_{2}\right]^{\mathrm{X2}}$ as an intermediate. Irrespective of this, cleavage of $\mathrm{O}_{2}$ in the current case must proceed quite slowly, as no signal for $\left[\left(\mathrm{Cu}_{2}{ }_{2} \mathrm{~L}^{1}\right)_{2}(\mathrm{OH})_{4}\right]^{\mathrm{X}}$ was observed when an oxygen-exposed anhydrous solution was sampled after one day at RT. The contribution of this reaction to $\left[\left(\mathrm{Cu}_{2}{ }_{2} \mathrm{~L}^{1}\right)_{2}\left(\mathrm{O}_{2}\right)(\mathrm{OH})_{2}\right]^{\mathrm{X} 2}$ formation at $-80^{\circ} \mathrm{C}$ is thus unlikely to be significant. These findings therefore give strong evidence suggesting that $\left[\left(\mathrm{Cu}^{\prime \prime}{ }_{2} \mathrm{~L}^{1}\right)_{2}\left(\mathrm{O}_{2}\right)(\mathrm{OH})_{2}\right]^{\mathrm{X2}}$ does not form under strictly anhydrous conditions, however, the results require verification by the application of supplementary investigative techniques. For example, resonance Raman spectroscopy could prove to be useful in monitoring formation of $\left[\left(\mathrm{Cu}_{2}{ }_{2} \mathrm{~L}^{1}\right)_{2}\left(\mathrm{O}_{2}\right)(\mathrm{OH})_{2}\right]^{\mathrm{X2}}$ in the presence and absence of water.

It must be highlighted that the above MS measurements provide information about the overall elemental composition of the ions of interest, but do not give insights into connectivity, or allow for unambiguous assignment of oxidation states. Thus, while the $\left[\left(\mathrm{Cu}_{2}{ }_{2} \mathrm{~L}^{1}\right)_{2}\left(\mathrm{O}_{2}\right)(\mathrm{OH})_{2}(\mathrm{OTf})\right]^{+}$has been formulated with a $\mathrm{Cu}_{4}{ }_{4}-\left(\mathrm{O}_{2}\right)(\mathrm{OH})_{2}$ configuration, the isoelectronic $\mathrm{Cu}_{2}{ }_{2} \mathrm{Cu}_{2}{ }_{2}-\left(\mathrm{O}_{2}\right)_{2}(\mathrm{H})_{2}$ adduct would result in the same peak set. The $\left[\left(\mathrm{Cu}_{2}{ }_{2} \mathrm{~L}^{1}\right)_{2}(\mathrm{O})_{2}(\mathrm{OH})_{2}(\mathrm{Na})\right]^{+}$cation is likewise also consistent with an alternative $\mathrm{Cu}_{2}^{\prime} \mathrm{Cu}_{2}^{\prime \prime}-\left(\mathrm{O}_{2}\right)(\mathrm{OH})_{2}$ configuration. The assignments in Table 4.1 which have been used to interpret the above MS findings are the most chemically sensible, and in agreement with the structures determined in the solid state. In addition, they are furthermore supported by the isotopic labelling experiments. The well-defined nature of the isotopically labelled $\left[\left(\mathrm{Cu}_{2}{ }_{2} \mathrm{~L}^{1}\right)_{2}\left({ }^{18} \mathrm{O}_{2}\right)(\mathrm{OH})_{2}(\mathrm{OTf})\right]^{+}$peak set provides strong evidence against a formulation involving two $\mathrm{O}_{2}$ molecules, as this would result in a shift of $8 \mathrm{Da}$. The partial isotopic 
enhancement for the $\left[\left(\mathrm{Cu}_{2}{ }_{2} \mathrm{~L}^{1}\right)_{2}(\mathrm{O})_{2}(\mathrm{OH})_{2}(\mathrm{Na})\right]^{+}$signal set when generated with ${ }^{18} \mathrm{O}_{2}$ also supports its assignment, as no peak set with a shift of 4 Da was observed.

Further crystallisation attempts were conducted by oxygenation of $\mathrm{Et}_{2} \mathrm{O}$ layered $\mathrm{EtCN}$ solutions of $\left[\mathrm{Cu}_{2}^{1} \mathrm{~L}^{1}\right]^{\mathrm{X}}$ in the presence of an equivalent of water at $-80{ }^{\circ} \mathrm{C}$, with and without additional $\mathrm{Bu}_{4} \mathrm{NX}\left(\mathrm{X}=\mathrm{PF}_{6}{ }^{-}, \mathrm{BF}_{4}{ }^{-}, \mathrm{ClO}_{4}{ }^{-}\right.$and $\left.\mathrm{OTf}^{-}\right)$, but no high quality crystalline material resulted. It is worth noting in this regard that, despite having established a role for water in the formation of $\left[\left(\mathrm{Cu}_{2}{ }_{2} \mathrm{~L}^{1}\right)_{2}\left(\mathrm{O}_{2}\right)(\mathrm{OH})_{2}\right]^{\mathrm{X2}}$, the mechanism by which the tetra-copper(II)-peroxo unit forms is still very much an open question. The above findings suggest that both hydroxide ions in $\left[\left(\mathrm{Cu}_{2}{ }_{2} \mathrm{~L}^{1}\right)_{2}\left(\mathrm{O}_{2}\right)(\mathrm{OH})_{2}\right]^{\mathrm{X} \mathbf{2}}$ are derived from water, however, this still does not adequately account for the changes in oxidation state needed to form the product from the starting materials. It is therefore likely that a more complex mechanism is involved, which is indeed consistent with the trimeric structure of the copper $(I)$ precursor, $\left(\left[\mathrm{Cu}_{2}^{1} \mathrm{~L}^{1}\right]^{\mathrm{X}}\right)_{3}($ Section 3.2.3). Analysis of the reaction by additional experimental methods is needed to gain further information. In this regard, valuable insights may be provided by determining the reaction stoichiometry through oxygen uptake experiments, in combination with kinetic measurements performed by low temperature stopped flow techniques. 


\subsection{Synthesis and Characterisation of $\left[\mathrm{Cu}_{2}{ }_{2} \mathrm{~L}^{2}\left(\mathrm{O}_{2}\right)\right]^{\mathrm{X}}$}

\subsubsection{Synthetic Considerations}

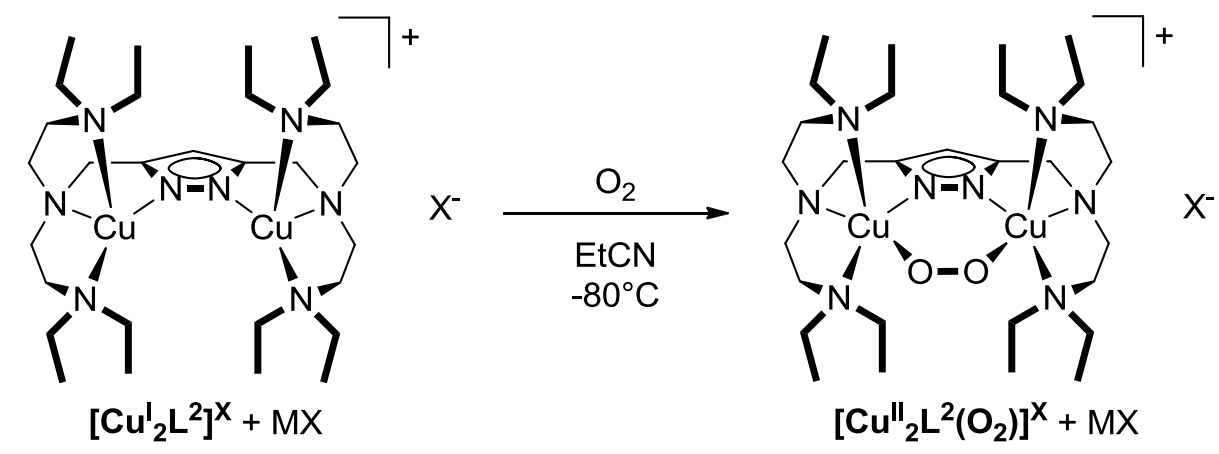

Scheme 4.3: Synthesis of $\left[\mathrm{Cu}^{\prime \prime}{ }_{2} \mathrm{~L}^{2}\left(\mathrm{O}_{2}\right)\right]^{\mathrm{X}} . \mathrm{M}=\mathrm{Na}^{+}$or $\mathrm{K}^{+}, \mathrm{X}=\mathrm{PF}_{6}^{-}, \mathrm{ClO}_{4}^{-}, \mathrm{OTf}{ }^{-}$, or $\mathrm{B}\left(\mathrm{C}_{6} \mathrm{~F}_{5}\right)_{4}^{-}$.

Formation of a violet to violet-brown transient intermediate, $\left[\mathrm{Cu}_{2}{ }_{2} \mathrm{~L}^{2}\left(\mathbf{O}_{2}\right)\right]^{\mathrm{PF}}$, upon reaction of $\left[\mathrm{Cu}_{2}{ }_{2} \mathbf{L}^{2}\right]^{\mathrm{PF} G}$ with air at low temperatures has been previously observed (Scheme 4.3). While the spectrum reported used EtCN as a solvent, in the same work DCM was found to enhance the stability of the resulting species, and was thus utilised for preliminary characterisation by $r R$ and stopped-flow UV-vis spectroscopy..$^{90}$ Chloride abstraction from the DCM solvent was proposed as a degradation pathway, and the intermediate was found to decompose completely within a minute, even at $-80^{\circ} \mathrm{C}$. Similar observations were made in the current work also, with at best only extremely short-lived brown solutions forming at $-80^{\circ} \mathrm{C}$ despite numerous efforts under various conditions, including the use of air or pure dried dioxygen and stabiliser-free DCM dried over molecular sieves or by distillation. Trial reactions with THF, MeTHF, toluene and diethyl ether were also unsuccessful, with solutions becoming briefly black and then green, or directly green without sign of an intermediate. While the intense violet colour of $\left[\mathbf{C u}^{11}{ }_{2} \mathbf{L}^{2}\left(\mathbf{O}_{2}\right)\right]^{\mathrm{X}}$ was observed in acetone when exposed to pure dried dioxygen, it rapidly became green within seconds, possibly as a result of the basic nature of $\left[\mathrm{Cu}^{\prime \prime}{ }_{2} \mathbf{L}^{2}\left(\mathrm{O}_{2}\right)\right]^{\mathrm{X}}$. The green colour observed in the above cases was interpreted as formation of a copper(II) decomposition product, and was generally not investigated further.

Conversely to the above results, $\left[\mathrm{Cu}_{2}{ }_{2} \mathrm{~L}^{2}\left(\mathrm{O}_{2}\right)\right]^{\mathrm{X}}$ formed herein with pure dioxygen in EtCN was stable over the course of several hours at $-80^{\circ} \mathrm{C}$, which allowed for the molar extinction coefficient of $\left[\mathrm{Cu}_{2}{ }_{2} \mathrm{~L}^{2}\left(\mathrm{O}_{2}\right)\right]^{\mathrm{X}}$ to be determined and for further investigation by $r R$ spectroscopy (Section 4.3.2). Furthermore, by using $\mathrm{HL}^{2}$ of high purity and substituting the $\mathrm{PF}_{6}{ }^{-}$counterion used in the synthesis for $\mathrm{BF}_{4}{ }^{-}, \mathrm{ClO}_{4}{ }^{-}$or $\mathrm{OTf}^{-}, \mathrm{B}\left(\mathrm{C}_{6} \mathrm{~F}_{5}\right)_{4}{ }^{-}$, solutions of $\left[\mathrm{Cu}_{2}{ }_{2} \mathbf{L}^{2}\left(\mathrm{O}_{2}\right)\right]^{\mathrm{X}}$ which were stable for up to two weeks at $-80{ }^{\circ} \mathrm{C}$ could be prepared. Unfortunately, no crystalline material could be obtained by ether layering or the use of concentrated solutions. Fluorinated organic counterions were also investigated, but due to their greater solubility diethyl ether is no longer sufficient for inducing precipitation. Extremely non-polar solvents like hexane and pentane were thus used but, while sufficiently miscible at RT, two-phase systems are observed at lower temperatures with EtCN. This is 
also the case with the more lipophilic ${ }^{i} \operatorname{PrCN},{ }^{n} \operatorname{PrCN}$ and ${ }^{n} \mathrm{BuCN}$, which were as well employed in crystallisation attempts.

Despite the relatively limited success described above, two crystallisation strategies should be investigated in more depth on the basis of the observations made, as follows. By using the sterically demanding $\mathrm{B}\left(\mathrm{C}_{6} \mathrm{H}_{5}\right)_{4}{ }^{-}$anion in combination with $\mathrm{MeOH}$, solid material resulted in the case of the dinuclear copper(I) complex $\left[\mathrm{Cu}_{2}{ }_{2} \mathrm{~L}^{2}\right]^{\mathrm{X}}$ (Section 3.3.1), and so an analogous synthetic strategy was investigated for $\left[\mathrm{Cu}^{\prime \prime}{ }_{2} \mathbf{L}^{2}\left(\mathbf{O}_{2}\right)\right]^{\mathrm{X}}$. Although $\left[\mathrm{Cu}^{\prime \prime}{ }_{2} \mathrm{~L}^{2}\left(\mathbf{O}_{2}\right)\right]^{\mathrm{X}}$ proved stable in the presence of this counterion at $-80^{\circ} \mathrm{C}$ in $\mathrm{EtCN}$, it decomposed rapidly upon introduction of $\mathrm{MeOH}$. Nonetheless, the $\mathrm{B}\left(\mathrm{C}_{6} \mathrm{H}_{5}\right)_{4}{ }^{-}$anion has been previously shown to have a profound effect on the stability of a related dioxygen adduct of $\mathrm{Me}_{6}$ tren, ${ }^{32}$ and should be further investigated. In a related approach, utilisation of the $\mathrm{B}\left(\mathrm{C}_{6} \mathrm{~F}_{5}\right)_{4}{ }^{-}$counterion in toluene afforded a white copper(I) precipitate which furthermore became intensely violet when exposed to $\mathrm{O}_{2}$ at $-80{ }^{\circ} \mathrm{C}$ in the solid state (Section 3.3.1). Attempts to crystallise $\left[\mathrm{Cu}^{\prime \prime}{ }_{2} \mathbf{L}^{2}\left(\mathbf{O}_{2}\right)\right]^{\mathrm{X}}$ with this counterion at low temperatures, with combinations of EtCN and toluene made by pre-mixing or layering, may thus hold further promise.

\subsubsection{Spectroscopic Characterisation and $\mathrm{O}_{2}$ uptake}

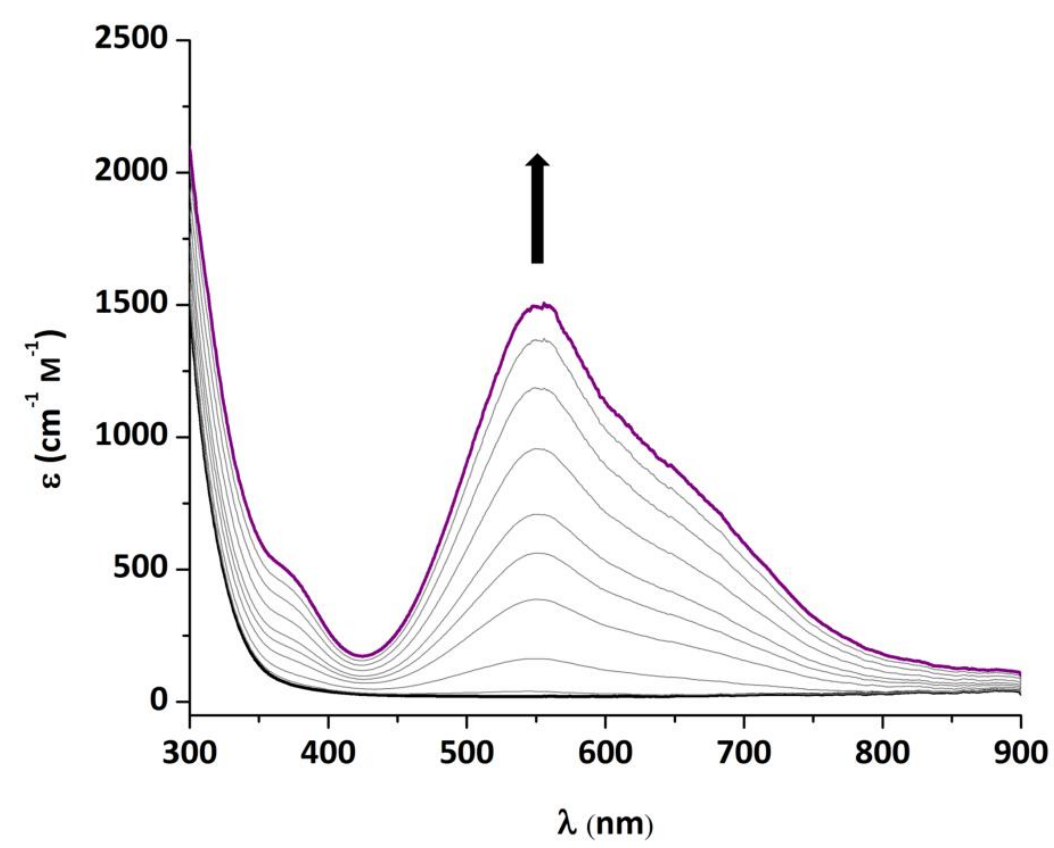

Figure 4.5: UV-vis spectroscopic monitoring of the reaction between $\left[\mathrm{Cu}_{2}{ }_{2} \mathrm{~L}^{2}\right]^{\mathrm{PF} 6}$ and $\mathrm{O}_{2}$ at $-80^{\circ} \mathrm{C}$ in $\mathrm{EtCN}(1 \times$ $\left.10^{-2} \mathrm{M}\right)$. The molar extinction coefficient $(\varepsilon)$ was found to vary depending on the batch and concentration of copper(I) complex used (see Section 4.4.5 for further detail).

When $\left[\mathrm{Cu}_{2}^{1} \mathrm{~L}^{2}\right]^{\mathrm{X}}\left(\mathrm{X}=\mathrm{PF}_{6}{ }^{-}, \mathrm{ClO}_{4}{ }^{-}, \mathrm{OTf}^{-}\right)$formed with a $10 \%$ excess of copper(I) source is oxygenated in $\mathrm{EtCN}$ at $-80{ }^{\circ} \mathrm{C}$, the resulting UV-vis spectrum (Figure 4.5) appears qualitatively similar to those of other crystallographically characterised $\mu-\eta^{1}-\eta^{1}$-peroxo species. ${ }^{14,155-157}$ The principal absorption band appears at $553 \mathrm{~nm}\left(\varepsilon \approx 2500 \mathrm{M}^{-1} \mathrm{~cm}^{-1}\right)$ with a 
broad shoulder at approximately $650 \mathrm{~nm}$, consistent with previous findings which resolved this feature into two respective peaks at 544 and $633 \mathrm{~nm}$ by Gaussian curve fitting. ${ }^{90}$ While the molar extinction coefficient determined herein is approximate as a result of variations depending on the batch and concentration of copper(I) complex used (see Section 4.4.5 for further detail about the variability of this feature), it was observed in all cases to be significantly lower than the majority of other characterised $\mu-\eta^{1}-\eta^{1}$-peroxo species. ${ }^{14,155-157}$ Applying high vacuum to EtCN solutions overnight at $-80{ }^{\circ} \mathrm{C}$ led to partial visual bleaching, after which exposure to additional dry dioxygen restored the original intense violet colour. However, attempts to further explore this reversibility by spectroscopic monitoring were hindered by the high temperature sensitivity of $\left[\mathrm{Cu}_{2}{ }_{2} \mathrm{~L}^{2}\left(\mathbf{O}_{2}\right)\right]^{\mathrm{X}}$, which generally resulted in decomposition before significant backward reaction.
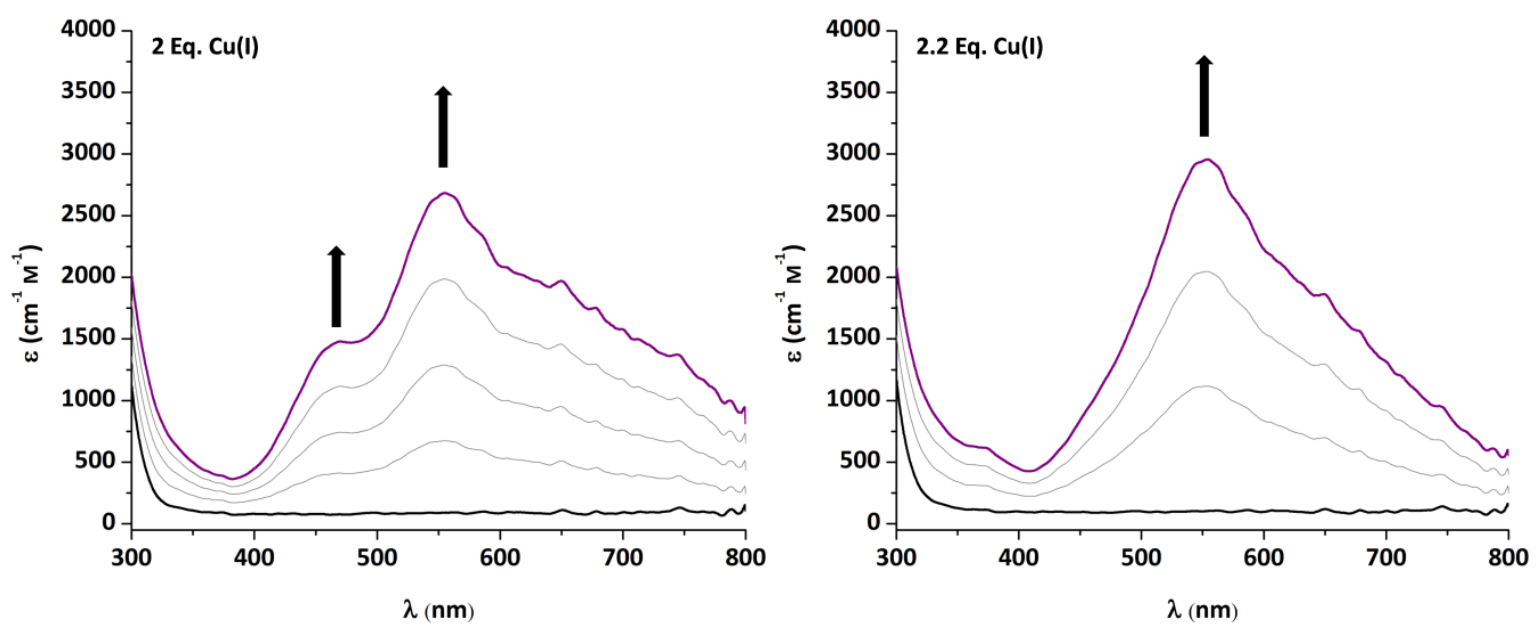

Figure 4.6: UV-vis spectroscopic monitoring of the reaction between $\left[\mathrm{Cu}_{2}^{1} \mathrm{~L}^{2}\right]^{\mathrm{OTf}}$ (formed with 2 or 2.2 equivalents of copper(I) salt) and $\mathrm{O}_{2}$ at $-80^{\circ} \mathrm{C}$ in $\operatorname{EtCN}\left(2.4 \times 10^{-3} \mathrm{M}\right)$.

In contrast to the previously reported findings, ${ }^{90}$ when $\left[\mathrm{Cu}_{2}^{1} \mathrm{~L}^{2}\right]^{\mathrm{X}}$ formed in situ from $\mathbf{H L}^{2}$, $\mathrm{KO}^{t} \mathrm{Bu}$, and two equivalents of $\operatorname{copper}(\mathrm{I})$ salt was oxygenated in the current work, an additional feature centred at approximately $460 \mathrm{~nm}$ was also visible (Figure 4.6, left). Variation in the relative rate of formation and decay of this band with respect to the more intense feature at $553 \mathrm{~nm}$ was sometimes observed between experiments, however, formation of the two peak sets was generally simultaneous. The $460 \mathrm{~nm}$ band usually arose with a fixed intensity ratio of approximately $1: 2$ relative to the major feature at $553 \mathrm{~nm}$. Although the $460 \mathrm{~nm}$ band was present regardless of the counterion used, when an excess of $10 \%$ copper(I) salt was added prior to $\mathrm{O}_{2}$ exposure this extra absorption was no longer observed (Figure 4.6, right).

Taken together with the finding that the mononuclear copper $(I)$ complex $\left[\mathrm{Cu}^{\prime} \mathrm{L}^{2}\right]$ is present when only two equivalents of copper(I) source are used to generate $\left[\mathrm{Cu}_{2}{ }_{2} \mathbf{L}^{2}\right]^{\mathrm{X}}$ (Section 3.3.3), the above observations imply the presence of a mononuclear copper(II)-superoxo adduct, $\left[\mathrm{Cu}^{\prime \prime} \mathbf{L}^{2}\left(\mathrm{O}_{2}{ }^{\circ}\right)\right]$. Such species are often observed as transient intermediates en route to the 
formation of dinuclear copper(II) $\mu-\eta^{1}-\eta^{1}$-peroxo adducts, ${ }^{37,125,157-160}$ but both can also coexist in solution under certain conditions. ${ }^{155,161}$ The generally observed simultaneous appearance of the 460 and $553 \mathrm{~nm}$ features described above suggests that $\left[\mathrm{Cu}^{\prime \prime} \mathbf{L}^{2}\left(\mathbf{O}_{2}{ }^{\circ}\right)\right.$ ] represents an independent species rather than an intermediate. This was confirmed by preliminary stopped flow UV-vis spectroscopy conducted at $-80{ }^{\circ} \mathrm{C}$, which showed only simultaneous formation of the two signal sets. Targeted synthesis using $\mathrm{HL}^{2}$ in combination with only one equivalent of copper(I) salt showed little promise, and formation of this mononuclear copper-dioxygen adduct was thus pursued no further.

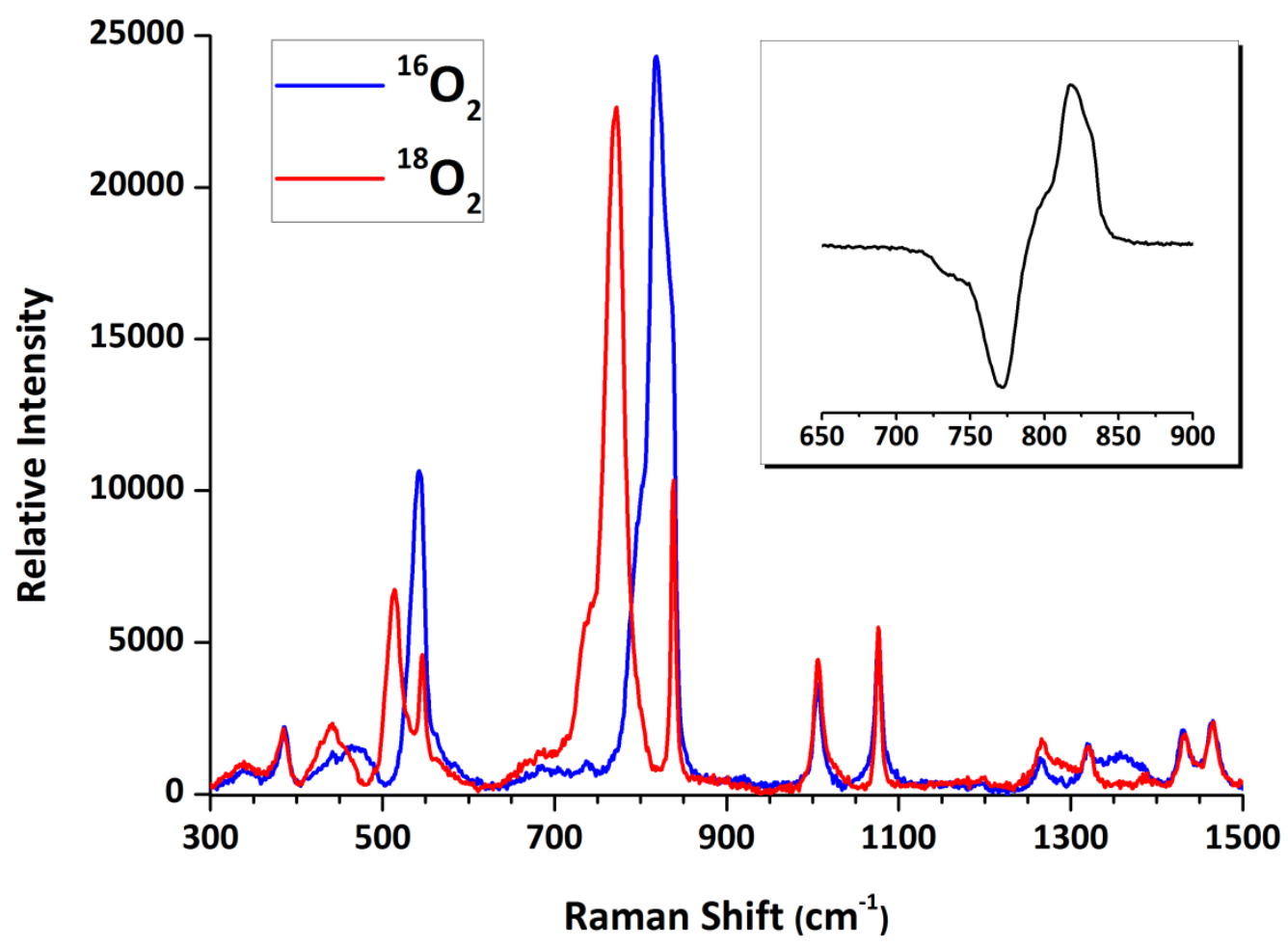

Figure 4.7: Resonance Raman spectrum of the reaction product when $\left[\mathrm{Cu}_{2}^{1} \mathrm{~L}^{2}\right]^{\mathrm{PF} 6}$ is exposed to $\mathrm{O}_{2}$ at $-80^{\circ} \mathrm{C}$ in $\operatorname{EtCN}\left(1 \times 10^{-2} \mathrm{M}, \lambda_{\text {exc }}=633 \mathrm{~nm}\right)$. The inset shows a difference spectrum for the region containing the O-O stretching frequency, showing a shoulder on the low energy side (lower wavenumber) of both bands. Isolated solvent bands were used to scale spectra relative to one another.

Resonance Raman (rR) spectroscopy of $\left[\mathrm{Cu}^{\prime \prime}{ }_{2} \mathrm{~L}^{2}\left(\mathrm{O}_{2}\right)\right]^{\mathrm{PF} 6}$ in $\mathrm{EtCN}$ at $-80{ }^{\circ} \mathrm{C}$ using a laser excitation of $633 \mathrm{~nm}$ provided additional evidence indicative of a copper-peroxo adduct (Figure 4.7). Preliminary experiments showed significant overlap with EtCN solvent bands, and therefore relatively high concentrations of $\left[\mathrm{Cu}^{\prime \prime}{ }_{2} \mathrm{~L}^{2}\left(\mathrm{O}_{2}\right)\right]^{\mathrm{PF} 6}$ were used in order to adequately distinguish the vibrational features of interest. A total of four isotope sensitive features were observed at 470, 540 and $817 \mathrm{~cm}^{-1}\left(\Delta^{16} \mathrm{O}_{2}{ }^{-18} \mathrm{O}_{2}=28,26\right.$ and $45 \mathrm{~cm}^{-1}$ respectively), with an overtone of the latter band visible at $1354 \mathrm{~cm}^{-1}$ (a shift is apparent upon isotopic labelling but the signal is not well resolved). On the lower energy side of the band at $817 \mathrm{~cm}^{-1}$ a shoulder with a frequency of approximately $800 \mathrm{~cm}^{-1}$ is visible, which shifted accordingly in the isotopically labelled spectrum. The dominant features in the spectrum are the two at 817 and $540 \mathrm{~cm}^{-1}$, which are in exceptionally good agreement with those known for reported trans- $\mu-\eta^{1}-\eta^{1}$-dicopper-peroxo species. ${ }^{14,32,46,156,162}$ The additional 
pair of vibrational bands at 800 and $480 \mathrm{~cm}^{-1}$ are not consistent with a superoxo adduct, for which a feature at approximately $1000-1150 \mathrm{~cm}^{-1}$ would be expected. ${ }^{14,44,61}$ Furthermore, it is worth noting that at the irradiation wavelength used $(633 \mathrm{~nm})$ only vibrational modes associated with the dominant UV-vis absorption bands at 553 and $650 \mathrm{~nm}$ would be enhanced. Therefore, as the above described $\left[\mathrm{Cu}^{\prime \prime} \mathbf{L}^{2}\left(\mathrm{O}_{2}{ }^{\circ}\right)\right]$ species was proposed on the basis of a UV-vis band at $460 \mathrm{~nm}$, its corresponding rR spectroscopic features would not be enhanced, and most likely would not be observed at this irradiation wavelength. Thus, the minor signal set in the $\mathrm{rR}$ spectrum may indicate the presence of a second, less abundant dicopper-peroxo species. This situation is not uncommonly observed in the literature, has been found to be highly dependent on several factors including the solvent employed and concentration, and may involve different conformers, or a mixture of inter-and intramolecular species. ${ }^{159,163,164}$

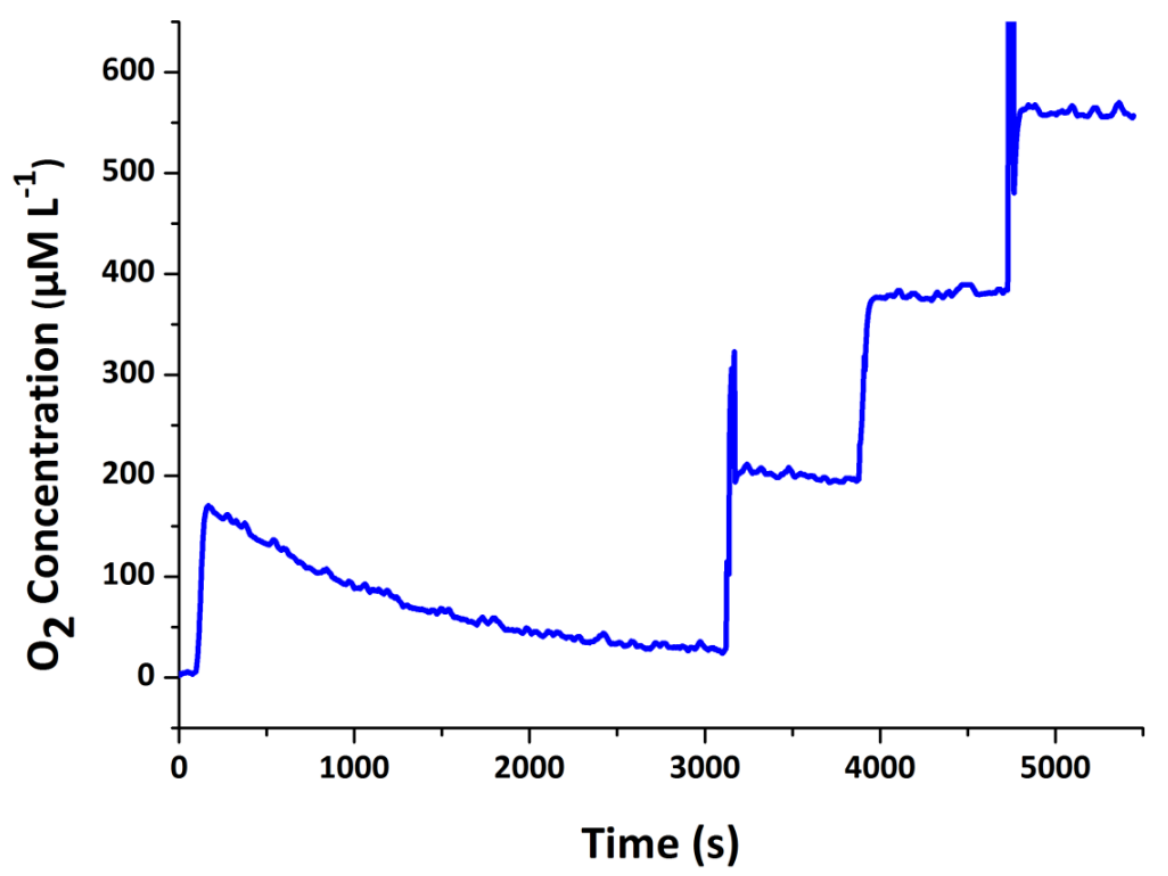

Figure 4.8: Oxygen uptake at $-80^{\circ} \mathrm{C}$ by $\left[\mathrm{Cu}_{2}{ }_{2} \mathrm{~L}^{2}\right]^{\mathrm{ClO}}$ in $\operatorname{EtCN}\left(1 \times 10^{-2} \mathrm{M}\right)$. Each injection of oxygen is equal to one equivalent of complex (dinuclear unit).

Assignment of the individual components described above on the basis of $r R$ alone is not straightforward, and based on their similar coordination environments they would furthermore not be expected to exhibit significantly differing UV-vis spectra. ${ }^{161,165}$ While the above techniques give strong evidence for formation of copper(II)-peroxo species with $\mu$ $\eta^{1}: \eta^{1}$-coordination, they do not provide information about the stoichiometry of the reaction or differentiate between intra- or inter-molecular dioxygen adducts. The reaction with $\mathrm{O}_{2}$ was thus assessed by monitoring uptake with a Clark electrode (Figure 4.8), and was found to proceed in EtCN in approximately $90 \%$ yield per dinuclear copper complex, suggesting 1:1 stoichiometry between $\left[\mathrm{Cu}_{2}{ }_{2}{ }^{2}\right]^{\mathrm{x}}$ and dioxygen. Although not readily apparent by application of the above techniques, Cryo-ESI-MS offered some insight into the possible speciation of the $\left[\mathrm{Cu}_{2}{ }_{2} \mathrm{~L}^{2}\left(\mathrm{O}_{2}\right)\right]^{\mathrm{X}}$ dioxygen adducts in solution. 


\subsubsection{Mass Spectrometry}

The positive mode HR Cryo-ESI-MS spectrum of $\left[\mathrm{Cu}_{2}{ }_{2}{ }^{2}{ }^{2}\left(\mathbf{O}_{2}\right)\right]^{\mathrm{PF} 6}$, acquired at $-80{ }^{\circ} \mathrm{C}$ in EtCN after generation and injection by hand at the same temperature, appears very similar to that of the dinuclear copper(I) complex $\left[\mathrm{Cu}_{2}^{1} \mathrm{~L}^{2}\right]^{\mathrm{PF} 6}$ measured under equivalent conditions. Although there is significant enhancement (40\%) of the signal corresponding to the decomposition product $\left[\left(\mathrm{Cu}_{2}{ }_{2} \mathrm{~L}^{2}\right)\left(\mathrm{PO}_{3} \mathrm{~F}\right)\right]^{+}(\mathrm{m} / \mathrm{z}=745.324)$, the most intense peak set is that of the starting material $\left[\mathrm{Cu}_{2}{ }_{2} \mathrm{~L}^{2}\right]^{+}(\mathrm{m} / z=647.360)$. Solutions rapidly became green during injection, and while the observed spectrum may partially result from fast decay owing to the temperature sensitivity of $\left[\mathrm{Cu}_{2}{ }_{2} \mathrm{~L}^{2}\left(\mathrm{O}_{2}\right)\right]^{\mathrm{PF} 6}$, the prevalence of the $\left[\mathrm{Cu}_{2}{ }_{2} \mathrm{~L}^{2}\right]^{+}$signal is not consistent with thermal decomposition. Indeed, solutions that were oxygenated and warmed to RT overnight showed almost exclusively $\left[\left(\mathrm{Cu}_{2}{ }_{2} \mathrm{~L}^{2}\right)\left(\mathrm{PO}_{3} \mathrm{~F}\right)\right]^{+}(\mathrm{m} / z=745.324)$, with minor amounts $(16 \%)$ of starting material, $\left[\mathrm{Cu}_{2}{ }_{2} \mathrm{~L}^{2}\right]^{+}$. Though the above results offer little insight with respect to the dioxygen adduct, $\left[\mathrm{Cu}_{2}{ }_{2} \mathrm{~L}^{2}\left(\mathrm{O}_{2}\right)\right]^{\mathrm{X}}$, more promising spectra were obtained by monitoring the anionic species present.

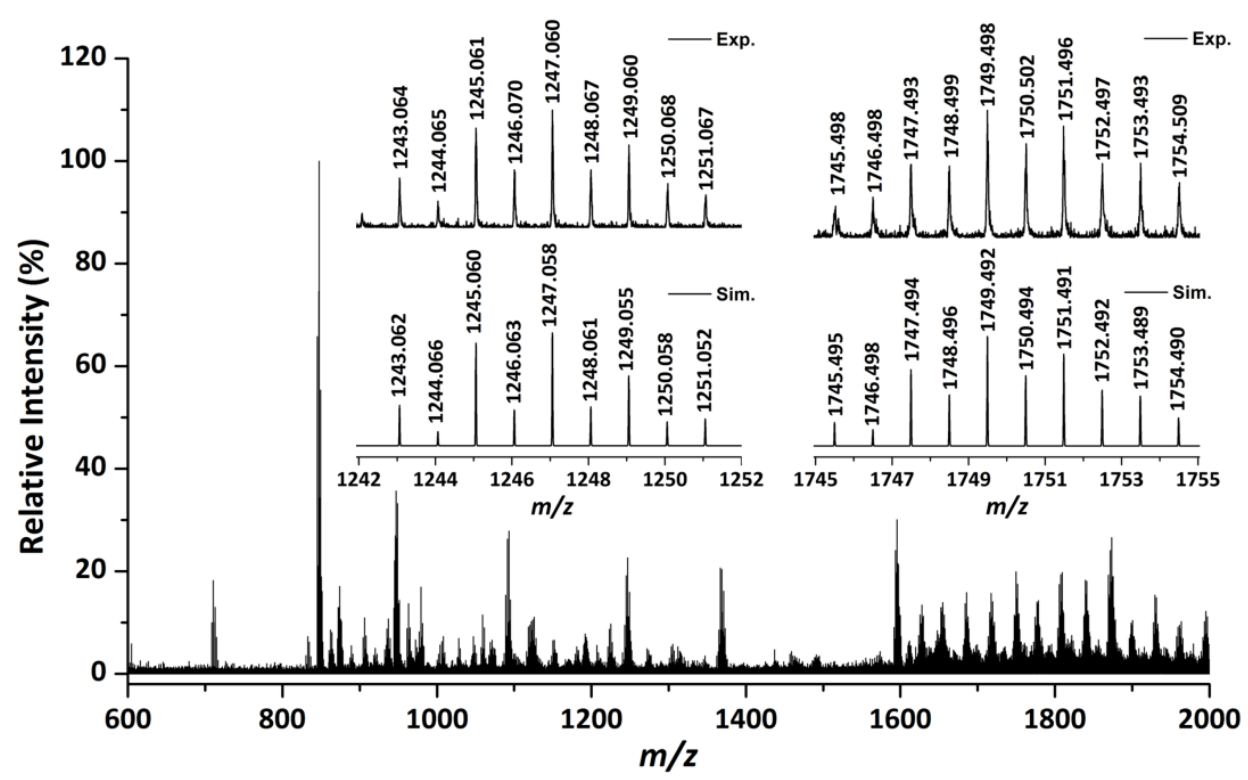

Figure 4.9: Negative mode HR-Cryo-ESI-MS spectrum of $\left[\mathrm{Cu}^{\prime \prime}{ }_{2} \mathrm{~L}^{2}\left(\mathrm{O}_{2}\right)\right]^{\mathrm{Cl04}}$ in EtCN, measured at $-80^{\circ} \mathrm{C}$. The insets show experimental and simulated isotopic distribution patterns for $\left[\mathrm{C}_{29} \mathrm{H}_{61} \mathrm{Cu}_{2} \mathrm{~N}_{8}\left(\mathrm{O}_{2}\right) \mathrm{Na}_{3}\left(\mathrm{ClO}_{4}\right)_{5}\right]^{-}$(left) and $\left[\left(\mathrm{C}_{29} \mathrm{H}_{61} \mathrm{Cu}_{2} \mathrm{~N}_{8}\right)_{2}\left(\mathrm{O}_{2}\right) \mathrm{Na}\left(\mathrm{ClO}_{4}\right)_{4}\right]^{-}$(right).

As in the case of the corresponding copper $(\mathrm{I})$ complex, $\left[\mathrm{Cu}_{2}{ }_{2} \mathbf{L}^{2}\right]^{\mathrm{X}}$, the HR Cryo-ESI-MS spectra of $\left[\mathrm{Cu}^{\prime \prime}{ }_{2} \mathrm{~L}^{2}\left(\mathrm{O}_{2}\right)\right]^{\mathrm{X}}$ were obtained in negative mode with either $\mathrm{KPF}_{6}$ or $\mathrm{NaClO}_{4}$ present. Once again, only a relatively limited number of peaks could be unambiguously assigned when $\mathrm{KPF}_{6}$ was present, and none of these corresponded to dioxygen adducts. On the other hand, the results with $\mathrm{NaClO}_{4}$ present were much more insightful (Figure 4.9). 


\begin{tabular}{|c|c|c|}
\hline$m / z$ & Intensity (\%) & Assignment* \\
\hline \multicolumn{3}{|c|}{ Monomeric Adducts } \\
\hline 847.255 & 100 & {$\left[\left(\mathrm{Cu}_{2}^{\prime} \mathrm{L}^{2}\right)\left(\mathrm{ClO}_{4}\right)_{2}\right]^{-}$} \\
\hline 963.210 & 13 & {$\left[\left(\mathrm{Cu}_{2}{ }_{2} \mathrm{~L}^{2}\right)(\mathrm{OH})\left(\mathrm{ClO}_{4}\right)_{3}\right]^{-}$} \\
\hline 1247.062 & 26 & {$\left[\left(\mathrm{Cu}_{2}{ }^{\mathrm{II}} \mathrm{L}^{2}\right)\left(\mathrm{O}_{2}\right)(\mathrm{Na})_{3}\left(\mathrm{ClO}_{4}\right)_{5}\right]^{-}$} \\
\hline 1367.005 & 23 & {$\left[\left(\mathrm{Cu}_{2}{ }_{2} \mathrm{~L}^{2}\right)\left(\mathrm{O}_{2}\right)(\mathrm{Na})_{4}\left(\mathrm{ClO}_{4}\right)_{6}\right]^{-}$} \\
\hline \multicolumn{3}{|c|}{ Dimeric Adducts } \\
\hline 1749.492 & 20 & {$\left[\left(\mathrm{Cu}^{\prime} \mathrm{Cu}^{\prime \prime} \mathrm{L}^{2}\right)_{2}\left(\mathrm{O}_{2}\right)(\mathrm{Na})\left(\mathrm{ClO}_{4}\right)_{4}\right]^{-}$} \\
\hline 1873.435 & 28 & {$\left[\left(\mathrm{Cu}^{\prime} \mathrm{Cu}^{\prime \prime} \mathrm{L}^{2}\right)_{2}\left(\mathrm{O}_{2}\right)(\mathrm{Na})_{2}\left(\mathrm{ClO}_{4}\right)_{5}\right]^{-}$} \\
\hline \multicolumn{3}{|c|}{$\begin{array}{l}\text { * Rather than purely empirical formulas the assignments presented here are grouped in order to allow for } \\
\text { easier interpretation, although it must be highlighted that the measurements give no direct information about } \\
\text { connectivity of the elements which make up the observed ion peaks. }\end{array}$} \\
\hline
\end{tabular}

When $\left[\mathrm{Cu}_{2}{ }_{2} \mathrm{~L}^{2}\left(\mathrm{O}_{2}\right)\right]^{\mathrm{ClO4}}$ was generated from dry $\mathrm{O}_{2}$ at $-80^{\circ} \mathrm{C}$ and rapidly injected by hand, the resulting cryo-ESI-MS spectrum revealed a roughly equal distribution between monomeric and dimeric dioxygen adducts. This finding is in stark contrast to the analogous $\left[\mathrm{Cu}_{2}^{1} \mathrm{~L}^{2}\right]^{\mathrm{ClO} 4}$ case, which showed dimeric adducts as the dominant species (Section 3.3.2). The dominant peak set in the current case was clearly formulated as $\left[\left(\mathrm{Cu}_{2}^{\prime} \mathrm{L}^{2}\right)\left(\mathrm{ClO}_{4}\right)_{2}\right]^{-}(\mathrm{m} / z=847.255)$. However, the monomeric dioxygen adducts $\left[\left(\mathrm{Cu}_{2}{ }_{2} \mathrm{~L}^{2}\right)\left(\mathrm{O}_{2}\right)(\mathrm{Na})_{3}\left(\mathrm{ClO}_{4}\right)_{5}\right]^{-}(\mathrm{m} / \mathrm{z}=1247.062)$ and $\left[\left(\mathrm{Cu}_{2}{ }_{2} \mathrm{~L}^{2}\right)\left(\mathrm{O}_{2}\right)(\mathrm{Na})_{4}\left(\mathrm{ClO}_{4}\right)_{6}\right]^{-}(\mathrm{m} / z=1367.005)$ could also be identified, as well as the related tetranuclear dimeric species $\left[\left(\mathrm{Cu}^{\prime} \mathrm{Cu}^{\prime \prime} \mathrm{L}^{2}\right)_{2}\left(\mathrm{O}_{2}\right)(\mathrm{Na})\left(\mathrm{ClO}_{4}\right)_{4}\right]^{-}(\mathrm{m} / z=1749.492)$ and $\left[\left(\mathrm{Cu}^{\prime} \mathrm{Cu}^{\prime \prime} \mathrm{L}^{2}\right)_{2}\left(\mathrm{O}_{2}\right)(\mathrm{Na})_{2}\left(\mathrm{ClO}_{4}\right)_{5}\right]^{-}(\mathrm{m} / z=1873.435)$, all with relative intensities of around $25 \%$. The spectrum resulting from labelling with isotopically enriched ${ }^{18} \mathrm{O}_{2}$ (Figure 4.10) confirmed the above assignments for the dioxygen adducts. The most intense signal in the case of this ${ }^{18} \mathrm{O}_{2}$ spectrum, also observed as a relatively minor species in the above ${ }^{16} \mathrm{O}_{2}$ spectrum and in the case of $\left[\mathrm{Cu}_{2}^{\prime} \mathrm{L}^{2}\right]^{\mathrm{ClO} 4}$, is consistent with a decomposition product, $\left[\left(\mathrm{Cu}_{2}{ }_{2} \mathrm{~L}^{2}\right)(\mathrm{OH})\left(\mathrm{ClO}_{4}\right)_{3}\right]^{-}$ $(\mathrm{m} / \mathrm{z}=963.210)$. This peak set displayed no appreciable isotopic enrichment, suggesting that the hydroxide group is derived from adventitious water. While fast exchange of this hydroxide bridging moiety with oxygen-16 water could lead to loss of the isotopically labelled signal, this scrambling process should be suppressed given that measurements were made at low temperatures and samples injected directly by hand. 

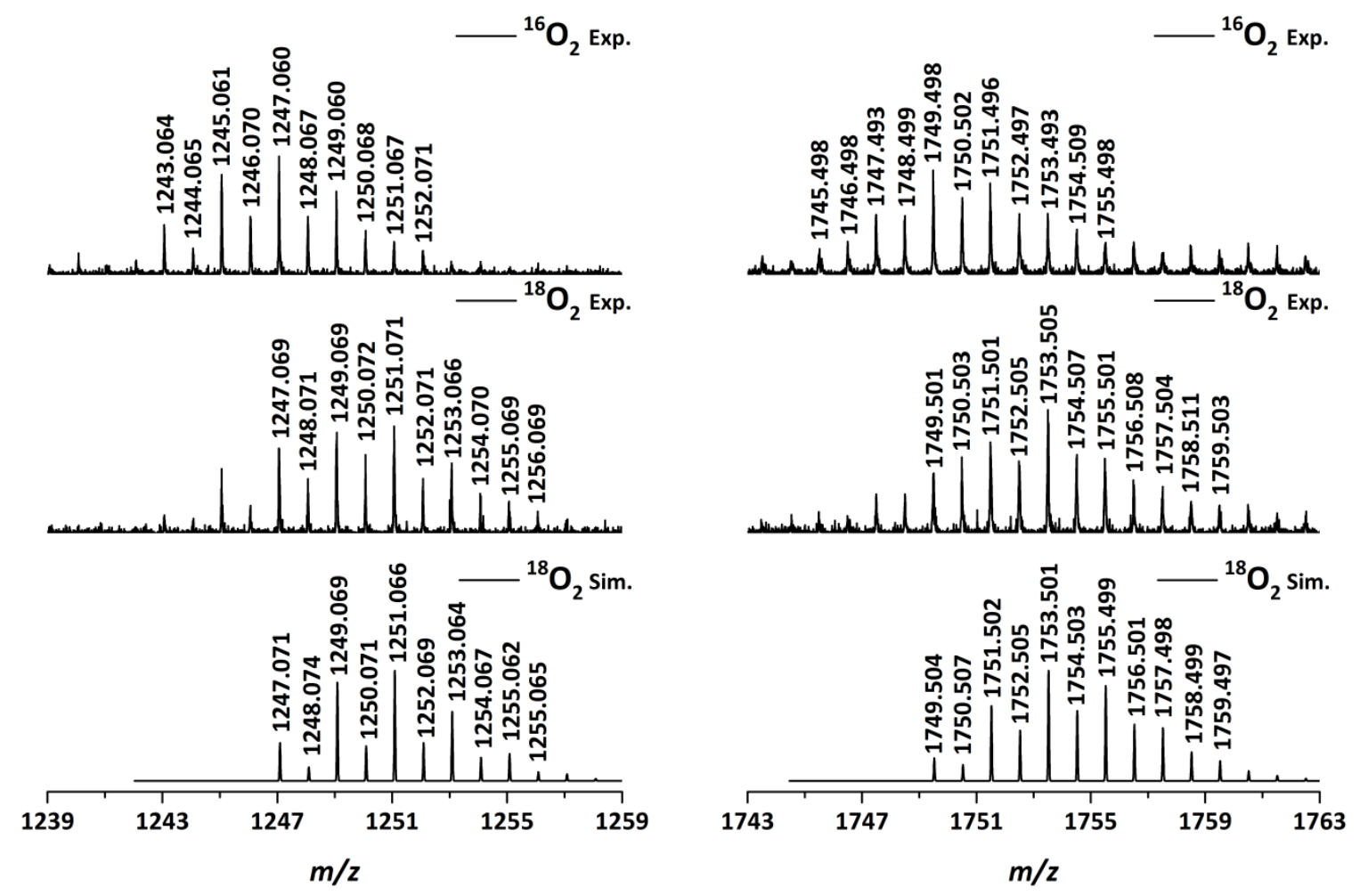

Figure 4.10: Experimental $\left({ }^{16} \mathrm{O}_{2}\right.$ and $\left.{ }^{18} \mathrm{O}_{2}\right)$ and simulated $\left({ }^{18} \mathrm{O}_{2}\right)$ isotopic distribution patterns for $\left[\mathrm{C}_{29} \mathrm{H}_{61} \mathrm{Cu}_{2} \mathrm{~N}_{8}\left(\mathrm{O}_{2}\right) \mathrm{Na}_{3}\left(\mathrm{ClO}_{4}\right)_{5}\right]^{-}$(left) and $\left[\left(\mathrm{C}_{29} \mathrm{H}_{61} \mathrm{Cu}_{2} \mathrm{~N}_{8}\right)_{2}\left(\mathrm{O}_{2}\right) \mathrm{Na}\left(\mathrm{ClO}_{4}\right)_{4}\right]^{-}$(right).

As mentioned above, the positive mode Cryo-HR-ESI-MS spectrum shows the dinuclear copper $(\mathrm{I})$ cation $\left[\mathrm{Cu}_{2} \mathrm{~L}^{2}\right]^{+}$as the dominant species, despite thoroughly dioxygen-exposed solutions being injected into the spectrometer. Although it was not possible to completely ensure that these solutions remained at $-80^{\circ} \mathrm{C}$ while being transferred into the instrument, observation of the starting material as opposed to decay products is suggestive of a backward reaction rather than decomposition. The binding of dioxygen in relevant model systems is often found to be reversible, and indeed observed for all other T3 binuclear copper enzymes. ${ }^{14,18}$ The above findings with respect to MS can thus be attributed to the enhanced lability of the dioxygen ligand under the high vacuum gas phase conditions inside the instrument, in contrast to the lack of reversibility observed in solution. The clustering observed in the negative mode spectrum may suppress this dissociation of dioxygen, though this effect is more apparent for $\left[\mathrm{Cu}_{2}{ }_{2} \mathrm{~L}^{3}\left(\mathrm{O}_{2}\right)\right]^{\mathrm{ClO4}}$, and is thus discussed in Section 4.4.3. Whether these clusters reflect the true speciation in solution is difficult to infer, although the above stoichiometry measurements provide strong evidence against formation of a $\mathrm{Cu}_{4}-\mathrm{O}_{2}$ adduct. Nonetheless, the oxygen uptake experiments do not rule out oligomeric $\left[\mathrm{Cu}_{2}{ }_{2} \mathrm{~L}^{2}\left(\mathrm{O}_{2}\right)\right]^{\mathrm{X}}{ }_{n}$ structures in which the ratio between copper and dioxygen is unchanged. In fact, given the dynamic behaviour involving pyrazole dissociation (Section 3.3.3) and tendency toward aggregation (Section 3.3.2) already observed for this system in solution, formation of such adducts is indeed feasible. A comparison with the system supported by ligand $\mathbf{H L}^{3}$ is informative in this regard, and can be found in Section 4.4.5. 


\subsection{Synthesis and characterisation of $\left[\mathrm{Cu}_{2}{ }_{2} \mathrm{~L}^{3}\left(\mathrm{O}_{2}\right)\right]^{\mathrm{X}}$}

\subsubsection{Synthetic Considerations}

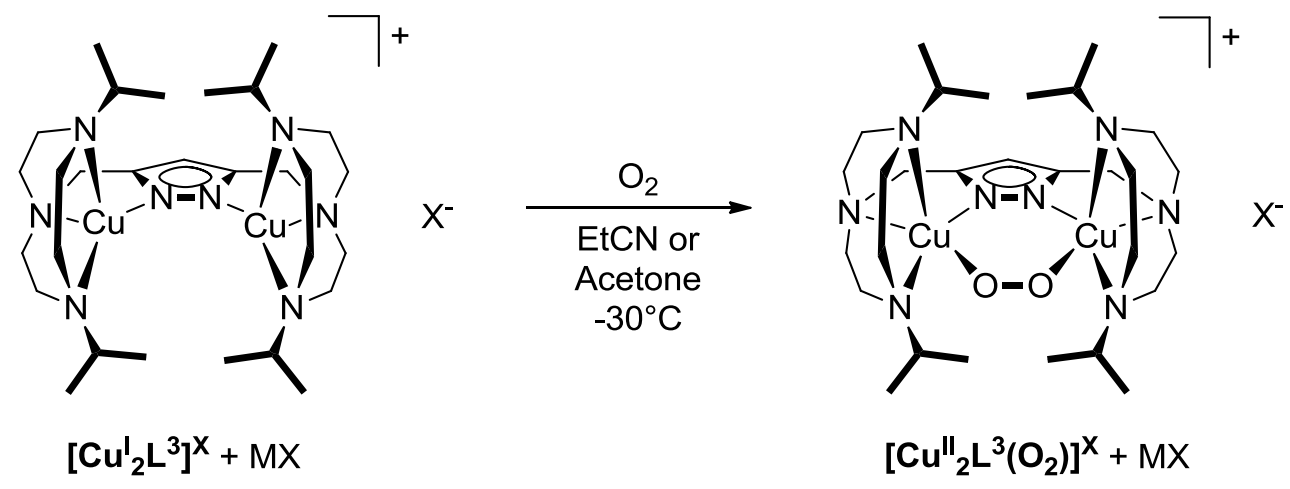

Scheme 4.4: Synthesis of $\left[\mathrm{Cu}_{2}^{\prime \prime} \mathrm{L}_{3}\left(\mathrm{O}_{2}\right)\right]^{\mathrm{X}} . \mathrm{M}=\mathrm{Na}^{+}$or $\mathrm{K}^{+}, \mathrm{X}=\mathrm{PF}_{6}{ }^{-}, \mathrm{ClO}_{4}{ }^{-}$or OTf .

The reaction of $\left[\mathrm{Cu}_{2}^{1} \mathrm{~L}^{3}\right]^{\mathrm{X}}$ with air results in an intensely violet, thermally labile dioxygen adduct, $\left[\mathrm{Cu}_{2}{ }_{2} \mathrm{~L}^{3}\left(\mathrm{O}_{2}\right)\right]^{\mathrm{X}}$ (Scheme 4.4), which even persists for some minutes at room temperature. Preliminary characterisation of this species by UV-vis ${ }^{91}$ and $r R^{90}$ spectroscopies was reported previously, conducted in EtCN and DCM respectively, although in the case of the latter overlap with a solvent band hindered interpretation. The decay of $\left[\mathrm{Cu}_{2}{ }_{2} \mathrm{~L}^{3}\left(\mathbf{O}_{2}\right)\right]^{\mathrm{X}}$ was also investigated, and although the product has not been unambiguously identified, some insight into the reaction was gained by using stopped-flow UV-vis spectroscopy with DCM as the solvent (see Section 6.2 for further details). Decomposition involving chloride abstraction was tentatively suggested. Therefore, taken together with the problem of signal overlap encountered in the $r R$ measurements described above, and the herein observed instability of $\left[\mathrm{Cu}_{2}{ }_{2} \mathbf{L}^{2}\right]^{\mathrm{X}}$ and $\left[\mathrm{Cu}^{\prime \prime}{ }_{2} \mathbf{L}^{2}\left(\mathbf{O}_{2}\right)\right]^{\mathrm{X}}$ in DCM (Sections 3.2.1 and 4.3.1, respectively), the use of this solvent for formation of $\left[\mathrm{Cu}_{2}{ }_{2} \mathrm{~L}^{3}\left(\mathrm{O}_{2}\right)\right]^{\mathrm{X}}$ was avoided in the current work.

Screening of conditions by in situ UV-vis spectroscopy showed that EtCN solutions at $-40{ }^{\circ} \mathrm{C}$ had sufficient long term stability to carry out crystallisation attempts. Initial attempts with $\mathrm{Et}_{2} \mathrm{O}$ layering and $\mathrm{PF}_{6}{ }^{-}, \mathrm{BF}_{4}{ }^{-}, \mathrm{ClO}_{4}{ }^{-}$and $\mathrm{OTf}^{-}$counterions showed promise in the latter two cases, with temperature sensitive purple-black solid material forming. Diffusion of $\mathrm{Et}_{2} \mathrm{O}$ at $-30{ }^{\circ} \mathrm{C}$ resulted in crystalline material which proved to be much more stable but diffracted poorly. Exchange of the EtCN solvent for $\mathrm{Me}_{2} \mathrm{CO}$, followed again by $\mathrm{Et}_{2} \mathrm{O}$ diffusion at $-30{ }^{\circ} \mathrm{C}$, then ultimately resulted in crystalline material of sufficient quality for structural determination by X-ray diffraction (Section 4.4.4). As a consequence, the majority of the characterisation has been performed in both the initially employed EtCN, and then afterwards in $\mathrm{Me}_{2} \mathrm{CO}$. The behaviour of $\left[\mathrm{Cu}_{2}{ }_{2} \mathrm{~L}^{3}\left(\mathrm{O}_{2}\right)\right]^{\mathrm{X}}\left(\mathrm{X}=\mathrm{PF}_{6}{ }^{-}, \mathrm{BF}_{4}{ }^{-}, \mathrm{ClO}_{4}{ }^{-}\right.$and $\left.\mathrm{OTf}^{-}\right)$with all counterions and in both solvents is qualitatively equivalent, as indicated by the experimental data, and any minor deviations from this trend are highlighted where significant. 


\subsubsection{Spectroscopic Characterisation and $\mathrm{O}_{2}$ uptake}

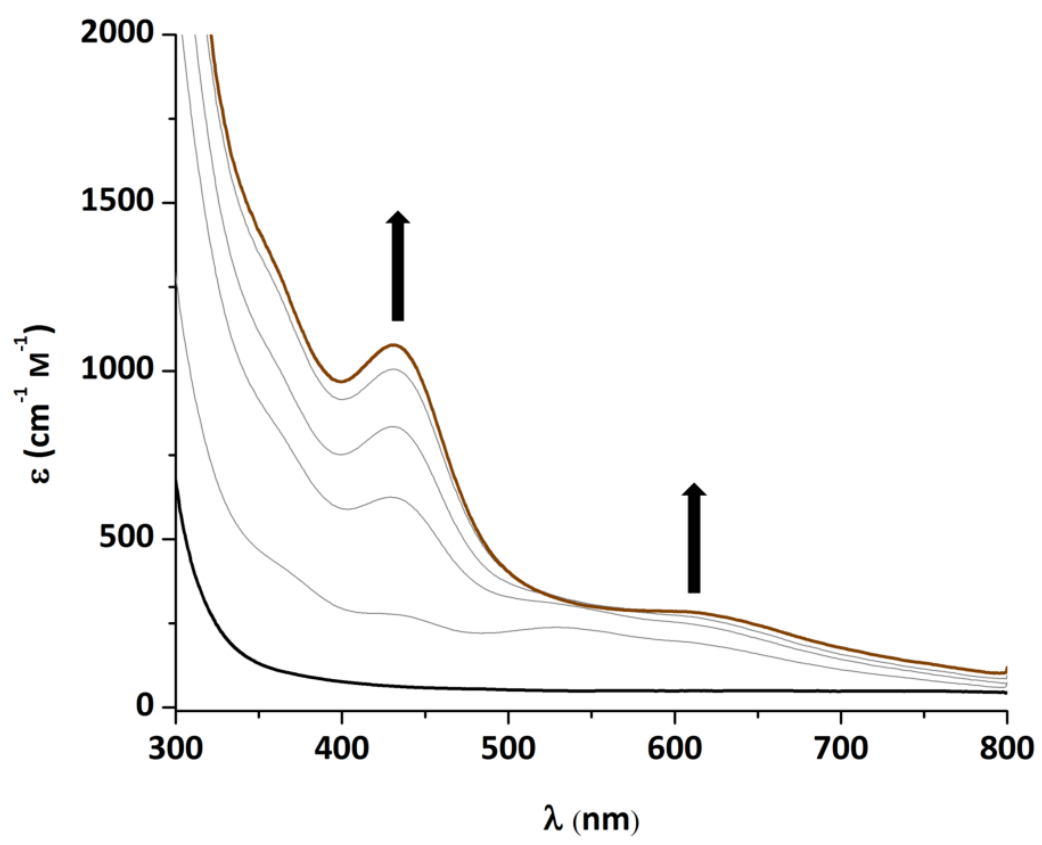

Figure 4.11: UV-vis spectroscopic monitoring of the reaction between $\left[\mathrm{Cu}_{2}{ }_{2} \mathrm{~L}^{3}\right]^{\mathrm{PF} 6}$ and $\mathrm{O}_{2}$ at $-80^{\circ} \mathrm{C}$ in $\mathrm{EtCN}(1 \times$ $\left.10^{-2} \mathrm{M}\right)$. Product yield is unkown, so use of the molar extinction coefficient $(\varepsilon)$ for the vertical axis is tentative.

Initial UV-vis investigation of the reaction between $\left[\mathrm{Cu}_{2}^{\prime} \mathrm{L}^{3}\right]^{\mathrm{X}}$ and $\mathrm{O}_{2}$ in the current work using EtCN and dry dioxygen at $-80^{\circ} \mathrm{C}$ resulted in the formation of brown solutions, with a major absorption band at $430 \mathrm{~nm}\left(\varepsilon \approx 1500 \mathrm{M}^{-1} \mathrm{~cm}^{-1}\right.$, tentative as adduct yield is unknown), and a less intense somewhat variable feature at approximately $600 \mathrm{~nm}$ (Figure 4.11). The appearance of this spectrum somewhat surprisingly corresponds to formation of a superoxo species, resulting from single electron reduction of dioxygen. ${ }^{14,44,61}$ Further analysis by $r R$ spectroscopy at $-80{ }^{\circ} \mathrm{C}$ with an irradiation wavelength of $457 \mathrm{~nm}$ supported this (Figure 4.12), showing oxygen-isotope sensitive bands at 1067 and $2116 \mathrm{~cm}^{-1}\left(\Delta^{18} \mathrm{O}_{2}{ }^{-16} \mathrm{O}_{2}=58,117\right.$ $\mathrm{cm}^{-1}$, respectively). 


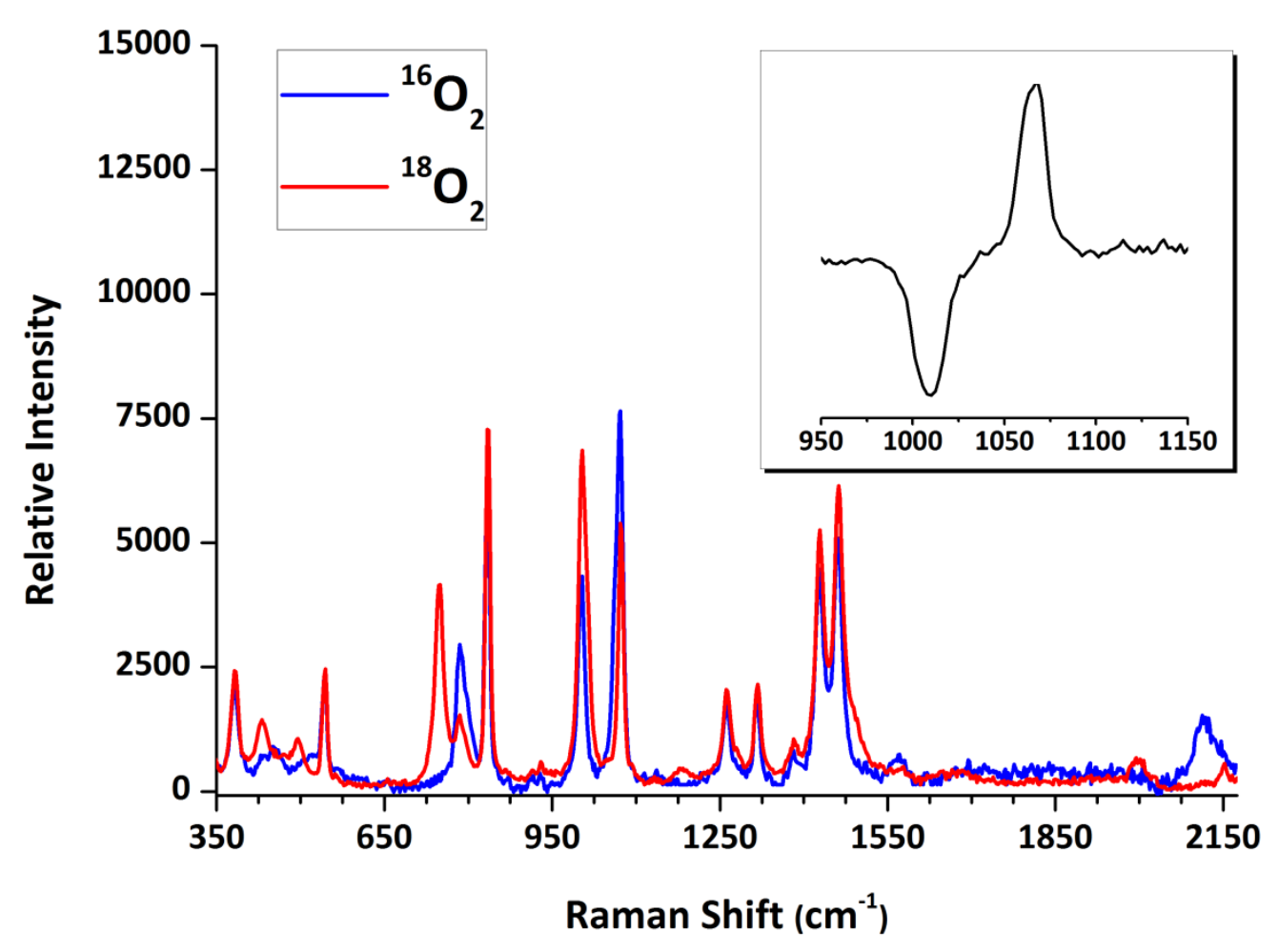

Figure 4.12: Resonance Raman spectrum of the reaction product when $\left[\mathrm{Cu}_{2}^{1}{ }_{2} \mathrm{~L}^{3}\right]^{\mathrm{clo4}}$ is exposed to $\mathrm{O}_{2}$ at $-80^{\circ} \mathrm{C}$ in $\operatorname{EtCN}\left(1 \times 10^{-2} \mathrm{M}, \lambda_{\text {exc }}=457 \mathrm{~nm}\right)$. The copper(II)-superoxo O-O stretching frequency of both the ${ }^{16} \mathrm{O}_{2}$ and ${ }^{18} \mathrm{O}_{2}$ samples overlap with solvent bands. The inset shows a difference spectrum for the region containing these two signals. Isolated solvent bands were used to scale spectra relative to one another.

These signals are in good agreement with the $0-0$ stretching frequency and first overtone of known copper(II)-superoxo species. ${ }^{14,44,61}$ Unambiguous assignment of a band corresponding to the expected $\mathrm{Cu}-\mathrm{O}$ vibration was not possible, due to the presence of an additional oxygen-isotope sensitive feature in the spectrum. This additional band which appears as a broad signal at approximately $790 \mathrm{~cm}^{-1}\left(\Delta^{18} \mathrm{O}_{2}-{ }^{16} \mathrm{O}_{2} \approx 42 \mathrm{~cm}^{-1}\right.$, an overtone is also observed for this signal at $1568 \mathrm{~cm}^{-1}$, but the isotopically labelled signal shows significant overlap with a solvent band) clearly indicates that a copper(II)-peroxo species is also present, thus complicating the assignment of features in the $\mathrm{Cu}-\mathrm{O}$ vibration region. The above observations may explain why solutions of $\left[\mathrm{Cu}^{\prime \prime}{ }_{2} \mathrm{~L}^{3}\left(\mathrm{O}_{2}\right)\right]^{\mathrm{X}}$ formed at $-80{ }^{\circ} \mathrm{C}$ were previously described as violet to violet-brown. ${ }^{90}$ Although the assignment of this species as a ${ }^{\mathrm{S}} \mathrm{S}$ or an ${ }^{\mathrm{E}} \mathbf{S}$ adduct is not easily made on the basis of $\mathrm{rR}$ data, the UV-vis spectrum is most consistent with an ${ }^{\mathrm{E}} \mathrm{S}$ arrangement. 


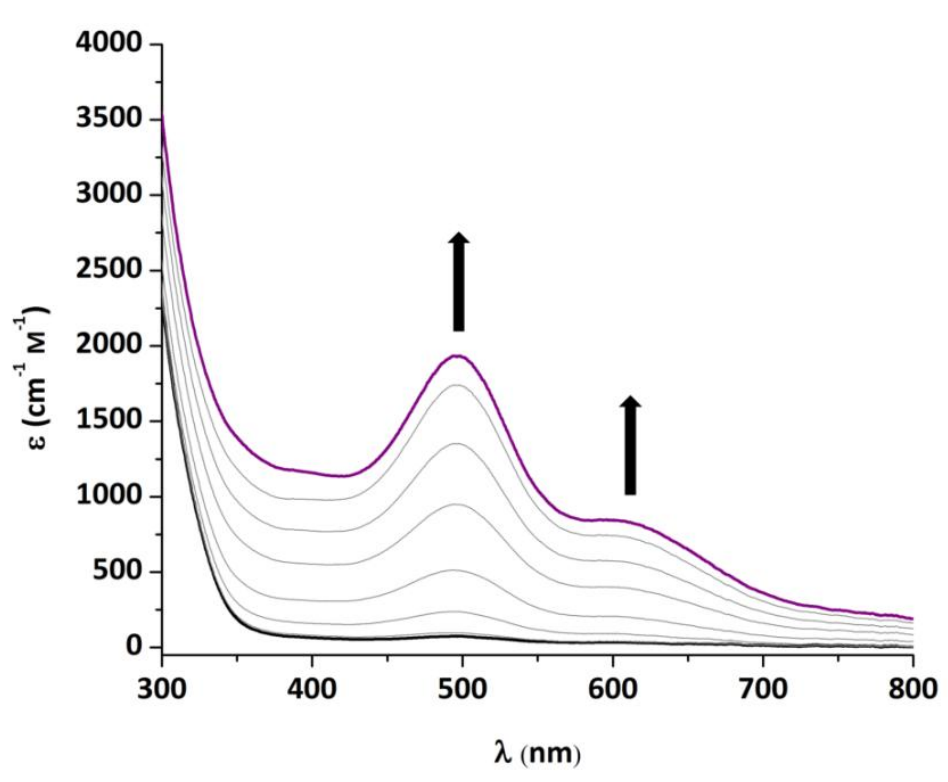

Figure 4.13: UV-vis spectroscopic monitoring of the reaction between $\left[\mathrm{Cu}_{2}{ }_{2} \mathrm{~L}^{3}\right]^{\mathrm{ClO} 4}$ and $\mathrm{O}_{2}$ at $-30{ }^{\circ} \mathrm{C}$ in EtCN $(1 \times$ $\left.10^{-2} \mathrm{M}\right)$. Formation was irreversible under these conditions (See text for details).

Alternatively to the observations described above, UV-vis spectroscopic analysis of $\left[\mathrm{Cu}_{2}{ }_{2} \mathbf{L}^{3}\left(\mathrm{O}_{2}\right)\right]^{\mathrm{X}}$ in EtCN or $\mathrm{Me}{ }_{2} \mathrm{CO}$ at $-30{ }^{\circ} \mathrm{C}$ with dry dioxygen revealed a principal band at 500 $\mathrm{nm}\left(\varepsilon \approx 3000 \mathrm{~m}^{-1} \mathrm{~cm}^{-1}\right.$, varied slightly with $\left[\mathrm{Cu}_{2}^{1} \mathrm{~L}^{3}\right]^{\mathrm{X}}$ batch and solvent), and a broad shoulder at $630 \mathrm{~nm}$ (Figure 4.13). These features are qualitatively similar to those of known dicopper(II) $\mu-\eta^{1}-\eta^{1}$-peroxo ${ }^{\top} \mathbf{P}$ species, although with substantially less intensity. ${ }^{14,155-157}$ No backward reaction was observed upon applying vacuum or purging with argon, with and without warming, indicating that reaction with $\mathrm{O}_{2}$ was irreversible under these conditions. Binding of $\mathrm{O}_{2}$ was found to proceed in acetone in $80-90 \%$ yield per dinuclear copper complex (Figure 4.13), demonstrating the 1:1 stoichiometry of the reaction between dinuclear $\left[\mathrm{Cu}_{2}^{\prime} \mathrm{L}^{3}\right]^{\mathrm{X}}$ and dioxygen.

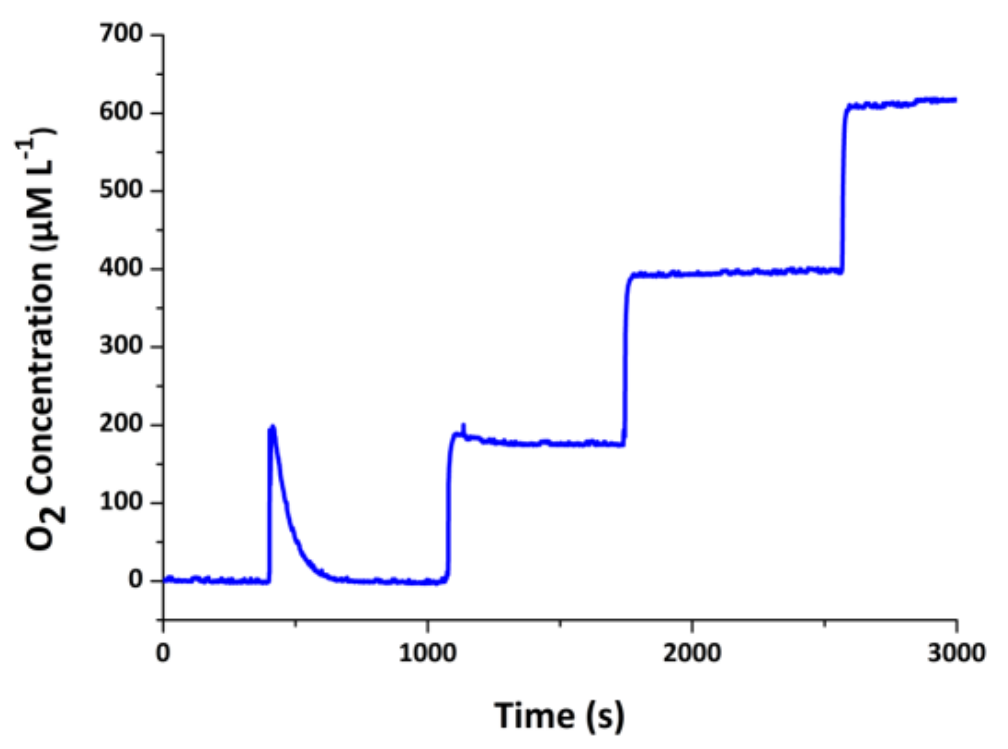

Figure 4.14: Oxygen uptake at $-30{ }^{\circ} \mathrm{C}$ by $\left[\mathrm{Cu}_{2}^{1} \mathrm{~L}^{3}\right]^{\mathrm{OTf}}$ in $\mathrm{Me}_{2} \mathrm{CO}\left(1 \times 10^{-2} \mathrm{M}\right)$. Each injection of oxygen is equal to one equivalent of complex (dinuclear unit). 
Further evidence confirming the formation of such a species, $\left[\mathrm{Cu}^{\prime \prime}{ }_{2} \mathbf{L}^{3}\left(\mathrm{O}_{2}\right)\right]^{\mathrm{X}}$, was obtained by rR spectroscopy with a laser excitation of $633 \mathrm{~nm}$ (Figure 4.15). EtCN solutions of $\left[\mathrm{Cu}_{2}{ }_{2} \mathbf{L}^{3}\left(\mathbf{O}_{2}\right)\right]^{\text {OTf }}$ cooled to $-30{ }^{\circ} \mathrm{C}$ showed three oxygen isotope sensitive features at approximately 445, 796 and $1574 \mathrm{~cm}^{-1}\left(\Delta^{16} \mathrm{O}_{2}{ }^{18} \mathrm{O}_{2}=15,41\right.$ and $\approx 81 \mathrm{~cm}^{-1}$ respectively $)$, characteristic of an end-on peroxide moiety bridging two copper(II) ions. ${ }^{14,32,46,156,162}$ The band at $445 \mathrm{~cm}^{-1}$ is shifted towards significantly lower energy than the typical literature values reported for $\mathrm{Cu}-\mathrm{O}$ stretching frequencies, and the signal corresponding to the $\mathrm{O}-\mathrm{O}$ stretch at $796 \mathrm{~cm}^{-1}$ is made up of two closely spaced peaks at 786 and $805 \mathrm{~cm}^{-1}$, consistent with the data previously reported, but unexplained, for DCM. Upon reaction with pure ${ }^{18} \mathrm{O}_{2}$ this signal collapses into a single band at $755 \mathrm{~cm}^{-1}$, which provides strong evidence for the presence of a single species in solution. Occurrence of the two bands in the ${ }^{16} \mathrm{O}_{2}$ spectrum can therefore be attributed to Fermi resonance, which has been previously observed in related systems. ${ }^{59,155,166-170}$ The remaining isotope sensitive signal at $1574 \mathrm{~cm}^{-1}$ can be attributed to the first overtone of the fundamental $\mathrm{O}-\mathrm{O}$ mode, though the corresponding peak in the ${ }^{18} \mathrm{O}_{2}$ is partially obscured by solvent overlap. Measurement in $\mathrm{Me}_{2} \mathrm{CO}$ gives the same qualitative result, with slight variation in the numerical values, although it is somewhat more complicated by overlap of the $\mathrm{O}-\mathrm{O}$ band with a solvent signal. Further investigation into the intra- or inter-molecular nature of $\left[\mathrm{Cu}_{2}{ }_{2} \mathrm{~L}^{3}\left(\mathrm{O}_{2}\right)\right]^{\mathrm{X}}$ was performed with MS.

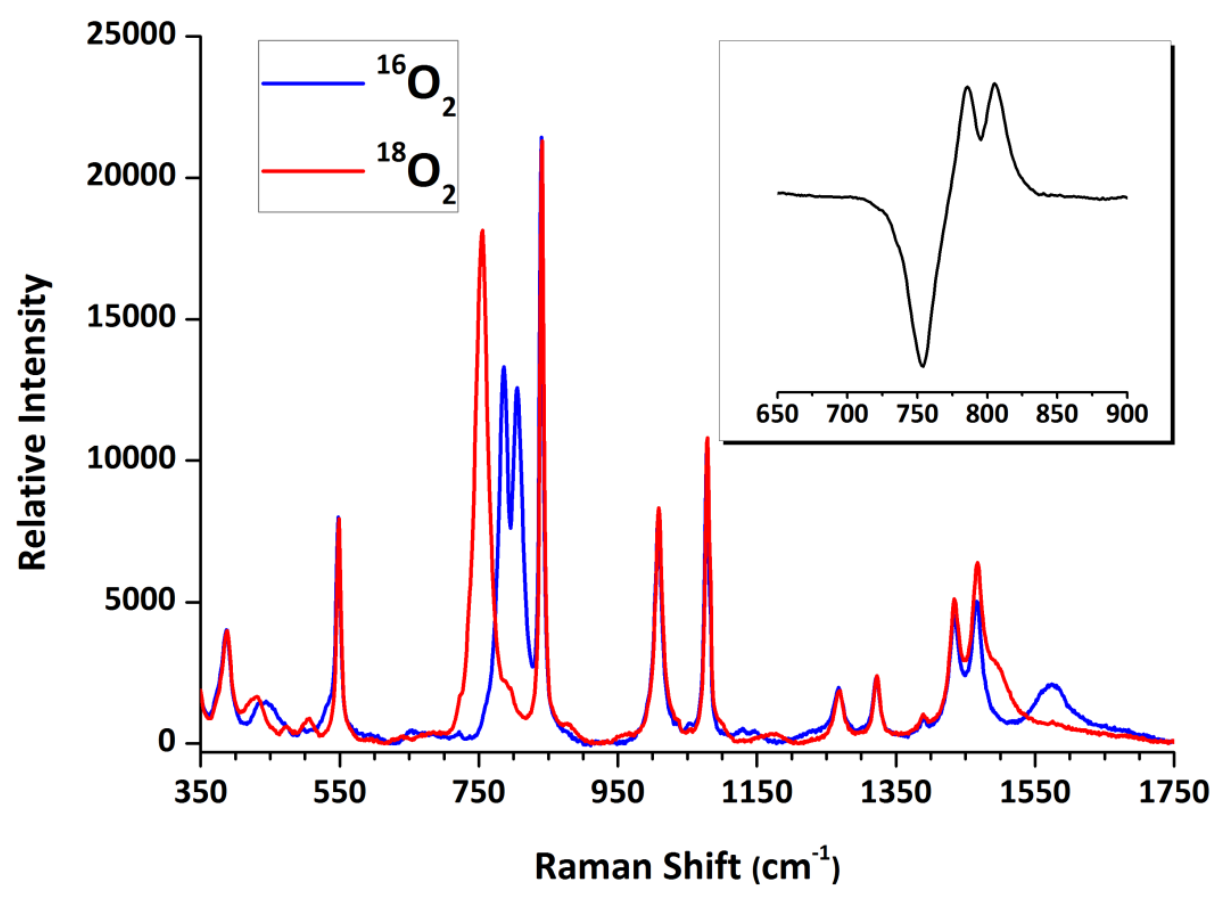

Figure 4.15: Resonance Raman spectrum of the reaction product when $\left[\mathrm{Cu}_{2}^{1} \mathrm{~L}^{3}\right]^{\mathrm{OTf}}$ is exposed to $\mathrm{O}_{2}$ at $-30^{\circ} \mathrm{C}$ in $\operatorname{EtCN}\left(1 \times 10^{-2} \mathrm{M}, \lambda_{\text {exc }}=633 \mathrm{~nm}\right)$. The inset shows a difference spectrum for the region containing the $\mathrm{O}-\mathrm{O}$ stretching frequency, showing the Fermi doublet in the ${ }^{16} \mathrm{O}_{2}$ case which disppears when the product is generated with ${ }^{18} \mathrm{O}_{2}$. Isolated solvent bands were used to scale spectra relative to one another. 


\subsubsection{Mass Spectrometry}

The low-resolution ESI-MS spectrum of $\left[\mathrm{Cu}_{2}{ }_{2} \mathrm{~L}^{3}\left(\mathbf{O}_{2}\right)\right]^{\mathrm{ClO} 4}$, generated in EtCN at $-30{ }^{\circ} \mathrm{C}$ with dry $\mathrm{O}_{2}$ and injected rapidly by hand after dilution with cold MeCN, shows a dominant signal corresponding to $\left[\left(\mathrm{Cu}_{2}{ }_{2} \mathrm{~L}^{3}\right)\right]^{+}(\mathrm{m} / \mathrm{z}=643.5)$. The major additional species with variable relative intensities could be identified as $\left[\left(\mathrm{Cu}_{2}{ }_{2} \mathrm{~L}^{3}\right)(\mathrm{OH})\right]^{2+}(\mathrm{m} / z=330.1)$ and $\left[\left(\mathrm{Cu}^{\prime \prime} \mathrm{L}^{3}\right)(\mathrm{OH})\left(\mathrm{ClO}_{4}\right)\right]^{+}$ $(\mathrm{m} / \mathrm{z}=761.4)$. Once again, as indicated by their copper(II) oxidation state, both likely represent decomposition products derived from reaction with dioxygen or residual water. The HR Cryo-ESI-MS spectrum measured at $-80^{\circ} \mathrm{C}$ in EtCN is similar, with $\left[\mathrm{Cu}^{\prime \prime}{ }_{2} \mathrm{~L}^{3}\left(\mathbf{O}_{2}\right)\right]^{\mathrm{X}}$ also generated at $-30{ }^{\circ} \mathrm{C}$ and injected rapidly by hand. Although dominated by the $\left[\mathrm{Cu}_{2}{ }_{2} \mathrm{~L}^{2}\right]^{+}$ molecular ion $(\mathrm{m} / \mathrm{z}=643.328)$ the spectrum also shows an appreciable amount of $\left[\left(\mathrm{Cu}_{2}^{\prime} \mathrm{L}^{3}\right)(\mathrm{Cu})(\mathrm{CN})\right]^{+}(\mathrm{m} / \mathrm{z}=732.262)$, which appears to overlap with an additional species in this case, likely $\left[\left(\mathrm{Cu}_{2}{ }_{2} \mathrm{~L}^{3}\right)\left(\mathrm{Cu} \mathrm{U}^{\prime \prime}\right)(\mathrm{H})(\mathrm{CN})\right]^{+}(\mathrm{m} / z=733.270)$. These findings are rather disappointing with respect to observation of the dioxygen adduct $\left[\mathrm{Cu}^{1{ }^{1}} \mathrm{~L}^{3}\left(\mathbf{O}_{2}\right)\right]^{\mathrm{X}}$, and while monitoring anions with low resolution ESI-MS showed no remarkable improvement in this regard, the Cryo-ESI-MS spectrum measured in negative mode granted far more interesting results.

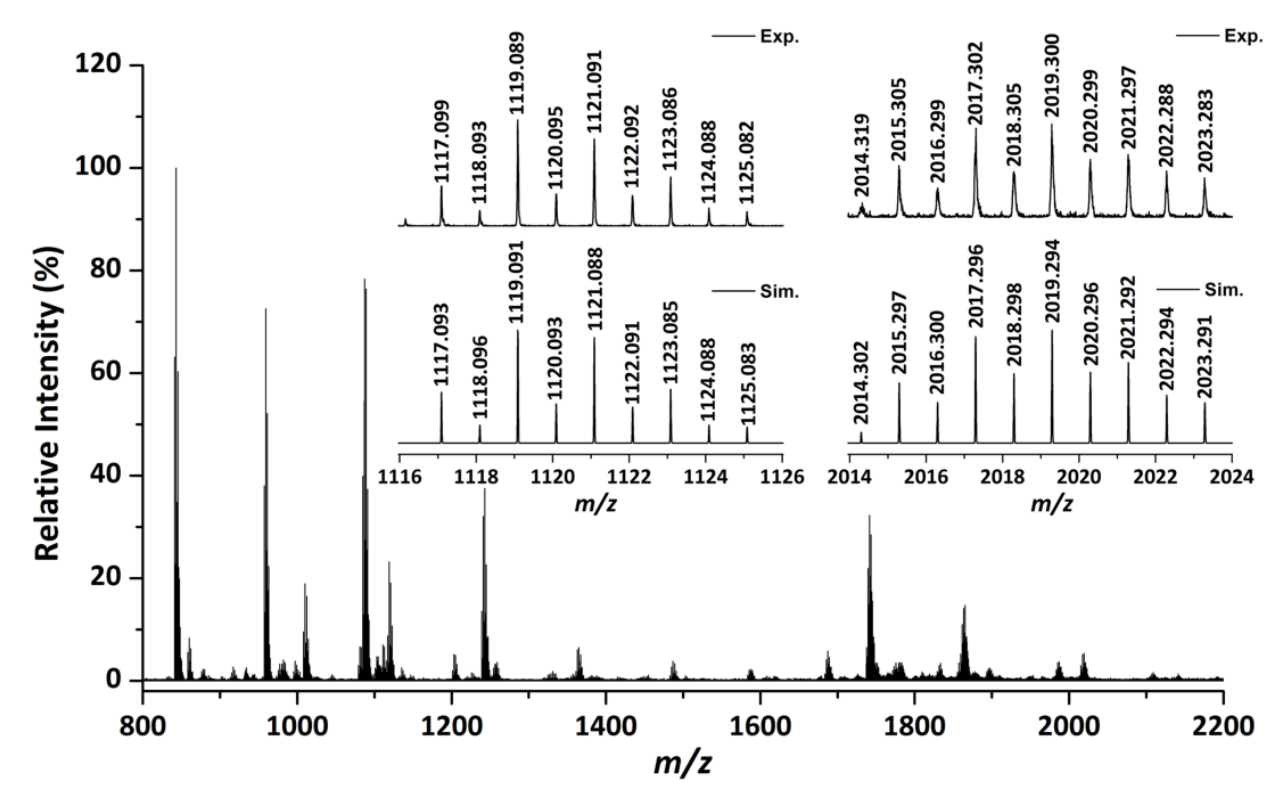

Figure 4.16: Negative mode HR-Cryo-ESI-MS spectrum of $\left[\mathrm{Cu}_{2}^{1} \mathrm{~L}^{3}\right]^{\mathrm{ClO} 4}$ in EtCN. The insets show experimental and simulated isotopic distribution patterns for $\left[\mathrm{C}_{29} \mathrm{H}_{57} \mathrm{Cu}_{2} \mathrm{~N}_{8}\left(\mathrm{O}_{2}\right) \mathrm{Na}_{2}\left(\mathrm{ClO}_{4}\right)_{4}\right]^{-}$(left) and

$\left[\left(\mathrm{C}_{29} \mathrm{H}_{57} \mathrm{Cu}_{2} \mathrm{~N}_{8}\right)_{2}\left(\mathrm{O}_{2}\right)_{2} \mathrm{Na}_{3}\left(\mathrm{ClO}_{4}\right)_{6}\right]^{-}$(right). 


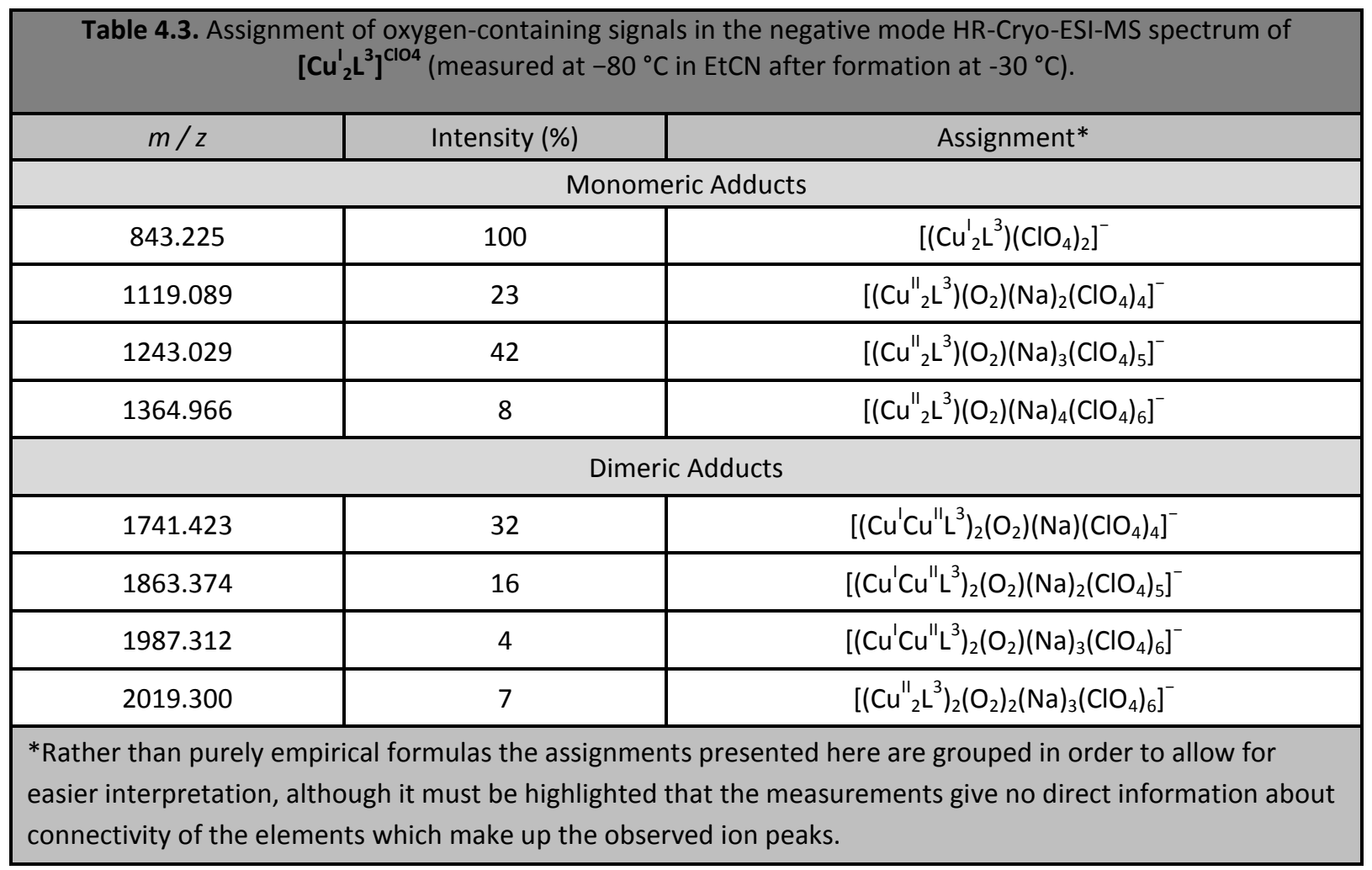

The negative mode Cryo-ESI-MS spectrum of $\left[\mathrm{Cu}_{2}{ }_{2} \mathrm{~L}^{3}\right]^{\mathrm{ClO} 4}$ was dominated by various dinuclear monomeric perchlorate adducts, the anions being required to impart an overall negative charge (Section 3.4.2). Although not discussed in the previous chapter due to their greater relevance to the current section, several additional signals were also observed in the negative mode Cryo-ESI-MS spectrum of $\left[\mathrm{Cu}_{2}{ }_{2} \mathrm{~L}^{3}\right]^{\mathrm{ClO} 4}$. These are consistent with perchlorate aggregates additionally containing dioxygen, such as $\left[\left(\mathrm{Cu}_{2}{ }_{2} \mathrm{~L}^{3}\right)\left(\mathrm{O}_{2}\right)(\mathrm{Na})_{2}\left(\mathrm{ClO}_{4}\right)_{4}\right]^{-}(\mathrm{m} / \mathrm{z}=$ 1119.089) and the related anions with one or two additional $\mathrm{NaClO}_{4}$ units (Table 4.3). Furthermore, at significantly higher masses a series of signals was present which can be identified as the corresponding tetranuclear dioxygen adducts, including $\left[\left(\mathrm{Cu}^{\prime} \mathrm{Cu}_{2}{ }_{2} \mathrm{~L}^{3}\right)_{2}\left(\mathrm{O}_{2}\right)(\mathrm{Na})\left(\mathrm{ClO}_{4}\right)_{4}\right]^{-}(\mathrm{m} / \mathrm{z}=1741.423)$ and the analogous anions with one or two additional $\mathrm{NaClO}_{4}$ units, as well as a fully dimeric species incorporating two dioxygen molecules, $\left[\left(\mathrm{Cu}_{2}{ }_{2} \mathrm{~L}^{3}\right)_{2}\left(\mathrm{O}_{2}\right)_{2}(\mathrm{Na})_{3}\left(\mathrm{ClO}_{4}\right)_{6}\right]^{-}(\mathrm{m} / \mathrm{z}=2019.300)$. 


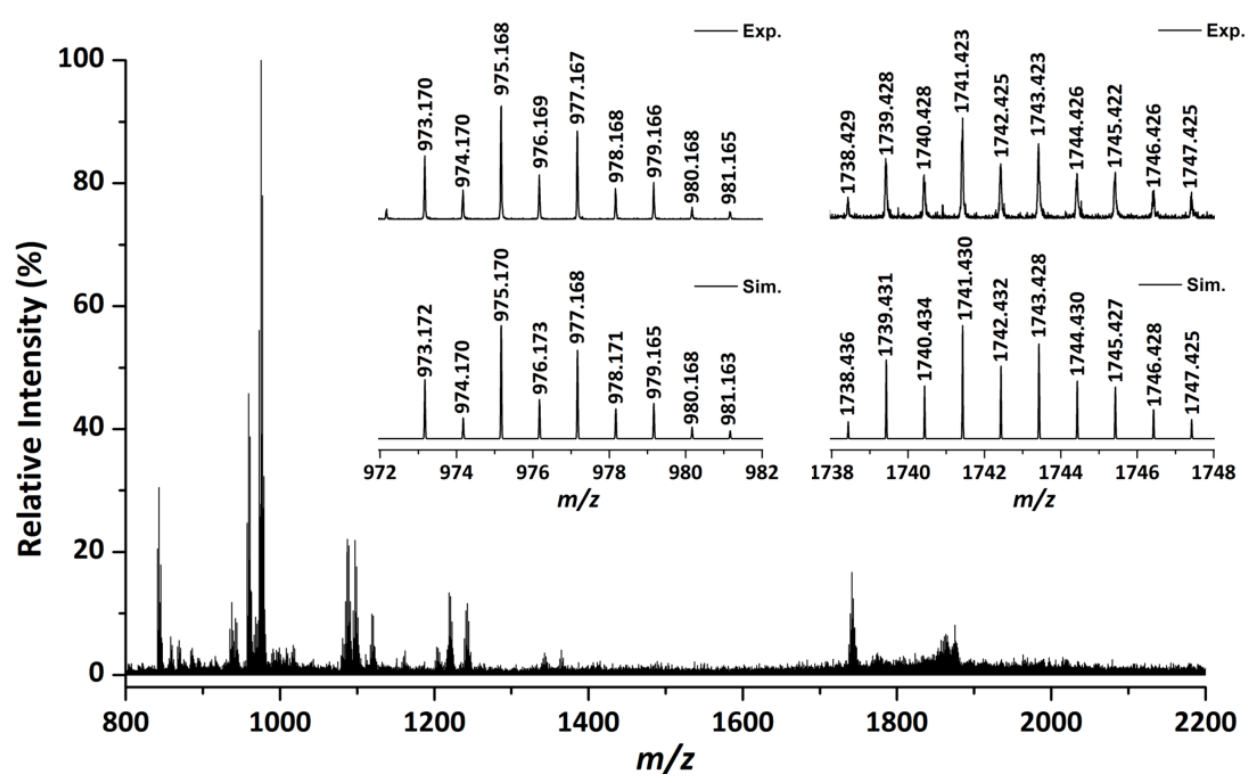

Figure 4.17: Negative mode HR-Cryo-ESI-MS spectrum of $\left[\mathrm{Cu}_{2}{ }_{2} \mathrm{~L}^{3}\left(\mathrm{O}_{2}\right)\right]^{\mathrm{ClO}}$ in EtCN. The insets show experimental and simulated isotopic distribution patterns for $\left[\mathrm{C}_{29} \mathrm{H}_{57} \mathrm{Cu}_{2} \mathrm{~N}_{8}\left(\mathrm{O}_{2}\right)_{2} \mathrm{H}\left(\mathrm{ClO}_{4}\right)_{3}\right]^{-}$(left) and $\left[\left(\mathrm{C}_{29} \mathrm{H}_{57} \mathrm{Cu}_{2} \mathrm{~N}_{8}\right)_{2}\left(\mathrm{O}_{2}\right) \mathrm{Na}\left(\mathrm{ClO}_{4}\right)_{4}\right]^{-}$(right).

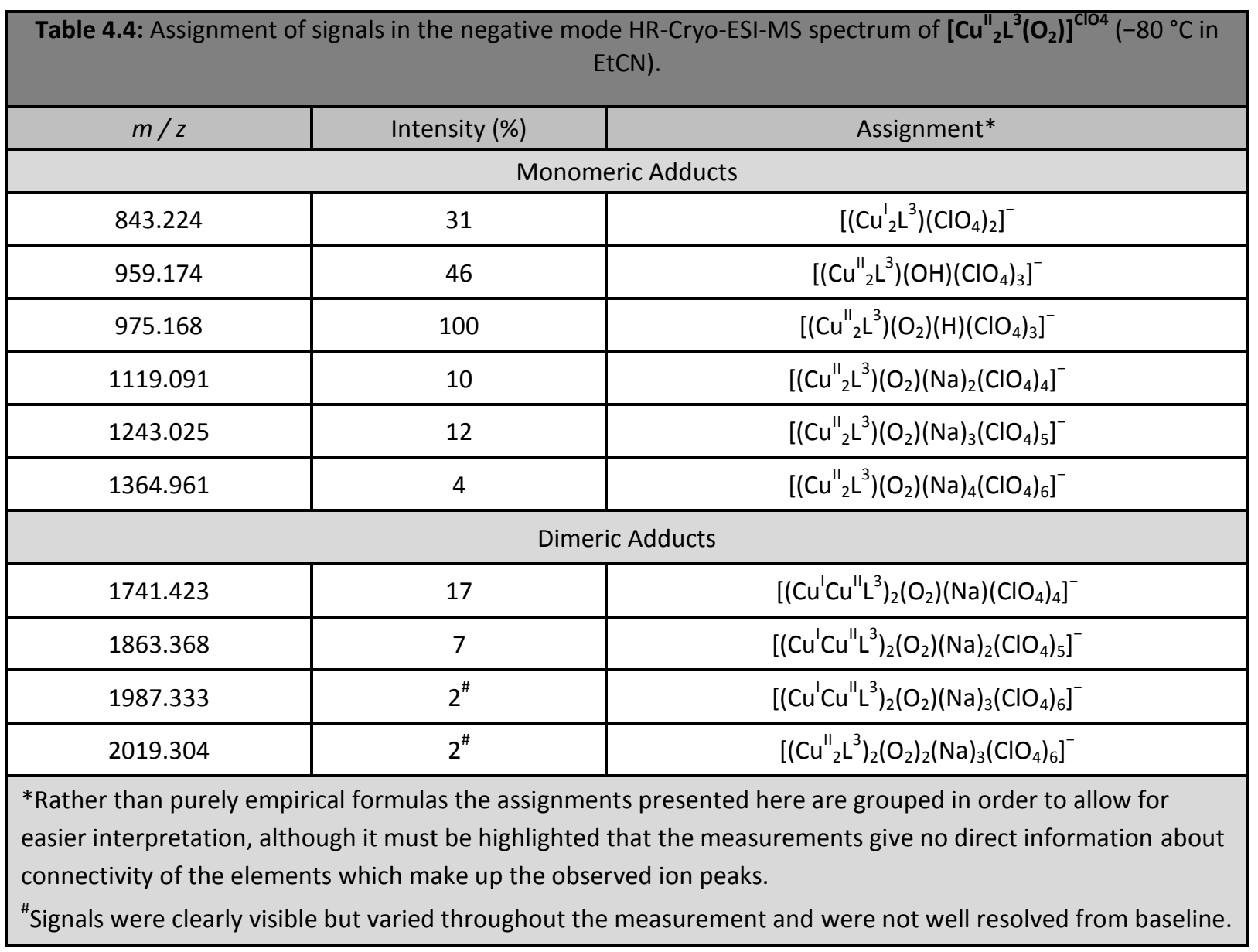


While the majority of these species were also observed in varying amounts when $\left[\mathrm{Cu}_{2}{ }_{2} \mathrm{~L}^{3}\left(\mathrm{O}_{2}\right)\right]^{\mathrm{ClO4}}$ was specifically targeted through reaction of $\left[\mathrm{Cu}_{2}^{\prime} \mathrm{L}^{3}\right]^{\mathrm{ClO4}}$ with dry dioxygen, a new signal became the most prominent when solutions were injected rapidly by hand (Table 4.4). The isotopic distribution pattern of this peak set is consistent with that calculated for the dinuclear dioxygen adduct $\left[\left(\mathrm{Cu}_{2}{ }_{2} \mathrm{~L}^{3}\right)\left(\mathrm{O}_{2}\right)(\mathrm{H})\left(\mathrm{ClO}_{4}\right)_{3}\right]^{-}(\mathrm{m} / z=975.168)$. Substituting the standard dioxygen gas used in generating $\left[\mathrm{Cu}_{2}{ }_{2} \mathrm{~L}^{3}\left(\mathrm{O}_{2}\right)\right]^{\mathrm{ClO} 4}$ for isotopically labelled ${ }^{18} \mathrm{O}_{2}$ with sample treatment otherwise identical gave rise to a spectrum dominated by $\left[\left(\mathrm{Cu}_{2}{ }_{2} \mathrm{~L}^{3}\right)\left({ }^{18} \mathrm{O}_{2}\right)(\mathrm{H})\left(\mathrm{ClO}_{4}\right)_{3}\right]^{-} \quad(\mathrm{m} / \mathrm{z}=979.181)$, providing confirmation of the proposed formulation (Figure 4.18). The remaining dioxygen adduct assignments discussed above were likewise confirmed, including that of the tetranuclear dimer, which shifted 8 Da upon labelling to give $\left[\left(\mathrm{Cu}_{2}{ }_{2} \mathrm{~L}^{3}\right)_{2}\left({ }^{18} \mathrm{O}_{2}\right)_{2}(\mathrm{Na})\left(\mathrm{ClO}_{4}\right)_{4}\right]^{-}(\mathrm{m} / z=2027.322)$. Interestingly, the $\left[\left(\mathrm{Cu}_{2}{ }_{2} \mathrm{~L}^{3}\right)(\mathrm{OH})\left(\mathrm{ClO}_{4}\right)_{3}\right]^{-}(\mathrm{m} / z=959.174)$ anion present in all cases showed no discernible isotopic enhancement whatsoever, as was the case for the analogous $\left[\left(\mathrm{Cu}_{2}{ }_{2} \mathrm{~L}^{2}\right)(\mathrm{OH})\left(\mathrm{ClO}_{4}\right)_{3}\right]^{-}$

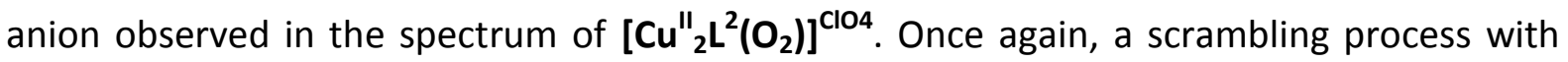
oxygen-16 water should be suppressed given that measurements were made at low temperatures and samples injected directly by hand. Therefore, the lack of isotope incorporation with respect to the $\left[\left(\mathrm{Cu}_{2}{ }_{2} \mathrm{~L}^{3}\right)(\mathrm{OH})\left(\mathrm{ClO}_{4}\right)_{3}\right]^{-}$signal suggests that the hydroxide moiety is derived from adventitious water.
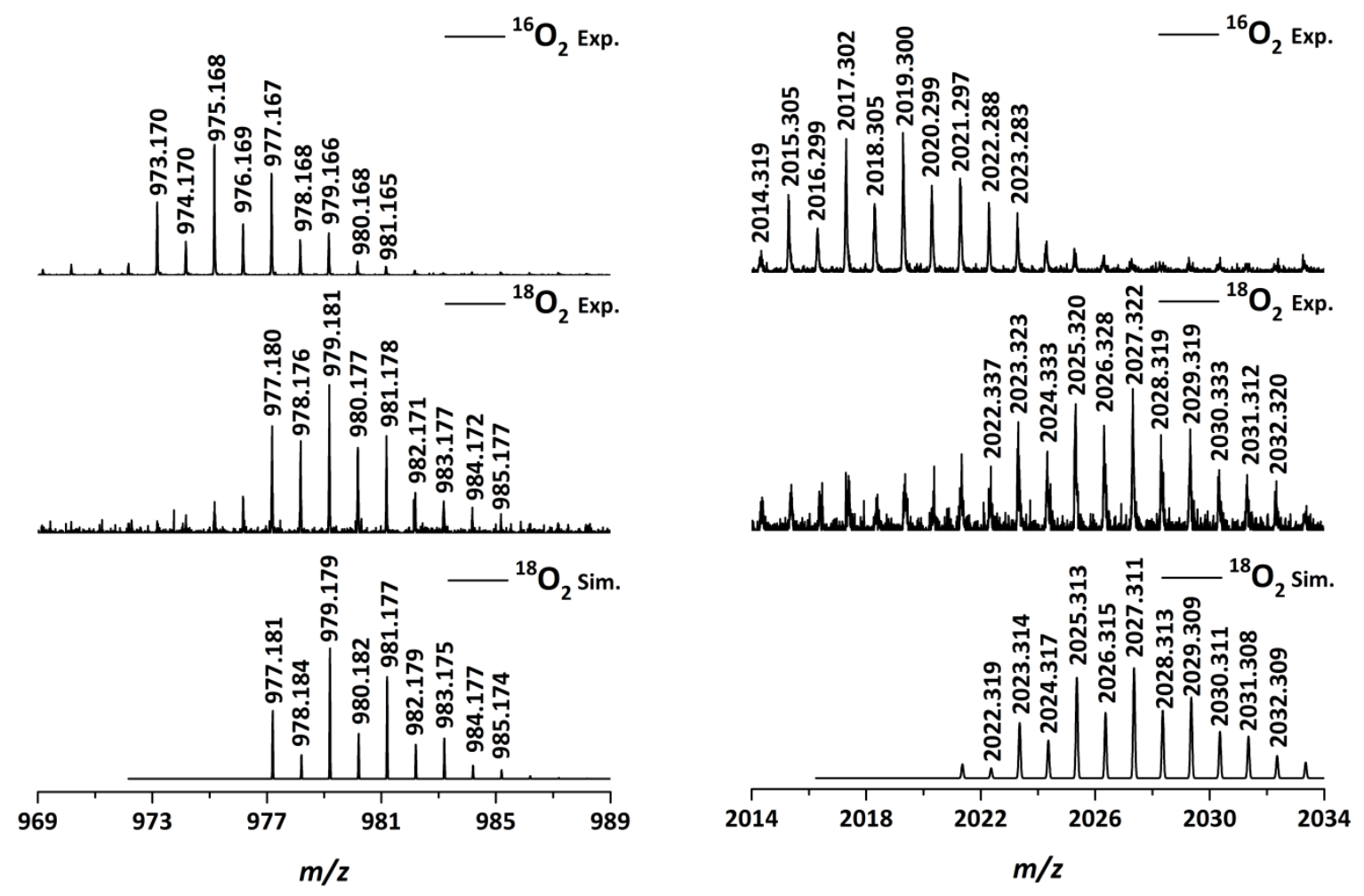

Figure 4.18: Experimental $\left({ }^{16} \mathrm{O}_{2}\right.$ and $\left.{ }^{18} \mathrm{O}_{2}\right)$ and simulated $\left({ }^{18} \mathrm{O}_{2}\right)$ isotopic distribution patterns for $\left[\mathrm{C}_{29} \mathrm{H}_{57} \mathrm{Cu}_{2} \mathrm{~N}_{8}\left(\mathrm{O}_{2}\right)_{2} \mathrm{H}\left(\mathrm{ClO}_{4}\right)_{3}\right]^{-}$(left) and $\left[\left(\mathrm{C}_{29} \mathrm{H}_{57} \mathrm{Cu}_{2} \mathrm{~N}_{8}\right)_{2}\left(\mathrm{O}_{2}\right)_{2} \mathrm{Na}_{3}\left(\mathrm{ClO}_{4}\right)_{6}\right]^{-}$(right). 
Despite visibly violet solutions being injected into the spectrometer, the positive mode CryoHR-ESI-MS spectrum once again showed the corresponding dinuclear copper(I) cation $\left[\mathrm{Cu}_{2} \mathrm{~L}^{3}\right]^{+}$as the major species, similarly to the findings for complex $\left[\mathrm{Cu}_{2}{ }_{2} \mathrm{~L}^{2}\left(\mathrm{O}_{2}\right)\right]^{\mathrm{X}}($ Section 4.3.3). This result is in agreement with the facile dissociation of dioxygen proposed for $\left[\mathrm{Cu}_{2}{ }_{2} \mathrm{~L}^{2}\left(\mathrm{O}_{2}\right)\right]^{\mathrm{X}}$. It furthermore contrasts with the irreversibility of dioxygen binding observed for $\left[\mathrm{Cu}_{2}{ }_{2} \mathrm{~L}^{3}\left(\mathrm{O}_{2}\right)\right]^{\mathrm{X}}$ in solution, likely due to the high vacuum and gas phase conditions inside the MS device. In comparison to the negative mode Cryo-HR-ESI-MS of $\left[\mathrm{Cu}^{1{ }^{\prime \prime}} \mathrm{L}^{2}\left(\mathbf{O}_{2}\right)\right]^{\mathrm{ClO}}$, $\left[\mathrm{Cu}_{2}{ }_{2} \mathrm{~L}^{3}\left(\mathrm{O}_{2}\right)\right]^{\mathrm{ClO} 4}$ shows a much greater proportion of dioxygen adducts, though in no case are any of these species observed without the presence of an additional cation, either a proton or sodium ion. The extra cation present in these species may hinder the dissociation of dioxygen, thereby stabilising the adducts sufficiently to allow for their observation. Whether this cation or the perchlorate anions also often seen associated contribute to the stability of the adducts is not easily assessed, especially given these interactions may merely be an artefact of the Cryo-ESI-MS measurements. Indeed, although $\mathrm{NaClO}_{4}$ clusters commonly appear as repeating units in ESI-MS analyses, they have only been observed in negative mode. ${ }^{171}$ On the other hand, literature exists to indicate that sodium and perchlorate ion pair to some extent in both organic ${ }^{144,171,172}$ and aqueous solvent systems. ${ }^{173,174}$ Evidence that these interactions are not entirely limited to the Cryo-ESI-MS measurements in the current case is provided by determination of the solid state structures (Sections 4.4 .4 and 4.4.6).

It must be further highlighted that the above formulations, including those for $\left[\mathrm{Cu}_{2}{ }_{2} \mathrm{~L}^{2}\left(\mathrm{O}_{2}\right)\right]^{\mathrm{X}}$ in Section 3.3.2, are to some extent ambiguous with respect to the oxidation state of the copper ions and the dioxygen derived ligands. This is especially true in the case of the dimeric species with a single $\mathrm{O}_{2}$ unit. While their assignment as $\mathrm{Cu}_{2}{ }_{2} \mathrm{Cu}_{2}{ }_{2}{ }^{-}-\left(\mathrm{O}_{2}{ }^{2-}\right)$ adducts is most consistent with the spectroscopic data described, isoelectronic $\mathrm{Cu}_{4}{ }_{4}-\left(\mathrm{O}^{2-}\right)_{2}$ configurations are possible. Literature precedent exists for copper-complex-mediated reduction of $\mathrm{O}_{2}$ to the corresponding $\mathrm{O}^{2-}$ ligands. ${ }^{122}$ Furthermore, a related di-iron(II) pyrazole-bridged complex can analogously reduce dioxygen through dimerisation, to form an overall tetranuclear iron(III)-bis( $\mu$-oxo) species framework supported by two multidentate pyrazole scaffolds. ${ }^{175}$ In fact, a complex cation which may result from complete cleavage of the dioxygen bond in $\left[\mathrm{Cu}^{\prime \prime} \mathrm{L}^{3}\left(\mathrm{O}_{2}\right)\right]^{\mathrm{X}}$ is reported in the current work (Section 6.2.1), though there is uncertainty about the source of the oxide-level ligands due to the possibility of exchange with oxygen-16 containing solvent or adventitious water. Although the isotopic labelling performed in the above Cryo-ESI-MS experiments clearly shows that both oxygen atoms in the relevant products originate from ${ }^{18} \mathrm{O}_{2}$, the formal oxidation states of the individual components remain unclear. 
Precise quantification is generally not possible in MS measurements without the use of an internal standard. ${ }^{176}$ However, it is clear that the dimeric tetranuclear species described above are quite prevalent when $\left[\mathrm{Cu}^{\prime \prime} \mathbf{L}^{2}\left(\mathbf{O}_{2}\right)\right]^{\mathrm{X}}$ is formed under limiting conditions by reaction of $\left[\mathrm{Cu}_{2}^{1} \mathrm{~L}^{3}\right]^{\mathrm{X}}$ with residual $\mathrm{O}_{2}$, but that monomeric species dominate when an excess of dioxygen is provided. In fact, the oxygen uptake experiments described above which indicate a 1:1 stoichiometry suggest these particular tetranuclear adducts are not present in appreciable amounts in the presence of even one equivalent of $\mathrm{O}_{2}$. On the other hand, the fully dimeric tetranuclear species containing two dioxygen units cannot be ruled out on the basis of the oxygen uptake experiments, and is particularly interesting considering the structures found in the solid state, discussed below. 


\subsubsection{Crystallographic Structural Determination of $\left[\mathrm{Cu}_{2}{ }_{2} \mathrm{~L}^{3}\left(\mathrm{O}_{2}\right)\right]^{\mathrm{X}}$}

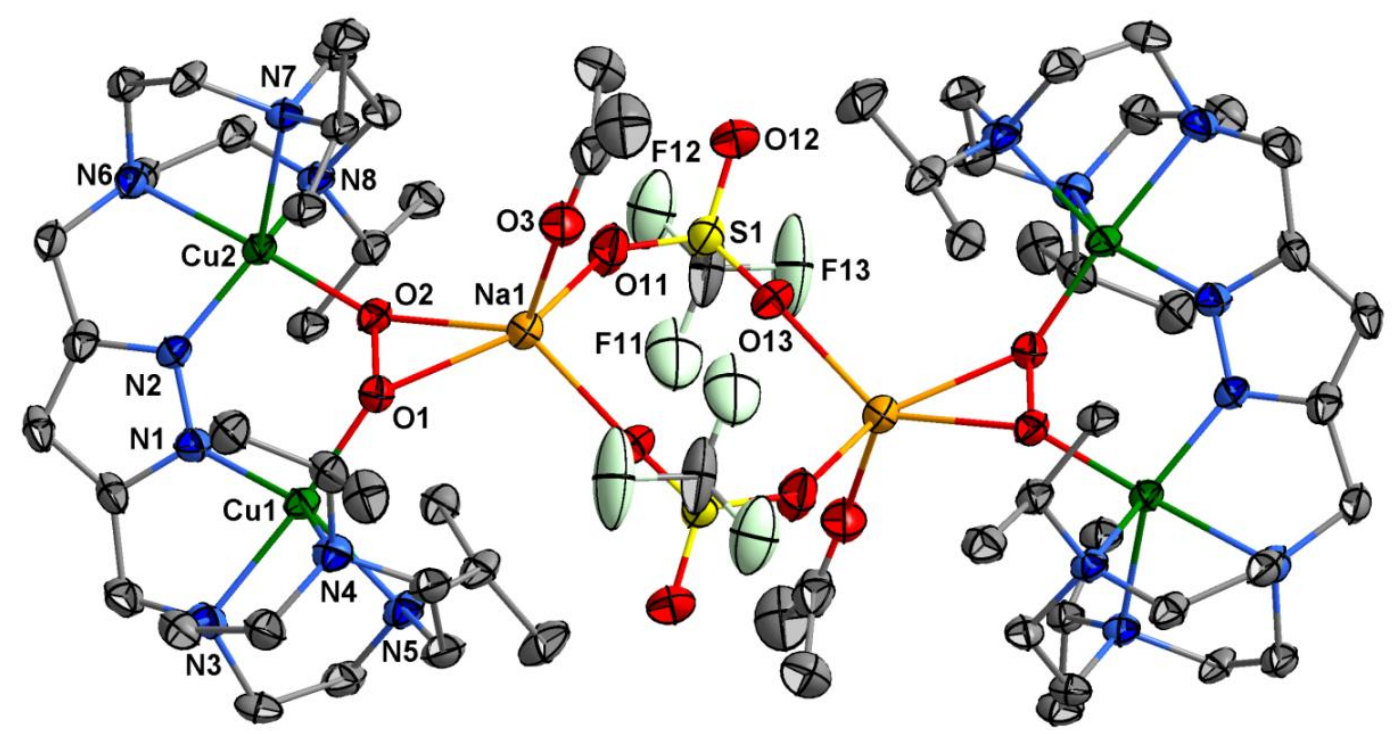

Figure 4.19: Molecular structure of $\left[\mathrm{Cu}_{2}{ }_{2} \mathrm{~L}^{3}\left(\mathrm{O}_{2}\right)\right]^{\text {OTf }} \cdot$ NNaOTf. Thermal displacement ellipsoids are shown at $30 \%$ probability. Hydrogen atoms and non-coordinated triflate counteranions have been omitted for clarity.

Symmetry transformation used to generate equivalent atoms: $1-x, 1-y, 1-z$.

\begin{tabular}{|c|c|c|c|c|c|}
\multicolumn{6}{|c|}{ Table 4.5: Selected bond lengths (Å) and angles $\left({ }^{\circ}\right)$ for $\left[\mathrm{Cu}_{2}{ }_{2} \mathrm{~L}^{3}\left(\mathrm{O}_{2}\right)\right]^{\text {OTf }} \cdot$ NaOTf. } \\
\hline Atoms & Bond Lengths & Atoms & Angles & Atoms & Angles \\
\hline Cu1-O1 & $1.899(5)$ & O1-Cu1-N1 & $98.9(2)$ & N2-Cu2-O2 & $98.5(2)$ \\
\hline Cu1-N1 & $1.916(7)$ & O1-Cu1-N3 & $171.2(2)$ & N2-Cu2-N6 & $80.1(3)$ \\
\hline Cu1-N3 & $2.141(7)$ & N1-Cu1-N3 & $79.7(3)$ & O2-Cu2-N6 & $172.3(2)$ \\
\hline Cu1-N5 & $2.175(6)$ & O1-Cu1-N5 & $103.8(2)$ & N2-Cu2-N7 & $138.2(2)$ \\
\hline Cu1-N4 & $2.194(7)$ & N1-Cu1-N5 & $136.1(3)$ & O2-Cu2-N7 & $103.6(2)$ \\
\hline Cu1-Cu2 & $3.7966(12)$ & N3-Cu1-N5 & $82.7(3)$ & N6-Cu2-N7 & $82.1(2)$ \\
\hline Cu2-N2 & $1.902(7)$ & O1-Cu1-N4 & $90.8(2)$ & N2-Cu2-N8 & $129.6(3)$ \\
\hline Cu2-O2 & $1.911(5)$ & N1-Cu1-N4 & $132.6(3)$ & O2-Cu2-N8 & $91.7(2)$ \\
\hline Cu2-N6 & $2.134(6)$ & N3-Cu1-N4 & $83.9(3)$ & N6-Cu2-N8 & $83.5(2)$ \\
\hline Cu2-N7 & $2.163(5)$ & N5-Cu1-N4 & $84.4(2)$ & N7-Cu2-N8 & $84.9(2)$ \\
\hline Cu2-N8 & $2.188(6)$ & N2-N1-Cu1 & $128.0(5)$ & N1-N2-Cu2 & $128.8(5)$ \\
\hline O1-O2 & $1.498(7)$ & O2-O1-Cu1 & $119.1(4)$ & O1-O2-Cu2 & $118.9(4)$ \\
\hline
\end{tabular}

Definitive elucidation of the peroxide binding mode in $\left[\mathrm{Cu}_{2}{ }_{2} \mathrm{~L}^{3}\left(\mathrm{O}_{2}\right)\right]^{\mathrm{X}}$ was provided by $\mathrm{X}$-ray diffraction. The molecular structure $\left(\left[\mathrm{Cu}_{2}{ }_{2} \mathrm{~L}^{3}\left(\mathrm{O}_{2}\right)\right]^{\mathrm{OTf}} \cdot \mathrm{NaOTf}\right.$, Figure 4.19$)$ represents the first crystallographically characterised end-on $\mathrm{Cu}_{2}{ }_{2}\left(\mu-\eta^{1}: \eta^{1}-\mathrm{O}_{2}\right)$ peroxide species with a cisgeometry $\left({ }^{C} \mathbf{P}\right)$, in contrast with the four known structurally authenticated examples of the trans- $\left({ }^{\top} \mathbf{P}\right)$ configuration. ${ }^{31,32,159,177}$ The complex cation crystallises in the triclinic $P-1$ space group with one molecule per unit cell, and is a dimeric structure bridged by co-crystallised NaOTf, $\left[\left\{\mathrm{Cu}_{2}{ }_{2} \mathrm{~L}^{3}\left(\mathrm{O}_{2}\right)\right\}\left\{\left(\mathrm{Me}_{2} \mathrm{CO}\right) \mathrm{Na}(\mathrm{OTf})\right\}\right]_{2}{ }^{2+}$, with a crystallographically imposed inversion centre. The coordination spheres around each copper atom lie at the mid-point between 
the idealised square pyramidal and trigonal bipyramidal geometries, with tau factors $(\tau)^{178}$ of 0.59 and 0.57 for $\mathrm{Cu} 1$ and Cu2, respectively. Copper-ligand bond lengths are significantly shorter for the peroxide and pyrazolate anionic bridging donors (1.899-1.916 $\AA$ ) than those of the neutral side-arm nitrogen atoms (2.134-2.194 $\AA$ ). Although these metric parameters all fall within the range already observed for ${ }^{\top} \mathbf{P}$ species, it should be noted that the peroxide ligand bond length $(\mathrm{O}-\mathrm{O}=1.498 \AA)$ is at the upper limit of those known. In contrast, the intermetallic distance in $\left[\mathrm{Cu}^{1{ }^{1}} \mathrm{~L}^{3}\left(\mathrm{O}_{2}\right)\right]^{\text {OTf }}$. NaOTf $(\mathrm{Cu} \cdots \mathrm{Cu}=3.797 \AA$ ) is substantially $(>0.5 \AA)$ shorter than in all ${ }^{\top} \mathbf{P}$ species, and this unique situation imposes a significant torsion angle $(\varphi)$ upon the bridging peroxide ligand $\left(\mathrm{Cu}-\mathrm{OO}-\mathrm{Cu}=65.2^{\circ}\right)$, the implications of which are examined in more detail in the next chapter. An additional remarkable feature is the close contact between the peroxide moiety and the co-crystallised sodium cation, which is discussed further in Section 4.4.6.

\subsubsection{Comparison of the $\left[\mathrm{Cu}_{2}{ }_{2} \mathrm{~L}^{2}\left(\mathrm{O}_{2}\right)\right]^{\mathrm{X}}$ and $\left[\mathrm{Cu}_{2}{ }_{2} \mathrm{~L}^{3}\left(\mathrm{O}_{2}\right)\right]^{\mathrm{X}}$ adducts}

The solid state structure of $\left[\mathrm{Cu}_{2}{ }_{2} \mathbf{L}^{3}\left(\mathrm{O}_{2}\right)\right]^{\text {OTf }} \cdot$ NaOTf described above provides significant insight with respect to the spectroscopic data discussed earlier (Sections 4.4.2). The good agreement between the solution and solid state $r R$ and UV-vis spectroscopic data (Section 5.3.1) indicate that the end-on cis-peroxo structural motif is retained in solution, allowing this species to act as a benchmark for comparison with $\left[\mathrm{Cu}^{\prime \prime}{ }_{2} \mathbf{L}^{2}\left(\mathbf{O}_{2}\right)\right]^{\mathrm{X}}$. The $\mathrm{rR}$ spectra of $\left[\mathrm{Cu}^{\prime \prime}{ }_{2} \mathbf{L}^{2}\left(\mathbf{O}_{2}\right)\right]^{\mathrm{X}}$ (Section 4.3.2) showed an intense pair and a relatively weak pair of isotopesensitive signals, consistent with the presence of two distinct dioxygen adducts. Comparison between the frequencies of the lower intensity peak set $\left(480\right.$ and $\left.800 \mathrm{~cm}^{-1}\right)$ and those obtained for $\left[\mathrm{Cu}_{2}{ }_{2} \mathrm{~L}^{3}\left(\mathrm{O}_{2}\right)\right]^{\mathrm{X}}\left(437\right.$ and $\left.795 \mathrm{~cm}^{-1}\right)$ shows reasonably good agreement, suggesting that the minor adduct may correspond to a ${ }^{C} \mathbf{P}$-type $\mathrm{Cu}^{\prime \prime}{ }_{2}\left(\mu-\eta^{1}: \eta^{1}-\mathrm{O}_{2}\right)$ species. In contrast, the frequencies of the signal set observed for the major product (540 and 817 $\mathrm{cm}^{-1}$ ) are much more consistent with literature-known values for trans-type ( $\left.{ }^{\top} \mathbf{P}\right)$ dioxygen adducts. ${ }^{14,32,46,156,162}$ Taking into account the geometric constraints imposed by ligand $\mathbf{H L}^{2}$, and assuming the pyrazole bridging unit remains coordinated to at least one copper(II) centre, a trans-configuration would require the product to be inter-molecular in nature.

Literature precedent for such a scenario exists. ${ }^{161,163}$ Dinucleating analogues of prominent mononucleating systems, such as TMPA (Scheme 1.4), have been previously shown to form inter-molecular dioxygen-adducts in solution. The ligand $\mathbf{T M P A}_{2} \mathbf{E t}$ consists of two mononucleating TMPA binding pockets, bridged by an ethylene linker attached to one of the 5-pyridyl-positions on each of the two subunits. Low temperature kinetic studies of the copper-dioxygen species generated with $\mathbf{T M P A}_{2}$-Et as a supporting ligand revealed the formation of a mixture of several inter-molecular ${ }^{\top} \mathbf{P}$ adducts, all of which furthermore displayed very similar UV-vis absorption spectra. ${ }^{161}$ The distribtion of these species was additionally found to be temperature dependent, and a cyclic hexanuclear trimeric adduct, $\left[\left\{\mathrm{Cu}_{2}^{\prime \prime}\left(\mathrm{TMPA}_{2} \mathrm{Et}\right)\left(\mathrm{O}_{2}\right)\right\}_{3}\right]^{6+}$, was found to be especially stable within a particular temperature range, although a well-defined structure was not proposed. A related example of specific 
relevance to $\left[\mathrm{Cu}_{2}{ }_{2} \mathrm{~L}^{2}\left(\mathrm{O}_{2}\right)\right]^{\mathrm{X}}$ is provided by a system supported by the dinucleating ligand $\mathrm{NO}_{2}-\mathrm{XYL}{ }^{163}$ This organic scaffold consists of two bis[2-(2-pyridyl)ethyl]amine metal-binding pockets bridged by a nitrated meta-xylyl linker (Scheme 4.5). When the copper(I) complex of this ligand is exposed to dioxygen at low concentrations $(\sim 4 \mathrm{mM})$, a band at $747 \mathrm{~cm}^{-1}$ is observed in the corresponding $\mathrm{rR}$ spectrum. This was assigned to the $\mathrm{O}-\mathrm{O}$ stretching frequency of an intra-molecular ${ }^{S} \mathbf{P}$ adduct. However, at slightly higher concentrations ( 8 $\mathrm{mm}$ ) a second band at $733 \mathrm{~cm}^{-1}$ was also present in the $r R$ spectrum. Furthermore, this additional feature became more intense as the concentration was increased. The authors propose that this second signal results from the formation of a dimeric tetranuclear intermolecular ${ }^{\mathbf{S}} \mathbf{P}$ species. ${ }^{163}$

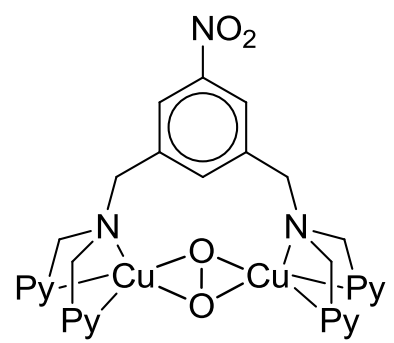

Low Concentrations

$\left[\mathrm{Cu}_{2}{ }_{2}\left(\mathrm{NO}_{2}-\mathrm{XYL}\right)\left(\mathrm{O}_{2}\right)\right]$

Intra-molecular ${ }^{\mathrm{S}_{\mathbf{P}}}$ Dinuclear Monomer

$v_{\mathrm{O}-\mathrm{O}}=747 \mathrm{~cm}^{-1}$

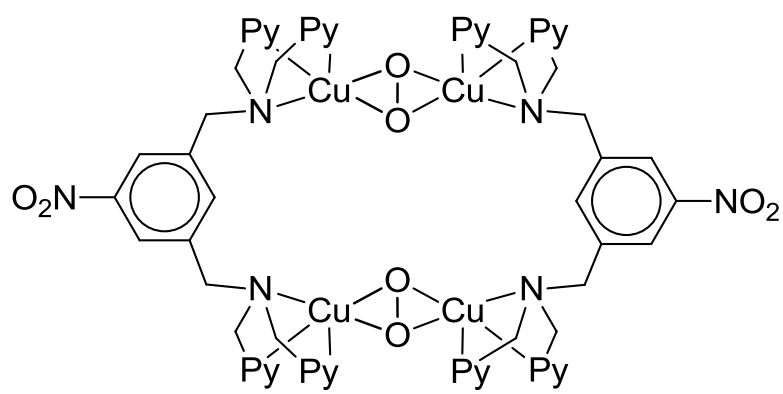

High Concentrations

$\left[\mathrm{Cu}_{2}{ }_{2}\left(\mathrm{NO}_{2}-\mathrm{XYL}\right)\left(\mathrm{O}_{2}\right)\right]_{2}$

Inter-molecular $\mathbf{S}_{\mathbf{P}}$ Tetranuclear Dimer

$v_{\mathrm{O}-\mathrm{O}}=733 \mathrm{~cm}^{-1}$

Scheme 4.5: Concentration dependent speciation of the ${ }^{\mathrm{S}} \mathrm{P}$ adduct formed with the $\mathrm{NO}_{\mathbf{2}}-\mathbf{X Y L}$ ligand system. Charges and counterions are omitted.

In solution, the $\left[\mathrm{Cu}_{2}{ }_{2} \mathbf{L}^{2}\right]^{\mathrm{X}}$ system was already shown to exhibit dynamic behaviour involving pyrazole dissociation (Section 3.3.3), and a tendency toward aggregation (Section 3.3.2), suggesting that formation of inter-molecular dioxygen-adducts in this system is indeed feasible. This proposal is furthermore supported by the presence of tetranuclear dimeric adducts in the Cryo-ESI-MS spectra of $\left[\mathrm{Cu}^{\prime \prime}{ }_{2} \mathrm{~L}^{2}\left(\mathrm{O}_{2}\right)\right]^{\mathrm{X}}$ and $\left[\mathrm{Cu}^{\prime \prime}{ }_{2} \mathrm{~L}^{3}\left(\mathrm{O}_{2}\right)\right]^{\mathrm{X}}$. Observation of these species suggests that formation of inter-molecular copper-dioxygen adducts is possible in both systems. However, these specific $\mathrm{Cu}_{4}-\mathrm{O}_{2}$ adducts can be ruled out by considering the 1:1 stoichiometry of the reaction between the respective copper(I) complexes and dioxygen (Section 4.3.2). This thereby implies that the dominant dioxygen adduct present in the solutions of $\left[\mathrm{Cu}^{\prime \prime}{ }_{2}{ }^{2}\left(\mathrm{O}_{2}\right)\right]^{\mathrm{X}}$ used for $\mathrm{rR}$ measurements is a $\mathrm{Cu}_{4}-\left(\mathrm{O}_{2}\right)_{2}$ or higher oligomer, with dioxygen-derived ligands bound in a ${ }^{\top} \mathbf{P}$ configuration. However, on the basis of comparison with other known ${ }^{\mathbf{T}} \mathbf{P}$ adducts it would then be expected to exhibit a greater molar extinction coefficient in solution than that observed in UV-vis experiments. It is also interesting to note that, aside from the Cryo-ESI-MS measurements, no other evidence indicates the presence of an inter-molecular dioxygen-adduct in the case of $\left[\mathrm{Cu}_{2}{ }_{2} \mathrm{~L}^{3}\left(\mathbf{O}_{2}\right)\right]^{\mathrm{X}}$. 


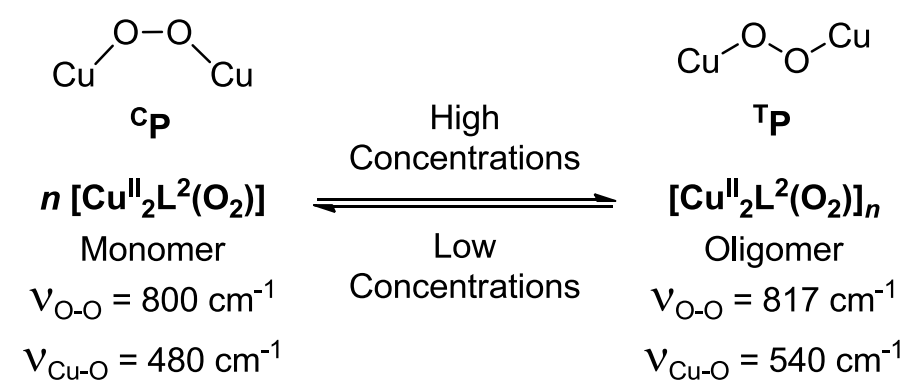

Scheme 4.6: Proposed equilibirum between a ${ }^{\mathbf{C}} \mathbf{P}$ monomeric and ${ }^{\top} \mathbf{P}$ oligomeric dioxygen adduct in the system supported by $\mathbf{H L}^{2}$. Frequencies of the relevant resonance Raman bands assigned to each species are included.

A proposal consistent with all of the above described experimental data is the existence of an equilibrium between intra- and inter-molecular dioxygen adducts in solution. As evidenced by qualitatively comparing the data for the $\left[\mathrm{Cu}^{1}{ }_{2} \mathbf{L}^{2}\right]^{\mathrm{X}}$ and $\left[\mathrm{Cu}_{2}{ }_{2} \mathrm{~L}^{3}\right]^{\mathrm{X}}$ systems, and the Cryo-ESI-MS measurements for $\left[\mathrm{Cu}^{\prime \prime}{ }_{2}{ }^{2}\left(\mathrm{O}_{2}\right)\right]^{\mathrm{X}}$ and $\left[\mathrm{Cu}^{\prime \prime}{ }_{2} \mathrm{~L}^{3}\left(\mathrm{O}_{2}\right)\right]^{\mathrm{X}}$, complexes of ligand $\mathrm{HL}^{2}$ are more flexible and have a greater tendency toward dimer formation than those generated with $\mathrm{HL}^{3}$. This indirectly indicates that the equilibrium for $\left[\mathrm{Cu}_{2}{ }_{2} \mathrm{~L}^{3}\left(\mathrm{O}_{2}\right)\right]^{\mathrm{X}}$ is much more strongly biased toward monomeric dinuclear adducts in solution, in contrast to the case of $\left[\mathrm{Cu}_{2}{ }_{2} \mathrm{~L}^{2}\left(\mathrm{O}_{2}\right)\right]^{\mathrm{X}}$. Assuming higher concentrations promote association to give the intermolecular adducts furthermore allows several of the experimental observations to be accounted for. The concentrations used for the UV-vis (Maximum of $1.0 \times 10^{-2} \mathrm{M}$ ) and $\mathrm{rR}$ $\left(2.5 \times 10^{-2} \mathrm{M}\right)$ spectroscopic studies of $\left[\mathrm{Cu}_{2}{ }_{2} \mathrm{~L}^{2}\left(\mathrm{O}_{2}\right)\right]^{\mathrm{X}}$ differed. The considerably higher concentrations used in the case of the $\mathrm{rR}$ measurements would thus favour the intermolecular ' $\mathbf{P}$ adduct, which is reflected by the dominance of its vibrational features in the corresponding spectrum. In contrast, the relatively low concentrations used in the UV-vis experiments would facilitate formation of an intra-molecular ${ }^{C} \mathbf{P}$ species similar to $\left[\mathrm{Cu}_{2}{ }_{2} \mathrm{~L}^{3}\left(\mathrm{O}_{2}\right)\right]^{\mathrm{X}}$, which provides an explanation for the diminished molar extinction coefficient.

Based on the current data alone this theory is tentative at best, but experiments aimed at assessing the concentration dependence of the two peak sets observed in the rR spectra would be especially informative in verifying or disproving such a proposal. Similar UV-vis experiments may also provide additional insights. The above considerations with respect to speciation, in combination with those regarding the formation of a superoxide adduct under certain conditions (Section 4.4.2), may also provide an explanation for the difficulties encountered in crystallising $\left[\mathrm{Cu}_{2}{ }_{2}{ }^{2}\left(\mathrm{O}_{2}\right)\right]^{\mathrm{X}}$. 


\subsubsection{Varying Counterions - Further Solid State Structures of $\left[\mathrm{Cu}_{2}{ }_{2} \mathrm{~L}^{3}\left(\mathrm{O}_{2}\right)\right]^{\mathrm{X}}$}

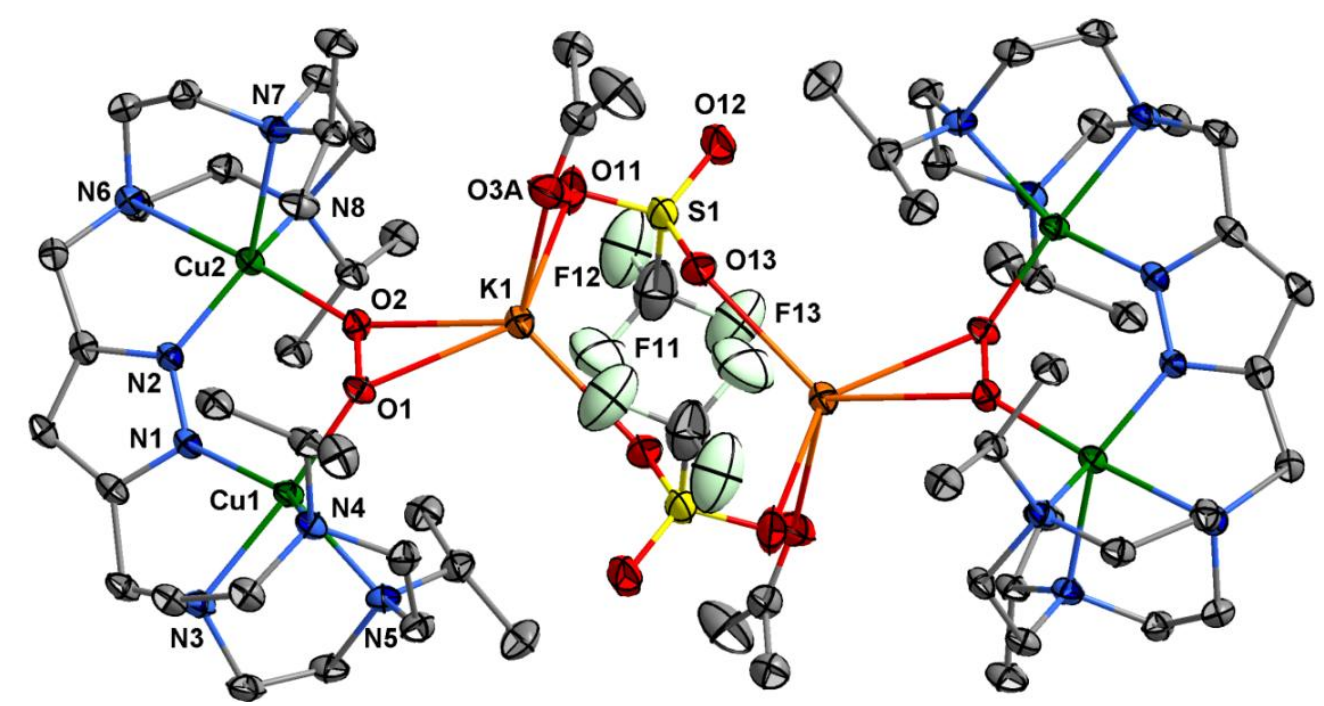

Figure 4.20: Molecular structure of $\left[\mathrm{Cu}_{2}{ }_{2} \mathrm{~L}^{3}\left(\mathrm{O}_{2}\right)\right]^{\mathrm{OTf}} \cdot \mathrm{KOTf}$. Thermal displacement ellipsoids are shown at $30 \%$ probability. Hydrogen atoms and non-coordinated triflate counteranions have been omitted for clarity.

\begin{tabular}{|c|c|c|c|c|c|}
\hline \multicolumn{5}{|c|}{ Table 4.6: Selected bond lengths $(\AA)$ and angles $\left({ }^{\circ}\right)$ for $\left[\mathrm{Cu}_{2}{ }_{2}{ }^{3}\left(\mathrm{O}_{2}\right)\right]^{\text {OTf }} \cdot{ }^{\text {KOTf. }}$} \\
\hline Atoms & Bond Lengths & Atoms & Angles & Atoms & Angles \\
\hline Cu1-O1 & $1.907(2)$ & O1-Cu1-N1 & $98.68(12)$ & O2-Cu2-N2 & $97.53(12)$ \\
\hline Cu1-N1 & $1.911(3)$ & O1-Cu1-N3 & $171.92(12)$ & O2-Cu2-N6 & $171.45(12)$ \\
\hline Cu1-N3 & $2.154(3)$ & N1-Cu1-N3 & $80.11(12)$ & N2-Cu2-N6 & $79.98(12)$ \\
\hline Cu1-N5 & $2.170(3)$ & O1-Cu1-N5 & $103.92(12)$ & O2-Cu2-N7 & $104.63(11)$ \\
\hline Cu1-N4 & $2.187(3)$ & N1-Cu1-N5 & $137.82(13)$ & N2-Cu2-N7 & $138.95(13)$ \\
\hline Cu1-Cu2 & $3.7979(7)$ & N3-Cu1-N5 & $81.87(12)$ & N6-Cu2-N7 & $82.19(12)$ \\
\hline Cu2-O2 & $1.908(3)$ & O1-Cu1-N4 & $91.77(11)$ & O2-Cu2-N8 & $91.94(11)$ \\
\hline Cu2-N2 & $1.909(3)$ & N1-Cu1-N4 & $130.55(13)$ & N2-Cu2-N8 & $129.29(12)$ \\
\hline Cu2-N6 & $2.136(3)$ & N3-Cu1-N4 & $83.14(12)$ & N6-Cu2-N8 & $83.51(12)$ \\
\hline Cu2-N7 & $2.178(3)$ & N5-Cu1-N4 & $84.13(13)$ & N7-Cu2-N8 & $84.46(11)$ \\
\hline Cu2-N8 & $2.191(3)$ & N2-N1-Cu1 & $127.3(2)$ & N1-N2-Cu2 & $128.7(2)$ \\
\hline O1-O2 & $1.4820(33)$ & O2-O1-Cu1 & $118.71(17)$ & O1-O2-Cu2 & $118.95(18)$ \\
\hline
\end{tabular}


The methodology used above to isolate crystalline $\left[\mathrm{Cu}_{2}{ }_{2} \mathrm{~L}^{3}\left(\mathrm{O}_{2}\right)\right]^{\text {OTf }} \cdot$ NaOTf could be further applied to obtain the homologous KOTf bridged adduct $\left(\left[\mathrm{Cu}_{2}{ }_{2} \mathrm{~L}^{3}\left(\mathrm{O}_{2}\right)\right]^{\text {OTf }} \cdot\right.$ KOTf, Figure 4.20$)$ by substituting $\mathrm{NaO}^{t} \mathrm{Bu}$ for $\mathrm{KO}^{t} \mathrm{Bu}$. The complex cation, $\left[\left\{\mathrm{Cu}_{2}{ }_{2} \mathrm{~L}^{3}\left(\mathrm{O}_{2}\right)\right\}\left\{\left(\mathrm{Me}_{2} \mathrm{CO}\right) \mathrm{K}(\mathrm{OTf})\right\}\right]_{2}{ }^{2+}$, also crystallises in the triclinic $P-1$ space group and is isostructural with that of $\left[\mathrm{Cu}_{2}{ }_{2} \mathbf{L}^{3}\left(\mathrm{O}_{2}\right)\right]^{\mathrm{OTf}} \cdot$ NaOTf, again composed of a dimeric structure having a crystallographically imposed inversion centre, with an almost identical cell volume. The major difference by simple visual inspection is a subtle shift in the bridging triflate anion orientation, which creates an additional interaction between it and the potassium ion $(013-\mathrm{K} 1=3.016 \AA)$. This effectively represents a change in bridging mode from an almost symmetric $\mu-\eta^{1}: \eta^{1}$ coordination in the case of the sodium adduct, $\left[\mathrm{Cu}^{\prime \prime}{ }_{2} \mathbf{L}^{3}\left(\mathbf{O}_{2}\right)\right]^{\text {OTf }} \cdot$ NaOTf, to a $\mu-\eta^{1}: \eta^{2}$ configuration for the potassium compound, $\left[\mathrm{Cu}_{2}{ }_{2} \mathrm{~L}^{3}\left(\mathrm{O}_{2}\right)\right]^{\mathrm{OTf}} \cdot \mathrm{KOTf}$, thereby increasing the coordination number of the latter alkali metal, consistent with its larger ionic radius. Apart from those metric parameters relating to the potassium ion and corresponding triflate oxygen donor atoms, all others remain largely equivalent (Table 4.8). The coordination spheres are once more extremely distorted, with $\tau$ factors of 0.57 and 0.54 for Cu1 and Cu2 respectively, and shorter copper-ligand bond lengths are again found for the anionic bridging donors (1.907-1.911 $\AA$ ) than those of the neutral side-arm nitrogen atoms (2.136-2.191 $\AA$ ). While the intermetallic distance in $\left[\mathrm{Cu}_{2}{ }_{2} \mathrm{~L}^{3}\left(\mathrm{O}_{2}\right)\right]^{\text {OTf }} \cdot$ KOTf $(\mathrm{Cu} \cdots \mathrm{Cu}=3.798 \AA)$ is essentially identical to that of $\left[\mathrm{Cu}_{2}{ }_{2} \mathrm{~L}^{3}\left(\mathrm{O}_{2}\right)\right]^{\text {OTf }} \cdot \mathrm{NaOTf}$, a marginally shorter peroxide bond length $(\mathrm{O}-\mathrm{O}=1.483 \AA$ ) is observed in the current case, together with a slightly larger torsion angle $\left(\mathrm{Cu}-\mathrm{OO}-\mathrm{Cu}=66.8^{\circ}\right)$. 


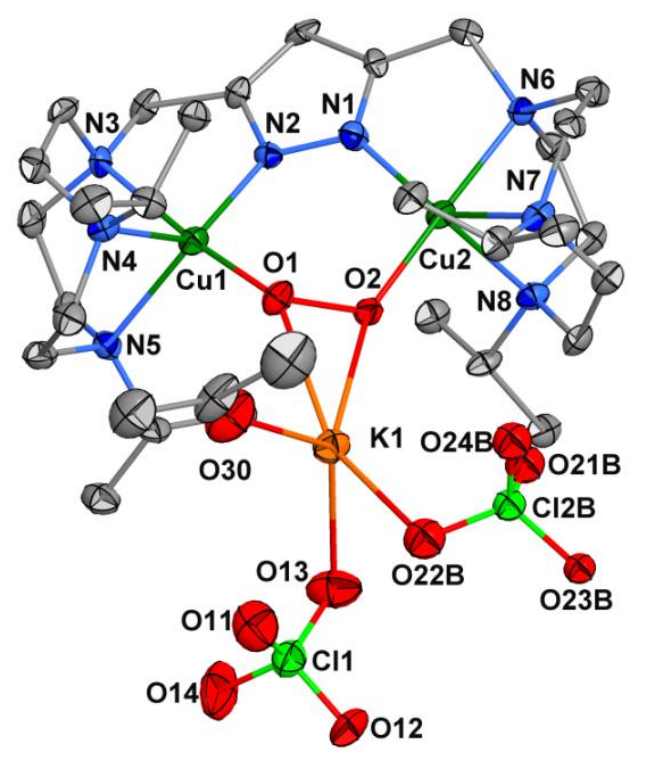

Figure 4.21: Molecular structure of $\left[\mathrm{Cu}_{2}{ }_{2} \mathrm{~L}^{3}\left(\mathrm{O}_{2}\right)\right]^{\mathrm{ClO} 4} \cdot \mathrm{KClO}_{4}$. Thermal displacement ellipsoids are shown at $30 \%$ probability. Hydrogen atoms have been omitted for clarity.

\begin{tabular}{|c|c|c|c|c|c|}
\multicolumn{6}{|c|}{ Table 4.7: Selected bond lengths (Å) and angles $\left({ }^{\circ}\right)$ for $\left[\mathrm{Cu}_{2}{ }_{2} \mathrm{~L}^{3}\left(\mathrm{O}_{2}\right)\right]^{\mathrm{CI04}} \cdot \mathrm{KClO}_{4} \cdot$} \\
\hline Atoms & Bond Lengths & Atoms & Angles & Atoms & Angles \\
\hline Cu1-N2 & $1.905(7)$ & N2-Cu1-O1 & $97.8(3)$ & N1-Cu2-O2 & $99.0(3)$ \\
\hline Cu1-O1 & $1.917(7)$ & N2-Cu1-N3 & $79.8(3)$ & N1-Cu2-N6 & $80.0(3)$ \\
\hline Cu1-N3 & $2.134(8)$ & O1-Cu1-N3 & $171.5(3)$ & O2-Cu2-N6 & $172.1(3)$ \\
\hline Cu1-N5 & $2.175(8)$ & N2-Cu1-N5 & $139.6(4)$ & N1-Cu2-N8 & $131.6(4)$ \\
\hline Cu1-N4 & $2.182(9)$ & O1-Cu1-N5 & $104.2(3)$ & O2-Cu2-N8 & $92.0(3)$ \\
\hline Cu1-Cu2 & $3.8242(17)$ & N3-Cu1-N5 & $82.5(3)$ & N6-Cu2-N8 & $83.0(3)$ \\
\hline Cu2-N1 & $1.907(8)$ & N2-Cu1-N4 & $128.8(3)$ & N1-Cu2-N7 & $136.5(3)$ \\
\hline Cu2-O2 & $1.910(6)$ & O1-Cu1-N4 & $91.6(3)$ & O2-Cu2-N7 & $103.4(3)$ \\
\hline Cu2-N6 & $2.150(8)$ & N3-Cu1-N4 & $83.7(3)$ & N6-Cu2-N7 & $82.3(3)$ \\
\hline Cu2-N8 & $2.167(9)$ & N5-Cu1-N4 & $84.3(3)$ & N8-Cu2-N7 & $84.5(3)$ \\
\hline Cu2-N7 & $2.198(8)$ & N1-N2-Cu1 & $129.6(6)$ & N2-N1-Cu2 & $127.1(6)$ \\
\hline O1-O2 & $1.502(9)$ & O2-O1-Cu1 & $119.2(5)$ & O1-O2-Cu2 & $120.2(5)$ \\
\hline
\end{tabular}


In addition to the structurally characterised triflate salts resulting from the above synthetic procedures, crystalline material was also obtained with both sodium and potassium cations when perchlorate was used as the counteranion. In these cases the crystals were much smaller and diffracted poorly, such that extended acquisition times were necessary for characterisation by X-ray diffraction. Nevertheless, the obtained data were sufficient to discern the molecular structure (Figure 4.21) when the ions potassium and perchlorate were used in combination to give the overall neutral compound, $\left[\mathrm{Cu}_{2}{ }_{2} \mathrm{~L}^{3}\left(\mathrm{O}_{2}\right)\right]^{\mathrm{ClO} 4} \cdot \mathrm{KClO}_{4}$. This product crystallises in the monoclinic $P 2_{1} / c$ space group with four molecules per unit cell. Although the composition of the complex, $\left[\left\{\mathrm{Cu}_{2}{ }_{2} \mathrm{~L}^{3}\left(\mathrm{O}_{2}\right)\right\}\left\{\left(\mathrm{Me}_{2} \mathrm{CO}\right) \mathrm{K}\left(\mathrm{ClO}_{4}\right)_{2}\right\}\right]$, in $\left[\mathrm{Cu}_{2}{ }_{2} \mathrm{~L}^{3}\left(\mathrm{O}_{2}\right)\right]^{\mathrm{ClO} 4} \cdot \mathrm{KClO}_{4}$ differs from the previous two cases, it is clear that the cis-peroxo structural motif is retained. In addition, a side-on contact with the potassium ion is once again present. The most significant distinction between $\left[\mathrm{Cu}_{2}{ }_{2} \mathrm{~L}^{3}\left(\mathrm{O}_{2}\right)\right]^{\mathrm{ClO}} \cdot \mathrm{KClO}_{4}$ and the two structures discussed above is the loss of the dimeric arrangement. Thus, while the coordination sphere of the alkali metal is once again completed by an acetone molecule and two weakly coordinating counteranions, the latter do not form a bridge to a second cation in the case of the perchlorate adduct $\left[\mathrm{Cu}_{2}{ }_{2} \mathrm{~L}^{3}\left(\mathrm{O}_{2}\right)\right]^{\mathrm{ClO}} \cdot \mathrm{KClO}_{4}$, in contrast to the triflatecontaining structures $\left[\mathrm{Cu}_{2}{ }_{2} \mathrm{~L}^{3}\left(\mathrm{O}_{2}\right)\right]^{\text {OTf }} \cdot \mathrm{NaOTf}$ and $\left[\mathrm{Cu}_{2}{ }_{2} \mathrm{~L}^{3}\left(\mathrm{O}_{2}\right)\right]^{\mathrm{OTf}} \cdot \mathrm{KOTf}$. Although the lower quality of structure $\left[\mathrm{Cu}_{2}{ }_{2} \mathrm{~L}^{3}\left(\mathrm{O}_{2}\right)\right]^{\mathrm{ClO} 4} \cdot \mathrm{KClO}_{4}$ must be taken into account with respect to the analysis of metric parameters, for the most part they do not appreciably deviate from those of the other structures (Table 4.8). The main difference is found upon examination of the geometry around one of the copper(II) atoms. The $\tau$ factors for Cu1 and Cu2 are 0.53 and 0.68 respectively, indicating that the latter has significantly more trigonal bipyramidal character. Despite this distinction the remaining values are quite similar, with copper-ligand bond lengths of the neutral side-arm nitrogen atoms (2.135-2.197 $\AA$ ) again longer than the anionic bridging donors (1.904-1.917 $\AA$ ), both the intermetallic distance ( $\mathrm{Cu} \cdots \mathrm{Cu}=3.824 \AA$ ) and peroxide bond lengths slightly elongated $(\mathrm{O}-\mathrm{O}=1.502 \AA)$, and a marginally reduced torsion angle $\left(\mathrm{Cu}-\mathrm{OO}-\mathrm{Cu}=63.8^{\circ}\right)$. 


\begin{tabular}{|c|c|c|c|}
\hline \multirow[t]{2}{*}{ Property } & \multicolumn{3}{|c|}{ Compound } \\
\hline & {$\left[\mathrm{Cu}_{2}{ }_{2} \mathrm{~L}^{3}\left(\mathrm{O}_{2}\right)\right]^{\mathrm{OTf}} \cdot \mathrm{NaOTf}$} & {$\left[\mathrm{Cu}_{2}{ }^{\prime \prime} \mathrm{L}^{3}\left(\mathrm{O}_{2}\right)\right]^{\mathrm{OTf}} \cdot \mathrm{KOTf}$} & {$\left[\mathrm{Cu}_{2}{ }_{2} \mathrm{~L}^{3}\left(\mathrm{O}_{2}\right)\right]^{\mathrm{ClO4}} \cdot \mathrm{KClO}_{4}$} \\
\hline$\tau$ factors & $0.59 / 0.57$ & $0.57 / 0.54$ & $0.53 / 0.68$ \\
\hline $\mathrm{Cu}-\mathrm{O}(\AA)$ & $1.900 / 1.912$ & $1.907 / 1.909$ & $1.917 / 1.909$ \\
\hline $\mathrm{Cu} \cdots \mathrm{Cu}(\AA ̊)$ & 3.800 & 3.798 & 3.824 \\
\hline O-O (Å) & 1.484 & 1.483 & 1.502 \\
\hline$\angle \mathrm{Cu}-\mathrm{OO}-\mathrm{Cu}, \varphi\left({ }^{\circ}\right)$ & 64.0 & 66.8 & 63.8 \\
\hline $\mathrm{M}-\mathrm{O}(\AA \AA \AA), \mathrm{M}=\mathrm{Na}^{+}$or $\mathrm{K}^{+}$ & $2.296 / 2.302$ & $2.606 / 2.646$ & $2.639 / 2.656$ \\
\hline
\end{tabular}

A remarkable structural feature observed in all of the complexes $\left[\mathrm{Cu}_{2}{ }_{2} \mathrm{~L}^{3}\left(\mathrm{O}_{2}\right)\right]^{\text {OTf }} \cdot$ NaOTf, $\left[\mathrm{Cu}_{2}{ }_{2} \mathrm{~L}^{3}\left(\mathrm{O}_{2}\right)\right]^{\mathrm{OTf}} \cdot \mathrm{KOTf}$ and $\left[\mathrm{Cu}_{2}{ }_{2} \mathrm{~L}^{3}\left(\mathrm{O}_{2}\right)\right]^{\mathrm{ClO} 4} \cdot \mathrm{KClO}_{4}$, is the close contact of the peroxide moiety with the alkali metal cation (Tables of bond lengths and angles assocaited with the alkali metal ions in each structure can be found in experimental Section 8.10). The $\mathrm{Na}-\mathrm{O}$ distances in $\left[\mathrm{Cu}_{2}{ }_{2} \mathrm{~L}^{3}\left(\mathrm{O}_{2}\right)\right]^{\mathrm{OTf}} \cdot$.NaOTf $(2.296 / 2.302 \AA)$, are shorter than those of the side-on bound sodium cations in anhydrous ionic $\mathrm{Na}_{2} \mathrm{O}_{2}(2.322 / 2.404 \AA)$. This is also the case when comparing the $\mathrm{K}-\mathrm{O}$ distances in $\left[\mathrm{Cu}_{2}{ }_{2} \mathrm{~L}^{3}\left(\mathrm{O}_{2}\right)\right]^{\text {OTf }} \cdot$ KOTf $(2.606 / 2.646 \AA)$ and $\left[\mathrm{Cu}_{2}{ }_{2} \mathrm{~L}^{3}\left(\mathrm{O}_{2}\right)\right]^{\mathrm{ClO} 4} \cdot \mathrm{KClO}_{4}(2.639 / 2.656 \AA)$ with their corresponding counterpart, anhydrous $\mathrm{K}_{2} \mathrm{O}_{2}$ $(2.697 / 2.699 \AA$ ) $)$. Other known metal- $\mathrm{O}_{2}{ }^{2-}$ complexes (metal $=\mathrm{Ti}^{179} \mathrm{Ga}^{180} \mathrm{Mo}^{181} \mathrm{Pu}^{182}$ ) exhibiting additional side-on peroxide-sodium cation interactions have an average $\mathrm{Na}-\mathrm{O}$ distance of $2.396 \AA$ (range: $2.251-2.604 \AA$ ), whereas the metal- $\mathrm{O}_{2}{ }^{2-}$ series (metal $=\mathrm{Mg}{ }^{183}$ $\mathrm{V}^{184} \mathrm{Ni}^{185} \mathrm{Zn},{ }^{186} \mathrm{Rb},{ }^{187} \mathrm{Pd},{ }^{188} \mathrm{U}^{189}$ ) in the case of potassium has an average $\mathrm{K}-\mathrm{O}$ distance of $2.747 \AA$ (range: $2.608-2.903 \AA$ ). Thus, while direct comparison is difficult owing to differing alkali metal co-ligands and co-ordination numbers, the $\mathrm{Me}-\mathrm{O}$ interactions observed in $\left[\mathrm{Cu}_{2} \mathrm{~L}^{3}\left(\mathrm{O}_{2}\right)\right]^{\mathrm{OTf}} \cdot \mathrm{NaOTf}, \quad\left[\mathrm{Cu}_{2}{ }_{2} \mathrm{~L}^{3}\left(\mathrm{O}_{2}\right)\right]^{\mathrm{OTf}} \cdot \mathrm{KOTf}$ and $\left[\mathrm{Cu}_{2}{ }_{2} \mathrm{~L}^{3}\left(\mathrm{O}_{2}\right)\right]^{\mathrm{ClO4}} \cdot \mathrm{KClO}_{4}$ suggest that the peroxide moiety retains a significant amount of negative charge in all cases. As the latter is directly related to the ability of the peroxide to donate charge onto the copper, ${ }^{190}{ }^{1}$ it qualitatively suggests that the interaction between the two elements in the above cases is diminished relative to that in known ${ }^{\top} \mathbf{P}$ species. This proposal is discussed in further detail in the following chapter. 


\subsection{Summary and Conclusions}

Building on the results of previous studies, the ability of three pyrazole supported copper(I) systems to bind and activate dioxygen was investigated in further detail. The adducts which resulted were all found to be temperature sensitive to varying degrees, leading to the extensive use of in situ characterisation techniques, which have provided significant insights in the case of each system.

Structural characterisation of the tetra-copper(II)-peroxo adduct which results upon reaction of the $\left[\mathrm{Cu}_{2}{ }_{2} \mathbf{L}^{1}\right]^{\mathrm{X}}$ system with dioxygen was previously published, but no details of the pathway by which the $\left[\left(\mathrm{Cu}^{\prime \prime}{ }_{2} \mathrm{~L}^{1}\right)_{2}\left(\mathrm{O}_{2}\right)(\mathrm{OH})_{2}\right]^{\mathrm{X} 2}$ complex forms were reported. Of particular interest was the possible role of water in this self-assembly reaction. Although efforts to isolate $\left[\left(\mathrm{Cu}_{2}{ }_{2} \mathrm{~L}^{1}\right)_{2}\left(\mathrm{O}_{2}\right)(\mathrm{OH})_{2}\right]^{\mathrm{X} \mathbf{2}}$ in the current work by applying the previously used synthetic methodology met with little success, an alternative procedure for generating $\left[\left(\mathrm{Cu}_{2}{ }_{2} \mathrm{~L}^{1}\right)_{2}\left(\mathrm{O}_{2}\right)(\mathrm{OH})_{2}\right]^{\mathrm{X2}}$ could be developed. This procedure led to the observation of an ESIMS signal which could be assigned to $\left[\left(\mathrm{Cu}^{1{ }^{\prime \prime}} \mathrm{L}^{1}\right)_{2}\left(\mathrm{O}_{2}\right)(\mathrm{OH})_{2}\right]^{\mathrm{X2}}$, thereby providing a indicator for the presence of this species in solution. Using this benchmark, in combination with ${ }^{18} \mathrm{O}_{2}$ isotopic labelling experiments, gave strong evidence to suggest that both hydroxide bridges in the $\left[\left(\mathrm{Cu}_{2}{ }_{2} \mathrm{~L}^{1}\right)_{2}\left(\mathrm{O}_{2}\right)(\mathrm{OH})_{2}\right]^{\mathrm{X} \mathbf{2}}$ complex are derived from water. Nevertheless, it is apparent from these experiments that this system can achieve cleavage of the dioxygen bond, but only after several days at ambient temperatures. Despite having established a role for water in the formation of $\left[\left(\mathrm{Cu}_{2}{ }_{2} \mathrm{~L}^{1}\right)_{2}\left(\mathrm{O}_{2}\right)(\mathrm{OH})_{2}\right]^{\mathbf{X}}$, the changes in oxidation state needed to form the product from the starting materials are still not adequately accounted for. This mechanistic complexity may in part result from the trimeric hexanuclear speciation of the copper(I) precursor, $\left([\mathbf{C u} \mathbf{2} \mathbf{L} 1]^{\mathrm{x}}\right)_{3}$, identified in the previous chapter, and additional investigation by complimentary experimental techniques may lead to further significant insights in this regard.

The transient species which forms when the $\left[\mathbf{C u}_{2}{ }_{2} \mathbf{L}^{2}\right]^{\mathrm{X}}$ system is exposed to dioxygen at low temperatures proved to be the most elusive in the current study, in large part due to its thermal instability. Although experimental conditions were developed under which the lifetime of this species was extended into the range of weeks at $-80{ }^{\circ} \mathrm{C}$, the $\left[\mathrm{Cu}^{\prime \prime}{ }_{2} \mathbf{L}^{2}\left(\mathbf{O}_{2}\right)\right]^{\mathrm{X}}$ adduct could not be successfully isolated. This may be partially accounted for by the complex speciation of the $\left[\mathrm{Cu}_{2}{ }_{2} \mathrm{~L}^{2}\left(\mathbf{O}_{2}\right)\right]^{\mathrm{X}}$ system in solution, as revealed by in situ characterisation. UV-vis spectroscopic data showed the presence of a major and minor adduct, consistent with the two species observed for the relevant $\left[\mathrm{Cu}_{2}{ }_{2} \mathbf{L}^{2}\right]^{\mathrm{X}}$ system in the previous chapter. When methodology to suppress the mononuclear $\left[\mathrm{Cu}^{\prime} \mathrm{L}^{2}\right.$ ] precursor complex was applied, the minor dioxygen adduct was no longer observed, and on the basis of its UV-vis features this minor species was then assigned as a mononuclear coppersuperoxo adduct, $\left[\mathrm{Cu}^{\prime \prime} \mathrm{L}^{2}\left(\mathrm{O}_{2}{ }^{\circ}\right)\right]^{\mathrm{X}}$. Through further application of $\mathrm{rR}$ spectroscopy the major species could be unambiguously identified as a $\mu-\eta^{1}-\eta^{1}$-peroxo adduct, however, the data indicated that this product also exhibits mixed speciation in solution. Through comparison 
with the extensive literature available for these systems, and by drawing on the structural information obtained for the precursor $\left[\mathrm{Cu}_{2}^{1} \mathrm{~L}^{2}\right]^{\mathrm{X}}$ and for the analogous $\left[\mathrm{Cu}^{11}{ }_{2} \mathrm{~L}^{3}\left(\mathrm{O}_{2}\right)\right]^{\mathrm{X}}$ system, a scenario involving an equilibrium between an intra- and inter-molecular $\mu-\eta^{1}-\eta^{1}$-peroxo adduct could be proposed. Assessing the validity of this hypothesis would greatly benefit from further concentration-dependent $r R$ and UV-vis spectroscopic experiments.

Oxygenation of the well-defined $\left[\mathrm{Cu}_{2}{ }_{2} \mathbf{L}^{3}\right]^{\mathrm{X}}$ complex in solution at $-80{ }^{\circ} \mathrm{C}$ unexpectedly led to a transient species which appeared to be significantly different to that previously described for this system. Further investigation by UV-vis and $r R$ spectroscopic techniques allowed this species to be unambiguously identified as a mononuclear $\left[\mathrm{Cu}^{\mathrm{II}} \mathrm{L}^{3}\left(\mathrm{O}_{2}{ }^{\circ}\right)\right]^{\mathrm{X}}$ adduct. Dioxygen exposure at $-30{ }^{\circ} \mathrm{C}$ led to a different product which was in much better agreement with prior investigations. Spectroscopic characterisation was most consistent with the presence of a single $\mu-\eta^{1}-\eta^{1}$-peroxo species, and after screening a range of conditions crystalline material of diffraction quality could be isolated.

Definitive elucidation of the peroxide binding mode in $\left[\mathrm{Cu}_{2}{ }_{2} \mathrm{~L}^{3}\left(\mathrm{O}_{2}\right)\right]^{\mathrm{X}}$ was thereby provided, revealing an end-on $\mathrm{Cu}_{2}{ }_{2}\left(\mu-\eta^{1}: \eta^{1}-\mathrm{O}_{2}\right)$ peroxide species with a cis-geometry $\left({ }^{\mathrm{C}} \mathbf{P}\right)$, the first known example of this type. In total, three different structural analogues of this compound could be isolated and crystallographically characterised, which differ only in the identity of the alkali metal cation and counteranion (MX) present. A remarkable structural feature of all of these compounds in the solid state is the close contact of the peroxide moiety with the co-crystallised alkali metal cation. This side-on binding interaction is facilitated by the unique peroxide bonding arrangement, which furthermore exhibits a significant torsion angle in all cases. The effect that this has on the magnetic coupling between the two copper(II) ions is investigated in more detail in the following chapter. Whether the aforementioned alkali metal cation binding interaction persists in solution is also addressed, as is the possible interplay between these two factors.

Interpretation of the findings described in this section have been greatly aided by the outcome of the preceding chapter. In the same way, several of the results elaborated on here with respect to the copper-dioxygen adducts studied may have significant implications for the subsequently investigated reactivity of these species. Of particular significance in this regard is the observation of transient copper-superoxo species in both the $\left[\mathrm{Cu}^{\prime \prime}{ }_{2} \mathbf{L}^{2}\left(\mathrm{O}_{2}\right)\right]^{\mathrm{X}}$ and $\left[\mathrm{Cu}^{11}{ }_{2} \mathbf{L}^{3}\left(\mathbf{O}_{2}\right)\right]^{\mathrm{X}}$ systems, especially given that the reactivity studies described in Chapter 6 were performed with in situ generated material.

In conclusion, the results described in this chapter have provided insights with regard to many aspects of the systems investigated. A role for water in the formation of $\left[\left(\mathrm{Cu}_{2}{ }_{2} \mathrm{~L}^{1}\right)_{2}\left(\mathrm{O}_{2}\right)(\mathrm{OH})_{2}\right]^{\mathrm{X}}$ could be established. In addition, the thermally labile intermediates which result in solution upon reaction of the $\left[\mathrm{Cu}_{2}{ }_{2} \mathbf{L}^{2}\right]^{\mathrm{X}}$ and $\left[\mathrm{Cu}_{2}{ }_{2} \mathbf{L}^{3}\right]^{\mathrm{X}}$ systems with dioxygen could be characterised in detail. This revealed complex speciation for the $\left[\mathrm{Cu}_{2}{ }_{2} \mathbf{L}^{2}\left(\mathbf{O}_{2}\right)\right]^{\mathrm{X}}$ system, most likely involving a mixture of intra- and inter-molecular $\mu-\eta^{1}: \eta^{1}-\mathrm{O}_{2}$ peroxide species. The $\left[\mathrm{Cu}_{2}{ }_{2} \mathrm{~L}^{3}\left(\mathrm{O}_{2}\right)\right]^{\mathrm{X}}$ system displayed less complicated behaviour in solution, a likely 
outcome of which was that it could be isolated in the solid state and crystallographically characterised. The structural determination revealed a ${ }^{\mathbf{C}} \mathbf{P}$ binding mode of the dioxygenderived ligand, which represents a novel type of $\mathrm{Cu}_{2} \mathrm{O}_{2}$ adduct, and achieves the synthetic goal outlined at the beginning of this work. 


\section{A Novel Copper-Dioxygen Adduct}

\subsection{Introduction}

Bonding between copper and peroxide in $\mathrm{Cu}_{2} \mathrm{O}_{2}$ species has been extensively investigated owing to relevance to T3 coupled binuclear copper centres (Section 1.2.2). ${ }^{16,18,24,35,190,191}$ The major contributor to $\mathrm{Cu}-\mathrm{O}$ bonding in both the natural $\left({ }^{\mathbf{S}} \mathbf{P}\right)$ and model $\left({ }^{\top} \mathbf{P}\right.$ and $\left.{ }^{\mathrm{S}} \mathbf{P}\right)$ systems is an interaction between one of the two $\mathrm{O}_{2}{ }^{2-} \pi *$ HOMOs and the symmetric combination of copper(II) $\mathbf{d}$ orbitals (Figure 5.1). The planar nature of the ${ }^{\mathbf{T}} \mathbf{P}$ and ${ }^{\mathrm{S}} \mathbf{P}$ cores maximizes this interaction, leading to energetic splitting of both the copper magnetic orbitals and the peroxide HOMOs. This in turn gives rise to the two $\mathrm{O}_{2}{ }^{2-} \pi * \rightarrow \mathrm{Cu}(\mathrm{II}) \mathrm{CT}$ transitions and the strong antiferromagnetic coupling observed in these systems. Furthermore, the $\mathrm{Cu}-\mathrm{O}$ interaction also helps dictate the $\mathrm{O}-\mathrm{O}$ bond strength as it transfers electron density from peroxide $\pi *$ to copper $d$ orbitals. The extent of planarity in these adducts therefore influences the strength of the $\mathrm{Cu}-\mathrm{O}$ bonding interaction, which is reflected in the intensity of the CT transitions, the magnitude of antiferromagnetic coupling, and the strength of the $\mathrm{O}-\mathrm{O}$ bond. It should be noted that the side-on binding mode in ${ }^{\mathrm{S}} \mathbf{P}$ adducts leads to an additional interaction between the antisymmetric combination of copper $d$ orbitals and the higher lying $\mathrm{O}_{2}{ }^{2-} \sigma^{*}$ LUMO. Population of the latter is extremely efficient at weakening the $\mathrm{O}-\mathrm{O}$ bond and accounts for the additional degree of oxygen activation achieved by species when compared with ${ }^{\mathbf{T}} \mathbf{P}$ adducts. ${ }^{16}$
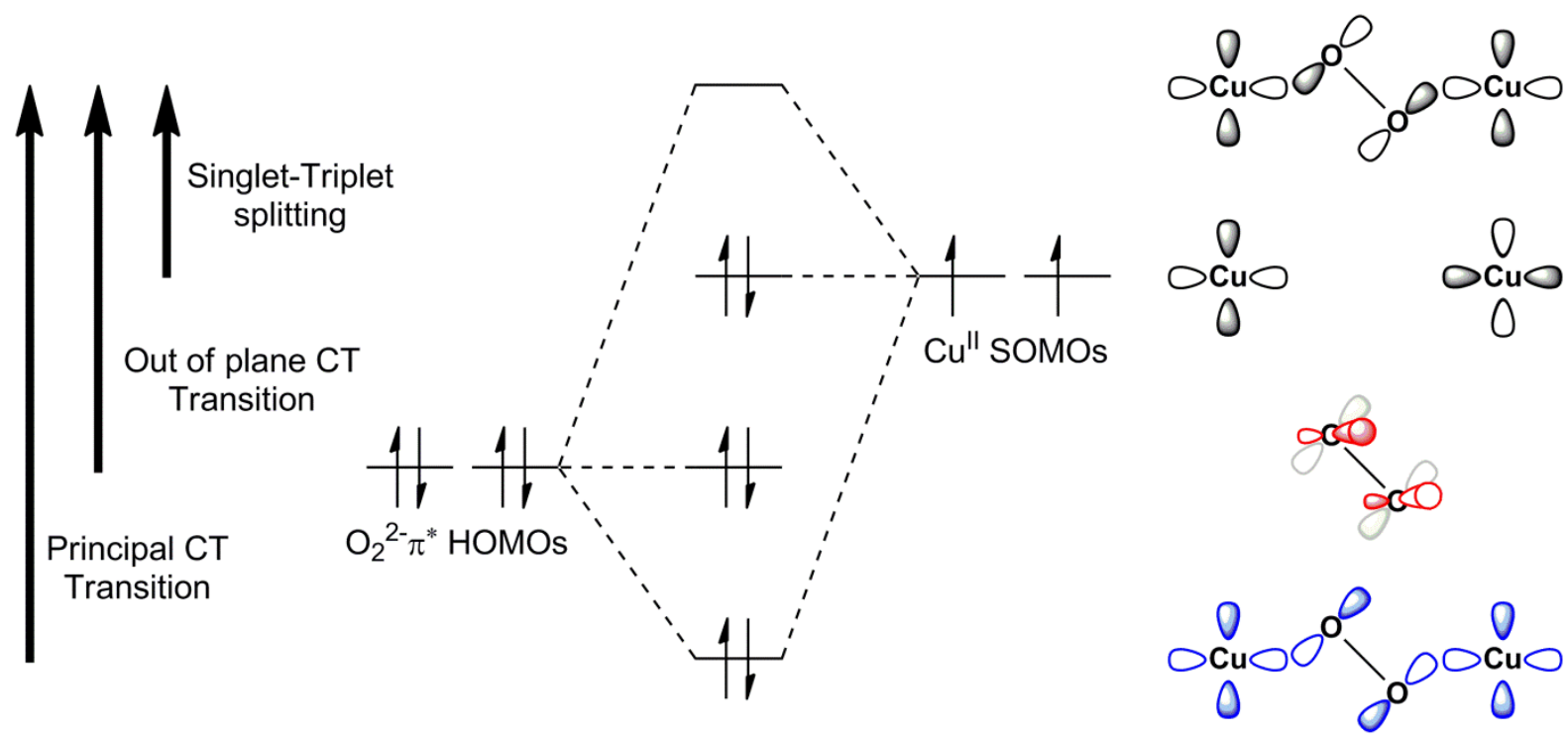

Figure 5.1: Electronic structure of ${ }^{\top} \mathbf{P}$ species, with MOs on the right. On the left are the associated spectroscopic features, which are proportional to the extent of copper(II)-peroxide bonding. 


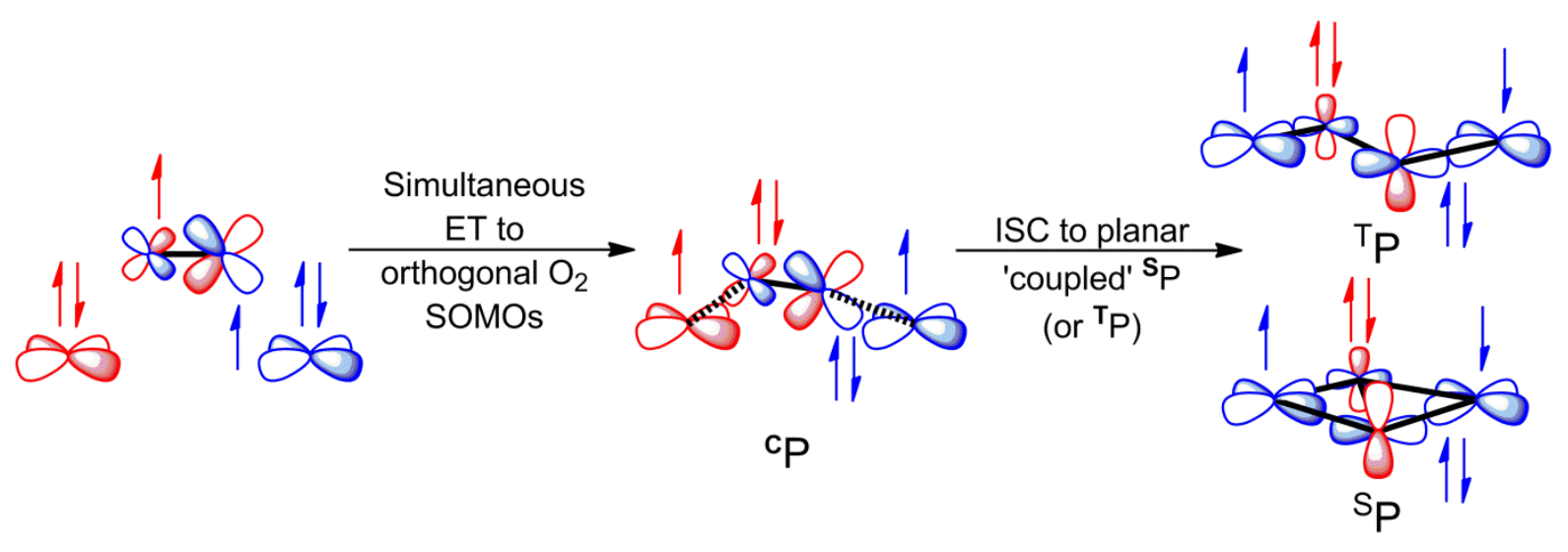

Figure 5.2: Mechanism for $\mathrm{O}_{2}$ binding by $\mathbf{H c}$ (and Tyr), which leads to a singlet state ${ }^{\mathbf{S}} \mathbf{P}$ core (or ${ }^{\top} \mathbf{P}$ in synthetic models). The intermediate is a ${ }^{\mathrm{C}} \mathbf{P}$ type $\mathrm{Cu}_{2} \mathrm{O}_{2}$ adduct.

Although the ${ }^{\top} \mathbf{P}$ species are not considered to be biologically relevant, a DFT study has identified an elegant mechanism for the spin forbidden activation of dioxygen by T3 centres in which a ${ }^{C} \mathbf{P}$ configuration is thought to play a significant role (Figure 5.2). ${ }^{24}$ In the initial stages of $\mathrm{O}_{2}$ binding, this ${ }^{\mathrm{C}} \mathbf{P}$ species has been shown to possess a $\mathrm{Cu}-\mathrm{OO}-\mathrm{Cu}$ torsion angle which allows the two perpendicular $\mathrm{O}_{2}{ }^{2-} \pi *$ orbitals to simultaneously interact with the bimetallic site, each with a different copper(I) ion. This allows synchronous transfer of two electrons of the same spin to orthogonal dioxygen orbitals, reducing $\mathrm{O}_{2}$ to $\mathrm{O}_{2}{ }^{2-}$ and delocalizing the unpaired spins to the distal copper(II) ions. Progression to the planar $\mathrm{Cu}_{2} \mathrm{O}_{2}$ core then establishes a superexchange pathway capable of overcoming spin-spin repulsion and enabling intersystem crossing (ISC) to the coupled singlet state. It should be highlighted that this mechanistic scenario is not applicable to $\mathrm{Cu}_{2} \mathrm{O}_{2}$ model systems which are formed by self-assembly of mononuclear copper(I) complexes, as such reactions generally proceed through copper(II)-superoxo intermediates (Section 1.3.1). Nevertheless, it is still relevant in the case of discrete dinuclear copper(I) complexes such as those discussed in the current work. In fact, the unique ${ }^{\mathbf{C}} \mathbf{P}$ binding mode and $\mathrm{Cu}-\mathrm{OO}-\mathrm{Cu}$ torsion angle found in structure $\left[\mathrm{Cu}^{1{ }^{\prime \prime}} \mathrm{L}^{3}\left(\mathrm{O}_{2}\right)\right]^{\text {OTf }} \cdot$ NaOTf suggest that it may serve as a model for the early stages of T3mediated $\mathrm{O}_{2}$ activation .

The copper $\mathrm{d}$ orbitals depicted in Figure 5.1 and Figure 5.2 are deliberately drawn in a nonspecific fashion. This is in order to highlight the commonalities in electronic structure between the ${ }^{\mathbf{T}} \mathbf{P}$ and ${ }^{\mathbf{S}} \mathbf{P}$ systems, and to show the general applicability of the proposed dinuclear mechanism of oxygen activation. In actuality a distinction between the bonding descriptions for the ${ }^{\top} \mathbf{P}$ and ${ }^{\mathbf{S}} \mathbf{P}$ species arises because of the different geometries adopted by the copper(II) ions in each system. The majority of ' $\mathbf{P}$ species exhibit trigonal bipyramidal geometry with the peroxide donor occupying an axial position. ${ }^{32,159,177}$ In contrast, the copper(II) ions in ${ }^{\mathrm{S}} \mathbf{P}$ adducts predominantly have square pyramidal coordination spheres with the dioxygen-derived ligand making up an edge of the basal plane. ${ }^{14}$ The specific copper $d$ orbitals which contribute to bonding and magnetic properties therefore differ between the two systems, with $\mathrm{d}_{z}{ }^{2}$ and $\mathrm{d}_{x}{ }^{2}-{ }_{y}{ }^{2}$ SOMOs for the ${ }^{\mathrm{T}} \mathbf{P}$ and ${ }^{\mathbf{S}} \mathbf{P}$ adducts, respectively. $^{2}$ A detailed theoretical analysis of the physicochemical properties of 
$\left[\mathrm{Cu}_{2}{ }_{2} \mathbf{L}^{3}\left(\mathbf{O}_{2}\right)\right]^{\text {OTf }} \cdot$ NaOTf must take this into account. However, the general concepts conveyed above apply equally to both the ${ }^{\top} \mathbf{P}$ and ${ }^{\mathbf{S}} \mathbf{P}$ systems, and are sufficient for understanding the qualitative description of bonding discussed in this chapter. 


\subsection{Bonding in $\left[\mathrm{Cu}_{2}{ }_{2} \mathrm{~L}^{3}\left(\mathrm{O}_{2}\right)\right]^{\mathrm{X}}$}

\subsubsection{Magnetism}

Preliminary attempts to assess the molecular size of $\left[\mathrm{Cu}^{11}{ }_{2} \mathrm{~L}^{3}\left(\mathbf{O}_{2}\right)\right]^{\text {OTf }} \cdot$ NaOTf by ${ }^{1} \mathrm{H}$ NMR DOSY at $-30{ }^{\circ} \mathrm{C}$ showed only extremely broad $(>100 \mathrm{~Hz})$, paramagnetically shifted $(\delta=5-54 \mathrm{ppm})$ resonances, already providing some insight into the magnetic properties of $\left[\mathrm{Cu}_{2}{ }_{2} \mathbf{L}^{3}\left(\mathrm{O}_{2}\right)\right]^{\mathrm{OTf}}$. NaOTf. It was also found to be surprisingly stable in the solid state by qualitative methods (heating to $60{ }^{\circ} \mathrm{C}$ or applying vacuum overnight caused no significant decomposition as monitored by $\mathrm{rR}$ ). Although comparable data is lacking for $\left[\mathrm{Cu}_{2}{ }_{2} \mathrm{~L}^{3}\left(\mathrm{O}_{2}\right)\right]^{\mathrm{OTf}} \cdot \mathrm{KOTf}$ and $\left[\mathrm{Cu}_{2}{ }_{2} \mathrm{~L}^{3}\left(\mathrm{O}_{2}\right)\right]^{\mathrm{ClO}} \cdot \mathrm{KClO}_{4}$, the robust nature of $\left[\mathrm{Cu}_{2}{ }_{2} \mathrm{~L}^{3}\left(\mathrm{O}_{2}\right)\right]^{\mathrm{OTf}} \cdot \mathrm{NaOTf}$ may be tentatively attributed to shielding of the peroxide moiety provided by the cocrystallised NaOTf, analogous to that of the $\left[\mathrm{B}\left(\mathrm{C}_{6} \mathrm{H}_{5}\right)_{4}\right]^{-}$counteranion recently observed by Schindler and co-workers. ${ }^{32}$ This high thermal stability in the solid state allowed for further investigation of the magnetic properties of $\left[\mathrm{Cu}_{2}{ }_{2} \mathrm{~L}^{3}\left(\mathrm{O}_{2}\right)\right]^{\text {OTf }} \cdot \mathrm{NaOTf}$ by SQUID magnetometry.

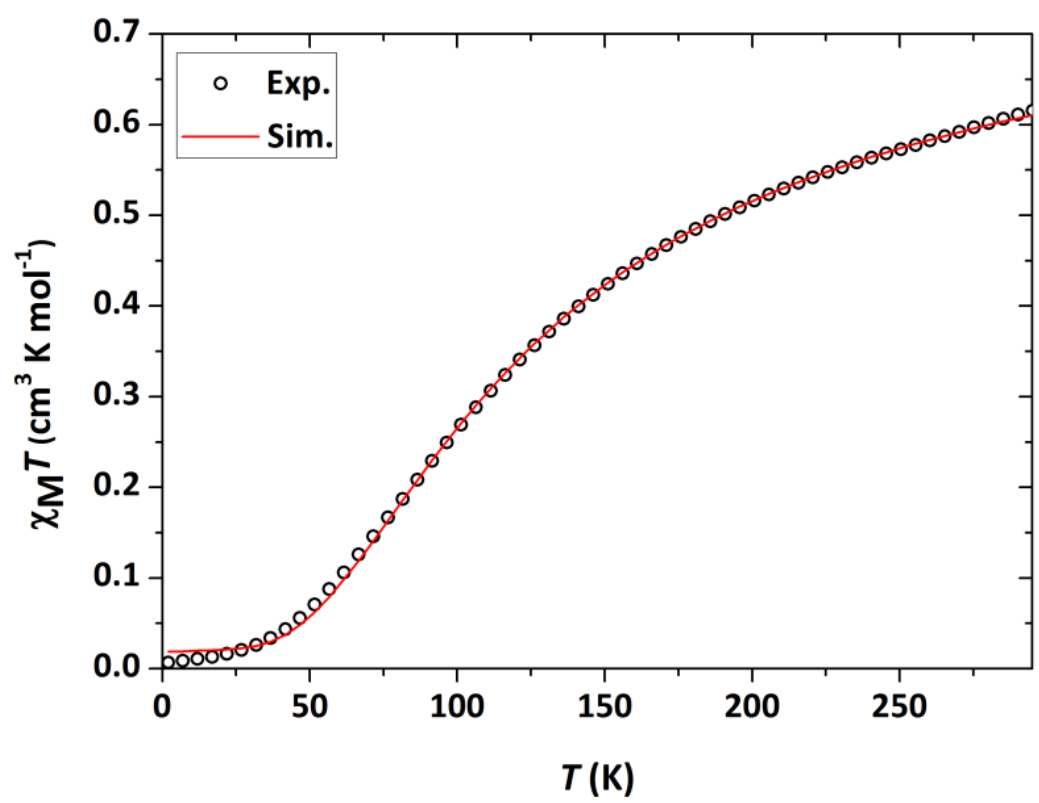

Figure 5.3: Temperature dependence of the $\chi_{M} T$ product for $\left[\mathrm{Cu}_{2}{ }_{2} \mathrm{~L}^{3}\left(\mathbf{O}_{2}\right)\right]^{\text {OTf }} \cdot$ NaOTf between 2 and $295 \mathrm{~K}$. The red line shows the best fit curve obtained with the following parameters: $J\left(\mathrm{~cm}^{-1}\right)=-77 ; \mathrm{g}=2.0$ (fixed); $P I(\%)=$ 4.9; $\operatorname{TIP}\left(\mathrm{cm}^{3} \mathrm{~mol}^{-1}\right)=1.2 \times 10^{-4}$.

The magnetic susceptibility data (Figure 5.3) indicate an $S=0$ ground state with a singlettriplet splitting of $-2 J=144 \mathrm{~cm}^{-1}\left(-2 J \mathrm{~S}_{1} \mathrm{~S}_{2}\right.$ model, see Experimental Section 8.8 for details). This value is significantly smaller than those experimentally determined as $-2 \mathrm{~J} \geq 600 \mathrm{~cm}^{-1}$ for the essentially diamagnetic ${ }^{\top} \mathbf{P}$ species $\left[(\mathrm{TMPA})_{2} \mathrm{Cu}_{2}\left(\mathrm{O}_{2}\right)\right]^{2+}(\mathrm{TMPA}=\text { see table } 1)^{192}$ and ${ }^{\mathrm{S}} \mathbf{P}$ species oxyhemocyanin $(\mathrm{oxyHc})^{193}$ and $\left[(\mathrm{N} 4) \mathrm{Cu}_{2}\left(\mathrm{O}_{2}\right)\right]^{2+}\left(\mathrm{N} 4=\mathrm{N}, \mathrm{N}, \mathrm{N}^{\prime}, \mathrm{N}^{\prime}\right.$-tetrakis(2-(pyridin-2yl)ethyl)butane-1,4-diamine). ${ }^{192}$ 
When present as the only pathway between two $\mathrm{Cu}(\mathrm{II})$ ions the pyrazolate unit mediates relatively weak to moderate $\left(-2 J=-26\right.$ to $\left.-70 \mathrm{~cm}^{-1}\right)$ antiferromagnetic coupling. ${ }^{194-196}$ To provide further reference data, magnetic measurements were also conducted for the related pyrazole-supported dinuclear copper(II) complex $\left[\mathrm{Cu}^{\prime \prime}{ }_{2} \mathbf{L}^{3}\left(\mathbf{H}_{3} \mathrm{O}_{2}\right)\right]^{\text {(OTf)2 }}$ (Section 6.2.1), which is structurally analogous with $\left[\mathrm{Cu}^{11}{ }_{2} \mathrm{~L}^{3}\left(\mathrm{O}_{2}\right)\right]^{\text {OTf }} \cdot \mathrm{NaOTf}$ apart from the replacement of the peroxide bridge by a water/hydroxide $\mathrm{H}_{3} \mathrm{O}_{2}$ moiety. Coupling through the latter $\mathrm{H}$ bonded functionality should be negligible, ${ }^{196}$ thus giving an estimate for the magnetic interaction produced by the pyrazole bridge alone. The data (Figure 5.4) once again show an $S=0$ ground state with a singlet-triplet splitting of $-2 J=72 \mathrm{~cm}^{-1}$.

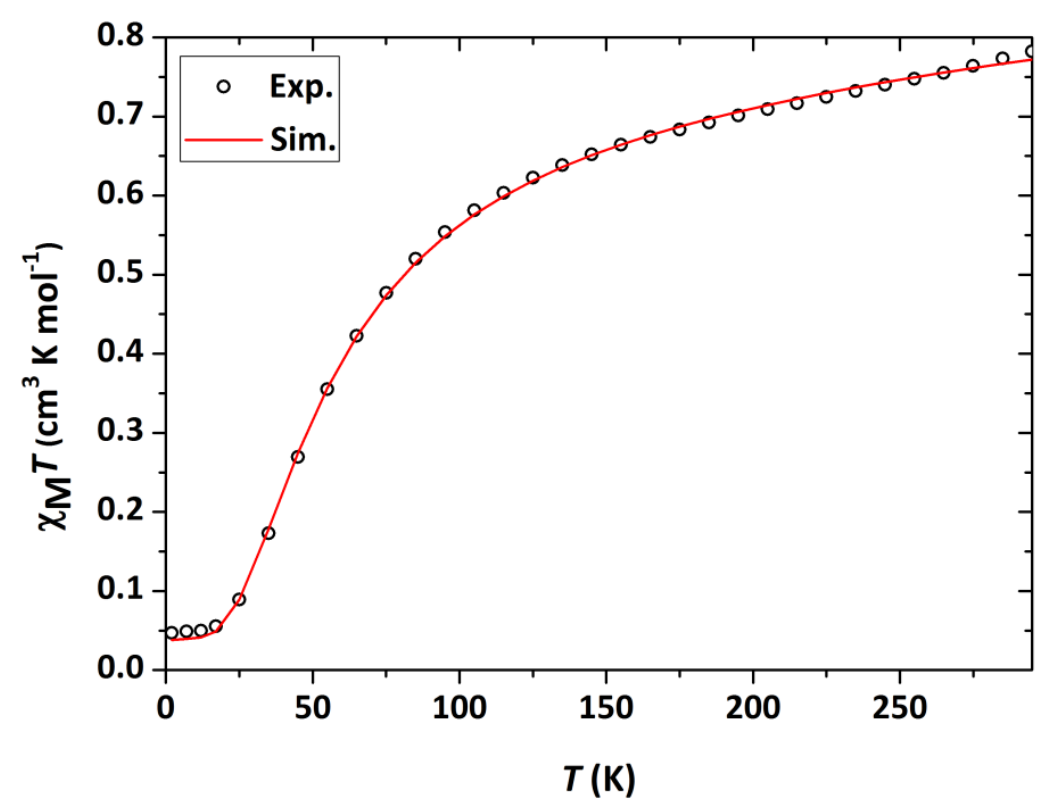

Figure 5.4: Temperature dependence of the $\chi_{M} T$ product for $\left[\mathrm{Cu}_{2}{ }_{2} \mathrm{~L}^{3}\left(\mathbf{H}_{3} \mathbf{O}_{2}\right)\right]^{(\mathrm{OTf}) \mathbf{2}}$ between 2 and $295 \mathrm{~K}$. The red line shows the best fit curve obtained with the following parameters: $J\left(\mathrm{~cm}^{-1}\right)=-36 ; \mathrm{g}=2.07 ; P I(\%)=10.0 ; \operatorname{TIP}$ $\left(\mathrm{cm}^{3} \mathrm{~mol}^{-1}\right)=2.7 \times 10^{-4}$. 


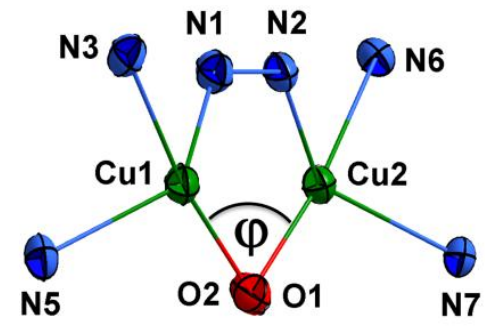

$\varphi=65.2^{\circ}$

Figure 5.5: The tosion angle $(\varphi)$ in $\left[\mathrm{Cu}_{2}{ }_{2}{ }^{3}{ }^{3}\left(\mathrm{O}_{2}\right)\right]^{\text {OTf }}$.NaOTf looking down the O1-O2 bond (N4 and N8 omitted for clarity). This angle in part gives rise to the weak antiferromagnetic coupling.

The superexchange contribution from the peroxide bridge in $\left[\mathrm{Cu}_{{ }_{2}}{ }_{2} \mathbf{L}^{3}\left(\mathrm{O}_{2}\right)\right]^{\mathrm{OTf}} \cdot \mathrm{NaOTf}$ is thus extremely diminished when compared with that of ${ }^{\top} \mathbf{P}$ and ${ }^{S} \mathbf{P}$ species. This can be rationalized by taking into account the unique bonding situation in $\left[\mathrm{Cu}^{1{ }^{\prime \prime}} \mathrm{L}^{3}\left(\mathrm{O}_{2}\right)\right]^{\text {OTf }} \cdot$ NaOTf. It was previously shown that the magnetic coupling in dinuclear copper(II) and nickel(II) complexes supported by pyrazolate-bridging ligand scaffolds strongly depends on the torsion angle along the pyrazolate $\mathrm{N}-\mathrm{N}$ bond ${ }^{85,86}$ and along the exogenous ligand. With respect to the latter, a ( $\mu_{1,3}$-azido)( $\mu$-pyrazolato)dinickel(II) complex was found to undergo reversible thermally induced conformational switching in the solid state, exhibiting a pronounced change in antiferromagnetic coupling $\left(-2 J=-162 \mathrm{~cm}^{-1}\right.$ versus $-48 \mathrm{~cm}^{-1}$ ) between the two conformers as a result of the differing $\mu_{1,3}$-azido torsion angles $\left(\mathrm{Ni}-\mathrm{NNN}-\mathrm{Ni}=4.3^{\circ}\right.$ vs $-46.6^{\circ}$, respectively). ${ }^{197}$ In the case of torsion angles approaching $90^{\circ}$, only orthogonal orbitals of the bridging ligand will be able to interact with the metal-based SOMOs, leading to ferromagnetic coupling. ${ }^{85,86}$ The $\mathrm{Cu}-\mathrm{OO}-\mathrm{Cu}$ torsion angle of $65.2^{\circ}$ in $\left[\mathrm{Cu}_{2}{ }_{2} \mathbf{L}^{3}\left(\mathrm{O}_{2}\right)\right]^{\mathrm{OTf}} \cdot$ NaOTf is thus in accordance with relatively weak antiferromagnetic coupling (Figure 5.5). 


\subsubsection{Biological relevance}

\begin{tabular}{|c|c|c|c|c|c|c|c|c|c|c|}
\hline \multicolumn{2}{|c|}{ Table 5.1: Selected metric and spectroscopic parameters of crystallographically characterised $\mathrm{Cu}{ }_{2}\left(\mu_{-1} \eta^{1}: \eta^{1}-\mathrm{O}_{2}\right)$} \\
complexes.
\end{tabular}

It is interesting to note that when taken together, the data for $\left[\mathrm{Cu}_{2}{ }_{2} \mathrm{~L}^{3}\left(\mathbf{O}_{2}\right)\right]^{\text {OTf }} \cdot$ NaOTf show that it indeed possesses characteristics that would be expected in an early stage of oxygen binding to T3 dicopper sites, as exemplified by comparison to the known $\mathrm{Cu}_{2}{ }_{2}\left(\mu-\eta^{1}: \eta^{1}-\mathrm{O}_{2}\right)$ species. The $\mathrm{Cu}-\mathrm{O}$ stretching vibration is found near $450 \mathrm{~cm}^{-1}$, lower by far than any other reported. This suggests a reduced degree of covalency, further supported by the molar extinction coefficient of $\approx 3000 \mathrm{M}^{-1} \mathrm{~cm}^{-1}$, which indicates that the peroxide $\pi^{*}$-donor interaction is significantly diminished. ${ }^{35,198}$ This in turn is reflected in the O-O stretching frequency of $799 \mathrm{~cm}^{-1}$, which is among the lowest reported values for $\mathrm{Cu}_{2}{ }_{2}\left(\mu-\eta^{1}: \eta^{1}-\mathrm{O}_{2}\right)$ species, and is consistent with the long O-O bond length of $1.498 \AA$ which lies at the upper limit of those known. These observations can be qualitatively explained by considering the description of bonding discussed earlier (Section 5.1). ${ }^{16,191}$ As a result of the torsion angle in $\left[\mathrm{Cu}_{2}{ }_{2} \mathbf{L}^{3}\left(\mathrm{O}_{2}\right)\right]^{\mathrm{OTf}} \cdot \mathrm{NaOTf}$, interaction between the valence peroxide and $\mathrm{Cu}$ orbitals is significantly reduced. This leads to a decrease in the covalency of the $\mathrm{Cu}-\mathrm{O}$ bonds while at the same time hindering the $\mathrm{O}_{2}{ }^{2-} \pi^{*} \rightarrow \mathrm{Cu}(\mathrm{II})$ charge transfer donation, resulting in more electron density in orbitals which are antibonding with respect to the $\mathrm{O}-\mathrm{O}$ bond. In addition, overlap of a single $\mathrm{O}_{2}{ }^{2-} \pi^{*}$ orbital with both half-filled $\mathrm{Cu}(\mathrm{II})$ orbitals is not possible. The torsion angle in $\left[\mathrm{Cu}^{1{ }^{11}} \mathrm{~L}^{3}\left(\mathrm{O}_{2}\right)\right]^{\text {OTf }}$.NaOTf in fact makes interaction with orthogonal $\mathrm{O}_{2}{ }^{2-} \pi^{*}$ 
orbitals much more feasible (Figure 5.5). This attenuates the superexchange pathway and results in weak antiferromagnetic coupling relative to ${ }^{\top} \mathbf{P}$ and ${ }^{\mathbf{S}} \mathbf{P}$ species, indicating that $\left[\mathrm{Cu}_{2}{ }_{2} \mathrm{~L}^{3}\left(\mathrm{O}_{2}\right)\right]^{\text {OTf }} \cdot$ NaOTf lies close to the border of the ISC event. $\left[\mathrm{Cu}_{2}{ }_{2} \mathrm{~L}^{3}\left(\mathrm{O}_{2}\right)\right]^{\text {OTf }} \cdot$ NaOTf thus represents a snapshot of an intermediate in the binding of $\mathrm{O}_{2}$ to $\mathrm{Hc}$, and provides strong experimental support for the aforementioned mechanism of dioxygen activation.

The above interpretation is largely qualitative, and relies heavily on the general bonding scenario described earlier (Section 5.1) being applicable to the herein discussed $\left[\mathrm{Cu}_{2}{ }_{2} \mathbf{L}^{3}\left(\mathrm{O}_{2}\right)\right]^{\mathrm{OTf}}$. NaOTf system. In this regard, it must be highlighted that the MO diagram (Figure 5.1) is strictly valid only for planar copper-peroxide systems with close to trigonal bipyramidal or square pyramidal geometries. In fact, several ${ }^{\top} \mathbf{P}$ adducts have been reported which display atypical UV-vis spectra, in comparison to those generally observed for ' $\mathbf{P}$ species, as a result of distortions away from ideal trigonal bipyramidal geometry. ${ }^{45,120,167,199}$ The $\left[\mathrm{Cu}_{2}{ }_{2} \mathrm{~L}^{3}\left(\mathrm{O}_{2}\right)\right]^{\text {OTf }}$. NaOTf system possesses a non-planar copper-peroxide core, and the coordination spheres of the copper(II) ions in $\left[\mathrm{Cu}_{2}{ }_{2} \mathrm{~L}^{3}\left(\mathrm{O}_{2}\right)\right]^{\text {OTf }}$. NaOTf display $\tau$ factors of 0.59 and 0.57 . This places their geometries approximately midway between trigonal bipyramidal and square pyramidal. Deviation from ideal spatial arrangements facilitates mixing of other $\mathrm{d}$ orbital character into the copper SOMOs, ${ }^{35}$ thereby altering the overlap between the orbitals involved in bonding. The geometric features of $\left[\mathrm{Cu}_{2}{ }_{2} \mathrm{~L}^{3}\left(\mathrm{O}_{2}\right)\right]^{\mathrm{OTf}} \cdot$ NaOTf are therefore likely to result in significant differences in the bonding contribution of the individual orbitals, and the degree of mixing required to construct the MOs in the final adduct. Despite this, the overall appearance of the UV-vis spectrum of $\left[\mathrm{Cu}_{2}{ }_{2} \mathrm{~L}^{3}\left(\mathrm{O}_{2}\right)\right]^{\text {OTf }}$. NaOTf is in good agreement with those of the of typical ${ }^{\top} \mathbf{P}$ adducts. An in-depth theoretical investigation of the bonding in $\left[\mathrm{Cu}_{2}{ }_{2} \mathrm{~L}^{3}\left(\mathrm{O}_{2}\right)\right]^{\mathrm{OTf}} \cdot$.NaOTf is thus a topic of future interest.

\subsection{Alkali cation binding in solution}

On the basis of the crystallographic structural determinations of $\left[\mathrm{Cu}^{1{ }^{\prime \prime}} \mathrm{L}^{3}\left(\mathrm{O}_{2}\right)\right]^{\text {OTf }} \cdot$ NaOTf, $\left[\mathrm{Cu}_{2}{ }_{2} \mathrm{~L}^{3}\left(\mathrm{O}_{2}\right)\right]^{\mathrm{OTf}} \cdot \mathrm{KOTf}$ and $\left[\mathrm{Cu}_{2} \mathrm{~L}^{3}\left(\mathrm{O}_{2}\right)\right]^{\mathrm{ClO} 4} \cdot \mathrm{KClO}_{4}$ discussed earlier, it appears likely that the alkali metals present have an influence upon the $\mathrm{Cu}-\mathrm{OO}-\mathrm{Cu}$ torsion angle. As this change in torsion angle is predicted to have a significant effect on the magnetic coupling, the corresponding alkali metal free analogue of these species was sought after. In this regard it is worth noting that the solid state structures of $\left[\mathrm{Cu}_{2}{ }_{2} \mathrm{~L}^{3}\left(\mathrm{O}_{2}\right)\right]^{\mathrm{OTf}} \cdot \mathrm{NaOTf},\left[\mathrm{Cu}_{2}{ }_{2} \mathrm{~L}^{3}\left(\mathrm{O}_{2}\right)\right]^{\text {OTf }} \cdot$ KOTf and $\left[\mathrm{Cu}_{2}{ }_{2} \mathrm{~L}^{3}\left(\mathrm{O}_{2}\right)\right]^{\mathrm{ClO4}} \cdot \mathrm{KClO}_{4}$ give no measure of the extent of alkali metal association in solution. Indeed, it is feasible that the cation coordinated adducts are a minor component at equilibrium, and favoured only by their removal upon crystallisation. Selection of a less coordinating counteranion in such a scenario could therefore potentially allow for isolation of the desired alkali metal free species. Furthermore, interaction of redox-inactive Lewis acidic metal cations with transition metal-oxygen adducts, such as calcium, zinc and scandium binding to high-valent manganese- or iron-oxo species, has been shown to significantly influence the reactivity of the oxo species, and is currently a topic of considerable interest in the literature. ${ }^{200-205}$ Very recently, such modulation of reactivity was 
also demonstrated in a mononuclear $\mathrm{Fe}^{\mathrm{III}}\left(\eta^{2}-\mathrm{O}_{2}\right)$ peroxo species. $^{206}$ Thus, $\left[\mathrm{Cu}_{2}{ }_{2} \mathbf{L}^{3}\left(\mathrm{O}_{2}\right)\right]^{\text {OTf }}$.NaOTf was thus used as a model system in order to further investigate the association of sodium ions in solution.

\subsubsection{Solid State versus Solution for $\left[\mathrm{Cu}_{2}{ }_{2} \mathrm{~L}^{3}\left(\mathrm{O}_{2}\right)\right]^{\mathrm{OTf}} \cdot \mathrm{NaOTf}$}

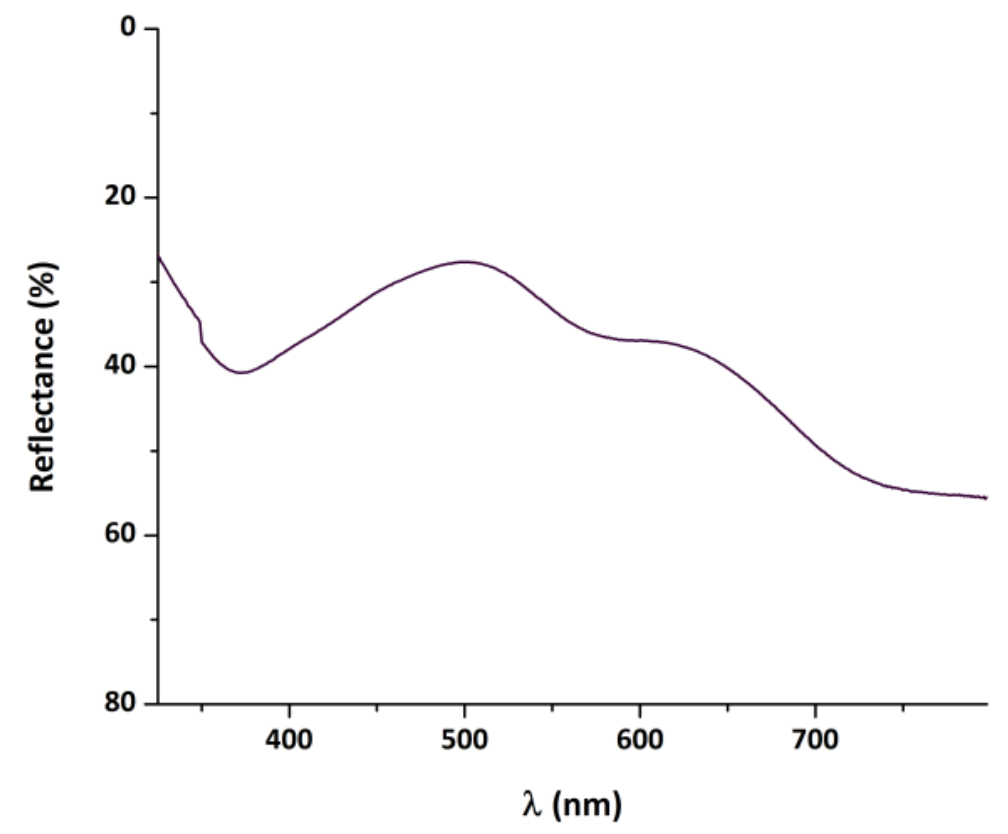

Figure 5.6: Reflectance spectrum of crystalline $\left[\mathrm{Cu}_{2}{ }_{2}{ }^{3}\left(\mathrm{O}_{2}\right)\right]^{\text {OTf }} \cdot$ NaOTf in the solid state at RT.

As a first step in determining whether the sodium cations found in the crystal structure of $\left[\mathrm{Cu}_{2}{ }_{2} \mathbf{L}^{3}\left(\mathrm{O}_{2}\right)\right]^{\mathrm{OTf}}$. NaOTf remain associated in solution, UV-vis and $\mathrm{rR}$ spectroscopies were carried out in the solid state using crystalline $\left[\mathrm{Cu}_{2}{ }_{2} \mathbf{L}^{3}\left(\mathbf{O}_{2}\right)\right]^{\text {OTf }} \cdot$ NaOTf. The reflectance spectrum was found to be in good agreement with the solution spectra, with a principal band at $500 \mathrm{~nm}$ and a shoulder at approximately $625 \mathrm{~nm}$ (Figure 5.6). On the other hand, rR measurements of $\left[\mathrm{Cu}_{2}{ }_{2} \mathrm{~L}^{3}\left(\mathrm{O}_{2}\right)\right]^{\mathrm{OTf}} \cdot$.NaOTf in the solid state (Figure 5.7) showed a difference of approximately $10 \mathrm{~cm}^{-1}$ in both the $\mathrm{O}-\mathrm{O}$ and $\mathrm{Cu}-\mathrm{O}$ stretches, with the former shifting to lower frequency and the latter to higher. 


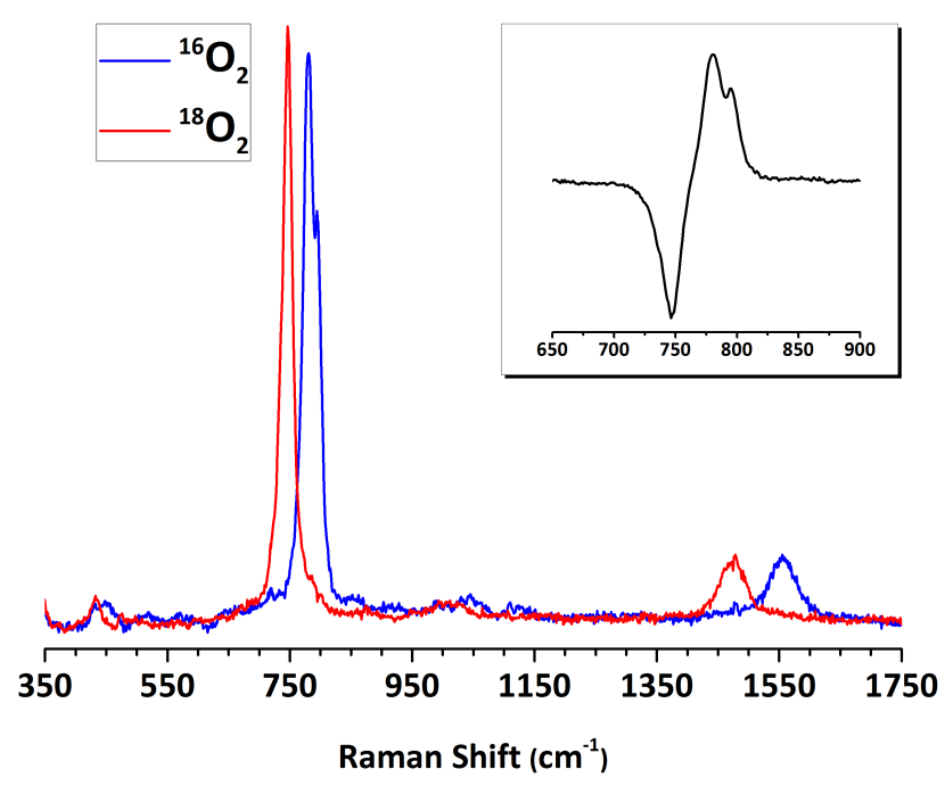

Figure 5.7: Resonance Raman spectrum of $\left[\mathrm{Cu}_{2}{ }_{2} \mathrm{~L}^{3}\left(\mathrm{O}_{2}\right)\right]^{\text {OTf }} \cdot$ NaOTf in the solid state $\left(\lambda_{\text {exc }}=633 \mathrm{~nm}\right)$. The inset shows a difference spectrum for the region containing the $\mathrm{O}-\mathrm{O}$ stretching frequency, showing the Fermi doublet in the ${ }^{16} \mathrm{O}_{2}$ case which disppears when the product is formed with ${ }^{18} \mathrm{O}_{2}$. Spectra were scaled relative to one another.

These changes in the vibrational spectrum are relatively minor and could potentially arise solely from solvation or alteration of the physical state of the sample. On the other hand, it seemed reasonable that interaction of the peroxide moiety with an alkali metal cation would be reflected in the relevant vibrational bands, and thus a more detailed investigation was conducted in solution by $r R$ spectroscopy.

\subsubsection{Solution State Resonance Raman Spectroscopy}

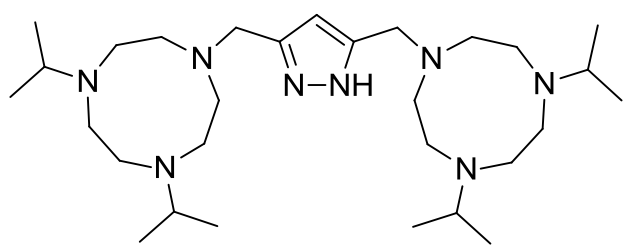

$H L^{3}$

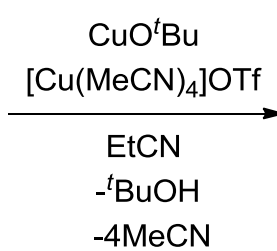

$-4 \mathrm{MeCN}$

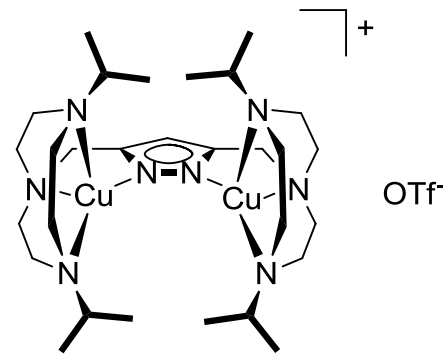

$-\mathrm{M}\left[\mathrm{Cu}_{2}^{\mathrm{I}} \mathrm{L}^{3}\right]^{\mathrm{OTf}}$

Scheme 5.1: Alternative route for preparation of dinuclear copper(I) complex free of alkali metal cations

$$
\left(\left[\mathrm{Cu}_{2}^{\prime} \mathrm{L}^{3}\right]^{-\mathrm{M}}\right) \text {. }
$$

In the previous sections the compound labels $\left[\mathrm{Cu}_{2}{ }_{2} \mathbf{L}^{3}\right]^{\mathrm{X}}$ and $\left[\mathrm{Cu}^{11}{ }_{2} \mathrm{~L}^{3}\left(\mathbf{O}_{2}\right)\right]^{\mathrm{X}}$ were used in a general sense to refer respectively to the $\left[\mathrm{Cu}_{2}{ }_{2} \mathrm{~L}^{3}\right]^{+}$and $\left[\mathrm{Cu}_{2}^{\prime \prime} \mathrm{L}^{3}\left(\mathrm{O}_{2}\right)\right]^{+}$cations present in solution, with the ' $X$ ' being substituted when a particular counteranion was being emphasised. The experiments conducted in the following sections were carried out entirely with $\left[\mathrm{Cu}_{2}^{1} \mathrm{~L}^{3}\right]^{\text {OTf }}$ and $\left[\mathrm{Cu}_{2}{ }_{2} \mathrm{~L}^{3}\left(\mathrm{O}_{2}\right)\right]^{\mathrm{OTf}}$, however, introduction of $\mathrm{NaBPh}_{4}$ is also involved where 
noted. To emphasize the presence or absence of alkali metal cations here, additional superscripts are also used. In order to investigate association of alkali metal cations with $\left[\mathrm{Cu}_{2}{ }_{2} \mathbf{L}^{3}\left(\mathbf{O}_{2}\right)\right]^{\mathrm{X}}$ in solution, the corresponding copper(I) complexes were prepared employing the general method previously outlined (Section 3.1.2). Thus, $\mathrm{HL}^{3}$ was deprotonated using either $\mathrm{NaO}{ }^{t} \mathrm{Bu}\left({ }^{\mathrm{Na}}\left[\mathrm{Cu}_{2}{ }_{2} \mathbf{L}^{3}\right]^{\mathrm{X}}\right)$ or $\mathrm{KO}^{t} \mathrm{Bu}\left({ }^{\mathrm{K}}\left[\mathrm{Cu}_{2}{ }_{2} \mathbf{L}^{3}\right]^{\mathrm{X}}\right)$ and two equivalents of $\left[\mathrm{Cu}(\mathrm{MeCN})_{4}\right] \mathrm{OTf}$. Dinuclear copper(I) complex free of alkali metal cations $\left({ }^{-M}\left[\mathbf{C u}_{2}{ }_{2} \mathbf{L}^{3}\right]^{\mathrm{X}}\right)$ was prepared analogously, with substitution of the metal tert-butoxide salt and one equivalent of $\left[\mathrm{Cu}(\mathrm{MeCN})_{4}\right]$ OTf for $\mathrm{CuO}^{t} \mathrm{Bu}$ (Scheme 5.1).

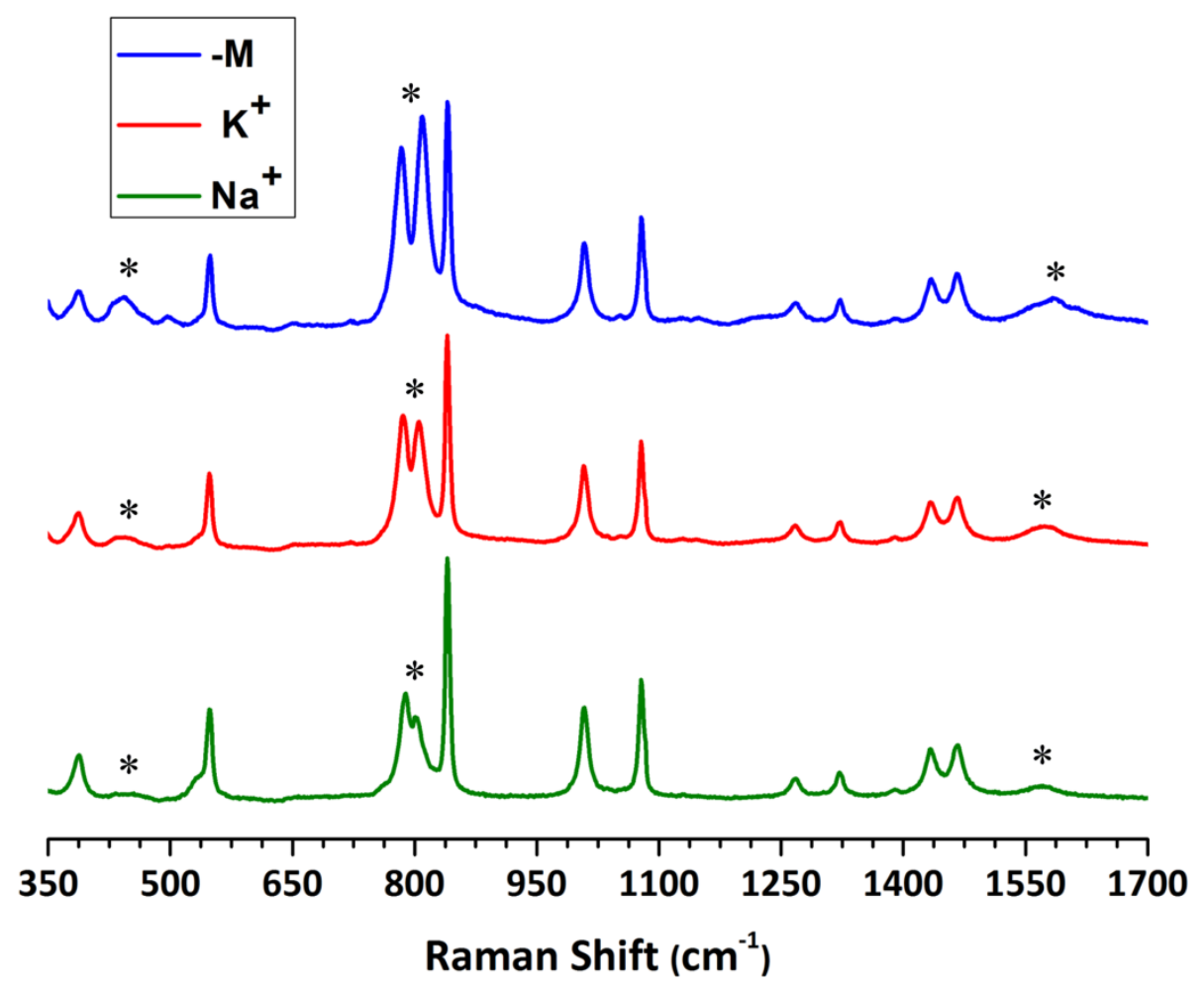

Figure 5.8: Resonance Raman spectra of the reaction product when ${ }^{-\mathrm{M}}\left[\mathrm{Cu}_{2}{ }_{2} \mathrm{~L}^{3}\left(\mathrm{O}_{2}\right)\right]^{\mathrm{OTf}},{ }^{\mathrm{K}}\left[\mathrm{Cu}_{2}{ }_{2}{ }^{3}\left(\mathrm{O}_{2}\right)\right]^{\text {OTf }}$ and ${ }^{\mathrm{Na}}\left[\mathrm{Cu}_{2}{ }_{2} \mathrm{~L}^{3}\left(\mathrm{O}_{2}\right)\right]^{\mathrm{OTf}}$ are exposed to ${ }^{16} \mathrm{O}_{2}$ at $-30{ }^{\circ} \mathrm{C}$ in EtCN $\left(1 \times 10^{-2} \mathrm{M}, \lambda_{\text {exc }}=633 \mathrm{~nm}\right)$. Signals of interest (discussed in the text) are labelled $\left({ }^{*}\right)$. The remaining signals arise from the solvent. Spectra have been scaled relative to these solvent signals, clearly showing the differing analyte signal intensities.

Equimolar solutions of ${ }^{\mathrm{Na}}\left[\mathrm{Cu}_{2}^{\prime} \mathrm{L}^{3}\right]^{\text {OTf }},{ }^{\mathrm{K}}\left[\mathrm{Cu}_{2}{ }_{2} \mathrm{~L}^{3}\right]^{\text {OTf }}$ and ${ }^{-\mathrm{M}}\left[\mathrm{Cu}_{2}^{1} \mathrm{~L}^{3}\right]^{\text {OTf }}$ were oxygenated in EtCN at $-30{ }^{\circ} \mathrm{C}$, giving intense violet solutions of ${ }^{\mathrm{Na}}\left[\mathrm{Cu}_{2}{ }_{2} \mathrm{~L}^{3}\left(\mathrm{O}_{2}\right)\right]^{\text {OTf }},{ }^{\mathrm{K}}\left[\mathrm{Cu}_{2}{ }_{2} \mathrm{~L}^{3}\left(\mathrm{O}_{2}\right)\right]^{\text {OTf }}$ and ${ }^{-M}\left[\mathrm{Cu}_{2}{ }_{2} \mathrm{~L}^{3}\left(\mathrm{O}_{2}\right)\right]^{\mathrm{OTf}}$. Comparison of the resulting $\mathrm{rR}$ spectra with irradiation at $633 \mathrm{~nm}$ showed a trend in the data (Figure 5.8), which is somewhat complicated by the Fermi resonance described in the previous chapter (Section 4.4.2). Close inspection of the corresponding overtone signals significantly simplified the trend, and in order to corroborate this finding the analogous ${ }^{18} \mathrm{O}_{2}$ spectra were also measured. From the combined data it is apparent that the $\mathrm{O}-\mathrm{O}$ stretching vibration loses intensity and is shifted toward lower energy in the presence of sodium ions, in comparison to the alkali metal free sample (Table 5.2). A similar loss in intensity occurs for the $\mathrm{Cu}-\mathrm{O}$ vibration. This feature is then poorly resolved for ${ }^{\mathrm{Na}}\left[\mathrm{Cu}_{2}{ }_{2} \mathrm{~L}^{3}\left(\mathrm{O}_{2}\right)\right]^{\mathrm{OTf}}$, making a definitive assignment of the frequency difficult. When potassium 
ions are present, the intensity and frequency of the $\mathrm{O}-\mathrm{O}$ band is intermediate between the two previously discussed spectra, in agreement with the weaker interaction observed in the crystal structures (Sections 4.4.4 and 4.4.6). A similar difference to that described above for sodium cations is also observed for ${ }^{\mathrm{Na}}\left[\mathrm{Cu}_{2}{ }_{2} \mathrm{~L}^{3}\left(\mathrm{O}_{2}\right)\right]^{\text {OTf }}$ and ${ }^{-\mathrm{M}}\left[\mathrm{Cu}_{2}{ }_{2} \mathrm{~L}^{3}\left(\mathrm{O}_{2}\right)\right]^{\text {OTf }}$ in acetone. These findings suggest that alkali metal cations interact with the dioxygen adduct $\left[\mathrm{Cu}^{\prime \prime}{ }_{2}{ }^{3}\left(\mathbf{O}_{2}\right)\right]^{\mathrm{X}}$ in solution. Further interpretation on the basis of these results alone is difficult, and so further investigation was carried out using UV-vis spectroscopy.

\begin{tabular}{|c|c|c|c|}
\hline & & Compound & \\
\hline Stretch $\left(\mathrm{cm}^{-1}\right)$ & ${ }^{-\mathrm{M}}\left[\mathrm{Cu}_{2}{ }_{2} \mathrm{~L}^{3}\left(\mathrm{O}_{2}\right)\right]^{\mathrm{OTf}}$ & ${ }^{\mathrm{K}}\left[\mathrm{Cu}_{2}{ }_{2} \mathrm{~L}^{3}\left(\mathrm{O}_{2}\right)\right]^{\mathrm{OTf}}$ & ${ }^{\mathrm{Na}}\left[\mathrm{Cu}_{2}{ }_{2} \mathrm{~L}^{3}\left(\mathrm{O}_{2}\right)\right]^{\mathrm{OTf}}$ \\
\hline$\tilde{v}_{\mathrm{O}-0,0 \rightarrow 1}\left({ }^{16} \mathrm{O}_{2}\right)$ & $797^{*}$ & $796^{*}$ & $795^{*}$ \\
\hline$\tilde{v}_{\mathrm{O}-\mathrm{O}, 0 \rightarrow 1}\left({ }^{18} \mathrm{O}_{2}\right)$ & 758 & 756 & 754 \\
\hline$\tilde{v}_{\mathrm{O}-\mathrm{O}, 0 \rightarrow 2}\left({ }^{16} \mathrm{O}_{2}\right)$ & 1585 & 1576 & 1571 \\
\hline$\tilde{v}_{\mathrm{O}-0,0 \rightarrow 2}\left({ }^{18} \mathrm{O}_{2}\right)$ & 1501 & $\#$ & \# \\
\hline $\begin{array}{l}\text { *Exact determination } \\
\text { bands is presented he } \\
\text { "These signals are shif }\end{array}$ & $\begin{array}{l}\text { equencies is compl } \\
\text { nd is more clearly } \\
\text { th solvent bands. }\end{array}$ & $\begin{array}{l}\text { Fermi resonance } \\
{ }^{16} \mathrm{O}_{2} \text { overtone }\end{array}$ & $\begin{array}{l}\text { incipal bands. } \\
\text { incipal the two }\end{array}$ \\
\hline
\end{tabular}




\subsubsection{UV-vis Spectroscopy}

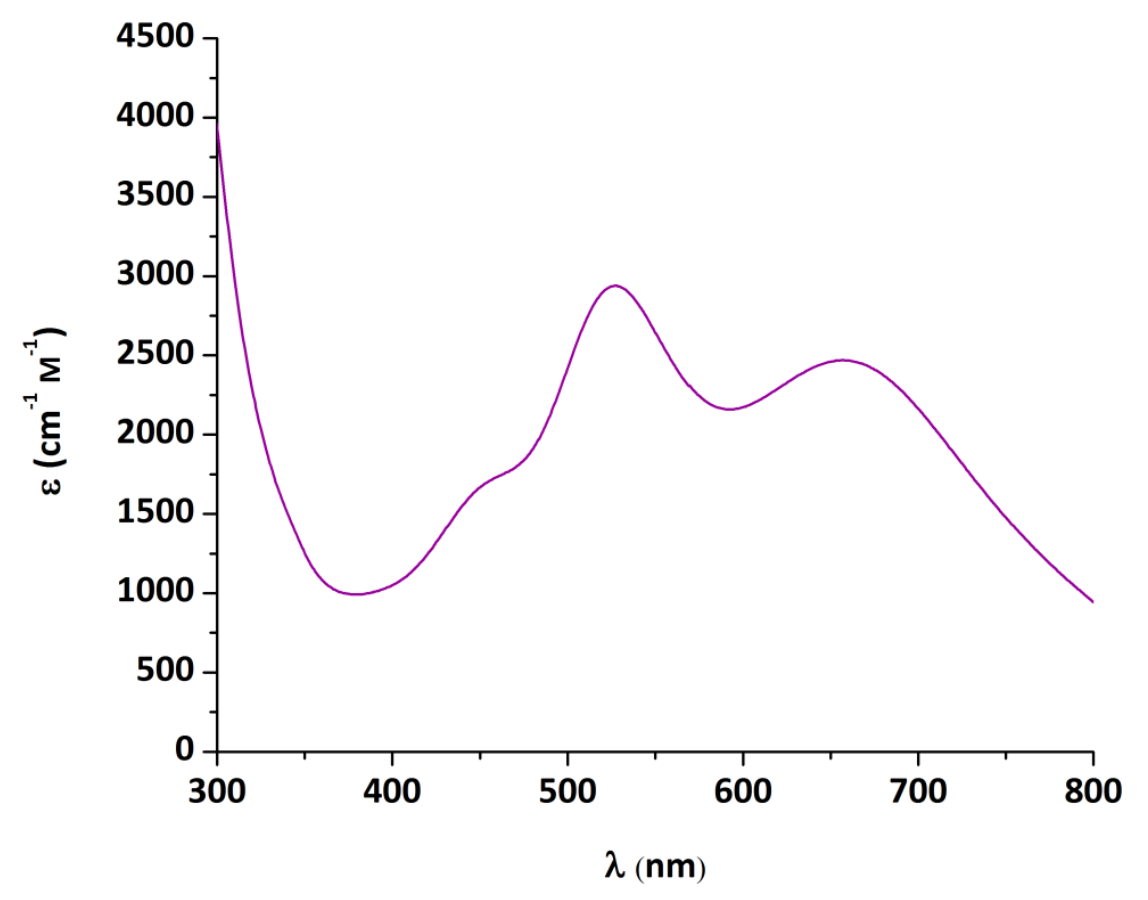

Figure 5.9: UV-vis spectra of ${ }^{\mathrm{Na}}\left[\mathrm{Cu}_{2}{ }_{2} \mathrm{~L}^{3}\left(\mathrm{O}_{2}\right)\right]^{\mathrm{OTf}}$ at RT in $\operatorname{EtCN}\left(2.5 \times 10^{-4} \mathrm{M}\right)$. The product decayed rapidly (see Section 6.3), and the spectrum displayed above was recorded within seconds of sample insertion into the spectrophotometer. The above spectrum is indistinguishable from those of sodium cation free samples.

The experiments described below were conducted at RT in order to facilitate easier handling and allow for high throughput. The results were qualitatively equivalent in both EtCN and $\mathrm{Me}_{2} \mathrm{CO}$. Compared with that of ${ }^{\mathrm{Na}}\left[\mathrm{Cu}_{2}{ }_{2} \mathrm{~L}^{3}\left(\mathrm{O}_{2}\right)\right]^{\text {OTf }}$, no considerable difference in the colour of the dioxygen adduct ${ }^{-\mathrm{M}}\left[\mathrm{Cu}_{2}{ }_{2} \mathrm{~L}^{3}\left(\mathrm{O}_{2}\right)\right]^{\mathrm{OTf}}$ was readily apparent upon visual inspection, however, the corresponding UV-vis spectrum was found to subtly but significantly differ. The two main peaks are red shifted to 530 and $653 \mathrm{~nm}$, the latter has gained considerable intensity such that it is now clearly resolved as a discrete band, and a new feature at approximately $450 \mathrm{~nm}$ is visible as a shoulder on the $530 \mathrm{~nm}$ absorption. While no concentration dependence was evident for solutions of ${ }^{-M}\left[\mathrm{Cu}_{2}{ }_{2} \mathrm{~L}^{3}\left(\mathbf{O}_{2}\right)\right]^{\text {OTf }}$, further investigation revealed that the aforementioned spectra of ${ }^{\mathrm{Na}}\left[\mathrm{Cu}_{2}{ }_{2} \mathrm{~L}^{3}\left(\mathrm{O}_{2}\right)\right]^{\mathrm{OTf}}$ (Section 4.4.2) are observed only for relatively concentrated solutions. Thus, while in good agreement with the solid state reflectance data at high concentrations $\left(\geq 5.0 \times 10^{-3} \mathrm{M}\right)$, at lower concentrations $\left(\leq 2.5 \times 10^{-4}\right.$ M) solution spectra of ${ }^{\mathrm{Na}}\left[\mathrm{Cu}_{2}{ }_{2} \mathrm{~L}^{3}\left(\mathrm{O}_{2}\right)\right]^{\text {OTf }}$ are indistinguishable from those of ${ }^{-\mathrm{M}}\left[\mathrm{Cu}^{\prime \prime}{ }_{2} \mathrm{~L}^{3}\left(\mathrm{O}_{2}\right)\right]^{\text {OTf }}$ (Figure 5.9). An additive spectrum with an intermediate $\lambda_{\max }$ value resulting from overlap of both peak sets was observed at concentrations between these two limiting spectra. 


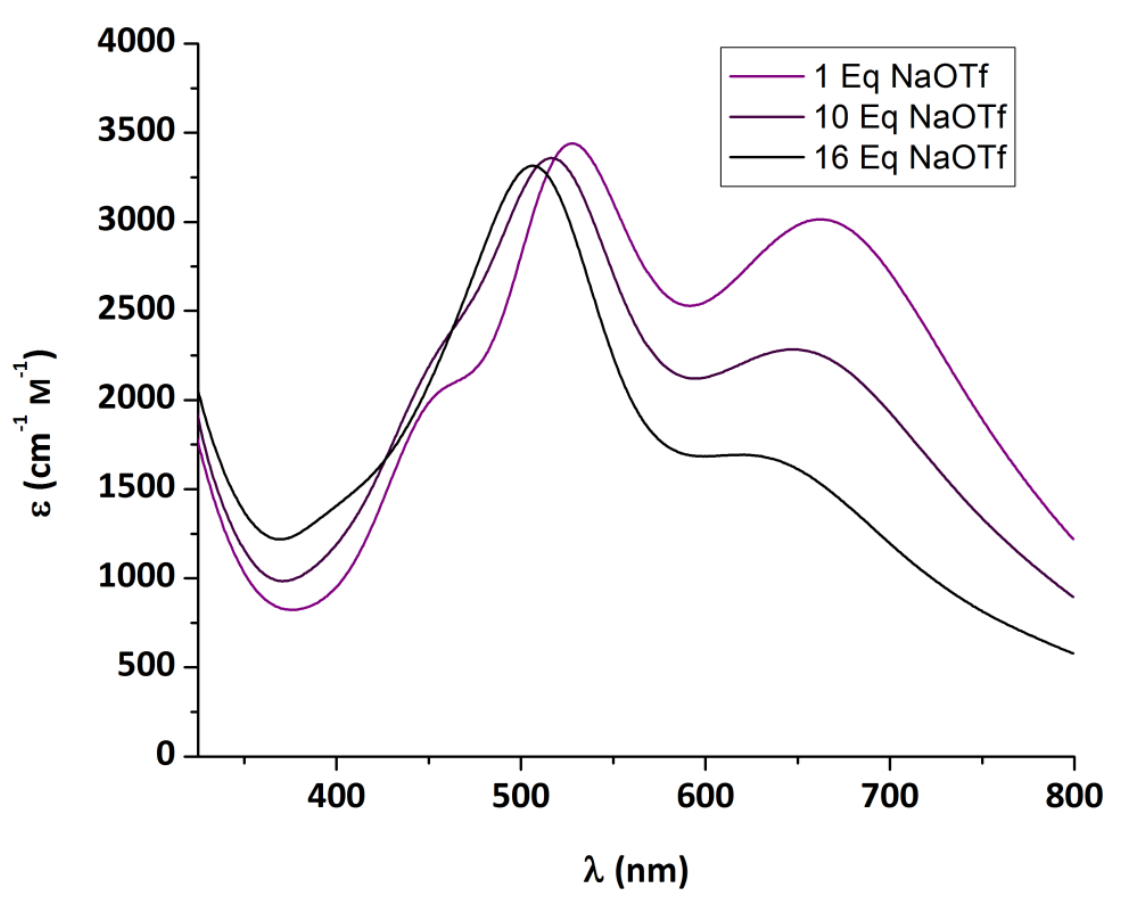

Figure 5.10: Overlay of three RT UV-vis spectra of ${ }^{\mathrm{Na}}\left[\mathrm{Cu}_{2} \mathrm{~L}^{3}\left(\mathrm{O}_{2}\right)\right]^{\mathrm{OTf}}\left(5.0 \times 10^{-4} \mathrm{M}\right)$ in $\mathrm{Me}_{2} \mathrm{CO}$ with increasing $\mathrm{NaOTf}$ presence (total of 1,10 or 16 equivalents). Each spectra was generated with the same stock solution of ${ }^{\mathrm{Na}}\left[\mathrm{Cu}_{2} \mathrm{~L}^{3}\left(\mathrm{O}_{2}\right)\right]^{\mathrm{OTf}}$. The spectra were chosen arbitrarily from within the first minutes after reaction with oxygen.

The influence of sodium cation concentration was then investigated. Formation of ${ }^{\mathrm{Na}}\left[\mathrm{Cu}_{2}{ }_{2} \mathrm{~L}^{3}\left(\mathrm{O}_{2}\right)\right]^{\mathrm{OTf}}$ at low $\left(2.5 \times 10^{-4}\right.$ and $\left.5.0 \times 10^{-4} \mathrm{M}\right)$ concentrations in the presence of increasing amounts of $\mathrm{NaOTf}$ or $\mathrm{NaBPh}_{4}$ thus resulted in spectra with $\lambda_{\max }$ values progressively shifted toward higher wavelength. The extent of the shift correlated with the amount of excess sodium salt added, up to the $500 \mathrm{~nm}$ maximum value observed for the solid state $\left(\left[\mathrm{Cu}_{2}{ }_{2} \mathrm{~L}^{3}\left(\mathrm{O}_{2}\right)\right]^{\mathrm{OTf}}\right.$. NaOTf) and concentrated solutions of ${ }^{\mathrm{Na}}\left[\mathrm{Cu}^{11}{ }_{2} \mathrm{~L}^{3}\left(\mathrm{O}_{2}\right)\right]^{\text {OTf }}$ (Figure 5.10). Interestingly, $\mathrm{NaBPh}_{4}$ was less effective at inducing the change in both solvents, bringing into question the role of triflate anions. Hence, up to nine equivalents of $\left[\mathrm{Bu}_{4} \mathrm{~N}\right] \mathrm{OTf}$ were added to dilute solutions of ${ }^{\mathrm{Na}}\left[\mathrm{Cu}_{2}{ }_{2} \mathrm{~L}^{3}\left(\mathrm{O}_{2}\right)\right]^{\text {OTf }}$ under identical conditions to those used above, which caused no change whatsoever in the resulting UV-vis spectra. This was confirmed by ${ }^{19} \mathrm{~F}$ NMR diffusion-ordered spectroscopy (DOSY) at $-30^{\circ} \mathrm{C}$. Solutions of ${ }^{\mathrm{Na}}\left[\mathrm{Cu}_{2}{ }_{2} \mathrm{~L}^{3}\left(\mathrm{O}_{2}\right)\right]^{\mathrm{OTf}}$ in $\mathrm{CD}_{3} \mathrm{CN}$ or $\left(\mathrm{CD}_{3}\right)_{2} \mathrm{CO}$ displayed diffusion coefficients identical to that of $\left[\mathrm{Bu}_{4} \mathrm{~N}\right] \mathrm{OTf}$, indicating complete dissociation of the triflate anions. Furthermore, the lack of change in the UV-vis spectra upon $\left[\mathrm{Bu}_{4} \mathrm{~N}\right] \mathrm{OTf}$ addition rules out alteration of the ionic strength as a causal factor, which could otherwise conceivably perturb the absorption profile as a result of changes in the solvent permittivity, akin to solvatochroism. ${ }^{207}$ Taken together, the above results indicate that sodium ions specifically bind to the peroxide moiety in solution in a concentration dependent equilibrium, without the involvement of triflate (Scheme 5.2). 

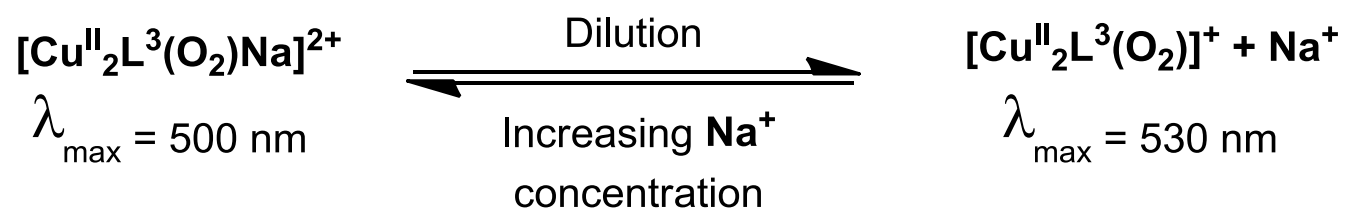

Scheme 5.2: Sodium cation binding equilibrium and associated dominant UV-vis feature.

The equilibrium behaviour described above was qualitatively demonstrated in both $\mathrm{Me}_{2} \mathrm{CO}$ and EtCN at RT. The observation that $\mathrm{NaBPh}_{4}$ is less effective than NaOTf at perturbing the equilibrium was more pronounced in $\mathrm{Me}_{2} \mathrm{CO}$, and might be attributed to the tetraphenylborate anion. Interaction between the phenyl rings and sodium cations in $\mathrm{NaBPh}_{4}$ has been observed in the solid state, such that it can be described as an organosodium compound, ${ }^{208}$ and pairing is known to occur between the two ions in $\mathrm{Me}_{2} \mathrm{CO} / \mathrm{Me}_{2} \mathrm{SO}$ solvent mixtures. ${ }^{209}$ Furthermore, stabilisation of a $\mathrm{Me}_{6}$ tren supported copper(I) complex was recently reported when tetraphenylborate was employed as the counteranion, implying an interaction between the two in solution. ${ }^{32}$ It is thus feasible that $\mathrm{BPh}_{4}{ }^{-}$anions might hinder sodium ion binding to ${ }^{-\mathrm{M}}\left[\mathrm{Cu}_{2}{ }_{2} \mathrm{~L}^{3}\left(\mathrm{O}_{2}\right)\right]^{\mathrm{OTf}}$ in solution, either by providing alternative cation binding sites, or through formation of a tight ion pair.

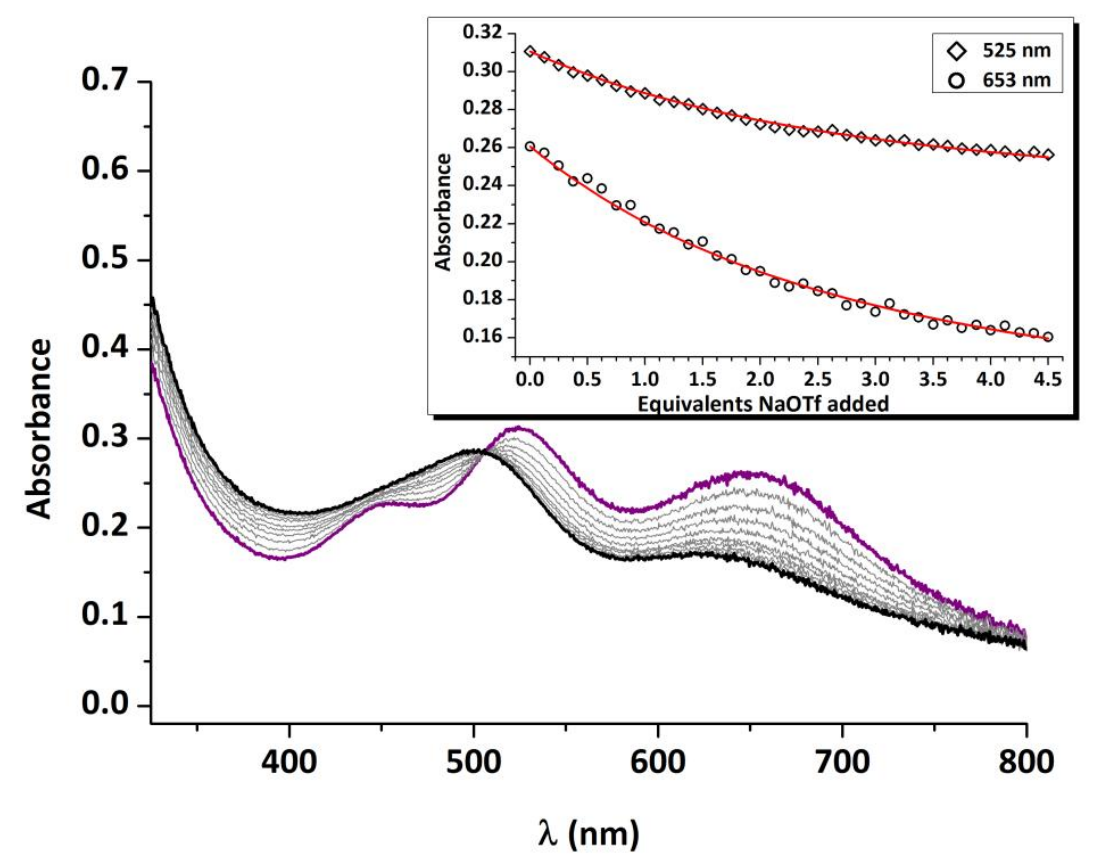

Figure 5.11: UV/Vis spectra of NaOTf titration of ${ }^{\mathrm{Na}}\left[\mathrm{Cu}_{2}{ }_{2} \mathrm{~L}^{3}\left(\mathrm{O}_{2}\right)\right]^{\text {OTf }}$ at $-30{ }^{\circ} \mathrm{C}$ in $\mathrm{Me}_{2} \mathrm{CO}$. The isosbestic point is at $507 \mathrm{~nm}$. The inset shows the changes in absorbance as a function of NaOTf added. The red curves in the inset show the best fit used to derive the binding constant.

In order to quantify the strength of sodium ion binding, pre-formed ${ }^{\mathrm{Na}}\left[\mathrm{Cu}^{\mathrm{II}}{ }_{2} \mathrm{~L}^{3}\left(\mathrm{O}_{2}\right)\right]^{\mathrm{OTf}}$ was then titrated with $\mathrm{NaOTf}$ in $(\mathrm{Me}){ }_{2} \mathrm{CO}$ at $-30^{\circ} \mathrm{C}$. Preliminary measurements indicated that at lower temperatures the binding affinity is significantly enhanced, so smaller relative amounts of NaOTf were required to shift the equilibrium. Thus, the decrease in intensity of the two $\mathrm{CT}$ features of ${ }^{-\mathrm{M}}\left[\mathrm{Cu}_{2}{ }_{2} \mathrm{~L}^{3}\left(\mathrm{O}_{2}\right)\right]^{\text {OTf }}$ at 530 and $653 \mathrm{~nm}$ was monitored as a function of 
$\mathrm{NaOTf}$ added (Figure 5.11), and fitting of the resulting binding isotherm gave an association constant $\left(K_{\mathrm{a}}\right)$ of $1700( \pm 10 \%) \mathrm{M}^{-1}$ for acetone at $-30^{\circ} \mathrm{C}$. Although potassium ion binding in solution was not quantitatively assessed by UV-vis spectroscopy at this point in time, it also clearly occurs. Weaker association is expected, as evidenced by the intermediate frequencies and intensities in the $\mathrm{rR}$ spectra, the longer distance in the solid state structures of $\left[\mathrm{Cu}_{2}{ }_{2} \mathrm{~L}^{3}\left(\mathrm{O}_{2}\right)\right]^{\mathrm{OTf}} \cdot \mathrm{KOTf}$ and $\left[\mathrm{Cu}_{2}{ }_{2} \mathrm{~L}^{3}\left(\mathrm{O}_{2}\right)\right]^{\mathrm{ClO}} \cdot \mathrm{KClO}_{4}$, and preliminary UV-vis data which show a lack of significant change in the absorption spectrum under conditions which the sodium cation has a considerable effect.

\subsubsection{Theoretical Considerations}

The origin of the changes observed in the UV-vis spectrum of ${ }^{-M}\left[\mathrm{Cu}_{2}{ }_{2} \mathrm{~L}^{3}\left(\mathrm{O}_{2}\right)\right]^{\text {OTf }}$ as a result of sodium cation association are not easily assigned without accurate theoretical investigations, but a number of considerations are worthy of further mention. The larger the difference in electronegativity between two elements, the greater the ionic character of a bonding interaction between them. ${ }^{207}$ This general definition of bonding strongly implies that the $\mathrm{Na}-\mathrm{O}$ contact is essentially ionic in nature. The mechanism by which this electrostatic interaction influences the MO energy levels in ${ }^{-M}\left[\mathbf{C u}_{2}{ }_{2} \mathbf{L}^{3}\left(\mathbf{O}_{2}\right)\right]^{\text {OTf }}$ is then of particular interest. It is worth noting that the observed blue shift of the UV-vis spectrum represents an increase in the energy separation between the donor and acceptor orbitals. As mentioned above, one plausible scenario could involve a change in the peroxide torsion angle, which would be expected to directly alter the orbital overlap between copper and oxygen, and therefore also change the resulting MO splitting diagram. An inductive effect might also stabilise individual orbitals without the need for a change in molecular geometry, and a contribution from both of these influencing factors is also plausible. Detailed computational studies would likely offer significant insights in this regard, and are furthermore essential in order to assess the validity of the bonding description discussed above (Section 5.2.2). Nonetheless, the differences in the absorption spectrum of ${ }^{-M}\left[\mathrm{Cu}_{2}{ }_{2} \mathrm{~L}^{3}\left(\mathrm{O}_{2}\right)\right]^{\text {OTf }}$ induced by the presence of sodium cations offer a qualitative explanation for some of the changes observed in the corresponding $r R$ experiments.

The enhancement of vibrational mode intensities in $\mathrm{rR}$ spectroscopy relies on irradiation at a wavelength resonant with excitation of an electronic transition. ${ }^{210}$ Furthermore, the degree of enhancement is proportional to the molar extinction coefficient of the corresponding absorption band. ${ }^{211}$ The $r R$ investigation of alkali metal cation binding performed in the current work was carried out with a fixed laser irradiation wavelength of $633 \mathrm{~nm}$. Inspection of Figure 5.11 reveals that sodium cation association is correlated with a significant decrease in the visible absorption at this wavelength, providing an explanation for the reduction in intensity of the vibrational features observed upon alkali metal binding (Section 5.3.2). Conversely, the vibrational band frequencies probed by this technique are those of the electronic ground state. ${ }^{210}$ The changes observed in the peak positions could potentially arise solely from an inductive effect exerted by the electrostatic interaction of 
the peroxide bridge with the alkali metals, ${ }^{212}$ but such a proposal is highly speculative in the absence of supporting theoretical studies. Variation in the torsion angle could also alter the vibrational frequencies by changing the electronic interaction between copper and oxygen, and once again these uncertainties highlight the need for computational analysis of this system.

\subsection{Summary and Conclusions}

Analysis of the $\left[\mathrm{Cu}_{2}{ }_{2} \mathrm{~L}^{3}\left(\mathrm{O}_{2}\right)\right]^{\mathrm{X}}$ system was carried out by comparing its physicochemical features to those of other known crystallographically characterised ${ }^{\top} \mathbf{P}$ adducts. This revealed a significantly diminished copper-oxygen interaction relative to those in other known 'coupled' $\mathrm{Cu}_{2} \mathrm{O}_{2}$ species. Evidence for this conclusion comes from several sources. The low molar extinction coefficient of $\approx 3000 \mathrm{M}^{-1} \mathrm{~cm}^{-1}$ indicates that the peroxide $\pi^{*}$-donor interaction is significantly diminished. This is further reflected in the $\mathrm{O}-\mathrm{O}$ stretching frequency falling below $800 \mathrm{~cm}^{-1}$ under all conditions. These values are among the lowest reported for $\mathrm{Cu}_{2}{ }_{2}\left(\mu-\eta^{1}: \eta^{1}-\mathrm{O}_{2}\right)$ species, and consistent with the long $\mathrm{O}-\mathrm{O}$ bond length of $1.498 \AA$, which lies at the upper limit of those known. In addition, magnetic susceptibility measurements were carried out on crystalline $\left[\mathrm{Cu}^{11}{ }_{2} \mathrm{~L}^{3}\left(\mathrm{O}_{2}\right)\right]^{\mathrm{OTf}} \cdot \mathrm{NaOTf}$. These revealed that the peroxide bridging moiety in the $\left[\mathrm{Cu}_{2}{ }_{2} \mathrm{~L}^{3}\left(\mathrm{O}_{2}\right)\right]^{\mathrm{OTf}} \cdot \mathrm{NaOTf}$ system mediates only weak antiferromagnetic coupling between the two copper(II) centres, in stark contrast to that generally observed in related di-copper(II)-peroxide adducts.

Taken together, these characteristics are comparable with those of a computationally predicted transition state for $\mathrm{O}_{2}$ binding to T3 copper centers, providing experimental evidence for the proposed mechanism of $\mathrm{O}_{2}$ activation and supporting the biological relevance of the $\mathrm{Cu}_{2}{ }_{2}\left(\mu-\eta^{1}: \eta^{1}-\mathrm{O}_{2}\right)$ cis-species. This novel structure thereby bridges the gap in biological relevance between the end-on and side-on $\mathrm{Cu}_{2}{ }_{2}\left(\mu-\mathrm{O}_{2}\right)$ cores. It is noteworthy in this regard that analogous nonheme diiron cis-peroxo species are also established intermediates in the related $\mathrm{O}_{2}$ activation achieved by enzymes such as soluble methane monooxygenase and ribonucleotide reductase. ${ }^{213,214}$

The peroxide bonding arrangement in the $\left[\mathrm{Cu}_{2}{ }_{2} \mathrm{~L}^{3}\left(\mathrm{O}_{2}\right)\right]^{\mathrm{X}}$ system also allows binding of sodium cations, observed both in the solid state and in solution by UV-vis and resonance Raman spectroscopies. Binding induces changes on an electronic level, as monitored by UV-vis spectroscopy $\left(K_{\mathrm{a}}=1700 \mathrm{M}^{-1}\right)$. Analogous behaviour involving binding of redoxinactive metal ions in solution has also been observed in synthetic manganese- and ironoxygen adducts. In conclusion, the $\left[\mathrm{Cu}^{\prime \prime}{ }_{2} \mathrm{~L}^{3}\left(\mathrm{O}_{2}\right)\right]^{\mathrm{X}}$ system serves to highlight the parallels between binuclear enzymatic oxygen activation pathways in copper and iron enzymes, which is further emphasized by the unusual alkali metal cation binding displayed by $\left[\mathrm{Cu}_{2}{ }_{2} \mathrm{~L}^{3}\left(\mathrm{O}_{2}\right)\right]^{\mathrm{X}}$.

Detailed computational analysis of the $\left[\mathrm{Cu}_{2}{ }_{2} \mathrm{~L}^{3}\left(\mathrm{O}_{2}\right)\right]^{\mathrm{X}}$ system is a topic of future interest. Such studies are needed to confirm the interpretation of the physicochemical properties of 
$\left[\mathrm{Cu}_{2}{ }_{2} \mathrm{~L}^{3}\left(\mathbf{O}_{2}\right)\right]^{\mathrm{X}}$ discussed herein. Theoretical investigations could potentially provide significant insights into the mechanism by which binding of sodium cations perturbs the electronic structure of $\left[\mathrm{Cu}_{2}{ }_{2} \mathrm{~L}^{3}\left(\mathrm{O}_{2}\right)\right]^{\mathrm{X}}$. Furthermore, the unique geometric and electronic structure of the $\left[\mathrm{Cu}^{1{ }^{\prime \prime}} \mathrm{L}^{3}\left(\mathrm{O}_{2}\right)\right]^{\mathrm{X}}$ system make it an interesting candidate for further reactivity studies. 


\section{Reactivity of Copper-Dioxygen Adducts}

\subsection{Introduction}

\subsubsection{Spin State Influences Reactivity}

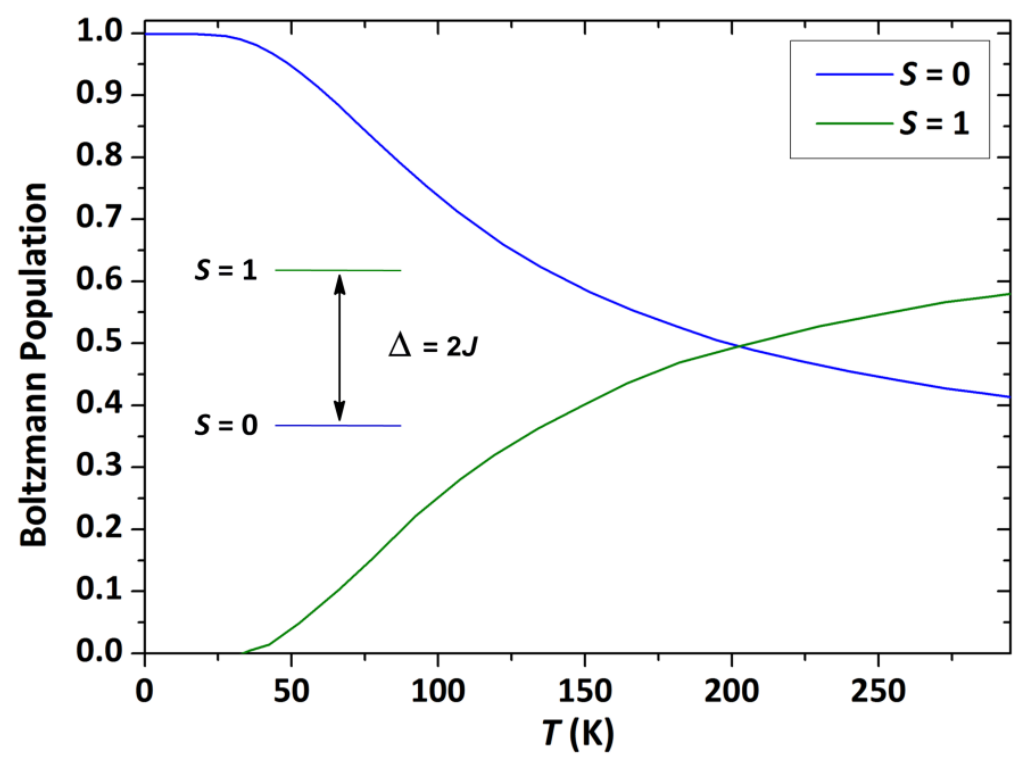

Figure 6.1: Boltzmann distribution simulated using $-2 J=144 \mathrm{~cm}^{-1}$ and showing the thermal population of the energetically higher $S=1$ spin state in $\left[\mathrm{Cu}_{2}{ }_{2} \mathrm{~L}^{3}\left(\mathrm{O}_{2}\right)\right]^{\text {OTf }} \cdot$ OTf.

The unique bonding situation in $\left[\mathrm{Cu}_{2}{ }_{2} \mathrm{~L}^{3}\left(\mathrm{O}_{2}\right)\right]^{\text {OTf }}$.NaOTf (Section 5.2 ) suggest that the peroxide moiety should retain significant charge density, as supported by the observed interaction with alkali metal cations in the solid state and in solution. The strong antiferromagnetic coupling typically observed for $\mathrm{Cu}_{2} \mathrm{O}_{2}$ systems means that the energetically higher triplet spin state is generally not significantly populated at $-30{ }^{\circ} \mathrm{C}$, making them essentially diamagnetic. ${ }^{192,193,215}$ Conversely, and as evidenced by ${ }^{1} \mathrm{H}$ NMR (Sections 5.2.1 and 5.3.3), the weak antiferromagnetic coupling in $\left[\mathrm{Cu}_{2}{ }_{2} \mathrm{~L}^{3}\left(\mathrm{O}_{2}\right)\right]^{\text {OTf }} \cdot \mathrm{NaOTf}$ results in considerable thermal population of the energetically higher $S=1$ spin state, even at $-30^{\circ} \mathrm{C}$ (Figure 6.1). Spin state is known to have a profound effect on resulting reactivity. ${ }^{216,217}$ The novel $\mathrm{Cu}_{2} \mathrm{O}_{2}$ system $\left[\mathrm{Cu}^{11}{ }_{2} \mathrm{~L}^{3}\left(\mathrm{O}_{2}\right)\right]^{\mathrm{X}}$, and by extension that of $\left[\mathrm{Cu}^{\prime \prime}{ }_{2} \mathrm{~L}^{2}\left(\mathrm{O}_{2}\right)\right]^{\mathrm{X}}$, may therefore potentially exhibit unique reactivity towards organic molecules. The oxidation and oxygenation capability of these two systems was thus investigated with a selection of external substrates (Section 6.4). Furthermore, the reactivity of the $\left[\mathrm{Cu}_{2}{ }_{2} \mathrm{~L}^{2}\left(\mathrm{O}_{2}\right)\right]^{\mathrm{X}}$ and $\left[\mathrm{Cu}^{\prime \prime}{ }_{2} \mathrm{~L}^{3}\left(\mathrm{O}_{2}\right)\right]^{\mathrm{X}}$ systems is not restricted to external substrates, and may also include the possibility of oxidative attack on their respective ligand scaffolds, a scenario which is often observed in related copper-dioxygen systems. 


\subsubsection{Hydrogen Abstraction and Intra-molecular Decomposition}
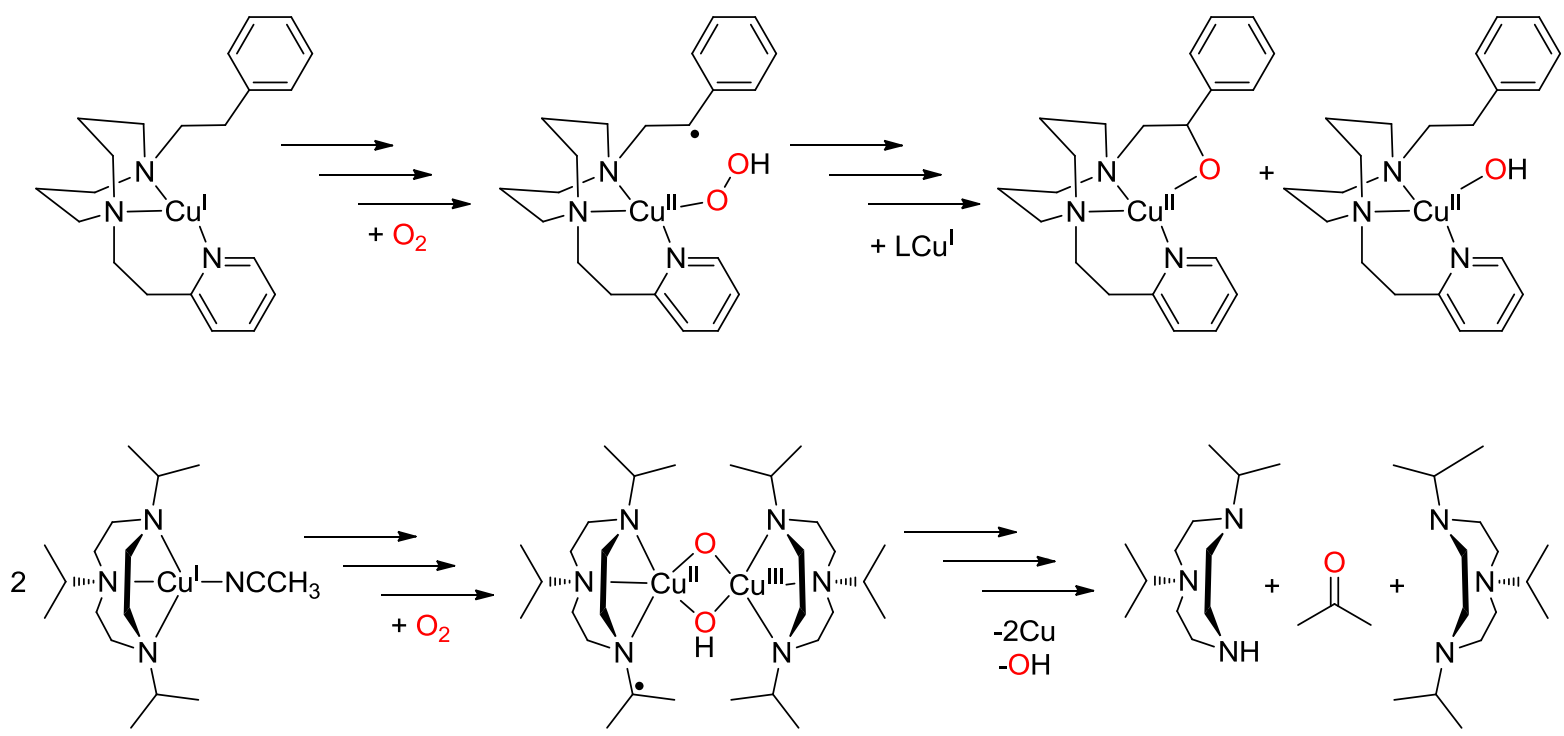

Scheme 6.1: Intra-molecular oxidative attack of an ${ }^{\mathrm{E}} \mathbf{S}$ (above) and ${ }^{\mathrm{B}} \mathbf{O}$ (below) species on their respective ligand scaffolds. Charges and counterions are omitted.

Many copper-dioxygen adducts are known to decompose through oxidative attack upon their supporting ligands. An illustrative example is the ${ }^{\mathrm{E}} \mathrm{S}$ species formed with the mononuclear copper(I) complex supported by the ligand, $N$-(phenylethyl)- $N$ '-(2pyridylethyl)-1,5-diazacyclooctane, DACO (Scheme 6.1, above). This adduct decomposes with concomitant hydroxylation of the chelating scaffold, displaying first order decay kinetics which strongly support an intra-molecular reaction mechanism. ${ }^{43,44}$ Computational analysis of the reaction pathway identified hydrogen-atom abstraction from the supporting ligand as the initial step, as per the general trend already described for these species (Section 1.3.4). ${ }^{43}$ Subsequent recombination of the resulting hydroperoxide moiety with the organic ligand radical is thought to complete formation of the new $\mathrm{C}-\mathrm{O}$ bond. Further reaction with a second copper(I) complex then provides the additional electron required to give the resulting alkoxide and hydroxide moieties observed in the two final products. It is interesting to note that there is substantial evidence indicating that numerous ${ }^{\mathrm{B}} \mathrm{O}$ adducts follow similar first-order intra-molecular rebound pathways. In fact, the systems used in the pioneering investigations of this type of copper-oxygen mediated $\mathrm{C}-\mathrm{H}$ abstraction reactivity were supported by alkylated triazacyclononane derivatives, such as ${ }^{i} \operatorname{Pr}_{3} \operatorname{TACN}$ (Scheme 6.1, below), which is closely related to the side arms in ligand $\mathbf{H L}^{\mathbf{3}} \cdot{ }^{15,30,218}$ The susceptibility of iso-propylated triazacyclononane ligand scaffolds to undergo intra-molecular oxidative decomposition and the observation of transient ${ }^{\mathrm{E}} \mathbf{S}$ species in both the $\left[\mathrm{Cu}^{\prime \prime}{ }_{2}{ }^{2}\left(\mathbf{O}_{2}\right)\right]^{\mathrm{X}}$ and $\left[\mathrm{Cu}_{2}{ }_{2} \mathrm{~L}^{3}\left(\mathrm{O}_{2}\right)\right]^{\mathrm{X}}$ systems are of particular relevance to the chemsitry discussed in this chapter. 


\subsection{A Decomposition Product from $\left[\mathrm{Cu}_{2}{ }_{2} \mathrm{~L}^{3}\left(\mathrm{O}_{2}\right)\right]^{\text {OTf }}$ Decay}

\subsubsection{Isolation and Crystallographic Structural Determination}

The decay of $\left[\mathrm{Cu}_{2}{ }_{2} \mathrm{~L}^{3}\left(\mathrm{O}_{2}\right)\right]^{\mathrm{PF} 6}$ has been previously investigated through the use of stoppedflow UV-vis spectroscopy. ${ }^{90}$ Using DCM as the solvent the reaction was found to be second order with respect to $\left[\mathrm{Cu}_{2}{ }_{2} \mathrm{~L}^{3}\left(\mathrm{O}_{2}\right)\right]^{\mathrm{PF} 6}$. This allowed for determination of a rate constant $(k=$ $0.274 \mathrm{M}^{-1} \mathrm{~s}^{-1}$ ), and a decomposition pathway involving chloride abstraction from the DCM solvent was proposed. ${ }^{90}$ The UV-vis spectrum resulting from thermal decomposition in EtCN was reported in a separate work, but the product could not be unambiguously identified. ${ }^{91}$ Interestingly, mass spectral analysis in the latter case revealed high similarity with an independently synthesised dinuclear copper(II) complex of ligand $\mathrm{HL}^{3}$, which could be furthermore isolated in the current work directly from decomposed solutions of $\left[\mathrm{Cu}_{2}{ }_{2} \mathrm{~L}^{3}\left(\mathrm{O}_{2}\right)\right]^{\mathrm{OTf}}$.

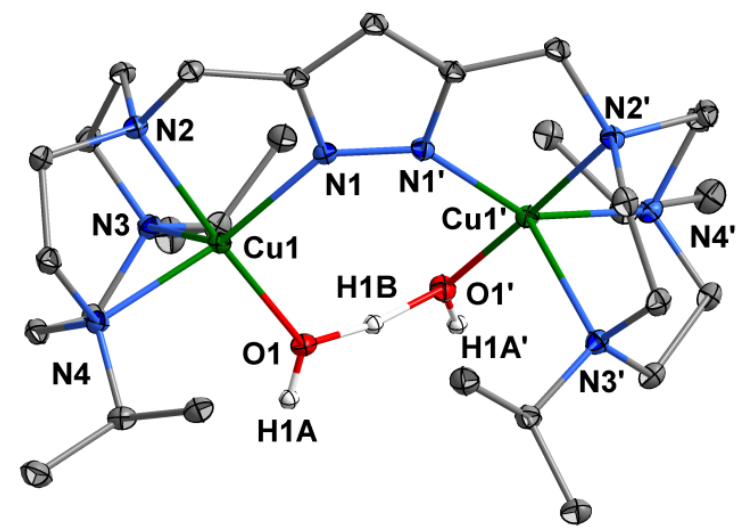

Figure 6.2: Molecular structure of $\left[\mathrm{Cu}_{2}{ }_{2} \mathrm{~L}^{3}\left(\mathrm{H}_{3} \mathrm{O}_{2}\right)\right]^{\text {(OTf)2 }}$. Symmetry transformation used to generate equivalent atoms: $-x, y, 1 / 2-z$. Thermal displacement ellipsoids are shown at $30 \%$ probability, except for the hydrogen atoms depicted, which were located crystallographically. Remaining hydrogen atoms and triflate counteranions have been omitted for clarity.

\begin{tabular}{|c|c|c|c|c|c|}
\hline \multicolumn{5}{|c|}{ Table 6.1: Selected bond lengths $(\AA)$ and angles $\left({ }^{\circ}\right)$ for $\left[\mathrm{Cu}_{2}{ }_{2} \mathrm{~L}^{3}\left(\mathrm{H}_{3} \mathrm{O}_{2}\right)\right]^{(\mathrm{OTf}) 2}$. } \\
\hline Atoms & Bond Lengths & Atoms & Angles & Atoms & Angles \\
\hline Cu1-O1 & $1.9123(14)$ & O1-Cu1-N1 & $94.67(7)$ & N2-Cu1-N4 & $83.11(7)$ \\
\hline Cu1-N1 & $1.9924(17)$ & O1-Cu1-N2 & $176.76(6)$ & O1-Cu1-N3 & $96.44(6)$ \\
\hline Cu1-N2 & $2.0640(17)$ & N1-Cu1-N2 & $82.29(7)$ & N1-Cu1-N3 & $118.92(7)$ \\
\hline Cu1-N4 & $2.1192(18)$ & O1-Cu1-N4 & $100.11(6)$ & N2-Cu1-N3 & $84.10(7)$ \\
\hline Cu1-N3 & $2.2275(18)$ & N1-Cu1-N4 & $149.36(7)$ & N4-Cu1-N3 & $86.04(6)$ \\
\hline Cu1-Cu1' & $4.3465(8)$ & & & & \\
\hline \multicolumn{7}{|c|}{ Symmetry transformation used to generate equivalent atoms: (') $-x, y, 1 / 2-z}$. \\
\hline
\end{tabular}

After allowing solutions of $\left[\mathrm{Cu}_{2}{ }_{2} \mathrm{~L}^{3}\left(\mathrm{O}_{2}\right)\right]^{\text {OTf }}$ to warm to RT under inert conditions, slow $\mathrm{Et}_{2} \mathrm{O}$ diffusion resulted in crystalline material suitable for $\mathrm{X}$-ray diffraction. The product 
crystallises in the orthorhombic Pbcn space group with only half of the molecule and a triflate anion in the asymmetric unit. The full dinuclear copper(II) cation, $\left[\mathrm{Cu}_{2}{ }_{2} \mathrm{~L}^{3}(\mathrm{HO} \cdots \mathrm{H} \cdots \mathrm{OH})\right]^{2+}\left(\left[\mathrm{Cu}^{11}{ }_{2} \mathrm{~L}^{3}\left(\mathrm{H}_{3} \mathrm{O}_{2}\right)\right]^{(\mathrm{OTf}) 2}\right.$, Figure 6.2$)$, is thus generated by the crystallographic $C_{2}$ symmetry and supported by completely intact ligand $\mathbf{L}^{3}$. The two copper(II) ions are thereby equivalent, and additionally spanned by a symmetric $\mathrm{H}_{3} \mathrm{O}_{2}$ bridge made up of two hydroxide ions sharing an additional central proton. No solvent molecules are present in the crystal lattice, which allowed $\left[\mathrm{Cu}_{2}{ }_{2} \mathrm{~L}^{3}\left(\mathrm{H}_{3} \mathrm{O}_{2}\right)\right]^{(\mathrm{OTf}) 2}$ to be isolated independently in separate experiments from either $\mathrm{MeCN}$ or $\mathrm{Me}_{2} \mathrm{CO}$. The analogous perchlorate salt structure was previously reported, ${ }^{79}$ but in that case additionally contained an acetone solvent molecule, was synthesised by direct reaction with $\mathrm{Cu}\left(\mathrm{ClO}_{4}\right)_{2} \cdot 6 \mathrm{H}_{2} \mathrm{O}$, and the complex cation lacked $C_{2}$ symmetry. The two structures are otherwise quite similar and further comparison offers little insight. The copper coordination spheres in $\left[\mathrm{Cu}_{2}{ }_{2}{ }^{2}{ }^{3}\left(\mathrm{H}_{3} \mathrm{O}_{2}\right)\right]^{\text {(OTf)2 }}$ are extremely distorted from ideal geometries $(\tau=0.46)$, similarly to the $\left[\mathrm{Cu}^{\prime \prime}{ }_{2} \mathbf{L}^{3}\left(\mathrm{O}_{2}\right)\right]^{\mathrm{X}} \cdot \mathbf{M X}$ structural series (Table 4.8). On the other hand, the metal separation $(\mathrm{Cu} \cdots \mathrm{Cu}=4.347 \AA)$ in $\left[\mathrm{Cu}_{2}{ }_{2} \mathbf{L}^{3}\left(\mathrm{H}_{3} \mathrm{O}_{2}\right)\right]^{(\mathrm{OTf}) 2}$ is now significantly larger $(>0.5 \AA)$. The greater intermetallic distance thereby allows for accommodation of the bridging proton in place of the peroxide bond. Similarly to the case of $\left[\left(\mathrm{Cu}_{2}{ }_{2} \mathrm{~L}^{1}\right)_{2}\left(\mathrm{O}_{2}\right)(\mathrm{OH})_{2}\right]^{\mathrm{X2}}$ (Section 4.2), the origin of both this proton and the hydroxide anions are of considerable interest with regards to the decomposition mechanism which leads from $\left[\mathrm{Cu}_{2}{ }_{2} \mathrm{~L}^{3}\left(\mathrm{O}_{2}\right)\right]^{\mathrm{OTf}}$ to $\left[\mathrm{Cu}_{2}{ }_{2} \mathrm{~L}^{3}\left(\mathrm{H}_{3} \mathrm{O}_{2}\right)\right]^{(\mathrm{OTf}) \mathbf{2}}$.

\subsection{2 $\left[\mathrm{Cu}_{2}{ }_{2} \mathrm{~L}^{3}\left(\mathrm{H}_{3} \mathrm{O}_{2}\right)\right]^{\mathrm{OTf}}$ Formation Pathways}

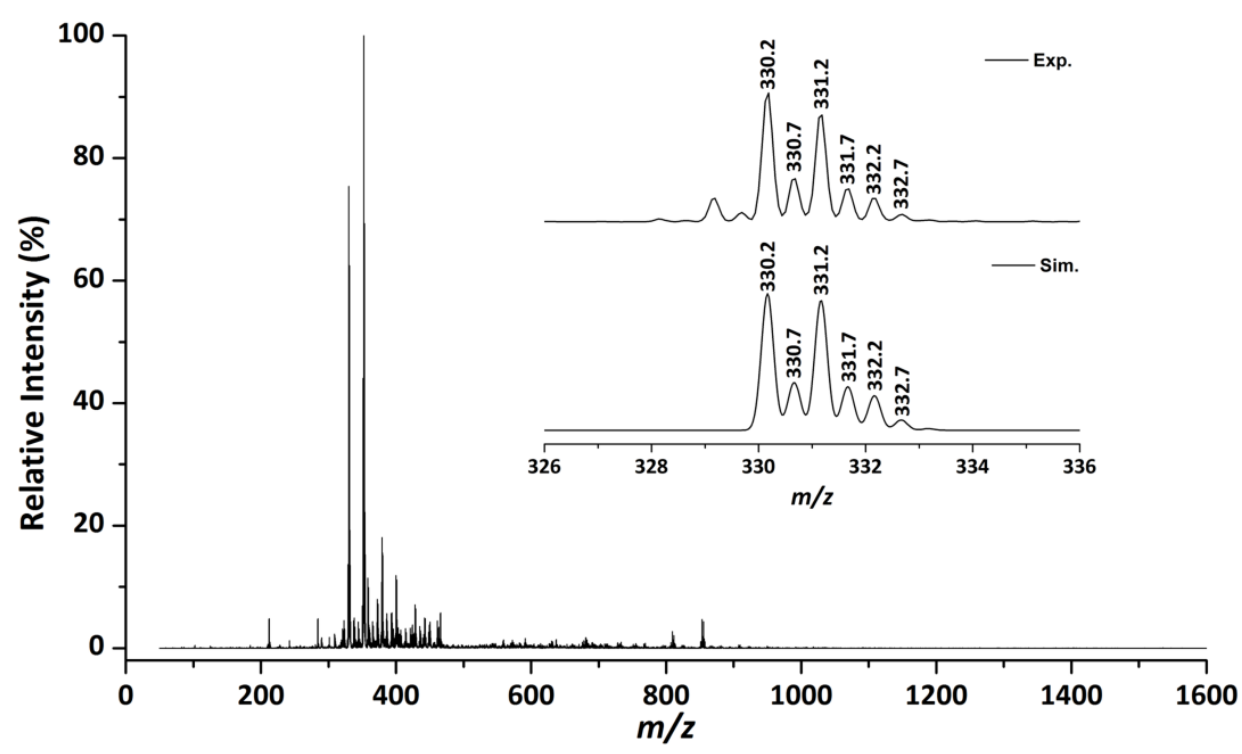

Figure 6.3: Positive mode ESI-MS spectrum of $\left[\mathrm{Cu}_{2}{ }_{2} \mathrm{~L}^{3}\left(\mathrm{O}_{2}\right)\right]^{\text {OTf }}$ when allowed to decay thermally, measured in $\mathrm{Me}_{2} \mathrm{CO}$ at RT. The inset shows experimental and simulated isotopic distribution patterns for $\left[\left(\mathrm{C}_{29} \mathrm{H}_{57} \mathrm{Cu}_{2} \mathrm{~N}_{6}\right) \mathrm{OH}\right]^{2+}$.

In contrast to the analogous perchlorate structure discussed above, the source of the bridging moiety in $\left[\mathrm{Cu}_{2}{ }_{2} \mathrm{~L}^{3}\left(\mathrm{H}_{3} \mathrm{O}_{2}\right)\right]^{(\mathrm{OTf}) \mathbf{2}}$ is ambiguous. It could result from adventitious water, or from further reduction of the peroxide unit in $\left[\mathrm{Cu}_{2}{ }_{2} \mathrm{~L}^{3}\left(\mathrm{O}_{2}\right)\right]^{\mathrm{OTf}}$. In order to investigate if dioxygen cleavage was occurring $\mathrm{MS}$ experiments were conducted using ${ }^{18} \mathrm{O}_{2}$ to test for 
isotopically enriched products. No evidence of this process was observed when similar experiments were performed in EtCN (Section 4.4.3), so measurements were conducted under strictly anhydrous conditions in acetone. Of the two most significant signals in the ${ }^{16} \mathrm{O}_{2}$ spectrum, one was consistent with $\left[\left(\mathrm{Cu}_{2}{ }_{2} \mathrm{~L}^{3}\right)(\mathrm{OH})\right]^{2+}(\mathrm{m} / \mathrm{z}=330.2)$. The second and most intense peak set showed fluctuations in the isotopic envelope during measurement, and appears to correspond to an overlap of two species which could not be unambiguously assigned. Adducts containing $\mathrm{Me}_{2} \mathrm{CO}$, or $\mathrm{CO}_{2}$ as carbonate anion, are feasible and would give $\left[\left(\mathrm{Cu}_{2}{ }_{2} \mathrm{~L}^{3}\right)\left(\mathrm{Me}_{2} \mathrm{CO}\right)(\mathrm{H})\right]^{2+}(\mathrm{m} / z=351.2)$ and $\left[\left(\mathrm{Cu}_{2}{ }_{2} \mathrm{~L}^{3}\right)\left(\mathrm{HCO}_{3}\right)\right]^{2+}(\mathrm{m} / z=352.2)$, respectively. Nevertheless, neither peak set showed clear isotopic enhancement in the corresponding ${ }^{18} \mathrm{O}_{2}$ spectrum. While this finding clearly does not support further reduction of the peroxide unit in $\left[\mathrm{Cu}_{2}{ }_{2} \mathrm{~L}^{3}\left(\mathrm{O}_{2}\right)\right]^{\mathrm{X}}$, it does not rule it out either. Facile exchange of such bridging units has been previously observed with related dinuclear pyrazole-bridged complexes in the cases of copper(II), ${ }^{78} \operatorname{zinc}(\mathrm{II}),{ }^{219}$ and nickel(II), ${ }^{220}$ and has even been quantified $\left(k_{\text {obs }}>10^{3} \mathrm{~s}^{-1}\right)^{75}$ in the case of the latter (see Scheme 6.3 for structures). Thus, despite the measurements being performed with an ESI-MS instrument directly coupled to a glovebox under strictly anhydrous conditions, extremely fast scrambling with adventitious natural abundance water present inside the mass spectrometer could mask any isotopic enhancement. A similar scenario has been previously observed with the same experimental setup in the case of a related pyrazole supported tetranuclear iron(III)-bis( $\mu$-oxo) species. ${ }^{175}$ Furthermore, the nucleophilic potential of a copper(II)-bound hydroxide moiety also makes scrambling with ${ }^{16} \mathrm{O}$-acetone feasible via a geminal diol intermediate. Further experimentation is needed to unambiguously identify the source of the hydroxide bridging units in $\left[\mathrm{Cu}_{2}{ }_{2} \mathrm{~L}^{3}\left(\mathrm{H}_{3} \mathrm{O}_{2}\right)\right]^{(\mathrm{OTf}) 2}$. Monitoring the decomposition reaction of $\left[\mathrm{Cu}_{2}{ }_{2} \mathrm{~L}^{3}\left(\mathrm{O}_{2}\right)\right]^{\mathrm{X}}$ by in situ IR spectroscopy in combination with ${ }^{18} \mathrm{O}_{2}$ isotopic labelling may provide additional insights in this regard.

The origin of the hydrogen atoms involved in bridging is clear in the event that the $\mathrm{H}_{3} \mathrm{O}_{2}$ moiety in $\left[\mathrm{Cu}_{2}{ }_{2} \mathrm{~L}^{3}\left(\mathrm{H}_{3} \mathrm{O}_{2}\right)\right]^{\text {(OTf)2 } 2}$ is derived entirely from adventitious water. On the other hand, the source of these hydrogen atoms is less obvious if scission of the peroxide bond in $\left[\mathrm{Cu}_{2}{ }_{2}{ }^{3}{ }^{3}\left(\mathrm{O}_{2}\right)\right]^{\mathrm{X}}$ occurs. In the latter case, they could result from an intra- or inter-molecular hydrogen-atom abstraction from the ligand scaffold. Alternatively, they could originate from the $\mathrm{MeCN}$ or $\mathrm{Me}_{2} \mathrm{CO}$ solvents through direct reaction, or even indirectly by residual water content. A combination of the above sources is also feasible. In this regard it is noteworthy that no $\left[\mathrm{Cu}_{2}{ }_{2} \mathrm{~L}^{3}\left(\mathrm{H}_{3} \mathrm{O}_{2}\right)\right]^{(\mathrm{OTf}) 2}$ resulted from the $\mathrm{MeCN} / \mathrm{Et}_{2} \mathrm{O}$ mixture until it was briefly exposed to air, after which a moderate yield of crystalline material was deposited overnight. Furthermore, although the same product was obtained directly from anhydrous $\mathrm{Me}_{2} \mathrm{CO} / \mathrm{Et}_{2} \mathrm{O}$ solution, the yield was extremely poor. While these findings implicate water as the hydrogen source, they offer little insight into the identity of the initial decay product. It should be furthermore stressed that the UV-vis spectrum of the initial decay product differs from that of $\left[\mathrm{Cu}_{2}{ }_{2} \mathrm{~L}^{3}\left(\mathrm{H}_{3} \mathrm{O}_{2}\right)\right]^{\text {(OTf)2 }}$, consistent with the previous study involving the perchlorate salt analogue of $\left[\mathrm{Cu}_{2}{ }_{2} \mathrm{~L}^{3}\left(\mathrm{H}_{3} \mathrm{O}_{2}\right)\right]^{\text {(OTf)2 }}{ }^{91}$. Further investigation into the decay of $\left[\mathrm{Cu}^{11}{ }_{2} \mathrm{~L}^{3}\left(\mathrm{O}_{2}\right)\right]^{\mathrm{X}}$ was conducted in the current work by thermally-induced decomposition kinetics. 


\subsection{Decay Kinetics of $\left[\mathrm{Cu}_{2}{ }_{2} \mathrm{~L}^{3}\left(\mathrm{O}_{2}\right)\right]^{\mathrm{X}}$}
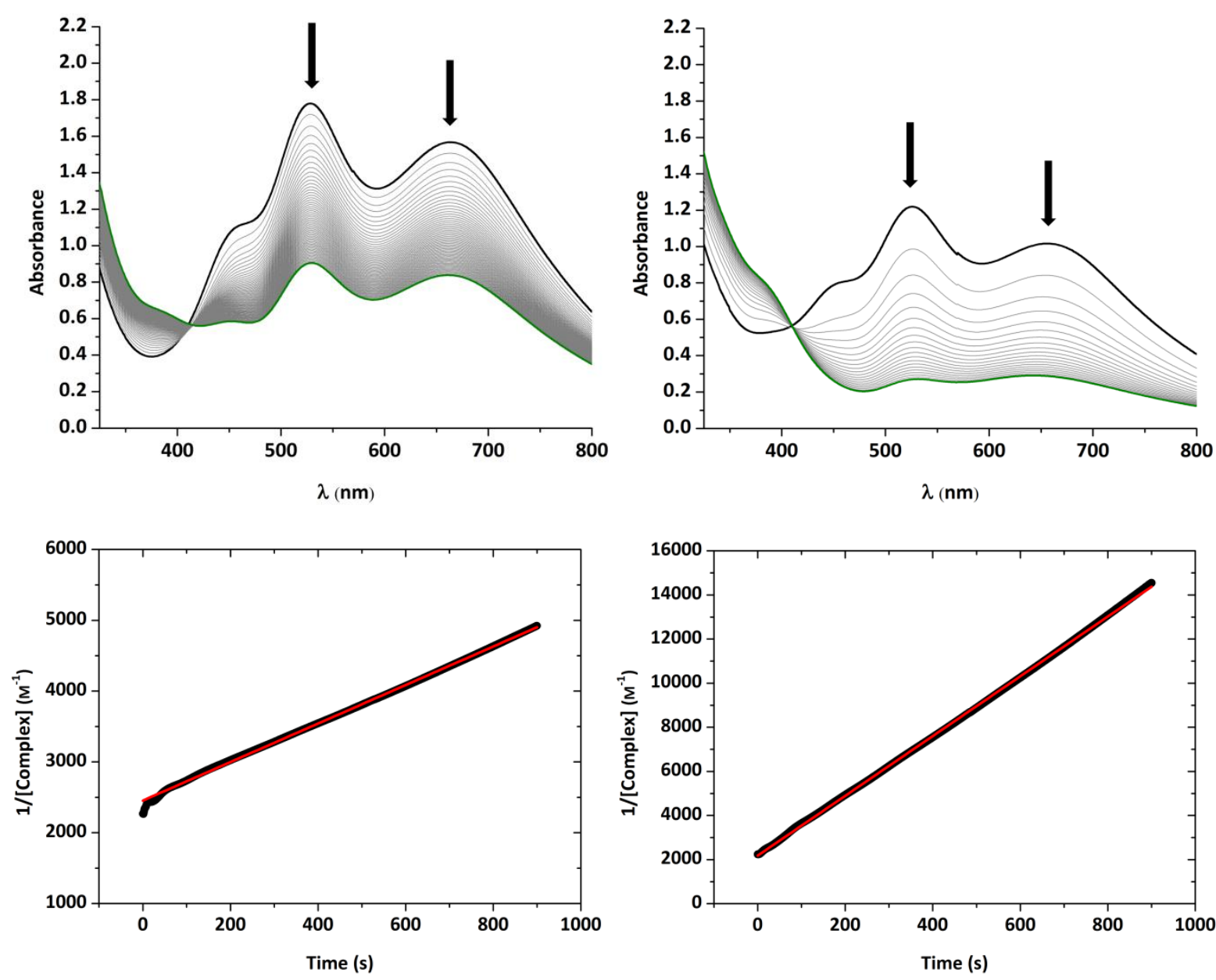

Figure 6.4: UV-vis spectroscopic monitoring of $\left[\mathrm{Cu}_{2}{ }_{2} \mathrm{~L}^{3}\left(\mathrm{O}_{2}\right)\right]^{\mathrm{clO} 4}$ decay (above) at $\mathrm{RT}$, in $\mathrm{Me}_{2} \mathrm{CO}$ (left) and EtCN (right, both $5.0 \times 10^{-4} \mathrm{M}$ ). Corresponding reciprocal plots (below) for which the slope of linear fits (red lines) yield the rate constants in Table 6.2 (separate experiments from above).

In the current work, when $\left[\mathrm{Cu}_{2}^{1} \mathrm{~L}^{3}\right]^{\mathrm{X}}\left(\mathrm{X}=\mathrm{ClO}_{4}{ }^{-}\right.$or $\left.\mathrm{OTf}^{-}\right)$was oxygenated by mixing with dry $\mathrm{O}_{2}$-saturated solvent, the decay of the resulting $\left[\mathrm{Cu}_{2}{ }_{2} \mathrm{~L}^{3}\left(\mathrm{O}_{2}\right)\right]^{\mathrm{X}}$ occurred sufficiently slowly to be monitored by standard UV-vis spectroscopy, even at RT. Solutions in MeCN, EtCN or $\mathrm{Me}_{2} \mathrm{CO}$ displayed qualitatively similar behaviour, in all cases showing an isosbestic point at approximately $400 \mathrm{~nm}$, and accompanied by bleaching of the CT features associated with $\left[\mathrm{Cu}_{2}{ }_{2}{ }^{2}{ }^{3}\left(\mathrm{O}_{2}\right)\right]^{\mathrm{X}}$ (Figure 6.4, above). Decay of the principal band was monitored, and plotting the reciprocal against time generally gave a linear relationship, indicating the decay rate was (pseudo-)second order with respect to $\left[\mathrm{Cu}_{2}{ }_{2} \mathrm{~L}^{3}\left(\mathrm{O}_{2}\right)\right]^{\mathrm{X}}$. While this is in agreement with the previous results where decay was monitored in $\mathrm{DCM}$ at $-10{ }^{\circ} \mathrm{C}$, the second order rate constants derived in the current case were found to significantly vary with differing initial concentrations of $\left[\mathrm{Cu}^{\prime \prime}{ }_{2} \mathbf{L}^{3}\left(\mathbf{O}_{2}\right)\right]^{\mathrm{X}}$. This implies the existence of a more complicated underlying process. The rate constants were distinct for each solvent but all followed a common trend, exhibiting faster decay rates at lower initial concentrations. All assays were conducted in triplicate, and reproducibly showed decomposition to be fastest in EtCN, significantly slower in $\mathrm{Me}_{2} \mathrm{CO}$, and slightly slower yet again in MeCN. 


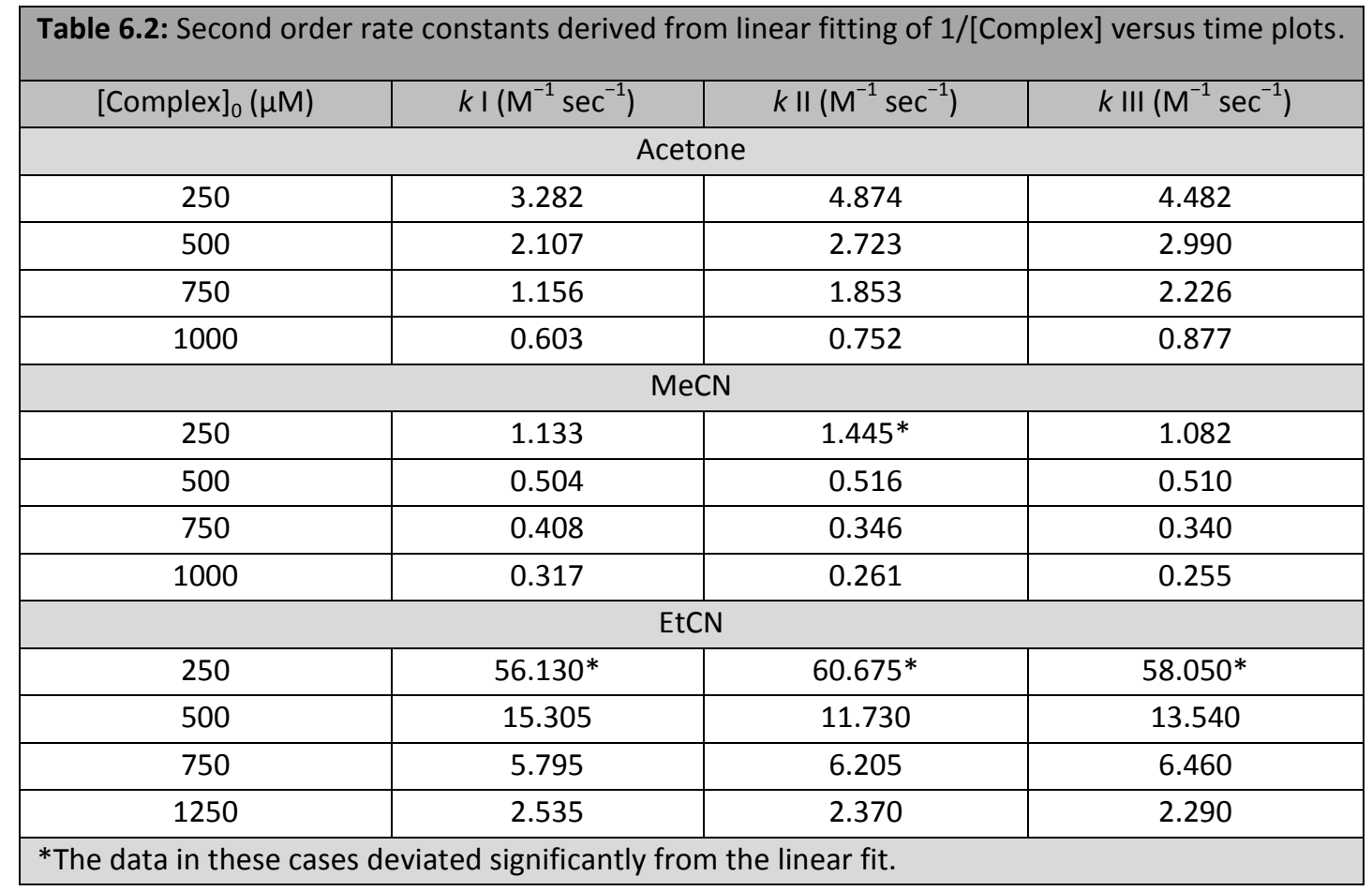
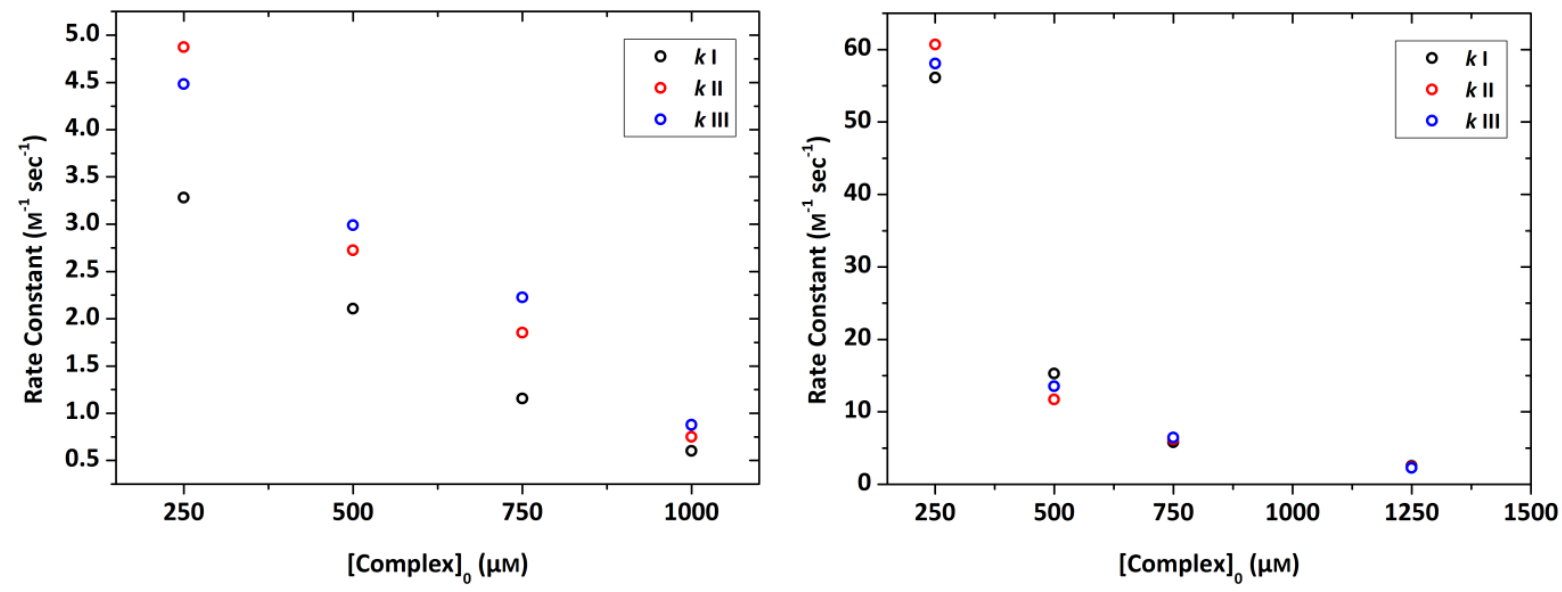

Figure 6.5: Plots showing variation of the rate constant with initial complex concentration for $\mathrm{Me}_{2} \mathrm{CO}$ (left) and EtCN (right). The data for the lowest concentration in EtCN deviated significantly from the linear fit.

The above findings which indicate that the decay rate is (pseudo-)second order with respect to $\left[\mathrm{Cu}_{2}{ }_{2} \mathbf{L}^{3}\left(\mathbf{O}_{2}\right)\right]^{\mathrm{X}}$ preclude an intra-molecular decomposition pathway, thereby providing strong evidence against the ligand-based oxidation reactions frequently observed in many $\mathrm{CuO}_{2}$ systems (Sections 1.3.4 and 6.1.2). While a reaction of this type could also occur by an inter-molecular mechanism, the steric shielding of the peroxide moiety in $\left[\mathrm{Cu}_{2}{ }_{2} \mathrm{~L}^{3}\left(\mathbf{O}_{2}\right)\right]^{\mathrm{X}}$ would significantly hinder such a process, and no apparent evidence for ligand oxygenation or $\mathrm{N}$-dealkylation has been observed in any of the MS experiments conducted (Section 4.4.3 and 6.2.1). The further dependence of the rate upon both initial concentration of $\left[\mathrm{Cu}^{\prime \prime}{ }_{2} \mathbf{L}^{3}\left(\mathbf{O}_{2}\right)\right]^{\mathrm{X}}$ and the nature of the solvent is unusual. Although reaction with solvent is a feasible decomposition pathway, it is constantly present in vast excess, such that it would be extremely unlikely to result in the observed concentration dependence. A fixed 
percentage of residual water content could account for the latter, given the data varied somewhat with different MeCN and EtCN batches. Alternatively, an unusual acceleration of decay rate as a function of excess $\mathrm{O}_{2}$ was recently reported for a trans-Cu" ${ }_{2}\left(\mu-\eta^{1}: \eta^{1}-\mathrm{O}_{2}\right)$ adduct supported by a dinucleating TMPA derivative, though justification for the observed effect is lacking. ${ }^{221}$ This could qualitatively explain the trends observed in the current case, with lower concentrations consuming less $\mathrm{O}_{2}$ and greater $\mathrm{O}_{2}$ solubility in $\mathrm{EtCN}$ versus $\mathrm{Me}_{2} \mathrm{CO}$ and $\mathrm{MeCN}$. Further experimental evidence is clearly needed in order to test if any of these factors are contributing significantly. For example, screening for a kinetic isotope effect using $\mathrm{CD}_{3} \mathrm{CN},\left(\mathrm{CD}_{3}\right)_{2} \mathrm{CO}$ or a deuterated analogue of $\mathrm{HL}^{3}$ may offer insights with regard to a decomposition pathway directly involving solvent. It must be highlighted that the lowest concentrations measured EtCN solutions reproducibly displayed significantly different behaviour not consistent with second order decay, suggesting that the decomposition mechanism may be even more complicated and competing pathways may exist.

\subsubsection{The Role of Sodium Cations}

The above described decomposition kinetics were conducted prior to elucidation of the sodium cation binding equilibrium, and thus any influence exerted by the presence of $\mathrm{Na}^{+}$ was not taken into account. While a stabilising interaction of sodium cations with $\left[\mathrm{Cu}_{2}{ }_{2} \mathbf{L}^{3}\left(\mathrm{O}_{2}\right)\right]^{\mathrm{X}}$ would satisfactorily explain the concentration dependence of the above data, analysis of the decay spectra of $\left[\mathrm{Cu}^{\prime \prime}{ }_{2} \mathbf{L}^{3}\left(\mathbf{O}_{2}\right)\right]^{\mathrm{X}}$ at fixed concentrations with increasing amounts of $\mathrm{Na}^{+}$(Section 5.3.3) showed no discernible trend relating decomposition rate with sodium cation presence. Furthermore, the faster rates of decay observed for EtCN when compared with $\mathrm{Me}_{2} \mathrm{CO}$ are difficult to account for, given that the $\mathrm{Na}^{+}$affinity for $\left[\mathrm{Cu}^{\prime \prime}{ }_{2} \mathbf{L}^{3}\left(\mathrm{O}_{2}\right)\right]^{\mathrm{X}}$ is greater in the former solvent than in the latter (This trend was observed qualitatively). One final observation which is relevant to all of the herein described kinetic determinations relates to the use of in situ prepared $\left[\mathrm{Cu}_{2}{ }_{2} \mathrm{~L}^{3}\left(\mathbf{O}_{2}\right)\right]^{\mathrm{X}}$. Although this species was shown to be of high purity without the application of further isolation procedures (Section 3.4), decomposition rates were found to be extremely sensitive to trace impurities. This is well illustrated by the introduction of excess copper(I) salt prior to dioxygen exposure. In contrast to the $\left[\mathrm{Cu}_{2}{ }_{2} \mathrm{~L}^{2}\left(\mathrm{O}_{2}\right)\right]^{\mathrm{X}}$ system, where excesses of $10 \%$ copper $(\mathrm{I})$ salt enhanced target product formation (Sections 4.3.2), in the case of $\left[\mathrm{Cu}_{2}{ }_{2} \mathrm{~L}^{3}\left(\mathrm{O}_{2}\right)\right]^{\mathrm{X}}$ an enormous acceleration of decomposition rate was observed, such that decay was complete within seconds rather than minutes. Although the mechanistic basis for this enhancement is unclear, this example helps to highlight the high sensitivity of this chemistry to trace impurities. Not only does this reaffirm the need for the use of precise stoichiometry (Section 3.4.1), but it also emphasises the difficulties which may be involved in accurately assigning reactive species in solution. 


\subsection{Reactivity Toward External Substrates}

\subsubsection{The Active Oxygenating Species in Tyrosinase}

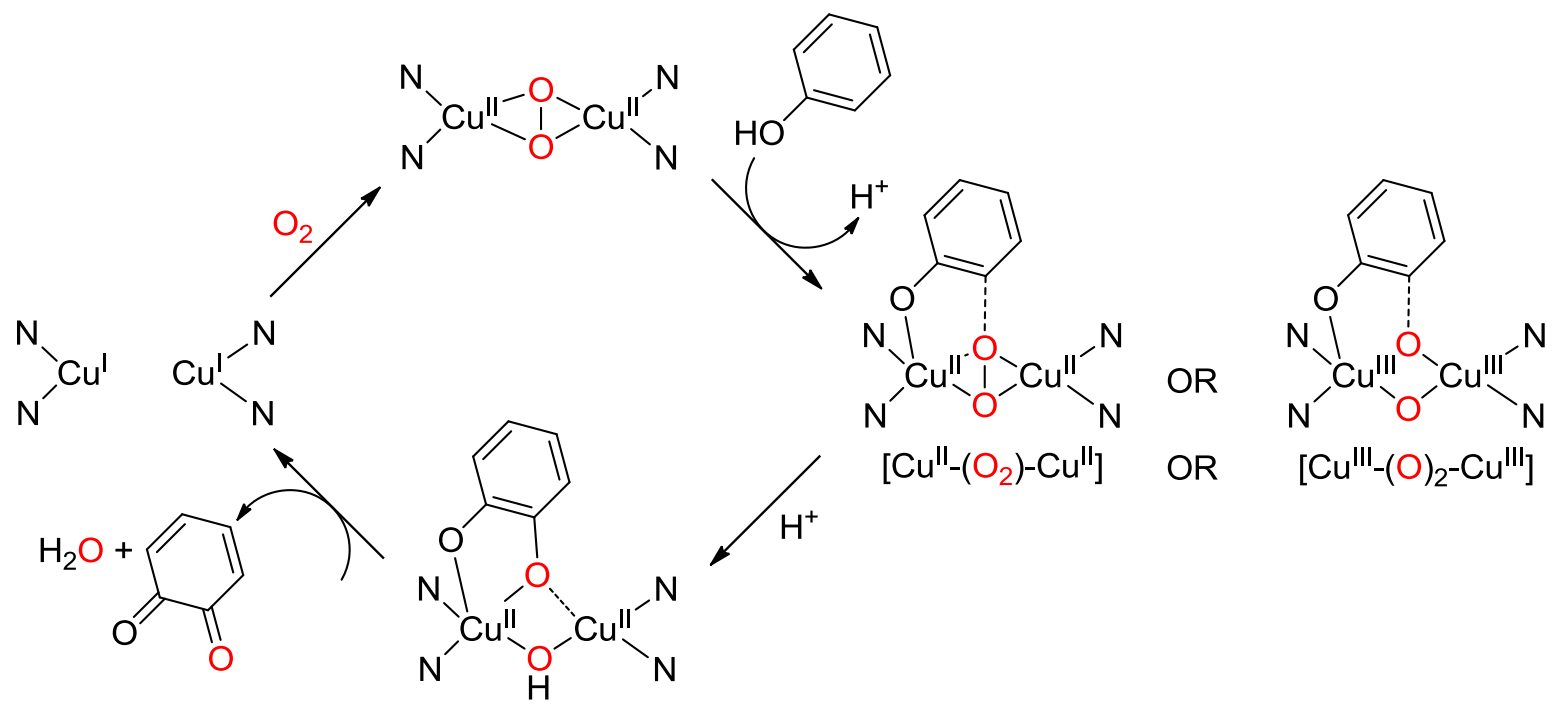

Scheme 6.2: Catalytic cycle of Tyr. The speciation of the active oxygenating species after substrate binding has occurred is still debated.

Incentive for studying copper-containing metalloenzymes is largely contributed to by their ability to activate dioxygen and for controlled oxidation and oxygenation of organic molecules. Much of the pioneering work conducted in this regard is highly applicable to T3 systems, especially to Tyr, which is the only member of this class capable of facilitating oxygen-atom transfer to substrates. ${ }^{16,18,25}$ As such, a detailed mechanistic picture for Tyr has emerged (Scheme 6.2), which is briefly described here given its relevance to the chemistry discussed in this section. Initial reaction of dioxygen with the fully reduced dicopper(I) state gives the well established ${ }^{S} \mathbf{P}$ adduct. Substrate coordination to a single copper(II) ion then occurs, resulting in a ternary complex which represents the key intermediate in the debate over the active hydroxylating species in this system. ${ }^{16,18,25}$ Whether the $\mathrm{C}-\mathrm{O}$ bond is formed by direct reaction of the ${ }^{\mathbf{S}} \mathbf{P}$ adduct with the substrate or after conversion to an isoelectronic ${ }^{B} O$ core is still unclear. Irrespective of which species is involved, the resulting catechol then donates two electrons to form the ortho-quinone product, simultaneously regenerating the original dicopper(I) state and thereby closing the catalytic cycle. The enzymatic activity described above is often resolved into sequential stages. The hydroxylation of monophenols to give $o$-diphenols is referred to as monophenolase or cresolase activity, whereas the oxidation of $o$-diphenols to give $o$-quinones is known as diphenolase or catacholase activity. ${ }^{222,223}$ To show genuine Tyr-like activity a model complex must therefore be competent at both the monopheloase and diphenolase steps, that is, it must not only activate and transfer oxygen to the substrate, but also oxidise the resulting 1,2-diol in order to complete the catalytic cycle. 


\subsubsection{Unprecedented ' $P$ Reactivity}

Initial studies indicated that the ${ }^{\top} \mathbf{P}$ species lack oxygen atom transfer capability, however, several examples which contradict this notion have since been reported. These include the 'P-mediated 4-electron oxidation of internal (ligand) or external saturated benzylic carbon atoms to the respective carbonyls, ${ }^{32,46,224}$ and hydroxylation of external para-substituted phenolates to give the corresponding catechols. ${ }^{225}$ However, in some of these cases this unprecedented reactivity has been attributed to one of several other species thought to be present in solution as a result of interconversion to isoelectronic $\mathrm{Cu}_{2} \mathrm{O}_{2}$ cores $^{46,224}$ or backward reaction to an ${ }^{\mathrm{E}} \mathrm{S}$ species. ${ }^{46}$ The aforementioned phenolate hydroxylation reactivity was very recently contested on the basis of an experimentally observed equilibrium between a related ${ }^{\top} \mathbf{P}$ adduct and $a{ }^{B} \mathbf{O}$ species, and further refuted by calculations which found reaction through the ${ }^{\mathrm{B}} \mathrm{O}$ analogue of the original complex to be the more energetically favourable pathway compared with the proposed ${ }^{\top} \mathbf{P}$ core. ${ }^{49}$ These findings, in addition to those discussed above pertaining to Tyr, highlight the complications which can be encountered in identifying the active species actually responsible for reactivity in these systems. 


\subsection{The $\left[\mathrm{Cu}_{2}{ }_{2} \mathrm{~L}^{2}\left(\mathrm{O}_{2}\right)\right]$ System}

\subsubsection{Tyrosinase-like Activity}

The monophenolase ability of $\left[\mathrm{Cu}^{\prime \prime} \mathrm{L}^{2}\left(\mathrm{O}_{2}\right)\right]^{\mathrm{X}}$ was previously tested with the activated substrate 2,4-di-tert-butylphenol (HDTBP), for which no acitivty was observed. ${ }^{90}$ In the current work, addition of five equivalents of this phenol to pre-formed $\left[\mathrm{Cu}_{2}{ }_{2}{ }^{2}\left(\mathrm{O}_{2}\right)\right]^{\mathrm{X}}$ at -80 ${ }^{\circ} \mathrm{C}$ (after removal of excess dioxygen, see Experimental Section 8.9) caused only a subtle change in the colour of the EtCN solution. Upon workup and analysis only the starting material was detected, and given the known nucleophilic/basic reactivity patterns of $\mathrm{Cu}_{2}{ }_{2}(\mu-$ $\eta^{1}: \eta^{1}-O_{2}$ ) peroxide species (Section 1.3.3), straightforward proton transfer from the relatively acidic phenol moiety is likely. Therefore the conjugate base was prepared by reaction with $\mathrm{NaH}$ and the isolated salt, sodium 2,4-di-tert-butylphenolate (NaDTBP), was used as a test substrate. Addition under identical conditions this time resulted in complete bleaching of the solution, becoming green already at $-80^{\circ} \mathrm{C}$. After allowing the solution to warm to RT, a further colour change to a light green-brown colour was observed.

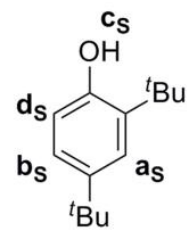

Substrate

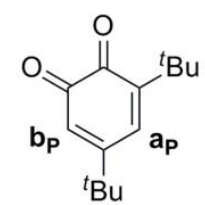

Product

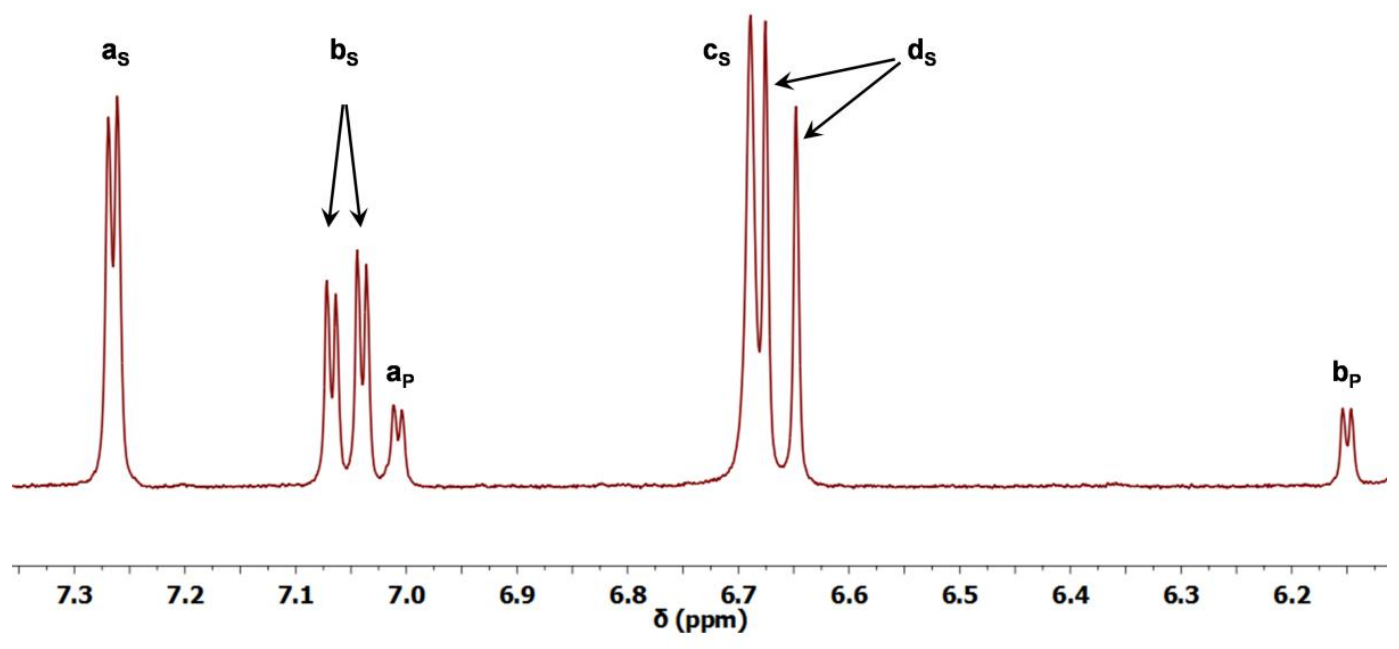

Figure 6.6: Aromatic region of the ${ }^{1} \mathrm{H}$ NMR spectrum which results after aerobic work-up (see text) of the reaction between $\left[\mathrm{Cu}_{2}{ }_{2} \mathrm{~L}^{2}\left(\mathbf{O}_{2}\right)\right]^{\mathrm{PF} 6}$ and NaDTBP (measured under ambient conditions in $\mathrm{CD}_{3} \mathrm{CN}$ at RT). Substrate and product signals are labelled with the subscripts $\mathbf{S}$ and $\mathbf{P}$, respectively.

Filtration through silica resulted in intense yellow solutions, though flushing with $\mathrm{MeOH}$ was required to elute the coloured compound, indicative of a highly polar product. GC-MS analysis showed two compounds with similar retention times, and while the unreacted starting material was easily identified, the second product could not be unambiguously assigned. It is worth noting that extreme deviations in GC-MS analysis results were observed 
when different counterions were employed for the complex synthesis, despite similar experimental observations during the substrate screening reactions. While this complication ruled out direct quantification by GC-MS, further evaluation was possible by ${ }^{1} \mathrm{H} N M R$ spectroscopy. Initial analysis revealed 3,5-di-tert-butylquinone (DTBQ) as the only transformation product (Figure 6.6), identified by comparison with literature chemical shift values and those of an independently synthesised batch of DTBQ. ${ }^{226}$ When $\mathrm{PF}_{6}{ }^{-}$was used as a counterion the yield for this oxygenation reaction gave a variable outcome, likely due to $\left[\mathrm{Cu}^{\prime \prime}{ }_{2} \mathbf{L}^{2}\left(\mathbf{O}_{2}\right)\right]^{\mathrm{X}}$ decomposition resulting from fluoride abstraction (Section 4.1). However, by using of $\mathrm{BF}_{4}^{-}, \mathrm{ClO}_{4}^{-}$or $\mathrm{OTf}^{-}$, together with addition of 1,3,5-trimethoxybenzene as an internal standard, a reproducible yield of approximately $25 \%$ could be determined. Addition of excess copper(I) salt also had no effect, strongly suggesting that $\left[\mathrm{Cu}^{\prime \prime}{ }_{2} \mathbf{L}^{2}\left(\mathbf{O}_{2}\right)\right]^{\mathrm{X}}$ was the active oxygen-transferring species.
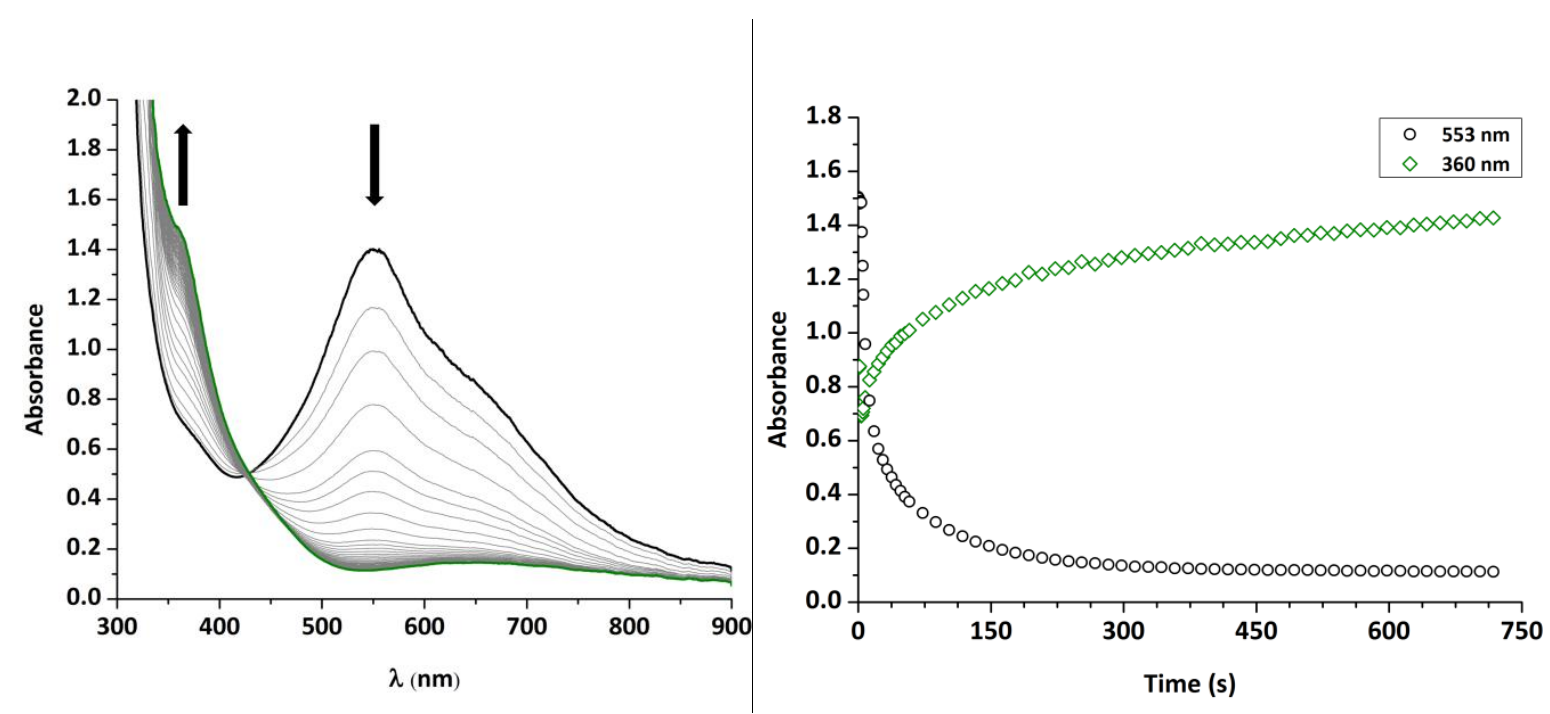

Figure 6.7: UV-vis spectroscopic monitoring of the reaction between $\left[\mathrm{Cu}^{\prime \prime}{ }_{2} \mathrm{~L}^{2}\left(\mathrm{O}_{2}\right)\right]^{\mathrm{PF} 6}$ and five equivalents of NaDTBP at $-80^{\circ} \mathrm{C}$ in EtCN $\left(1 \times 10^{-2} \mathrm{M}\right)$. Bleaching of the copper-peroxo $\mathrm{CT}$ features occurred simultaneously with formation of the new band at $360 \mathrm{~nm}$ (left). The reaction is complete after 15 minutes at $-80^{\circ} \mathrm{C}$ (right).

The above observations suggest that this oxygenation can potentially proceed in a catalytic fashion, resulting in both regeneration of the $\left[\mathrm{Cu}_{2}{ }_{2} \mathbf{L}^{2}\right]^{\mathrm{X}}$ precursor complex and production of DTBQ. This product has a distinctive absorption feature at approximately $400 \mathrm{~nm}$, so the reaction was thus monitored under anaerobic conditions by in situ UV-vis spectroscopy in order to observe a single turnover. Upon addition of the NaDTBP substrate to pre-formed $\left[\mathrm{Cu}_{2}{ }_{2} \mathrm{~L}^{2}\left(\mathrm{O}_{2}\right)\right]^{\mathrm{PF} 6}$ at $-80{ }^{\circ} \mathrm{C}$ bleaching of the copper-peroxo $\mathrm{CT}$ feature occurred, simultaneously with the appearance of a new band (Figure 6.7, similar spectra resulted when $\mathrm{ClO}_{4}{ }^{-}$or $\mathrm{OTf}^{-}$were used). This new band is centred at $360 \mathrm{~nm}$, differing significantly from the $400 \mathrm{~nm}$ absorbance expected to arise from formation of DTBQ. ${ }^{227}$ 
Although there appears to be an isosbestic point in the spectrum at $425 \mathrm{~nm}$, closer inspection revealed that the absorbance at this wavelength varies somewhat throughout the reaction. This suggests that the two species observed spectroscopically are not linearly related by stoichiometry, and that there is an intermediate involved in the underlying chemical reaction. Numerous attempts to reproduce the features of the UV-vis spectrum shown in Figure 6.7 indirectly were unsuccessful, for example by reaction of 3,5-di-tertbutylcatechol $\left(\mathrm{H}_{2} \mathrm{DTBC}\right)$ with $\left[\mathrm{Cu}_{2}{ }_{2} \mathbf{L}^{2}\left(\mathrm{O}_{2}\right)\right]^{\mathrm{X}}$. Fortunately, by maintaining low temperatures for an extended time period (see Experimental section 8.3.9), single crystals suitable for X-ray diffraction could be isolated directly from the reaction. Re-dissolution of this crystalline material in EtCN (Figure 6.8) resulted in a spectrum consistent with that described above, showing an absorption feature at $360 \mathrm{~nm}\left(\varepsilon=3080 \mathrm{M}^{-1} \mathrm{~cm}^{-1}\right)$.

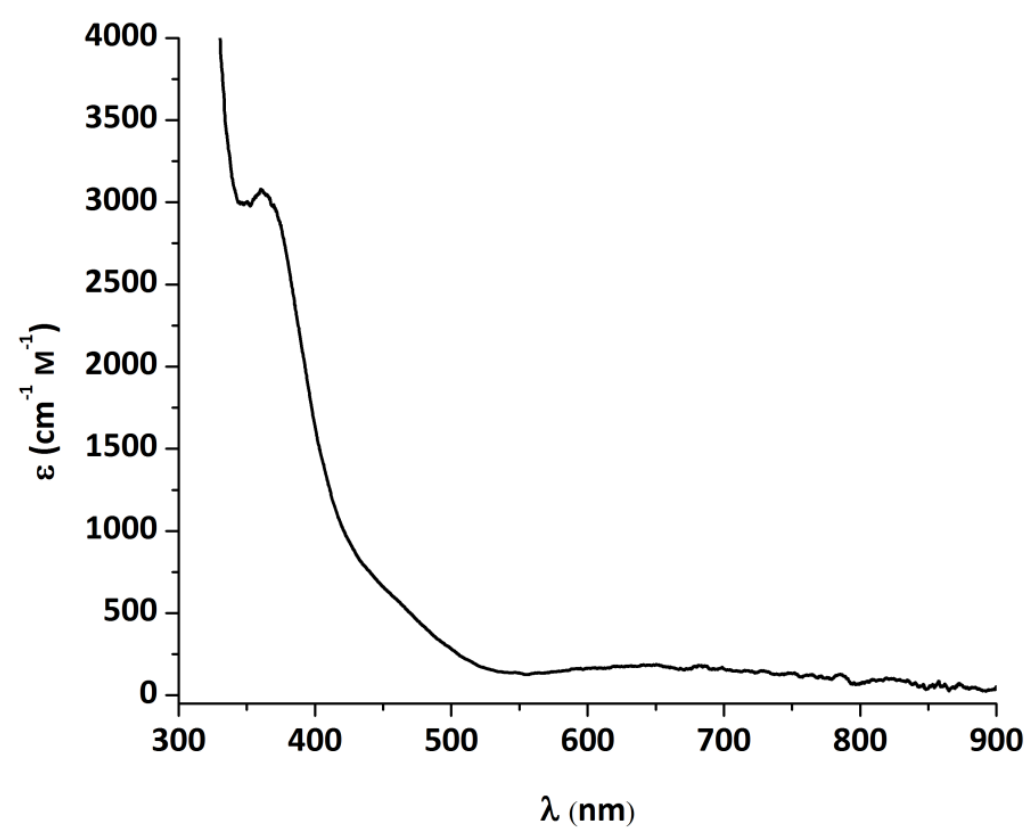

Figure 6.8: UV-vis spectrum of the crystalline product $\left(\left[\mathrm{Cu}^{\prime \prime}{ }_{2} \mathrm{~L}^{2}(\mathrm{OH})(\mathrm{DTBP})_{2}\right]\right.$, see below) isolated after reaction between $\left[\mathrm{Cu}_{2}{ }_{2} \mathrm{~L}^{2}\left(\mathrm{O}_{2}\right)\right]^{\mathrm{ClO4}}$ and NaDTBP, measured at RT after re-dissolution in $\operatorname{EtCN}\left(3.0 \times 10^{-3} \mathrm{M}\right)$. 


\subsubsection{A Substrate Adduct Complex}

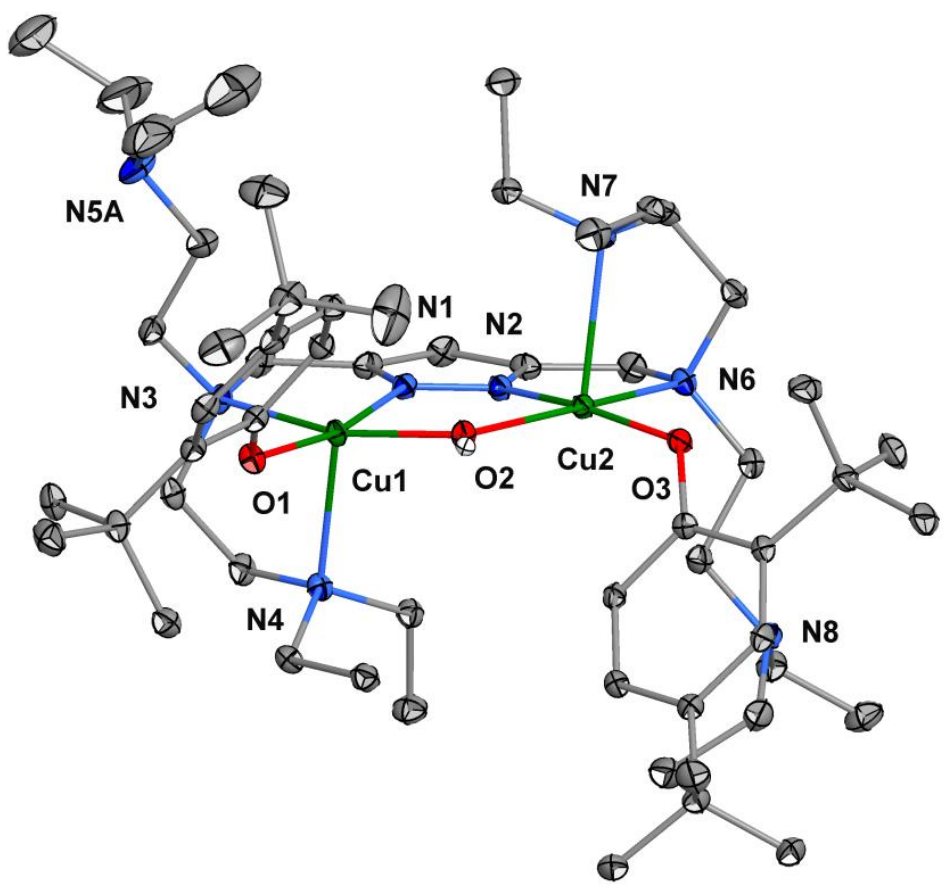

Figure 6.9: Molecular structure of $\left[\mathrm{Cu}_{2}{ }_{2} \mathrm{~L}^{2}(\mathrm{OH})(\mathrm{DTBP})_{2}\right]$. Thermal displacement ellipsoids are shown at $30 \%$ probability, except for the hydrogen atom depicted, which was located crystallographically. Remaining hydrogen atoms have been omitted for clarity.

\begin{tabular}{|c|c|c|c|c|c|}
\hline \multicolumn{5}{|c|}{ Table 6.3: Selected bond lengths $(\AA)$ and angles $\left({ }^{\circ}\right)$ for $\left[\mathrm{Cu}_{2}{ }_{2}{ }^{2}(\mathrm{OH})(\mathrm{DTBP})_{2}\right]$} \\
\hline Atoms & Bond Lengths & Atoms & Angles & Atoms & Angles \\
\hline Cu1-O1 & $1.8890(15)$ & O1-Cu1-N1 & $168.60(8)$ & O3-Cu2-N2 & $168.36(7)$ \\
\hline Cu1-N1 & $1.8985(18)$ & O1-Cu1-O2 & $103.25(6)$ & O3-Cu2-O2 & $103.45(6)$ \\
\hline Cu1-O2 & $1.9713(15)$ & N1-Cu1-O2 & $84.11(7)$ & N2-Cu2-O2 & $83.93(7)$ \\
\hline Cu1-N3 & $2.2240(18)$ & O1-Cu1-N3 & $94.56(7)$ & O3-Cu2-N6 & $94.45(7)$ \\
\hline Cu1-N4 & $2.4431(17)$ & N1-Cu1-N3 & $77.08(7)$ & N2-Cu2-N6 & $77.18(7)$ \\
\hline Cu1-Cu2 & $3.4623(5)$ & O2-Cu1-N3 & $160.38(7)$ & O2-Cu2-N6 & $160.40(7)$ \\
\hline Cu2-O3 & $1.8951(15)$ & O1-Cu1-N4 & $97.25(6)$ & O3-Cu2-N7 & $96.44(6)$ \\
\hline Cu2-N2 & $1.9036(18)$ & N1-Cu1-N4 & $88.90(7)$ & N2-Cu2-N7 & $90.27(7)$ \\
\hline Cu2-O2 & $1.9644(15)$ & O2-Cu1-N4 & $106.05(6)$ & O2-Cu2-N7 & $104.57(7)$ \\
\hline Cu2-N6 & $2.2132(18)$ & N3-Cu1-N4 & $79.40(7)$ & N6-Cu2-N7 & $80.92(7)$ \\
\hline Cu2-N7 & $2.4147(18)$ & Cu2-O2-Cu1 & $123.22(8)$ & & \\
\hline
\end{tabular}

Structural determination of the material isolated from reaction between $\left[\mathrm{Cu}_{2}{ }_{2} \mathbf{L}^{2}\left(\mathbf{O}_{2}\right)\right]^{\mathrm{X}}$ and NaDTBP revealed a neutral complex, $\left[\mathrm{Cu}_{2}{ }_{2} \mathrm{~L}^{3}(\mathrm{OH})(\mathrm{DTBP})_{2}\right]\left(\left[\mathrm{Cu}_{2}{ }_{2} \mathrm{~L}^{2}(\mathrm{OH})(\mathrm{DTBP})_{2}\right]\right.$, Figure 6.9). This substrate adduct crystallises in the triclinic $P-1$ space group with two molecules per unit cell, and consists of a dinuclear copper(II) complex supported by deprotonated $\mathbf{H L}^{2}$. The two 
copper ions are also each further coordinated by an anionic 2,4-di-tert-butylphenolate (DTBP) molecule, and are additionally tethered by a hydroxide moiety. Interestingly, $\mathbf{H L}^{\mathbf{2}}$ is usually observed to impose a metal-metal separation $(M \cdots M=4.533,4.452$ and $4.374 \AA$ for $\mathrm{Cu}^{\prime \prime}, \mathrm{Ni}$ " and $\mathrm{Zn}^{\prime \prime}$ respectively, Scheme 6.3) which makes the resulting complexes unsuitable for accommodating single atom bridging molecules such as hydroxide. Instead, incorporation of an additional water or other solvent molecule, such as $\mathrm{MeOH}$ to give a multi-component RO $\cdots H \cdots O R(R=H, M e)$ moiety is often observed. ${ }^{78,219,220}$

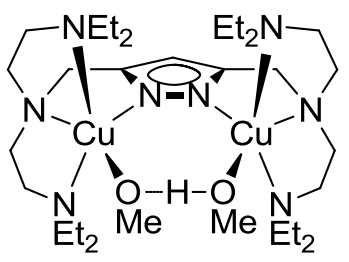

VIII

$$
\begin{aligned}
\mathrm{d}(\mathrm{Cu} \cdots \mathrm{Cu}) & =4.533 \AA \\
\tau & =0.64
\end{aligned}
$$

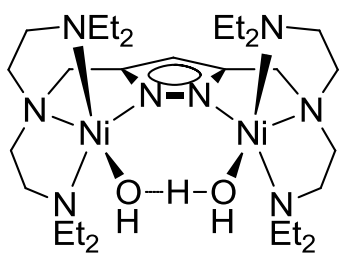

XIII

$$
\begin{gathered}
\mathrm{d}(\mathrm{Ni} \cdots \mathrm{Ni})=4.452 \AA \\
\tau=0.60,0.69
\end{gathered}
$$

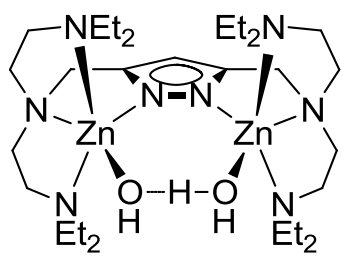

XIV

$$
\begin{gathered}
\mathrm{d}(\mathrm{Zn} \cdots \mathrm{Zn})=4.374 \AA \\
\tau=0.74,0.80
\end{gathered}
$$

Scheme 6.3: Known crystallographically characterised complexes supported by deprotonated $\mathbf{H L}^{2}$, which highlight the tendency of this scaffold to impose metal-metal separations that result in multi-component bridging moieties. Charges and counterions are omitted for clarity.

In comparison with these related structures, which have largely trigonal bipyramidal geometries ( $\tau=0.64$ (symmetric), 0.60 and 0.69 , and 0.74 and 0.80 for $\mathrm{Cu}^{\prime \prime}, \mathrm{Ni}^{\prime \prime}$ and $\mathrm{Zn}{ }^{\prime \prime}$ respectively, Scheme 6.3), the metal coordination spheres in $\left[\mathrm{Cu}_{2}{ }_{2} \mathrm{~L}^{2}(\mathrm{OH})(\mathrm{DTBP})_{2}\right]$ have a distinctly different spatial arrangement. $\left[\mathrm{Cu}_{2}{ }_{2}{ }^{2}(\mathrm{OH})(\mathrm{DTBP})_{2}\right]$ lies much more towards square pyramidal on the structural continuum $(\tau=0.14$ and 0.13$)$, and only the pyrazole and shoulder nitrogen atoms are found in the equatorial plane. While two of the four side arms are dissociated, the remaining coordinated side arms occupy Jahn-Teller distorted axial positions with elongated bond lengths (Cu1-N4 = 2.443 and Cu2-N7 = 2.415 $\AA$ ) in comparison to the equitorial donor distances (1.889-2.224 $\AA$ ). The sidearm donors are generally responsible for pulling the metal ions back and apart in the related structures above, thereby enforcing large metal separations. However, their contribution to dictating the metal-metal distance in $\left[\mathrm{Cu}^{\prime \prime}{ }_{2} \mathrm{~L}^{2}(\mathrm{OH})(\mathrm{DTBP})_{2}\right]$ is negligible, and thus the two copper ions can approach each other sufficiently closely $(\mathrm{Cu} \cdots \mathrm{Cu}=3.462 \AA)$ to allow for a relatively small hydroxide to occupy a bridging position. The proton on this bridge could be located crystallographically, and provides the charge balance required to give an overall neutral complex. The origin of this proton, together with the dissociation of the side arms, may have implications for the mechanism of DTBP hydroxylation (Section 6.7.1). 


\subsubsection{Closing the Catalytic Cycle}

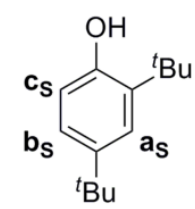

Substrate

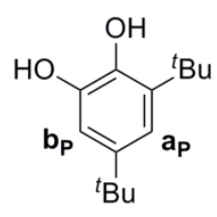

Product

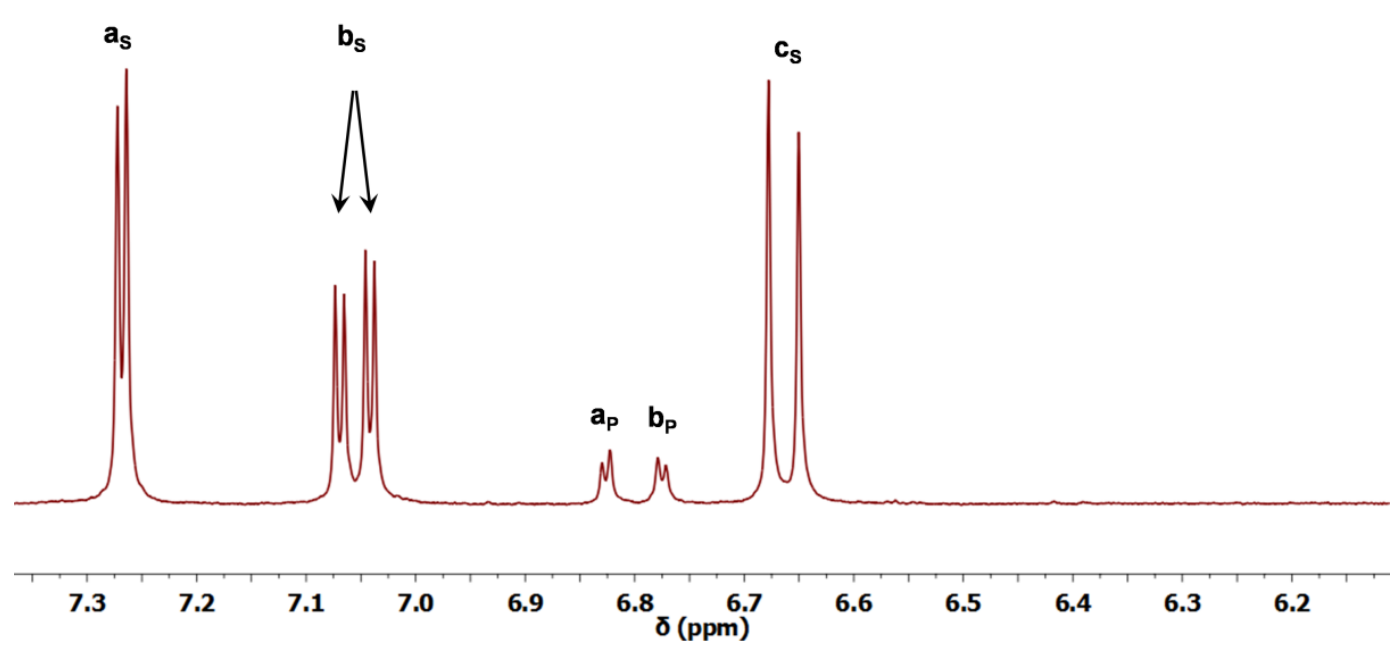

Figure 6.10: Aromatic region of the ${ }^{1} \mathrm{H}$ NMR spectrum which results after anaerobic work-up (see text) of the reaction between $\left[\mathrm{Cu}_{2}{ }_{2} \mathrm{~L}^{2}\left(\mathrm{O}_{2}\right)\right]^{\mathrm{ClO} 4}$ and NaDTBP (measured under inert conditions in dry $\mathrm{CD}_{3} \mathrm{CN}$ at $\mathrm{RT}$ ). Substrate and product signals are labelled with the subscripts $\mathbf{S}$ and $\mathbf{P}$, respectively.

When the reaction between $\left[\mathrm{Cu}_{2}{ }_{2} \mathrm{~L}^{2}\left(\mathrm{O}_{2}\right)\right]^{\mathrm{X}}$ and NaDTBP was conducted as described above, but with workup and ${ }^{1} \mathrm{H}$ NMR analyses performed under strictly anaerobic conditions, a different signal set for the product was observed. The spectrum instead revealed the presence of 3,5-di-tert-butylcatechol $\left(\mathrm{H}_{2} \mathrm{DTBC}\right)$, which was quantitatively converted to DTBQ by simply exposing the NMR analyte solutions to air. Previously published data indicate that a dicopper(II) complex supported by deprotonated $\mathbf{H L}^{2}$ is indeed capable of oxidising $\mathbf{H}_{2}$ DTBC to DTBQ, ${ }^{78}$ making the complete lack of DTBQ in samples analysed under inert conditions surprising. One possibility implied by $\left[\mathrm{Cu}_{2}{ }_{2} \mathrm{~L}^{2}(\mathrm{OH})(\mathrm{DTBP})_{2}\right]$ is that the anionic phenolate substrate acts as an inhibitor, blocking free coordination sites in the dinuclear copper(II) complex $\left(\left[\mathrm{Cu}_{2}{ }_{2} \mathrm{~L}^{2}\right]^{\mathrm{X}}\right)$. Furthermore, under the reaction conditions employed herein NaDTBP is present in relatively large excess compared with $\mathbf{H}_{2}$ DTBC. This inhibition hypothesis was tested by reducing the amount of NaDTBP used for oxygenation experiments from five equivalents to only one. Workup under aerobic conditions revealed no change in the yield of the resulting DTBQ, implying that the presence of excess substrate has little effect on the outcome of the oxygenation and oxidation reactions. 
Two further experiments were conducted to assess whether $\left[\mathrm{Cu}_{{ }_{2}} \mathbf{L}^{2}\right]^{\mathrm{X}}$ is capable of achieving the transformation of $\mathbf{H}_{2}$ DTBC to DTBQ needed to close the catalytic cycle under the conditions studied. In order to entirely eliminate any excess NaDTBP present, $\left[\mathrm{Cu}^{11}{ }_{2} \mathbf{L}^{2}\right]^{\text {OTf }}$ was generated in situ by deprotonation of ligand $\mathrm{HL}^{2}$ with $\mathrm{KO}^{t} \mathrm{Bu}$, followed by addition of anhydrous $\mathrm{Cu}(\mathrm{OTf})_{2}$. To this solution was added one equivalent of either $\mathbf{H}_{2}$ DTBC or dipotassium 3,5-di-tert-butylcatecholate, $\mathrm{K}_{2} \mathrm{DTBC}$. In both cases this caused a very slight change in the dark green colour, and the solutions were then stirred under anaerobic conditions at RT. No further colour change was observed over the course of 10 days, and following inert workup as for the oxygenation reactions described above ${ }^{1} \mathrm{H} N M R$ spectroscopic analysis showed only $\mathbf{H}_{2}$ DTBC (Figure 6.11).<smiles>CC(C)(C)c1ccc(Br)c(C(=O)O)c1O</smiles>

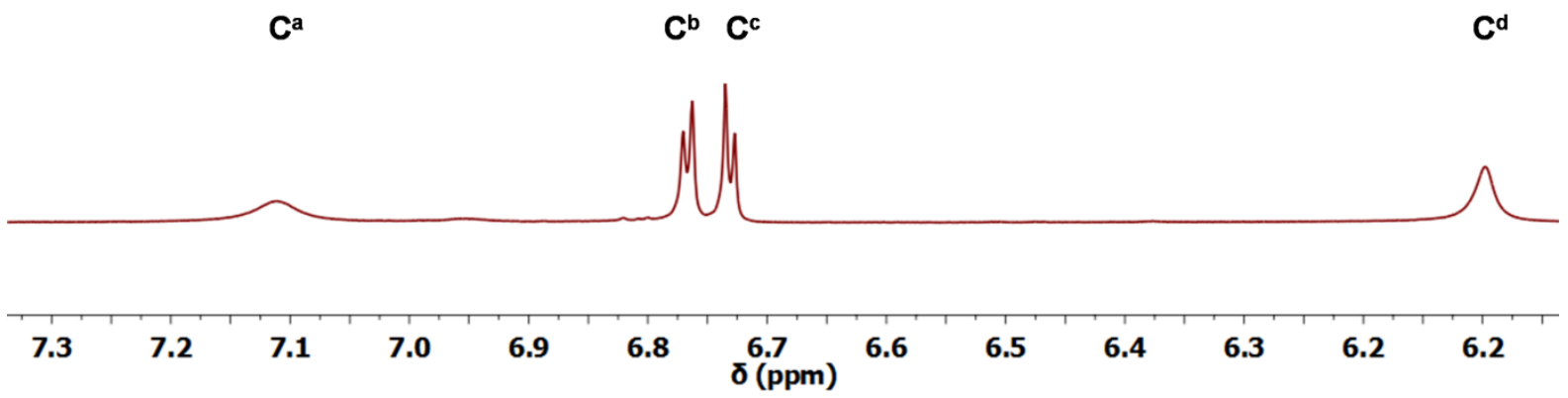

Figure 6.11: Aromatic region of the ${ }^{1} \mathrm{H}$ NMR spectrum which results when $\left[\mathrm{Cu}^{\prime \prime}{ }_{2}{ }^{2}\right]^{\text {OTf }}$ and $\mathbf{H}_{2} \mathrm{DTBC}$ are mixed at $\mathrm{RT}$ for 10 days under anaerobic conditions (measured under inert conditions in dry $\mathrm{CD}_{3} \mathrm{CN}$ at RT). 
In a converse approach, the reaction between $\left[\mathrm{Cu}_{2}{ }_{2} \mathbf{L}^{2}\right]^{\text {OTf }}$ and DTBQ at $-80{ }^{\circ} \mathrm{C}$ was monitored by in situ UV-vis spectroscopy. Upon addition of DTBQ to a pre-cooled solution of $\left[\mathrm{Cu}_{2}{ }_{2} \mathbf{L}^{2}\right]^{\text {OTf }}$ in EtCN, the solution became green-brown in colour over the course of approximately 30 $\min$. Two new broad features developed in the UV-vis spectrum, one at $800 \mathrm{~nm}(\varepsilon=\sim 300$ $\mathrm{M}^{-1} \mathrm{~cm}^{-1}$ ) and the second in the UV region with a broad shoulder at about $375 \mathrm{~nm}$. Very similar bands also appear in the UV-vis spectrum of zinc(II) coordinated to 3,5-di-tertbutylsemiquinone (DTBSQ), thereby indicating that the $800 \mathrm{~nm}$ absorbance in the current case does not arise from a d-d transition. ${ }^{228,229}$ In fact, this feature at approximately $800 \mathrm{~nm}$ has been suggested as a diagnostic for the semiquinone character of a coordinated dioxolene ligand $^{229}$ (the term dioxolene collectively refers to the catecholate dianion, semiquinone anion, and neutral quinone of a particular 1,2-O,O-phenylene ligand) ${ }^{230-232}$.

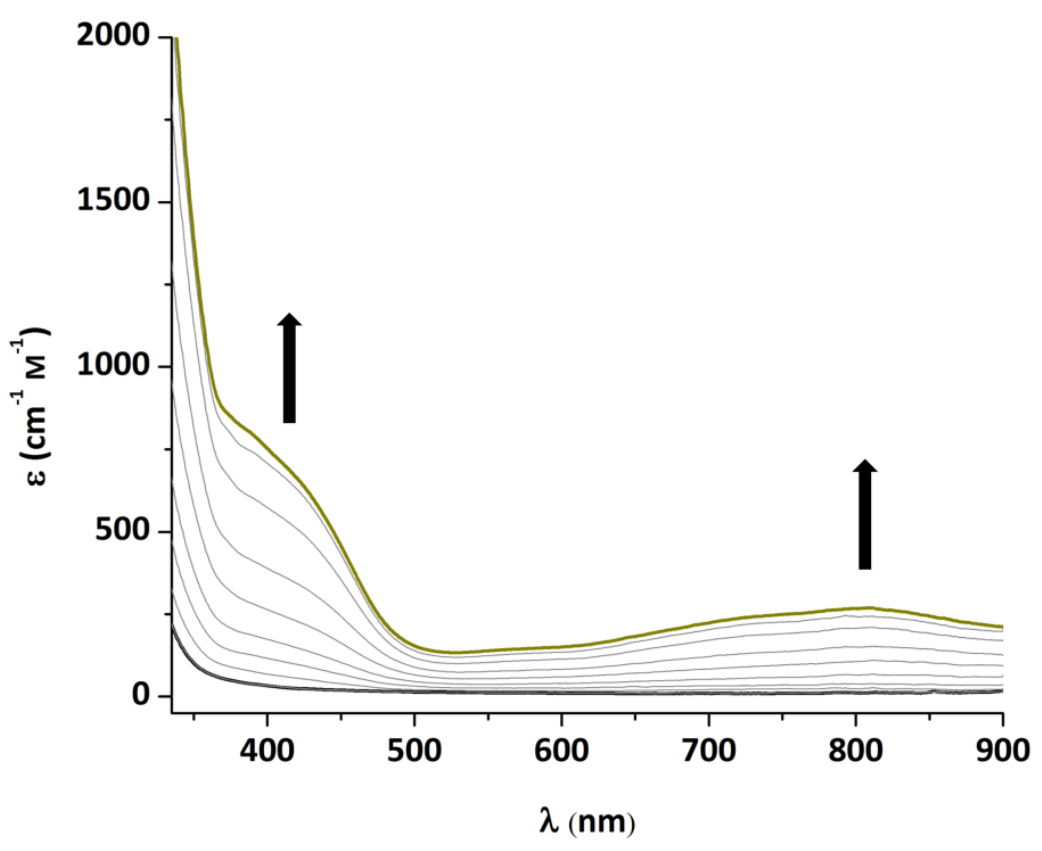

Figure 6.12: UV-vis spectroscopic monitoring of the reaction between $\left[\mathrm{Cu}_{2}{ }_{2} \mathrm{~L}^{2}\right]^{\text {OTf }}$ and $\mathrm{DTBQ}$ at $-80^{\circ} \mathrm{C}$ in EtCN $(1$ $\left.\times 10^{-2} \mathrm{M}\right)$. The observed features are diagnostic for formation of a semiquinone.

These results are consistent with the formation of an adduct between $\left[\mathrm{Cu}_{2}{ }_{2} \mathbf{L}^{2}\right]^{\mathrm{X}}$ and DTBQ involving the transfer of a single electron to give a mixed-valent copper complex and DTBSQ. ${ }^{233-235}$ Both absorbance bands also decreased over time, which may indicate further formation of the corresponding catechol. ${ }^{233,235,236}$ The rate of reaction may possibly be hindered by the low temperature and the tendency of the dioxolene ligands to coordinate to only one copper centre (Section 6.7.3). ${ }^{78}$ Nevertheless, the combined observations discussed above qualitatively demonstrate that $\left[\mathrm{Cu}^{\prime \prime}{ }_{2} \mathbf{L}^{2}\right]^{\mathrm{X}}$ does not possess suitable characteristics favourable for DTBQ formation, and the equilibrium lies strongly toward DTBC. Therefore, this system does not mediate a truly catalytic cycle under the conditions studied, and $\left[\mathrm{Cu}_{2}{ }_{2} \mathrm{~L}^{2}\left(\mathrm{O}_{2}\right)\right]^{\mathrm{X}}$ acts only as a stoichiometric oxygen transfer reagent with respect to NaDTBP. 
<smiles>CC(C)(C)C1=CC(=O)C(=O)C(C(C)(C)C)=C1</smiles>

Scheme 6.4: Stoimetric oxygenation of the biomimetic substrate, DTBP, mediated by $\left[\mathrm{Cu}_{2} \mathrm{~L}^{2}\left(\mathrm{O}_{2}\right)\right]^{\mathrm{X}}$.

The dioxygen adduct $\left[\mathrm{Cu}^{\prime \prime}{ }_{2} \mathbf{L}^{2}\left(\mathbf{O}_{2}\right)\right]^{\mathrm{X}}$ showed no reactivity towards 9,10-dihydroanthracene, diphenylmethane, norbornene and adamantane in preliminary substrate screening experiments. However, it should be highlighted that the general workup and testing procedures were still being optimised at this point in time, and thus the analysis was conducted only by GC-MS. Given the complications encountered with the NaDTBP substrate described above, a complete lack of reactivity of $\left[\mathrm{Cu}_{2}{ }_{2} \mathrm{~L}^{2}\left(\mathrm{O}_{2}\right)\right]^{\mathrm{X}}$ toward the aforementioned substrates is proposed only tentatively, pending confirmation by ${ }^{1} \mathrm{H} N \mathrm{NMR}$ analysis.

\subsection{The $\left[\mathrm{Cu}_{2}{ }_{2} \mathrm{~L}^{3}\left(\mathrm{O}_{2}\right)\right]^{\mathrm{X}}$ System}

Both the activated substrate 2,4-di-tert-butylphenol and the related structural isomer 3,5di-tert-butylphenol previously showed no transformation in monophenolase activity tests of $\left[\mathrm{Cu}^{\prime \prime}{ }_{2} \mathbf{L}^{3}\left(\mathbf{O}_{2}\right)\right]^{\mathrm{X}}$. ${ }^{11}$ Whereas the use of the corresponding sodium 2,4-di-tert-butylphenolate altered this outcome in the case of $\left[\mathrm{Cu}^{11}{ }_{2} \mathrm{~L}^{2}\left(\mathrm{O}_{2}\right)\right]^{\mathrm{X}}$, no such reactivity was observed here. Thus, addition of NaDTBP to $\left[\mathrm{Cu}_{2}{ }_{2} \mathrm{~L}^{3}\left(\mathrm{O}_{2}\right)\right]^{\mathrm{X}}$ at $-30{ }^{\circ} \mathrm{C}$ resulted in no significant colour change to the EtCN solution, which remained stable over the course of several hours at this low temperature. While warming to RT gave a brown coloured solution, subsequent workup showed no obviously coloured species, and no substrate transformation was detected by ${ }^{1} \mathrm{H}$ NMR analysis regardless of the counterion used $\left(\mathrm{PF}_{6}^{-}, \mathrm{BF}_{4}{ }^{-}, \mathrm{ClO}_{4}{ }^{-}\right.$or $\left.\mathrm{OTf}^{-}\right)$. Given the considerations relating to spin state discussed earlier (Section 6.1.1), a variety of substrates encompassing a broader range of differing character were then further screened in an effort to establish the reactivity patterns of $\left[\mathrm{Cu}^{\prime \prime}{ }_{2} \mathrm{~L}^{3}\left(\mathrm{O}_{2}\right)\right]^{\mathrm{X}}$. 


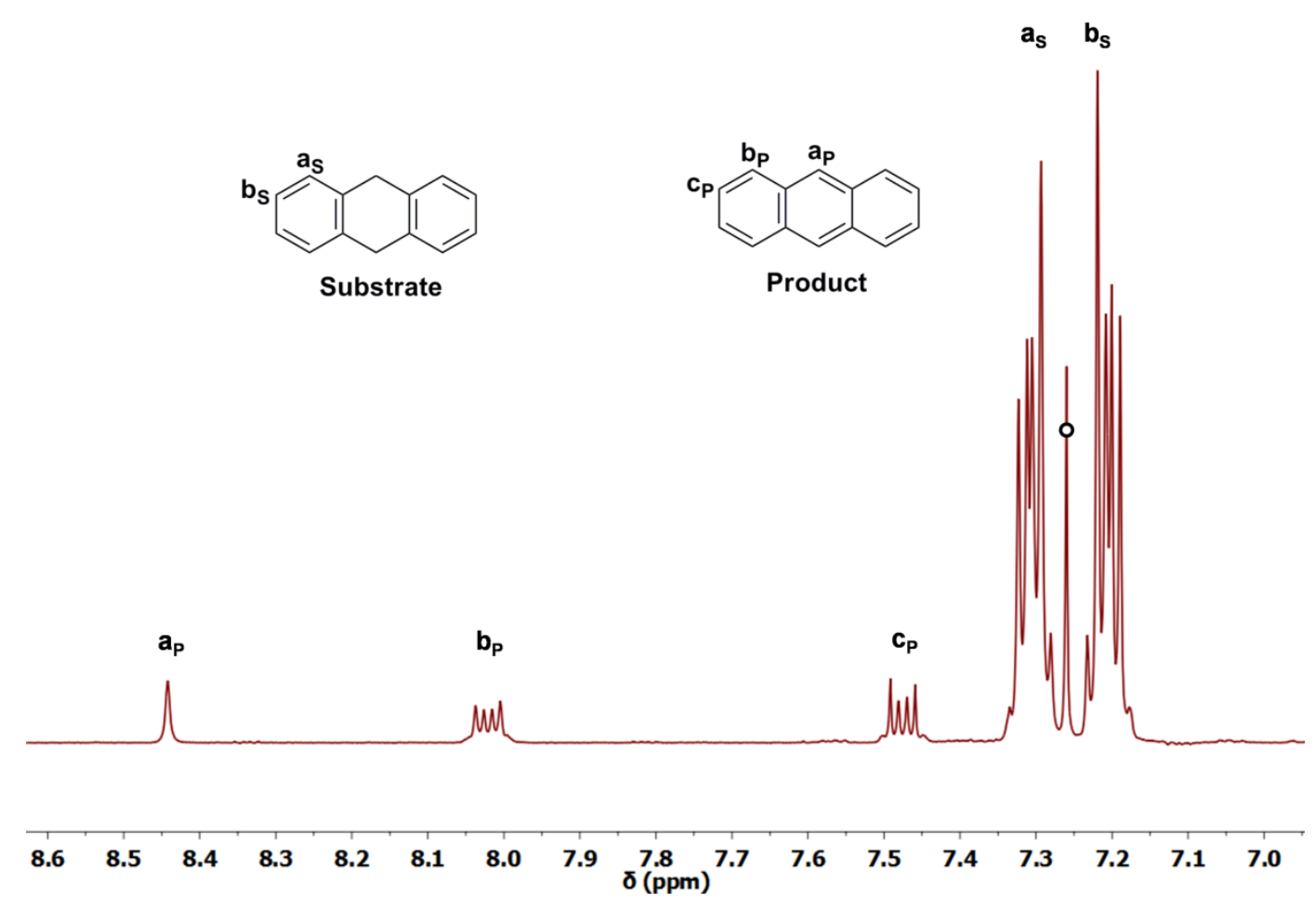

Figure 6.13: Aromatic region of the ${ }^{1} \mathrm{H}$ NMR spectrum which results after work-up (see text) of the reaction between $\left[\mathrm{Cu}_{2}{ }_{2} \mathrm{~L}^{3}\left(\mathrm{O}_{2}\right)\right]^{\mathrm{OTf}}$ and DHA (measured under ambient conditions in $\mathrm{CDCl}_{3}$ at RT). Residual solvent signals are labelled (o). Substrate and product signals are labelled with the subscripts $\mathbf{S}$ and $\mathbf{P}$, respectively.

\subsubsection{Radical-like Reactivity}

Introduction of the substrates 9,10-dihydroanthracene (DHA), diphenylmethane, norbornene, adamantane, toluene or styrene to solutions of pre-formed $\left[\mathrm{Cu}^{\prime \prime} \mathrm{L}^{3}\left(\mathrm{O}_{2}\right)\right]^{\mathrm{X}}$ at -30 ${ }^{\circ} \mathrm{C}$ (after removal of excess $\mathrm{O}_{2}$, see Experimental Section 8.9) again gave no significant colour change, even when maintained at low temperature over several hours. Although the majority of samples became green at ambient temperatures, and showed only unreacted starting material upon analysis, solutions containing DHA appeared distinctly different in colour when allowed to warm to RT. Despite the apparent lack of reactivity at low temperature, workup of the resulting brown solutions followed by ${ }^{1} H$ NMR analysis reproducibly revealed the presence of anthracene (Anth) with a yield of approximately $25 \%$. The presence or absence of sodium cations had no significant influence on the yield, and blank tests with solutions containing equivalent amounts of neutral ligand or $\left[\mathrm{Cu}(\mathrm{MeCN})_{4}\right]$ OTf which were treated identically showed only unreacted DHA.

\subsection{Active species}

\subsubsection{Involvement of ${ }^{\mathrm{E}} \mathrm{S}$ Species?}

The reactivity of $\left[\mathrm{Cu}^{\prime \prime}{ }_{2} \mathbf{L}^{2}\left(\mathrm{O}_{2}\right)\right]^{\mathrm{X}}$ is atypical. The ability to mediate ortho-phenol hydroxylation has only once been reported for a ${ }^{\top} \mathbf{P}$ species (Section 6.4.2), which has now been challenged 
and suggested to result from an ${ }^{\mathrm{B}} \mathrm{O}$-type dioxygen-adduct. The presence of such a ${ }^{\mathrm{B}} \mathbf{O}$ species is unlikely in the $\left[\mathrm{Cu}_{2}{ }_{2} \mathrm{~L}^{2}\left(\mathrm{O}_{2}\right)\right]^{\mathrm{X}}$ system due to the geometric constraints imposed by the ligand system, although it cannot be ruled out entirely, as these limitations would be relaxed if inter-molecular dioxygen adducts form (as proposed in Section 4.4.5). Nonetheless, the spectroscopic findings presented herein give no indication for formation of any $\mathrm{Cu}_{2} \mathrm{O}_{2}$ species other than end-on ( ${ }^{\mathbf{P}} \mathbf{P}$ and ${ }^{\top} \mathbf{P}$ ) adducts. On the other hand, there is a significant amount of evidence supporting the presence of an ${ }^{\mathrm{E}} \mathrm{S}$ species (Section 4.3.2). In this regard it is worth noting that experiments in which formation of the mononuclear $\left[\mathrm{Cu}^{\prime \prime} \mathbf{L}^{2}\left(\mathrm{O}_{2}{ }^{\circ}\right)\right.$ ] adduct was suppressed by addition of excess copper(I) salt showed comparable yields for the hydroxylation reaction (Section 6.5.1). Nevertheless, the mononuclear and dinuclear dioxygen adducts may still both be present in equilibrium. Furthermore, there is literature precedent to suggest that the speciation of copper-dioxygen adducts may indeed be influenced by substrate coordination (Section 1.3.3), which provides the basis for the ongoing debate regarding the active hydroxylating species in Tyr (Section 6.4.1).

The ${ }^{\mathrm{E}} \mathbf{S}$ adduct is known to be capable of facilitating oxygen atom transfer to aromatic organic substrates, making it a possible candidate for the active species in the conversion of NaDTBP to $\mathbf{H}_{2}$ DTBC. ${ }^{60,61}$ However, the ${ }^{\mathrm{E}} \mathrm{S}$ species is generally thought to initiate hydrogenabstraction reactions which then proceed through radical intermediates (Sections 1.3.4). In this regard it is worth noting that the use of the neutral parent HDTBP did not lead to any substrate transformation whatsoever. Furthermore, no radical coupling products were observed in the reaction between $\left[\mathrm{Cu}_{2}{ }_{2} \mathbf{L}^{2}\left(\mathbf{O}_{2}\right)\right]^{\mathrm{X}}$ and NaDTBP. It is nevertheless feasible in the latter case that coordination of the phenolate substrate to the second copper ion may promote selectivity in the $\left[\mathrm{Cu}_{2}{ }_{2} \mathrm{~L}^{2}\left(\mathbf{O}_{2}\right)\right]^{\mathrm{X}}$ system. Unfortunately, detailed reactivity studies of ${ }^{\mathrm{E}} \mathrm{S}$ adducts are still somewhat limited in number, with contrasting mechanistic scenarios put forward depending on the individual systems. ${ }^{42,43,60}$ It is also noteworthy that the pathways followed by the DBM and PHM enzymes after $\mathrm{C}-\mathrm{H}$ bond activation are poorly understood, with numerous suggestions originating from different research groups. ${ }^{59}$ To propose a detailed mechanism in the current case, especially on the basis of the limited data, would thus be largely speculation. One point worthy of consideration is that the dioxygen bond must be cleaved during the hydroxylation, with concurrent formation of a new $\mathrm{C}-\mathrm{O}$ bond. These events may provide a spectroscopic handle to monitor the reaction through $r R$ experiments. Further insight into the mechanism would also likely be provided by kinetic analysis, screening of differently derivatised phenolate substrates, and computational studies. 


\subsubsection{DHA Formation Mechanisms}

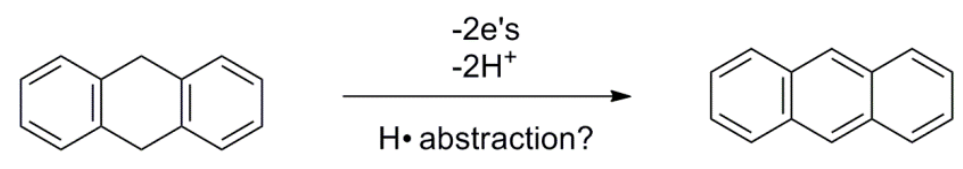

Scheme 6.5: Oxidation of DHA to give Anth, a reaction frequently used to screen for hydrogen-abstraction capability of dioxygen-activating coordination compounds.

The transformation of DHA to Anth is often employed to screen for hydrogen-abstraction reactivity of dioxygen-activating bioinspired coordination compounds, thereby implying that the reactive species involved possesses some radical-like character. ${ }^{59,237,238}$ The findings described herein hint at such reactivity in the case of $\left[\mathrm{Cu}^{\prime \prime} \mathbf{L}^{3}\left(\mathbf{O}_{2}\right)\right]^{\mathrm{X}}$. However, reaction with DHA was only observed to occur upon warming to RT, implicating a decomposition product as the active species. As described earlier (Section 6.2), there is uncertainty about the structure of the initial product which results upon thermally-induced decomposition of $\left[\mathrm{Cu}_{2}{ }_{2} \mathbf{L}^{3}\left(\mathrm{O}_{2}\right)\right]^{\mathrm{X}}$. Definitive conclusions about the reactive species are thus not easily made, but some points are worthy of further consideration. Spectroscopic evidence for this system suggests that an ${ }^{\mathrm{E}} \mathrm{S}$ species is accessible (Section 4.4.2). However, while such an adduct could potentially facilitate $\mathrm{H}$-atom abstraction from DHA, it was found to be favoured only at lower temperatures. Although unequivocal proof that the dioxygen bond is broken during decay of $\left[\mathrm{Cu}^{1{ }^{\prime \prime}} \mathrm{L}^{3}\left(\mathbf{O}_{2}\right)\right]^{\mathrm{X}}$ is still lacking (Section 6.2 .2 ), such a pathway could result in a transient terminal (pseudo-)mononuclear copper-oxygen species. Such intermediates resulting from cleavage of $\mathrm{Cu}_{2} \mathrm{O}_{2}$ adducts are thought to be especially reactive (Section 1.3.4). However, lack of reactivity toward any of the other activated substrates which were screened would be surprising if this proposal is accurate. The involvement of a hydrogenabstraction process could possibly be identified by the use of deuterated substrate.

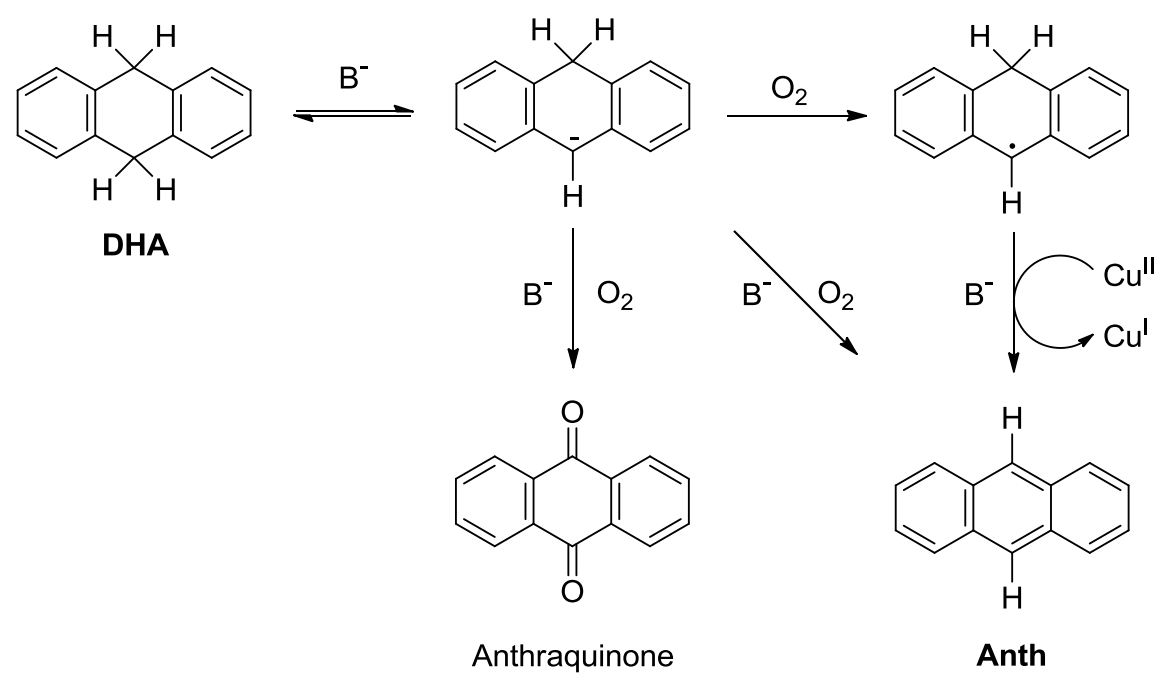

Scheme 6.6: Possible pathways for oxidation of DHA to Anth without the necessary involvement of a copperoxygen active species. 
As opposed to the $\left[\mathrm{Cu}^{\prime \prime}{ }_{2} \mathrm{~L}^{2}\left(\mathrm{O}_{2}\right)\right]^{\mathrm{X}}$-mediated formation of $\mathrm{H}_{2} \mathrm{DTBC}$ (Section 6.5), cleavage of the dioxygen bond is not necessary to produce Anth from DHA. In fact, while an electron acceptor is required in order to transform DHA into Anth, there is no requirement that the reaction involve $\mathrm{H}$-atom abstraction at all. The base-catalysed autoxidation of DHA has been the subject of a considerable amount of literature attention. ${ }^{239,240}$ Following deprotonation, the resulting conjugate base can react with free dioxygen in solution to generate the corresponding radical anion, which can subsequently disproportionate or react with additional $\mathrm{O}_{2}$ to give anthracene. ${ }^{241}$ Dioxygen could be liberated by backward reaction in the case of $\left[\mathrm{Cu}_{2}{ }_{2} \mathrm{~L}^{3}\left(\mathrm{O}_{2}\right)\right]^{\mathrm{X}}$, but the presence of $\mathrm{O}_{2}$ usually leads to mixtures containing the oxygenated product anthraquinone in addition to Anth. ${ }^{240,242}$ On the other hand, the radical anion could also plausibly donate an electron to copper(II) to give Anth. ${ }^{243,244}$ Both of these processes could contribute to formation of Anth without direct involvement of a copperoxygen active species (Scheme 6.6). The only other requirement would then be the presence of a sufficiently strong base. In this regard it is interesting to note that $\mathrm{KO}^{\mathrm{t}} \mathrm{Bu}$ was employed as the base in several of the above studies, and could thus also be screened for Anth production with and without the presence of $\mathrm{O}_{2}$ or copper.

\subsection{3 $\left[\mathrm{Cu}_{2}{ }_{2} \mathrm{~L}^{2}\left(\mathrm{O}_{2}\right)\right]^{\mathrm{X}}$ versus $\left[\mathrm{Cu}_{2}{ }_{2} \mathrm{~L}^{3}\left(\mathrm{O}_{2}\right)\right]^{\mathrm{X}}$ - Comparing Reactivity}

The lack of reactivity towards DHA displayed by $\left[\mathrm{Cu}_{2}{ }_{2} \mathrm{~L}^{2}\left(\mathrm{O}_{2}\right)\right]^{\mathrm{X}}$ is unexpected, considering that shown by $\left[\mathrm{Cu}_{2}{ }_{2} \mathbf{L}^{3}\left(\mathbf{O}_{2}\right)\right]^{\mathrm{X}}$. Although this finding is tentative in the case of $\left[\mathrm{Cu}_{2}{ }_{2} \mathrm{~L}^{2}\left(\mathbf{O}_{2}\right)\right]^{\mathrm{X}}$, it nevertheless provides evidence against $\mathrm{KO}^{t} \mathrm{Bu}$ playing a role in the reaction, as both $\left[\mathrm{Cu}_{2}{ }_{2} \mathrm{~L}^{2}\left(\mathrm{O}_{2}\right)\right]^{\mathrm{X}}$ and $\left[\mathrm{Cu}_{2}{ }_{2} \mathrm{~L}^{3}\left(\mathrm{O}_{2}\right)\right]^{\mathrm{X}}$ were generated under comparable conditions for substrate screening. While the differences in the copper-dioxygen adducts formed in the two systems likely contribute, the possible involvement of a decomposition product indicated by the lack of direct reactivity in the case of $\left[\mathrm{Cu}_{2}{ }_{2} \mathrm{~L}^{3}\left(\mathbf{O}_{2}\right)\right]^{\mathrm{X}}$ is a complicating factor. This decomposition product might potentially also act as a base. Further conclusions about this reaction are not easily drawn, but additional investigation of the decay pathway followed by $\left[\mathrm{Cu}_{2}{ }_{2} \mathrm{~L}^{2}\left(\mathbf{O}_{2}\right)\right]^{\mathrm{X}}$ could be insightful in this regard. 


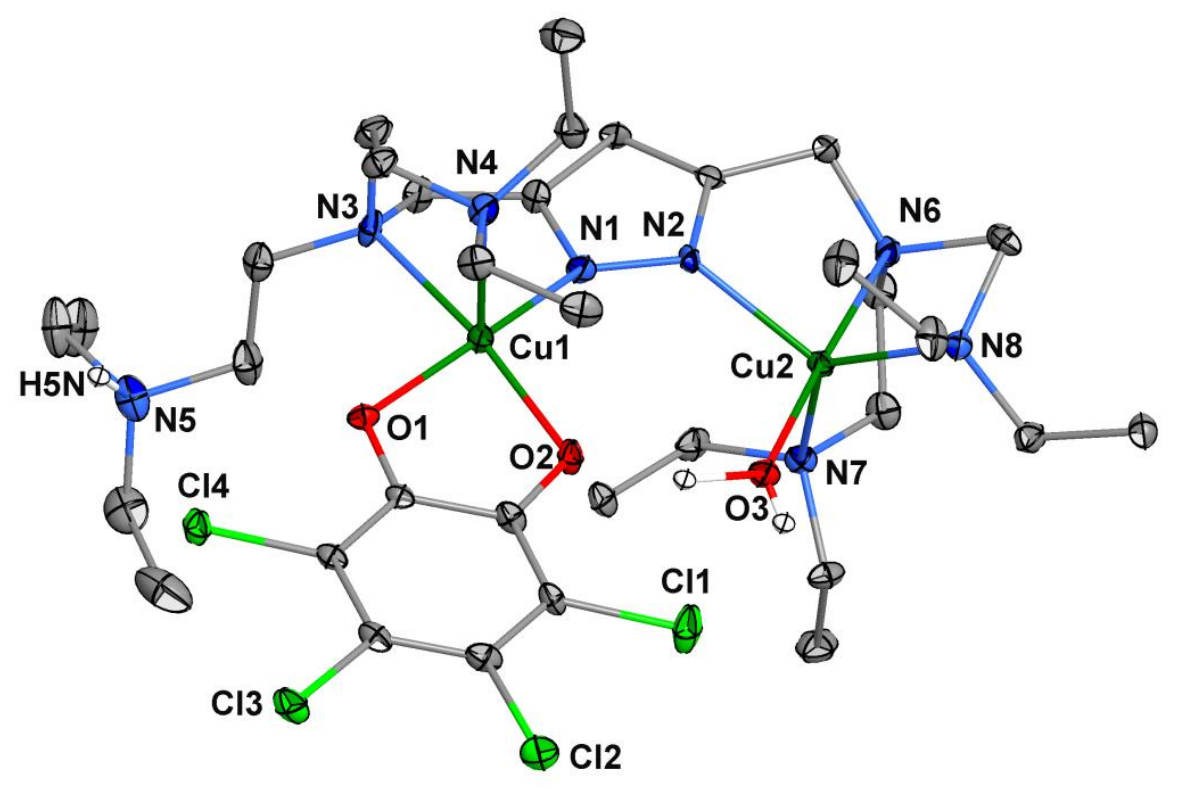

Figure 6.14: Molecular structure of $\left[\mathrm{Cu}_{2}{ }_{2} \mathrm{~L}^{2}(\mathrm{TCC})\right]^{\mathrm{ClO} 4}$, synthesised in a previous work (see text for details).

The poor diphenolase activity of $\left[\mathrm{Cu}^{\prime \prime}{ }_{2}{ }^{2}\left(\mathrm{O}_{2}\right)\right]^{\mathrm{X}}$ was previously proposed to result from a combination of factors, including its unfavourable redox potential and relatively large copper separation $\left(\mathrm{Cu} \cdots \mathrm{Cu}=4.533 \AA\right.$ ).$^{78}$ One apparent consequence of this intermetallic distance is that catechol substrates are prone to coordinate in a bidentate fashion to a

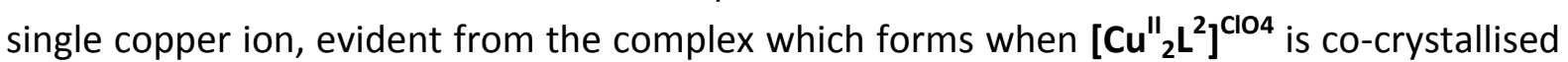
with the inactivated substrate tetrachlorocatechol $\left(\mathrm{H}_{2} \mathrm{TCC}\right.$ ) (Figure 6.14). ${ }^{78}$ The resulting solid state structure, $\left[\mathrm{Cu}_{2}{ }_{2} \mathrm{~L}^{2}(\mathrm{TCC})\right]^{\mathrm{ClO} 4}$, is indeed in agreement with the above finding that reaction of DTBQ with $\left[\mathrm{Cu}_{2}^{\prime} \mathrm{L}^{2}\right]^{\mathrm{X}}$ leads to a UV-vis spectrum consistent with formation of DTBSQ, resulting from single electron transfer. Although binding of catechol to only one of the two copper(II) ions in Tyr is sufficient for oxidation to the corresponding quinone, the transfer of two electrons requires efficient antiferromagnetic coupling between the copper centres in order to overcome the non-bridging coordination mode. ${ }^{18}$ Whether the pyrazole bridging unit alone can mediate a sufficient superexchange pathway to achieve this is unclear. In any case, the poor diphenolase activity of $\left[\mathrm{Cu}^{\prime \prime}{ }_{2} \mathbf{L}^{2}\right]^{\mathrm{X}}$ under the conditions studied is much more likely to result from its unsuitably high reduction potential, as qualitatively demonstrated by its inability to oxidise $\mathbf{H}_{2}$ DTBC, or the corresponding more activated conjugate base, $\mathrm{K}_{2} \mathrm{DTBC}$. One feature of structure $\left[\mathrm{Cu}_{2}{ }_{2} \mathrm{~L}^{2}(\mathrm{TCC})\right]^{\mathrm{ClO} 4}$ worthy of further consideration is that coordination of $\mathbf{H}_{2}$ TCC induces dissociation of one side arm, reminiscent of the $\left[\mathrm{Cu}_{2}{ }_{2} \mathrm{~L}^{2}(\mathrm{OH})(\mathrm{DTBP})_{2}\right]$ complex (Section 6.5.2).

Although direct coordination of phenolic substrate to copper is not a requirement for subsequent oxygenation, there is significant evidence to suggest that this occurs in the natural Tyr systems (Section 6.4.1). The copper(II) ions in the peroxo species $\left[\mathrm{Cu}_{2}{ }_{2} \mathbf{L}^{2}\left(\mathbf{O}_{2}\right)\right]^{\mathrm{X}}$ and $\left[\mathrm{Cu}_{2}{ }_{2} \mathrm{~L}^{3}\left(\mathrm{O}_{2}\right)\right]^{\mathrm{X}}$ are each ligated by an $\mathrm{N}_{4} \mathrm{O}$ donor set, and are furthermore sterically crowded. Accommodation of an additional substrate molecule is thus likely to cause substantial rearrangement of the existing coordination spheres. This may possibly even 
induce sidearm dissociation, a process which would be enabled by the far greater lability of the ligand scaffold in $\left[\mathrm{Cu}_{2}{ }_{2} \mathrm{~L}^{2}\left(\mathrm{O}_{2}\right)\right]^{\mathrm{X}}$ compared with $\left[\mathrm{Cu}_{2}{ }_{2} \mathrm{~L}^{3}\left(\mathrm{O}_{2}\right)\right]^{\mathrm{X}}$. The structure of $\left[\mathrm{Cu}_{2}{ }_{2} \mathrm{~L}^{2}(\mathrm{OH})(\mathrm{DTBP})_{2}\right]$ indirectly supports this proposal, as does $\left[\mathrm{Cu}_{2}{ }_{2} \mathrm{~L}^{2}(\mathrm{TCC})\right]^{\mathrm{ClO} 4}$, in both of which a sidearm has dissociated in order to accommodate a phenolic substrate. ${ }^{78}$ Whether these processes occur by associative or dissociative mechanisms is unknown. However, it is noteworthy that in the case of $\left[\mathrm{Cu}_{2}{ }_{2} \mathrm{~L}^{2}(\mathrm{TCC})\right]^{\mathrm{ClO} 4}$ this may be facilitated by proton transfer from the $\mathrm{H}_{\mathbf{2}} \mathrm{TCC}$ to the sidearm nitrogen atom, thereby attenuating its donor ability. On the other hand, $\left[\mathrm{Cu}_{2}{ }_{2} \mathrm{~L}^{2}(\mathrm{OH})(\mathrm{DTBP})_{2}\right.$ ] shows that this protonation event is not necessary for dissociation.

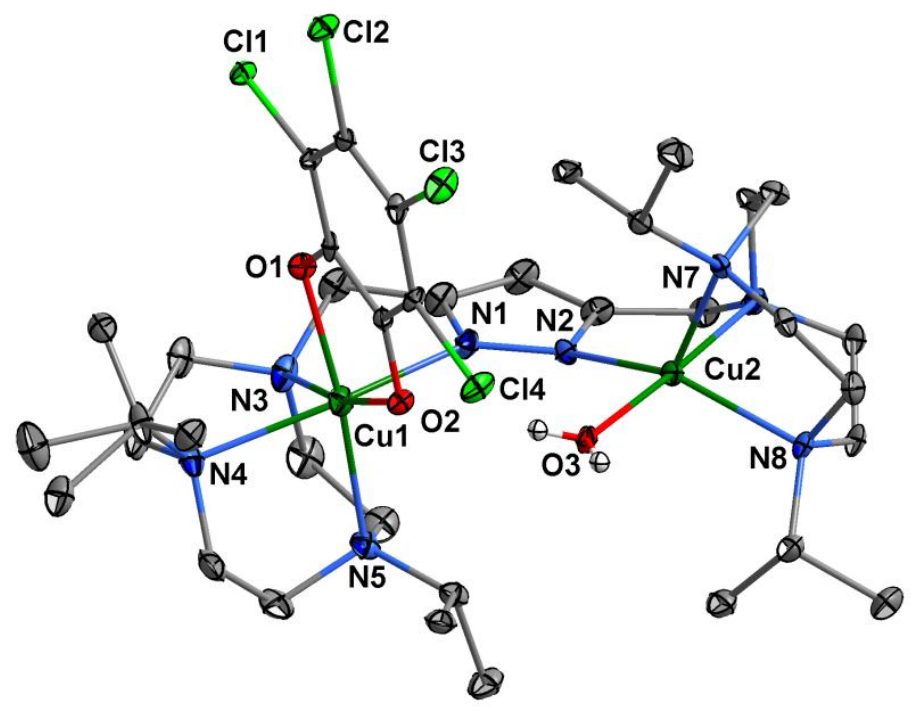

Figure 6.15: Molecular structure of $\left[\mathrm{Cu}_{2}{ }_{2} \mathrm{~L}^{3}(\mathrm{TCC})\right]^{\mathrm{ClO} 4}$, synthesised in a previous work (see text for details).

While the vast majority of dinuclear copper(II) pyrazolate-bridged complexes have an upper coordination number of five (Section 1.4), a structure possessing a six-coordinate copper(II) ion was previously isolated by co-crystallisation of $\mathbf{H}_{\mathbf{2}}$ TCC with a copper(II) complex supported by deprotonated $\mathrm{HL}^{3} .{ }^{91}$ In $\left[\mathrm{Cu}^{1{ }^{11}} \mathrm{~L}^{3}(\mathrm{TCC})\right]^{\mathrm{ClO4}}$ (Figure 6.15), TCC is once again coordinated in a bidentate fashion to a single copper ion, and yet in contrast to $\left[\mathrm{Cu}_{2}{ }_{2} \mathbf{L}^{3}(\mathrm{TCC})\right]^{\mathrm{ClO} 4}$ all donor atoms from the $\mathrm{HL}^{3}$ ligand remain coordinated. This serves to illustrate that coordinative saturation is not necessarily the reason for lack of $\left[\mathrm{Cu}^{\prime \prime}{ }_{2} \mathrm{~L}^{3}\left(\mathrm{O}_{2}\right)\right]^{\mathrm{X}}$ monophenolase activity. Once coordinated, orientation of the substrate such that there is sufficient overlap between the participating reactant orbitals is thought to be crucial to achieving $o$-hydroxylation in both the model systems and parent Tyr enzyme. ${ }^{18,25}$ This implies that the differences in structural flexibility between $\left[\mathrm{Cu}_{2}{ }_{2} \mathrm{~L}^{2}\left(\mathrm{O}_{2}\right)\right]^{\mathrm{X}}$ and $\left[\mathrm{Cu}_{2}{ }_{2} \mathrm{~L}^{3}\left(\mathrm{O}_{2}\right)\right]^{\mathrm{X}}$ may have a significant impact on the resulting reactivity, even if both allow for substrate coordination. Regardless of the precise mechanism, the considerable steric demand of $\left[\mathrm{Cu}_{2}{ }_{2} \mathbf{L}^{\mathbf{3}}\left(\mathbf{O}_{2}\right)\right]^{\mathrm{X}}$ is likely a major factor which inhibits its monophenolase potential. Thus, while 3,5-di-tert-butylphenol was used as a test substrate previously, the deprotonated form should also be investigated as it has less steric crowding directly adjacent to its donor oxygen atom. 


\subsection{Summary and Conclusions}

This chapter has investigated the reactivity properties of the two temperature sensitive copper-peroxo species, $\left[\mathrm{Cu}_{2}{ }_{2} \mathbf{L}^{2}\left(\mathbf{O}_{2}\right)\right]^{\mathrm{X}}$ and $\left[\mathrm{Cu}^{\prime \prime}{ }_{2} \mathrm{~L}^{3}\left(\mathrm{O}_{2}\right)\right]^{\mathrm{X}}$. The thermally induced decomposition of $\left[\mathrm{Cu}^{\prime \prime}{ }_{2} \mathrm{~L}^{3}\left(\mathrm{O}_{2}\right)\right]^{\mathrm{X}}$ was studied in detail, and the ability of both systems to mediate the oxidation and oxygenation of external substrates was explored.

Thermally induced decomposition of $\left[\mathrm{Cu}_{2}{ }_{2} \mathrm{~L}^{3}\left(\mathrm{O}_{2}\right)\right]^{\text {OTf }}$ solutions led to the isolation of a pyrazole-bridged dinuclear copper(II) complex, $\left[\mathrm{Cu}_{2}{ }_{2} \mathrm{~L}^{3}\left(\mathrm{H}_{3} \mathrm{O}_{2}\right)\right]^{(\mathrm{OTf}) 2}$. Material suitable for crystallographic structural determination could be obtained from both EtCN and $\mathrm{Me}_{2} \mathrm{CO}$ solutions of $\left[\mathrm{Cu}_{2}{ }_{2} \mathrm{~L}^{3}\left(\mathrm{O}_{2}\right)\right]^{\mathrm{OTf}}$, and characterisation revealed a structure wherein the peroxide moiety had been replaced by an $\mathrm{H}_{3} \mathrm{O}_{2}$ tether. Attempts to identify the origin of this bridging array were inconclusive, but further investigation by in situ IR spectroscopy may provide significant insights. Kinetic analysis of the thermally induced decay of $\left[\mathrm{Cu}^{\prime \prime}{ }_{2} \mathbf{L}^{3}\left(\mathbf{O}_{2}\right)\right]^{\mathrm{X}}$ was conducted and found to be consistent with a second order reaction, in agreement with previous studies. These findings rule out a decomposition pathway involving intra-molecular oxidative attack on the ligand scaffold. An unusual rate dependence upon both concentration and solvent was observed, which may be indicative of a more complex decomposition pathway. This behaviour has yet to be accounted for, although the use of deuterated analogues in future studies may help to identify the origins of the concentration and solvent dependence. Given the sodium cation binding equilibrium identified in the previous chapter, the influence of these alkali metal ions on the decay rate was also considered. No indication for such an effect could be identified.

Reactivity of the $\left[\mathrm{Cu}^{\prime \prime}{ }_{2}{ }^{2}\left(\mathbf{O}_{2}\right)\right]^{\mathrm{X}}$ system toward the activated 2,4-di-tert-butylphenol substrate was investigated in detail. No transformation of the substrate was observed when the neutral phenol was used, in agreement with previous findings. However, when the corresponding sodium salt was utilised transfer of an oxygen atom to the ortho-position could be achieved. The product initially identified was 3,5-di-tert-butylquinone, implying that the reaction might proceed catalytically. However, further detailed investigation through the use of in situ UV-vis spectroscopy and additional analysis of the reaction under anaerobic conditions revealed that 3,5-di-tert-butylcatechol was the primary reaction product, and that subsequent exposure to air induced further oxidation to give the quinone. These results thereby indicate that $\left[\mathrm{Cu}_{2}{ }_{2} \mathrm{~L}^{2}\left(\mathbf{O}_{2}\right)\right]^{\mathrm{X}}$ acts as a stoichiometric oxygen-transfer reagent. Efforts to elucidate the mechanism by which this system mediates orthohydroxlation may benefit from the use of additionally derivatised phenolate substrates in combination with kinetic measurements.

A selection of substrates were screened in order to assess the reactivity profile of the $\left[\mathrm{Cu}^{\prime \prime}{ }_{2} \mathbf{L}^{3}\left(\mathbf{O}_{2}\right)\right]^{\mathrm{X}}$ system. In contrast to the $\left[\mathrm{Cu}^{\prime \prime}{ }_{2} \mathbf{L}^{2}\left(\mathbf{O}_{2}\right)\right]^{\mathrm{X}}$ system, no oxygen atom transfer ability could be observed. However, it could be shown that $\left[\mathrm{Cu}^{\prime \prime}{ }_{2} \mathrm{~L}^{3}\left(\mathbf{O}_{2}\right)\right]^{\mathrm{X}}$ is capable of mediating the oxidation of 9,10-dihydroanthracene. One complicating aspect in relation to this 
transformation was that the reaction only proceeded when the relevant solutions were warmed to RT. This finding implies that a decomposition product of $\left[\mathrm{Cu}_{2}{ }_{2} \mathrm{~L}^{3}\left(\mathrm{O}_{2}\right)\right]^{\mathrm{X}}$ may be the actual reactive species responsible for carrying out the oxidation reaction. Furthermore, several mechanistic pathways exist which can account for formation of the anthracene product without direct involvement of a copper-oxygen active species. Further investigation is required in order to elucidate the pathway by which the product is formed and identify the role played by $\left[\mathrm{Cu}_{2}{ }_{2} \mathrm{~L}^{3}\left(\mathrm{O}_{2}\right)\right]^{\mathrm{X}}$ in the reaction mechanism. The use of an isotopically labelled analogue of the substrate may provide additional information in this regard.

The unusual reactivity of the systems described herein merits further investigation. The spectroscopic observation of transient copper-superoxo species in both the $\left[\mathrm{Cu}^{\prime \prime}{ }_{2} \mathrm{~L}^{2}\left(\mathrm{O}_{2}\right)\right]^{\mathrm{X}}$ and $\left[\mathrm{Cu}_{2}{ }_{2} \mathrm{~L}^{3}\left(\mathrm{O}_{2}\right)\right]^{\mathrm{X}}$ systems is significant in this regard. Although no direct evidence has been found for involvement of the $\left[\mathrm{Cu}^{\prime \prime} \mathrm{L}^{2}\left(\mathrm{O}_{2}{ }^{\circ}\right)\right]$ and $\left[\mathrm{Cu}^{\prime \prime} \mathrm{L}^{3}\left(\mathrm{O}_{2}{ }^{\circ}\right)\right]$ species in the substrate transformations described here, literature evidence suggests that related terminal (pseudoImononuclear copper-oxygen species exhibit enhanced reactivity, and may result directly from $\mathrm{Cu}_{2} \mathrm{O}_{2}$ adducts under certain circumstances. The possibility of such interconversion processes is clearly a complication in assigning the active species in both the current case and in general, and the short-lived nature of highly reactive intermediates also represents a particularly challenging aspect of this chemistry. Nevertheless, detailed knowledge of these factors is a necessary requirement for a true appreciation of how nature achieves remarkable reactivity. 


\section{Summary and Outlook}

In many metalloproteins two proximal copper ions act together, granting the ability to transport oxygen or transfer it to organic substrates. Such functionality provides motivation for gaining a detailed understanding of how these processes occur on a molecular level, and how they can be applied to achieve mild oxidation reactions promoted by bioinspired catalysts. In the current work, several compartmental pyrazole-bridging ligands were successfully used to gain insights into copper-mediated dioxygen activation chemistry, and thus expand on the proven potential of these organic scaffolds for emulating features of dinuclear metallobiosites.

The ligand systems investigated herein were previously proposed to be capable of supporting di-copper(II)-cis- $\mu$-1,2-peroxide complexes, a $\mathrm{Cu}_{2} \mathrm{O}_{2}$ core arrangement absent from the synthetic literature, but thought to play a significant role in facilitating $\mathrm{O}_{2}$ binding to type 3 enyzmatic copper centres. The current investigation was therefore largely focussed on isolation and detailed characterisation of these elusive $\mathrm{Cu}_{2} \mathrm{O}_{2}$ species. To this end, previously established synthetic methods for the preparation of three pyrazolebridging ligand scaffolds and their corresponding copper(I) complexes were re-investigated and optimised $\left(\left[\mathrm{Cu}_{2}^{1} \mathbf{L}^{1}\right]^{\mathrm{X}},\left[\mathrm{Cu}_{2}{ }_{2} \mathbf{L}^{2}\right]^{\mathrm{X}}\right.$ and $\left.\left[\mathrm{Cu}_{2}{ }_{2} \mathbf{L}^{3}\right]^{\mathrm{X}}\right)$. The complexes were thereby shown to be significantly more stable at room temperature than previously observed, which allowed for their detailed characterisation in solution by various NMR spectroscopic techniques and (cryo-)mass spectrometry. This provided significant insights into the solution speciation of the copper(I) complexes, which proved especially useful for interpreting the outcome of experiments aimed at exploring the dioxygen-activating potential of these systems.

Exposure of the pyrazole-bridged copper(I) complexes to dioxygen results in adducts which were all found to be temperature sensitive to varying degrees, leading to the extensive use of in situ characterisation techniques. In addition to establishing a role for water in formation of the tetranuclear copper(II)-peroxo adduct, $\left[\left(\mathrm{Cu}_{2}{ }_{2} \mathrm{~L}^{2}\right)\left(\mathrm{O}_{2}\right)(\mathrm{OH})_{2}\right]^{\mathbf{2}}$, the thermally labile intermediates of the $\left[\mathrm{Cu}_{2}{ }_{2} \mathbf{L}^{2}\right]^{\mathrm{X}}$ and $\left[\mathrm{Cu}_{2}{ }_{2} \mathbf{L}^{3}\right]^{\mathrm{X}}$ systems have been extensively investigated by in situ dioxygen uptake experiments, UV-vis and resonance Raman spectroscopies, and cryo-ESI mass spectrometry. The outcome of these experiments contributed to establishing conditions under which crystalline material of $\left[\mathrm{Cu}^{11}{ }_{2} \mathbf{L}^{3}\left(\mathrm{O}_{2}\right)\right]^{\mathrm{X}}$ could be isolated and structurally characterised by X-ray diffraction, providing definitive evidence for the cis- $\mu-1,2-$ peroxide binding mode. Structural determination additionally revealed that the unique peroxide bonding arrangement promotes a side-on interaction with sodium cations in the solid state, and by applying the same synthetic methodology an analogous interaction could be demonstrated in the case of potassium cations. Unambiguous elucidation of the peroxide binding mode and the good agreement between the solution and solid state spectroscopic data for $\left[\mathrm{Cu}^{\prime \prime}{ }_{2} \mathbf{L}^{3}\left(\mathbf{O}_{2}\right)\right]^{\mathrm{X}}$ furthermore allowed it to act as a benchmark for comparison with the 
related $\left[\mathrm{Cu}^{\prime \prime}{ }_{2}{ }^{2}\left(\mathrm{O}_{2}\right)\right]^{\mathrm{X}}$ adduct. A scenario involving an equilibrium between an intra- and inter-molecular $\mu$-1,2-peroxo adduct in the latter system could thereby be proposed.

Analysis of the $\left[\mathrm{Cu}_{2}{ }_{2} \mathrm{~L}^{3}\left(\mathrm{O}_{2}\right)\right]^{\mathrm{X}}$ system was then carried out by comparing its physicochemical features to those of related crystallographically characterised di-copper(II)-trans- $\mu-1,2-$ peroxide adducts. This revealed a significantly diminished copper-oxygen interaction relative to those in other known $\mathrm{Cu}_{2} \mathrm{O}_{2}$ species. In addition, SQUID magnetometry measurements were carried out on crystalline $\left[\mathrm{Cu}_{2}{ }_{2} \mathrm{~L}^{3}\left(\mathrm{O}_{2}\right)\right]^{\mathrm{X}}$, which showed that the peroxide bridging moiety in the $\left[\mathrm{Cu}_{2}{ }_{2} \mathrm{~L}^{3}\left(\mathrm{O}_{2}\right)\right]^{\mathrm{X}}$ system mediates only weak antiferromagnetic coupling between the two copper(II) centres, in stark contrast to the generally observed very strong antiferromagnetic coupling in related di-copper(II)-peroxide adducts. Interestingly, $\left[\mathrm{Cu}_{2}{ }_{2} \mathrm{~L}^{3}\left(\mathrm{O}_{2}\right)\right]^{\mathrm{X}}$ thus exhibits characteristics that are comparable with those of a theoretically predicted transition state for $\mathrm{O}_{2}$ binding to type 3 enzymatic copper centres, providing experimental evidence for the computationally proposed mechanism of $\mathrm{O}_{2}$ activation, and supporting the biological relevance of the di-copper(II)-cis- $\mu$-1,2-peroxide motif.

In addition, further investigation into the binding of sodium cations was conducted by UVvis and resonance Raman spectroscopies, providing evidence that the interaction persists in solution. Binding of sodium cations induces changes on an electronic level, and an association constant could thereby be determined by UV-vis spectroscopy. Analogous behaviour involving binding of redox-inactive metal ions in solution has also been observed in synthetic manganese- and iron-oxygen adducts, and is known to modulate reactivity in these related systems. In combination with the unusual magnetic coupling evidenced by magnetic susceptibility measurements, these findings suggest that the novel $\mathrm{Cu}_{2} \mathrm{O}_{2}$ system $\left[\mathrm{Cu}_{2}{ }_{2} \mathbf{L}^{3}\left(\mathbf{O}_{2}\right)\right]^{\mathrm{X}}$, and by extension that of $\left[\mathrm{Cu}^{\prime \prime}{ }_{2} \mathbf{L}^{2}\left(\mathbf{O}_{2}\right)\right]^{\mathrm{X}}$, may potentially exhibit unique reactivity towards organic molecules.

The reactivity profiles of the two copper-peroxo species, $\left[\mathrm{Cu}^{\prime \prime}{ }_{2} \mathbf{L}^{2}\left(\mathrm{O}_{2}\right)\right]^{\mathrm{X}}$ and $\left[\mathrm{Cu}^{\prime \prime}{ }_{2} \mathrm{~L}^{3}\left(\mathbf{O}_{2}\right)\right]^{\mathrm{X}}$, were thus investigated. The thermally induced decomposition of $\left[\mathrm{Cu}_{2}{ }_{2} \mathrm{~L}^{3}\left(\mathbf{O}_{2}\right)\right]^{\mathrm{X}}$ was studied in detail, and the ability of both systems to mediate the oxidation and oxygenation of external substrates was explored. The $\left[\mathrm{Cu}^{\prime \prime}{ }_{2} \mathrm{~L}^{2}\left(\mathrm{O}_{2}\right)\right]^{\mathrm{X}}$ system showed the ability to mediate the ortho-hydroxylation of an activated aromatic substrate, 2,4-di-tert-butylphenol, to give the corresponding 3,5-di-tert-butylquinone. Although biomimetic in this regard, further indepth investigation demonstrated that $\left[\mathrm{Cu}^{\prime \prime}{ }_{2}{ }^{2}\left(\mathrm{O}_{2}\right)\right]^{\mathrm{X}}$ acts only as a stoichiometric oxygentransfer reagent, giving 3,5-di-tert-butylcatechol, which can be further oxidised directly by adventitious dioxygen. In contrast, no oxygen atom transfer ability was observed for the $\left[\mathrm{Cu}^{\prime \prime}{ }_{2} \mathbf{L}^{3}\left(\mathbf{O}_{2}\right)\right]^{\mathrm{X}}$ species. However, it could be shown that this system is capable of mediating oxidation of 9,10-dihydroanthracene. One complicating aspect in relation to this transformation was that the reaction only proceeded when the relevant solutions were warmed to room temperature, implying that a decomposition product of $\left[\mathrm{Cu}^{\prime \prime}{ }_{2} \mathbf{L}^{3}\left(\mathrm{O}_{2}\right)\right]^{\mathrm{X}}$ may be the actual reactive species. 
The present work has significantly elaborated on pyrazole-supported copper-mediated dioxygen activation chemistry. Several systems were investigated in detail, leading to identification of a novel type of $\mathrm{Cu}_{2} \mathrm{O}_{2}$ adduct. Crystallographic structural determination revealed an unprecedented cis- $\mu-1,2$-peroxide binding mode of the dioxygen-derived ligand. This in turn results in properties consistent with a computationally proposed enzymatic mechanism for dioxygen activation, and allows for binding of alkali metal cations in both solution and the solid state. Detailed computational analysis of the $\left[\mathrm{Cu}^{\prime \prime}{ }_{2} \mathbf{L}^{3}\left(\mathbf{O}_{2}\right)\right]^{\mathrm{X}}$ system is a topic of future interest, and such studies are needed to confirm the interpretation of the physicochemical properties of $\left[\mathrm{Cu}_{2}{ }_{2} \mathrm{~L}^{3}\left(\mathrm{O}_{2}\right)\right]^{\mathrm{X}}$ discussed herein. Furthermore, the unusual reactivity of the systems described warrants further investigation. At this point in time the identity of the active species responsible for achieving the reactivity is very much an open question. The most highly reactive species are inherently also transient, though it is exactly these elusive intermediates which are of greatest interest for gaining an intimate understanding of how copper-mediated oxidation and oxygenation of organic substrates can be achieved catalytically, under mild sustainable conditions. 


\section{Experimental Section}

\subsection{General}

All air-sensitive reactions were carried out under an atmosphere of purified argon using standard Schlenk techniques, or in a glovebox (MBRAUN LabMaster) under a nitrogen atmosphere with $<0.1 \mathrm{ppm} \mathrm{O}_{2}$ and $\mathrm{H}_{2} \mathrm{O}$. Glassware for such experiments was dried at $120^{\circ} \mathrm{C}$ overnight prior to use. Solvents were dried and degassed by standard procedures before use. Acetone ( $\mathrm{Me}_{2} \mathrm{CO}$ ) was stirred over $\mathrm{B}_{2} \mathrm{O}_{3}$ for at least $24 \mathrm{~h}$, distilled and then degassed by purging with Argon. ${ }^{245}$ Dioxygen gas was dried by passage through a $\mathrm{P}_{2} \mathrm{O}_{5}$ column.

Chemicals were purchased from commercial sources and used as received. [Cu(MeCN $\left.)_{4}\right] \mathrm{X}$ salts (where $\mathrm{X}=\mathrm{PF}_{6}{ }^{-}, \mathrm{BF}_{4}{ }^{-}, \mathrm{ClO}_{4}{ }^{-}$or $\mathrm{CF}_{3} \mathrm{SO}_{3}{ }^{-}$) were prepared from the corresponding acids (concentrated aqueous or neat $\mathrm{HX}$ ) and $\mathrm{Cu}_{2} \mathrm{O},{ }^{246}$ and $\mathrm{CuO}^{t} \mathrm{Bu}$ was prepared from $\mathrm{KOtBu}$ and $\mathrm{Cul}^{247}$ by adapting known literature procedures.

Sodium 2,4-di-tert-butylphenolate (NaDTBP) was isolated as the corresponding monotetrahydrofuran adduct according to a reported synthetic route, by reaction of the neutral 2,4-di-tert-butylphenol (HDTBP) with an excess of $\mathrm{NaH}$ in THF. ${ }^{248}$

3,5-Di-tert-butylquinone (DTBQ) was prepared by using a known literature procedure involving oxidation of HDTBP with dimethyldioxirane, formed in situ by reaction of oxone with acetone in an aqueous $\mathrm{NaHCO}_{3}$ medium. ${ }^{249}$ DTBQ was then isolated as a dark brown crystalline solid after purification by standard column chromatography using DCM as the eluent.

NMR spectra were recorded on Bruker Avance 300 or DRX $500 \mathrm{MHz}$ spectrometers. Chemical shifts are reported in ppm relative to residual proton and carbon signals of the solvents $\left(\mathrm{CDCl}_{3}: \delta \mathrm{H}=7.26, \delta \mathrm{C}=77.16 ; \mathrm{CD}_{3} \mathrm{CN}: \delta \mathrm{H}=1.94, \delta \mathrm{C}=1.32 ;\left(\mathrm{CD}_{3}\right)_{2} \mathrm{CO}: \delta \mathrm{H}=2.05, \delta \mathrm{C}=\right.$ 29.84; $\left.\mathrm{CD}_{3} \mathrm{OD}: \delta \mathrm{H}=3.31, \delta \mathrm{C}=49.00 ; \mathrm{C}_{4} \mathrm{H}_{8} \mathrm{O}: \delta \mathrm{H}=1.72, \delta \mathrm{C}=67.21 \mathrm{ppm}\right)$.

LR-ESI-MS spectra were recorded using a Bruker HCT Ultra spectrometer coupled to a glovebox, and HR-ESI-MS spectra using a Bruker maXis QTOF.

UHR-ESI-MS measurements were performed on an UHR-TOF Bruker Daltonik maxis, which was coupled to a Bruker cryospray unit, an ESI-TOF MS capable of resolution of at least 40,000 FWHM. Detection was in either positive-ion or negative-ion mode and the source voltage was $5 \mathrm{kV}$. The flow rates were $500 \mu \mathrm{L} /$ hour. The drying gas $\left(\mathrm{N}_{2}\right)$, was held at $-75^{\circ} \mathrm{C}$ and the spray gas was held at $-80^{\circ} \mathrm{C}$. The machine was calibrated prior to every experiment via direct infusion of the Agilent ESI-TOF low concentration tuning mixture, which provided an $\mathrm{m} / \mathrm{z}$ range of singly charged peaks up to $2700 \mathrm{Da}$ in both ion modes.

Detailed information pertaining to UV/Vis measurements can be found in experimental Section 8.5. Microanalyses were performed by the analytical laboratory of the Institute of 
Inorganic Chemistry at the Georg-August-University Göttingen using an ElementarVario EL III instrument.

\subsection{Synthesis of Ligands and Ligand Precursors}

\subsubsection{Preparation of $\mathrm{HL}^{1}$}

The preparation of this compound was reported previously. ${ }^{250} 3,5$-bis(chloromethyl)- $1 \mathrm{H}$ pyrazole hydrochloride $\left(\mathbf{P z}^{\mathrm{A}}\right)(1.85 \mathrm{~g}, 9.2 \mathrm{mmol})$ and $\mathrm{Na}_{2} \mathrm{CO}_{3}(10.7 \mathrm{~g}, 100 \mathrm{mmol})$ were suspended in MeCN (200 ml). N,N,N'-Tetramethylethylenediamine $(2.0 \mathrm{~g}, 19.6 \mathrm{mmol})$ was added and the mixture was then refluxed overnight (approx. $16 \mathrm{~h}$ ). After cooling to RT the mixture was roughly decanted, centrifuged, and the supernatant was then filtered. The solvent was removed in vacuo resulting in an amber coloured oil. This oil was redissolved in THF, filtered and concentrated in vacuo, affording the product as a yellow oil $(2.15 \mathrm{~g}, 7.2$ mmol, $79 \%$ yield).

${ }^{1} \mathrm{H}$ NMR $\left(300 \mathrm{MHz}\right.$, Dry $\left.\mathrm{CD}_{3} \mathrm{CN}\right): \delta(\mathrm{ppm})=5.99\left(\mathrm{~s}, 1 \mathrm{H},{ }^{\mathrm{Pz}} \mathrm{CH}\right), 3.51\left(\mathrm{~s}, 4 \mathrm{H}, \mathrm{Pz}-\mathrm{CH}_{2}\right), 2.48-2.40$ $\left(\mathrm{m}, 4 \mathrm{H}, \mathrm{Pz}-\mathrm{CH}_{2}-\mathrm{N}-\mathrm{CH}_{2}\right), 2.39-2.32\left(\mathrm{~m}, 4 \mathrm{H}, \mathrm{CH}_{2}-\mathrm{N}-\left(\mathrm{CH}_{3}\right)_{2}\right), 2.18\left(\mathrm{~s}, 6 \mathrm{H}, \mathrm{Pz}-\mathrm{CH}_{2}-\mathrm{N}-\mathrm{CH}_{3}\right), 2.15$ $\left(\mathrm{s}, 12 \mathrm{H}, \mathrm{N}-\left(\mathrm{CH}_{3}\right)_{2}\right)$.

${ }^{13} \mathrm{C}\left\{{ }^{1} \mathrm{H}\right\}$ NMR $\left(75 \mathrm{MHz}\right.$, Dry $\left.\mathrm{CD}_{3} \mathrm{CN}\right): \delta(\mathrm{ppm})=146.62\left(\mathrm{br},{ }^{\mathrm{Pz}} \mathrm{C}\right), 104.96\left({ }^{\mathrm{Pz}} \mathrm{CH}\right), 58.38$ $\left(\mathrm{CH}_{2}-\mathrm{N}-\left(\mathrm{CH}_{3}\right)_{2}\right), \quad 55.67 \quad\left(\mathrm{Pz}-\mathrm{CH}_{2}-\mathrm{N}-\mathrm{CH}_{2}\right), \quad 54.71 \quad\left(\mathrm{Pz}-\mathrm{CH}_{2}\right), 46.00 \quad\left(\mathrm{~N}-\left(\mathrm{CH}_{3}\right)_{2}\right), \quad 42.98$, $\left(\mathrm{Pz}-\mathrm{CH}_{2}-\mathrm{N}-\mathrm{CH}_{3}\right)$.

\subsubsection{Preparation of ${ }^{A m d} \mathrm{HL}^{2}$}

The preparation of this compound was reported previously. ${ }^{98} \mathrm{~N}, \mathrm{~N}, \mathrm{~N}^{\prime}, \mathrm{N}^{\prime}-$ tetraethyldiethylenetriamine $(1.98 \mathrm{~g}, 9.2 \mathrm{mmol})$ was dissolved in THF $(200 \mathrm{ml})$, together with triethylamine $(1.83 \mathrm{ml}, 1.32 \mathrm{~g}, 13.1 \mathrm{mmol})$. This solution was added dropwise to a suspension of 3,5-bis(chlorocarbonyl)- $1 \mathrm{H}$-pyrazole hydrochloride $\left(\mathbf{P z}^{\mathrm{B}}\right)(1.00 \mathrm{~g}, 4.4 \mathrm{mmol})$ in THF (100 ml). The resulting solution was stirred overnight at room temperature (approx. 16 h). After filtering, the solvent was removed in vacuo, resulting in a yellow oil. This oil was redissolved in DCM $(15 \mathrm{ml})$, and stirred overnight at room temperature with a saturated solution of $\mathrm{Na}_{2} \mathrm{CO}_{3}(15 \mathrm{ml})$. After separating the organic phase, the aqueous phase was washed with DCM $(2 \times 15 \mathrm{ml})$, and the combined organic phases concentrated to dryness. Volatile impurities were removed from the product by Kügelrohr distillation $\left(10^{-3} \mathrm{mbar}\right.$, $50-70^{\circ} \mathrm{C}$ ) affording a slightly yellow oil (1.32 g, $2.5 \mathrm{mmol}, 55 \%$ yield).

${ }^{1} \mathrm{H}$ NMR $\left(300 \mathrm{MHz}, \mathrm{CD}_{3} \mathrm{CN}\right): \delta(\mathrm{ppm})=6.83\left(\mathrm{~s}, 1 \mathrm{H},{ }^{\mathrm{Pz}} \mathrm{CH}\right), 3.68\left(\mathrm{t},{ }^{3} \mathrm{~J}_{\mathrm{H}, \mathrm{H}}=6.0 \mathrm{~Hz}, 4 \mathrm{H}\right.$, $\left.\mathrm{CO}-\mathrm{N}-\mathrm{CH}_{2}\right), 3.47\left(\mathrm{t},{ }^{3} \mathrm{~J}_{\mathrm{H}, \mathrm{H}}=6.9 \mathrm{~Hz}, 4 \mathrm{H}, \mathrm{CO}-\mathrm{N}-\mathrm{CH}_{2}\right), 2.71\left(\mathrm{t},{ }^{3} \mathrm{~J}_{\mathrm{H}, \mathrm{H}}=6.0 \mathrm{~Hz}, 4 \mathrm{H}, \mathrm{CH}_{2}-\mathrm{N}-\mathrm{Et}_{2}\right)$, $2.65\left(\mathrm{t}, 4 \mathrm{H},{ }^{3} \mathrm{~J}_{\mathrm{H}, \mathrm{H}}=6.7 \mathrm{~Hz}, \mathrm{CH}_{2}-\mathrm{N}-\mathrm{Et}_{2}\right), 2.54\left(\mathrm{q},{ }^{3} \mathrm{~J}_{\mathrm{H}, \mathrm{H}}=7.1 \mathrm{~Hz}, 16 \mathrm{H},{ }^{\mathrm{Et}} \mathrm{CH}_{2}\right), 1.00\left(\mathrm{t},{ }^{3} \mathrm{~J}_{\mathrm{H}, \mathrm{H}}=7.1\right.$ $\left.\mathrm{Hz}, 24 \mathrm{H},{ }^{\mathrm{Et}} \mathrm{CH}_{3}\right)$.

${ }^{13} \mathrm{C}\left\{{ }^{1} \mathrm{H}\right\}$ NMR $\left(75 \mathrm{MHz}, \mathrm{CD}_{3} \mathrm{CN}\right): \delta(\mathrm{ppm})=163.34\left(\mathrm{CONR}_{2}\right), 143.96\left(\mathrm{br},{ }^{\mathrm{Pz}} \mathrm{C}\right), 110.52\left({ }^{\mathrm{Pz}} \mathrm{CH}\right)$, $52.83\left(\mathrm{CH}_{2}-\mathrm{N}-\mathrm{Et}_{2}\right), 51.20\left(\mathrm{CH}_{2}-\mathrm{N}-\mathrm{Et}_{2}\right), 49.25\left(\mathrm{Pz}-\mathrm{CO}-\mathrm{N}-\mathrm{CH}_{2}\right), 48.67\left({ }^{\mathrm{Et}} \mathrm{CH}_{2}\right), 48.31\left({ }^{\mathrm{Et}} \mathrm{CH}_{2}\right)$, $45.90\left(\mathrm{Pz}-\mathrm{CO}-\mathrm{N}-\mathrm{CH}_{2}\right), 12.65\left({ }^{\mathrm{Et}} \mathrm{CH}_{3}\right), 12.14\left({ }^{\mathrm{Et}} \mathrm{CH}_{3}\right)$. 


\subsubsection{Preparation of $\mathrm{HL}^{2}$}

The preparation of this compound was reported previously. ${ }^{98}{ }^{A m d} \mathrm{HL}^{2}(1.23 \mathrm{~g}, 2.2 \mathrm{mmol})$ dissolved in THF was added dropwise to a suspension of $\mathrm{LiAlH}_{4}(2.0 \mathrm{~g}, 53 \mathrm{mmol})$ suspended in THF $(100 \mathrm{ml})$. The mixture was then heated to reflux for $18 \mathrm{~h}$. After cooling to $0{ }^{\circ} \mathrm{C}$, distilled water was added in small aliquots until effervescence ceased. The resulting suspension was then filtered, the filter cake washed three times with THF ( $3 \times 75 \mathrm{ml})$, and the resulting clear solution evaporated to dryness. After drying under high vacuum overnight, a colourless oil resulted (1.11 g, $2.1 \mathrm{mmol}, 95 \%$ yield).

${ }^{1} \mathrm{H}$ NMR $\left(300 \mathrm{MHz}, \mathrm{CD}_{3} \mathrm{CN}\right): \delta(\mathrm{ppm})=5.91\left(\mathrm{~s}, 1 \mathrm{H},{ }^{\mathrm{Pz}} \mathrm{CH}\right), 3.64\left(\mathrm{~s}, 4 \mathrm{H}, \mathrm{Pz}-\mathrm{CH}_{2}\right), 2.57-2.45(\mathrm{~m}$, $\left.{ }^{\#} \mathrm{H}, \mathrm{CH}_{2} \mathrm{CH}_{2}\right), 2.48\left(\mathrm{q},{ }^{3} \mathrm{~J}_{\mathrm{H}, \mathrm{H}}=7.2 \mathrm{~Hz},{ }^{\#} \mathrm{H},{ }^{\mathrm{Et}} \mathrm{CH}_{2}\right), 0.97\left(\mathrm{t},{ }^{3} \mathrm{~J}_{\mathrm{H}, \mathrm{H}}=7.1 \mathrm{~Hz}, 24 \mathrm{H},{ }^{\mathrm{Et}} \mathrm{CH}_{3}\right) .{ }^{\#}$ Overlapping. Total of $32 \mathrm{H}$.

${ }^{13} \mathrm{C}\left\{{ }^{1} \mathrm{H}\right\} \quad \mathrm{NMR} \quad\left(75 \mathrm{MHz}, \quad \mathrm{CD}_{3} \mathrm{CN}\right): \delta(\mathrm{ppm})=147.58\left(\mathrm{br},{ }^{\mathrm{Pz}} \mathrm{C}\right), 102.96\left({ }^{\mathrm{Pz}} \mathrm{CH}\right), \quad 53.91$ $\left(\mathrm{Pz}-\mathrm{CH}_{2}-\mathrm{N}-\mathrm{CH}_{2}\right), 52.47\left(\mathrm{CH}_{2}-\mathrm{N}-\mathrm{Et}_{2}\right), 51.83\left(\mathrm{Pz}-\mathrm{CH}_{2}\right), 48.16\left({ }^{\mathrm{Et}} \mathrm{CH}_{2}\right), 12.35\left({ }^{\mathrm{Et}} \mathrm{CH}_{3}\right)$.

${ }^{1} \mathrm{H}$ NMR $\left(500 \mathrm{MHz}\right.$, Dry $\left.\mathrm{CD}_{3} \mathrm{CN}\right): \delta(\mathrm{ppm})=12.77\left(\mathrm{~s}_{\mathrm{br}}, 1 \mathrm{H},{ }^{\mathrm{Pz}} \mathrm{NH}\right), 5.89\left(\mathrm{~s}, 1 \mathrm{H},{ }^{\mathrm{Pz}} \mathrm{CH}\right), 3.72\left(\mathrm{~s}_{\mathrm{br}}\right.$, $\left.2 \mathrm{H}, \mathrm{Pz}-\mathrm{CH}_{2}\right), 3.56\left(\mathrm{sbr}, 2 \mathrm{H}, \mathrm{Pz}-\mathrm{CH}_{2}\right), 2.62-2.40\left(\mathrm{~m}, 32 \mathrm{H}, \mathrm{CH}_{2} \mathrm{CH}_{2}\right.$ and $\left.{ }^{\mathrm{Et}} \mathrm{CH}_{2}\right), 0.97\left(\mathrm{~s}_{b r}, 24 \mathrm{H}\right.$, ${ }^{\mathrm{Et}} \mathrm{CH}_{3}$ ).

${ }^{13} \mathrm{C}\left\{{ }^{1} \mathrm{H}\right\}$ NMR (126 MHz, Dry $\left.\mathrm{CD}_{3} \mathrm{CN}\right): \delta(\mathrm{ppm})=151.37\left({ }^{\mathrm{Pz}} \mathrm{C}\right), 143.76\left({ }^{\mathrm{Pz}} \mathrm{C}\right), 102.75\left({ }^{\mathrm{Pz}} \mathrm{CH}\right)$, 54.84-50.52 (br*, Pz-CH $-\mathrm{N}-\mathrm{CH}_{2}, \mathrm{CH}_{2}-\mathrm{N}-\mathrm{Et}_{2}$ and $\left.\mathrm{Pz}-\mathrm{CH}_{2}\right), 48.21\left({ }^{\mathrm{Et}} \mathrm{CH}_{2}\right), 12.50\left({ }^{\mathrm{Et}} \mathrm{CH}_{3}\right) .{ }^{*} 5-6$ signals not clearly resolved.

${ }^{15} \mathrm{~N} N M R\left(50 \mathrm{MHz}, \mathrm{CD}_{3} \mathrm{CN}\right): \delta(\mathrm{ppm})=-85\left({ }^{\mathrm{Pz}} \mathrm{N}\right),-175\left({ }^{\mathrm{Pz}} \mathrm{NH}\right)$. No additional resonances were clearly visible under these conditions.

\subsubsection{Preparation of ${ }^{A m d} \mathrm{HL}^{3}$}

The preparation of this compound was reported previously. ${ }^{77}$ 1,4-Diisopropyl-1,4,7triazonane $\left(\mathrm{sa}^{3}\right)(2.75 \mathrm{~g}, 12.9 \mathrm{mmol})$ was dissolved in THF $(50 \mathrm{ml})$, together with triethylamine $(2.55 \mathrm{ml}, 1.85 \mathrm{~g}, 18.2 \mathrm{mmol})$. This solution was added dropwise to a suspension of 3,5-bis(chlorocarbonyl)- $1 \mathrm{H}$-pyrazole hydrochloride $\left(\mathbf{P z}^{\mathbf{B}}\right)(1.40 \mathrm{~g}, 6.1 \mathrm{mmol})$ in THF (100 ml). The resulting solution was stirred overnight at room temperature (approx. 16 h). After filtering, the solvent was removed in vacuo, resulting in a yellow foam. This foam was redissolved in DCM $(15 \mathrm{ml})$, and stirred overnight at room temperature with a saturated solution of $\mathrm{Na}_{2} \mathrm{CO}_{3}(15 \mathrm{ml})$. After separating the organic phase, the aqueous phase was washed with DCM $(2 \times 15 \mathrm{ml})$, and the combined organic phases concentrated to dryness. Recrystallisation from MeCN afforded pale white crystals (1.72 g, $3.15 \mathrm{mmol}, 52 \%$ yield).

${ }^{1} \mathrm{H}$ NMR $\left(300 \mathrm{MHz}, \mathrm{CD}_{3} \mathrm{OD}\right): \delta(\mathrm{ppm})=6.89\left(\mathrm{~s}, 1 \mathrm{H},{ }^{\mathrm{Pz}} \mathrm{CH}\right), 3.70\left(\mathrm{~s}_{\mathrm{br}}, 8 \mathrm{H}, \mathrm{CO}-\mathrm{N}-\mathrm{CH}_{2}\right), 3.25\left(\mathrm{~s}_{\mathrm{br}}\right.$, $\left.4 \mathrm{H}, \mathrm{CO}-\mathrm{N}-\mathrm{CH}_{2}-\mathrm{CH}_{2}\right), 2.92\left(\mathrm{~m}_{\mathrm{br}},{ }^{3} \mathrm{~J}_{\mathrm{H}, \mathrm{H}}=6.4 \mathrm{~Hz}, 2 \mathrm{H},{ }^{i P r} \mathrm{CH}\right), 2.92\left(\mathrm{p},{ }^{3} \mathrm{~J}_{\mathrm{H}, \mathrm{H}}=6.6 \mathrm{~Hz}, 2 \mathrm{H},{ }^{i \mathrm{Pr}} \mathrm{CH}\right)$, $2.80\left(\mathrm{t},{ }^{3} \mathrm{~J}_{\mathrm{H}, \mathrm{H}}=4.6 \mathrm{~Hz} 4 \mathrm{H}, \mathrm{CO}-\mathrm{N}-\mathrm{CH}_{2}-\mathrm{CH}_{2}\right), 2.74-2.62\left(\mathrm{~m}, 4 \mathrm{H},{ }^{i} \mathrm{Pr}-\mathrm{N}-\left(\mathrm{CH}_{2}\right)_{2}-\mathrm{N}-{ }^{i} \mathrm{Pr}\right), 2.63-2.50$ $\left(\mathrm{m}, 4 \mathrm{H},{ }^{i} \mathrm{Pr}-\mathrm{N}-\left(\mathrm{CH}_{2}\right)_{2}-\mathrm{N}-{ }^{i} \mathrm{Pr}\right), 1.06\left(\mathrm{~d},{ }^{3} \mathrm{~J}_{\mathrm{H}, \mathrm{H}}=6.4 \mathrm{~Hz}, 12 \mathrm{H},{ }^{i \mathrm{Pr}} \mathrm{CH}_{3}\right), 1.00\left(\mathrm{~d},{ }^{3} \mathrm{~J}_{\mathrm{H}, \mathrm{H}}=6.6 \mathrm{~Hz}, 12 \mathrm{H}\right.$, $\left.{ }^{i \mathrm{Pr}} \mathrm{CH}_{3}\right)$.

${ }^{13} \mathrm{C}\left\{{ }^{1} \mathrm{H}\right\}$ NMR $\left(75 \mathrm{MHz}, \mathrm{CD}_{3} \mathrm{OD}\right): \delta(\mathrm{ppm})=165.19\left(\mathrm{CONR}_{2}\right), 144.55\left(\mathrm{br},{ }^{\mathrm{Pz}} \mathrm{C}\right), 109.85\left({ }^{\mathrm{Pz}} \mathrm{CH}\right)$, $56.14\left({ }^{i \mathrm{Pr}} \mathrm{CH}\right), 55.87\left({ }^{i} \mathrm{Pr}-\mathrm{N}-\left(\mathrm{CH}_{2}\right)_{2}-\mathrm{N}-{ }^{i} \mathrm{Pr}\right), 54.20\left(\mathrm{CO}-\mathrm{N}-\mathrm{CH}_{2}\right), 54.14\left({ }^{\mathrm{iPr}} \mathrm{CH}\right), 52.51\left(\mathrm{CO}-\mathrm{N}-\mathrm{CH}_{2}\right.$, 
$\left.\mathrm{CO}-\mathrm{N}-\mathrm{CH}_{2}-\mathrm{CH}_{2}\right), 52.01\left({ }^{i} \mathrm{Pr}-\mathrm{N}-\left(\mathrm{CH}_{2}\right)_{2}-\mathrm{N}-{ }^{i} \mathrm{Pr}\right), 47.74\left(\mathrm{br}, \mathrm{CO}-\mathrm{N}-\mathrm{CH}_{2}-\mathrm{CH}_{2}\right) 18.42\left({ }^{i \mathrm{Pr}} \mathrm{CH}_{3}\right), 18.30$ $\left({ }^{\mathrm{iPr}} \mathrm{CH}_{3}\right)$.

${ }^{1} \mathrm{H}$ NMR $\left(300 \mathrm{MHz}, \mathrm{CDCl}_{3}\right): \delta(\mathrm{ppm})=15.26\left(\mathrm{~s}_{\mathrm{br}}, 1 \mathrm{H},{ }^{\mathrm{Pz}} \mathrm{NH}\right), 6.97\left(1 \mathrm{H}, \mathrm{s},{ }^{\mathrm{Pz}} \mathrm{CH}\right), 4.07-2.25\left(\mathrm{~m}_{\mathrm{br}}{ }^{*}\right.$, $28 \mathrm{H}, \quad \mathrm{CO}-\mathrm{N}-\mathrm{CH}_{2}, \mathrm{CO}-\mathrm{N}-\mathrm{CH}_{2}-\mathrm{CH}_{2}$, and $\left.{ }^{i} \mathrm{Pr}-\mathrm{N}-\left(\mathrm{CH}_{2}\right)_{2}-\mathrm{N}-{ }^{i} \mathrm{Pr},{ }^{i \mathrm{Pr}} \mathrm{CH}\right), 1.19$ (s br, $6 \mathrm{H}$, $\left.{ }^{\mathrm{Pz}} \mathrm{NH} \cdots \mathrm{N}-{ }^{\mathrm{PPr}} \mathrm{CH}_{3}\right), 0.95\left(\mathrm{~d}, 18 \mathrm{H}, J=6.4 \mathrm{~Hz},{ }^{i \mathrm{Pr}} \mathrm{CH}_{3}\right) .{ }^{*} 7$ signals not clearly resolved, although a septet is clearly discernible at 2.83 (sept, ${ }^{3} \mathrm{~J}_{\mathrm{H}, \mathrm{H}}=6.5 \mathrm{~Hz},{ }^{\#} \mathrm{H},{ }^{i \mathrm{Pr}} \mathrm{CH}$ ).

${ }^{13} \mathrm{C}\left\{{ }^{1} \mathrm{H}\right\}$ NMR $\left(75 \mathrm{MHz}, \mathrm{CDCl}_{3}\right): \delta(\mathrm{ppm})=164.83\left(\mathrm{CONR}_{2}\right), 161.89\left(\mathrm{CONR}_{2}\right), 149.18\left({ }^{\mathrm{Pz}} \mathrm{C}\right)$, $137.60\left({ }^{\mathrm{Pz}} \mathrm{C}\right), 109.41\left({ }^{\mathrm{Pz}} \mathrm{CH}\right), 56.53-48.53\left(\mathrm{br} *,{ }^{i P r} \mathrm{CH}, \mathrm{CO}-\mathrm{N}-\mathrm{CH}_{2}, \mathrm{CO}-\mathrm{N}-\mathrm{CH}_{2}-\mathrm{CH}_{2}\right.$ and ${ }^{i} \mathrm{Pr}-\mathrm{N}-\left(\mathrm{CH}_{2}\right)_{2}-\mathrm{N}-{ }^{i} \mathrm{Pr}$ ), 44.22 (not assignable owing to broad ${ }^{1} \mathrm{H}$ signals), 18.16 (br, $\left.{ }^{i \mathrm{Pr}} \mathrm{CH}_{3}\right) .{ }^{*} \mathrm{At}$ least 7 signals not clearly resolved, except for one at $53.23\left({ }^{\mathrm{iPr}} \mathrm{CH}\right)$.

Elemental Analysis (calcd., found for $\left.\mathrm{C}_{29} \mathrm{H}_{54} \mathrm{~N}_{8} \mathrm{O}_{2}\right)$ : \% $=\mathrm{C}(63.70,63.77), \mathrm{H}(9.95,10.18), \mathrm{N}$ $(20.49,20.51)$.

\subsubsection{Preparation of $\mathrm{HL}^{3}$}

The preparation of this compound was reported previously. ${ }^{77}$ Crystalline ${ }^{\mathrm{Amd}} \mathrm{HL}^{3}$ (1.67 g, 3.1 $\mathrm{mmol})$ dissolved in THF was added dropwise to a suspension of $\mathrm{LiAlH}_{4}(2.0 \mathrm{~g}, 53 \mathrm{mmol})$ suspended in THF $(100 \mathrm{ml})$. The mixture was then heated to reflux for $18 \mathrm{~h}$. After cooling to $0{ }^{\circ} \mathrm{C}$, distilled water was added in small aliquots until effervescence ceased. The resulting suspension was then filtered, the filter cake washed three times with THF $(3 \times 75 \mathrm{ml})$, and the resulting clear solution evaporated to dryness. After drying under high vacuum overnight, a highly viscous, colourless oil resulted ( $1.54 \mathrm{~g}, 3.0 \mathrm{mmol}, 97 \%$ yield).

${ }^{1} \mathrm{H}$ NMR $\left(300 \mathrm{MHz}, \mathrm{CD}_{3} \mathrm{CN}\right): \delta(\mathrm{ppm})=5.94\left(\mathrm{~s}, 1 \mathrm{H},{ }^{\mathrm{Pz}} \mathrm{CH}\right), 3.69\left(\mathrm{~s}, 4 \mathrm{H}, \mathrm{Pz}-\mathrm{CH}_{2}\right), 2.86\left(\mathrm{p},{ }^{3} \mathrm{~J}_{\mathrm{H}, \mathrm{H}}=\right.$ $\left.6.5 \mathrm{~Hz},{ }^{\#} \mathrm{H}, \quad{ }^{i \mathrm{Pr}} \mathrm{CH}\right), \quad 2.77-2.69 \quad\left(\mathrm{~m},{ }^{\#} \mathrm{H}, \quad \mathrm{Pz}-\mathrm{CH}_{2}-\mathrm{N}-\left(\mathrm{CH}_{2}\right)_{2}-\mathrm{N}-{ }^{i} \mathrm{Pr}\right), 2.68 \quad\left(\mathrm{~s},{ }^{\#} \mathrm{H}\right.$, $\left.{ }^{i} \mathrm{Pr}-\mathrm{N}-\left(\mathrm{CH}_{2}\right)_{2}-\mathrm{N}-{ }^{i} \mathrm{Pr}\right), 2.67-2.59\left(\mathrm{~m},{ }^{\#} \mathrm{H}, \mathrm{Pz}-\mathrm{CH}_{2}-\mathrm{N}-\left(\mathrm{CH}_{2}\right)_{2}-\mathrm{N}-{ }^{i} \mathrm{Pr}\right), 2.44\left(\mathrm{~s}_{\mathrm{br}}, \mathrm{H}_{2} \mathrm{O}\right), 0.97\left(\mathrm{~d},{ }^{3} \mathrm{~J}_{\mathrm{H}, \mathrm{H}}\right.$ $\left.=6.6 \mathrm{~Hz}, 24 \mathrm{H},{ }^{i \mathrm{Pr}} \mathrm{CH}_{3}\right)$. ${ }^{\#}$ Overlapping with large $\mathrm{H}_{2} \mathrm{O}$ peak.

${ }^{13} \mathrm{C}\left\{{ }^{1} \mathrm{H}\right\}$ NMR $\left(75 \mathrm{MHz}, \mathrm{CD}_{3} \mathrm{CN}\right): \delta(\mathrm{ppm})=148.45\left(\mathrm{br},{ }^{\mathrm{Pz}} \mathrm{C}\right), 102.51\left({ }^{\mathrm{Pz}} \mathrm{CH}\right), 57.15$ $\left.\left(\mathrm{Pz}-\mathrm{CH}_{2}-\mathrm{N}-\mathrm{CH}_{2}\right), \quad 55.43 \quad{ }^{i \mathrm{Pr}} \mathrm{CH}\right), \quad 54.40 \quad\left(\mathrm{Pz}-\mathrm{CH}_{2}\right), \quad 53.78 \quad\left({ }^{i} \mathrm{Pr}-\mathrm{N}-\left(\mathrm{CH}_{2}\right)_{2}-\mathrm{N}-{ }^{i} \mathrm{Pr}\right), \quad 51.65$ $\left(\mathrm{Pz}-\mathrm{CH}_{2}-\mathrm{N}-\mathrm{CH}_{2} \mathrm{CH}_{2}\right), 18.52\left({ }^{i \mathrm{Pr}} \mathrm{CH}_{3}\right)$.

${ }^{1} \mathrm{H}$ NMR $\left(500 \mathrm{MHz}\right.$, Dry $\left.\mathrm{CD}_{3} \mathrm{CN}\right) \delta(\mathrm{ppm})=13.20\left(\mathrm{~s}, 1 \mathrm{H},{ }^{\mathrm{Pz}} \mathrm{NH}\right), 5.90\left(\mathrm{~s}, 1 \mathrm{H},{ }^{\mathrm{Pz}} \mathrm{CH}\right), 3.82(\mathrm{~s}, 2 \mathrm{H}$, $\left.\mathrm{Pz}-\mathrm{CH}_{2}\right), 3.56\left(\mathrm{~s}, 2 \mathrm{H}, \mathrm{Pz}-\mathrm{CH}_{2}\right), 2.82(\mathrm{~s}, 8 \mathrm{H}), 2.79(\mathrm{~s}, 4 \mathrm{H}), 2.69(\mathrm{~s}, 4 \mathrm{H}), 2.63(\mathrm{~s}, 4 \mathrm{H}), 2.59(\mathrm{~s}, 4 \mathrm{H})$, $2.54(\mathrm{~s}, 4 \mathrm{H}), 0.99\left(\mathrm{~d},{ }^{3} \mathrm{~J}_{\mathrm{H}, \mathrm{H}}=5.3 \mathrm{~Hz}, 12 \mathrm{H},{ }^{i} \mathrm{Pr}-\mathrm{CH}_{3}\right), 0.94\left(\mathrm{~d},{ }^{3} \mathrm{~J}_{\mathrm{H}, \mathrm{H}}=5.3 \mathrm{~Hz}, 12 \mathrm{H},{ }^{i} \mathrm{Pr}-\mathrm{CH}_{3}\right)$.

${ }^{13} \mathrm{C}\left\{{ }^{1} \mathrm{H}\right\}$ NMR $\left(126 \mathrm{MHz}\right.$, Dry CD $\left.{ }_{3} \mathrm{CN}\right): \delta(\mathrm{ppm})=152.90\left({ }^{\mathrm{Pz}} \mathrm{C}\right), 144.80\left({ }^{\mathrm{Pz}} \mathrm{C}\right), 101.80\left({ }^{\mathrm{Pz}} \mathrm{CH}\right), 59.06$ $\left(\mathrm{Pz}-\mathrm{CH}_{2}-\mathrm{N}-\mathrm{CH}_{2}\right), 56.24\left(\mathrm{Pz}-\mathrm{CH}_{2}\right), 56.04\left(\mathrm{Pz}-\mathrm{CH}_{2}-\mathrm{N}-\mathrm{CH}_{2}\right), 55.55\left({ }^{\mathrm{iPr}} \mathrm{CH}\right), 55.48\left({ }^{\mathrm{iPr}} \mathrm{CH}\right), 55.06$ ('Pr-N-(CH $\left.)_{2}-\mathrm{N}-{ }^{i} \mathrm{Pr}\right), 53.62\left({ }^{i} \mathrm{Pr}-\mathrm{N}-\left(\mathrm{CH}_{2}\right)_{2}-\mathrm{N}-{ }^{i} \mathrm{Pr}\right), 53.45\left(\mathrm{Pz}-\mathrm{CH}_{2}-\mathrm{N}-\mathrm{CH}_{2} \mathrm{CH}_{2}\right), 52.96\left(\mathrm{Pz}-\mathrm{CH}_{2}\right)$, $51.08\left(\mathrm{Pz}-\mathrm{CH}_{2}-\mathrm{N}-\mathrm{CH}_{2} \mathrm{CH}_{2}\right), 18.66\left({ }^{i P r} \mathrm{CH}_{3}\right), 18.45\left({ }^{\mathrm{iPr}} \mathrm{CH}_{3}\right)$.

${ }^{15} \mathrm{~N}$ NMR $\left(30 \mathrm{MHz}, \mathrm{CD}_{3} \mathrm{CN}\right): \delta(\mathrm{ppm})=-87\left({ }^{\mathrm{Pz}} \mathrm{N}\right),-174\left({ }^{\mathrm{Pz}} \mathrm{NH}\right),-336\left({ }^{\mathrm{iPr}} \mathrm{N}\right)$. No additional resonances were clearly visible.

\subsection{Synthesis of complexes}

\subsubsection{Preparation of $\left[\mathrm{NaL}^{1}\right]$}

$\mathrm{HL}^{1}$ (100 mg, $0.3 \mathrm{mmol}$ ) was dissolved in THF (20 ml). NaH (70 mg, $29.2 \mathrm{mmol}$ ) was added, and the mixture was then stirred until gas evolution ceased (approx. $3 \mathrm{~h}$ ). The dark yelllow 
solution was separated from unreacted $\mathrm{NaH}$ using a filter canula, and the solvent then removed in vacuo resulting in an amber coloured oil. After drying in vacuo overnight, this oil was redissolved in EtCN $(10-15 \mathrm{ml})$ and stored at $-20{ }^{\circ} \mathrm{C}$. After 2 weeks, colourless crystalline material resulted ( $83 \mathrm{mg}, 0.25 \mathrm{mmol}, 84 \%$ yield).

${ }^{1} \mathrm{H}$ NMR $\left(300 \mathrm{MHz}, \mathrm{CD}_{3} \mathrm{CN}\right): \delta(\mathrm{ppm})=5.76\left(\mathrm{~s}, 1 \mathrm{H},{ }^{\mathrm{Pz}} \mathrm{CH}\right), 3.45\left(\mathrm{~s}, 4 \mathrm{H}, \mathrm{Pz}-\mathrm{CH}_{2}\right), 2.43-2.36(\mathrm{~m}$, $\left.4 \mathrm{H}, \mathrm{Pz}-\mathrm{CH}_{2}-\mathrm{N}-\mathrm{CH}_{2}\right), 2.33-2.62\left(\mathrm{~m}, 4 \mathrm{H}, \mathrm{CH}_{2}-\mathrm{N}-\left(\mathrm{CH}_{3}\right)_{2}\right), 2.20\left(\mathrm{~s}, 6 \mathrm{H}, \mathrm{Pz}-\mathrm{CH}_{2}-\mathrm{N}-\mathrm{CH}_{3}\right), 2.03(\mathrm{~s}$, $\left.12 \mathrm{H}, \mathrm{N}-\left(\mathrm{CH}_{3}\right)_{2}\right)$.

${ }^{13} \mathrm{C}\left\{{ }^{1} \mathrm{H}\right\}$ NMR $\left(75 \mathrm{MHz}, \mathrm{CD}_{3} \mathrm{CN}\right): \delta(\mathrm{ppm})=149.05\left(\mathrm{br},{ }^{\mathrm{Pz}} \mathrm{C}\right), 103.24\left({ }^{\mathrm{Pz}} \mathrm{CH}\right), \quad 58.45$ $\left(\mathrm{CH}_{2}-\mathrm{N}-\left(\mathrm{CH}_{3}\right)_{2}\right), \quad 57.55\left(\mathrm{Pz}-\mathrm{CH}_{2}\right), \quad 55.21 \quad\left(\mathrm{Pz}-\mathrm{CH}_{2}-\mathrm{N}-\mathrm{CH}_{2}\right), \quad 45.99 \quad\left(\mathrm{~N}-\left(\mathrm{CH}_{3}\right)_{2}\right), \quad 43.43$, $\left(\mathrm{Pz}-\mathrm{CH}_{2}-\mathrm{N}-\mathrm{CH}_{3}\right)$.

MS $(\mathrm{ESI}+, \mathrm{MeCN}): m / z=319.0,[\mathrm{M}]^{+}, 615.5,\left[\mathrm{M}+\mathrm{L}^{1}+2 \mathrm{H}\right]^{+}, 659.5,[2 \mathrm{M}+\mathrm{Na}]^{+}, 977.8[3 \mathrm{M}+$ $\mathrm{Na}]^{+}$.

Elemental Analysis (calcd., found for $\left.\mathrm{C}_{15} \mathrm{H}_{31} \mathrm{~N}_{6} \mathrm{Na}\right)$ : \% $=\mathrm{C}(56.58,55.71), \mathrm{H}(9.81,9.60), \mathrm{N}$ $(26.39,26.74)$.

\subsubsection{Preparation of $\left[\mathrm{NaL}^{3}\right]$}

$\mathrm{HL}^{3}$ (50.0 mg, $0.10 \mathrm{mmol}$ ) and $\mathrm{NaO}^{\mathrm{t}} \mathrm{Bu}(9.3 \mathrm{mg}, 0.10 \mathrm{mmol})$ were dissolved in $\mathrm{EtCN}(5 \mathrm{ml})$ to give a faint yellow solution. After standing at RT for two days, white diffraction quality crystals resulted. After cooling to $-30^{\circ} \mathrm{C}$ overnight the mother liquor was removed and the crystals washed with cold EtCN. White crystalline material resulted $(37.4 \mathrm{mg}, 0.07 \mathrm{mmol}$, $70 \%$ yield).

${ }^{1} \mathrm{H}$ NMR $\left(300 \mathrm{MHz}, \mathrm{C}_{4} \mathrm{D}_{8} \mathrm{O}, 55^{\circ} \mathrm{C}\right): \delta(\mathrm{ppm})=5.86\left(\mathrm{~s}, 1 \mathrm{H},{ }^{\mathrm{Pz}} \mathrm{CH}\right), 3.63\left(\mathrm{~s}, 4 \mathrm{H}, \mathrm{Pz}-\mathrm{CH}_{2}\right), 2.89(\mathrm{p}$, $\left.{ }^{3} J_{\mathrm{H}, \mathrm{H}}=6.6 \mathrm{~Hz}, 4 \mathrm{H},{ }^{i \mathrm{Pr}} \mathrm{CH}\right), 2.70\left(\mathrm{br} \mathrm{s}, 8 \mathrm{H}, \mathrm{Pz}-\mathrm{CH}_{2}-\mathrm{N}-\mathrm{CH}_{2}\right), 2.61\left(\mathrm{~s}, 8 \mathrm{H},{ }^{i} \mathrm{Pr}-\mathrm{N}-\left(\mathrm{CH}_{2}\right)_{2}-\mathrm{N}-{ }^{i} \mathrm{Pr}\right)$, 2.48 (br s, 8H, Pz- $\left.\mathrm{CH}_{2}-\mathrm{N}-\mathrm{CH}_{2}-\mathrm{CH}_{2}\right), 0.90\left(\mathrm{~d},{ }^{3} \mathrm{~J}_{\mathrm{H}, \mathrm{H}}=6.5 \mathrm{~Hz}, 24 \mathrm{H},{ }^{i \mathrm{Pr}} \mathrm{CH}_{3}\right)$.

${ }^{13} \mathrm{C}\left\{{ }^{1} \mathrm{H}\right\}$ NMR $\left(75 \mathrm{MHz}, \mathrm{C}_{4} \mathrm{D}_{8} \mathrm{O}, 55^{\circ} \mathrm{C}\right): \delta(\mathrm{ppm})=150.06\left({ }^{\mathrm{Pz}} \mathrm{C}\right), 103.20\left({ }^{\mathrm{Pz}} \mathrm{CH}\right), 57.89\left(\mathrm{Pz}-\mathrm{CH}_{2}\right)$, $55.88\left(\mathrm{Pz}-\mathrm{CH}_{2}-\mathrm{N}-\mathrm{CH}_{2}\right), 55.34\left({ }^{i \mathrm{Pr}} \mathrm{CH}\right), 52.84\left({ }^{i} \mathrm{Pr}-\mathrm{N}-\left(\mathrm{CH}_{2}\right)_{2}-\mathrm{N}-{ }^{i} \mathrm{Pr}\right), 50.38\left(\mathrm{br}, \mathrm{Pz}-\mathrm{CH}_{2}-\mathrm{N}-\right.$ $\left.\mathrm{CH}_{2} \mathrm{CH}_{2}\right), 18.76\left({ }^{i P r} \mathrm{CH}_{3}\right)$.

Elemental Analysis (calcd., found for $\left.\mathrm{C}_{29} \mathrm{H}_{57} \mathrm{~N}_{8} \mathrm{Na}\right)$ : \% $=\mathrm{C}(64.41,64.16), \mathrm{H}(10.62,10.89), \mathrm{N}$ (20.72, 20.64).

$\mathrm{MS}\left(\mathrm{ESI}+, \mathrm{Me}_{2} \mathrm{CO}\right): m / z=541.5,[\mathrm{M}+\mathrm{H}]^{+}, 563.5,[\mathrm{M}+\mathrm{Na}]^{+}$.

\subsubsection{Preparation of $\left[\mathrm{Cu}_{2}^{1} \mathrm{~L}^{1}\right]^{\mathrm{X}}$}

A synthetic procedure using the triflate copper salt is outlined here as a representative example. [ $\mathrm{NaL}^{1}$ ] $(25.0 \mathrm{mg}, 0.08 \mathrm{mmol})$ was dissolved in $\operatorname{EtCN}(3 \mathrm{ml})$, and a solution of $\left[\mathrm{Cu}(\mathrm{MeCN})_{4}\right]$ OTf $(25.7 \mathrm{mg}, 0.16 \mathrm{mmol})$ in EtCN $(1 \mathrm{ml})$ was added dropwise. The resulting colourless solutions were used for further experiments as detailed in Sections 3.2 and 4.2.3.

${ }^{1} \mathrm{H}$ NMR $\left(300 \mathrm{MHz}, \mathrm{CD}_{3} \mathrm{CN}\right): \delta(\mathrm{ppm})=5.99\left(\mathrm{~s}, 1 \mathrm{H},{ }^{\mathrm{Pz}} \mathrm{CH}\right), 3.67\left(\mathrm{~s}, 4 \mathrm{H}, \mathrm{Pz}-\mathrm{CH}_{2}\right), 2.63(\mathrm{~s}, 6 \mathrm{H}$, $\left.\mathrm{Pz}-\mathrm{CH}_{2}-\mathrm{N}-\mathrm{CH}_{3}\right), 2.52\left(\mathrm{~s}, 4 \mathrm{H}, \mathrm{Pz}-\mathrm{CH}_{2}-\mathrm{N}-\mathrm{CH}_{2}\right), 2.37$ (s, 4H, $\left.\mathrm{CH}_{2}-\mathrm{N}-\left(\mathrm{CH}_{3}\right)_{2}\right), 2.23$ (s, 12H, $\left.\mathrm{N}-\left(\mathrm{CH}_{3}\right)_{2}\right)$.

${ }^{13} \mathrm{C}\left\{{ }^{1} \mathrm{H}\right\}$ NMR $\left(75 \mathrm{MHz}, \mathrm{CD}_{3} \mathrm{CN}\right): \delta(\mathrm{ppm})=149.60\left(\mathrm{br},{ }^{\mathrm{Pz}} \mathrm{C}\right), 122.06\left(\mathrm{q},{ }^{1} \mathrm{~J}_{\mathrm{C}-\mathrm{F}}=320.5 \mathrm{~Hz}\right), 103.97$ (br, $\left.{ }^{\mathrm{Pz}} \mathrm{CH}\right), 59.02\left(\mathrm{CH}_{2}-\mathrm{N}-\left(\mathrm{CH}_{3}\right)_{2}\right), 58.22\left(\mathrm{Pz}-\mathrm{CH}_{2}\right), 55.75\left(\mathrm{Pz}-\mathrm{CH}_{2}-\mathrm{N}-\mathrm{CH}_{2}\right), 47.99\left(\mathrm{~N}-\left(\mathrm{CH}_{3}\right)_{2}\right)$, $46.23\left(\mathrm{Pz}-\mathrm{CH}_{2}-\mathrm{N}-\mathrm{CH}_{3}\right)$. 
${ }^{15} \mathrm{~N} \mathrm{NMR}\left(30 \mathrm{MHz}, \mathrm{CD}_{3} \mathrm{CN}, 70{ }^{\circ} \mathrm{C}\right): \delta(\mathrm{ppm})=-117\left({ }^{\mathrm{Pz}} \mathrm{N}\right),-349\left({ }^{\text {tert }} \mathrm{N}\right),-361\left({ }^{\text {tert }} \mathrm{N}\right)$. MS $(E S I+, E t C N): m / z=421.0,[M]^{+}$. See Figure 3.1/Table 3.1 for detail.

MS (ESI -, EtCN): $m / z=1291.0,[2 \mathrm{M}+30 \mathrm{Of}]^{-}$. See Figure 3.2/Table 3.2 for detail.

\subsubsection{Preparation of $\left[\mathrm{Cu}_{2}^{\prime} \mathrm{L}^{2}\right]^{\mathrm{X}}$}

An example procedure using the hexafluorophosphate copper salt is described here. $\mathbf{H L}^{2}$ $(50.0 \mathrm{mg}, 0.10 \mathrm{mmol})$ and $\mathrm{KO}^{\mathrm{t}} \mathrm{Bu}(10.8 \mathrm{mg}, 0.10 \mathrm{mmol})$ were dissolved in $\mathrm{EtCN}(9 \mathrm{ml})$ to give a yellow solution. After stirring for $2 \mathrm{~h}$ at $\mathrm{RT}$, $\left[\mathrm{Cu}(\mathrm{MeCN})_{4}\right] \mathrm{ClO}_{4}(71.3 \mathrm{mg}, 0.2 \mathrm{mmol})$ dissolved in EtCN $(1 \mathrm{ml})$ was added dropwise to give an almost colourless solution. After evaporation of all volatile material under reduced pressure, the resulting residue was re-dissolved in EtCN. The resulting faintly yellow coloured solutions were used for further experiments as detailed in Sections 3.3 and 4.3. Details about substrate screening experiments can be found in Experimental Section 8.9 below.

${ }^{1} \mathrm{H}$ NMR $\left(300 \mathrm{MHz}, \mathrm{CD}_{3} \mathrm{CN}, 70{ }^{\circ} \mathrm{C}\right): \delta(\mathrm{ppm})=6.30-5.75\left(\mathrm{sbr}, 1 \mathrm{H},{ }^{\mathrm{Pz}} \mathrm{CH}\right), 3.76\left(\mathrm{~s}, 4 \mathrm{H}, \mathrm{Pz}-\mathrm{CH}_{2}\right)$, 2.80-2.48 (m, $\left.{ }^{\#} \mathrm{H}, \mathrm{CH}_{2} \mathrm{CH}_{2}\right), 2.58\left(\mathrm{q},{ }^{3} \mathrm{~J}_{\mathrm{H}, \mathrm{H}}=7.2 \mathrm{~Hz},{ }^{\#} \mathrm{H},{ }^{\mathrm{Et}} \mathrm{CH}_{2}\right), 1.06\left(\mathrm{t},{ }^{3} \mathrm{~J}_{\mathrm{H}, \mathrm{H}}=7.1 \mathrm{~Hz}, 24 \mathrm{H},{ }^{\mathrm{Et}} \mathrm{CH}_{3}\right)$. \#Overlapping. Total of $32 \mathrm{H}$.

${ }^{13} \mathrm{C}\left\{{ }^{1} \mathrm{H}\right\} \mathrm{NMR}\left(75 \mathrm{MHz}, \mathrm{CD}_{3} \mathrm{CN}, 70{ }^{\circ} \mathrm{C}\right): \delta(\mathrm{ppm})=151.09\left(\mathrm{br},{ }^{\mathrm{Pz}} \mathrm{C}\right), 55.86\left(\mathrm{CH}_{2}\right), 55.19\left(\mathrm{br}, \mathrm{CH}_{2}\right)$, $53.33\left(\mathrm{CH}_{2}\right), 48.34\left({ }^{\mathrm{Et}} \mathrm{CH}_{2}\right), 11.64\left({ }^{\mathrm{Et}} \mathrm{CH}_{3}\right)$. The ${ }^{\mathrm{Pz}} \mathrm{CH}$ resonance was not observed at this temperature.

${ }^{15} \mathrm{~N}$ NMR $\left(30 \mathrm{MHz}, \mathrm{CD}_{3} \mathrm{CN}, 70{ }^{\circ} \mathrm{C}\right): \delta(\mathrm{ppm})=-338\left({ }^{\text {tert }} \mathrm{N}\right),-344\left({ }^{\text {tert }} \mathrm{N}\right)$. The ${ }^{\mathrm{Pz}} \mathrm{N}$ resonance was not observed.

HR-Cryo-MS (ESI +, EtCN, $\left.-80^{\circ} \mathrm{C}\right): \mathrm{m} / \mathrm{z}=647.360,[\mathrm{M}]^{+}$. See Figure 3.4/Table 3.3 for detail.

HR-Cryo-MS (ESI -, EtCN, $\left.-80{ }^{\circ} \mathrm{C}\right): m / z=937.294\left[\mathrm{M}+2 \mathrm{PF}_{6}\right]^{-}$. See Figure 3.5/Table 3.4 for detail.

\subsubsection{Preparation of $\left[\mathrm{Cu}_{2}^{\prime} \mathrm{L}^{3}\right]^{\mathrm{X}}$}

$\mathrm{HL}^{3}$ (50.0 mg, $0.10 \mathrm{mmol}$ ) and $\mathrm{NaO}^{\mathrm{t}} \mathrm{Bu}(9.3 \mathrm{mg}, 0.10 \mathrm{mmol})$ were dissolved in $\mathrm{EtCN}(9 \mathrm{ml})$ to give a faint yellow solution. After stirring for $2 \mathrm{~h}$ at RT, [Cu(MeCN) ${ }_{4}$ ]OTf $(72.6 \mathrm{mg}, 0.20$ $\mathrm{mmol})$ dissolved in EtCN $(1 \mathrm{ml})$ was added dropwise to give an almost colourless solution. After evaporation of all volatile material under reduced pressure, the resulting residue was re-dissolved in $\mathrm{Me}_{2} \mathrm{CO}$ or EtCN. The resulting almost colourless solutions were used for further experiments as detailed in Sections 3.4, 4.4, and 5.3. Details about decay kinetics and substrate screening experiments can be found in Experimental Sections 8.5 and 8.9, respectively.

${ }^{1} \mathrm{H}$ NMR $\left(300 \mathrm{MHz},\left(\mathrm{CD}_{3}\right)_{2} \mathrm{CO}\right): \delta(\mathrm{ppm})=5.72\left(\mathrm{~s}, 1 \mathrm{H},{ }^{\mathrm{Pz}} \mathrm{CH}\right), 3.86\left(\mathrm{~s}, 4 \mathrm{H}, \mathrm{Pz}-\mathrm{CH}_{2}\right), 3.14-2.65$ $\left(\mathrm{m}^{*}, 25 \mathrm{H}, 12 \times{ }^{\text {tacn }} \mathrm{CH}_{2},{ }^{i \mathrm{Pr}} \mathrm{CH}_{3}\right), 1.42\left(\mathrm{~d},{ }^{3} \mathrm{~J}_{\mathrm{H}, \mathrm{H}}=6.6 \mathrm{~Hz}, 12 \mathrm{H},{ }^{i \mathrm{Pr}} \mathrm{CH}_{3}\right), 1.22\left(\mathrm{~d},{ }^{3} \mathrm{~J}_{\mathrm{H}, \mathrm{H}}=6.4 \mathrm{~Hz},{ }^{\#} \mathrm{H}\right.$, $\left.{ }^{i \mathrm{Pr}} \mathrm{CH}_{3}\right)$. *While sharp, the numerous overlapping signals are not well resolved, although a pentet is discernible at $3.08\left(\mathrm{p},{ }^{3} \mathrm{~J}_{\mathrm{H}, \mathrm{H}}=6.4 \mathrm{~Hz},{ }^{\#} \mathrm{H},{ }^{i \mathrm{Pr}} \mathrm{CH}\right) .{ }^{\#}$ Intergration not possible because of overlap with residual solvent signal. 
${ }^{13} \mathrm{C}\left\{{ }^{1} \mathrm{H}\right\}$ NMR $\left(75 \mathrm{MHz},\left(\mathrm{CD}_{3}\right)_{2} \mathrm{CO}\right): \delta(\mathrm{ppm})=151.35\left({ }^{\mathrm{Pz}} \mathrm{C}\right), 122.31\left(\mathrm{q}, \mathrm{J}=322.0 \mathrm{~Hz}, \mathrm{CF}_{3} \mathrm{SO}_{3}\right)$, $98.36\left({ }^{\mathrm{Pz}} \mathrm{CH}\right), 58.34\left({ }^{\mathrm{iPr}} \mathrm{CH}\right), 55.52\left(\mathrm{Pz}-\mathrm{CH}_{2}\right), 53.22\left({ }^{i} \mathrm{Pr}-\mathrm{N}-\left(\mathrm{CH}_{2}\right)_{2}-\mathrm{N}-{ }^{i} \mathrm{Pr} / \mathrm{Pz}-\mathrm{CH}_{2}-\mathrm{N}-\mathrm{CH}_{2} \mathrm{CH}_{2}\right)$, $51.93\left(\mathrm{Pz}-\mathrm{CH}_{2}-\mathrm{N}-\mathrm{CH}_{2}\right), 50.16\left({ }^{i} \mathrm{Pr}-\mathrm{N}-\left(\mathrm{CH}_{2}\right)_{2}-\mathrm{N}-{ }^{i} \mathrm{Pr} / \mathrm{Pz}-\mathrm{CH}_{2}-\mathrm{N}-\mathrm{CH}_{2} \mathrm{CH}_{2}\right), 23.01\left({ }^{i \mathrm{Pr}} \mathrm{CH}_{3}\right), 19.30$ $\left({ }^{\mathrm{iPr}} \mathrm{CH}_{3}\right)$.

${ }^{1} \mathrm{H}$ NMR $\left(300 \mathrm{MHz}, \mathrm{CD}_{3} \mathrm{CN}\right): \delta(\mathrm{ppm})=5.71\left(\mathrm{~s}, 1 \mathrm{H},{ }^{\mathrm{Pz}} \mathrm{CH}\right), 3.81\left(\mathrm{~s}, 4 \mathrm{H}, \mathrm{Pz}-\mathrm{CH}_{2}\right), 2.99(\mathrm{p}, \mathrm{J}=6.5$ $\left.\mathrm{Hz}, 4 \mathrm{H},{ }^{i \mathrm{Pr}} \mathrm{CH}\right), 3.07-2.49\left(\mathrm{~m}^{*}, 29 \mathrm{H}, 12 \times{ }^{\mathrm{tacn}} \mathrm{CH}_{2},{ }^{\mathrm{iPr}} \mathrm{CH}_{3}\right), 1.35\left(\mathrm{~d},{ }^{3} \mathrm{~J}_{\mathrm{H}, \mathrm{H}}=6.6 \mathrm{~Hz}, 12 \mathrm{H},{ }^{i \mathrm{Pr}} \mathrm{CH}_{3}\right)$, $1.15\left(\mathrm{~d},{ }^{3} \mathrm{~J}_{\mathrm{H}, \mathrm{H}}=6.4 \mathrm{~Hz},{ }^{\#} \mathrm{H},{ }^{i P r} \mathrm{CH}_{3}\right)$. *While sharp, the numerous overlapping signals are not well resolved, although a pentet is discernible at $2.99\left(p,{ }^{3} J_{H, H}=6.5 \mathrm{~Hz},{ }^{*} \mathrm{H},{ }^{i P r} \mathrm{CH}\right)$. \#Intergration not possible because of overlap with residual solvent signal.

${ }^{13} \mathrm{C}\left\{{ }^{1} \mathrm{H}\right\} \mathrm{NMR}\left(75 \mathrm{MHz}, \mathrm{CD}_{3} \mathrm{CN}\right): \delta(\mathrm{ppm})=151.82\left({ }^{\mathrm{Pz}} \mathrm{C}\right), 122.14\left(\mathrm{q}, \mathrm{J}=321.0 \mathrm{~Hz}, \mathrm{CF}_{3} \mathrm{SO}_{3}\right), 98.54$ $\left({ }^{\mathrm{Pz}} \mathrm{CH}\right), 58.45\left({ }^{i \mathrm{Pr}} \mathrm{CH}\right), 55.63\left(\mathrm{Pz}-\mathrm{CH}_{2}\right), 53.25\left({ }^{i} \mathrm{Pr}-\mathrm{N}-\left(\mathrm{CH}_{2}\right)_{2}-\mathrm{N}-{ }^{i} \mathrm{Pr} / \mathrm{Pz}-\mathrm{CH}_{2}-\mathrm{N}-\mathrm{CH}_{2} \mathrm{CH}_{2}\right), 52.14$ $\left(\mathrm{Pz}-\mathrm{CH}_{2}-\mathrm{N}-\mathrm{CH}_{2}\right), \quad 50.18 \quad\left({ }^{i} \mathrm{Pr}-\mathrm{N}-\left(\mathrm{CH}_{2}\right)_{2}-\mathrm{N}-{ }^{i} \mathrm{Pr} / \mathrm{Pz}-\mathrm{CH}_{2}-\mathrm{N}-\mathrm{CH}_{2} \mathrm{CH}_{2}\right), \quad 23.00 \quad\left({ }^{i \mathrm{Pr}} \mathrm{CH}_{3}\right), \quad 19.26$ $\left({ }^{\mathrm{iPr}} \mathrm{CH}_{3}\right)$.

${ }^{15} \mathrm{~N}$ NMR $\left(30 \mathrm{MHz}, \mathrm{CD}_{3} \mathrm{CN}\right): \delta(\mathrm{ppm})=-119\left({ }^{\mathrm{Pz}} \mathrm{N}\right),-338\left(\mathrm{Pz}_{-} \mathrm{CH}_{2}-\mathrm{N}\right),-355\left({ }^{\mathrm{iPr}} \mathrm{N}\right)$.

HR-MS (ESI +, MeCN): $m / z=643.329,[\mathrm{M}]^{+}$.

The following data was obtained in the presence of $\mathrm{ClO}_{4}{ }^{-}$counterions:

HR-Cryo-MS $\left(E S I+, E t C N,-80^{\circ} \mathrm{C}\right): m / z=643.328,[\mathrm{M}]^{+}$. See Figure 3.9/Table 3.5 for detail. HR-Cryo-MS (ESI -, EtCN, $\left.-80^{\circ} \mathrm{C}\right): m / z=843.225,\left[\mathrm{M}+2 \mathrm{ClO}_{4}\right]^{-}$. See Figure 3.10/Table 3.6 for detail.

\subsubsection{Preparation of ${ }^{-M}\left[\mathrm{Cu}_{2}^{\prime} \mathrm{L}^{3}\right]^{\mathrm{X}}$}

The alkali metal free variant of $\left[\mathrm{Cu}_{2}{ }_{2} \mathrm{~L}^{3}\right]$ was prepared in an analogous fashion by substituting one equivalent of $\left[\mathrm{Cu}(\mathrm{MeCN})_{4}\right] \mathrm{OTf}$ for $\mathrm{CuO}^{t} \mathrm{Bu}$, thereby eliminating the need for $\mathrm{MOtBu}(\mathrm{M}=$ $\left.\mathrm{Na}^{+}, \mathrm{K}^{+}\right)$. Thus, $\mathrm{HL}^{3}(50.0 \mathrm{mg}, 0.10 \mathrm{mmol})$ was dissolved in EtCN $(8 \mathrm{ml})$ and $\mathrm{CuO}^{\mathrm{t}} \mathrm{Bu}(13.1 \mathrm{mg}$, $0.10 \mathrm{mmol}$ ) dissolved in toluene $(1 \mathrm{ml})$ was added dropwise (EtCN can also be used for dissolution of the $\mathrm{CuO}^{t} \mathrm{Bu}$, however, trace amounts $(<0.2 \mathrm{mg})$ of an insoluble orange solid were then present). An EtCN $(1 \mathrm{ml})$ solution of $\left[\mathrm{Cu}(\mathrm{MeCN})_{4}\right] \mathrm{OTf}(36.3 \mathrm{mg}, 0.20 \mathrm{mmol})$ was then added dropwise, leading to a faintly yellow solution. After evaporation of all volatile material under reduced pressure, the resulting residue was re-dissolved in $\mathrm{Me}_{2} \mathrm{CO}$ or EtCN. These faintly yellow coloured stock solutions were used for further experiments, discussed in Section 5.3.

\section{Preparation of $\left[\left\{\mathrm{Cu}_{2}{ }_{2} \mathrm{~L}^{3}\left(\mathrm{O}_{2}\right)\right\}\left\{\left(\mathrm{Me}_{2} \mathrm{CO}\right) \mathrm{Na}(\mathrm{OTf})\right\}\right]_{2}(\mathrm{OTf})_{2} \cdot \mathrm{H}_{2} \mathrm{O}\left(\left[\mathrm{Cu}_{2}{ }_{2} \mathrm{~L}^{3}\left(\mathrm{O}_{2}\right)\right]^{\mathrm{OTf}} \cdot \mathrm{NaOTf}\right)$}

Preparation of crystalline material of the $\left[\mathrm{Cu}^{\prime \prime} \mathrm{L}^{3}\left(\mathrm{O}_{2}\right)\right]^{\mathrm{MX}}$ complexes was carried out following a general procedure. The synthesis of $\left[\mathrm{Cu}_{2}{ }_{2} \mathrm{~L}^{3}\left(\mathrm{O}_{2}\right)\right]^{\mathrm{OTf}} \cdot$.NaOTf is described here in detail as an example. $\mathrm{HL}^{3}$ (100.0 $\left.\mathrm{mg}, 0.20 \mathrm{mmol}\right)$ and $\mathrm{NaO}^{\mathrm{t}} \mathrm{Bu}(18.6 \mathrm{mg}, 0.20 \mathrm{mmol}$ ) were dissolved in EtCN (4 ml) to give a faint yellow solution. After stirring for $2 \mathrm{~h}$ at RT, [Cu(MeCN) 4 ]OTf (145.2 $\mathrm{mg}, 0.40 \mathrm{mmol})$ dissolved in EtCN $(1 \mathrm{ml})$ was added dropwise to give an almost colourless solution. After evaporation of all volatile material under reduced pressure, the resulting residue was dissolved in acetone $(6 \mathrm{ml})$. After filtration through a pipette tip plugged with tissue paper, the solution was divided into three equal portions and each cooled to $-30{ }^{\circ} \mathrm{C}$. The headspace of each reaction vessel was then exchanged to dry dioxygen gas (brief evacuation followed by flooding with $\mathrm{O}_{2}$ ), and the solutions became intensely purple in colour. Slow diffusion of $\mathrm{Et}_{2} \mathrm{O}$ at $-30{ }^{\circ} \mathrm{C}$ over approximately two weeks resulted in crystalline material (32.6 mg, $0.034 \mathrm{~mol}, 50 \%$ yield based on one crop) suitable for X-ray diffraction. 
Elemental Analysis (calcd., found for $\left.\mathrm{C}_{68} \mathrm{H}_{128} \mathrm{Cu}_{4} \mathrm{~F}_{12} \mathrm{~N}_{16} \mathrm{Na}_{2} \mathrm{O}_{19} \mathrm{~S}_{4}\right): \%=\mathrm{C}(38.34,38.54), \mathrm{H}$ $(6.06,5.87), \mathrm{N}(10.52,10.54)$.

UV/Vis (Solid State, RT): $\lambda_{\max }[\mathrm{nm}]=500,615$ (not well resolved). As discussed in the main text, spectra of this compound are concentration dependent in solution. See Section 5.3.3 for more details.

Resonance Raman (solid state, $\left.\lambda_{\text {exc }}=633 \mathrm{~nm}\right): \tilde{v}\left(\mathrm{~cm}^{-1}\right)=448,788,1556\left(\Delta^{16} \mathrm{O}_{2}-{ }^{18} \mathrm{O}_{2}=15,41\right.$ and $81 \mathrm{~cm}^{-1}$, respectively). Values are taken from the spectra shown in Figure 5.7 . These features are dependent on both the solvent, and the presence of alkali metal cations in solution. See Section 5.3.2 for more detail.

HR-Cryo-MS (ESI -, EtCN, $\left.-80{ }^{\circ} \mathrm{C}\right): m / z=975.168,\left[\mathrm{M}+\mathrm{O}_{2}+\mathrm{H}+3 \mathrm{ClO}_{4}\right]^{-}$. This spectrum resulted when $\left[\mathrm{Cu}_{2}^{\prime} \mathrm{L}^{3}\right]$ was exposed to oxygen in situ at $-30^{\circ} \mathrm{C}$. See Section 4.4.3 for detail.

\subsubsection{Preparation of ${ }^{-\mathrm{M}}\left[\mathrm{Cu}_{2}^{\prime} \mathrm{L}^{3}\left(\mathrm{O}_{2}\right)\right]^{\mathrm{X}}$}

${ }^{-M}\left[\mathrm{Cu}_{2}{ }_{2} \mathrm{~L}^{3}\left(\mathrm{O}_{2}\right)\right]^{\text {OTf }}$ was prepared from stock solutions of ${ }^{-\mathrm{M}}\left[\mathrm{Cu}_{2}^{1} \mathrm{~L}^{3}\right]^{\mathrm{X}}$ in the same manner as described for $\left[\mathrm{Cu}_{2}{ }_{2} \mathbf{L}^{3}\left(\mathrm{O}_{2}\right)\right]^{\mathrm{X}}$. Attempts to crystallise the product are ongoing. The data reported below are for the product when formed in situ.

UV/Vis $\left(\mathrm{Me}_{2} \mathrm{CO}\right.$ solution, RT): $\lambda_{\max }[\mathrm{nm}]\left(\varepsilon\left[\mathrm{M}^{-1} \mathrm{~cm}^{-1}\right]\right)=530(\approx 3300), 666$ (shoulder). See Section 5.3.3 for more details.

Resonance Raman (solid state, $\left.\lambda_{\text {exc }}=633 \mathrm{~nm}\right): \tilde{v}\left(\mathrm{~cm}^{-1}\right)=435,796,1584\left(\Delta^{16} \mathrm{O}_{2}-{ }^{18} \mathrm{O}_{2}=18,39\right.$ and $81 \mathrm{~cm}^{-1}$, respectively). These features are dependent on both the solvent, and the presence of alkali metal cations in solution. See Section 5.3.2 for more detail.

\subsubsection{Preparation of $\left[\mathrm{Cu}_{2}{ }_{2} \mathrm{~L}^{3}\left(\mathrm{H}_{3} \mathrm{O}_{2}\right)\right](\mathrm{OTf})_{2}$}

The preparation of this compound was reported previously. ${ }^{91}$ The title compound $\left[\mathrm{Cu}_{2}{ }_{2}{ }^{3}{ }^{3}\left(\mathrm{H}_{3} \mathrm{O}_{2}\right)\right](\mathrm{OTf})_{2}$ was isolated in the current work in two experiments, as a decay product during $\left[\mathrm{Cu}_{2}{ }_{2} \mathrm{~L}^{3}\left(\mathrm{O}_{2}\right)\right](\mathrm{OTf})_{2}$ crystallisation attempts. When $\mathrm{Me}_{2} \mathrm{CO}$ was used as the solvent and solutions maintained under inert conditions at $-30{ }^{\circ} \mathrm{C}$, very few blue-green crystals could be isolated in a single case, despite the bulk solution remaining intensely purple in colour. As discussed in the main text (Section 6.2.2), when an MeCN solution which had decayed was very briefly exposed to air the product yield was greatly enhanced. The latter case is therefore detailed here. $\mathrm{HL}^{3}(25.0 \mathrm{mg}, 0.05 \mathrm{mmol})$ and $\mathrm{NaO}^{\mathrm{t}} \mathrm{Bu}(4.7 \mathrm{mg}$, $0.05 \mathrm{mmol}$ ) were dissolved in $\operatorname{EtCN}(4 \mathrm{ml})$ to give a faint yellow solution. After stirring for $2 \mathrm{~h}$ at $\mathrm{RT},\left[\mathrm{Cu}(\mathrm{MeCN})_{4}\right] \mathrm{OTf}(36.3 \mathrm{mg}, 0.10 \mathrm{mmol})$ dissolved in $\mathrm{EtCN}(1 \mathrm{ml})$ was added dropwise to give an almost colourless solution. Following evaporation of all volatile material under reduced pressure, the resulting residue was dissolved in MeCN $(1 \mathrm{ml})$. After filtration through a pipette tip plugged with tissue paper, the solution was divided into two portions $(0.2 \mathrm{ml}$ and $0.8 \mathrm{ml}$ ), and both portions further diluted with MeCN (to give a total of $1 \mathrm{ml}$ each). Both solutions were then transferred to a crystallisation vessel containing diethyl ether which was subsequently cooled to $-30^{\circ} \mathrm{C}$. The headspace of this vessel was then exchanged to dry dioxygen gas (brief evacuation followed by flooding with $\mathrm{O}_{2}$ ), and the solutions became intensely purple in colour. During the course of slow diffusion of $\mathrm{Et}_{2} \mathrm{O}$ at $-30{ }^{\circ} \mathrm{C}$ over several weeks this solution became green in colour. After releasing excess 
pressure by opening the flask momentarily, the sealed vessel was allowed to warm to RT overnight, affording blue-green crystalline material $(24.1 \mathrm{mg}, 0.025 \mathrm{mmol}, 62 \%$ yield based on the larger scale reaction) suitable for X-ray diffraction. The entirety of the crystalline material obtained above was used for SQUID measurements. The remaining characterisation data reported below was obtained from in situ formation of the product under anhydrous conditions.

UV/Vis (EtCN solution, RT): $\lambda_{\max }[\mathrm{nm}]\left(\varepsilon\left[\mathrm{M}^{-1} \mathrm{~cm}^{-1}\right]\right)=387$ (shoulder), 530 (532), 644 (580).

$\mathrm{MS}\left(\mathrm{ESI}+, \mathrm{Me}_{2} \mathrm{CO}\right): \mathrm{m} / z=330.2\left[\mathrm{Cu}_{2} \mathrm{~L}^{3}+\mathrm{OH}\right]^{2+}, 351.2,\left[\mathrm{Cu}_{2} \mathrm{~L}^{3}+\left(\mathrm{CH}_{3}\right)_{2} \mathrm{CO}+\mathrm{H}\right]^{+}, 352.2\left[\mathrm{Cu}_{2} \mathrm{~L}^{3}+\right.$ $\left.\mathrm{HCO}_{3}\right]^{+}$.

$\mathrm{MS}(\mathrm{ESI}+, \mathrm{MeCN}): \mathrm{m} / \mathrm{z}=330.1\left[\mathrm{Cu}_{2} \mathrm{~L}^{3}+\mathrm{OH}\right]^{2+}, 703.4,\left[\mathrm{Cu}_{2} \mathrm{~L}^{3}+\mathrm{CH}_{3} \mathrm{CO}_{2} \mathrm{H}\right]^{+}, 759.4\left[\mathrm{Cu}_{2} \mathrm{~L}^{3}+\mathrm{OH}\right.$ $\left.+\mathrm{ClO}_{4}\right]^{+}$.

$\mathrm{MS}(\mathrm{ESI}-, \mathrm{MeCN}): \mathrm{m} / z=959.2,\left[\mathrm{Cu}_{2} \mathrm{~L}^{3}+\mathrm{OH}+3 \mathrm{ClO}_{4}\right]^{-}$.

\subsubsection{Preparation of $\left[\mathrm{Cu}_{2}{ }_{2} \mathrm{~L}^{3}(\mathrm{OH})(\mathrm{DTBP})_{2}\right]$}

The product $\left[\mathrm{Cu}_{2}{ }_{2} \mathrm{~L}^{2}(\mathrm{OH})(\mathrm{DTBP})_{2}\right.$ ] was isolated from several substrate screening experiments after EtCN solutions of sodium 2,4-di-tert-butylphenolate-THF (NaDTBP) and pre-fromed $\left[\mathrm{Cu}_{2}{ }_{2} \mathrm{~L}^{2}\left(\mathrm{O}_{2}\right)\right]^{\mathrm{X}}$ were allowed to react at $-80{ }^{\circ} \mathrm{C}$, and subsequently warmed slowly to RT. An attempt to specifically target this product also proved successful, and is detailed here. $\mathrm{HL}^{2}$ $(50.0 \mathrm{mg}, 0.10 \mathrm{mmol})$ and $\mathrm{KO}^{\mathrm{t}} \mathrm{Bu}(10.8 \mathrm{mg}, 0.10 \mathrm{mmol})$ were dissolved in $\mathrm{EtCN}(6 \mathrm{ml})$ to give a yellow solution. After stirring overnight at $\mathrm{RT},\left[\mathrm{Cu}(\mathrm{MeCN})_{4}\right] \mathrm{ClO}_{4}(62.6 \mathrm{mg}, 0.20 \mathrm{~mol})$ was added as a solid to give an almost colourless solution. After exposure of this solution to dry $\mathrm{O}_{2}$ for $20 \mathrm{~min}$ at $-80{ }^{\circ} \mathrm{C}$ and removal of excess $\mathrm{O}_{2}$ by brief vacuum cycles, an EtCN solution ( 4 $\mathrm{ml}$ ) of NaDTBP (143.6 mg, $0.50 \mathrm{~mol}$ ) was added. When no further colour change was observed at $-80{ }^{\circ} \mathrm{C}$, the mixture was transferred to a freezer at $-30^{\circ} \mathrm{C}$. After two weeks at this temperature a mixture of dark green and colourless crystalline material was deposited. These products were separated as far as possible visually to yield the product ( $38 \mathrm{mg}, 0.03$ $\mathrm{mmol}$, $30 \%$ yield).

UV/Vis (EtCN solution, RT): $\lambda_{\max }[\mathrm{nm}]\left(\varepsilon\left[\mathrm{M}^{-1} \mathrm{~cm}^{-1}\right]\right)=360$ (3080), 650 (185). No satisfactory elemental analysis of this compound was yet obtained.

$\mathrm{MS}(\mathrm{ESI}+\mathrm{MeCN}): \mathrm{m} / \mathrm{z}=523.5,\left[\mathrm{HL}^{2}+\mathrm{H}\right]^{+}, 585.4\left[\mathrm{HL}^{2}+\mathrm{Cu}\right]^{+}, 620.3\left[\mathrm{HL}^{2}+\mathrm{Cu}+\mathrm{Cl}\right]^{+}$. Several other minor species were present at higher masses but could not be unambiguously identified.

\subsection{Diffusion Ordered NMR Spectroscopy}

NMR Diffusion ordered spectroscopy (DOSY) measurements were conducted at RT (for ${ }^{1} \mathrm{H}$; 23-25 ${ }^{\circ} \mathrm{C}$, probe heater off and allowed to cool for at least one hour) or $-30{ }^{\circ} \mathrm{C}$ (for ${ }^{19} \mathrm{~F}$; with a convection suppressing pulse program). ${ }^{1} \mathrm{H}$ Diffusion coefficients were standardised relative to the residual solvent signal $\left(\mathrm{CD}_{3} \mathrm{CN}\right.$, taken as $\left.3.55 \mathrm{~m}^{2} \mathrm{~s}^{-1}\right)$ when measured on 
different spectrometers, whereas ${ }^{19} \mathrm{~F}$ measurements were only interpreted relatively, and conducted entirely on a single spectrometer using the same gradient calibration constant. The diffussion coefficients obtained from the ${ }^{1} \mathrm{H}$ DOSY NMR experiments were then used to calculate the molecular radii of the analytes being studied using the Stokes-Einstein equation (Equation 8.1), and the known viscosity $(\eta)$ of $\mathrm{MeCN}$ at $25^{\circ} \mathrm{C}(0.369 \mathrm{cP}) .{ }^{251}$

$$
D=\frac{k_{\mathrm{B}} \cdot T}{6 \cdot \Pi \cdot \eta \cdot r_{\mathrm{H}}} \quad(\text { Equation 8.1) }
$$

The results of these calculations are tabulated below:

\begin{tabular}{|c|c|c|c|c|c|}
\hline Species & $D\left(\mathrm{~m}^{2} \mathrm{~s}^{-1}\right)$ & $D\left(\mathrm{~m}^{2} \mathrm{~s}^{-1}\right)$ & $r(\AA ̊)$ & $V\left(\AA^{3}\right)$ & $V_{\text {Complex }} / V_{\text {Ligand }}$ \\
\hline $\mathrm{HL}^{1}$ & -8.84 & $1.45 \times 10^{-9}$ & 4.1 & 287 & - \\
\hline$\left[\mathrm{Cu}_{2}^{1} \mathrm{~L}^{1}\right]$ & -8.97 & $1.07 \times 10^{-9}$ & 5.5 & 704 & 2.5 \\
\hline $\mathrm{HL}^{2}$ & -9.01 & $0.98 \times 10^{-9}$ & 6.1 & 927 & - \\
\hline$\left[\mathrm{Cu}^{\prime} \mathrm{L}^{2}\right]$ (Species B) & -9.04 & $0.91 \times 10^{-9}$ & 6.5 & 1141 & 1.2 \\
\hline$\left[\mathrm{Cu}_{2} \mathrm{~L}^{2}\right]$ (Species A) & -9.07 & $0.85 \times 10^{-9}$ & 6.9 & 1404 & 1.5 \\
\hline $\mathrm{HL}^{3}$ & -8.99 & $1.02 \times 10^{-9}$ & 5.8 & 808 & - \\
\hline$\left[\mathrm{Cu}_{2}{ }_{2} \mathrm{~L}^{3}\right]$ & -9.02 & $0.96 \times 10^{-9}$ & 6.2 & 994 & 1.2 \\
\hline
\end{tabular}

\subsection{UV/Vis Spectroscopy}

Low temperature UV-vis spectra were measured with a Varian Cary 50 Bio instrument coupled to a quartz immersion probe (1 or $5 \mathrm{~mm}$, Hellma Analytics). Pre-cooled temperature regulated solutions were exposed to gaseous dioxygen by atmosphere exchange, through the brief application of vacuum.

UV-vis spectra at ambient temperature were measured with a Cary 5000 Bio spectrophotometer using quartz cuvettes. Decay kinetics and qualitative measurements relevant to the sodium binding equilibrium were carried out with this instrument, at RT. Suitably diluted EtCN or $\mathrm{Me}_{2} \mathrm{CO}$ solutions of $\left[\mathrm{Cu}_{2}{ }_{2} \mathrm{~L}^{3}\left(\mathrm{O}_{2}\right)\right]$, prepared as described above, were used to half fill a cuvette (after mixing with the relevant sodium or triflate salt solutions, where appropriate, to give in all cases 1.5 or $0.3 \mathrm{ml}$ for 1.0 or $0.2 \mathrm{~cm}$ cuvettes, respectively) which was then sealed with a rubber septum inside the glovebox. A dioxygen saturated solution of the relevant dry solvent ( 1.5 or $0.3 \mathrm{ml}$ for 1.0 or $0.2 \mathrm{~cm}$ cuvettes, respectively) was then injected outside the glovebox and the cuvette immediately inserted into the spectrophotometer.

Solid state spectra were recorded using the Cary 5000 Bio spectrophotometer but with a Praying Mantis ${ }^{\mathrm{TM}}$ diffuse reflection attachment equipped with a sample chamber with quartz windows (Harrick Scientific Products). 
The binding constant was obtained by fitting the decrease in absorbance at both 525 and $653 \mathrm{~nm}$ to 1:1 equilibrium binding isotherm models with non-linear regression. Origin $\AA$ was used to fit each data set independently, expressed as fractional saturation (Equation 8.2), where $\theta=\Delta \mathrm{Abs}_{(\mathrm{x})} / \Delta \mathrm{Abs}_{(\text {total) }}, K_{\mathrm{a}}=$ the association constant, and [G] = guest concentration at equilibrium.

$$
\theta=\frac{K_{\mathrm{a}} \cdot[\mathrm{G}]}{1+K_{\mathrm{a}} \cdot[\mathrm{G}]} \quad(\text { Equation } 8.2)
$$

Results using this equation were in reasonable agreement $\left(K_{\mathrm{a}} \pm 350 \mathrm{M}^{-1}\right)$ with those obtained for local fitting of the individual data sets using initial component concentrations (Equation 8.3) with the Thordarson program, ${ }^{252}$ running under Matlab®. [HG] = host-guest concentration at equilibrium, $[\mathrm{G}]_{0}=$ initial guest concentration, $[\mathrm{H}]_{0}=$ initial host concentration, and $K_{\mathrm{a}}=$ the association constant.

$$
[\mathrm{HG}]=\frac{1}{2} \cdot\left([\mathrm{G}]_{0}+[\mathrm{H}]_{0}+\frac{1}{K_{\mathrm{a}}}\right)-\left(\left([\mathrm{G}]_{0}+[\mathrm{H}]_{0}+\frac{1}{K_{\mathrm{a}}}\right)^{2}-4 \cdot[\mathrm{H}]_{0} \cdot[\mathrm{G}]_{0}\right)^{\frac{1}{2}} \quad \text { (Equation 8.3) }
$$

The final value of $K_{\mathrm{a}}=1700\left( \pm 10 \%\right.$, from asymptotic error) $\mathrm{M}^{-1}$ was given by global (simultaneous) fitting of both data sets.

\subsection{Oxygen Uptake}

Oxygen uptake experiments were performed in a small $(<5 \mathrm{ml})$ cell closed with a septum and maintained at $-80{ }^{\circ} \mathrm{C}\left(\mathrm{L}^{2}\right)$ or $-30{ }^{\circ} \mathrm{C}\left(\mathrm{L}^{3}\right)$. A Clark-type gas phase oxygen sensor $(\mathrm{Ox}-\mathrm{N}$ sensor and Oxy-meter, Unisense) was inserted through the septum into the head space of the cell. The sensor was calibrated before each experiment. A Hamilton Sample Lock syringe was thus used to add $250 \mu \mathrm{L}$ portions of oxygen to the gas phase of the cell, containing $1 \mathrm{~mL}$ of dry, degassed EtCN $\left(\mathrm{L}^{2}\right)$ or $\mathrm{Me}_{2} \mathrm{CO}\left(\mathrm{L}^{3}\right)$. The dried cell was then filled with $1 \mathrm{~mL}$ of a $1 \times$ $10^{-2} \mathrm{M}$ solution of $\left[\mathrm{Cu}_{2}{ }_{2} \mathrm{~L}^{2}\right]$ or $\left[\mathrm{Cu}_{2}{ }_{2} \mathrm{~L}^{3}\right]$ inside the glovebox and closed with a new septum. After temperature equilibration, the sensor was inserted into the cell (very slight colour change of the solution was observed) and, after waiting until the signal was stable (typically $10 \mathrm{~min}$ ), $250 \mu \mathrm{L}$ of $\mathrm{O}_{2}$ was injected. Further $\mathrm{O}_{2}$ injections were carried out after signal stabilization to check for further reaction and confirm that the cell was gastight.

\subsection{Resonance Raman Spectroscopy}

Resonance raman spectra were measured using a HORIBA Scientific LabRAM HR 800 (400-1100 nm) spectrometer with open-electrode CCD detector and a confocal pinhole with user controlled variable aperture, in combination with a free space optical microscope and a He:Ne-laser (632.8 nm). A CryoVac KONTI-Cryostat-Mikro cell with liquid nitrogen cooling 
was used for solution measurements. A $2.5 \times 10^{-2} \mathrm{M}\left(\left[\mathrm{Cu}^{\prime \prime}{ }_{2} \mathbf{L}^{2}\left(\mathbf{O}_{2}\right)\right]\right)$ or $1 \times 10^{-2} \mathrm{M}$ $\left(\left[\mathrm{Cu}_{2}{ }_{2} \mathrm{~L}^{3}\left(\mathrm{O}_{2}\right)\right]\right)$ solution was prepared as described above, and injected into the cell. After allowing the temperature to equilibrate, dioxygen gas was admitted to the cell. Solid state measurements were performed under air with the sample mounted on a glass slide.

\subsection{Magnetic Susceptibility Measurements}

Temperature-dependent magnetic susceptibility measurements were carried out with a Quantum-Design MPMS-XL-5 SQUID magnetometer equipped with a 5 Tesla magnet in the range from 2 to $295 \mathrm{~K}$ at a magnetic field of $0.5 \mathrm{~T}$. The powdered sample was contained in a gel bucket and fixed in a non-magnetic sample holder. Each raw data file for the measured magnetic moment was corrected for the diamagnetic contribution of the sample holder and the gel bucket. The molar susceptibility data were corrected for the diamagnetic contribution.

Experimental data for complex $\left[\mathrm{Cu}_{2}{ }_{2} \mathrm{~L}^{3}\left(\mathrm{O}_{2}\right)\right]^{\text {OTf }} \cdot \mathrm{NaOTf}$ and $\left[\mathrm{Cu}_{2}{ }_{2} \mathrm{~L}^{3}\left(\mathrm{H}_{3} \mathrm{O}_{2}\right)\right]^{\text {(OTf)2 }}$ were modelled by using a fitting procedure to the appropriate Heisenberg-Dirac-van-Vleck (HDvV) spin Hamiltonian for isotropic exchange coupling and Zeeman splitting (Equation 8.4).

$$
\hat{H}=2 J \hat{S}_{1} \cdot \hat{S}_{2}+g \mu_{B}\left(\vec{S}_{1}+\vec{S}_{2}\right) B \quad(\text { Equation 8.4) }
$$

Temperature-independent paramagnetism $(T I P)$ and a Curie-behaved paramagnetic impurity $(P I)$ with spin $S=1 / 2$ were included according to $\chi_{\text {calc }}=(1-P I) \cdot \chi+P I \cdot \chi_{\text {mono }}+T I P$. Simulation of the experimental magnetic data and Boltzmann population was performed with the julX program (E. Bill: Max-Planck Institute for Chemical Energy Conversion, Mülheim/Ruhr, Germany, http://www.cec.mpg.de/forschung/molekulare-theorie-undspektroskopie-molecular-theory-and-spectroscopy/moessbauer-mcd.html).

\subsection{Substrate reactivity screening}

Screening for substrate reactivity (oxygenation or oxidation) was carried out following a general procedure. Typically, the neutral ligand $(50.0 \mathrm{mg}, 0.10 \mathrm{mmol})$ dissolved in EtCN (9 $\mathrm{ml})$ was reacted with $\mathrm{MO}^{t} \mathrm{Bu}\left(0.10 \mathrm{mmol}, \mathrm{M}=\mathrm{Na}^{+}, \mathrm{K}^{+}\right.$or $\left.\mathrm{Cu}^{+}\right)$. The solution was then divided in four parts and $\left[\mathrm{Cu}(\mathrm{MeCN})_{4}\right] \mathrm{X}$ in $\mathrm{EtCN}(1 \mathrm{ml})$ amount of copper(I) salt required to give two equivalents total, $\mathrm{X}=\mathrm{PF}_{6}{ }^{-}, \mathrm{BF}_{4}{ }^{-}, \mathrm{ClO}_{4}{ }^{-}$or $\mathrm{CF}_{3} \mathrm{SO}_{3}{ }^{-}$) was added, or vice versa depending on the specific experiment. After removal of all volatile material, the resulting residues were redissolved in EtCN (1,5 ml each). These solutions were then cooled (either -30 or $-78{ }^{\circ} \mathrm{C}$ depending on the complex used) and exposed to dry dioxygen gas by atmosphere exchange. After 10 minutes excess $\mathrm{O}_{2}$ was removed by vacuum-argon cycles and a cooled EtCN substrate solution $\left(-30\right.$ or $-78^{\circ} \mathrm{C}, 5$ equivalents in $1 \mathrm{ml}$ ) added through a canula (pre-cooled 
by passage of solvent). Any colour change over the hour after addition was noted and the solutions then allowed to warm to RT under argon overnight. Copper complex was then removed by passage through a short silica column ( $1 \mathrm{ml}$ analyte solution, followed by $\mathrm{MeOH}$ or $\mathrm{Me}_{2} \mathrm{CO}$ ( $\approx 5 \mathrm{ml}$, MeOH was required for full elution in the case of NaDTBP investigations). Although direct quantitative assessment attempts were made by GC-MS, incomplete removal of counterions ( $X$ above) led to irreproducible spectra. Thus, after removal of all volatiles, the residue was redissolved in $\mathrm{CDCl}_{3}$ and analysed by ${ }^{1} \mathrm{H} \mathrm{NMR}$. For quantitative analyses 1,3,5-triemthoxybenzene $(2.5 \mathrm{mg}$ ) was added to the NMR samples. "Blank" tests were conducted with equimolar solutions of copper salt treated identically, and showed no substrate transformation.

\subsection{Crystallographic Details}

X-ray data were collected on a STOE IPDS II diffractometer with an area detector (graphite monochromated Mo-K $\alpha$ radiation, $\lambda=0.71073 \AA$ ) by use of $\omega$ scans at $133 \mathrm{~K}$. Structures were solved by direct methods (SHELXS) and refined on $F^{2}$ using all reflections with SHELX97 or SHELXL-2013 ${ }^{x}$. Most non-hydrogen atoms were refined anisotropically (Sometimes not in the case of disorder). Hydrogen atoms were placed in calculated positions, unless otherwise indicated, and assigned to an isotropic displacement parameter of $1.2 / 1.5 U_{\text {eq }} \mathrm{C}$, $\mathrm{N}$, or $\mathrm{O}$, where applicable. Face-indexed absorption corrections were performed numerically with the program X-RED ${ }^{\mathrm{X}}$. 


\begin{tabular}{|c|c|c|c|}
\hline Compound & ${ }^{\text {Amide }} \mathrm{HL}^{3}$ & {$\left[\mathrm{NaL}^{1}\right]$} & {$\left[\mathrm{NaL}^{3}\right]$} \\
\hline empirical formula & $\mathrm{C}_{29} \mathrm{H}_{54} \mathrm{~N}_{8} \mathrm{O}_{2}$ & $\mathrm{C}_{60} \mathrm{H}_{124} \mathrm{~N}_{24} \mathrm{Na}_{4} \mathrm{O}$ & $\mathrm{C}_{59.50} \mathrm{H}_{116.50} \mathrm{~N}_{16.50} \mathrm{Na}_{2}$ \\
\hline formula weight & 546.80 & 1289.79 & 1109.17 \\
\hline$T[\mathrm{~K}]$ & $133(2)$ & $133(2)$ & $133(2)$ \\
\hline crystal size $\left[\mathrm{mm}^{3}\right]$ & $0.44 \times 0.18 \times 0.11$ & $0.25 \times 0.12 \times 0.11$ & $0.50 \times 0.44 \times 0.17$ \\
\hline crystal system & monoclinic & monoclinic & monoclinic \\
\hline space group & $C 2 / c$ & $C 2 / c$ & $P 2_{1} / C$ \\
\hline$a[\AA]$ & $25.6385(13)$ & $21.328(2)$ & $11.9067(3)$ \\
\hline$b[\AA]$ & $6.1444(2)$ & $13.1504(13)$ & $44.9605(11)$ \\
\hline$c[\AA]$ & $21.6483(11)$ & $27.062(3)$ & $12.4560(4)$ \\
\hline$\alpha\left[^{\circ}\right]$ & 90 & 90.00 & 90.00 \\
\hline$\beta\left[^{\circ}\right]$ & $113.088(4)$ & $95.193(8)$ & $102.659(2)$ \\
\hline$\nu\left[^{\circ}\right]$ & 90 & 90.00 & 90.00 \\
\hline$V\left[\AA^{3}\right]$ & $3137.2(3)$ & $7559.1(13)$ & $6506.0(3)$ \\
\hline$Z$ & 4 & 4 & 4 \\
\hline$\rho\left[\mathrm{g} \mathrm{cm}^{-3}\right]$ & 1.158 & 1.133 & 1.132 \\
\hline$F(000)$ & 1200 & 2816 & 2444 \\
\hline$\mu\left[\mathrm{mm}^{-1}\right]$ & 0.075 & 0.092 & 0.081 \\
\hline$T_{\min } / T_{\max }$ & $-/-$ & $-/-$ & 0.9655 / 0.9869 \\
\hline$\theta$-range $\left[{ }^{\circ}\right]$ & $1.727-25.596$ & $1.51-25.00$ & $1.74-24.62$ \\
\hline$h k l$-range & $\pm 30, \pm 7, \pm 26$ & $-25-23, \pm 15, \pm 32$ & $\pm 13,-46-52, \pm 14$ \\
\hline measured refl. & 19161 & 23765 & 53221 \\
\hline unique refl. $\left[R_{\text {int }}\right]$ & $2947[0.1010]$ & $6657[0.2020]$ & $10855[0.0686]$ \\
\hline observed refl. $I>2 \sigma(I)$ & 2384 & 1833 & 8733 \\
\hline data / restraints / param. & 2947 / 63 / 219 & 6657 / 6 / 407 & 10855 / 47 / 737 \\
\hline goodness-of-fit $\left(F^{2}\right)$ & 1.183 & 0.925 & 1.055 \\
\hline$R 1, w R 2(I>2 \sigma(I))$ & $0.0818,0.1854$ & $0.1004,0.2286$ & $0.0437,0.1161$ \\
\hline$R 1, w R 2$ (all data) & $0.0968,0.1916$ & $0.2786,0.3208$ & $0.0561,0.1220$ \\
\hline resid. el. dens. $\left[\mathrm{e}^{\circ} \AA^{-3}\right]$ & $-0.262 / 0.519$ & $-0.351 / 0.592$ & $-0.274 / 0.754$ \\
\hline
\end{tabular}




\begin{tabular}{|c|c|c|c|}
\hline Compound & {$\left[\mathrm{Cu}_{2}{ }_{2} \mathrm{~L}^{3}\left(\mathrm{O}_{2}\right)\right]^{\text {OTf }} \cdot$ NaOTf } & {$\left[\mathrm{Cu}_{2}{ }^{\mathrm{II}} \mathrm{L}^{3}\left(\mathrm{O}_{2}\right)\right]^{\text {OTf }} \cdot \mathrm{KOTf}$} & {$\left[\mathrm{Cu}_{2}{ }^{11} \mathrm{~L}^{3}\left(\mathrm{O}_{2}\right)\right]^{\mathrm{ClO} 4} \cdot \mathrm{ClO}_{4}$} \\
\hline empirical formula & $\mathrm{C}_{68} \mathrm{H}_{126} \mathrm{Cu}_{4} \mathrm{~F}_{12} \mathrm{~N}_{16} \mathrm{Na}_{2} \mathrm{O}_{19} \mathrm{~S}_{4}$ & $\mathrm{C}_{68} \mathrm{H}_{126} \mathrm{Cu}_{4} \mathrm{~F}_{12} \mathrm{~K}_{2} \mathrm{~N}_{16} \mathrm{O}_{18.50} \mathrm{~S}_{4}$ & $\mathrm{C}_{32} \mathrm{H}_{63} \mathrm{Cl}_{2} \mathrm{Cu}_{2} \mathrm{KN}_{8} \mathrm{O}_{11}$ \\
\hline formula weight & 2128.22 & 2152.44 & 972.98 \\
\hline$T[\mathrm{~K}]$ & $133(2)$ & $133(2)$ & $133(2)$ \\
\hline crystal size $\left[\mathrm{mm}^{3}\right]$ & $0.20 \times 0.19 \times 0.09$ & $0.50 \times 0.21 \times 0.09$ & $0.38 \times 0.06 \times 0.05$ \\
\hline crystal system & triclinic & triclinic & monoclinic \\
\hline space group & $P-1$ & $P-1$ & $P 2_{1} / c$ \\
\hline$a[\AA]$ & $10.9645(10)$ & $10.8272(5)$ & $10.644(2)$ \\
\hline$b[\AA]$ & $12.7788(12)$ & $12.8073(6)$ & $21.583(4)$ \\
\hline$c[\AA]$ & $17.5450(14)$ & $17.8554(8)$ & $19.261(4)$ \\
\hline$\alpha\left[^{\circ}\right]$ & $72.769(7)$ & $72.844(4)$ & 90 \\
\hline$\beta\left[^{\circ}\right]$ & $80.175(7)$ & $81.765(4)$ & $103.68(3)$ \\
\hline$\nu\left[^{\circ}\right]$ & $84.956(7)$ & $86.531(4)$ & 90 \\
\hline$V\left[\AA^{3}\right]$ & $2311.7(4)$ & 2340.96(19) & $4299.4(16)$ \\
\hline$Z$ & 1 & 1 & 4 \\
\hline$\rho\left[\mathrm{g} \mathrm{cm}^{-3}\right]$ & 1.529 & 1.527 & 1.503 \\
\hline$F(000)$ & 1108 & 1120 & 2040 \\
\hline$\mu\left[\mathrm{mm}^{-1}\right]$ & 1.103 & 1.168 & 1.273 \\
\hline$T_{\min } / T_{\max }$ & $0.8355 / 0.9058$ & $0.6301 / 0.9058$ & $0.4995 / 0.8015$ \\
\hline$\theta$-range $\left[{ }^{\circ}\right]$ & $1.670-24.640$ & $1.204-25.677$ & $1.440-26.904$ \\
\hline$h k l$-range & $\pm 12, \pm 14, \pm 20$ & $-13-12, \pm 15, \pm 21$ & $-12-13, \pm 27, \pm 24$ \\
\hline measured refl. & 25361 & 29369 & 50613 \\
\hline unique refl. $\left[R_{\text {int }}\right]$ & $7740[0.1250]$ & $8834[0.0535]$ & $9169[0.2762]$ \\
\hline observed refl. $I>2 \sigma(I)$ & 4805 & 7043 & 4421 \\
\hline data / restraints / param. & 7740 / 57 / 593 & 8834 / 70 / 614 & 9169 / 10 / 503 \\
\hline goodness-of-fit $\left(F^{2}\right)$ & 1.051 & 1.043 & 1.066 \\
\hline$R 1, w R 2(I>2 \sigma(I))$ & $0.0773,0.1866$ & $0.0514,0.1193$ & $0.1187,0.2054$ \\
\hline$R 1, w R 2$ (all data) & $0.1254,0.2096$ & $0.0678,0.1259$ & $0.2202,0.2476$ \\
\hline resid. el. dens. $\left[\mathrm{e} \AA^{-3}\right.$ ] & $-0.573 / 0.763$ & $-0.803 / 0.768$ & $-0.835 / 0.682$ \\
\hline
\end{tabular}




\begin{tabular}{|c|c|c|}
\hline \multicolumn{3}{|c|}{ Table 8.4: Crystal data and refinement details } \\
\hline Compound & {$\left[\mathrm{Cu}_{2}{ }_{2} \mathrm{~L}^{3}\left(\mathrm{H}_{3} \mathrm{O}_{2}\right)\right]^{(\mathrm{OTf}) 2}$} & {$\left[\mathrm{Cu}_{2}{ }_{2} \mathrm{~L}^{2}(\mathrm{OH})(\mathrm{DTBP})_{2}\right]$} \\
\hline empirical formula & $\mathrm{C}_{15.50} \mathrm{H}_{30} \mathrm{CuF}_{3} \mathrm{~N}_{4} \mathrm{O}_{4} \mathrm{~S}$ & $\mathrm{C}_{60.75} \mathrm{H}_{110.25} \mathrm{Cu}_{2} \mathrm{~N}_{9.25} \mathrm{O}_{3}$ \\
\hline formula weight & 489.03 & 1145.41 \\
\hline$T[\mathrm{~K}]$ & $133(2)$ & $133(2)$ \\
\hline crystal size $\left[\mathrm{mm}^{3}\right]$ & $0.43 \times 0.16 \times 0.13$ & $0.38 \times 0.30 \times 0.23$ \\
\hline crystal system & orthorhombic & triclinic \\
\hline space group & $P b c n$ & $P-1$ \\
\hline$a[\AA ̊]$ & $15.877(3)$ & $12.3728(6)$ \\
\hline$b[\AA]$ & $16.529(3)$ & $14.4073(7)$ \\
\hline$c[\AA ̊]$ & $15.595(3)$ & 20.3940(9) \\
\hline$\alpha\left[^{\circ}\right]$ & 90 & $101.597(4)$ \\
\hline$\beta\left[^{\circ}\right]$ & 90 & $98.822(4)$ \\
\hline$\nu\left[^{\circ}\right]$ & 90 & $109.291(4)$ \\
\hline$V\left[\AA^{3}\right]$ & 4092.9(14) & $3264.9(3)$ \\
\hline$z$ & 8 & 2 \\
\hline$\rho\left[\mathrm{g} \mathrm{cm}^{-3}\right]$ & 1.587 & 1.165 \\
\hline$F(000)$ & 2040 & 1243 \\
\hline$\mu\left[\mathrm{mm}^{-1}\right]$ & 1.226 & 0.699 \\
\hline$T_{\min } / T_{\max }$ & $0.5347 / 0.7908$ & 0.7912 / 0.8764 \\
\hline$\theta$-range $\left[{ }^{\circ}\right]$ & $2.207-26.731$ & $1.56-25.69$ \\
\hline hkl-range & $\pm 20, \pm 20, \pm 19$ & $\pm 15, \pm 17, \pm 24$ \\
\hline measured refl. & 39808 & 36959 \\
\hline unique refl. $\left[R_{\text {int }}\right]$ & $4179[0.0755]$ & $12286[0.0581]$ \\
\hline observed refl. $I>2 \sigma(I)$ & 3564 & 10029 \\
\hline data / restraints / param. & 4179 / 1 / 266 & $12286 / 136 / 733$ \\
\hline goodness-of-fit $\left(F^{2}\right)$ & 0.977 & 1.025 \\
\hline$R 1, w R 2(I>2 \sigma(I))$ & $0.0337,0.0815$ & $0.0385,0.0954$ \\
\hline$R 1, w R 2$ (all data) & $0.0438,0.0862$ & $0.0522,0.1001$ \\
\hline resid. el. dens. $\left[\mathrm{e} \AA^{-3}\right]$ & $-0.353 / 0.643$ & $-0.476 / 0.735$ \\
\hline
\end{tabular}




\begin{tabular}{|c|c|c|c|}
\hline \multicolumn{4}{|c|}{ Table 8.5: Selected bond lengths $[\AA]$ for $\left[\mathrm{NaL}^{1}\right]$. } \\
\hline Atoms & Bond lengths & Atoms & Bond lengths \\
\hline Na1-N1 & $2.403(7)$ & Na3-O1 & $2.04(2)$ \\
\hline Na1-N1' & $2.403(7)$ & Na3-N11 & $2.405(9)$ \\
\hline Na1-N4' & $2.586(7)$ & Na3-N12" & $2.414(9)$ \\
\hline Na1-N4 & $2.586(7)$ & Na3-N14 & $2.594(9)$ \\
\hline Na1-N3' & $2.792(8)$ & Na3-N16A" & $2.610(13)$ \\
\hline Na1-N3 & $2.792(8)$ & Na3-N13 & $2.709(9)$ \\
\hline $\mathrm{Na} 2-\mathrm{N} 2$ & $2.433(7)$ & Na3-N15" & $2.764(8)$ \\
\hline $\mathrm{Na2-N2}$ & $2.433(7)$ & Na3-N16B" & $2.79(4)$ \\
\hline Na2-N6 & $2.603(8)$ & N12-Na3" & $2.414(9)$ \\
\hline $\mathrm{Na2-N6'}$ & $2.603(8)$ & N15-Na3" & $2.763(8)$ \\
\hline Na2-N5 & $2.755(8)$ & N16A-Na3" & $2.609(13)$ \\
\hline Na2-N5' & $2.755(8)$ & N16B-Na3" & $2.79(4)$ \\
\hline $\mathrm{Na1}-\mathrm{Na} 2$ & $4.5106(56)$ & Na3-Na3" & $4.5246(56)$ \\
\hline
\end{tabular}

Symmetry transformations used to generate equivalent atoms: (') 1-x, y, 3/2-z; (") 3/2-x, 3/2-y, 1-z.

\begin{tabular}{|c|c|c|c|}
\hline \multicolumn{4}{|c|}{ Table 8.6: Selected bond angles $\left({ }^{\circ}\right)$ for $\left[\mathrm{NaL}^{1}\right]$. } \\
\hline Atoms & Bond angles & Atoms & Bond angles \\
\hline N1-Na1-N1' & $100.2(3)$ & O1-Na3-N11 & $132.3(7)$ \\
\hline N1-Na1-N4' & $98.3(2)$ & O1-Na3-N12" & $129.3(7)$ \\
\hline N1'-Na1-N4' & $105.6(2)$ & N11-Na3-N12" & $98.4(3)$ \\
\hline N1-Na1-N4 & $105.6(2)$ & O1-Na3-N14 & $71.7(8)$ \\
\hline N1'-Na1-N4 & $98.3(2)$ & N11-Na3-N14 & $105.9(3)$ \\
\hline N4'-Na1-N4 & $142.3(4)$ & N12"-Na3-N14 & $98.9(3)$ \\
\hline N1-Na1-N3' & $155.8(3)$ & O1-Na3-N16A" & $71.2(8)$ \\
\hline N1'-Na1-N3' & $66.9(2)$ & N11-Na3-N16A" & $99.4(4)$ \\
\hline N4'-Na1-N3' & $67.8(2)$ & N12"-Na3-N16A" & $103.9(4)$ \\
\hline N4-Na1-N3' & $96.7(2)$ & N14-Na3-N16A" & $142.9(3)$ \\
\hline N1-Na1-N3 & $66.9(2)$ & O1-Na3-N13 & $68.7(7)$ \\
\hline N1'-Na1-N3 & $155.8(3)$ & N11-Na3-N13 & $66.1(3)$ \\
\hline N4'-Na1-N3 & $96.7(2)$ & N12"-Na3-N13 & $156.3(3)$ \\
\hline N4-Na1-N3 & $67.8(2)$ & N14-Na3-N13 & $70.3(2)$ \\
\hline N3'-Na1-N3 & $132.2(4)$ & N16A"-Na3-N13 & $96.6(3)$ \\
\hline N2-Na2-N2' & $98.0(3)$ & O1-Na3-N15" & $64.2(7)$ \\
\hline N2-Na2-N6 & $104.0(2)$ & N11-Na3-N15" & $157.2(3)$ \\
\hline N2'-Na2-N6 & $99.6(2)$ & N12"-Na3-N15" & $67.1(3)$ \\
\hline N2-Na2-N6' & $99.6(2)$ & N14-Na3-N15" & $94.1(3)$ \\
\hline N2'-Na2-N6' & $104.0(2)$ & N16A"-Na3-N15" & $69.0(3)$ \\
\hline N6-Na2-N6' & $143.7(4)$ & N13-Na3-N15" & $132.9(2)$ \\
\hline N2-Na2-N5 & $68.2(2)$ & O1-Na3-N16B" & $62.4(11)$ \\
\hline N2'-Na2-N5 & $156.9(3)$ & N11-Na3-N16B" & $106.0(8)$ \\
\hline N6-Na2-N5 & $67.8(2)$ & N12"-Na3-N16B" & $108.2(7)$ \\
\hline N6'-Na2-N5 & $96.8(2)$ & N14-Na3-N16B"' & $134.1(7)$ \\
\hline N2-Na2-N5' & $156.9(3)$ & N16A"-Na3-N16B" & $8.8(7)$ \\
\hline N2'-Na2-N5' & $68.2(2)$ & N13-Na3-N16B"' & $93.8(7)$ \\
\hline N6-Na2-N5' & $96.8(2)$ & N15"-Na3-N16B" & $65.0(7)$ \\
\hline N6'-Na2-N5' & $67.8(2)$ & N12-N11-Na3 & $131.4(6)$ \\
\hline N5-Na2-N5' & $130.6(4)$ & N11-N12-Na3" & $130.1(6)$ \\
\hline
\end{tabular}

Symmetry transformations used to generate equivalent atoms: (') 1-x, y, 3/2-z; (") 3/2-x, 3/2-y, 1-z. 


\begin{tabular}{|c|c|c|c|}
\hline \multicolumn{4}{|c|}{ Table 8.7: Selected bond lengths $(\AA)$ for $\left[\mathrm{NaL}^{3}\right.$ ]. } \\
\hline Atoms & Bond lengths & Atoms & Bond lengths \\
\hline Na1-N11 & $2.3869(15)$ & Na2-N1 & $2.4340(15)$ \\
\hline Na1-N12 & $2.4342(15)$ & Na2-N11 & $2.4350(14)$ \\
\hline Na1-N4 & $2.4429(15)$ & Na2-N2 & $2.4901(15)$ \\
\hline Na1-N3 & $2.4595(15)$ & Na2-N14 & $2.5162(15)$ \\
\hline Na1-N1 & $2.4838(14)$ & Na2-N15 & $2.5339(15)$ \\
\hline Na1-N5 & $2.5515(14)$ & Na2-N13 & $2.5648(15)$ \\
\hline Na1-Na2 & $3.2912(8)$ & & \\
\hline
\end{tabular}

\begin{tabular}{|c|c|c|c|}
\hline \multicolumn{4}{|c|}{ Table 8.8: Selected bond angles $\left({ }^{\circ}\right)$ for $\left[\mathrm{NaL}^{3}\right.$ ]. } \\
\hline Atoms & Bond angles & Atoms & Bond angles \\
\hline N11-Na1-N12 & $33.07(5)$ & N1-Na2-N11 & $32.97(5)$ \\
\hline N11-Na1-N4 & $139.03(6)$ & N1-Na2-N2 & $120.04(5)$ \\
\hline N12-Na1-N4 & $108.98(5)$ & N11-Na2-N2 & $148.76(5)$ \\
\hline N11-Na1-N3 & $146.91(6)$ & N1-Na2-N14 & $97.57(5)$ \\
\hline N12-Na1-N3 & $165.64(5)$ & N11-Na2-N14 & $119.30(5)$ \\
\hline N4-Na1-N3 & $74.01(5)$ & N2-Na2-N14 & $112.52(5)$ \\
\hline N11-Na1-N1 & $93.90(5)$ & N1-Na2-N15 & $141.77(5)$ \\
\hline N12-Na1-N1 & $118.97(5)$ & N11-Na2-N15 & $95.45(5)$ \\
\hline N4-Na1-N1 & $100.55(5)$ & N2-Na2-N15 & $74.17(5)$ \\
\hline N3-Na1-N1 & $73.18(5)$ & N14-Na2-N15 & $139.49(5)$ \\
\hline N11-Na1-N5 & $113.16(5)$ & N1-Na2-N13 & $71.75(5)$ \\
\hline N12-Na1-N5 & $95.00(5)$ & N11-Na2-N13 & $159.69(5)$ \\
\hline N4-Na1-N5 & $73.85(5)$ & N14-Na2-N13 & $71.73(5)$ \\
\hline N3-Na1-N5 & $72.05(5)$ & N15-Na2-N13 & $70.23(5)$ \\
\hline N1-Na1-N5 & $144.97(5)$ & Na2-N1-Na1 & $84.01(5)$ \\
\hline Na1-N11-Na2 & $86.08(5)$ & & \\
\hline
\end{tabular}

\begin{tabular}{|c|c|c|c|}
\hline \multicolumn{4}{|c|}{ Table 8.9: Selected bond lengths $(\AA)$ for $\left[\mathrm{Cu}_{2}{ }_{2} \mathrm{~L}^{\mathbf{3}}\left(\mathrm{O}_{2}\right)\right]^{\text {OTf }} \cdot \mathrm{NaOTf}$} \\
\hline Atoms & Bond lengths & Atoms & Bond lengths \\
\hline Na1-O11 & $2.281(7)$ & Na1-O13' & $2.310(6)$ \\
\hline Na1-O1 & $2.296(6)$ & Na1-O3 & $2.316(7)$ \\
\hline Na1-O2 & $2.303(6)$ & & \\
\hline
\end{tabular}

\begin{tabular}{|c|c|c|c|}
\hline \multicolumn{4}{|c|}{ Table 8.10: Selected bond angles $\left({ }^{\circ}\right)$ for $\left[\mathrm{Cu}_{2}{ }_{2} \mathrm{~L}^{3}\left(\mathrm{O}_{2}\right)\right]^{\text {OTf }} \cdot \mathbf{N a O T f}$} \\
\hline Atoms & Bond angles & Atoms & Bond angles \\
\hline O11-Na1-O1 & $136.6(3)$ & O11-Na1-O3 & $93.3(3)$ \\
\hline O11-Na1-O2 & $100.8(2)$ & O1-Na1-O3 & $114.1(2)$ \\
\hline O1-Na1-O2 & $38.02(18)$ & O2-Na1-O3 & $97.9(2)$ \\
\hline O11-Na1-O13' & $100.3(2)$ & O13'-Na1-O3 & $71.3(3)$ \\
\hline O1-Na1-O13' & $108.3(2)$ & O2-O1-Na1 & $70.7(3)$ \\
\hline O2-Na1-O13' & $140.1(2)$ & O1-O2-Na1 & \\
\hline
\end{tabular}

Symmetry transformation used to generate equivalent atoms: (') 1-x, 1-y, 1-z. 


\begin{tabular}{|c|c|c|c|}
\hline \multicolumn{4}{|c|}{ Table 8.11: Selected bond lengths $(\AA)$ for $\left[\mathrm{Cu}_{2}{ }_{2} \mathrm{~L}^{3}\left(\mathrm{O}_{2}\right)\right]^{\text {OTf }} \cdot \mathrm{KOTf}$} \\
\hline Atoms & Bond lengths & Atoms & Bond lengths \\
\hline K1-O2 & $2.606(3)$ & $\mathrm{K} 1-\mathrm{O} 13$ & $2.734(3)$ \\
\hline K1-O1 & $2.646(3)$ & $\mathrm{K} 1-011$ & $2.861(4)$ \\
\hline K1-O3A & $2.674(5)$ & $\mathrm{K} 1-013$ & $3.016(4)$ \\
\hline
\end{tabular}

\begin{tabular}{|c|c|c|c|}
\hline \multicolumn{3}{|c|}{ Table 8.12: Selected bond angles $\left({ }^{\circ}\right)$ for $\left[\mathrm{Cu}{ }_{2} \mathrm{~L}^{3}\left(\mathbf{O}_{2}\right)\right]^{\text {OTf }} \cdot$ KOTf. $^{-}$} \\
\hline Atoms & Bond angles & Atoms & Bond angles \\
\hline O2-K1-O1 & $32.79(8)$ & O13'-K1-O11 & $111.65(11)$ \\
\hline O2-K1-O3A & $112.4(2)$ & O2-K1-O13 & $138.04(10)$ \\
\hline O1-K1-O3A & $111.7(2)$ & O1-K1-O13 & $83.43(10)$ \\
\hline O2-K1-O13' & $132.28(10)$ & O3A-K1-O13 & $66.47(11)$ \\
\hline O1-K1-O13' & $110.43(9)$ & O13'-K1-O13 & $48.45(9)$ \\
\hline O3A-K1-O13' & $110.7(2)$ & O11-K1-O13 & $72.13(13)$ \\
\hline O2-K1-O11 & $93.36(9)$ & O2-O1-K1 & $75.08(14)$ \\
\hline O1-K1-O11 & $126.14(9)$ & O1-O2-K1 & $113.54(11)$ \\
\hline O3A-K1-O11 & $82.6(2)$ & K1'-O13-K1 & \\
\hline
\end{tabular}

Symmetry transformation used to generate equivalent atoms: (') 1-x, 1-y, 1-z.

\begin{tabular}{|c|c|c|c|}
\hline \multicolumn{4}{|c|}{ Table 8.13: Selected bond lengths $(\AA \circ)$ for $\left[\mathrm{Cu}_{2}{ }_{2} \mathrm{~L}^{3}\left(\mathrm{O}_{2}\right)\right]^{\mathrm{CO} 4} \cdot \mathrm{KClO}_{4} \cdot$} \\
\hline Atoms & Bond lengths & Atoms & Bond lengths \\
\hline O1-K1 & $2.639(7)$ & O13-K1 & $2.849(11)$ \\
\hline O2-K1 & $2.656(7)$ & $\mathrm{K} 1-\mathrm{O} 22 \mathrm{~B}$ & $3.77(2)$ \\
\hline O30-K1 & $2.733(13)$ & $\mathrm{K} 1-\mathrm{O} 21 \mathrm{~B}$ & \\
\hline O11-K1 & $2.996(11)$ & & \\
\hline
\end{tabular}

\begin{tabular}{|c|c|c|c|}
\hline \multicolumn{4}{|c|}{ Table 8.14: Selected bond angles $\left({ }^{\circ}\right)$ for $\left[\mathrm{Cu}_{2}{ }_{2} \mathrm{~L}^{3}\left(\mathrm{O}_{2}\right)\right]^{\mathrm{ClO4}} \cdot \mathrm{KClO}_{4 \cdot}$} \\
\hline Atoms & Bond angles & Atoms & Bond angles \\
\hline O2-O1-K1 & $74.1(4)$ & O1-K1-O11 & $133.2(3)$ \\
\hline O1-O2-K1 & $72.9(4)$ & O2-K1-O11 & $144.6(3)$ \\
\hline O1-K1-O2 & $33.0(2)$ & O30-K1-O11 & $84.9(3)$ \\
\hline O1-K1-O30 & $89.5(3)$ & O22B-K1-O11 & $73.2(5)$ \\
\hline O2-K1-O30 & $117.7(3)$ & O13-K1-O11 & $46.9(3)$ \\
\hline O1-K1-O22B & $151.0(5)$ & O1-K1-O21B & $117.5(4)$ \\
\hline O2-K1-O22B & $134.0(4)$ & O2-K1-O21B & $88.9(4)$ \\
\hline O30-K1-O22B & $80.3(5)$ & O30-K1-O21B & $114.4(5)$ \\
\hline O1-K1-O13 & $114.4(3)$ & O22B-K1-O21B & $46.6(5)$ \\
\hline
\end{tabular}




\section{Appendices}

\section{Bibliography}

(1) Koval, I. A.; Gamez, P.; Belle, C.; Selmeczi, K.; Reedijk, J. Chem. Soc. Rev. 2006, 35, 814-840.

(2) Solomon, E. I.; Sarangi, R.; Woertink, J. S.; Augustine, A. J.; Yoon, J.; Ghosh, S. Acc. Chem. Res. 2007, 40, 581-591.

(3) Balasubramanian, R.; Smith, S. M.; Rawat, S.; Yatsunyk, L. A.; Stemmler, T. L.; Rosenzweig, A. C. Nature 2010, 465, 115-119.

(4) Que, L.; Tolman, W. B. Nature 2008, 455, 333-340.

(5) Aguilera, F.; McDougall, C.; Degnan, B. M. BMC Evol. Biol. 2013, 13, 2-12.

(6) Kumar, V.; Dooley, D. M.; Freeman, H. C.; Guss, J. M.; Harvey, I.; McGuirl, M. A.; Wilce, M. C.; Zubak, V. M. Structure 1996, 4, 943-955.

(7) Buffoni, F.; Ignesti, G. Inflammopharmacology 2003, 11, 203-209.

(8) Van der Vlugt, J. I.; Meyer, F. Top. Organomet. Cat. 2007, 22, 191-240.

(9) Hermans, I.; Spier, E. S.; Neuenschwander, U.; Turrà, N.; Baiker, A. Top. Catal. 2009, $52,1162-1174$.

(10) Schindler, S. Eur. J. Inorg. Chem. 2000, 2000, 2311-2326.

(11) Himes, R. A.; Karlin, K. D. Proc. Natl. Acad. Sci. U. S. A. 2009, 106, 18877-18878.

(12) Solomon, E. I.; Sundaram, U. M.; Machonkin, T. E. Chem. Rev. 1996, 96, 2563-2606.

(13) Chen, P.; Solomon, E. I. J. Am. Chem. Soc. 2004, 126, 4991-5000.

(14) Mirica, L. M.; Ottenwaelder, X.; Stack, T. D. P. Chem. Rev. 2004, 104, 1013-1045.

(15) Himes, R. A.; Karlin, K. D. Curr. Opin. Chem. Biol. 2009, 13, 119-131.

(16) Solomon, E. I.; Ginsbach, J. W.; Heppner, D. E.; Kieber-Emmons, M. T.; Kjaergaard, C. H.; Smeets, P. J.; Tian, L.; Woertink, J. S. Faraday Discuss. 2011, 148, 11-39.

(17) Rosenzweig, A. C.; Sazinsky, M. H. Curr. Opin. Struct. Biol. 2006, 16, 729-735. 
(18) Solomon, E. I.; Heppner, D. E.; Johnston, E. M.; Ginsbach, J. W.; Cirera, J.; Qayyum, M.; Kieber-Emmons, M. T.; Kjaergaard, C. H.; Hadt, R. G.; Tian, L. Chem. Rev. 2014, 114, 3659-3853.

(19) Prigge, S. T.; Eipper, B. A.; Mains, R. E.; Amzel, L. M. Science 2004, 304, 864-867.

(20) Solomon, E. I.; Chen, P.; Metz, M.; Lee, S.-K.; Palmer, A. E. Angew. Chem. Int. Ed. 2001, 40, 4570-4590.

(21) Klinman, J. P. J. Biol. Chem. 2006, 281, 3013-3016.

(22) Cuff, M. E.; Miller, K. I.; van Holde, K. E.; Hendrickson, W. A. J. Mol. Biol. 1998, 278, 855-870.

(23) Decker, H.; Schweikardt, T.; Tuczek, F. Angew. Chem. Int. Ed. 2006, 45, 4546-4550.

(24) Metz, M.; Solomon, E. I. J. Am. Chem. Soc. 2001, 123, 4938-4950.

(25) Rolff, M.; Schottenheim, J.; Decker, H.; Tuczek, F. Chem. Soc. Rev. 2011, 40, 40774098.

(26) Smith, S. M.; Rawat, S.; Telser, J.; Hoffman, B. M.; Stemmler, T. L.; Rosenzweig, A. C. Biochemistry 2011, 50, 10231-10240.

(27) Lieberman, R. L.; Rosenzweig, A. C. Nature 2005, 434, 177-182.

(28) Kitajima, N.; Fujisawa, K.; Morooka, Y.; Toriumi, K. J. Am. Chem. Soc. 1989, 111, 89758976.

(29) Hatcher, L. Q.; Karlin, K. D. J. Biol. Inorg. Chem. 2004, 9, 669-683.

(30) Lewis, E. A.; Tolman, W. B. Chem. Rev. 2004, 104, 1047-1076.

(31) Hoppe, T.; Schaub, S.; Becker, J.; Würtele, C.; Schindler, S. Angew. Chem. Int. Ed. 2013, 52, 870-873.

(32) Würtele, C.; Sander, O.; Lutz, V.; Waitz, T.; Tuczek, F.; Schindler, S. J. Am. Chem. Soc. 2009, 131, 7544-7545.

(33) Citek, C.; Lyons, C. T.; Wasinger, E. C.; Stack, T. D. P. Nat. Chem. 2012, 4, 317-322.

(34) Jacobson, R. R.; Tyeklar, Z.; Farooq, A.; Karlin, K. D.; Liu, S.; Zubieta, J. J. Am. Chem. Soc. 1988, 110, 3690-3692.

(35) Baldwin, M. J.; Root, D. E.; Pate, J. E.; Fujisawa, K.; Kitajima, N.; Solomon, E. I. J. Am. Chem. Soc. 1992, 114, 10421-10431. 
(36) Halfen, J. A.; Mahapatra, S.; Wilkinson, E. C.; Kaderli, S.; Jr, V. G. Y.; Jr, L. Q.;

Zuberbuhler, A. D.; Tolman, W. B. Science 1996, 271, 1397-1400.

(37) Karlin, K. D.; Wei, N.; Jung, B.; Kaderli, S.; Zuberbuehler, A. D. J. Am. Chem. Soc. 1991, $113,5868-5870$.

(38) Karlin, K. D.; Wei, N.; Jung, B.; Kaderli, S.; Niklaus, P.; Zuberbuehler, A. D. J. Am. Chem. Soc. 1993, 115, 9506-9514.

(39) Fujisawa, K.; Tanaka, M.; Moro-oka, Y.; Kitajima, N. J. Am. Chem. Soc. 1994, 116, 12079-12080.

(40) Chen, P.; Root, D. E.; Campochiaro, C.; Fujisawa, K.; Solomon, E. I. J. Am. Chem. Soc. 2003, 125, 466-474.

(41) Würtele, C.; Gaoutchenova, E.; Harms, K.; Holthausen, M. C.; Sundermeyer, J.; Schindler, S. Angew. Chem. Int. Ed. 2006, 45, 3867-3869.

(42) Tano, T.; Okubo, Y.; Kunishita, A.; Kubo, M.; Sugimoto, H.; Fujieda, N.; Ogura, T.; Itoh, S. Inorg. Chem. 2013, 52, 10431-10437.

(43) Kunishita, A.; Ertem, M. Z.; Okubo, Y.; Tano, T.; Sugimoto, H.; Ohkubo, K.; Fujieda, N.; Fukuzumi, S.; Cramer, C. J.; Itoh, S. Inorg. Chem. 2012, 51, 9465-9480.

(44) Kunishita, A.; Kubo, M.; Sugimoto, H.; Ogura, T.; Sato, K.; Takui, T.; Itoh, S. J. Am. Chem. Soc. 2009, 131, 2788-2789.

(45) Kim, S.; Ginsbach, J. W.; Billah, A. I.; Siegler, M. A.; Moore, C. D.; Solomon, E. I.; Karlin, K. D. J. Am. Chem. Soc. 2014, 136, 8063-8071.

(46) Lucas, H. R.; Li, L.; Narducci Sarjeant, A. A.; Vance, M.; Solomon, E. I.; Karlin, K. D. J. Am. Chem. Soc. 2009, 131, 3230-3245.

(47) Maiti, D.; Woertink, J. S.; Narducci Sarjeant, A. A.; Solomon, E. I.; Karlin, K. D. Inorg. Chem. 2008, 47, 3787-3800.

(48) Wick, P. K.; Karlin, K. D.; Suzuki, M.; Zuberbühler, A. D. Micron 2004, 35, 137-139.

(49) Kieber-Emmons, M. T.; Ginsbach, J. W.; Wick, P. K.; Lucas, H. R.; Helton, M. E.; Lucchese, B.; Suzuki, M.; Zuberbühler, A. D.; Karlin, K. D.; Solomon, E. I. Angew. Chem. Int. Ed. 2014, 53, 4935-4939.

(50) Jung, B.; Karlin, K. D.; Zuberbühler, A. D. J. Am. Chem. Soc. 1996, 118, 3763-3764.

(51) Woertink, J. S.; Smeets, P. J.; Groothaert, M. H.; Vance, M. A.; Sels, B. F.; Schoonheydt, R. A.; Solomon, E. I. Proc. Natl. Acad. Sci. U. S. A. 2009, 106, 1890818913. 
(52) Groothaert, M. H.; van Bokhoven, J. A.; Battiston, A. A.; Weckhuysen, B. M.; Schoonheydt, R. A. J. Am. Chem. Soc. 2003, 125, 7629-7640.

(53) Groothaert, M. H.; Smeets, P. J.; Sels, B. F.; Jacobs, P. A.; Schoonheydt, R. A. J. Am. Chem. Soc. 2005, 127, 1394-1395.

(54) Smeets, P. J.; Hadt, R. G.; Woertink, J. S.; Vanelderen, P.; Schoonheydt, R. A.; Sels, B. F.; Solomon, E. I. J. Am. Chem. Soc. 2010, 132, 14736-14738.

(55) Hoffmann, A.; Citek, C.; Binder, S.; Goos, A.; Rübhausen, M.; Troeppner, O.; IvanovićBurmazović, I.; Wasinger, E. C.; Stack, T. D. P.; Herres-Pawlis, S. Angew. Chem. Int. Ed. 2013, 52, 5398-5401.

(56) Mirica, L. M.; Vance, M.; Rudd, D. J.; Hedman, B.; Hodgson, K. O.; Solomon, E. I.; Stack, T. D. P. Science 2005, 308, 1890-1892.

(57) Shiota, Y.; Yoshizawa, K. Inorg. Chem. 2009, 48, 838-845.

(58) Karlin, K. D.; Itoh, S.; Rokita, S. Copper-Oxygen Chemistry; Wiley, 2011.

(59) Peterson, R. L.; Himes, R. A.; Kotani, H.; Suenobu, T.; Tian, L.; Siegler, M. A.; Solomon, E. I.; Fukuzumi, S.; Karlin, K. D. J. Am. Chem. Soc. 2011, 133, 1702-1705.

(60) Maiti, D.; Lee, D.-H.; Gaoutchenova, K.; Würtele, C.; Holthausen, M. C.; Narducci Sarjeant, A. A.; Sundermeyer, J.; Schindler, S.; Karlin, K. D. Angew. Chem. Int. Ed. 2008, 47, 82-85.

(61) Maiti, D.; Fry, H. C.; Woertink, J. S.; Vance, M. A.; Solomon, E. I.; Karlin, K. D. J. Am. Chem. Soc. 2007, 129, 264-265.

(62) Donoghue, P. J.; Gupta, A. K.; Boyce, D. W.; Cramer, C. J.; Tolman, W. B. J. Am. Chem. Soc. 2010, 132, 15869-15871.

(63) Pirovano, P.; Magherusan, A. M.; McGlynn, C.; Ure, A.; Lynes, A.; McDonald, A. R. Angew. Chem. Int. Ed. 2014, 53, 5946-5950.

(64) Liang, H. C.; Karlin, K. D.; Dyson, R.; Kaderli, S.; Jung, B.; Zuberbühler, A. D. Inorg. Chem. 2000, 39, 5884-5894.

(65) Mahapatra, S.; Kaderli, S.; Llobet, A.; Neuhold, Y.; Palanché, T.; Halfen, J. A.; Young,, V. G.; Kaden, T. A.; Que,, L.; Zuberbühler, A. D.; Tolman, W. B. Inorg. Chem. 1997, 36, 6343-6356.

(66) Lee, D.; Wei, N.; Murthy, N. N.; Tyeklar, Z.; Karlin, K. D.; Kaderli, S.; Jung, B.; Zuberbuehler, A. D. J. Am. Chem. Soc. 1995, 117, 12498-12513.

(67) Börzel, H.; Comba, P.; Katsichtis, C.; Kiefer, W.; Lienke, A.; Nagel, V.; Pritzkow, H. Chem. - Eur. J. 1999, 5, 1716-1721. 
(68) Kodera, M.; Katayama, K.; Tachi, Y.; Kano, K.; Hirota, S.; Fujinami, S.; Suzuki, M. J. Am. Chem. Soc. 1999, 121, 11006-11007.

(69) Gavrilova, A. L.; Bosnich, B. Chem. Rev. 2004, 104, 349-383.

(70) Piñero, D.; Baran, P.; Boca, R.; Herchel, R.; Klein, M.; Raptis, R. G.; Renz, F.; Sanakis, Y. Inorg. Chem. 2007, 46, 10981-10989.

(71) Bauer-Siebenlist, B.; Meyer, F.; Farkas, E.; Vidovic, D.; Dechert, S. Chem. - Eur. J. 2005, 11, 4349-4360.

(72) Klingele, J.; Dechert, S.; Meyer, F. Coord. Chem. Rev. 2009, 253, 2698-2741.

(73) Burger, B.; Dechert, S.; Grosse, C.; Demeshko, S.; Meyer, F. Chem. Commun. 2011, 10428-10430.

(74) Burger, B.; Demeshko, S.; Bill, E.; Dechert, S.; Meyer, F. Angew. Chem. Int. Ed. 2012, 51, 10045-10049.

(75) Kryatov, S. V.; Rybak-Akimova, E. V.; Meyer, F.; Pritzkow, H. Eur. J. Inorg. Chem. 2003, 2003, 1581-1590.

(76) Meyer, F. Progress in Inorganic Chemistry; Karlin, K. D., Ed.; John Wiley \& Sons, Inc.: Hoboken, NJ, USA, 2009; Vol. 56, pp. 487-542.

(77) Buchler, S.; Meyer, F.; Kaifer, E.; Pritzkow, H. Inorg. Chim. Acta 2002, 337, 371-386.

(78) Ackermann, J.; Meyer, F.; Kaifer, E.; Pritzkow, H. Chem. - Eur. J. 2002, 8, 247-258.

(79) Ackermann, J.; Buchler, S.; Meyer, F. C. R. Chim. 2007, 10, 421-432.

(80) Bauer-Siebenlist, B.; Dechert, S.; Meyer, F. Chem. - Eur. J. 2005, 11, 5343-5352.

(81) Meyer, F. Eur. J. Inorg. Chem. 2006, 2006, 3789-3800.

(82) Wöckel, S.; Galezowska, J.; Dechert, S.; Meyer, F. Inorg. Chem. 2012, 51, 2486-2493.

(83) Müller, H.; Bauer-Siebenlist, B.; Csapo, E.; Dechert, S.; Farkas, E.; Meyer, F. Inorg. Chem. 2008, 47, 5278-5292.

(84) Prokofieva, A.; Prikhod'ko, A. I.; Enyedy, E. A.; Farkas, E.; Maringgele, W.; Demeshko, S.; Dechert, S.; Meyer, F. Inorg. Chem. 2007, 46, 4298-4307.

(85) Blusch, L. K.; Craigo, K. E.; Martin-Diaconescu, V.; McQuarters, A. B.; Bill, E.; Dechert, S.; DeBeer, S.; Lehnert, N.; Meyer, F. J. Am. Chem. Soc. 2013, 135, 13892-13899.

(86) Frensch, L. K.; Pröpper, K.; John, M.; Demeshko, S.; Brückner, C.; Meyer, F. Angew. Chem. Int. Ed. 2011, 50, 1420-1424. 
(87) Prokofieva, A.; Prikhod'ko, A. I.; Dechert, S.; Meyer, F. Chem. Commun. 2008, 10051007.

(88) Prokofieva, A.; Dechert, S.; Grosse, C.; Sheldrick, G. M.; Meyer, F. Chem. - Eur. J. 2009, 15, 4994-4997.

(89) Meyer, F.; Pritzkow, H. Angew. Chem. Int. Ed. 2000, 39, 2112-2115.

(90) Ackermann, J. Biomimetische Oxidationsreaktionen mit zweikernigen

Kupferpyrazolatkomplexen, Georg-August-Universität Göttingen, 2003, pp. 102-234.

(91) Buchler, S. Präorganisierte Zweikernkomplexe neuer Pyrazolat-

Kompartimentliganden, Ruprecht-Karls-Universität Heidelburg, 2002, pp. 32-241.

(92) Schenck, T. G.; Downes, J. M.; Milne, C. R. C.; Mackenzie, P. B.; Boucher, T. G.;

Whelan, J.; Bosnich, B. Inorg. Chem. 1985, 24, 2334-2337.

(93) Müller, H.; Bauer-Siebenlist, B.; Csapo, E.; Dechert, S.; Farkas, E.; Meyer, F. Inorg. Chem. 2008, 47, 5278-5292.

(94) Acerete, C.; Bueno, J. M.; Campayo, L.; Navarro, P.; Rodriguez-Franco, M. I.; Samat, A. Tetrahedron 1994, 50, 4765-4774.

(95) Röder, J. C.; Meyer, F.; Konrad, M.; Sandhöfner, S.; Kaifer, E.; Pritzkow, H. Eur. J. Org. Chem. 2001, 2001, 4479-4487.

(96) Röder, J. C.; Meyer, F.; Pritzkow, H. Organometallics 2001, 20, 811-817.

(97) Meyer, F.; Ruschewitz, U.; Schober, P.; Antelmann, B.; Zsolnai, L. J. Chem. Soc. Dalt. Trans. 1998, 1181-1186.

(98) Meyer, F.; Beyreuther, S.; Heinze, K.; Zsolnai, L. Chem. Ber. 1997, 130, 605-613.

(99) Halfen, J. A.; Tolman, W. B.; Weighardt, K. Inorg. Synth. 1998, 32, 75-81.

(100) White, D. W.; Karcher, B. A.; Jacobson, R. A.; Verkade, J. G. J. Am. Chem. Soc. 1979, 101, 4921-4925.

(101) Claramunt, R. M.; López, C.; Santa María, M. D.; Sanz, D.; Elguero, J. Prog. Nucl. Magn. Reson. Spectrosc. 2006, 49, 169-206.

(102) Aguilar-Parrilla, F.; Cativiela, C.; de Villegas, M. D. D.; Elguero, J.; Foces-Foces, C.; Laureiro, J. I. G.; Cano, F. H.; Limbach, H.; Smith, J. A. S.; Toiron, C. J. Chem. Soc. Perkin Trans. 2 1992, 3, 1737-1742.

(103) Schuster, I. I.; Dyllick-Brenzinger, C.; Roberts, J. D. J. Org. Chem. 1979, 44, 1765-1768.

(104) Chen, B. C.; Von Philipsborn, W.; Nagarajan, K. Helv. Chim. Acta 1983, 66, 1537-1555. 
(105) Hesse, M.; Meier, H.; Zeeh, B. Spektroskopische Methoden in der organischen Chemie; 5th ed.; Thieme, 1995; pp. 107,211-212.

(106) Faure, R.; Vincent, É.-J.; Rousseau, A.; Claramunt, R. M.; Elguero, J. Can. J. Chem. $1988,66,1141-1146$.

(107) Steiner, T. Angew. Chem. Int. Ed. 2002, 41, 49-76.

(108) Arunan, E.; Desiraju, G. R.; Klein, R. A.; Sadlej, J.; Scheiner, S.; Alkorta, I.; Clary, D. C.; Crabtree, R. H.; Dannenberg, J. J.; Hobza, P.; Kjaergaard, H. G.; Legon, A. C.; Mennucci, B.; Nesbitt, D. J. Pure Appl. Chem. 2011, 83, 1637-1641.

(109) Stewart, W. E.; Siddall, T. H. Chem. Rev. 1970, 70, 517-551.

(110) Gasparro, F. P.; Kolodny, N. H. J. Chem. Educ. 1977, 54, 258-261.

(111) Chenon, M. T.; Coupry, C.; Grant, D. M.; Pugmire, R. J. J. Org. Chem. 1977, 42, 659661.

(112) Burg, A.; Maimon, E.; Cohen, H.; Meyerstein, D. Eur. J. Inorg. Chem. 2007, 2007, 530536.

(113) Atkins, P. Shriver and Atkins' Inorganic Chemistry; Fifth.; OUP Oxford, 2010.

(114) Karlin, K. D.; Hayes, J. C.; Gultneh, Y.; Cruse, R. W.; McKown, J. W.; Hutchinson, J. P.; Zubieta, J. J. Am. Chem. Soc. 1984, 106, 2121-2128.

(115) Tyeklar, Z.; Jacobson, R. R.; Wei, N.; Murthy, N. N.; Zubieta, J.; Karlin, K. D. J. Am. Chem. Soc. 1993, 115, 2677-2689.

(116) Becker, M.; Heinemann, F. W.; Schindler, S. Chem. - Eur. J. 1999, 5, 3124-3129.

(117) Kang, P.; Bobyr, E.; Dustman, J.; Hodgson, K. O.; Hedman, B.; Solomon, E. I.; Stack, T. D. P. Inorg. Chem. 2010, 49, 11030-11038.

(118) Wei, N.; Murthy, N. N.; Tyeklar, Z.; Karlin, K. D. Inorg. Chem. 1994, 33, 1177-1183.

(119) Wei, N.; Murthy, N. N.; Chen, Q.; Zubieta, J.; Karlin, K. D. Inorg. Chem. 1994, 33, 19531965.

(120) Lee, Y.; Lee, D.-H.; Park, G. Y.; Lucas, H. R.; Narducci Sarjeant, A. A.; Kieber-Emmons, M. T.; Vance, M. A.; Milligan, A. E.; Solomon, E. I.; Karlin, K. D. Inorg. Chem. 2010, 49, 8873-8885.

(121) Lee, D.; Wei, N.; Murthy, N. N.; Tyeklar, Z.; Karlin, K. D.; Kaderli, S.; Jung, B.;

Zuberbuehler, A. D. J. Am. Chem. Soc. 1995, 117, 12498-12513. 
(122) Haack, P.; Kärgel, A.; Greco, C.; Dokic, J.; Braun, B.; Pfaff, F. F.; Mebs, S.; Ray, K.; Limberg, C. J. Am. Chem. Soc. 2013, 135, 16148-16160.

(123) Tepper, A. W. J. W.; Bubacco, L.; Canters, G. W. J. Biol. Chem. 2002, 277, 3043630444.

(124) Mealli, C.; Arcus, C. S.; Wilkinson, J. L.; Marks, T. J.; Ibers, J. A. J. Am. Chem. Soc. 1976, 98, 711-718.

(125) Zhang, C. X.; Kaderli, S.; Costas, M.; Kim, E.-I.; Neuhold, Y.-M.; Karlin, K. D.; Zuberbühler, A. D. Inorg. Chem. 2003, 42, 1807-1824.

(126) Carrier, S. M.; Ruggiero, C. E.; Houser, R. P.; Tolman, W. B. Inorg. Chem. 1993, 32, 4889-4899.

(127) Mohamed, A. A. Coord. Chem. Rev. 2010, 254, 1918-1947.

(128) Halcrow, M. A. Dalton Trans. 2009, 9226, 2059-2073.

(129) Viciano-Chumillas, M.; Tanase, S.; de Jongh, L. J.; Reedijk, J. Eur. J. Inorg. Chem. 2010, 2010, 3403-3418.

(130) Singh, K.; Long, J. R.; Stavropoulos, P. Inorg. Chem. 1998, 37, 1073-1079.

(131) Stollenz, M.; John, M.; Gehring, H.; Dechert, S.; Grosse, C.; Meyer, F. Inorg. Chem. 2009, 48, 10049-10059.

(132) Stollenz, M.; Gehring, H.; Konstanzer, V.; Fischer, S.; Dechert, S.; Grosse, C.; Meyer, F. Organometallics 2011, 30, 3708-3725.

(133) Scheele, U. J.; Georgiou, M.; John, M.; Dechert, S.; Meyer, F. Organometallics 2008, $27,5146-5151$.

(134) Konstanzer, V. Multinuclear Pyrazolate-Based Copper Complexes Inspired by the CuZSite of N2O-Reductase, Georg-August-Universität Göttingen, 2011, pp. 88-183.

(135) Veronelli, M.; Kindermann, N.; Dechert, S.; Meyer, S.; Meyer, F. Inorg. Chem. 2014, 53, 2333-2341.

(136) Müller, H.; Bauer-Siebenlist, B.; Csapo, E.; Dechert, S.; Farkas, E.; Meyer, F. Inorg. Chem. 2008, 47, 5278-5292.

(137) Sakamoto, S.; Fujita, M.; Kim, K.; Yamaguchi, K. Tetrahedron 2000, 56, 955-964.

(138) Yamaguchi, K. J. Mass Spectrom. 2003, 38, 473-490.

(139) Miras, H. N.; Wilson, E. F.; Cronin, L. Chem. Commun. 2009, 1297-1311. 
(140) Zanello, P. Inorganic Electrochemistry; Royal Society of Chemistry: Cambridge, 2003; pp. 152-152.

(141) Kim, C. W.; Ahn, J.; Kim, S. M.; Noh, T. H.; Jung, O.-S. Trans. Met. Chem. 2011, 36, 545-551.

(142) Borzel, H.; Comba, P.; Hagen, K.; Katsichtis, C.; Pritzkow, H. Chem. - Eur. J. 2000, 6, 914-919.

(143) Weitzer, M.; Schatz, M.; Hampel, F.; Heinemann, F. W.; Schindler, S. J. Chem. Soc. Dalt. Trans. 2002, 686-694.

(144) Berman, H. A.; Yeh, H. J. C.; Stengle, T. R. J. Phys. Chem. 1975, 79, 2551-2555.

(145) Berman, H. A.; Stengle, T. R. J. Phys. Chem. 1975, 79, 1001-1005.

(146) Mishustin, A. I. Russ. J. Inorg. Chem. 2013, 58, 684-690.

(147) Nicolas, M.; Reich, R. J. Phys. Chem. 1979, 83, 749-756.

(148) Yamaguchi, K.; Sakamoto, S. JEOL News. 2002, pp. 2-5.

(149) Berreau, L. M.; Halfen, J. A.; Young, V. G.; Tolman, W. B. Inorg. Chim. Acta 2000, 297, 115-128.

(150) Mahadevan, V.; Henson, M. J.; Solomon, E. I.; Stack, T. D. P. J. Am. Chem. Soc. 2000, $122,10249-10250$.

(151) Ottenwaelder, X.; Rudd, D. J.; Corbett, M. C.; Hodgson, K. O.; Hedman, B.; Stack, T. D. P. J. Am. Chem. Soc. 2006, 128, 9268-9269.

(152) Carrier, S. M.; Ruggiero, C. E.; Houser, R. P.; Tolman, W. B. Inorg. Chem. 1993, 32, 4889-4899.

(153) Obias, H. V; Lin, Y.; Murthy, N. N.; Pidcock, E.; Solomon, E. I.; Ralle, M.; Blackburn, N. J.; Neuhold, Y.; Zuberbühler, A. D.; Karlin, K. D. J. Am. Chem. Soc. 1998, 120, 1296012961.

(154) Jacobson, R. R.; Tyeklar, Z.; Karlin, K. D.; Zubieta, J. Inorg. Chem. 1991, 30, 2035-2040.

(155) Lee, Y.; Park, G. Y.; Lucas, H. R.; Vajda, P. L.; Kamaraj, K.; Vance, M. a; Milligan, A. E.; Woertink, J. S.; Siegler, M. A.; Narducci Sarjeant, A. A.; Zakharov, L. N.; Rheingold, A. L.; Solomon, E. I.; Karlin, K. D. Inorg. Chem. 2009, 48, 11297-11309.

(156) Garcia-Bosch, I.; Company, A.; Frisch, J. R.; Torrent-Sucarrat, M.; Cardellach, M.; Gamba, I.; Güell, M.; Casella, L.; Que, L.; Ribas, X.; Luis, J. M.; Costas, M. Angew. Chem. Int. Ed. 2010, 49, 2406-2409. 
(157) Würtele, C.; Heinemann, F. W.; Schindler, S. J. Coord. Chem. 2010, 63, 2629-2641.

(158) Weitzer, M.; Schindler, S.; Brehm, G.; Schneider, S.; Hörmann, E.; Jung, B.; Kaderli, S.; Zuberbühler, A. D. Inorg. Chem. 2003, 42, 1800-1806.

(159) Komiyama, K.; Furutachi, H.; Nagatomo, S.; Hashimoto, A.; Hayashi, H.; Fujinami, S.; Suzuki, M.; Kitagawa, T. Bull. Chem. Soc. Jpn. 2004, 77, 59-72.

(160) Karlin, K. D.; Wei, N.; Jung, B.; Kaderli, S.; Niklaus, P.; Zuberbuehler, A. D. J. Am. Chem. Soc. 1993, 115, 9506-9514.

(161) Lee, D.; Wei, N.; Murthy, N. N.; Tyeklar, Z.; Karlin, K. D.; Kaderli, S.; Jung, B.; Zuberbuehler, A. D. J. Am. Chem. Soc. 1995, 117, 12498-12513.

(162) Comba, P.; Haaf, C.; Helmle, S.; Karlin, K. D.; Pandian, S.; Waleska, A. Inorg. Chem. 2012, 51, 2841-2851.

(163) Pidcock, E.; Obias, H. V.; Zhang, C. X.; Karlin, K. D.; Solomon, E. I. J. Am. Chem. Soc. 1998, 120, 7841-7847.

(164) Weitzer, M.; Schindler, S.; Brehm, G.; Schneider, S.; Hörmann, E.; Jung, B.; Kaderli, S.; Zuberbühler, A. D. Inorg. Chem. 2003, 42, 1800-1806.

(165) Karlin, K. D.; Lee, D.-H.; Kaderli, S.; Zuberbühler, A. D. Chem. Commun. 1997, 475476.

(166) Henson, M. J.; Vance, M. A.; Zhang, C. X.; Liang, H.-C.; Karlin, K. D.; Solomon, E. I. J. Am. Chem. Soc. 2003, 125, 5186-5192.

(167) Lee, D.-H.; Hatcher, L. Q.; Vance, M. a; Sarangi, R.; Milligan, A. E.; Narducci Sarjeant, A. A. N.; Incarvito, C. D.; Rheingold, A. L.; Hodgson, K. O.; Hedman, B.; Solomon, E. I.; Karlin, K. D. Inorg. Chem. 2007, 46, 6056-6068.

(168) Maiti, D.; Woertink, J. S.; Vance, M. A.; Milligan, A. E.; Narducci Sarjeant, A. A.; Solomon, E. I.; Karlin, K. D. J. Am. Chem. Soc. 2007, 129, 8882-8892.

(169) Comba, P.; Haaf, C.; Helmle, S.; Karlin, K. D.; Pandian, S.; Waleska, A. Inorg. Chem. 2012, 51, 2841-2851.

(170) Halfen, J. A.; Mahapatra, S.; Wilkinson, E. C.; Kaderli, S.; Young, V. G.; Que, L.; Zuberbühler, A. D.; Tolman, W. B. Science 1996, 271, 1397-1400.

(171) Keller, B. O.; Sui, J.; Young, A. B.; Whittal, R. M. Anal. Chim. Acta 2008, 627, 71-81.

(172) Greenberg, M. S.; Popov, A. I. J. Solution Chem. 1976, 5, 653-665.

(173) Miller, A. G.; Macklin, J. W. J. Phys. Chem. 1985, 89, 1193-1201. 
(174) Miller, A. G.; Franz, J. A.; Macklin, J. W. J. Phys. Chem. 1985, 89, 1190-1193.

(175) Burger, B. Structure, Dynamics and Bioinspired Reactivity of Novel Pyrazolate-based Diiron Complexes, Georg-August-Universität Göttingen, p. 2012.

(176) Di Marco, V. B.; Bombi, G. G. Mass Spectrom. Rev. 2006, 25, 347-379.

(177) Jacobson, R. R.; Tyeklar, Z.; Farooq, A.; Karlin, K. D.; Liu, S.; Zubieta, J. J. Am. Chem. Soc. 1988, 110, 3690-3692.

(178) Addison, A. W.; Rao, T. N.; Reedijk, J.; van Rijn, J.; Verschoor, G. C. J. Chem. Soc. Dalt. Trans. 1984, 1349-1356.

(179) Liu, Q.-X.; Zhou, Z.-H. Polyhedron 2012, 35, 1-6.

(180) Uhl, W.; Halvagar, M. R.; Rogel, F.; Massa, W. Eur. J. Inorg. Chem. 2009, 2009, 489492.

(181) Grzywa, M.; Nitek, W.; Łasocha, W. J. Mol. Struct. 2008, 888, 318-326.

(182) Runde, W.; Brodnax, L. F.; Goff, G. S.; Peper, S. M.; Taw, F. L.; Scott, B. L. Chem. Commun. 2007, 1728-1729.

(183) Kennedy, A. R.; Mulvey, R. E.; Roberts, B. A.; Rowlings, R. B.; Raston, C. L. Chem. Commun. 1999, 353-354.

(184) Gabriel, C.; Kaliva, M.; Venetis, J.; Baran, P.; Rodriguez-Escudero, I.; Voyiatzis, G.; Zervou, M.; Salifoglou, A. Inorg. Chem. 2009, 48, 476-487.

(185) Yao, S.; Xiong, Y.; Vogt, M.; Grützmacher, H.; Herwig, C.; Limberg, C.; Driess, M. Angew. Chem. Int. Ed. 2009, 48, 8107-8110.

(186) Forbes, G. C.; Kennedy, A. R.; Mulvey, R. E.; Rowlings, R. B.; Clegg, W.; Liddle, S. T.; Wilson, C. C. Chem. Commun. 2000, 1759-1760.

(187) Chen, W.-J.; Yu, D.-H.; Xiao, X.; Zhang, Y.-Q.; Zhu, Q.-J.; Xue, S.-F.; Tao, Z.; Wei, G. Inorg. Chem. 2011, 50, 6956-6964.

(188) Erhardt, S.; Grushin, V. V; Kilpatrick, A. H.; Macgregor, S. a; Marshall, W. J.; Roe, D. C. J. Am. Chem. Soc. 2008, 130, 4828-4845.

(189) Jones, G. M.; Arnold, P. L.; Love, J. B. Angew. Chem. Int. Ed. 2012, 51, 12584-12587.

(190) Ross, P. K.; Solomon, E. I. J. Am. Chem. Soc. 1991, 113, 3246-3259.

(191) Baldwin, M. J.; Ross, P. K.; Pate, J. E.; Tyeklar, Z.; Karlin, K. D.; Solomon, E. I. J. Am. Chem. Soc. 1991, 113, 8671-8679. 
(192) Karlin, K. D.; Tyeklár, Z.; Farooq, A.; Jacobson, R. R.; Sinn, E.; Lee, D. W.; Bradshaw, J. E.; Wilson, L. J. Inorg. Chim. Acta 1991, 182, 1-3.

(193) Solomon, E. I.; Dooley, D. M.; Wang, R.-H.; Gray, H. B.; Cerdonio, M.; Mogno, F.; Romani, G. L. J. Am. Chem. Soc. 1976, 98, 1029-1031.

(194) Driessen, W. L.; Chang, L.; Finazzo, C.; Gorter, S.; Rehorst, D.; Reedijk, J.; Lutz, M.; Spek, A. L. Inorg. Chim. Acta 2003, 350, 25-31.

(195) Iskander, M. F.; Khalil, T. E.; Haase, W.; Werner, R.; Svoboda, I.; Fuess, H. Polyhedron 2001, 20, 2787-2798.

(196) Prokofieva, A.; Prikhod'ko, A. I.; Enyedy, E. A.; Farkas, E.; Maringgele, W.; Demeshko, S.; Dechert, S.; Meyer, F. Inorg. Chem. 2007, 46, 4298-4307.

(197) Leibeling, G.; Demeshko, S.; Dechert, S.; Meyer, F. Angew. Chem. Int. Ed. 2005, 44, 7111-7114.

(198) Schenker, R.; Kieber-Emmons, M. T.; Riordan, C. G.; Brunold, T. C. Inorg. Chem. 2005, $44,1752-1762$.

(199) Hatcher, L. Q.; Lee, D.-H.; Vance, M. A.; Milligan, A. E.; Sarangi, R.; Hodgson, K. O.; Hedman, B.; Solomon, E. I.; Karlin, K. D. Inorg. Chem. 2006, 45, 10055-10057.

(200) Park, J.; Morimoto, Y.; Lee, Y.-M.; You, Y.; Nam, W.; Fukuzumi, S. Inorg. Chem. 2011, 50, 11612-11622.

(201) Park, J.; Morimoto, Y.; Lee, Y.; Nam, W.; Fukuzumi, S. J. Am. Chem. Soc. 2011, 133, 5236-5239.

(202) Chen, J.; Lee, Y.-M.; Davis, K. M.; Wu, X.; Seo, M. S.; Cho, K.-B.; Yoon, H.; Park, Y. J.; Fukuzumi, S.; Pushkar, Y. N.; Nam, W. J. Am. Chem. Soc. 2013, 135, 6388-6391.

(203) Fukuzumi, S.; Morimoto, Y.; Kotani, H.; Naumov, P.; Lee, Y.-M.; Nam, W. Nat. Chem. 2010, 2, 756-759.

(204) Leeladee, P.; Baglia, R. A.; Prokop, K. A.; Latifi, R.; de Visser, S. P.; Goldberg, D. P. J. Am. Chem. Soc. 2012, 134, 10397-10400.

(205) Morimoto, Y.; Kotani, H.; Park, J.; Lee, Y.-M.; Nam, W.; Fukuzumi, S. J. Am. Chem. Soc. 2011, 133, 403-405.

(206) Lee, Y.-M.; Bang, S.; Kim, Y. M.; Cho, J.; Hong, S.; Nomura, T.; Ogura, T.; Troeppner, O.; Ivanović-Burmazović, I.; Sarangi, R.; Fukuzumi, S.; Nam, W. Chem. Sci. 2013, 4, 3917.

(207) Atkins, P. Shriver and Atkins' Inorganic Chemistry; OUP Oxford, 2010; p. 59,497. 
(208) Behrens, U.; Hoffmann, F.; Olbrich, F. Organometallics 2012, 31, 905-913.

(209) Schiavo, S.; Fuoss, R. M.; Marrosu, G. J. Solution Chem. 1980, 9, 563-579.

(210) McHale, J. L. In Handbook of Vibrational Spectroscopy; John Wiley \& Sons, Ltd, 2006; pp. 535-556.

(211) Tuschel, D. D.; Mikhonin, A. V; Lemoff, B. E.; Asher, S. A. Appl. Spectrosc. 2010, 64, 425-432.

(212) Rocher, N. M.; Frech, R. Macromolecules 2005, 38, 10561-10565.

(213) Chachiyo, T.; Rodriguez, J. H. Dalton Trans. 2012, 41, 995-1003.

(214) Tinberg, C. E.; Lippard, S. J. Acc. Chem. Res. 2011, 44, 280-288.

(215) Dooley, D. M.; Scott, R. A.; Ellinghaus, J.; Solomon, E. I.; Gray, H. B. Proc. Natl. Acad. Sci. U. S. A. 1978, 75, 3019-3022.

(216) Shaik, S.; Chen, H.; Janardanan, D. Nat. Chem. 2011, 3, 19-27.

(217) Comba, P.; Martin, B.; Muruganantham, A.; Straub, J. Inorg. Chem. 2012, 51, $9214-$ 9225.

(218) Mahapatra, S.; Halfen, J. A.; Wilkinson, E. C.; Pan, G.; Wang, X.; Young, V. G.; Cramer, C. J.; Que,, L.; Tolman, W. B. J. Am. Chem. Soc. 1996, 118, 11555-11574.

(219) Meyer, F.; Rutsch, P. Chem. Commun. 1998, 1037-1038.

(220) Meyer, F.; Kaifer, E.; Kircher, P.; Heinze, K.; Pritzkow, H. Chem. - Eur. J. 1999, 5, 16171630.

(221) Gomila, A.; Le Poul, N.; Kerbaol, J.-M.; Cosquer, N.; Triki, S.; Douziech, B.; Conan, F.; Le Mest, Y. Dalton Trans. 2013, 42, 2238-2253.

(222) Gregg, D. C.; Nelson, J. M. J. Am. Chem. Soc. 1940, 62, 2500-2505.

(223) Espin, J. C.; Morales, M.; Varon, R.; Tudela, J.; Garcia-Canovas, F. J. Agric. Food Chem. 1995, 43, 2807-2812.

(224) Halfen, J. A.; Young, V. G.; Tolman, W. B. J. Am. Chem. Soc. 1996, 118, 10920-10921.

(225) Garcia-Bosch, I.; Company, A.; Frisch, J. R.; Torrent-Sucarrat, M.; Cardellach, M.; Gamba, I.; Güell, M.; Casella, L.; Que, L.; Ribas, X.; Luis, J. M.; Costas, M. Angew. Chem. Int. Ed. 2010, 122, 2456-2459.

(226) Wagner, M.; Limberg, C.; Tietz, T. Chem. - Eur. J. 2009, 15, 5567-5576. 
(227) Gentschev, P.; Möller, N.; Krebs, B. Inorg. Chim. Acta 2000, 300-302, 442-452.

(228) Bodini, M. E.; Copia, G.; Robinson, R.; Sawyer, D. T. Inorg. Chem. 1983, 22, 126-129.

(229) Benelli, C.; Dei, A.; Gatteschi, D.; Pardi, L. Inorg. Chem. 1989, 28, 1476-1480.

(230) Griffith, W. P. Trans. Met. Chem. 1993, 18, 250-256.

(231) Ladd, J. A.; Olmstead, M. M.; Balch, A. L. Inorg. Chem. 1984, 23, 2318-2323.

(232) Balch, A. L. J. Am. Chem. Soc. 1973, 95, 2723-2724.

(233) Stallings, M. D.; Morrison, M. M.; Sawyer, D. T. Inorg. Chem. 1981, 20, 2655-2660.

(234) Thompson, J. S.; Calabrese, J. C. Inorg. Chem. 1985, 24, 3167-3171.

(235) Harmalker, S.; Jones, S. E.; Sawyer, D. T. Inorg. Chem. 1983, 22, 2790-2794.

(236) Brown, D. G.; Hughes, W. J.; Knerr, G. Inorg. Chim. Acta 1980, 46, 123-126.

(237) Wang, K.; Mayer, J. M. J. Am. Chem. Soc. 1997, 119, 1470-1471.

(238) Fujii, T.; Yamaguchi, S.; Hirota, S.; Masuda, H. Dalton Trans. 2008, 164.

(239) Russell, G. A.; Janzen, E. G.; Strom, E. T. J. Am. Chem. Soc. 1962, 84, 4155-4157.

(240) Hawthorne, J. O.; Schowalter, K. A.; Sime, A. W. In Oxidation of Organic Compounds; 1968; pp. 203-215.

(241) Russell, G. A.; Janzen, E. G.; Bemis, A. G.; Geels, E. J.; Moye, A. J.; Mak, S.; Strom, E. T. In Selective Oxidation Processes; 1965.

(242) Osa, T.; Ohkatsu, Y.; Tezuka, M. Chem. Lett. 1973, 99-102.

(243) Kaim, W. Dalton Trans. 2003, 2002, 761-768.

(244) Pratt, R. C.; Stack, T. D. P. Inorg. Chem. 2005, 44, 2367-2375.

(245) Burfield, D. R.; Smithers, R. H. J. Org. Chem. 1978, 43, 3966-3968.

(246) Badiei, Y. M.; Warren, T. H.; Chiang, K. P.; Holland, P. L. Inorg. Synth. 2010, 28, 50-53.

(247) Kubas, G. J.; Monzyk, B.; Crumbliss, A. L. Inorg. Synth. 1990, 28, 68-70.

(248) Haack, P.; Limberg, C.; Ray, K.; Braun, B.; Kuhlmann, U.; Hildebrandt, P.; Herwig, C. Inorg. Chem. 2011, 50, 2133-2142. 
(249) Crandall, J. K.; Zucco, M.; Kirsch, R. S.; Coppert, D. M. Tetrahedron Lett. 1991, 32, 5441-5444.

(250) Meyer, F.; Ruschewitz, U.; Schober, P.; Antelmann, B.; Zsolnai, L. J. Chem. Soc. Dalt. Trans. 1998, 1181-1186.

(251) Lide, D. R.; Baysinger, G.; Berger, L. I.; Goldberg, R. N.; Kehiaian, H. V; Kuchitsu, K.; Rosenblatt, G.; Roth, D. L.; Zwillinger, D. In CRC Handbook of Chemistry and Physics; 2005; pp. 6-187.

(252) Thordarson, P. Chem. Soc. Rev. 2011, 40, 1305-1323. 


\section{Structures of Ligands, Ligand Precursors, and Sodium Complexes}

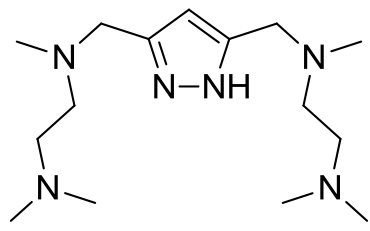

$\mathrm{HL}^{1}$

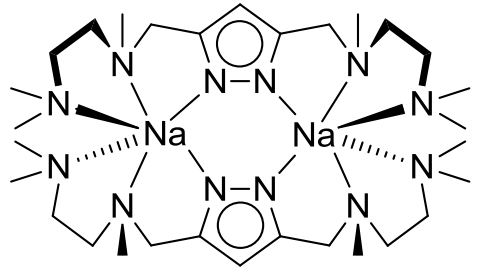

$\left[\mathrm{NaL}^{1}\right]$<smiles>CCN(CC)CCN(CC)CCN(CC)CCN(CC)CC</smiles>

${ }^{A m d} H_{L}{ }^{2}$

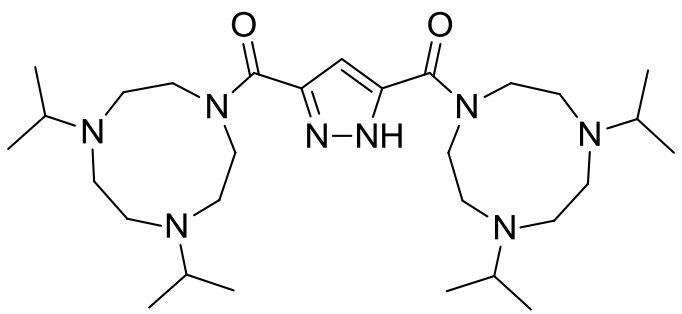

${ }^{A m d} H_{L^{3}}$

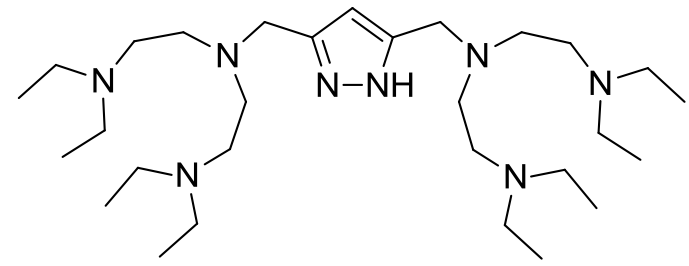

$\mathrm{HL}^{2}$

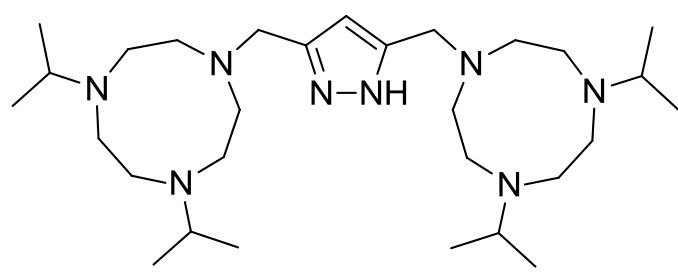

$H L^{3}$

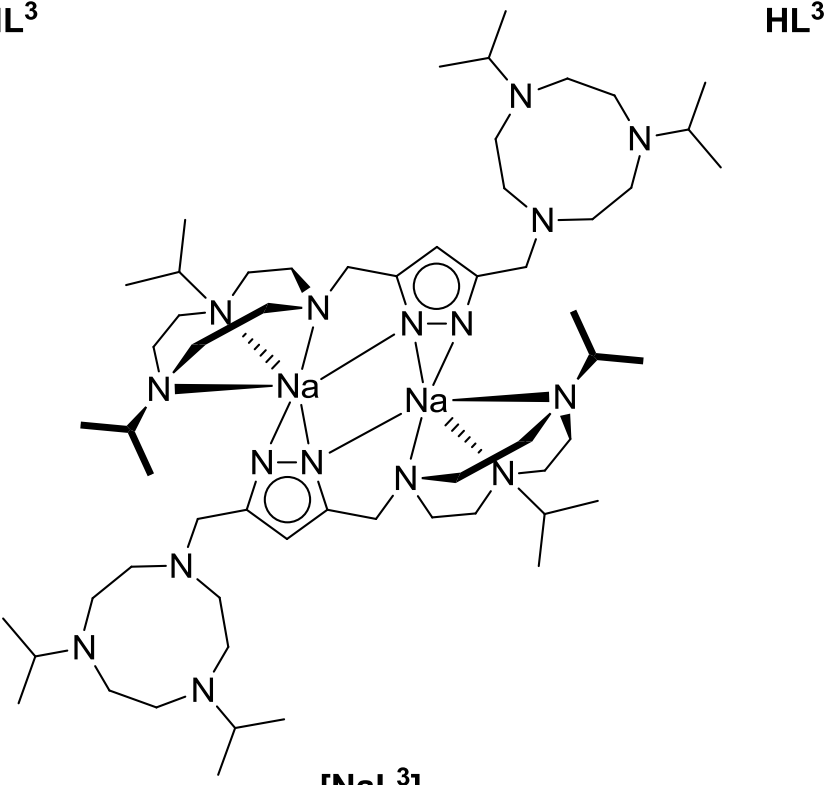

$\left[\mathrm{NaL}^{3}\right]$

Scheme A.1: Structures of ligand precursors, ligands, and sodium complexes. 


\section{Structures of Copper Complexes}

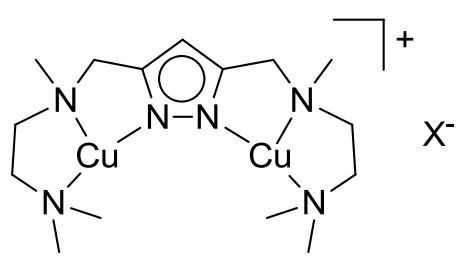

$\left[\mathrm{Cu}_{2}^{\mathrm{I}} \mathrm{L}^{1}\right]^{\mathrm{X}}+\mathrm{MX}$

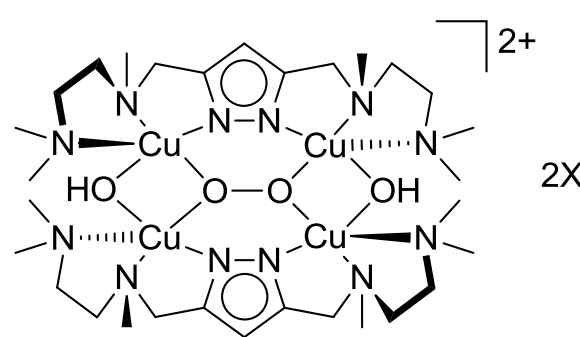

$\left[\left(\mathrm{Cu}_{2}{ }_{2} \mathrm{~L}^{1}\right)_{2}\left(\mathrm{O}_{2}\right)(\mathrm{OH})_{2}\right]^{\mathrm{X}}$

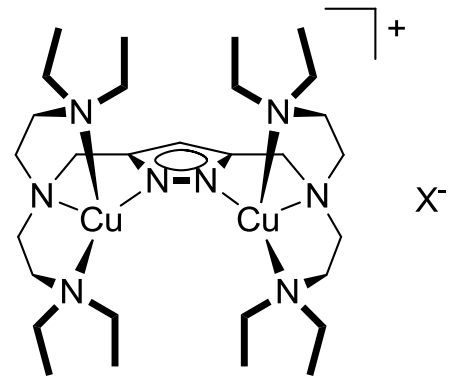

$\left[\mathrm{Cu}_{2}{ }^{\mathrm{L}}{ }^{2}\right]^{\mathrm{X}}+\mathrm{MX}$

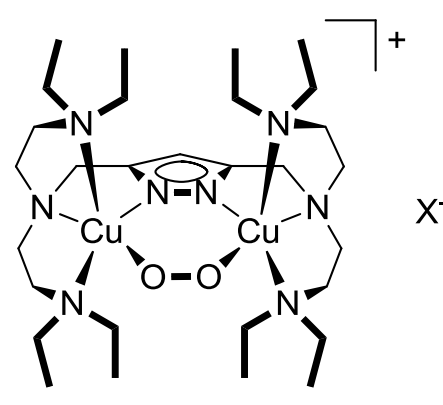

$\left[\mathrm{Cu}^{\prime \prime}{ }_{2} \mathrm{~L}^{2}\left(\mathrm{O}_{2}\right)\right]^{\mathrm{X}}+\mathrm{MX}$

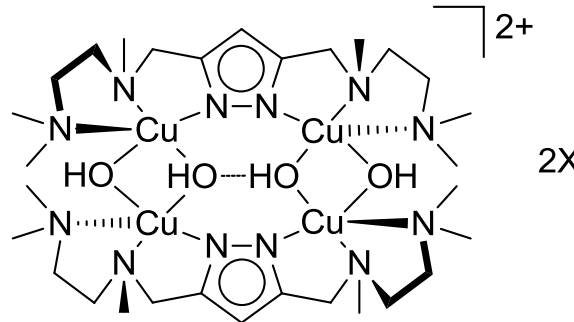

$\left[\left(\mathrm{Cu}_{2} \mathrm{~L}^{1}\right)_{2}(\mathrm{OH})_{4}\right]^{\mathrm{X2}}$

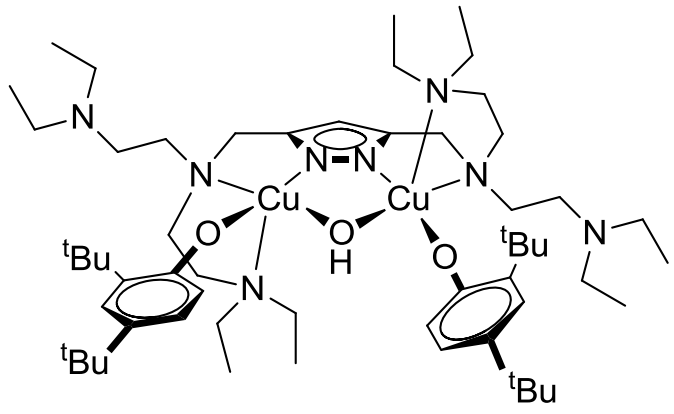

$\left[\mathrm{Cu}_{2}{ }_{2} \mathrm{~L}^{2}(\mathrm{OH})(\mathrm{DTBP})_{2}\right]$

Scheme A.2: Structures of copper complexes investigated in the current work. The tetranuclear species were crystallographically characterised previously, as $\mathrm{PF}_{6}^{-}$salts. $\mathrm{M}=\mathrm{Na}+$ or $\mathrm{K}+, \mathrm{X}=\mathrm{PF}_{6}^{-}, \mathrm{BF}_{4}^{-}, \mathrm{ClO}_{4}^{-}, \mathrm{OTf}^{-}$. 


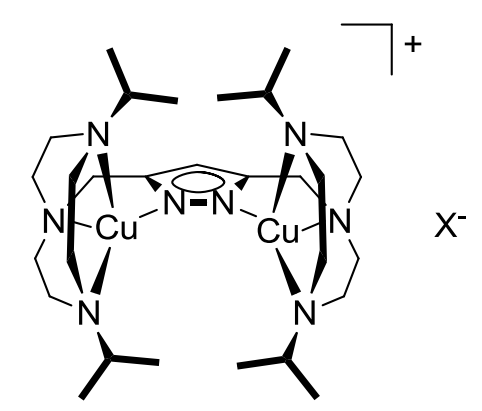

$\left[\mathrm{Cu}_{2}{ }_{2} \mathrm{~L}^{3}\right]^{\mathrm{X}}+\mathrm{MX}$

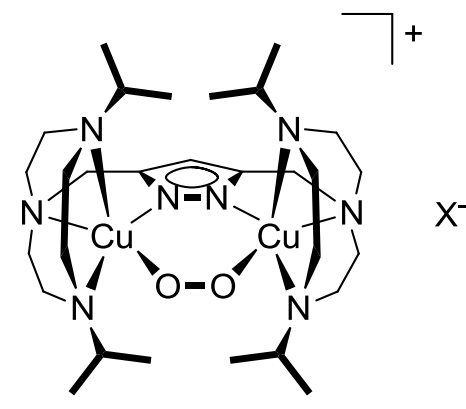

$\left[\mathrm{Cu}_{2}{ }_{2} \mathrm{~L}^{3}\left(\mathrm{O}_{2}\right)\right]^{\mathrm{X}}+\mathrm{MX}$

$\longrightarrow 2+$
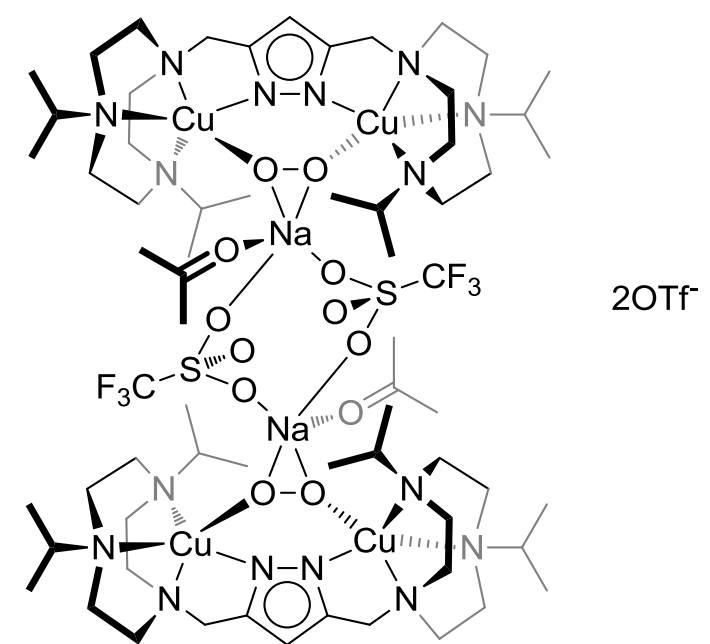

$\left[\mathrm{Cu}_{2}{ }_{2} \mathrm{~L}^{3}\left(\mathrm{O}_{2}\right)\right]^{\mathrm{OTf}} \cdot \mathrm{NaOTf}$

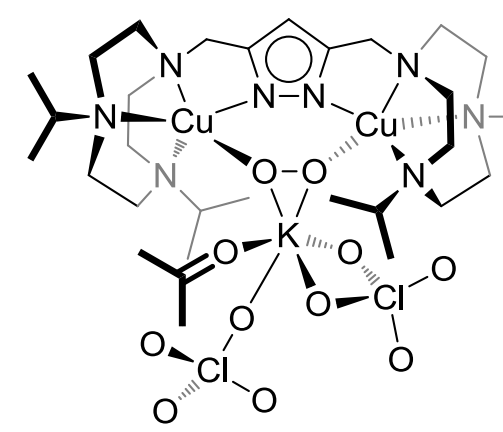

$\left[\mathrm{Cu}_{2}{ }_{2} \mathrm{~L}^{3}\left(\mathrm{O}_{2}\right)\right]^{\mathrm{ClO} 4} \cdot \mathrm{KClO}_{4}$
$\left[\mathrm{Cu}_{2} \mathrm{~L}^{3}\left(\mathrm{O}_{2}\right)\right]^{\mathrm{OTf}} \cdot \mathrm{KOTf}$
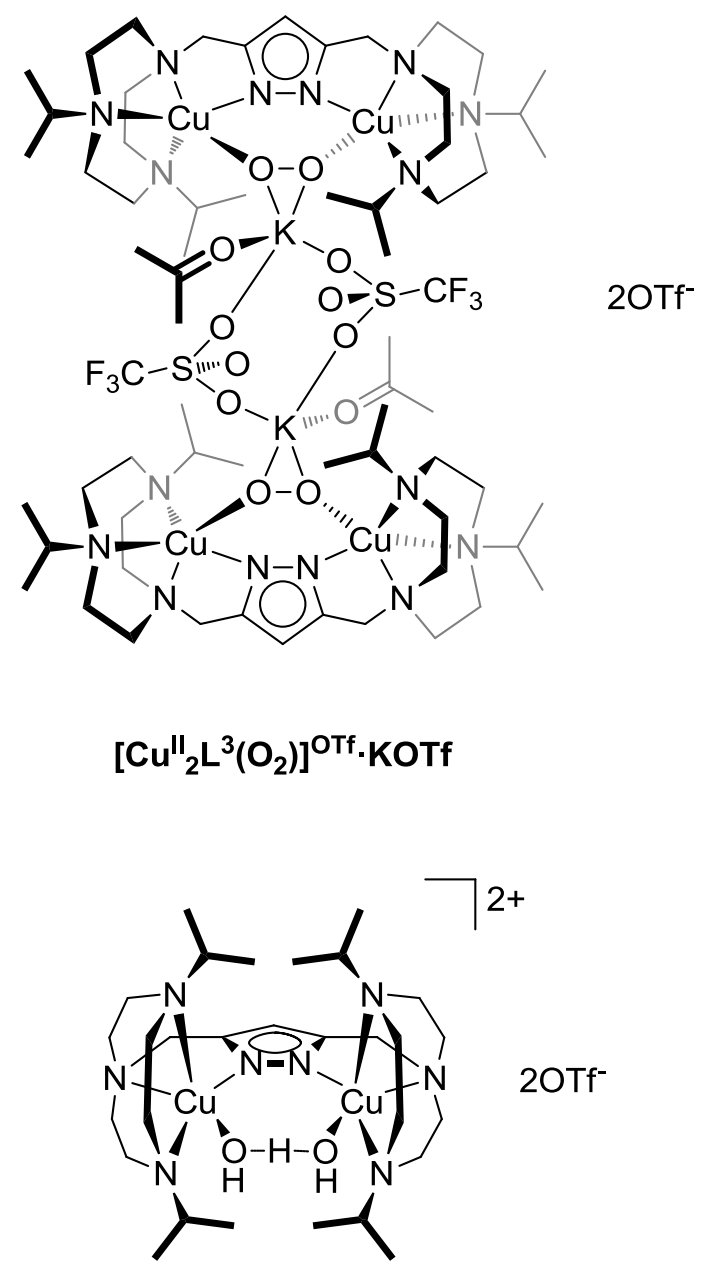

$\left[\mathrm{Cu}_{2} \mathrm{~L}^{3}\left(\mathrm{H}_{3} \mathrm{O}_{2}\right)\right]^{(\mathrm{OTf}) 2}$

Scheme A.3: Structures of copper complexes. 


\section{List of Scientific Contributions}

\section{Publications}

Dalle, K.E.; Gruene, T.; Dechert, S.; Demeshko, S.; Meyer, F.; "Weakly Coupled Biologically Relevant $\mathrm{Cu}(\mathrm{II})_{2}\left(\mu-\eta^{1}: \eta^{1}-\mathrm{O}_{2}\right)$ cis-Peroxo Adduct that Binds Side-On to Additional Metal Ions", J. Am. Chem. Soc. 2014, 136, 7428-7434.

Dalle, K.E.; Daumann, L.J.; Schenk, G.; McGeary, R.P.; Hanton, L.R.; Gahan, L.R.; "Ligand modifications modulate the mechanism of binuclear phosphatase biomimetics", Polyhedron 2013, 52, 1336-1343.

Daumann, L. J.; Dalle, K. E.; Schenk, G.; McGeary, R. P.; Bernhardt, P. V.; Ollis, D. L.; Gahan, L. R.; "The role of $\mathrm{Zn}-\mathrm{OR}$ and $\mathrm{Zn}-\mathrm{OH}$ nucleophiles and the influence of para-substituents in the reactions of binuclear phosphatase mimetics", Dalton Trans. 2012, 41, 1695-1708.

Hayes, A.; Piggott, A.; Dalle, K.; Capon R.; "Microbial biotransformation as a source of chemical diversity in cane toad steroid toxins", Bioorg. Med. Chem. Lett. 2009, 19, 17901792.

\section{Presentations at Conferences and International Workshops}

Dalle, K.E.; "Bioinspired Activation of Oxygen: A Novel Peroxo-Dicopper(II) Adduct", Koordinationschemie Tagung, Kaiserslautern, Germany, March 2014.

Dalle, K.E.; "Bioinspired Activation of Oxygen with Bimetallic Copper Complexes", Meeting of the Chemistry and Molecular Sciences and Technologies Action CM1003 "Biological oxidation reactions - mechanisms and design of new catalysts", Mainz, Germany, May 2013.

Dalle, K.E.; "Bioinspired Activation of Oxygen with Bimetallic Copper Complexes", EFI-IRTG Joint Workshop, Homburg (Hülsa), Germany, May 2013.

\section{Posters at Conferences and International Workshops}

Dalle, K.E.; "Bioinspired Activation of Oxygen with Bimetallic Copper Complexes", Meeting of the Chemistry and Molecular Sciences and Technologies Action CM1003 "Biological oxidation reactions - mechanisms and design of new catalysts", Mainz, Germany, May 2013.

Dalle, K.E.; "Bioinspired Activation of Oxygen with Bimetallic Copper Complexes", 7th Joint Workshop of the International Research Training Group 1422 "Metals Sites in Biomolecules: Structures, Regulation and Mechanisms" and the Emerging Fields Initiative "Medicinal Redox Inorganic Chemistry", Homburg (Hülsa), Germany, May 2013. 
Dalle, K.E.; "Bioinspired Activation of Dioxygen with Pyrazolate-Based Bimetallic Copper Complexes", 11th European Biological Inorganic Chemistry Conference (EuroBIC 11)", Granada, Spain, September 2012.

Dalle, K.E.; "Bioinspired Activation of Dioxygen with Pyrazolate-Based Bimetallic Copper Complexes", 7th Joint Workshop of the International Research Training Group 1422 "Metals Sites in Biomolecules: Structures, Regulation and Mechanisms" and the DFG Forschergruppe 1405 "Dynamics of Electron Transfer Processes within Transition Metals Sites in Biological and Bioinorganic Systems", Homburg (Hülsa), Germany, April 2012.

Dalle, K.E.; "Bioinspired Activation of Small Molecules with Bimetallic Copper Complexes", 6th Workshop of the International Research Training Group 1422 "Metals Sites in Biomolecules: Structures, Regulation and Mechanisms", Lund, Sweden, February 2011. 


\section{List of Abbreviations}

\begin{tabular}{|c|c|}
\hline${ }^{\mathrm{B}} \mathrm{O}$ & Bis-mu-oxo \\
\hline $\mathrm{CO}$ & Catechol Oxidase \\
\hline $\mathrm{CT}$ & Charge Transfer \\
\hline$d$ & doublet (NMR) \\
\hline DBM & Dopamine $\beta$-monooxygenase \\
\hline DCM & dichloromethane \\
\hline delta & chemical shift \\
\hline DHP & 3,4-dihydro-2H-pyran \\
\hline DOSY & diffusion-ordered spectroscopy \\
\hline${ }^{\mathrm{E}} \mathrm{S}$ & end-on-superoxo \\
\hline ESI & electrospray ionisation \\
\hline Et & ethyl \\
\hline $\mathrm{GC}$ & Gas Chromatography \\
\hline $\mathrm{Hc}$ & hemocyanin \\
\hline $\mathrm{HMBC}$ & Heteronuclear multiple bond correlation \\
\hline HR & high resolution \\
\hline HSQC & heteronuclear single quantum coherence \\
\hline${ }^{i} \mathrm{Pr}$ & iso-propyl \\
\hline $\mathrm{m}$ & multiplet (NMR) \\
\hline Me & methyl \\
\hline${ }^{\mathrm{M} O}$ & mu-oxo \\
\hline MS & mass spectrometry \\
\hline${ }^{n} \mathrm{Bu}$ & normal-butyl \\
\hline NMR & nuclear magnetic resonance \\
\hline${ }^{n} \operatorname{Pr}$ & normal-propyl \\
\hline PDB & Protein Data Bank \\
\hline $\mathrm{Ph}$ & phenyl \\
\hline PHM & Peptidylglycine $\alpha$-hydroxylating monooxygenase \\
\hline$P I$ & paramagnetic impurity \\
\hline pMMO & particulate methane monooxygenase \\
\hline $\mathrm{Pz}$ & pyrazole \\
\hline $\mathrm{q}$ & quartet (NMR) \\
\hline RT & room temperature \\
\hline s & singlet (NMR \\
\hline sept & septet (NMR) \\
\hline
\end{tabular}




$\begin{aligned}{ }^{S} \mathrm{P} & \text { side-on-peroxo } \\ \text { SQUID } & \text { superconducting quantum interference device } \\ \mathrm{t} & \text { triplet (NMR) } \\ \text { SS } & \text { Side-on superoxo } \\ \text { T2 } & \text { Type } 2 \text { copper centre } \\ \text { T3 } & \text { Type } 3 \text { copper centre } \\ \text { T4 } & \text { Type 4 copper centre } \\ \text { THF } & \text { tetrahydrofuran } \\ \text { THP } & \text { tetrahydropyran } \\ \text { TIP } & \text { temperature independent magnetism } \\ \text { TP } & \text { trans-peroxo } \\ \text { Ts } & \text { tosylate } \\ \text { Tyr } & \text { tyrosinase } \\ \text { UV-Vis } & \text { ultraviolet-visible } \\ \text { WCA } & \text { weakly coordinating anion }\end{aligned}$




\section{Acknowledgements}

I would like to express my gratitude to a number of people who helped facilitate this work in one way or another throughout my doctoral studies. Your support is very much appreciated.

Countless thanks go to my Doktorvater Prof. Dr. Franc Meyer for his guidance and endless optimism, and the chance to come halfway across the globe to his extremely well-equipped laboratories. Thank you for fostering my scientific curiousity, providing me with motivation, and cultivating a great working environment. Thank you to Prof. Dr. Ulf Diederichsen for acting as my co-supervisor, and to my thesis committee for their time and dedication.

I am very thankful to my co-workers in the institute for their efforts; Dr. Sebastian Dechert for his patience and perseverance in crystallography, resonance raman spectroscopy, calculations, and theoretical discussions; Dr. Serhiy Demeshko for SQUID magnetometry; Nicole Kindermann, Dr. Steffen Meyer, and Anne Schober for X-ray diffraction and data refinement; Dr. Tim Grüne for our trip to BESSI and his committment to the results; Jörg Teichgräber and Andreas Schwarz for intermediate compounds; Rolf Schöne for NMR knowhow; workshop staff (especially Berndt Wichmann) for technical assistance; Dr. Claudia Stückl for EPR measurements and, together with Petra Unger and Hanna Steininger, for administrative matters; Dr. Inke Siewert for insightful and helpful discussions, and sound judgement on hospital visits; and all members of AK Meyer who helped maintain shared resources and equipment, such as the 'Nasch/Bierkasse', distills, ESI-MS, and gloveboxes.

Thank you to Prof. Dr. Ivana Ivanović-Burmazović for allowing me to visit her fine laboratories in Erlangen, and Oliver Tröppner for persistence in acquiring Cryo-ESI-MS data.

I gratefully acknowledge the IRTG 1422 'Metal Sites in Biomolecules: Structures, Regulation and Mechanisms' for financial support, and all IRTG members for interesting, productive, and enjoyable workshops and conferences.

To my labmates Dr. Stefan Fischer and Torben Böhnisch, thank you for the thoughtprovoking ambiance. The welcome and enjoyable distractions from the ups and downs of day-to-day experiments were invaluable for maintaining some kind of sanity. Thanks also to my students Jochen Jung and Julia Nomrowski.

I thank Anne Bretschneider, Mattia Veronelli, Markus Steinert, Dr. Sebastian Dechert, and Markus Scheibel for suggesting improvements and proofreading this thesis.

Finally, thank you to all of AK Meyer for the fantastic atmosphere; in the coffee room, on the balcony, on group tours, and around Göttingen. My deepest gratitude to Smorkas, Tia, Anne, Ischi, DSD, Netti, Jann, Ele, Stasi, Marten, Teffen, Phelix, Ritti, Oli, Benni, Vandana, and Adam. You helped keep up my spirits when times were tough. Herzlichen Dank für alles. 